Portland State University

PDXScholar

2-21-1996

\title{
A Cross-cultural Study of the Speech Act of Refusing in English and German
}

Charla Margaret Teufel

Portland State University

Follow this and additional works at: https://pdxscholar.library.pdx.edu/open_access_etds

Part of the Bilingual, Multilingual, and Multicultural Education Commons Let us know how access to this document benefits you.

\section{Recommended Citation}

Teufel, Charla Margaret, "A Cross-cultural Study of the Speech Act of Refusing in English and German" (1996). Dissertations and Theses. Paper 5212.

https://doi.org/10.15760/etd.7088

This Thesis is brought to you for free and open access. It has been accepted for inclusion in Dissertations and Theses by an authorized administrator of PDXScholar. Please contact us if we can make this document more accessible: pdxscholar@pdx.edu. 


\section{THESIS APPROVAL}

The abstract and thesis of Charla Margaret Teufel for the Master of Arts in Teaching

English to Speakers of Other Languages were presented February 21, 1996, and accepted by the thesis committee and the department.

COMMITTEE APPROVALS:

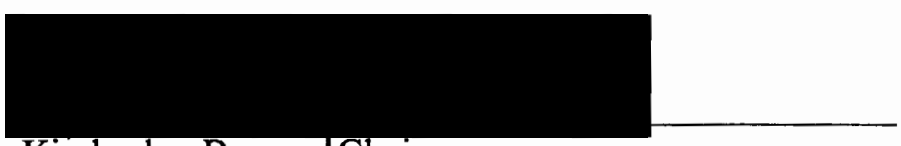

Kimberley Brown,IChair

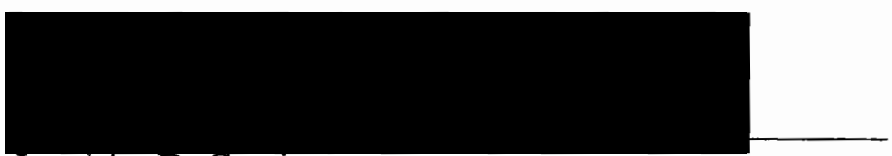

Jeanefte DeCarrico

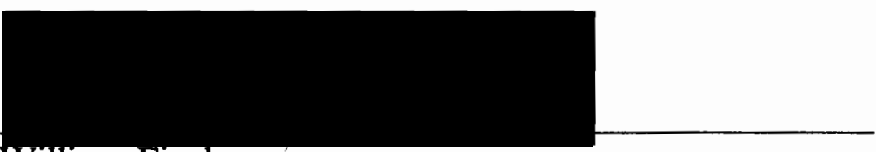

William Fischer

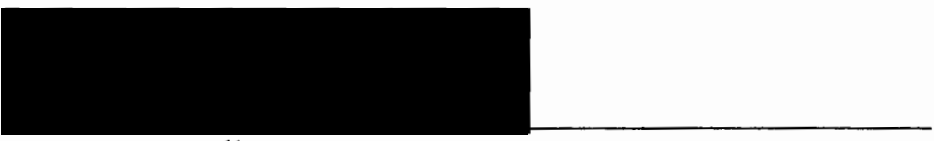

Steven Fuller

Representative of the Office of Graduate Studies

DEPARTMENT APPROVAL:

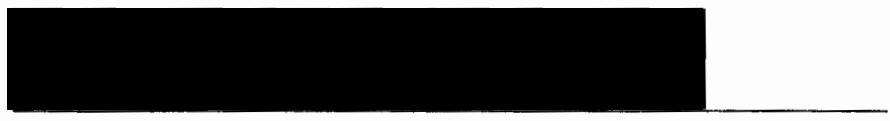

Beatrice Oshika, Chair

Department of Applied Linguistics

$* * * * * * * * * * * * * * * * * * * * * * * * * * * * * * * * * * * * * * * * * * * * * * * * * * * * * * * * * * * * * * * * * * * * * * * * *$ on

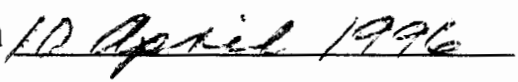




\section{ABSTRACT}

An abstract of the thesis of Charla Margaret Teufel for the Master of Arts in Teaching English to Speakers of Other Languages presented February 21, 1996.

Title: A Cross-Cultural Study of the Speech Act of Refusing in English and German.

Language students must learn to communicate effectively in cross-cultural settings, avoiding unwitting violations of culturally determined norms of behavior. This study compares German learners of English (GEs) with native speakers of English (AEs) and German (GGs), studying pragmatic transfer associated with the face-threatening speech act of refusal.

Data elicitation involved a written role-play questionnaire composed of twelve refusal situations, including four refusal stimulus types (requests, invitations, offers, and suggestions) and interlocutors of higher, lower, and equal status. Response strategies were identified and classified, and the three groups were compared in terms of frequency and content of strategies chosen.

Overall, the findings suggest that the AEs strove for friction-free interactions, while the German subjects tended to be candid. The AEs opted for inoffensive, routinized responses, emphasizing face-protection, and eschewing expressions of unwillingness. The AEs generally provided only vague excuses, relying extensively on positive forms aimed at preserving rapport. Social distance affected AE levels of politeness. By contrast, GG response patterns were situation-specific. Toward unjustified requests or unwelcome suggestions, the GGs exhibited directness, outspokenness with critical remarks, and 
willingness to risk confrontation, regardless of relative status. In more neutral situations, status and social distance influenced levels of politeness.

The GEs appeared to assess situational factors in much the same way as the GGs; however, GE responses were consistently more tempered. Both groups of Germans were more open with expressions of unwillingness than the AEs. They tended to provide solid justification for refusals, while maintaining a more aloof stance.

When there was no cause for irritation, the GEs recognized the need for greater tactfulness in English (probably responding according to explicit teaching). When aggravated, however, they lapsed into pragmatic patterns of their native language, following their "gut reactions."

Sometimes GE efforts to exceed German native speaker levels of politeness led to "hyper-correction" (i.e., going beyond the AEs' degree of politeness). Occasionally, the GEs transferred German native speaker strategies for increasing politeness.

In situations of potential conflict, the GEs might startle native speakers with unexpected candor, the shock exacerbated by cultural proximity and the GEs' near approach of native speaker norms on other levels. 
A CROSS-CULTURAL STUDY

OF THE SPEECH ACT OF REFUSING

IN ENGLISH AND GERMAN

\title{
by
}

CHARLA MARGARET TEUFEL

A thesis submitted in partial fulfillment of the requirements for the degree of

\author{
MASTER OF ARTS \\ in \\ TEACHING ENGLISH TO SPEAKERS OF OTHER LANGUAGES
}

Portland State University

1996 


\section{Acknowledgments}

A number of individuals gave generously of their time, effort, and knowledge to help make this research project possible. My heartfelt gratitude goes out to:

- Kimberley Brown, my thesis advisor, for her valuable observations and recommendations;

- Marjorie Terdal, for her help in the initial planning of this research project and the data collection process;

- Jeanette DeCarrico, who provided feedback concerning issues of Linguistic Pragmatics;

- William Fischer, who carried out the back-translation of the German version of the DCT;

- Paul Bingman and Karen Shoemaker, who provided a FAX connection for contacting individuals in Germany, who "rescued" me on numerous occasions when I had "computer emergencies", and who were an inestimable moral support;

- Michael and Judy Gendreau, for initiating me into the mysteries of word processing and allowing me frighteningly extensive use of their laser printer;

- Abraham Salzberg, for his considerable support with technical aspects of computer use and encouragement;

- Kristine Demien, who critiqued Chapter II and the abstract, making valuable suggestions; 
- Diedre Cain, who analyzed a portion of the data in order to establish interrater reliability;

- Shanti Leslie, for her enormous moral support and feedback on the "flow" of translations of German responses into English;

- David Anderson, who showed great empathy and patience in tolerating my rantings...;

- the German informants who confirmed the accuracy of translations and my analysis of German questionnaire responses; and

- the participants in the pilot study, who provided useful feedback regarding the validity of the data collection instrument and other issues concerning data elicitation.

Two individuals in particular were "life-savers":

Karen Shoemaker made an invaluable contribution in the creation of tables and formatting. William Hoffman devoted considerable effort to preparing the document for printing and generously allowed me use of his laser printer.

I would also like to express my appreciation and love to my parents, Ingrid $\mathrm{P}$. Teufel and Karl C. Teufel. 


\section{Table of Contents}

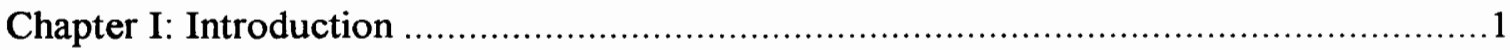

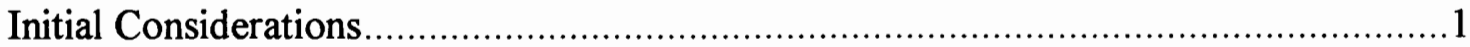

Rationale for Comparing the Performance of Native Speakers of English and German with German Nonnative Speakers of English in the Production of the Speech Act of Refusal

Research Questions and the Beebe, Takahashi, and Uliss-Weltz Study of Refusals in Japanese and English

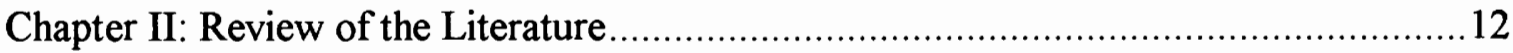

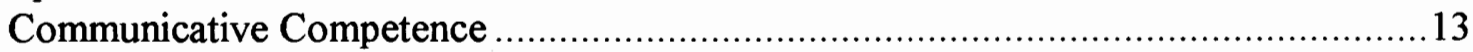

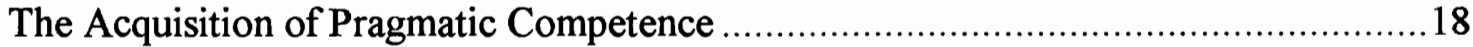

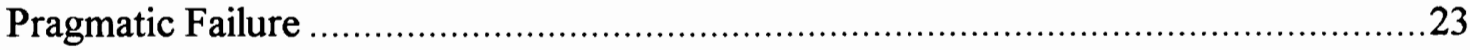

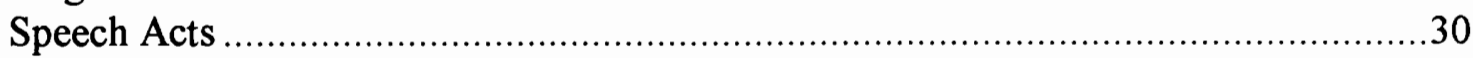

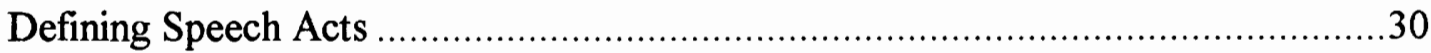

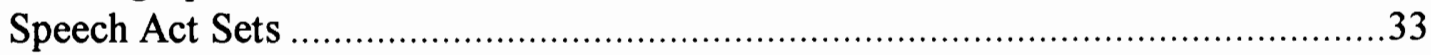

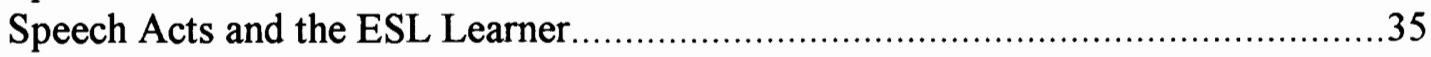

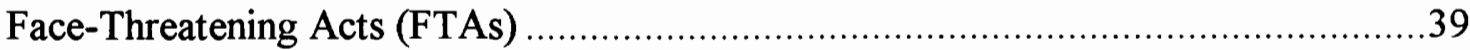

The Concept of "Face" and Social Dimensions of FTAs........................................39

Brown and Levinson's Model of Speakers' Considerations when Performing FTAs 44

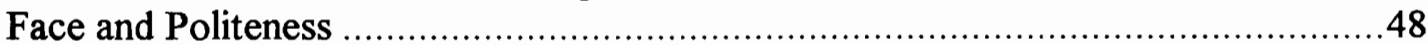

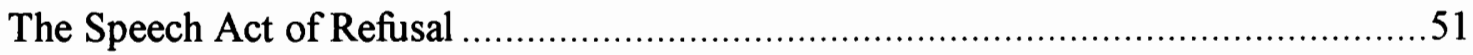

The Impact of Language Transfer on Second Language Performance .........................55

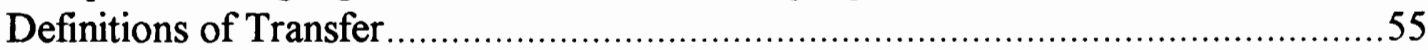

Aspects of the Native Language Linguistic System Most Likely to be Transferred ..59

The Concept of Transfer as It Relates to Pragmatic Competence ..........................63

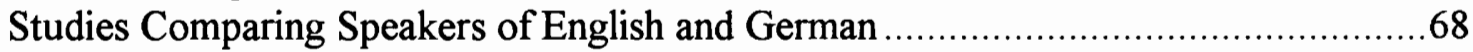

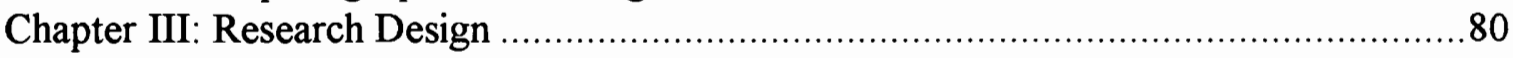

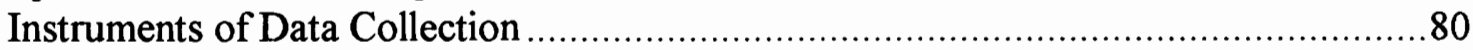

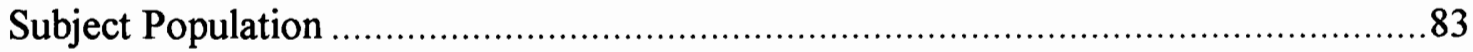

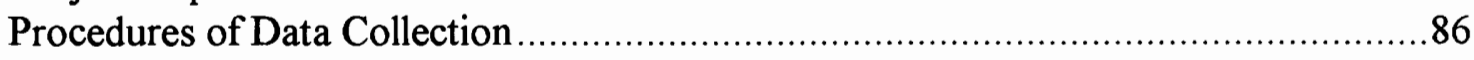

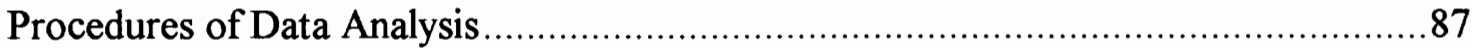

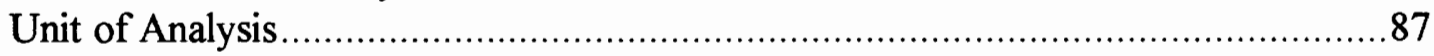

System of Classification: Functional Categories (i.e., Refusal Strategies and

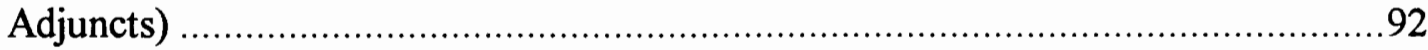

Modifications of Beebe et al's Classification of Functional Categories involved in

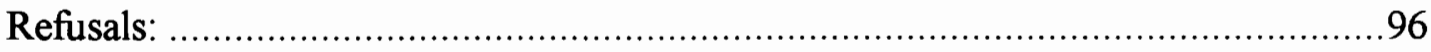

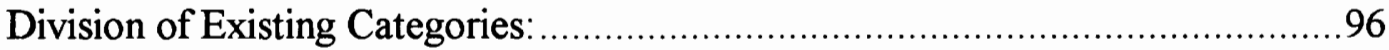

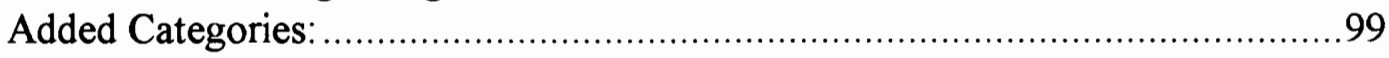

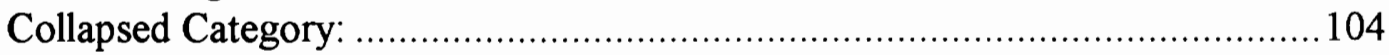

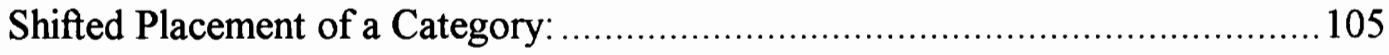

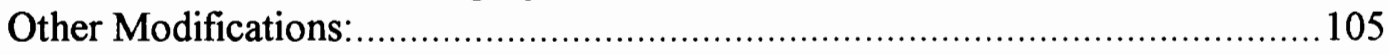

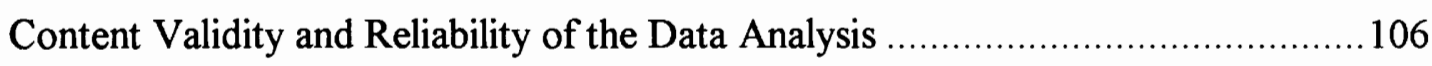


Chapter IV: Results $\quad$ ii

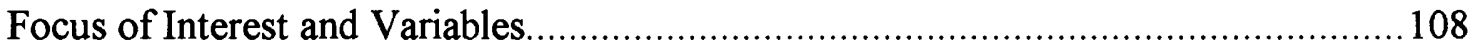

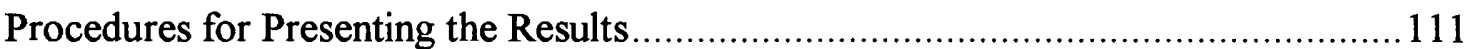

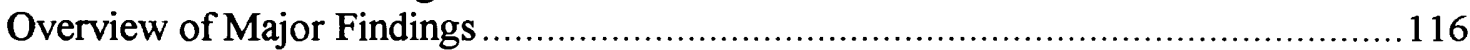

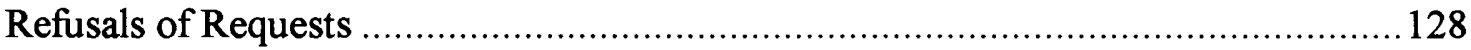

DCT \#1: Refusal of Lower-Status Interlocutor's Request ...................................131

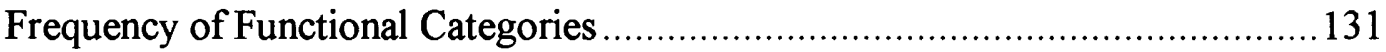

Content of Functional Categories..................................................................139

Summary of Results: Refusal of Request Made by a Lower-Status Interlocutor

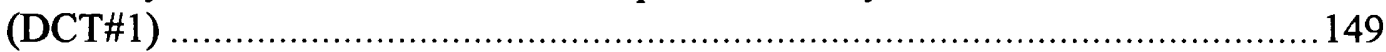

DCT \#2: Refusal of Equal-Status Interlocutor's Request ...............................152

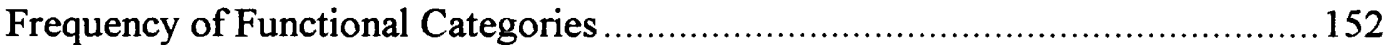

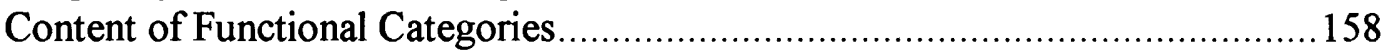

Summary of Results: Refusal of Request Made by a Equal-Status Interlocutor

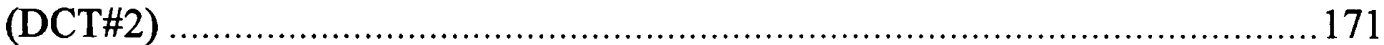

DCT \#12: Refusal of Higher-Status Interlocutor's Request................................175

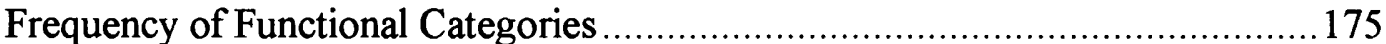

Content of Functional Categories............................................................... 179

Summary of Results: Refusal of Request Made by a Higher-Status Interlocutor

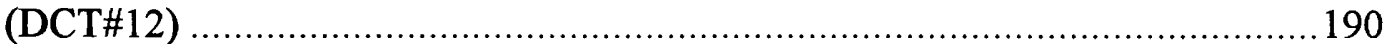

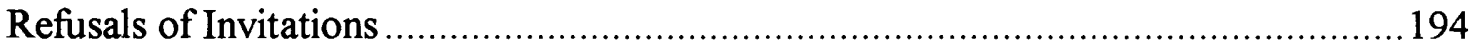

DCT \#3: Refusal of Lower-Status Interlocutor's Invitation ................................... 198

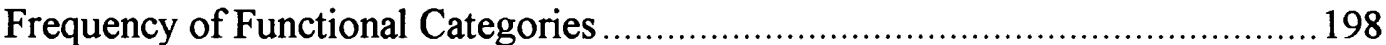

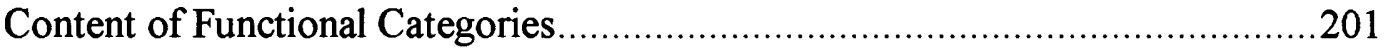

Summary of Results: Refusal of Invitation Made by a Lower-Status Interlocutor

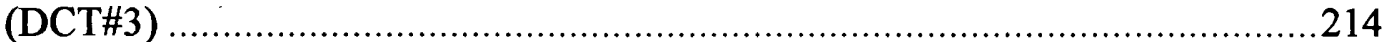

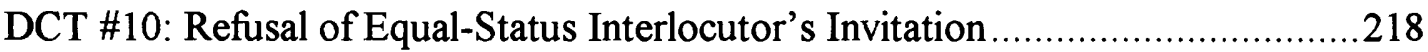

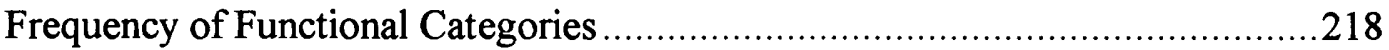

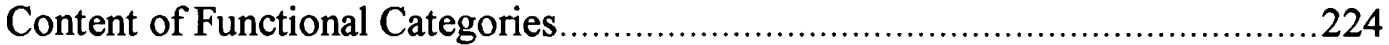

Summary of Results: Refusal of Invitation Made by an Equal-Status Interlocutor

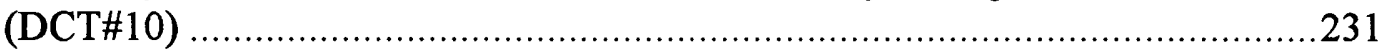

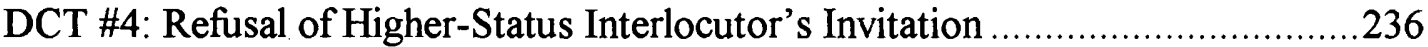

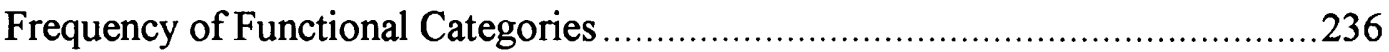

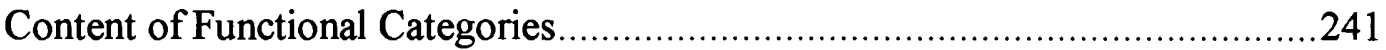

Summary of Results: Refusal of Invitation Made by a Higher-Status Interlocutor

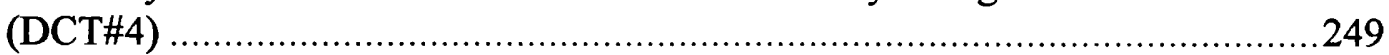

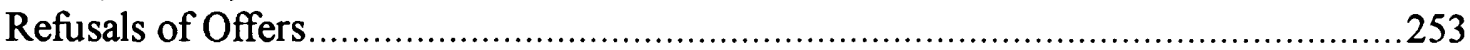

DCT \#7: Refusal of Lower-Status Interlocutor's Offer ......................................256

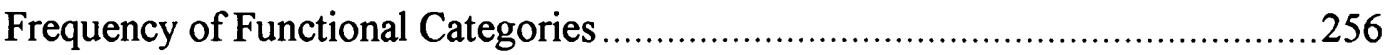

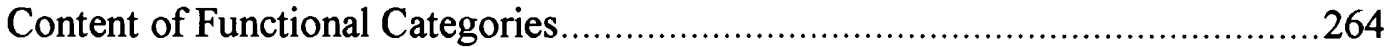

Summary of Results: Refusal of Offer Made by a Lower-Status Interlocutor

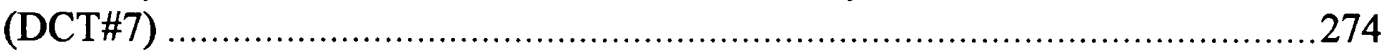

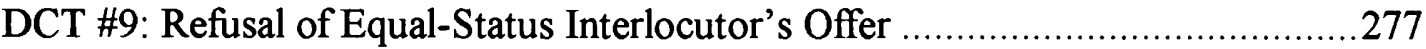


iii

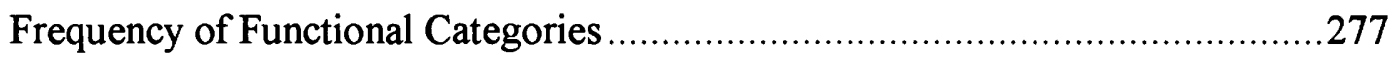

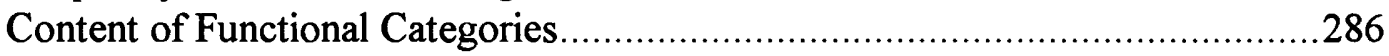

Summary of Results: Refusal of Offer Made by an Equal-Status Interlocutor

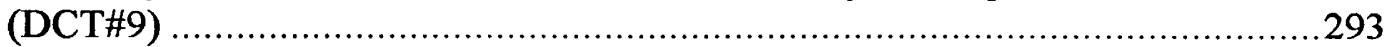

DCT \#11: Refusal of Higher-Status Interlocutor's Request..............................296

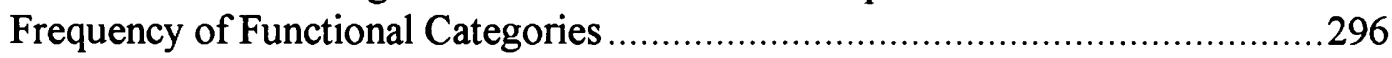

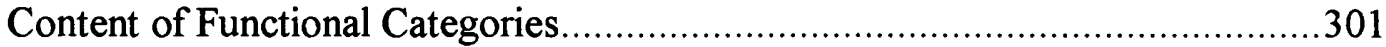

Summary of Results: Refusal of Offer Made by a Higher-Status Interlocutor

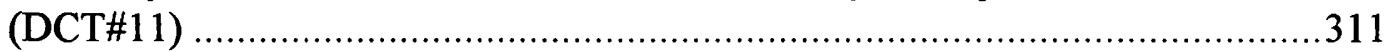

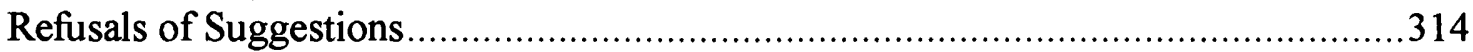

DCT \#8: Refusal of Lower-Status Interlocutor's Suggestion .............................318

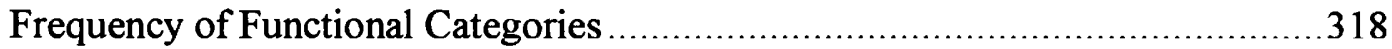

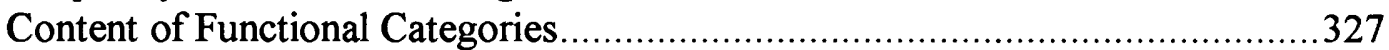

Summary of Results: Refusal of Suggestion Made by a Lower-Status Interlocutor

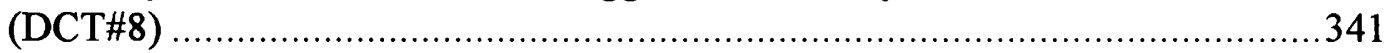

DCT \#5: Refusal of Equal-Status Interlocutor's Suggestion.................................344

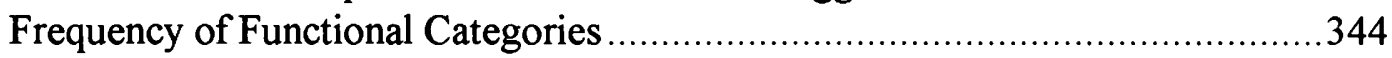

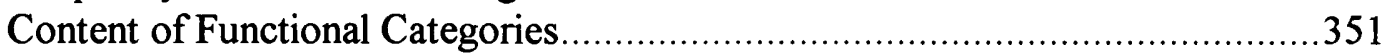

Summary of Results: Refusal of Suggestion Made by an Equal-Status Interlocutor

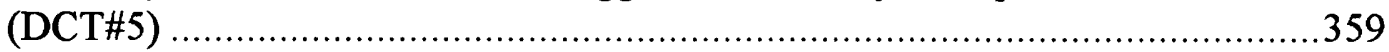

DCT \#6: Refusal of Higher-Status Interlocutor's Suggestion ................................363

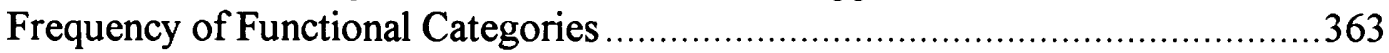

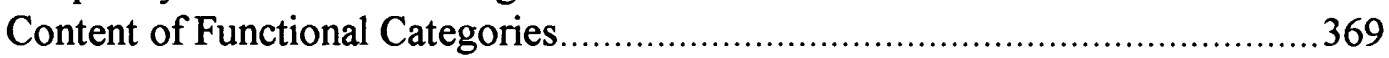

Summary of Results: Refusal of Suggestion Made by a Higher-Status Interlocutor

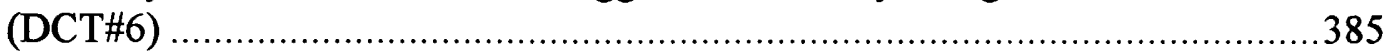

Major Differences between the three Groups ...................................................387

Dealings with Higher-Status Interlocutors (Bosses) .......................................38

Interactions with Equal-Status Addressees (Friends, Acquaintances, and Classmate)391

Interchanges with Lower-Status Addressees (Employee, Salesman, Cleaning Lady,

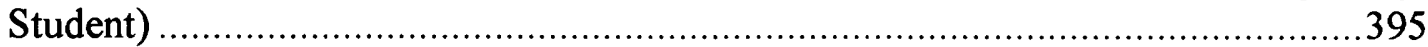

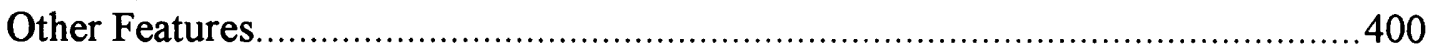

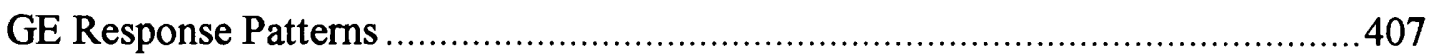

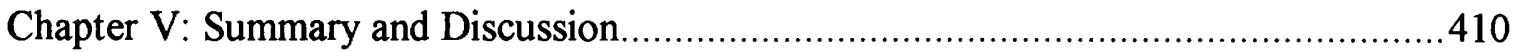

Summary of Research Purpose and Methodology ...............................................410

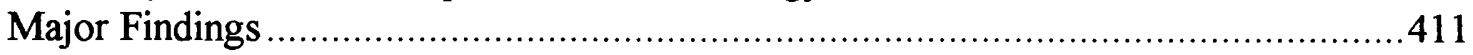

Differences between the Subject Groups .....................................................411

A Consideration of the Research Questions ....................................................418

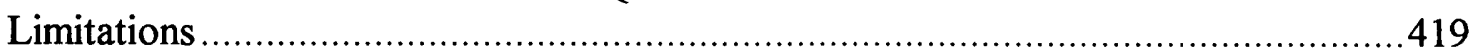

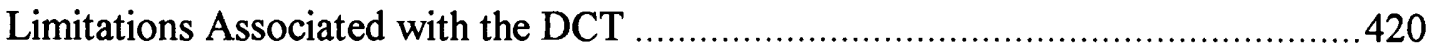

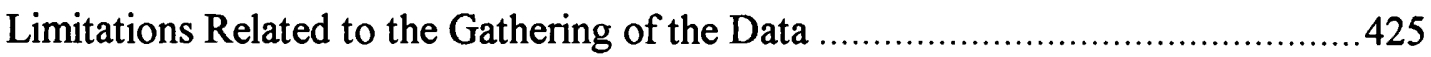

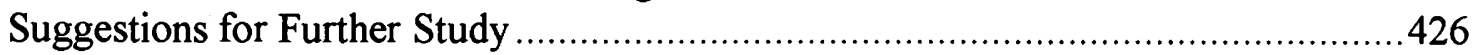

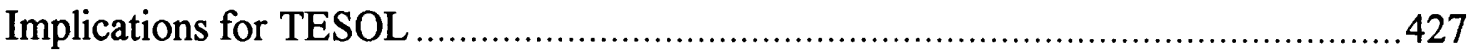

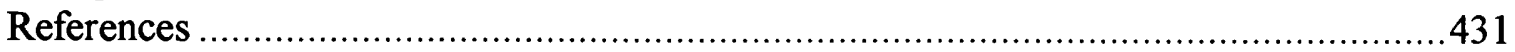


Appendix A Dialogue Completion Test ..................................................... iv

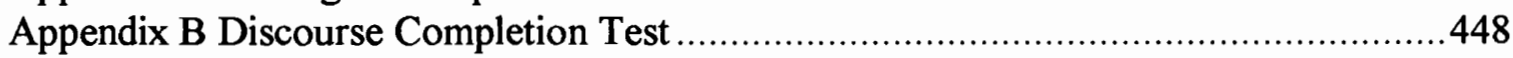

Appendix C Modifications of the Discourse Completion Test ....................................451

Appendix D German Translation of Discourse Completion Test ...............................453

Appendix E Classification of Discourse Completion Test (DCT) Stimulus According to

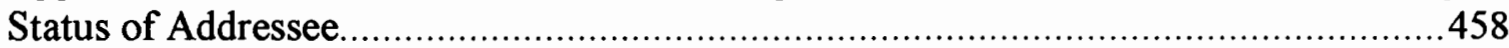

Appendix F Classification of Refusals used in this Study ..........................................459

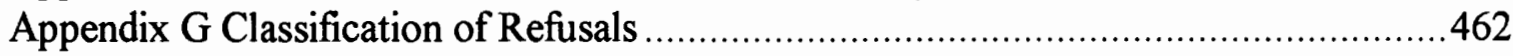

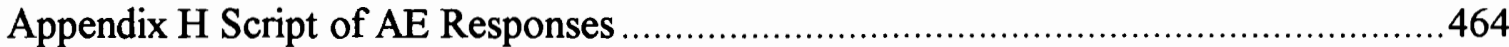

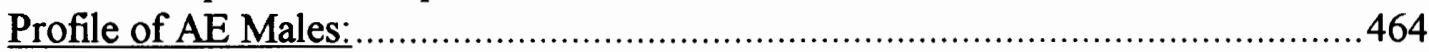

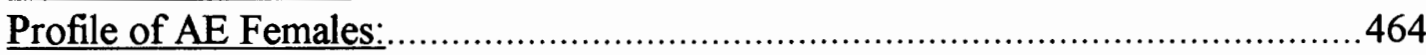

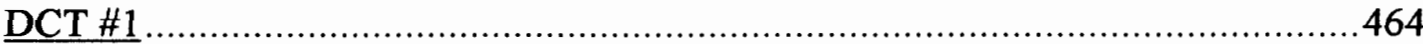

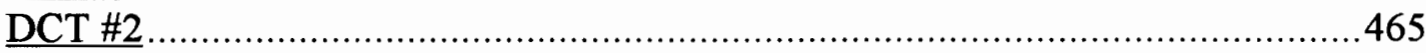

DCT \#3

DCT \#4

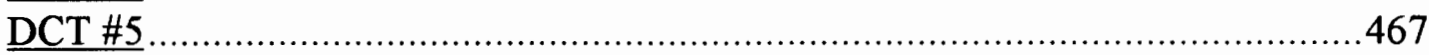

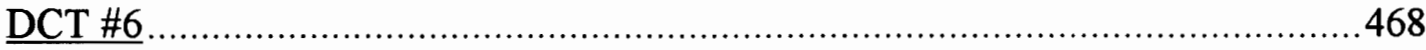

DCT \#7

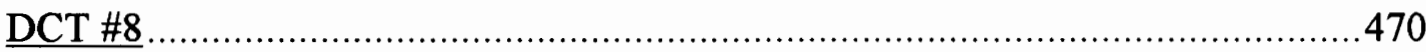

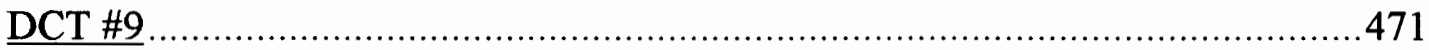

DCT \#10

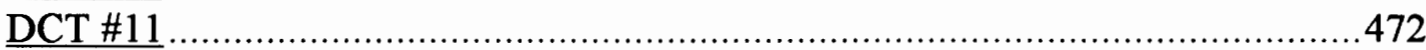

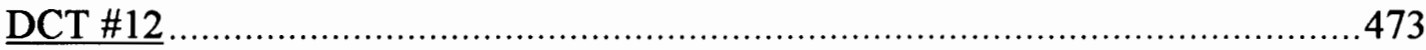

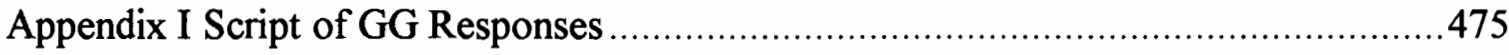

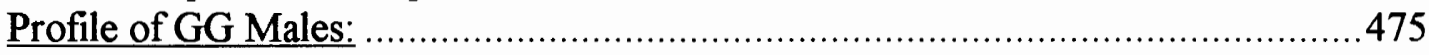

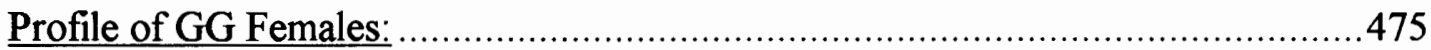

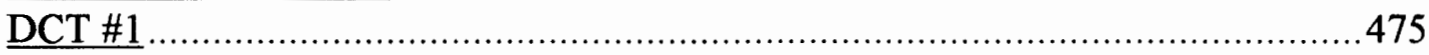

DCT \#2

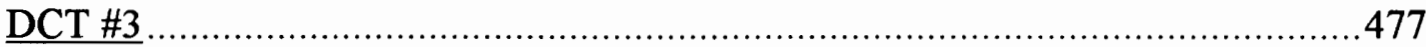

DCT \#4

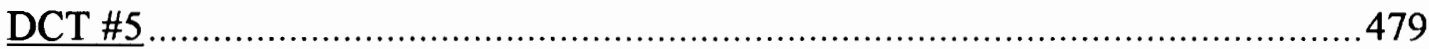

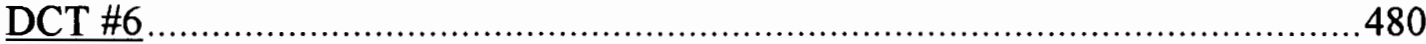

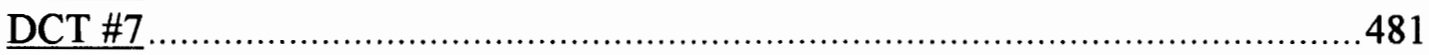

DCT \#8

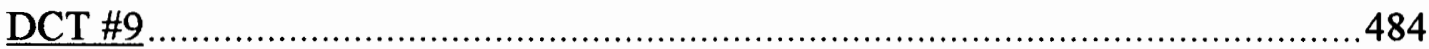

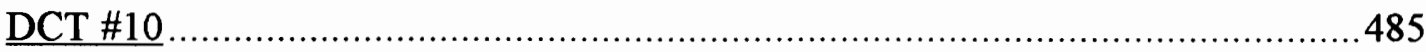

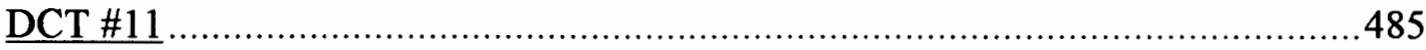

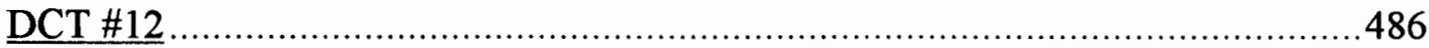

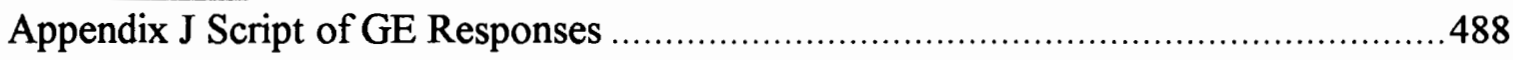

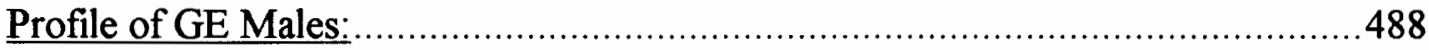

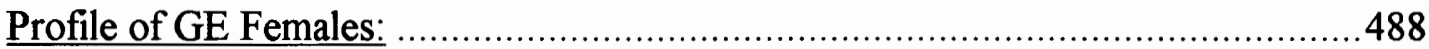

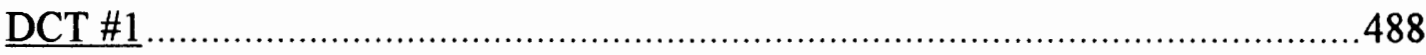

DCT \#2 


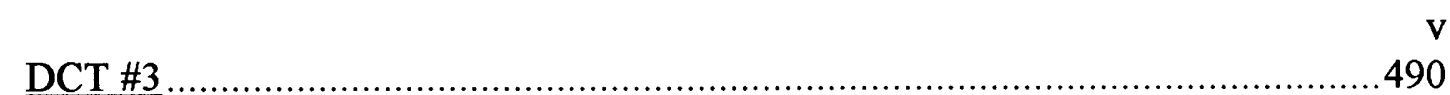

DCT \#4

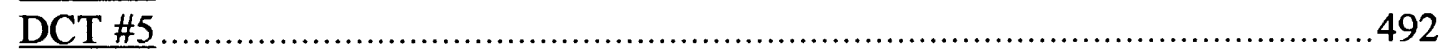

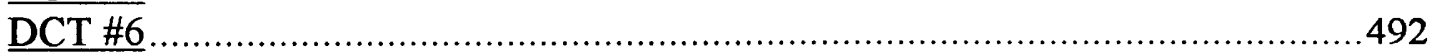

DCT \#7

DCT \#8

DCT \#9

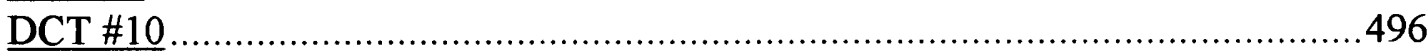

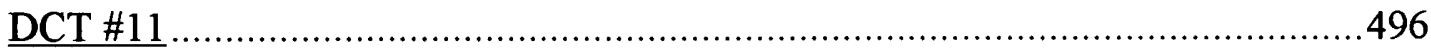

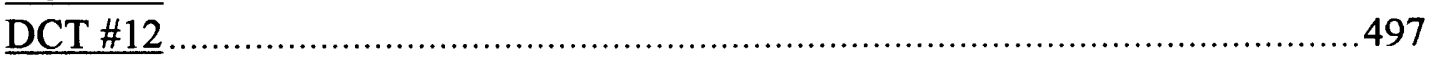

Appendix K Classification of AE Responses in terms of Functional Categories ............499

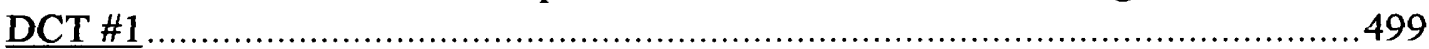

DCT \#2

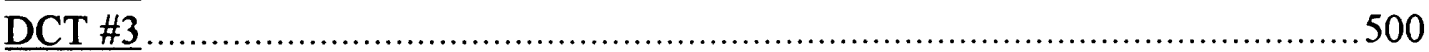

DCT \#4

DCT \#5

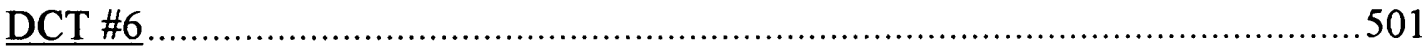

DCT \#7

DCT \#8

DCT \#9

DCT \#10

DCT \#11

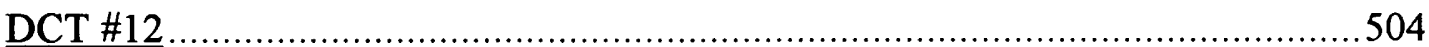

Appendix L Classification of GG Responses in terms of Functional Categories .............505

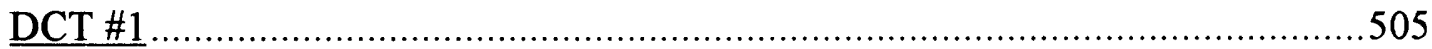

DCT \#2

DCT \#3

DCT \#4

DCT \#5

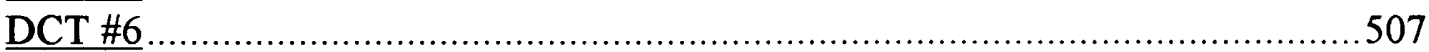

DCT \#7

DCT \#8

DCT \#9

DCT \#10

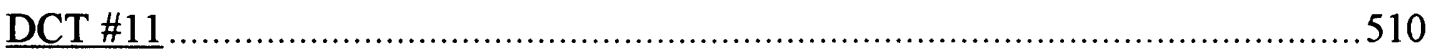

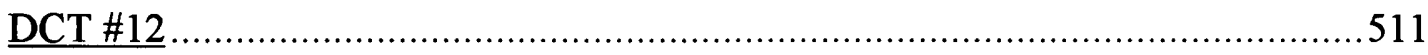

Appendix M Classification of GE Responses in terms of Functional Categories ...........512

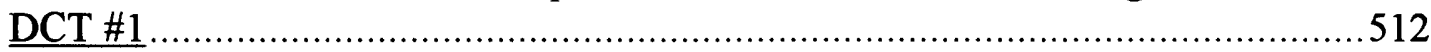

DCT \#2

DCT \#4

DCT \#5

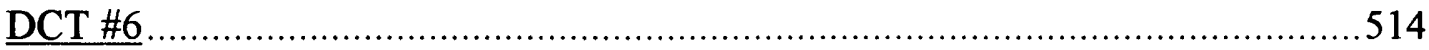

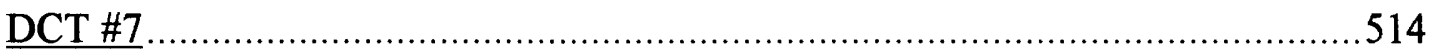




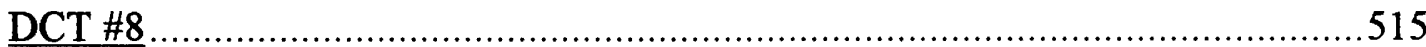

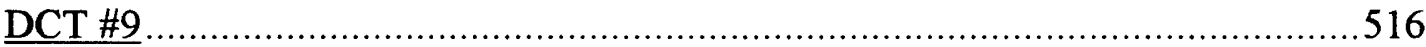

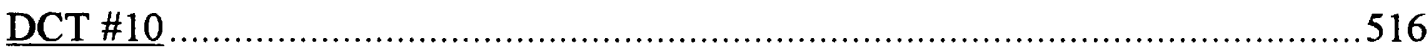

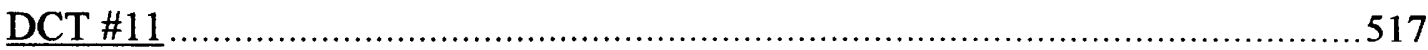

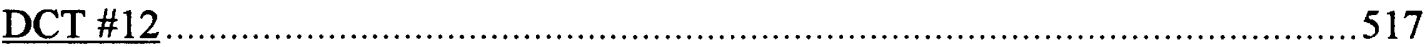




\section{Chapter I: Introduction}

\section{Initial Considerations}

Green (1989) defines communication as "the successful interpretation by an addressee of a speaker's intent in performing a linguistic act" (p. 1). As a second language instructor, my primary concern for my students is that they learn to communicate effectively in cross-cultural settings. This aim takes precedence over command of grammar, pronunciation, or other aspects of language, because my own experience has taught me that grammatical errors, for instance, can be more easily recognized and remedied than unwitting violations of culturally determined norms of behavior.

While living in Germany for twelve years, I experienced a good share of crosscultural misunderstandings. Service encounters in shops, restaurants, or administrative offices were particularly tricky. When making requests in German, I simply translated from English (e.g., "Could you please help me find [x]?") and often added some sort of softener (e.g., “...if you're not too busy right now”). As a foreigner, I felt a particular need to be polite and make a favorable impression. To my chagrin, however, I often endured unfriendly and uncooperative responses to my requests on the part of shop clerks, waitresses, and receptionists. When I tried to make friendly small talk with them, it generally backfired. (I'll never forget the day I went into a shop looking for thermal underwear, explaining to the clerk that I didn't know what to look for because I was accustomed to the balmy climate of Florida. She looked as though I had exposed intimate details of my private life in public.) 
Occasionally, I observed friends ordering in a restaurant. To me their choice of language seemed inappropriate, as though they were treating the waitress like a servant. But my friends always got a more pleasant response than I did. Being "overbearing" (i.e., ordering them around) seemed to get the desired response. It never occurred to me that courtesy was not expressed the same way in German as in American English; I alternately felt either that I was somehow inadequate or that German service personnel tended to have some sort of attitude disorder, i.e., bowing to the bossy customer whom they feared would give them trouble if displeased, and releasing their pent-up hostilities on the friendlier client. In hindsight, I realize that they thought I was trying to ingratiate myself in an annoying, unnecessary, and possibly insincere manner. It did not occur to them, either, that my communication style reflected culture-bound norms of behavior.

Since then, my study of cross-cultural linguistics has demonstrated the possibility of helping second-language learners avoid similar pitfalls by 1) drawing their attention to differences in communication conventions between their first and second languages, and 2) increasing their consciousness of how native speakers of the target language use words to accomplish things. For this reason, I felt drawn to the idea of devoting this research project to a comparison of communication patterns in two cultures with which I am closely connected, in the hope that my findings might make some contribution towards facilitating cross-cultural understanding.

The first section of this chapter presents arguments for studying how native speakers (NSs) of English and German compare with German nonnative speakers (NNSs) of English in the production of the speech act of refusal. This includes a discussion of 
pragmatic and sociocultural competence and its significance for NNSs as well as an examination of refusals as inherently face-threatening acts with great potential for miscommunication between NSs and NNSs. Terms such as "communicative competence", "pragmatic competence", "pragmatic failure", and "speech acts" will be defined.

The second section presents the research questions guiding the study, and a discussion of the 1990 study by Beebe, Takahashi, and Uliss-Weltz which has served as a starting point for this study.

\section{Rationale for Comparing the Performance of Native Speakers of English and German with German Nonnative Speakers of English in the Production of the Speech Act of Refusal}

This study of cross-cultural differences is intended to contribute to the body of linguistic research examining what it is NNSs must know in order to communicate effectively in their target language.

Language is much more than just a system of sounds, units of meaning, and syntactic rules. As Wolfson (1989) asserts, language is also social behavior. "Communicative competence" is the term Dell Hymes (1962, 1964, 1972a, 1972b, 1974) introduced to refer to the ability of NSs to use their language in ways that are not only linguistically accurate but also socially appropriate. In other words, the ability to produce grammatically correct sentences does not, in itself, constitute knowledge of a language.

Successful communication requires more than mastery of grammar rules alone; one must assimilate the rules of appropriate social use of language as well, that is, knowing 
when and under what circumstances to use specific linguistic forms. As Rintell (1990) argues:

"The second language learner is now widely seen as not only requiring a target language grammar that produces target language sentences, but as gradually learning a complex network of interdependent social and linguistic conventions concerning who may say what to whom, when, and under what circumstances. It is this knowledge that encompasses a great deal of what we term communicative competence" (p. 75).

"Pragmatics" is the study of how context influences the interpretation of utterances. Kasper and Blum-Kulka (1993) describe pragmatics as "the study of people's comprehension and production of linguistic action in context" (p. 3). While both semantics and pragmatics are theories of meaning, semantic meaning is at the sentence level while pragmatics is at the discourse level. Thus, pragmatic meaning includes the added dimension of information provided by context. Semantically, the sentence, "Your cookies smell delicious," is simply a statement about a state of affairs (i.e., a characteristic of baked goods produced by the hearer). On the basis of contextual factors (the domain of pragmatics), however, the hearer can determine if this utterance should be interpreted as straightforward information, a compliment, or a request. Bialystok (1993) points out that semantics relates form and meaning, whereas pragmatics relates "form and social context, with meaning held constant across intentions within a socially defined situation" (p. 51).

Pragmatic competence involves knowing which linguistic structure is appropriate, based on the given situation and on the relationship between speaker and addressee. Sociocultural competence entails communicating in ways considered appropriate within a particular sociocultural context, based on implicit knowledge of norms of interaction and societal values (e.g., attitudes towards the elderly, emphasizing individuality versus 
collectivity, etc.), which reflect a particular cultural world view. In Wardhaugh's (1986) words, this kind of competence is the "ability to handle ... the various uses of language in society" (p. 362).

Because there is a great deal of overlap between pragmatic competence and sociolinguistic competence, some clarification of terminology as used here is necessary. Wolfson (1989) offers a useful distinction: in the discussion of cross-cultural differences, the field of linguistic pragmatics focuses primarily on examining interpersonal interaction, while sociolinguistics views interaction more at the societal level. Pragmatics has its basis in the fields of philosophy and formal linguistics, whereas sociolinguistics is strongly influenced by anthropology and sociology. Sociolinguists generally study how sociolinguistic diversity is organized, while the research in pragmatics tends to look for universals of human behavior. As Wolfson asserts, however, both pragmatics and sociolinguistics can be defined as "language in use." Both forms of competence play a crucial role in the successful performance and interpretation of speech acts such as invitations, requests, or refusals. Schmidt's (1993) statement regarding the study of pragmatics is equally applicable to the study of sociolinguistics:

Just as linguists seek to discover general principles of language that are reflected in the effortless control of grammar by native speakers but of which they have no conscious awareness, research in pragmatics seeks to identify patterns and general principles that native speakers are equally unable to articulate based on introspection (p. 23).

As Richards (1983) notes, although a variety of linguistic forms can be used to express a particular meaning, these forms are not equally appropriate. In choosing a particular form, the speaker must consider his or her relationship with the hearer and the 
constraints imposed by the setting and circumstances in which the act of communication is embedded. For example, the utterance "What's your name?" is a well-formed question in English, but it would not be an appropriate way of asking the identity of a telephone caller. According to Richards, factors such as age, gender, familiarity, and the role of speaker and hearer determine whether a speaker chooses linguistic forms that mark "affiliation" or "dominance." To express affiliation, a speaker might use a form such as “Got a match?"to request a match, whereas the expression of dominance would require a more elaborate utterance, such as "I wonder if I could bother you for a match."

This aspect of communication poses a difficulty for language learners who are constrained by the limits of their proficiency, lacking the option of choosing from a repertoire of linguistic forms that express varying degrees of formality and politeness. Even at a higher level of proficiency, as much current research indicates, language learners often transfer pragmatic rules from their native language to the target language, and these rules frequently do not apply in the same way in different languages. The intended meaning of an utterance may not be apparent in its surface form, and thus cannot be interpreted correctly without background knowledge of the language and culture. A NNS's ignorance of the culturally determined implicit meanings beneath the surface meaning of the words can cause misunderstanding.

Since pragmatic rules are often subtle and speakers are generally not consciously aware of their operation, there is great potential for intercultural miscommunication. According to Wolfson (1989), a NNS's pronunciation or syntactic errors are rarely considered offensive by NSs; errors involving the rules of speaking, however, are 
perceived very differently. Misinterpretation of pragmatic rules in the target language actually presents a far greater danger of misunderstanding than do grammatical errors because participants often do not realize that they have misunderstood each other, while grammatical errors are more likely to be detected. When one of these unconscious sociocultural rules is broken by a NNS, a serious breakdown in communication may result. Unfortunately, NSs tend to make negative character judgements in such cases. Wolfson argues that

Tolerance of sociolinguistic violations is uncommon precisely because the rules are so much a part of unconscious expectations concerning proper behavior. ... An inappropriate question or the failure to utter the customary apology, compliment, or congratulation will not be judged as an error natural to the process of language learning or, indeed, of intercultural differences, but as a personal affront. (pp. 25-26)

There is a universal tendency for members of a speech community to judge the speech behavior of others by their own standards. Because most individuals tend to take their own behavior patterns for granted and assume that every well-brought-up person knows these rules of behavior, they are likely to interpret pragmatic rule-breaking as a sign of flawed character. If they have had many such experiences with members of a particular group, they are likely to stigmatize the entire group. As Wolfson asserts,

appropriate speech usage within the context of a given society is so linked to such attributes as good manners, honesty, sincerity, and good character generally that it is often difficult for language learners, and for native speakers with whom they interact, to accept the notion of diversity along these lines. $(1989$, p. 15)

This lack of knowledge about sociolinguistic diversity is the cause of much intercultural misunderstanding, or "pragmatic failure," which Thomas (1983) defines as "the inability to understand what is meant by what is said." My own experience with pragmatic failure in 
Germany (described at the beginning of this chapter) illustrates this point, as does an observation of Olshtain and Cohen (1981). They note that speakers of English tend to use more direct expressions of apology (regardless of the situation) than Hebrew speakers. When learners transfer the feature of higher or lower apology intensity to the new language, it can lead to judgements of Hebrew speakers as "arrogant" on the one hand, and the belief that English speakers say "polite" things which are not sincere on the other hand.

A useful framework for the analysis of pragmatic and sociolinguistic problems in language acquisition is provided by "speech act theory", which was originally developed by philosophers of language such as Austin (1962) and Searle (1969, 1975, 1976, 1979). Austin recognized that some utterances in a language function as acts and that a certain set of verbs in English, which he called "performatives", can be used in the first person present to perform acts. Examples of these kinds of utterances are: "I promise to come home at 3 o'clock", "I now pronounce you husband and wife", or "I give and bequeath my watch to my brother" (occurring in a will). In these examples, the speakers explicitly perform acts by speaking. Utterances that do not contain performative verbs can also be used to perform speech acts, such as "I'll come home at 3 o'clock", which implies that a promise is being made. In other words, the "illocutionary force,"or intended meaning, of the utterance is that of a promise. Difficulties in communication can arise when language learners translate sentences with a particular illocutionary force in their first language into the target language, in which the utterance may be interpreted very differently, having lost the intended illocutionary force. 
As speech acts with a high potential for risk of loss of face, refusals can present a particular danger of miscommunication for NNSs; therefore a greater understanding of the pragmatic norms governing their linguistic realization can contribute to successful crosscultural communication.

Whereas considerable research has been devoted to speech acts such as requests and apologies, there has been much less investigation of thanking, complaining, correcting, or refusing. Beebe, Takahashi, and Uliss-Weltz (1990) have compared the refusals of Japanese subjects speaking Japanese, Americans speaking English, and Japanese speaking English in order to find evidence of pragmatic transfer. While there have been a number of studies comparing the speech act performance of NSs of German and English (including Blum-Kulka \& House, 1989; Edmondson, House, Kasper, \& Stemmer, 1982; House, 1978, 1986 and 1989b, House \& Kasper, 1981 and 1987; Kasper, 1981; and Vollmer \& Olshtain, 1989), they have focused primarily on requests, complaints and apologies. I have encountered only one study that examines the performance of refusals by German learners of English: Kasper, 1981.

\section{Research Questions and the Beebe, Takahashi, and Uliss-Weltz Study of Refusals in Japanese and English}

The previous section of this chapter provides a rationale for research comparing how the speech act of refusal is performed by Americans and Germans in their native languages and by Germans in English as a Foreign Language (EFL). This section presents the research questions at the heart of this study and discusses the role that research by 
Beebe, Takahashi, and Uliss-Weltz has played in providing a format for this study. The study raises the following research questions:

- Do German learners of English perform the speech act of refusal in ways that differ from the performance of NSs of American English speaking English and NSs of German speaking German?

- Does native language transfer affect German speakers of English in the performance of the refusal speech act, and if so, how?

On the basis of the answers to these research questions and my own NS intuition, I have considered differences between the ESL learners' production of refusals and native American English norms for refusing that seem most likely to lead to sociopragmatic failure. A discussion of these potential pitfalls can be found in Chapter V, Summary and Discussion.

Beebe, Takahashi, and Uliss-Weltz's (1990) study of the speech act of refusal as performed by NSs of English and Japanese using their first languages, and NSs of Japanese using English as a second language, provides the basis for the design of this study. Their study offers evidence that pragmatic transfer from Japanese affects the performance of Japanese speakers of English in the production of the speech act of refusal in terms of order, frequency, and content of semantic formulas used. Beebe et al collected data for their study using a Discourse Completion Test, a written role-play questionnaire with twelve situations designed to elicit refusals. Their subjects consisted of 20 NSs of Japanese, 20 NSs of American English, and 20 Japanese NNSs of English. 
Beebe et al's instrument of data collection was used in the present study, modified slightly to accommodate differences in the subject populations of the two studies. In addition, I based the methods of data collection and analysis on their study. This is described in greater detail in Chapter III, Research Design, and Chapter IV, Results. 


\section{Chapter II: Review of the Literature}

A number of studies show that typical pragmatic errors of Germans speaking English as a foreign language (GEFLs) involve a high level of directness combined with a lack of mitigating features in their performance of speech acts. Such errors are particularly prevalent in the so-called "face-threatening acts", speech acts that hold some potential for conflict, embarrassment, insult, or imposition (e.g., censure or requests). By transferring German native speaker (NS) norms of linguistic behavior into English, GEFLs risk being perceived as brusque, even rude, by native speakers (NSs) of American English.

In examining the performance of the speech act of refusal by German learners of English, as compared with NSs of German and English, a number of issues arise. Thus, this literature review explores a wide range of different elements as background information for this cross-cultural study of speech act realization, in order to create a basis for understanding the questions involved.

The first section of this chapter provides information on the importance of pragmatic competence for English as a Second Language (ESL) students as a component of overall communicative competence. Next, the acquisition of pragmatic competence and pragmatic failure are discussed. The following section of the chapter focuses on speech acts as they relate to pragmatic competence. A special class of speech acts, the so-called "face-threatening acts," to which refusals belong, are then examined, and politeness phenomena are considered. A discussion of linguistic transfer from the native to the target 
language follows, and the chapter concludes with a review of research comparing the pragmatic performance of speakers of English and German.

\section{Communicative Competence}

According to Larsen-Freeman and Long (1991), enormous changes have taken place in the way researchers in the field of second language acquisition (SLA) regard language proficiency. Until recently, most SLA research was based on the mainstream transformational linguists' view of language, which places syntax in a focal position. Nowadays, however, researchers emphasize the need for students to develop "communicative competence" rather than mere linguistic proficiency.

In order to understand the discussion of the transformational-generative view of competence and the position taken by sociolinguists, such as Hymes, it is necessary to distinguish between "competence" and "performance." Citing Chomsky, Brown (1987) describes competence as "one's underlying knowledge of a system, event, or fact. It is the nonobservable, idealized ability to do something, to perform something" whereas performance is the "overtly observable and concrete manifestation or realization of competence" (p. 24). In terms of language, competence is an individual's implicit knowledge of the system of a language, including grammar rules, vocabulary, etc., and how these elements fit together within the system. Performance refers to production (speaking, writing) or comprehension (listening, reading) of utterances, i.e., actual language used for communication. 
Chomsky (1965) deliberately excludes performance from his definition of competence, as it is an imperfect reflection of the underlying linguistic knowledge of a competent speaker. His description of competence is based on an idealized speaker-hearer who is free of performance phenomena like slips of the tongue, memory lapses, distractions, errors, repetitions, false starts, pauses, omissions, etc. Chomsky reasons that a theory of language must be a theory of competence, dealing only with the generation of grammatically correct sentences, "lest the linguist vainly try to categorize an infinite number of performance variables which are not reflective of the underlying linguistic ability of the speaker-hearer" (Brown, 1987, p. 25). Chomsky's focus is on language structure rather than language use, i.e., on grammatical rather than pragmatic competence. Many researchers, however (Hymes, 1962, 1964, 1972a, 1972b, 1974; Canale and Swain, 1980; Wolfson, 1986, 1989; Olshtain and Cohen, 1983, 1991; and Larsen-Freeman and Long, 1991, among others) argue that knowledge of a language involves more than just the ability to produce grammatically correct sentences because language is also social behavior, requiring the acquisition of rules of appropriate social use of language. ${ }^{1}$ Campbell and Wales (1970) claim that the work of Chomsky and other generative grammarians fails to characterize the nature of competence because they have omitted the "most important linguistic ability", namely "the ability to produce or understand utterances which are not so much grammatical but, more important, appropriate to the context in which they are made" (p. 247). Lyons (1970) states that:

\footnotetext{
${ }^{1}$ It should be noted that Chomsky distinguishes grammatical and pragmatic competence (involving background knowledge and nonlinguistic information such as social norms). See for example Chomsky 1977.
} 
The ability to use one's language correctly in a variety of socially determined situations is as much and as central a part of linguistic 'competence' as the ability to produce grammatically well-formed sentences. (p. 287)

Hymes introduced the term, "communicative competence", to refer to the ability of NSs to use their language in ways that are not only linguistically accurate but also socially appropriate. In his words, communicative competence is the "knowledge of the rules for understanding and producing both the referential and the social meaning of language" (1964, p. 288). Communicative competence involves judgements of grammaticality (i.e., knowledge of linguistic rules) and of acceptability of utterances in relation to contextual features (i.e., knowledge of sociocultural rules for appropriate use of language). Knowledge of how to speak appropriately within one's community, like other forms of tacit cultural knowledge (i.e., competence) enables people to participate in and interpret social life. Gumperz (1972) distinguishes between linguistic and communicative competence as follows:

"Whereas linguistic competence covers the speaker's ability to produce grammatically correct sentences, communicative competence describes his ability to select, from the totality of grammatically correct expressions available to him, forms which appropriately reflect the social norms governing behavior in specific encounters" (p. 205).

Hymes argues against a dissociation of language structure from language use, maintaining that any realistic theory of language ability should be a theory of communicative competence. Thus, a grammar should account not only for the ability to produce and comprehend sentences, but also for the production of contextually appropriate utterances, and the recognition of inappropriateness. For Hymes (1972a), 
[A] description that does not specify linguistic features in relation to a community of speakers, their repertoires and the uses of these, has hardly validity, relevance, or interest. (p. 5).

Thus, Hymes' model of language encompasses not only linguistic competence and knowledge of language structure, but also the sociocultural dimensions of language.

Canale and Swain (1980) present a theoretical model of communicative competence consisting of three components: grammatical competence, strategic competence, and sociolinguistic competence. (As Larsen-Freeman and Long (1991) note, Canale revised his original analysis in 1983 to include a fourth component: discourse competence.) According to Canale and Swain's original framework, sociolinguistic competence consists of two sets of rules: sociocultural rules of use, and rules of discourse. The sociocultural rules of use determine how utterances are produced and understood appropriately, based on social, pragmatic, and cultural considerations, whereas the rules of discourse govern the combination of utterances and communicative functions. There are two aspects of discourse competence: cohesion, which holds sentences together within a larger piece of discourse, and coherence, which consists of organizational rules that make the sequence of the text meaningful. Strategic competence enables a speaker to rely on a repertoire of both verbal and nonverbal communication strategies to cope with or compensate for breakdowns in communication. An example of such a strategy is using paraphrase when one does not know a word, or when one does not know how to address someone because of uncertainty about the addressee's status.

Closely related to sociolinguistic competence is pragmatic competence (See Chapter I for a discussion of the distinction between 'pragmatic' and 'sociolinguistic' 
competence). Bialystok (1993) views pragmatic competence as the "interpretation of meaning in contexts" (p. 51). A variety of abilities are involved in pragmatic competence: the speaker's ability to achieve different purposes through the use of language, such as requesting or instructing, and the listener's ability to interpret linguistic forms in order to understand the full meaning of the message, also when the forms do not express the speaker's intentions directly, as is the case with indirect requests, irony and sarcasm.

Interpreting and producing language in contexts requires recognition of grammatically well-formed structures and appropriate use of language based on the specific situation, as well as knowledge of the relation between linguistic forms and the meanings of those forms in specific contexts. Competent speakers realize that a particular linguistic form may serve several different pragmatic functions, and that different forms may have the same illocutionary force (in other words, a given meaning can have a wide range of possible forms) and they evaluate contextual and social factors in order to select an appropriate form. As Bialystok notes, the goal of pragmatic learning is "to develop the resource of equivalents from which selections can occur. The richer the repertoire, the greater would be the pragmatic competence" (p. 51). Long (1990) provides several amusing examples of contextually inappropriate choices of linguistic forms in greeting and leave-taking:

(1) University vice-chancellor: Assistant lecturer:

'Morning, Smithers.

(2) Wife:

Husband:

(3) General:

Private Pilkington:

*Hi!

'Bye, darling. I'll leave your lunch in the oven.

*It's been a great pleasure.

Good luck, Pilkington. Remember, the honor of the

Regiment depends on this mission.

*'Bye, sir. Have a nice day! (p. 304) 
Long points out that judging the appropriateness of linguistic forms in a given social context enables NSs to use language effectively. Such judgments determine choices on the levels of syntax (I've never... versus Never have I...), lexicon (Pass the sodium chloride is appropriate in a laboratory but sounds odd or humorous at the dinner table), and phonology (an individual's speech will be more carefully articulated when presenting a formal lecture than engaging in a casual chat)(See Long, p. 304). Knowledge of contextual appropriacy rules allows people to communicate successfully, encoding meaning in the utterances they produce and decoding it from utterances they hear, based on their perceptions of the situation. Failure to do so can hinder communication (See section on pragmatic failure, this chapter.).

\section{The Acquisition of Pragmatic Competence}

Schmidt (1993) and Bialystok (1993) examine two different aspects of acquisition of pragmatic competence: Schmidt examines the role that conscious awareness plays in the acquisition of pragmatic competence in a second language, while Bialystok investigates differences in the pragmatic developmental stages of adult second language learners and children acquiring their first language.

Schmidt argues that, in order for pragmatic learning to take place, it is necessary to focus attention on the pragmatic information to be acquired. He examines other researchers' claims regarding the degree to which pragmatic knowledge is accessible to consciousness, citing Wolfson's (1989) assertion that NS knowledge of pragmatic and discoursal rules is primarily unconscious: 
Rules of speaking and ... norms of interaction are ... largely unconscious. What this means is that native speakers, although perfectly competent in the uses and interpretation of the patterns of speech behavior which prevail in their own communities are, with the exception of a few explicitly taught formulas, not even aware of the patterned nature of their speech behavior. [Native speakers] $\ldots$ are not able ... to describe their own rules of speaking. (Wolfson, 1989, 37)

A number of factors contribute to the fallibility of NSs' intuitions, including the effects of prescriptive norms and folk-linguistic beliefs. As Schmidt notes, "when asked what they do, informants are likely to report what they think they should do" (p. 22).

Schmidt asserts that while NSs do not always have access to their own rules of speaking, it is not true that they never have access to these rules. As evidence, Schmidt cites Blum-Kulka and Sheffer's (1993) and Olshtain and Blum-Kulka's (1989) findings that Hebrew-English bilinguals in Israel display an awareness of their code-switching behavior and Ochs' (1979) observation that both spontaneity and planning play a role in conversations. Pragmatic knowledge is sometimes used consciously, for example in preplanned telephone conversations, in the forethought involved in writing, and in efforts made to use polite language.

Schmidt maintains that "noticing" is an essential component of first language (L1) and second language (L2) acquisition. He argues that ethnographic studies of language socialization "show that an important child-rearing goal is to develop the child's communicative competence" (p. 28). Schmidt cites research by Demuth (1986), Ochs (1986), Clancy (1986), and Watson-Gegeo and Gegeo (1986) suggesting that care-givers employ various socialization strategies in teaching children what to say and when to say it. As Gleason and Perlmann (1985) assert: 
Unlike the acquisition of syntax, semantics, and even some sociolinguistic rules, when it comes to speaking politely adults do not leave it to the child to construct the rules on his or her own. Here, they take an active, even energetic part in directly instructing their children in the use of the various politeness devices. (p. 102).

In regards to L2 pragmatic learning, Schmidt asserts that there is a close connection between noticing and understanding pragmatic elements and pragmatic learning. Attention to input is indispensable for any learning to occur. Furthermore, attention must be drawn to the specific features of the input involved in the system to be learned. In the case of L2 pragmatics, this would be "attention to linguistic forms, functional meanings, and the relevant contextual features" (p. 35).

In Schmidt's view, L2 learners cannot acquire pragmatic knowledge through exposure to sociolinguistically appropriate input alone because they may fail to recognize relations between linguistic forms and pragmatic functions. They may interpret contextual factors differently from NSs or overlook them. Schmidt believes that, in L1 acquisition, it is the efforts of caregivers to teach communicative competence that prevents this from happening, rather than some sort of innate pragmatic acquisition device.

Schmidt encourages second language instructors to use classroom activities that will alert learners to pragmatic features, for example, task-based language teaching (Long, in press). Schmidt also recommends that instructors provide explicit information about the pragmatics of the target language, taking care to provide accurate information that does not rely only on "fallible native speaker intuitions"(p. 36).

Bialystok (1993) discusses differences in children acquiring L1 pragmatics and adults learning L2 pragmatics. Children need to learn the wide range of language functions 
expressed by NSs in everyday life, developing associations between linguistic forms and pragmatic functions. Adult L2 learners, on the other hand, need to learn about social conventions operating in the new language and recognize relationships between forms and social contexts, but they have already organized a linguistic system according to speech functions in their first language. For adults, acquiring pragmatic competence entails developing strategies for interpreting utterances as intended in given contexts and selecting linguistic forms from the set of alternate possibilities that are socially and contextually appropriate to the communicative situation.

Bialystok's model of pragmatic development consists of three stages:

- Conceptual representation: The speaker is able to form utterances to express specific speech acts but the focus is on the intended meaning without consideration of the forms used to express that intention;

- Formal representations: Speakers recognize sets of utterances as belonging to a particular category of speech acts, e.g., requests or assertions, and perceive the connection between direct and indirect speech acts (Note: In an indirect speech act, the linguistic form does not match the illocutionary force, e.g., "Could you pass the salt?" has the form of a yes/no question, but serves as a request);

- Symbolic representation: In addition to the foregoing, the speaker has developed a repertoire of different forms to express a particular pragmatic content and an understanding of the relations between linguistic forms and pragmatic functions. Such speakers grasp how linguistic devices such as politeness markers modify the interpretation of utterances in specific social contexts. 
According to Bialystok, adult second language learners normally begin the process of acquiring the pragmatic structure of the target language at the second (formal) level of representation, whereas children "begin with the problem of "how to mean"' (p. 53). In other words, they need to develop a repertoire of speech acts and learn how to engage in conversation and evaluate the discourse of others.

Clark and Clark (1977) observe that young children in the earliest stages of L1 acquisition are generally limited to the production of assertions regarding the existence, location, and properties of objects, and requests motivated by needs or wants, such as food, drink, or toys. Children gradually expand their repertoire of speech acts and learn to modify their utterances to accommodate social norms, they learn how to interpret indirect forms, and acquire knowledge of conversational conventions. While these abilities are present in a rudimentary form from a very early age, the development of real pragmatic competence takes until a child reaches school age.

Adult learners have already accomplished these tasks in their L1. Their next step is to learn the appropriateness of a particular form in a given context and to expand their range of alternative forms for expressing specific pragmatic functions in the target culture. They may have to learn new categories because of differences in social distinctions made in the speakers' native language and target language, for example, distinctions regarding social status, age, or gender of the listener. Conversational rules regarding turn-taking, interrupting, and opening and closing conversations will require attention. In addition, some languages tend to be more indirect in the realization of speech acts than others. 
Some languages contain a greater variety of ways to express a given intention. Learning these pragmatic conventions and forms is requisite for developing pragmatic competence.

\section{Pragmatic Failure}

Olshtain (1983) notes that despite a high level of proficiency in a target language, adult second language learners can experience difficulty interacting with NSs. ESL students might come to feel that "Americans don't mean what they say" after misinterpreting utterances such as the typical signal for closing a conversation, "You'll have to come and visit me sometime." The results of taking such a form literally can be embarrassment and resentment. Unfamiliarity with sociocultural rules can also cause learners to unwittingly violate target language norms. Olshtain (1983) observes that Hebrew speakers of English who express apologies by providing an excuse without using an expression like "I'm sorry" might sound rude or aloof to NSs.

Kasper and Blum-Kulka (1993) outline three major approaches to the study of pragmatic failure. Miscommunication research analyzes naturally occurring communication along sociolinguistic lines in order to identify pragmatic failure. It detects "problematic features at the levels of prosody, pragmatics, syntax, lexis, discourse organization, conversational management, and nonverbal behavior"(p. 12). Contrastive pragmatics describes cross-cultural differences and similarities in the realm of pragmatics. A third line of research, which Kasper and Blum-Kulka refer to as "Interlanguage Pragmatics," examines the relationship between learners' knowledge of their L1 and L2 and their pragmatic behavior. Comparing learners' pragmatic performance and 
interpretation with corresponding $\mathrm{L} 1$ and $\mathrm{L} 2$ data enables researchers to: 1) recognize pragmatic differences in learners' production and comprehension from NS norms; 2) determine where learners carry over L1 knowledge to their target language performance; and 3) recognize other sources for learner-specific pragmatic behaviors besides transfer (e.g., see Kasper, 1981; Blum-Kulka, 1982; Schmidt, 1983; Olshtain \& Cohen, 1989). All three forms of research are necessary for recognizing the interconnectedness of crosscultural differences, learner-specific pragmatic features, and communicative effects. In addition, Kasper and Blum-Kulka assert the importance of other kinds of research, such as NS judgements of learners' performance (See for example Fraser, Rintell, \& Walters, 1980; Eisenstein \& Bodman, 1986, 1993), for gaining insight into communicative effect.

A considerable body of literature examines the potential for miscommunication in cross-cultural encounters. Among the more compelling are Cohen and Olshtain (1981); Rubin (1983); Wolfson (1983a and b); Scarcella (1990); and Olshtain and Blum-Kulka (1985). Wolfson (1983b) emphasizes the importance for nonnative speakers (NNSs) of understanding the cultural values underlying speech because this is the basis for using language appropriately and interpreting utterances accurately. According to Lovik (1987), shared knowledge of the culture and language enables NSs to understand conversational intentions even when these are not explicitly expressed. Bialystok (1993) notes that it is particularly difficult for NNSs to interpret the intentions behind nonliteral forms, such as metaphorical uses of language and indirect requests (e.g., "Gee, it's hot in here..."). Because of the nonuniversality of the rules of speaking, NNSs are often unable to see beyond the surface meanings of words to recognize the implicit meanings. 
Olshtain and Blum-Kulka (1985) stress the need for L2 learners to acquire sociocultural rules of appropriacy in addition to grammar rules, because without sociocultural competence, a grammatically competent NNS may experience breakdowns in communication. According to Wolfson (1983b), rules for appropriate speech vary so greatly from one society to another that communicative competence in one's native language will not translate into an ability to interact successfully with NSs of the target language community. Paulston (1990) notes that even a proficient bilingual may not exhibit full communicative competence:

"It is easier to keep one's linguistic codes separate than one's social codes as one often is not aware of the social codes on a conscious level until they are violated. It is much easier to be bilingual than bicultural" (p. 291).

Thomas (1983) examines the difficulty NNSs experience in cross-cultural realization of speech acts. She distinguishes between two types of "pragmatic failure" (i.e., the inability to understand what is meant by what is said): "pragmalinguistic failure" and "sociopragmatic failure." Pragmalinguistic failure involves direct translation of a first language utterance into the target language resulting in an utterance that fails to express the intended meaning because of differences in communicative conventions. An example of this is the typical English convention of making an indirect request by using a question form, such as "Can you open the window?" NSs of English recognize such forms as requests for action rather than requests for information. However, if an American speaker transfers this rule for making requests to say, Russian, his or her addressee will be unlikely to interpret the utterance as the intended request (This type of indirect speech act will be discussed further in the section on speech acts below.). Rubin (1983) notes that linguistic 
forms that appear to be translatable from one language to another can be misleading, serving different, and sometimes even opposite, pragmatic functions. The German-English cognates 'thank you' and 'danke' are an example of this. Both can be used to respond to offers; however, in English, when one responds to an offer with 'thank you,' it signals acceptance of the offer, whereas in German, a response of 'danke' expresses refusal:

English: A: Would you like a piece of cake?

B: Thanks. (= 'yes')

German: A: Möchtest du etwas Kuchen?

B: Danke. (= 'no, thanks') (Also see Lovik, 1987, pp. 40-41).

Sociopragmatic failure, on the other hand, refers to knowing what to say and whom to say it to. According to Thomas, misunderstandings can result from differing perceptions of relative power or social distance, taboos, size of imposition, and value judgements. For example, a Japanese visitor to the USA might have difficulty with American invitations. In Japan, urging a guest to accept an invitation signals hospitality, whereas American speakers avoid imposing on the addressee what might be an unwanted invitation. As neither party is aware of the other's rules, misunderstandings can easily result-in such a situation, the Japanese addressee might feel that the invitation is not truly sincere.

Acceptable topics of conversation also vary greatly across cultures. Thomas notes that, whereas a Ukrainian speaker would consider it perfectly polite to ask direct questions about a stranger's income, political views, religion, or marital status, his or her American addressee might perceive such questions as invasive. As Eisenstein and Bodman (1993) observe, violation of social norms may result in loss of face with accompanying negative feelings on the part of one or both participants. 
A number of studies suggest that even relatively advanced second language learners fail to achieve native-like communicative competence, both in terms of speech act performance and overall sociolinguistic competence (House and Kasper 1981, Cohen and Olshtain 1981, Blum-Kulka 1982, Thomas 1983, among many others.). Olshtain and Blum-Kulka's (1985) study of the effects of acculturation on NNSs' reactions to native speech act behavior, on the other hand, seems to indicate that regardless of the level of linguistic competence, the longer L2 learners stay in the target speech community, the more their judgements of acceptability approximate target language norms. Their findings suggest the possibility that language learners' receptive speech act behavior is more responsive to the effects of acculturation than their production of speech acts. It must be noted, however, that it took over ten years for the response patterns of the NNSs in this study to resemble those of NSs.

Scarcella (1990) notes that cross-cultural differences in the rules governing conversation (including elements such as thematic development, turn-taking, and topic change) can cause communication difficulties in conversations between second language learners and NSs, because the intent of the speaker is misunderstood by the addressee. According to Scarcella, NNSs frequently transfer the conversational rules of their first language into the second, leading to inaccurate assessments of NSs' communicative intent.

Scarcella reviews research findings related to character judgments, noting that:

- Within individual cultures there is considerable consensus about personality traits associated with specific conversational features (See Giles 1979);

- Different cultures and subcultures associate these traits and features differently; 
- Linking of personality traits with conversational features often leads to negative and erroneous stereotyping (See Giles and Saint Jacques, 1979; and Scherer and Giles, 1979); and

- People tend to be so tenacious in upholding character judgments that they become oblivious to contradictions between their prejudices and others' actual behavior (See Gumperz and Tannen 1979)

Scarcella's survey of research demonstrates that pragmatic failure can have serious negative consequences in cross-cultural encounters. Violations of sociocultural rules can lead to misjudgments of character, which in turn hinder individuals in achieving personal goals, for example, by spoiling business negotiations or job interviews. Gumperz (1978) found that, because of communication difficulties, British professionals frequently made negative and inaccurate character judgments of Indian and Pakistani workers, resulting in the NNSs' inability to attain job positions for which they were qualified. Graham (1981, cited by Scarcella, 1990) contends that American businesspeople have lost billions of dollars in business transactions because they misinterpreted the conversational features of their Japanese clients during sales negotiations.

In schools, when teachers misinterpret the interactional patterns of children from other cultures, students can be erroneously perceived as language deficient or uncooperative. This can adversely affect academic achievement (Scarcella cites the following studies: Gumperz and Tannen 1979; Philips 1970, 1972, 1983; Mohatt and Erickson 1981; Weeks 1983; Heath 1982; Boggs 1972; Dumont 1972; Jaramillo 1973; Spindler and Spindler 1987). 
Communicative failure can also have a negative impact on second language acquisition. Scarcella argues that repeated communication difficulties can cause language learners to draw back from speakers of the target language, "clinging to their own cultural groups instead of interacting with members of the target culture" (p. 342), which prevents them from getting input needed for further acquisition (see Gumperz and Tannen's 1979 “clannishness" hypothesis). According to Krashen's (1981) input hypothesis, the greater the social distance between learners and NSs of a target language, the less likely it is that the learner will be adequately exposed to comprehensible input.

According to Krashen (1981) and Dulay, Burt, and Krashen (1982), learning is resisted in an anxiety-filled or unpleasant environment. A learner's attitudes and emotions can act as a filter, blocking L2 input and impacting acquisition; they refer to this phenomenon as the "affective" or "socioaffective filter." While there is no empirical evidence for such a filter, this concept provides a reasonable explanation for observed effects. Scarcella asserts that communication difficulties can cause psychological discomfort, creating a strong affective filter that inhibits acquisition.

To avoid misunderstandings and interact successfully with NSs, it is essential that language students be familiarized with the pragmatic and sociocultural aspects of the target language and receive instruction in appropriate usage. As Schmidt and Richards (1980) maintain, second language learning and teaching should "include knowledge of the rules of use and communicatively appropriate performance" (p. 129). At the very least, language learners should be sensitized to the fact that differing sociolinguistic patterns exist. 


\section{Speech Acts}

\section{Defining Speech Acts}

Speech act theory (Austin 1962; Searle 1969, 1975, 1976, and 1979; Davison 1975; Sinclair and Coulthard 1975; among other researchers) is concerned with identifying the functions of utterances, in Hatch's (1983) words, "what we do with language" (p. x). The term "speech acts" generally refers to a category of speech acts called illocutionary acts, which, according to Fraser (1985, cited by Rintell, 1990), are used by a speaker to make the hearer aware of some state-of-the-world and in so doing, to make the hearer recognize the speaker's intended communicative force (e.g., a promise, complaint, request, etc.). According to Rintell (1990), a speech act "is successfully performed when the hearer recognizes the speaker's intent to perform it" (p. 77).

Austin (1962) observed that certain verbs "name" the act that is being performed, for example, "to request," or "to complain." He referred to these verbs as "performative verbs." However, as Searle (1976) pointed out, a variety of verbs differing in semantic meaning can be used to realize the same speech function. Indeed, performative verbs are generally only used in very formal speech events, e.g., "I request..." or "I apologize...", in contrast to more common expressions like "Please give me..." or "I'm sorry." Searle (1975 and 1979) also noted that sometimes speech acts are expressed indirectly through the performance of a different speech act. Thus a request could take the form of a compliment (e.g., "Gee, those cookies look good...") or of an information-seeking question (e.g., "Can you lift the TV set?"). A speech act, then, according to Searle, can be performed in various ways: by using the corresponding performative verb (e.g., 
"apologize"); in a direct speech act by using an explicit verb (e.g., "be sorry"); or though an indirect speech act by making a statement about some state of affairs which, in the particular context, is intended to be interpreted as the appropriate speech act (e.g., an excuse or explanation instead of a direct apology). Hatch (1983) illustrates this point with an example: a single pragmatic function can take the form of "a question (can we have quiet?), an embedded imperative (would you please be quiet), an imperative (be quiet!), a hint (sure is noisy in here), etc." (p. x). The choice of syntactic form will be determined on the basis of a variety of contextual factors such as gender, age, and relative status of the interlocutors. According to Searle (1975), the primary motive for using indirect forms is politeness, as the form gives (or appears to give) the hearer more options. In the case of a request, for example, using the form of a yes/no question allows "no" as a response, making it easier to refuse. Thus, fulfilling the request appears to be an act of free will rather than following an order. Davison (1975), on the other hand, asserts that indirect speech acts are not so much used for politeness, as for maintaining personal distance and disarming resistance, unpleasantness or potential conflict arising from the speaker's intention to share bad news, express unfavorable opinions, or ask intrusive questions, etc.

In Searle's (1979) view, there are five major types of language functions. His exhaustive list of possible speech acts includes: directives (e.g., commands or requests), commissives (promises to do something), expressives (statements of feelings), representatives (statements that have verifiable truth value), and declaratives (statements which change the real world when uttered, e.g., "I declare you guilty as charged"). According to Hatch (1983), these categories can be subdivided: 
[C]ommissives may be vows, pledges, promises, agreements, showing a willingness, obligation, or only a proposal to act; representatives may be assertions, and the speaker may show that the truth value is sure, probable, possible, uncertain, or negative. Speakers may be convinced, doubtful, making a conjecture, or hedging, or they may even disassociate themselves from the truth value of the statement. An expressive may show one's (dis)approval, valuation, state of (un)happiness, etc. A directive may be a permission, a recommendation, an inciting, an invitation, an order, or a command..."(p. ix).

Other systems have been proposed, such as Halliday's (1975) distinctions between the ideational, interpersonal, and textual functions of language, or Leech's (1983) functional classification, e.g., "convivial acts" such as thanking and apologizing, and "competitive" acts such as complaining, requesting, or correcting. All of these taxonomies share a common feature, namely the fact that NSs are normally expected to master the different linguistic functions represented by the categories.

As Hatch (1983) notes, not only can a single speech act function be expressed in a variety of syntactic forms, but also, one syntactic form can have a variety of functions (see this chapter, section on pragmatic failure.). Hatch provides an example: A statement such as "McDonald's just opened" could be used as an invitation for a meal, an explanation for a traffic jam, or a contradiction of "McDonald's is closed" (p. x). Hatch asserts that

The context in which the utterance is made determines the speech act function of the utterance and, along with other sociolinguistic variables, may determine its syntactic form." (p. x).

Rubin (1983) asserts that in order to interpret a speech act, one must understand it "as a totality." Merely looking at the form-function relation within a speech act is not sufficient to interpret its message —one must also recognize "the underlying values inherent in the speech act" (p. 11). This is the kind of knowledge referred to by the term "communicative competence." Thus, three levels of knowledge are necessary for 
successful realization of speech acts: recognition of the appropriate form-function relations, an understanding of social dimensions of a given speech act, and an awareness of the underlying values of the culture in question. A number of researchers discuss the appropriate realization of speech acts as a component of communicative competence (e.g., Schmidt and Richards, 1980; Blum-Kulka, 1982; Olshtain and Blum-Kulka, 1985).

\section{Speech Act Sets}

According to Olshtain and Cohen (1991, also Cohen and Olshtain 1981, Olshtain 1983, and Olshtain and Cohen 1983), every language has "routinized realization patterns" for performing functions such as apologies, requests, complaints, refusals, and compliments, which they call "speech act sets." Olshtain (1983) states that the various utterances that can function as a particular speech act together make up the set of semantic formulas that constitute a speech act set. These semantic formulas have been described by Fraser (1980) as linguistic and pragmatic strategies used to perform a speech act. Olshtain and Cohen (1983) state that "[e]ach semantic formula consists of a word, phrase, or sentence which meets a particular semantic criterion or strategy, and any one or more of these can be used to perform the act in question" (p. 20).

An example of a speech act set is Olshtain and Cohen's (1991) model of the apology speech act set, which consists of five strategies or realization patterns:

1. the explicit expression of an apology, using a formulaic, routinized utterance (e.g., "I'm sorry," "Excuse me," "I regret," "I apologize");

2. an acknowledgement of responsibility, which reflects the speaker's degree of willingness to admit to fault for the offense; 
3. an explanation of the situation which caused the speaker to commit the offense;

4. an offer of repair (e.g., payment to cover damage caused by the speaker); and

5. a promise of nonrecurrence.

The latter three strategies are situation-specific and semantically reflect the content of the situation. According to Olshtain and Cohen, these five strategies apply universally to apologies in any language; however, the choice of apology strategies used depends on the specific situation within the given language and cultural group. Olshtain(1983) notes that while the need to apologize in certain situations may be universal (e.g., insulting or injuring a person), perceptions of the severity of an offense or circumstances related to the offense might differ cross-culturally, leading to differing choices of semantic formulas and apology intensities.

In addition to the main strategies, apologies can be modified through intensification or downgrading. Intensification usually consists of internal modification of the apology expression using forms like "really", "very", or "terribly." External modification can take the form of an additional comment signaling concern for the hearer. The apology can be downgraded through the use of a comment that minimizes either the offense or the harm it may have caused. (For further information regarding the apology as a speech act set and cross-cultural differences in the norms related to apologies, as well as considerations for syllabus and textbook design, see Olshtain and Cohen, 1983. Olshtain and Cohen, 1991, provide suggestions for teaching techniques for speech acts.) 
Beebe, Takahashi, and Uliss-Weltz (1990) as well have proposed a set of realization strategies and modifications for the speech act of refusal (See section on refusals, this chapter).

\section{Speech Acts and the ESL Learner}

A considerable body of research (e.g., Cohen and Olshtain, 1981; Manes and Wolfson, 1981; Manes, 1983; Olshtain and Cohen 1983; Rubin 1983, Blum-Kulka 1983; Takahashi and Beebe, 1987; Blum-Kulka, House, and Kasper, 1989; and Beebe, Takahashi, and Uliss-Weltz, 1990) explores the degree to which speech acts are universal, with results that suggest the nonuniversality of speech act rules. Hatch (1983) observes that, while every language may have the same categories of speech acts, i.e., directives, commissives, representatives, expressives, and declaratives, the strategies for expressing them will vary in different languages. Wolfson (1983b) asserts that universals "exist only at a very general functional level while the actual realizations of speech acts are strongly conditioned by culture-specific rules...” (p. 4).

ESL students often face difficulties in the interpretation and performance of speech acts. Hatch notes that in contrast to NSs, who usually recognize the pragmatic function of utterances, NNSs sometimes are unable to identify the intended function of a given form. Wolfson's (1970) findings show that ESL students have a hard time determining whether ambiguous invitations (such as "Let's get together sometime soon") are intended as directives or are simply "expressive speech acts with a friendship bonding function" (p. xi). In a study of the language used by ESL students (both beginners and university students) to perform idiomatic, stereotyped speech acts, Scarcella (1979a) found numerous errors 
involving expressions like 'shut up', 'hurry up', 'bless you', 'come on in', and 'time's up'. The errors included (1) paraphrases ('who's behind the door?' for 'who's there?'); (2) incompletely learned formulas ('watch up!' for 'watch out!'); (3) translations ('congratulations' from 'felicidades' for 'happy birthday'); and (4) substitutions ('welcome' for 'bless you').

According to Hatch, learners often focus on learning the most polite forms, assuming that they'll avoid the most faux pas that way, but this isn't always the case because unexpected formality can be misinterpreted as hostility or distancing, even if that was not the NNS's intention. At the same time, ESL learners in the USA are exposed to many informal, colloquial forms, which mix in with the politeness register, creating inappropriate juxtapositions of formal and casual forms, such as Scarcella's (1979b) example, "Hi, sir" (p. 285).

It was noted above that pragmalinguistic failure can occur when a NNS translates an utterance with a particular illocutionary force in his or her first language into the target language, not realizing that the utterance may be interpreted differently. Such miscommunication is particularly likely with indirect speech acts because form and function do not coincide. For example, the question form, 'Can you open the window?', may be used to make a request. This utterance carries both a basic, propositional meaning (i.e., questioning the addressee's ability to perform an action) and an intended illocutionary meaning (in a given context, the speaker is requesting that the addressee perform the action). By viewing the content of the utterance in its situational context, NSs recognize the illocutionary force of the utterance. If this question is translated directly into 
another language, it may lose its illocutionary force as a request and be interpreted in terms of its propositional meaning, i.e., as a request for information about the addressee's ability to open the window.

Kasper \& Blum-Kulka (1993) state that conventionalized expressions (e.g., 'I'm sorry' or 'thank you') are frequently used to perform speech acts and that they are more common in some speech acts than others. Therefore, in addition to knowing which acts are appropriate or expected in the target community, learners must recognize what standardized routines need to be used and how they should be combined with other expressions of a given content, such as gratitude or regret.

A vast number of speech act tokens will be interpreted very differently in different cultures. (It is also important to note that not all speakers of a language share the same rules of speaking: Within a culture, speaking conventions can vary along geographic, socioeconomic, and racial lines.) The speech act of complimenting is a good example of how conventions contrast across cultures. Wolfson (1989) states that compliments occur more frequently and in a wider range of speech situations amongst Americans than in many other cultures. As Wolfson (1983a) and Manes (1983) note, compliments can function as a "social strategy" for establishing or maintaining rapport by expressing admiration or approval. Compliments are frequently used as part of a greeting, to open a conversation, or as an expression of gratitude. Compliments are also often used to reinforce desired behavior, and frequently co-occur with apologies, thanks, and greetings, for example: "That was a delicious dinner. Thanks for having us." Compliments are also often used to soften criticism. In cross-cultural interactions, the American custom of 
praising the belongings, accomplishments, and appearance of others violates the expectations of non-Americans. They may react by viewing Americans as "effusive, insincere, and possibly motivated by ulterior considerations" (Wolfson, 1989, p. 23 ${ }^{2}$ ). Wolfson (1983a) notes that the typical American style of teaching through encouragement and compliments can shock students from different cultures.

According to Wolfson's (1986) study, in American English, almost half of the time an adjective is used in a compliment, it is either "nice" or "good", and another $25 \%$ of the time it is "beautiful", "pretty", or "great." The fact that the linguistic forms of American compliments are so repetitive is evidence that their significance lies more in their social purpose than in their "truth value." Olshtain and Cohen (1991) maintain that in other cultures where compliments occur less frequently and speakers are expected to commit themselves to the content of the compliment, such adjectives are likely to be considered "empty" and "meaningless."

Some of the comments that Americans perceive as compliments might actually seem insulting to someone who interprets the statement differently. Stating that someone looks unusually nice is generally positive for Americans. Wolfson (1986) gives examples of this kind of compliment:

(1) Hey, what's the occasion? You look really nice today.

(2) Wow! Linda! What did you do to your hair? I almost didn't recognize you. It looks great (p. 114)

\footnotetext{
'I might note that my own experience in Germany strongly supports Wolfson's assertion. Compliments there serve a much more limited range of functions than in American English.
} 
Wolfson (1986) provides an anecdote about a bilingual French graduate student in America who had felt hurt by such a compliment from a classmate, assuming that an insult had been intended. The same kind of cultural clash could easily take place between Americans and Germans. (To further explore the pragmatic dimensions of compliments, see Wolfson, 1983a and 1986; and Manes, 1983.).

\section{Face-Threatening Acts (FTAs)}

\section{The Concept of "Face" and Social Dimensions of FTAs}

As Takahashi and Beebe (1993) observe, face-threatening speech acts (FTAs) are an important object of study because they are the root of a great deal of cross-cultural miscommunication. Brown and Levinson $(1978,1987)$ have devoted considerable research towards defining FTAs and creating a theoretical framework outlining the decision-making process that speakers go through when choosing strategies for performing these speech acts. According to Brown and Levinson, realization of the entire gamut of pragmatic functions boils down to variation of three basic contextual factors: social distance, power, and culture-specific evaluations of threat to face. As Olshtain and Blum-Kulka (1985) and Gumperz (1987) assert, Brown and Levinson's theoretical framework provides a means for making cross-cultural comparisons, and can be used as a basis for predictions that can be verified through empirical research. Blum-Kulka, House, and Kasper (Blum-Kulka \& Olshtain, 1984; Blum-Kulka, House, and Kasper, 1989), for example, have documented complex patterns of interaction between features of social context and the linguistic realizations of speech acts in their analysis of CCSARP (Cross-Cultural Speech Act 
Realization Patterns) data (a large-scale project investigating requests and apologies in Hebrew, Danish, German, Canadian French, and British, American and Australian English).

Goffman (1972) observes that individuals have an emotional investment in their "face," which is "an image of self, delineated in terms of approved social attributes" and "the positive social value a person effectively claims for himself by the line others assume he has taken during a particular contact" (p. 319). Brown and Levinson (1987) view "face" as an individual's "self-esteem" or "public self-image", consisting of two aspects: negative face and positive face. Negative face involves "freedom from imposition" and "the desire to be unimpeded in one's actions", whereas positive face refers to one's positive self-image in social interaction and the desire for others to approve of this selfimage (p. 61). This concept of "face" is derived from the expression "losing face" which refers to being embarrassed or humiliated. Because of the emotional significance of face, and because of individuals' mutual vulnerability of face and interdependence, people generally cooperate and expect others to cooperate in maintaining face in interaction. Goffman (1972) observes that individuals have a two-fold concern in regards to facesaving: a defensive impulse to save one's own face and a protective tendency to save the hearer's. As Brown and Levinson assert:

“... normally everyone's face depends on everyone else's being maintained, and since people can be expected to defend their faces if threatened, and in defending their own to threaten others' faces, it is in general in every participant's best interest to maintain each others' face..." (p. 61).

Certain kinds of acts are inherently face-threatening because they go against the face wants of hearer and/or speaker. Brown and Levinson distinguish between acts that 
threaten negative face and those that threaten positive face, and threats to $\mathrm{H}^{\prime} \mathrm{s}(\mathrm{H}=$ the hearer) face as opposed to threats to $S$ 's $(S=$ the speaker) face. Acts that threaten the hearer's negative face hamper H's freedom of action by a) speaking of a future act to be performed by $\mathrm{H}$, e.g., orders, requests, suggestions, advice, warnings, dares, etc.; b) stating a future act of $\mathrm{S}$ toward $\mathrm{H}$, which $\mathrm{H}$ must either reject, or accept with the possibility of becoming indebted to S, e.g., offers and promises; and c) expressing an interest on S's part toward $\mathrm{H}$ or H's belongings, potentially forcing $\mathrm{H}$ to protect the object of S's desire or give it to S, e.g., compliments, expressions of envy or admiration, or expressions of strong emotion toward $\mathrm{H}$, such as hatred anger, or lust.

Acts that threaten positive face indicate that $\mathrm{S}$ does not care about $\mathrm{H}$ 's feelings, wants, etc. by a) displaying a negative evaluation of some aspect of H's positive face, e.g., expressions of disapproval, criticism, ridicule, complaints, reprimands, accusations, insults, or disagreements; or b) exhibiting a lack of concern about H's positive face, e.g., expressions of violent emotions, irreverence, mention of taboo topics, blatant noncooperation in an activity (such as disruptive interruptions), or use of address terms and other status-marked identifications in an offensive or embarrassing way. There is overlap of categories because some FTAs threaten both negative and positive face, e.g., complaints, interruptions, threats, or requests for personal information.

Acts that primarily threaten S's face may also potentially threaten H's face because $\mathrm{S}$ and $\mathrm{H}$ cooperate to maintain face. FTAs that are threatening to $\mathrm{S}$ include threats to negative face, such as expressions of gratitude, excuses, unwilling promises or offers, and 
acceptance of H's thanks, apologies, or offers. Damage to S's positive face includes apologies, acceptance of a compliment, confessions, etc.

Tricky situations often arise when preserving another individual's face comes into conflict with a speaker's own need or wish to say things that infringe on the hearer's face. According to Brown and Levinson, when speakers assess of the seriousness of an FTA, they consider the following sociological variables: the "social distance" (D) between S and $\mathrm{H}$; the relative "power" $(\mathrm{P})$ of $\mathrm{S}$ and $\mathrm{H}$; and the ranking $(\mathrm{R})$ of impositions involved in performing the FTA in the given culture. Brown and Levinson illustrate the independence and relevance of the $\mathrm{D}, \mathrm{P}$, and $\mathrm{R}$ factors with the following examples:

Keeping $\mathrm{P}$ and $\mathrm{R}$ constant, and varying only $\mathrm{D}$ in the two utterances (that is, the relative power of $\mathrm{S}$ and $\mathrm{H}$ is more or less equal, and the imposition is small, but social distance varies):

1. Excuse me, would you by any chance have the time?

2. Got the time, mate?

In (1), $\mathrm{S}$ and $\mathrm{H}$ are distant, whereas in (2), $\mathrm{S}$ and $\mathrm{H}$ are close (either acquainted or linked by shared social characteristics).

$\mathrm{D}$ and $\mathrm{R}$ are kept constant and have small values (in other words, $\mathrm{S}$ and $\mathrm{H}$ know each other by sight, and the imposition is a request for something inconsequential), but the $\mathrm{P}$ variables is manipulated:

(3) Excuse me sir, would it be all right if I smoke?

(4) Mind if I smoke? 
Brown and Levinson suggest that (3) might be said by an employee to his boss, whereas the boss might say (4) to the employee under the same circumstances. (p. 80)

$\mathbf{R}$ is modified while $\mathbf{P}$ is small and $\mathrm{D}$ is great ( $\mathrm{S}$ and $\mathrm{H}$ are strangers):

(5) Look, I'm terribly sorry to bother you but would there be any chance of your lending me just enough money to get a railway ticket to get home? I must have dropped my purse and I just don't know what to do.

(6) Hey, got change for a quarter? (p. 81)

Either of these forms might be said to a stranger, but (5) implies a much more serious imposition than (6).

In each of the examples above (1-6), the first member of each pair (examples 1, 3, and 5) represents the negative politeness strategy, and the second $(2,4$, and 6$)$ demonstrates positive politeness.

Brown and Levinson's arguments can be summarized as follows: All competent adult members of a society have positive face and negative face. Because of mutual vulnerability of face, speakers generally try to avoid face-threatening acts, or use certain strategies to minimize the threat. In other words, speakers consider and prioritize three factors: (1) the relative importance of communicating the content of the FTA; (2) the urgency of the situation or the need for efficiency; and (3) the concern to protect H's face. Unless S's need to perform an FTA with maximum efficiency takes precedence over his or her desire to maintain H's face, $S$ will try to minimize the face threat of the FTA. The more an act threatens S's or H's face, the harder S will try to choose a strategy that will either minimize risk or increase benefits from payoffs. On the other hand, individuals will 
not choose a strategy less risky than necessary, as $\mathrm{H}$ might interpret this as a signal that the FTA is more threatening than it actually is.

\section{Brown and Levinson's Model of Speakers' Considerations when Performing FTAs}

Brown and Levinson provide a model to outline speakers' choices of strategies for the performance of FTAs. At the basis of their model of politeness phenomena is the assumption that a speaker who intends to perform a FTA (such as a complaint or request) has a series of options to consider. At each juncture of this option-choosing process, the speaker makes a decision:

Table 2.1: Choices Involved in the Performance of Face-Threatening Speech Acts (adapted from Brown and Levinson, 1987, and Olshtain and Blum-Kulka, 1985)

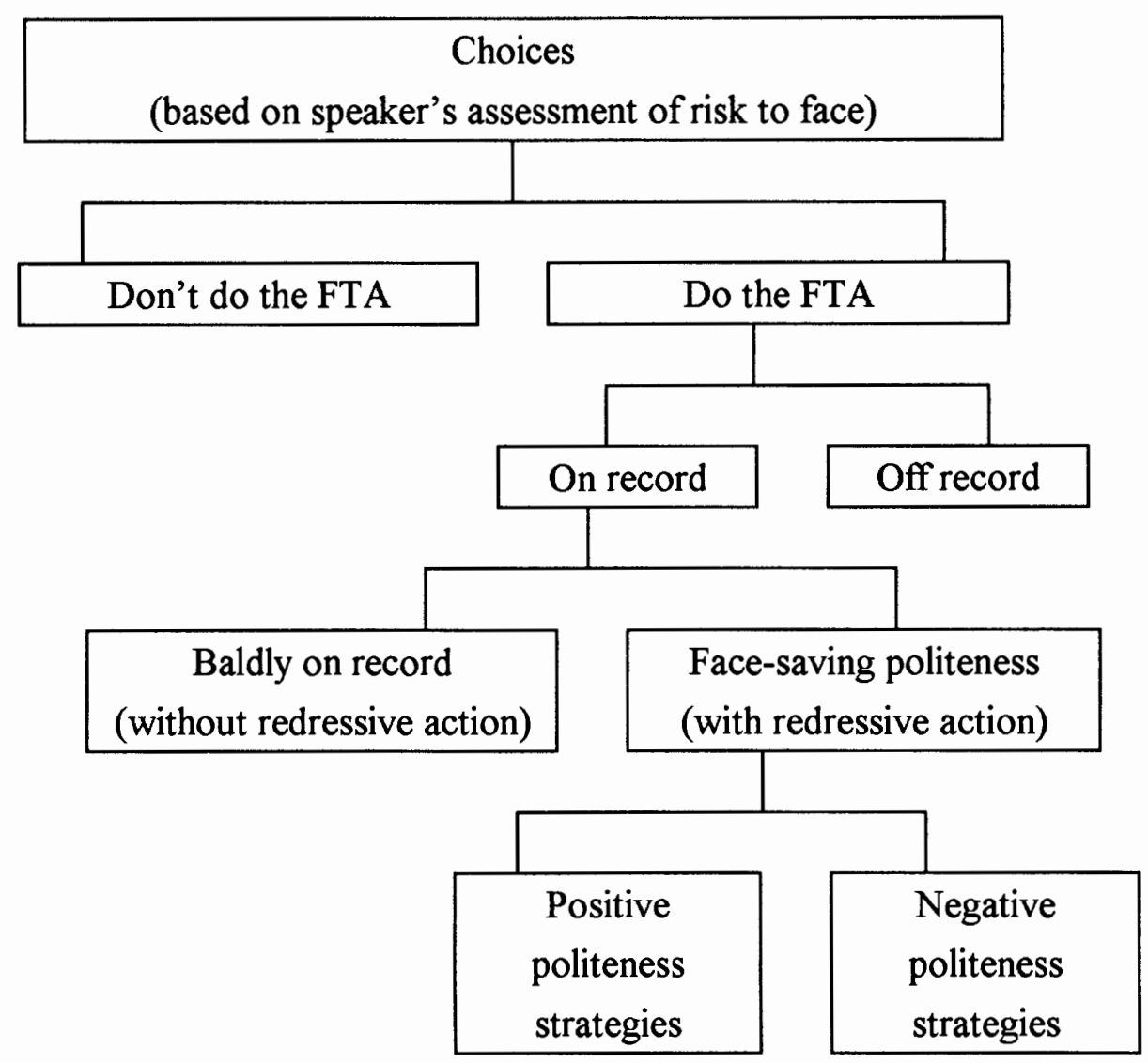


At the first juncture of decision making, the speaker can choose to completely opt out from performing the act. In the case of the speech act of censure, according to Olshtain \& Weinbach (1993), S would refrain from expressing the reproach altogether. The payoff for not doing the FTA at all would include being perceived as tactful and avoiding the consequences of damaging H's face (who has committed the infraction). The disadvantage, of course, is that $\mathrm{S}$ also fails to communicate the content of the FTA and might remain frustrated because of unexpressed annoyance.

At the second node, S can choose to carry out the act "on" or 'off' record. A speaker performs an FTA on record if the act is expressed unambiguously, e.g., committing oneself to a future act by saying "I promise to come tomorrow." According to Brown and Levinson, the advantages of going on record are being perceived as honest and outspoken and avoiding being misunderstood or considered manipulative.

An FTA that is performed off record will be ambiguous, a hint to which more than one intention can be attributed, so that the speaker need not commit him/herself to a particular intent; thus, this choice offers similar payoffs for S as not doing the FTA in the first place. Brown and Levinson's example of a speaker saying, "Damn, I'm out of cash, I forgot to go to the bank today" (p. 69), can be intended as a request for a loan, but does not commit $\mathrm{S}$ to that intent. The benefit of doing an FTA off record is the possibility of being considered diplomatic and avoiding accountability for a potentially face-damaging interpretation of the FTA. The speaker can maintain negative face to a greater extent than by using the negative-politeness strategy. In the case of performing a complaint off record, 
for example, by using this evasive strategy, there is the possibility that $\mathrm{H}$ will take the hint and apologize or offer to remedy the situation, which will make $\mathrm{S}$ feel better.

If $\mathrm{S}$ decides to perform the FTA on record, he or she will continue on to the next juncture of options and payoff considerations, facing the choice of performing the speech act either with or without modifications to soften the impact of the FTA. If an act is done baldly, without redress, it will be as direct, unambiguous and concise as possible (e.g., a request, "Do X!"). This option will normally be avoided except when 1) urgency or efficiency take precedence over face concerns (e.g., "Help!" or "Watch out!"), 2) the risk to the hearer's face is small (e.g., in a polite offer or request, such as "Come in" or "Do sit down"), 3) intimacy between $\mathrm{S}$ and $\mathrm{H}$ permits them to dispense with politeness strategies, or 4) $\mathrm{S}$ has considerably more power than $\mathrm{H}$. In these cases, the speaker does not fear retribution for a threat to the addressee's face. The payoff for performing the FTA baldly on record is efficiency. Olshtain and Weinbach describe this strategy regarding the expression of censure. In this case, S's frustration will be expressed without mitigation in "a statement or request that explicitly mentions the SUA [i.e., socially unacceptable act] and/or $\mathrm{H}$ as violator" (p. 110). S might even go so far as to make a threat or insult $\mathrm{H}$. As Olshtain and Weinbach point out, when this strategy is used, S risks open conflict with $\mathrm{H}$. It is possible that the addressee will retaliate for the loss of face he or she has suffered.

The use of redress counteracts any potential face damage by showing that a threat to face is not intended, that $S$ recognizes H's face wants, and that $S$ is willing to make an effort to maintain H's face. This is achieved by performing the FTA with modifications or 
additions that soften the effect. If redressive action is chosen, the speaker has the option of emphasizing either positive or negative face.

Brown and Levinson state that positive politeness is directed toward the positive face of $\mathrm{H}$, his or her positive self-image. Olshtain \& Blum-Kulka (1985) express it thus: positive politeness strategies "emphasize common ground between speaker and hearer, make use of in-group markers, presuppose cooperation on the part of the hearer" (p. 308). A speaker who goes on record with positive politeness can minimize the face risk of an FTA by emphasizing mutual friendship and assuring the addressee of S's solidarity.

Negative politeness, on the other hand, maintains H's negative face by trying to avoid imposing on $\mathrm{H}$ or impeding $\mathrm{H}$ 's freedom of action. Brown and Levinson characterize negative politeness as involving "self-effacement, formality and restraint" ( $p$. 70) and state that the speaker's payoffs for going on record with negative politeness are: compensating for the FTA by showing respect or deference to the hearer, thus avoiding or lessening a future debt; preserving social distance and avoiding increased familiarity with the addressee; providing the addressee an "escape route" (e.g., in the case of an offer, by making it clear that $\mathrm{H}$ need not accept, thus lowering the risk of mutual face loss if $\mathrm{H}$ refuses); or pretending to offer an "out" without really doing so. Olshtain and Blum-Kulka (1985) note that because negative politeness strategies "reflect a desire to maintain social distance [and] unhindered freedom of action for both the hearer and the speaker, ... cooperation of the hearer is ... not assumed" (p. 308).

Olshtain and Weinbach describe positive politeness and negative politeness in terms of the speech act of censure. A speaker opting for positive politeness would 
probably still explicitly mention both the socially unacceptable act and $\mathrm{H}$, but would mitigate the FTA by emphasizing solidarity and social affiliation. This choice allows $\mathrm{S}$ to express frustration in a context of personal interest or understanding towards $\mathrm{H}$. If the speaker decides to use negative politeness, the complaint might be expressed explicitly, but in a mitigated form, such as a statement referring to the socially unacceptable act but not directly to $\mathrm{H}$.

Brown and Levinson's model was a primary resource in the analysis of the crosscultural data for this study, employed in conjunction with a set of "functional categories"(a system for interpreting and classifying responses-see Chapter III, "Procedures of Data Analysis", and Appendix F, "Classification of Refusals used in this Study") as a tool for comparing features, such as directness, willingness to risk confrontation, politeness involving formality, politeness aimed at strengthening social bonds, and evasiveness.

\section{Face and Politeness}

A number of researchers have examined politeness strategies (Brown \& Levinson, 1978, 1987; R. Lakoff, 1973, 1975; Leech, 1983. See Takahashi \& Beebe, 1993.). Politeness and the concept of "face" are pancultural in Brown and Levinson's view:

the mutual knowledge of members' public self-image or face, and the social necessity to orient oneself to it in interaction, are universal" (p. 62).

Despite the universality of these principles, however, the actual attributes of face and politeness differ across cultures. House \& Kasper (1981) similarly view politeness as a universal social value, while recognizing that social norms defining polite and impolite behavior vary across cultures. For Gumperz (1987), politeness phenomena are "universal 
principles of human interaction, ... reflected in language," yet realized differently across cultures:

Societies everywhere, no matter what their degree of isolation or their socioeconomic complexity, show these same principles at work; yet what counts as polite may differ from group to group, from situation to situation, or from individual to individual" (p. xiii).

According to Brown and Levinson, there is considerable cross-cultural variation in terms of the kinds of acts that are considered a face threat, the social characteristics that entitle to people to special face-protection, and the elements of personal style that are most valued (e.g., graciousness, ease of social relations, etc.). Olshtain and Blum-Kulka (1985) assert that the series of choices outlined in Brown and Levinson's model represent various means to communicative ends that are available in all languages. At the same time, these choices are culture-dependent, since different cultures give preference to different strategies, e.g., cultural preferences for positive versus negative politeness strategies. While both types of strategies are linguistically possible in different cultures, societies that emphasize respect for privacy and personal space will be inclined towards negative politeness, in contrast to societies with minimal social distance that will tend to favor positive politeness strategies. Olshtain and Blum-Kulka provide a characterization of a speech community according to Brown and Levinson's model, describing speakers of Hebrew as having a preference for "bald on record" performance of speech acts, a "direct and unmitigated form which seriously encroaches on the hearer's territory" (p. 309), and preferring positive politeness strategies over negative politeness.

House and Kasper (1981) see politeness as a form of emotional control practiced in order to maintain both one's own and the other person's face. This relates to Leech's 
1977 definition of politeness, or tact, as “strategic conflict avoidance", and R. Lakoff's 1975 view that politeness serves the function of "reduc[ing] friction in personal interaction" (p. 64). House and Kasper's view of Brown and Levinson's three major politeness strategies, equates positive politeness with the expression of solidarity, negative politeness with the expression of restraint, and off-record politeness with the avoidance of impositions.

R. Lakoff (1973) describes three "Rules of Politeness" ("rules" in the sense of unconscious principles guiding behavior): “1. Don't impose. 2. Give options. 3. Encourage feelings of camaraderie-Make A feel good-be friendly" (p. 298). Following the first rule means avoiding, mitigating or apologizing for any utterance that might impede H's desire to do as he or she pleases, and not sharing personal information or opinions. It is the impersonal politeness of social distance and unequal status. The second rule is less formal than the first, and is based on social distance between peers. The speaker's wording is ambiguous enough that the hearer does not to need to respond to the speaker's actual intent (e.g., "Have you finished reading that newspaper?," used as a request). Rule 3 governs the politeness of friends and solidarity, involving signals of intimacy, such as nicknames, personal remarks, and expression of feelings.

There are many parallels between Lakoff's and Brown and Levinson's models. Both work with a definition of politeness that encompasses both formal and informal behavior used to show consideration for one's addressee. Lakoff's first rule (Don't impose) corresponds to Brown and Levinson's option of not performing the FTA, the second rule (Give options) corresponds with negative politeness and off-record strategies, 
and rule 3 (Encourage feelings of camaraderie) corresponds to the bald on record (the speaker and hearer are close enough that they do not need to beat around the bush) and positive politeness strategies. One difference between the two systems is that interlocutors of differing social power use different politeness strategies with each other in Brown and Levinson's model, a distinction not made by Lakoff.

Lakoff's second rule in particular corresponds with the parameters Leech (1977) developed for determining the level of politeness in discourse. For Leech, the politeness of a given speech act corresponds with considerations of cost versus benefit, i.e., the extent to which the speech act will cost or benefit $\mathrm{S}$ or $\mathrm{H}$, and "optionality", i.e., the degree to which performing the content of the speech act is carried out voluntarily by $\mathrm{S}$ or $\mathrm{H}$. The greater the optionality and the benefit, and the lower the cost, from H's point of view, the more polite the speech act is. Leech's "Tact Maxim" states that indirect and circumlocutionary forms are generally more tactful than direct and concise ones.

For more information about linguistic research of politeness phenomena, see Kasper's (1990) review of the literature on politeness.

\section{The Speech Act of Refusal}

Beebe et al (1990) describe refusals as complex speech acts that pose a great risk of cross-cultural miscommunication. As Beebe et al note, the act of refusing can occur in response to an interlocutor's offer, suggestion, request, or invitation. According to Brown and Levinson's (1987) classification of FTAs (see section on "Face-Threatening Acts", this chapter), requests, invitations, offers, and suggestions can all be described as acts that 
threaten the hearer's negative face, i.e., that restrict his/her freedom of action. All four of these FTAs speak of a future act to be performed by the hearer, which the hearer must either reject or accept. In the case of invitations and offers, acceptance might entail the possibility of the hearer becoming indebted to the speaker. Refusal, thus, is a means of defending one's negative face wants. Refusals express the speaker's unwillingness or inability to (1) carry out an action requested by the hearer, or (2) accept an action, suggestion, invitation or goods offered by the hearer to the speaker. Following Brown and Levinson's arguments, refusals obviously pose a face threat to the hearer (and in the case of refusing requests, to the speaker). As Beebe et al point out, refusals are quite complex speech acts:

"Refusals, in that they involve telling a listener something he or she does not want to hear, require the speaker to build support and help the listener avoid embarrassment. They require a high level of pragmatic competence" (p. 68).

Beebe et al note that insufficient knowledge of $\mathrm{L} 2$ sociolinguistic patterns combined with a very human need to draw on the values of one's native culture, mean that "transfer will be complex and prevalent in second language refusals" (p. 68). Several researchers examine the refusal strategies used by NSs of American English and ESL students (Takahashi \& Beebe, 1987; Beebe et al, 1990; King \& Silver, 1993).

Speakers usually opt for some degree of indirectness when uttering refusals because of the inherent risk of offending one's conversational partner. Thus, in naturalistic settings, refusals "often involve a long negotiated sequence" (p. 55) rather than a single utterance. In addition, as Beebe et al have found, the form and content of refusals vary in 
response to the eliciting speech act (e.g., invitation, request, offer, or suggestion) and can be strongly influenced by factors such as the relative status of the interlocutors.

In terms of Brown and Levinson's (1987) classification, refusals can be categorized as FTAs that threaten H's face and sometimes S's, and, depending on the particular type of refusal (i.e., refusal of an offer or refusal of a request), can either be negative-face threatening or positive-face threatening. In this researcher's view:

- A refused offer poses a threat to H's positive face (S does not like or want what $\mathrm{H}$ has offered);

- Refused advice or suggestions pose a threat to H's positive face (S's negative evaluation of H's advice or suggestion; disagreement; S's opinion that $\mathrm{H}$ is wrong);

- A refused request might threaten H's negative face (S's refusal of H's request could result in an imposition on $\mathrm{H}$ ) or positive face ( $\mathrm{H}$ may feel rejected or insulted by having the request refused), or threaten S's positive face (S's unwillingness to fulfill H's request may cause $\mathrm{S}$ to appear in an unfavorable light);

- A refused invitation risks a threat to H's positive face (S does not value H's invitation).

The performance of refusals involves the various strategies outlined in Brown and Levinson's model of FTA realization. Possible strategies can be illustrated with a set of different responses to an item from the Discourse Completion Test (DCT) used to elicit data for both Beebe et al's and the present study: In this situation, a fellow student who rarely comes to class is once again asking the respondent for his or her notes. If the respondent chose to opt out from refusing, he or she would simply give the classmate the 
notes even though s/he would prefer not to. An off-record response might be: "I'm afraid I don't have my notes with me now." On record, without redress: "No, I won't" or "I'm tired of always lending you my notes when you don't even bother to come to class." On record, with redress, positive politeness: “Gee, I'm sorry. I'd really like to help you, but I absolutely need them myself tonight. I hope you can get someone else's notes." On record, with redress, negative politeness: "I'm sorry to disappoint you, but I need my notes myself tonight.." These different options vary considerably in their potential impact on the addressee, determining whether the risk to the hearer's face is averted, minimized, or sharpened.

Beebe, Takahashi, and Uliss-Weltz observe that speakers performing the speech act of refusal employ a number of politeness strategies, such as positive remarks (e.g., "I wish I could, but..."), expressions of regret (e.g., "I'm sorry"), excuses (e.g., "I have to pick up my son at football practice this evening"), offers of an alternative ("How about tomorrow evening?"), and other softeners to make the refusal itself (e.g., "I can't come") less face-threatening and to ease communication. This ties in with Olshtain and Cohen's (1991) assertion that every language has "routinized realization patterns" for performing functions such as apologies, requests, complaints, refusals, and compliments, which they call "speech act sets." Each speech act set consists of a set of linguistic and pragmatic strategies used to represent the particular speech act (See section on speech acts, this chapter.).

Beebe et al provide evidence that pragmatic transfer from Japanese affects the realization of the speech act of refusing by Japanese speakers of English, in terms of the 
order, frequency, and content (or tone) of strategies used. The responses of the Japanese ESL learners more closely resembled the native Japanese responses than those of the Americans. Discrepancies between American responses and those of Japanese learners of English included a tendency amongst the Japanese (in both groups) to omit an apology and express empathy or a positive opinion when leading into a refusal to a lower-status interlocutor. In terms of the location of refusals, the Japanese speakers often expressed thanks early on in a response, in contrast to the Americans, who did so at the end. Transfer also appeared to be the reason why Japanese respondents offered an apology much more frequently than Americans when refusing requests (95\% of the Japanese L1 responses and $85 \%$ of the L2 responses contained apologies, versus $40 \%$ of the American speakers' responses). The data suggested that the Japanese transferred into English "a sensitivity to status that exists in Japanese" (p. 61). The Japanese subjects tended to respond differently to high- and low-status interlocutors, in contrast to the Americans, who reacted in similar ways to status unequals (both higher and lower), but gave different responses to same-status acquaintances. Unlike the Japanese, the American subjects increased the length of their refusals when responding to someone they knew.

\section{The Impact of Language Transfer on Second Language Performance}

\section{Definitions of Transfer}

Researchers have presented a wide range of views as to what transfer is: a process, an action, a set of constraints, or a filter through which target language input is viewed. These contrasting views are discussed below. 
In his study of transfer of syntactic structure from Hebrew into English, Selinker (1983) defines language transfer as the "'transfer' of the structural patterns of one's native language to a foreign language" (p. 33). Olshtain (1983) defines transfer as "the learner's strategy of incorporating native-language-based elements in target language production and behavior" (p. 233). According to Selinker, languages are universally susceptible to influence from other languages. Transfer can occur on all levels of the linguistic hierarchy, e.g., phonology (e.g., an Israeli might substitute a voiced velar fricative for the English retroflex /r/), syntax (an Israeli might make word order mistakes such as I like very much cats, based on word order patterns in Hebrew), semantics (Israelis often use the wrong lexical item when one Hebrew word covers the same semantic area as two English words, e.g., lehazmin "order, invite": I shall order my colleagues for dinner.) (p. 36). Selinker finds evidence for three types of transfer: positive transfer (transfer results in nonerrors), negative transfer (transfer which produces errors), and neutral transfer (either nonerrors or errors, neither predominating).

According to Gass (1983), "transfer", a term taken from the psychology of learning, refers to "the imposition of previously learned patterns onto a new learning situation" (p. 70). She defines "language transfer" as "a subset of this more general process," in which linguistics forms and functions of the native language are "superimposed on the patterns learned in a second language" (p. 70). Selinker, however, cautions against adapting the concept of "transfer of training" from the field of psychology to the study of interference in second language learning. In his view, a concept of transfer of training that explains the learning behavior involved in simple conditioning (such as 
white rats running through a maze) is insufficient for addressing the complexity of human linguistic performance. In Selinker's view, transfer is a process in which the speaker makes the same choice of linguistic structure (on the levels of syntax, phonology, etc.) in the target language as he or she would in the native language, regardless of actual correctness.

Schachter (1983) asserts that transfer is not a process or action, in the sense that a learner might "transfer" a structure or lexical item from the $\mathrm{L} 1$ to the $\mathrm{TL}$, but rather a set of constraints, imposed by previous knowledge, on the kinds of hypotheses a language learner is likely to make about how the L2 is structured. In other words, previous knowledge imposes constraints on the hypotheses that will be made about the new data. In Schachter's view of transfer, a learner's previous knowledge consists not only of knowledge of his or her L1, but also any knowledge of the target language he or she may have acquired, including inaccurate knowledge and the learner's expectations regarding the target language. In Schachter's view, transfer can both facilitate and limit hypothesis testing.

Andersen (1983) views transfer as "a filter that governs the learner's perception and retention of specific features of the second language (L2) input" (p. 177) that can either support or hamper acquisition of a target language structure. Building on Zobl's work (1980a, 1980b, 1980c), he has developed the "transfer to somewhere principle (TTS)", based on the idea that "natural acquisitional processes and the learner's perception of structural relations within the L2 input provide a necessary catalyst for transfer to operate" (p. 178). According to the TTS, a structure will only be transferred if "there already exists within the L2 input the potential for (mis-) generalization from the 
input to produce the same form or structure" (p. 178). Andersen provides examples of SLA data that supports the TTS principle:

For Inf. marker

$\mathrm{SVO}+$ pronouns

No/not + verb

Modal/verb + not
The woman open the door for welcome visitors (French L1)

Oui, j'aime le. (For "Je l'aime." "I love him.") (English L1)

I no have a bike. José no wanna go. (Spanish L1)

Shut not your mouth. I cannot say that word. (German L1)

The TTS principle is modified by the fact that transfer conforms to operating principles (as defined by Slobin, 1973, 1977) that determine speakers' selections of linguistic forms to express intended meanings. According to Slobin's (1977) framework of rules governing the nature of language, the structure of language is determined by the needs of speakers and listeners to process language quickly, clearly, efficiently, and effectively. A communication system can only function as a fully developed human language if it complies with four basic rules: "(1) Be clear. (2) Be humanly processible in ongoing time. (3) Be quick and easy. (4) Be expressive" (cited by Andersen, p. 179). Based on Zobl's (1980a, 1980b, 1980c) studies, Andersen asserts that when an L1 structure conforms more to Slobin's operating principles than the corresponding L2 structure does (i.e., is clearer, quicker, more efficient or more effective than the L2 structure), transfer is more likely:

... if an L2 form conforms well to natural acquisitional processes..., it will be acquired early... If an $\mathrm{L} 1$ form conforms well to these natural acquisitional processes, it will be transferred to the interlanguage. If the $\mathrm{L} 1$ and the $\mathrm{L} 2$ forms are congruent and conform well to the natural acquisitional processes, the form will emerge early in interlanguage" (p. 182). 
The plethora of analyses of transfer as a negative phenomenon reflects the fact that negative transfer is an inhibiting factor in language acquisition, while positive transfer does not lead to the production of errors. Researchers would naturally gravitate towards gaining a better understanding of the dynamics of negative transfer, leading to insight into means of helping language learners more easily overcome their learning difficulties; also, positive transfer can be difficult to distinguish from good acquisition in general.

Language contact can result in other phenomena besides negative and positive transfer. For the sake of clarity, a number of researchers now distinguish between "transfer," the incorporation of L1 features into the L2, and other phenomena resulting from language contact (Kellerman and Sharwood-Smith 1986; Weltens, de Bot and van Els 1986). Sharwood-Smith (1983) has proposed the term, "cross-linguistic influence" to denote a wide range of phenomena, such as interference, positive transfer, avoidance, borrowing, over-production and L2-related aspects of language loss (Also see LarsenFreeman \& Long, p. 97.).

\section{Aspects of the Native Language Linguistic System Most Likely to be Transferred}

In the 1950s and 1960s, many researchers (including Lado, 1957 and Weinreich, 1953) believed that the $\mathrm{L} 1$ played a negative role in acquiring a second language, referred to as "interference." Contrastive analyses of languages (i.e., systematic comparisons of languages, determining similarities and differences in structures) were undertaken because it was assumed that linguistic differences were the source of learning difficulties. The contrastive analysis hypothesis $(\mathrm{CAH})$ predicts that similarities will be most readily 
learned, whereas differences will result in a larger number of errors, i.e., interference. Research findings, however, have refuted the CAH (Alatis 1968, Whitman and Jackson 1972, Hyltenstam 1977; Dulay and Burt 1974; Hammerly 1982; Long and Sato 1984).

Numerous studies (Koutsoudas and Koutsoudas 1962, Wode 1978, Kellerman 1977 and 1983, Gass 1983, Ard and Homburg 1983) suggest that both positive and negative transfer are most likely when there is considerable similarity between the L1 and the L2. Gass (1983) states that

Language transfer in large part depends on the learner's notion of distance between the native and target languages. ... language transfer is more likely to occur in the case where two languages are close." (p. 80)

This relates to Kellerman's (1978) and Olshtain's (1983) findings that learner's perceptions of language specificity and language distance between their native and target languages influence their assessment of the transferability of linguistic elements (i.e., the probability that an L1 structure will be transferred.). The findings of Olshtain's (1983) study, which compares Hebrew NS norms for apologizing with the communicative competence exhibited by English and Russian learners, suggest that learners are more likely to transfer features from L1 to L2 if they perceive the realization of a given speech act as language universal rather than language specific. Olshtain assessed the respondents' perception of universality by asking subjects if speakers of Hebrew apologize more or less than speakers of the subject's native language and if speakers of Hebrew might apologize differently from a speaker of the subject's native language. When the respondents said that in the L2 speakers apologize differently than in their native language, the response was interpreted in favor of language specificity. If respondents claimed that one apologizes 
according to the situation and that it does not matter what language is used, then the answer was interpreted as a language universal view. The NSs of English exhibited an orientation towards language specificity, and had less of a tendency to transfer sociocultural rules from their L1 to their L2 than the Russian speakers, who displayed a much more universal perception of the apology speech act.

Kellerman (1983) cites Kellerman 1977, stating that when there is structural similarity between an L1 and an L2, learners are likely to take advantage of the relative ease of identifying cognate forms and structures. This linguistic closeness can, however, result in either "facilitation" or "interference" (p. 114). As Kellerman observes,

“...certain interference errors would be resistant to eradication, particularly in environments of minimal linguistic difference. ... Conversely, if L1 and L2 were very different, the lack of available correspondences would, in the initial stages at least, act as a bar to transfer, since the learner is unable to take the necessary cross-lingual tie-ups" (p. 114).

In support of his assertions, Kellerman (1983) cites a number of studies comparing NSs of different languages learning the same L2 as well as NSs of the same language learning different L2s. For example, he cites Sjöholm's (1976) observation that while Swedish speakers of English make a relatively large number of errors that can be attributed to transfer, it is more difficult to identify L1 sources of errors in the L2 English of Finnish speakers. This indicates that Finns, "at least at university level, realize that their mother tongue is not a useful basis for making predictions about the form of English utterances." Instead, they tend to make generalizations within the target language (p. 114). 
Kellerman (1983) also examines research involving students of the same L1 background learning different second languages. Perceptions of language distance affect learners' likelihood to transfer L1 forms into the L2. Kellerman notes that Dutch learners of German (Jordens 1977) were much more likely than Dutch learners of English (Kellerman 1977) to accept idiomatic expressions in the L2 that resembled Dutch expressions, regardless of actual correctness.

In Zobl's (1980a, 1980b) investigation of L2 acquisition of certain syntactic structures, it appeared that if there is a developmental stage in the acquisition of an L2 structure that resembles the learner's L1 equivalent, this may hinder progression towards target performance, or even result in fossilization.

Kellerman asserts that linguistic closeness between L1 and L2 will not guarantee transfer because of constraining factors, such as the transferability of a particular L1 structure as compared with other L1 structures. If NSs perceive a feature of their language to be "infrequent, irregular, semantically or structurally opaque, or in any other way exceptional", i.e., "marked", then it will be less likely to be transferred to an L2 (p. 117). The likelihood of transfer of an $\mathrm{Ll}$ feature, then, depends on two interacting factors: the learners' perception of the relatedness of the L1 and L2, and the degree of "markedness" of a given L1 structure. The probability of transfer diminishes when the L2 and L2 are considered linguistically distant and when a particular structure in the $\mathrm{Ll}$ is viewed as being "marked."

Ard and Homburg (1983) likewise assert that the more similar an L1 and an L2 are, the more likely transfer is to occur. They argue that the influence of the native 
language on acquisition of the target language lexicon is dependent upon similarity between the $\mathrm{L} 1$ and $\mathrm{L} 2$.

\section{The Concept of Transfer as It Relates to Pragmatic Competence}

When the pragmatic performance of learners violates NS standards, this is often due to transfer of first language assumptions to the target language, what Coulmas (1978) refers to as "pragmatic interference." As Kasper and Blum-Kulka (1993) note, researchers tend to focus more attention on negative pragmatic transfer than positive transfer (i.e., when pragmatic norms are compatible across cultures). This emphasis stems from the fact that negative transfer can lead to miscommunication and breaches of social norms. In addition, it is difficult to distinguish positive transfer from universal pragmatic knowledge and inferencing based on what the learner already knows about the pragmatics of the target language.

Blum-Kulka (1983) suggests that the existence of cross-culturally shared rules of speech act realization is evidence of a universal pragmatic competence for interpreting and performing speech acts. Blum-Kulka interprets her findings as suggesting that learners make use of this non-language-specific pragmatic competence when they seek to communicate in a second language. These findings include the sensitivity to contextual constraints displayed by learners in their choice of speech act forms in different situations and their use of a range of forms, including both direct forms (such as imperatives used in requests) and more conventional indirect forms (e.g., 'Could you...?').

Blum-Kulka states that speech acts are universal only in terms of their basic properties (such as direct versus indirect expressions), while the actual realizations of 
these properties are language- and culture-specific. Because many pragmatic rules are not shared across cultures, transferring pragmatic competence from the $\mathrm{L} 1$ will not necessarily guarantee appropriate and successful speech act performance in the L2. Blum-Kulka's findings in her cross-cultural study of social control acts (requests, etc.) suggest that the performance of second language learners differs from both first and second language native usage. Their speech-act performance displays (1) usages that resemble those of NSs, (2) usages that contrast with NS production in terms of directness, and (3) differences from NS patterns regarding linguistic realization. The latter two cases can result in violations of social-appropriateness norms in the target language and in linguistic realizations of speech acts that fail to communicate the intended illocutionary force. BlumKulka concludes that the pragmatic performance of L2 learners seems to approach NS norms in cases "where the rules are cross-culturally shared" and to differ from NS patterns "where the rules are language- and culture-specific" (p. 48).

It should be noted that various factors contribute to the appearance of pragmatic transfer. According to Beebe, Takahashi, and Uliss-Weltz (1990), incomplete knowledge of sociolinguistic patterns in the target language is not the only cause of transfer-the influence of "deeply held cultural values" can also lead to sociocultural transfer in the performance and interpretation of speech acts (p. 68).

There are literally hundreds of studies that investigate transfer and pragmatic competence by comparing L2 performance, comprehension, and interpretation of speech acts with NS norms of both the target language and the first language. Numerous studies have documented the existence of negative transfer at the sociopragmatic level (See 
discussion of Thomas' 1983 terminology, "sociopragmatic" and "pragmalinguistic failure" in the section of this chapter dealing with pragmatic failure.). Olshtain (1983) observes the effects of transfer on learners' perceptions of the need to apologize in different situations, while Eisenstein \& Bodman's (1993) findings suggest that transfer influences learners' assessment of the kinds of situations and relationships between interlocutors that necessitate expressions of gratitude. Wolfson (1989) notes learners' violations of target norms for giving and receiving compliments (as do Wolfson, 1983a; and Manes 1983) and making and responding to invitations. Olshtain and Weinbach's (1993) findings suggest that learners' assessment of contextual factors impact their performance of complaints. In regards to utterances that express emotions as a pragmatic function, negative transfer can impact interpretation (Rintell, 1984) and production (Rintell, 1990). Other studies document the effects of negative transfer in terms of learners' levels of politeness (Olshtain \& Cohen, 1989, Blum-Kulka, 1982) and in their choices of strategies for realizing speech acts (House, 1989a; Beebe, Takahashi, \& Uliss-Weltz, 1990; Bergman \& Kasper, 1993). Beebe, Takahashi, and Uliss-Weltz (1990) and Takahashi and Beebe (1993) have found that Japanese EFL performance of refusals seems to reflect Japanese norms regarding perceptions of status.

Most findings regarding pragmalinguistic transfer involve effects on choices of strategies in the performance of speech acts and forms that affect the level of politeness, e.g., in apologies (Olshtain \& Cohen, 1989; Trosborg, 1987; House, 1989a; Blum-Kulka, House, \& Kasper, 1989; Bergman \& Kasper, 1993), in requests (Blum-Kulka, 1982 and 
1983; Blum-Kulka \& Levenston, 1987; Faerch \& Kasper, 1989), in saying "no" (Rubin, 1983), and in expressing disagreement (Beebe \& Takahashi, 1989).

Kasper and Blum-Kulka (1993) emphasize that "negative" pragmatic transfer does not necessarily indicate a lack of pragmatic competence in the target language. When a NNS's communication style differs from that of NSs, this can be seen as simply different, rather than deficient. Likewise, the retention of such a style over time can be viewed "negatively, as fossilization, or positively, as a marker of cultural identity" (p. 11). As Kasper and Blum-Kulka point out, the extent to which a NNS assimilates sociocultural norms of the target community is determined by choice as well as ability. In other words, a proficient second language speaker may prefer to maintain an identity separate from the second language culture, rather than integrating. It is also important to note that a nonnative communication style (i.e., "negative" pragmatic transfer) does not inevitably lead to pragmatic failure. Kasper and Blum-Kulka cite Tannen's (1985) observation that some cases of "negative" transfer make a favorable impression on NSs, in much the same way as a "charming" foreign accent might. Differing styles can be compatible rather than discordant. Kasper and Blum-Kulka also cite Clyne's (1979) assertion that such differences are not the source of miscommunication unless they violate "interlocutors' perceptions of power, trust and solidarity" (p. 13).

Transfer is not the only source of pragmatic errors in L2 speech acts (e.g., see Kasper, 1981; and Kasper and Blum-Kulka, 1993). Indeed, Kasper (1981) attributes the majority of the pragmatic errors of German learners of English (60\%) to "generalization" (defined below), versus $28 \%$ resulting from transfer. Besides transfer and generalization, 
Kasper lists other sources of learner errors in the realm of cross-cultural pragmatics, including: avoidance of transfer, functional reduction, inferencing, and error induction caused by the foreign language instructional setting.

While transfer in Kasper's view involves wholesale or partial carry-over of knowledge from the $\mathrm{L} 1$, in the case of generalization, learners carry over previously acquired knowledge about the L2 (i.e., functions, rules and other elements) to new contexts. An example of this is use of the expression, 'well', which would not be used in either the first or target language in the following context: (responding to the question, "What's your address in Germany?") "Well, my address is Markstraße 100." According to Kasper, it is likely that the speaker in this case perceived it as "typically English" to begin an utterance with 'well'.

Avoidance of transfer occurs when learners believe that a feature of the $\mathrm{L} 1$ is untransferable to the target language, e.g., a German learner of English who does not say anything when another person sneezes, assuming that doing so is culturally specific to German. Functional reduction results when, due to a lack of linguistic means to express a communicative intent, the speaker realizes the utterance in a reduced form or avoids a speech act or discourse function altogether by changing the topic. While transfer, generalization, and functional reduction have to do with errors in production, inferencing can influence receptive processes. Inferencing is a strategy used to interpret unfamiliar linguistic elements in an utterance by using familiar attributes and contexts to recognize what is not familiar. 


\section{Studies Comparing Speakers of English and German}

Although there are cultural differences between Germans and Americans, many similarities and a great deal of mutual influence exist as well. Both Germany and America can be characterized as Western, industrialized societies. Certain shared traditions, brought by German immigrants to America (such as rituals for celebrating Christmas), and the current massive influence of American culture in Germany (pop music, films, and commercial products, to mention a few) can fool one into unawareness of subtle and notso-subtle differences in beliefs, values, and norms.

Perceptions of linguistic features show a corresponding pattern: because of linguistic similarities between German and English, such as parallels in syntactic structure and a large number of cognates, a German learner of English can easily be lulled into a false sense of security in trusting his or her pragmatic intuitions, just as $s /$ he might fail to recognize false cognates. ${ }^{3}$ Indeed, differing social norms across the two speech communities produce different conventions of what is considered polite linguistic behavior. Ignorance of differing cultural expectations combined with the assumption that pragmatic standards are shared across the two cultures can lead to miscommunication between Germans and Americans. In fact, misinterpretation is more likely under conditions of similarity than if one's conversational partner operates according to a clearly different

\footnotetext{
${ }^{3}$ Examples of false cognates: 'Menü' and 'menu' can easily be confused because of their use in both languages in a restaurant context. Menü means 'today's special', consisting of soup, main course, and dessert, whereas in English, a menu is what food is ordered from. A 'Drogerie' sells toilet articles and patent medicines, while prescription drugs are sold at an 'Apotheke' ('pharmacy'). A 'drugstore', on the other hand, sells everything from prescription drugs to magazines.
} 
system (See discussion of how similarity rather than difference leads to transfer, in section on transfer, this chapter.). If a difference is obvious, it is easier to recognize that disparate cultural norms are affecting communication, and explanations can be sought (although people sometimes reject starkly contrasting cultural norms without seeking to understand the underlying meanings).

According to House and Kasper (1981), the "the verbal behavior of German learners of English is often considered impolite by native speakers" (p. 158), and Fill (1989) asserts that German speakers of English tend to be deficient when it comes to verbally expressing considerateness towards the hearer. In Fill's view, this tactlessness has little to do with lack of proficiency (i.e., a lack of English equivalents of what they would say in their native language) and even less with the German national character. Rather, it is due to a lack of awareness of cultural differences. In other words, Germans are not less polite than English speakers, even if their linguistic behavior is sometimes perceived as inappropriate by NSs of English. In this connection, it might be helpful to consider Pike's (1967) differentiation between two ways of regarding behavior: the "emic" and "etic" views. The emic perspective examines the context and function of a given behavior within a system of cultural meaning, whereas the etic perspective views behavior from the perspective of an "outside observer." From an etic point of view, the way German speakers perform FTAs may indeed seem impolite by English NS standards. An emic viewpoint, however, would view behavioral differences between German and English speakers as a reflection of two cultural systems that are organized differently. As House and Kasper (1981) point out, a complaint at a certain level of directness in the German 
culture is not necessarily equivalent to a similarly structured complaint in English, because they are used and interpreted differently in the two cultural systems.

As Lovik (1987) notes, contrastive pragmatic analysis of standard German and American English can provide valuable insight into potential sources of cultural clash. Numerous studies compare German NSs, English NSs, and German EFL learners in the performance of various speech acts, including:

- opening and closing moves, expressions of gratitude and responses to thanks, censure/reproaches, directives/requests, and use of gambits (House, 1978);

- requests, suggestions, offers/invitations, complaints, acceptance (of offers, etc.), promises, objections (disagreement)/refusals, apologies, expressions of gratitude, and gambits (Kasper, 1981);

- complaints \& requests (House \& Kasper, 1981);

- requests (House-Edmondson, 1986; and House \& Kasper, 1987);

- $\quad$ apologies (House 1989a); and

- opening and closing phrases and other speech acts (Edmondson, House, Kasper, and Stemmer, 1982).

The overall results of these studies show that German NSs and EFL learners exhibit a considerably higher level of directness than NSs of English in the performance of various speech acts, especially FTAs. In addition, they also tend to use fewer “downgraders" and more "upgraders" than English NSs. (Downgraders are "modality markers" that mitigate the directness of a speech act, e.g., a politeness marker such as 'please'. Upgraders, on the other hand, intensify the impact of a speech act, e.g., a form 
such as, "It's absolutely revolting that...." Downgraders and upgraders are discussed in more detail in the section on modality markers below.) Further differences between speakers of English and German involve the use of gambits and routinized utterances.

Directness: In House's (1978) study, English and German speakers exhibit differences in terms of the directness of their censure and reproaches. The expression of a reproach can be more or less direct, depending on whether or not the speaker: implicitly or explicitly mentions the offending act, expresses a negative opinion of the offending act, implicitly or explicitly mentions the hearer's role as agent in the offending act, or implicitly or explicitly expresses a negative judgment of the hearer. House categorizes these realization patterns on a scale of seven levels of directness, with level 1 (the speaker mentions the offending act) as the most indirect and level 7 (the speaker makes a negative judgment of the hearer) as the most direct. Out of 16 situations, level 7 reproaches appeared in ten situations in the German data, whereas the English data did not contain a single instance of level 7. The German subjects also tended to use more direct reproaches than the English speakers in parallel situations.

In House and Kasper's (1981) study, complaint realization follows a similar pattern. The most frequently used complaint level in the German data is considerably more direct than the "standard complaint format" chosen by the English speakers. House and Kasper found that the two most direct levels of complaints never occurred in the data from the English speakers, whereas these two levels occurred in more than 8 percent of the German speakers' complaints, in both + and-social distance and authority role relationships. In addition, the English speakers were twice as likely to use the lowest level 
of directness in complaints than the German speakers. House and Kasper suggest that, although "attacking one's interlocutor's identity seems to be a taboo in the British cultural context, ... it seems perfectly appropriate behavior for Germans under specific interactional conditions" (p. 183).

Kasper's (1981) data on complaints shows that German NSs are the most direct, followed by Germans speaking English (GEFL), with English NSs being least direct. Kasper explains the lower level of directness for the Germans speaking English than those speaking their native language as follows: the circumstances of the study prevented them from being as aggressive linguistically as they would be in natural situations, or that they lack the linguistic means of expressing themselves as aggressively in English as they would in German (This information is based on interviews with subjects.).

House's (1978) data also show that German NSs tend to interact with greater directness than English NSs. While indirect speech acts appear frequently in both English and German directives (orders, requests, offers), regardless of social distance or dominance, explicit performative specifications occur four times more frequently in the German data than in the English data. According to Kasper's (1981) data on requests using a directness scale from 1 to $8(8=$ most direct $)$, German NSs, English NSs, and German learners all used level 3 frequently $(47.4 \% \mathrm{E} ; 35.5 \%$ learners; $26.9 \% \mathrm{G})$. The learners, however, frequently used level 8 requests (imperatives-29\%), whereas German NSs frequently used level 6 (30.7\%) and English NSs frequently used level 1 (21.1\%). Kasper surmises that the learners frequently used level 8 requests because of the relative simplicity of linguistic realization. 
House and Kasper (1981) also found that requests were considerably more direct in the speech of German students than in their British counterparts. Whereas the relatively low level 3 was used most often by the NSs of English, the rather high level 6 was by far the most frequently chosen level in German.

In her study of request realization, House-Edmondson (1986) found that German learners of English did not use the imperative as frequently as German NSs, but they did use it much more than the English speakers. She conducted an experiment in which German and English NSs assessed the degree of politeness of various request utterances (which represented different request strategies at different levels of directness, such as "explicit performative", "hedged performative", "strong hint", and "mild hint") in their respective languages. In relating the subjects' perceptions of politeness to their performance of requests, House-Edmondson found that the English NSs avoided using "impolite" forms. The German NSs, on the other hand, used them frequently in so-called "standard situations", which House-Edmondson defines as being "characterized by a certain pre-fixed allocation of rights and obligations which make it unlikely that the request is perceived as a face-threatening imposition by the hearer" (p. 286), e.g., a policeman asking a driver to move his car.

Modality Markers: House and Kasper (1981) observe that, in addition to using disparate levels of directness, NSs of German and English also make different use of modality markers. House and Kasper note the effect of modality markers on requests and complaints. A highly directly request like: come here! differs significantly from the utterance: please come here, will you. Both requests are at the same directness level, but 
differ in terms of use of modality markers. House and Kasper discuss two major types of modality markers: “downgraders” (which lessen the impact of the speaker's utterance) and "upgraders" (which increase the impact of the utterance). Downgraders include "politeness markers" (such as 'please') and "play-downs", syntactic devices such as use of past tense ('I wondered if...'), or negation, interrogative, and modal ('Mightn't it be a good idea...'). Upgraders included “overstaters", adverbial modifiers used by the speaker to increase the force of the utterance (such as 'absolutely', 'terribly', 'I'm absolutely disgusted that...'), and "aggressive interrogatives", interrogatives used to explicitly involve the addressee ('Why haven't you told me before?'). In this study, German speakers used upgraders 4.6 times as frequently as English speakers, whereas English speakers used downgraders 1.5 times as often as the German speakers. On the basis of their data, House and Kasper observe that "German speakers display more aggressive verbal behavior in socially delicate situations" than English speakers (p. 177). In Kasper's (1981) study, the frequency with which the various kinds of gambits and modality markers appear in the GEFL, German NS and English NS data suggests that GEFL usage patterns resemble those of German NS more so than those of English NSs. Both groups of Germans, for example, make much more frequent use of upgraders, such as "intensifiers" and "aggressive interrogatives." Kasper takes this as evidence of pragmatic transfer.

As noted above, Kasper (1981) found that GEFLs frequently use imperatives to perform requests. In addition, they are much less likely to use downgraders with their imperatives than English NSs, resulting in forms such as, "you do X" or "oh please do X." On the other hand, the learners' speech makes frequent use of supporting moves 
(considerably more than either English or German NSs). Kasper interprets this phenomenon thus: as the learners become aware of their communicative shortcomings, they attempt to compensate and avoid potential conflicts by using "preparators" (i.e., the speaker hints at his/her conversational intention, e.g., "there's something I wanted to discuss") and "grounders" (i.e., an utterance used to justify the speaker's speech act, e.g., 'I haven't got any decent records to take along-could you lend me some of yours perhaps?').

Gambits: Edmondson (1977) defines 6 different types of gambits: uptaker, pickup, underscorer, aside, cajoler, downtoner. House (1978) examines the use of downtoners, which are used to increase the harmony between speaker and hearer by softening the speaker's utterance, making it more acceptable to the hearer. German and English differ in terms of the tokens used as downtoners. The semantic equivalents of frequently-used English downtoners such as 'you know', 'I mean', 'you see' are rarely employed in German for this purpose, whereas expressions such as 'ja', 'also', 'doch', 'schon', 'mal', 'eigentlich', and 'eben' are preferred (These expressions, as used in context, are almost impossible to translate.). House also notes that downtoners are more explicit, more elaborate, and occur more frequently in the English NS data than in the German data. This is another factor contributing to the greater degree of directness in the speech of the German subjects.

Kasper (1981) notes that in the performance of objections (disagreement), speakers of English typically use gambits in the realization of objections. Often disagreement will be introduced by a "receipt" or "agree", and then followed by a signal 
indicating dissent ("but"), e.g., "Yeah, but it'll cost a fortune...." Gambits (particularly "cajolers") and modality markers such as "downtoners", "hedgers", and "forewarns" are frequently employed , e.g., "Yeah, but he's a good fellow, isn't he you know. We can't just sort of you know just ignore him." Learners use these gambits and modality markers much less often, although the softening "forewarn" was occasionally used, e.g., "Yes, I can understand your situation but I have to work." Refusals in English often begin with a "starter" (such as "well...") and the impact of the refusal is often weakened by use of softening modality markers such as downtoners and forewarns. The learners use gambits such as "uptaker" and "starter" much less than the NSs and make less use of modality markers.

Routinized Utterances: Edmondson, House, Kasper, and Stemmer (1982) found that British English NSs are considerably more likely than German NSs to make use of routinized utterances in opening and closing phases and other speech acts. The Germans, on the other hand, tended to "improvise" more and use a wider range of tokens in different areas of interaction.

House's (1978) findings indicate that routinized formulas are frequently employed by NSs of both English and German (but to varying degrees) for greetings and thanking. In the case of directives (orders, requests, offers), House observes that English NSs frequently use conventionalized, idiomatic forms such as 'would you mind signing it, Sir', 'I'm just wondering if I could possibly back down on tomorrow', 'why don't you turn it down', 'are you sure you don't want to come in', whereas German speakers tend to use downtoners or structuring signals like 'vielleicht', 'doch', 'mal', 'einfach'. 
House (1989a) notes that, in the performance of apologies, English NSs tend to use the highly routinized expression 'sorry' very frequently, as compared with Germans (speaking either language), who use a wider range of tokens to make explicit apologies. House suggests that this may explain why "German speakers rate the imposition on the part of the speaker to perform an apology consistently higher than British speakers" (p. 322). This relates to an observation by Fill (1989), based on Brown and Levinson's (1987) discussion of politeness and the performance of FTAs (see section on "Face-Threatening Acts", this chapter): In German, "saving face" focuses more on the speaker's face (e.g., not making a fool of oneself), whereas in English, it is the hearer's face which is emphasized. House also found that in using the apology strategy of "expressing responsibility", Germans are twice as likely as English speakers to use expressions of "selfdeficiency" (e.g., 'I have a lot of trouble being on time') and more than three times as likely to express their "lack of intent" (e.g., 'I didn't mean to hurt you'). English speakers, are the other hand, are more than twice as likely to use the strategy of expressing "concern for the hearer" (e.g., 'Are you okay?'). In other words, "German speakers tend to prefer self-directed strategies whereas English NSs resort more frequently to interpersonal, hearer-related strategies" (p. 321).

Summary: In the studies cited, Germans speaking either their L1 or L2 demonstrate higher levels of directness in the performance of various speech acts, particularly FTAs, and use fewer downgraders than English speakers. According to Kasper, the pragmatic errors of GEFLs generally involve missing or inappropriate modality markers and an inappropriate degree of directness. House and Kasper (1981) 
found that German subjects generally selected higher levels of directness for both complaints and requests and used upgraders more frequently than English speakers. Thus, according to House and Kasper, "German speakers show a stronger tendency to intensify the force of their speech act in actual or potential conflict situations" (p. 182).

The German learners of English in House and Kasper's (1987) study chose more direct levels of realizing requests than the English NSs, mirroring German NS performance, which the researchers took as evidence of pragmatic transfer. In House and Kasper's data, the learners also made considerably less use of modality markers than either English or German NSs (both downgraders and upgraders), which was attributed to a "restricted pragmatic repertoire." Because of their choice of high directness levels and lack of modality markers, their requests are "less mitigated" than those of both NS groups. For reasons discussed above, such differences in linguistic behavior can result in English NSs perceiving German speakers of English as impolite, even when this is not intended.

Kasper (1981) investigates typical discrepancies between the discourse of German EFL learners and British NSs of English, and seeks explanations for these "errors" related to psycholinguistic factors and the context of learning and communication. According to Kasper, there are several causes of pragmatically inappropriate utterances on the part of German learners of English: first language transfer, generalization from previously acquired knowledge of the target language, functional reduction, inferencing, and induction in classroom settings.

In this chapter, a number of issues were discussed in order to provide a sound theoretical basis for analyzing and interpreting the data in this cross-cultural pragmatic 
study. Examining the following components served to establish a sense of the interacting factors influencing L2 pragmatic performance: communicative competence, the acquisition of pragmatic competence, pragmatic failure, the impact of language transfer on second language performance, and the concept of transfer as it relates to pragmatic competence. Considering speech acts, face-threatening acts (FTAs), and the speech act of refusal identified characteristics of the forms under investigation, and the review of studies comparing speakers of English and German provided a perspective on typical differences in the linguistic performance of NSs of German and English and German learners of English. 


\section{Chapter III: Research Design}

This chapter presents a discussion of methodology used in this research project, including information on the instruments of data elicitation, a profile of the subjects, and procedures used in collecting and analyzing data.

This study compares German learners of English as a Second/Foreign Language (ESL/EFL) with NSs of German and American English regarding their production of the refusal speech act. It is based on a study by Beebe, Takhashi, and Uliss-Weltz (1990) which compares data from Japanese NNSs of English with American English and Japanese NS baseline data.

\section{Instruments of Data Collection}

The data for my research was elicited through the use of a Discourse Completion Test (DCT) developed by Beebe, Takahashi, and Uliss-Weltz (see Appendix A). It was modified slightly in order to maintain cultural plausibility for a German subject population, to remove instances of gender bias and the potentially disturbing expression, "Oh God", and to allow for honest responses as well as polite fibs in two items (These adjustments are discussed below.). The DCT is a written role-play questionnaire composed of a set of twelve situations designed to elicit refusals. The respondents were provided with a description of each situation, including information regarding the context of the encounter and the social distance between and relative social status of the interlocutors. The presentation of each situation was followed by a dialogue in which one of the responses was left blank for the subject's written response. The respondents were asked to read the 
situation and the incomplete dialogue which followed, and then to complete the role-play by writing in what they would say in the given situation. No mention was made of the term, "refusal", to avoid influencing responses; however, the nature of the interlocutors' rejoinders following the blanks made it practically impossible to write anything but a refusal.

The twelve DCT situations included four stimulus types that can elicit a refusal: three requests, three invitations, three offers, and three suggestions. For each of these stimulus types, there were three situations involving differences in relative social status, including one refusal to a higher status person, one to a lower status person, and one to an equal status person (see appendix B). Questionnaire items included refusing an employee's request for a raise, refusing a friend's suggestion to try out a new diet, and refusing an offer by one's boss of a raise and promotion because it would involve relocation.

Minor modifications of the original DCT, as designed by Beebe, Takahashi, and Uliss-Weltz, were made for the following reasons:

- to compensate for cultural differences in the subject populations (e.g., to alter a situation which would be possible in the U.S., but not in Germany);

- to avoid gender bias and the expression, "Oh God"; and

- to allow for honest responses rather than just polite fibs.

Altogether, these modifications resulted in very minor wording changes in items $\# 2$, \#3, $\# 4, \# 7$, \#10, and \#11 that do not affect the overall character of the DCT. (For specific details, see Appendix ?, Modifications of the Discourse Completion Test.) 
Considerations of reliability and validity of the instruments were also addressed. I translated the DCT into German and then had a member of the German department at Portland State University translate it back into English. The comparison of the backtranslation with the original English version established the reliability of the translation. In order to establish the reliabilty/validity of the responses elicited by the instrument, pilot groups of English-speaking and German-speaking subjects were asked to answer DCT questions and comment on the instrument, i.e., if any of the situations struck them as implausible, or if there were any other problems associated with responding to the DCT. The purpose of the pilot study was to determine subject reactions to the DCT, initial impression of the kinds of responses to expect, and to determine the amount of time involved in completing the questionnaire, etc. The reliability of my analysis of the data was established through an interrater reliability test (discussed in the section of this chapter on "Data Analysis").

The DCT developed by Beebe, Takahashi, and Uliss-Weltz in their study of refusals impressed me as being a good measure for the intended purpose and research context. They have constructed a very thorough instrument, which considers different types of situations eliciting refusals and the effects of the relative status of speaker and addressee. The face validity of the instrument has been established through Beebe et al's study (In letters to Beebe, I requested information regarding validity data for the measures used in their study, but received no response.).

As discussed above, the DCT items were constructed in such a way as to force subjects to respond with refusals, even though they might not do so in real life when 
confronted with similar situations. In order to take this into account, I added an assessment form at the end of the DCT. Subjects were able to note if they had found any of the situations "odd" (i.e., unlikely to occur in real-life), or had been forced by the interlocutor's rejoinder to give a response that they never would have made in real conversation.

In addition to the DCT and assessment form, all subjects were asked to fill out a background questionnaire consisting of questions regarding gender, age, and native language, and for the Germans responding in English, pertinent information about experience with the English language (i.e., length of study of English; sojourn in an English-speaking country), and variety of English spoken (i.e., American English, British English, etc.). The identities of the subjects were kept confidential. All respondents were asked to sign a consent form permitting use of their questionnaire responses for the purposes of the study.

\section{Subject Population}

The thirty-eight subjects participating in this study belonged to three groups: twelve American NSs of English, speaking English (AEs), fourteen NSs of German speaking German (GGs), and twelve NSs of German speaking English as a Second Language (GEs). The respondents were university students, most of whom were of similar age (All were in their twenties, with the exception of one AE and three GGs. The median age of the AEs was 24.5, of the GGs, 23, and of the GEs, 22.). 
All of the AEs said that they speak English as a sole native language and that the U.S.A. is their country of origin, with the exception of AE5, who named both the U.S.A. and Syria as his countries of origin. All of the GGs gave German as their sole native language and Germany as their country of origin, with the exception of GG2, a bilingual speaker of German and French, who claimed both Germany and France as his countries of origin. All of the GEs were native speakers of German, with Germany as their country of origin.

There was a somewhat higher proportion of female subjects: AEs: 6 males / 6 females; GGs: 6 males / 8 females; and GEs: 4 males and 8 females. The population of AEs were students at Portland State University (Portland, Oregon, USA) and both the GGs and GEs were students at the Albert-Ludwigs-Universität (Freiburg, Germany). The GEs were students in the Anglistik (English Language and Linguistics) department of the university. Data for the study was collected in late October and November 1994.

Selection of the American and German respondents took place through the cooperation of university faculty and was based on the students' willingness to volunteer for the study. The Americans were students in PSU's LING 290 (Introduction to Language) and LING 390 (Introduction to Linguistics) classes, the GEs were students in Discourse Analysis and Second Language Acquisition classes at the Albert-LudwigsUniversität, and the GGs were friends and acquaintances of the GEs (and also students at the university).

The fact that the GEs had been admitted to the Freiburg University Anglistik program attested to an advanced level of English language ability. Normally, entry into the 
program is open only to individuals who have studied English for nine years in school and passed rigorous high school final exams-the $A b i t u r-i n$ English grammar and in written and spoken English. When there is a large number of applicants seeking to enter the program in a given term, admission is limited to those with the highest grade point average.

Variability in the subjects' proficiency level in English was determined through their responses to the background questionnaire (discussed above) question regarding their experience with the English language.

The following table provides a profile of the GE subjects in terms of gender, age, length of study of ESL/EFL, length of sojourn in an English-speaking country, and variety of English spoken:

Table 3. 1: A Profile of the GE Subjects

\begin{tabular}{|c|c|c|c|c|c|}
\hline Subject & Gender & Age & Length of Study & $\begin{array}{l}\text { Length of } \\
\text { Sojourn }\end{array}$ & Variety of English \\
\hline GE1 & male & 20 & 9 years & 10 days & British English \\
\hline GE2 & male & 20 & 6 years & 5 weeks & Virginia slang \\
\hline GE3 & male & 23 & 12 years & 7 weeks & British English \\
\hline GE4 & male & 22 & 7 years & no sojourn & British English \\
\hline GE5 & female & 24 & 10 years & 3 weeks & Jamaican Patois \\
\hline GE6 & female & 21 & 7 years & no sojourn & British English \\
\hline GE7 & female & 20 & 9 years & $\begin{array}{l}\text { more than } 10 \\
\text { weeks }\end{array}$ & $\begin{array}{l}\text { Am. and Brit. } \\
\text { English }\end{array}$ \\
\hline GE8 & female & 22 & 11 years & no sojourn & American English \\
\hline GE9 & female & 24 & 14 years & 1 year & American English \\
\hline GE10 & female & 21 & 11 years & 2 weeks & $\begin{array}{lr}\text { no specific variety, } \\
\text { but } & \text { tendency } \\
\text { towards } & \text { Brit. } \\
\text { English } & \\
\end{array}$ \\
\hline GE11 & female & 27 & 17 years & 1 year & British English \\
\hline GE12 & female & 23 & 10 years & 6 months & American English \\
\hline
\end{tabular}




\section{Procedures of Data Collection}

As noted above, the respondents in the $\mathrm{AE}$ group were volunteers from two different classes at PSU. Because of scheduling difficulties, it was impossible to administer the questionnaire to all ten members of the group at the same time. On three different occasions, I gathered the responses of the $\mathrm{AE}$ group.

The DCT was administered to the GE group by a professor from the Applied Linguistics Department at PSU who was at the time participating in a professor exchange program in Freiburg. She gave the test to students in two classes she was teaching. Students in her Discourse Analysis class were instructed to give the German version of the DCT to German friends. This served as the means of eliciting data from the GG group.

Before completing the DCT, subjects were not informed that the study entailed a cross-cultural comparison of German ESL responses with English and German NS answers in order to avoid influencing their responses.

The subjects were permitted to take as much time as needed to complete the questionnaire dialogues. It was reported that a number of the German respondents required more time than expected, and that impatience might have affected some of the responses towards the end of the DCT. The group of Germans speaking English were allowed to use dictionaries, although none did so. A couple of respondents, however, did ask the meaning of a word or two. 


\section{Procedures of Data Analysis}

\section{Unit of Analysis}

As in Beebe et al's study, the refusals in this study were analyzed as sequences of functional categories ${ }^{4}$ (see Appendices $\mathrm{E}$ and $\mathrm{F}$ ), investigating the frequency of use of the various functional categories by the three groups of subjects, and examining the content of the strategies. In contrast to Beebe et al, however, I found that it was not possible with my data to determine a "typical" order of functional categories used for refusals responding to a particular eliciting speech act. This was due to the fact that the subjects were responding to such a wide array of variables (e.g., unjustified versus justified requests, invitations involving last-minute notification, bribery, or antipathy towards the would-be host/ess's spouse, offers where a refusal would be to the interlocutor's benefit or disadvantage, etc.).

The subjects made very different choices about confronting issues (such as undesirable behavior on the part of the interlocutor) head on or opting for "negative politeness" (Brown and Levinson's term, see Chapter II). This means that sometimes there were different patterns of strategy choices within a population group. It was rare that individual functional categories were used by more than $50 \%$ of the respondents within each group (although, in certain DCT items, excuses and reasons appeared with very high frequency). There was sufficient congruity amongst the responses to allow comparisons of the frequency counts (i.e., frequency of use of excuses, positive forms, face-threatening

\footnotetext{
${ }^{4}$ The term used by Beebe et al was "semantic formula". Because this study focuses on pragmatic functions rather than meaning on the semantic level, the terms, "functional categories" and "strategies" were preferred. Also, the word "formula" is used in this study to refer to routinized utterances that serve a function but carry little meaning beyond the function (e.g., "How are you?" used as a greeting).
} 
strategies, etc. by the AEs, GGs, and GEs, and the degree of confrontration or face-saving politeness effected by the three groups), but not to determine characteristic orderings of functional categories.

Each response was analyzed at the level of functional units rather than sentences. For example, the sentence, “I'm sorry, I can't give it to you because we don't have enough of a profit coming in," contains three functional units: 1. [I'm sorry] 2. [I can't give it to you] 3. [because we don't have enough of a profit coming in]. Beebe et al provide an example of how a repondent's refusal of a friend's invitation to dinner might be analyzed: "I'm sorry, I have theater tickets that night. Maybe I could come by later for a drink." This would consist of [expression of regret] [excuse] [offer of alternative]. Refusals are often preceded by remarks that of themselves could not function as refusals; these are referred to as "adjuncts." An example of an adjunct would be the expression of positive feelings (e.g., "I'd love to...") before giving an excuse (e.g., "but I have to go to my daughter's basketball game"). If it were not followed by the refusal, such an expression of positive feelings would sound like an acceptance.

A frequency count of the functional categories was conducted in order to determine the frequency of each strategy (e.g., the number of excuses) in each of the three subject groups, for each situation (e.g., refusal to lend class notes). The content of certain functional categories was also examined. As Beebe et al note, "I'm busy" and "I have three final exams tomorrow" both function as excuses, but the phrase, "I'm busy," is rather vague compared to the statement about the final exams, and is thus less convincing. Analyzing the content of the formulas is important because it would not be possible to 
characterize each group's responses without taking into account what excuses or offers of alternatives (for example) would be considered appropriate in a given situation.

Like Beebe et al's study, this research is concerned with the frequency and content of the functional categories used by the AEs, GGs, and GEs. The grammatical accuracy of the GEs' responses is not under investigation and thus has not been included in the examination of evidence of negative transfer from the native language.

Interpreting the responses in terms of functional categories proved to be an art as well as a science, requiring insight into the speakers' intentions. The majority of responses permitted unambiguous coding according to the system described. There were, however, individual functional units that were not so clear-cut, where differing interpretations seemed equally plausible. Lacking phonological cues, such as intonation and stress, haptics (i.e., nonverbal cues) and paralinguistic cues involving the broader context in which a conversational exchange took place (e.g., how the respondent envisioned the relationship between speaker and hearer in terms of affinity, antipathy, and other interpersonal dynamics), the data analysis required numerous judgment calls. In such cases, interpretation involved attributing a conversational intention to the speaker. Judgment calls were based on certain principles: consistency in the interpretation of features across different responses and logical attribution of the most likely intention to a given remark (avoiding conjecture).

The analysis of a number of responses required a judgment call on which categories to choose. Basically, I sought to apply criteria from a particular interpretation consistently across subject populations and DCT situations. For example, a response like, 
"I can't afford to give you a raise", could be viewed as either [negative ability] or [excuse] (i.e., financial reason), or both. While "I can't" clearly expressed negative ability, the utterance contained more information than merely that-it also stated why the speaker was unable to comply with the request. Thus, this clause contains two amalgamated functional categories according to my system of analysis. Obviously, one could argue for the validity of a different interpretation. The crucial element, in this researcher's view, is congruity in the overall analysis.

The process of determining a speaker's intentions involved making certain assumptions based on principles of conversation outlined by Grice (1975). First of all, it was assumed that the respondents were operating according to the principle of cooperation to promote the purpose of conversation. In addition, it was assumed that they were following maxims of conversational cooperation described by Grice:

- expressing oneself clearly, without being obscure or unnecessarily ambiguous;

- making statements relevant to the conversation;

- speaking honestly; and

- saying no more than necessary to communicate a given content.

I avoided "digging" for obscured intentions, assuming that the respondents were being as straightforward as politeness conventions and social variables allowed. When responses seemed to violate a particular maxim, I assumed that the respondents were following the cooperative principle and inferred meanings that were conveyed without being directly uttered. Some examples illustrate this point: In DCT\#6, an employee rejects his/her boss' suggestion of writing lots of little notes as reminders in order to diminish the clutter on 
his/her desk. Several subjects began their responses with remarks such as, "I've tried different approaches like that..." or "I've tried that!." Initially, a linguist might classify these remarks as "self-defense," because the employee seems to be saying that $\mathrm{s} / \mathrm{he}$ is doing everything possible to remedy the situation. Upon closer examination, however, it becomes clear that only part of the statement has been made. The speaker is actually saying, "I've tried that and it didn't work." In other words, the speaker is expressing a negative opinion in a highly indirect way. The indirectness of the strategy was chosen because of the power differential between speaker and hearer. So, despite the overtones of self-justification, I categorized these remarks as [negative opinion].

Some remarks can be interpreted as having two levels of functional meaning, e.g., “... I understand that accidents happen. ..." (in response to interlocutor's offer to pay for a vase she broke while cleaning, DCT\#7, AE2). On a more superficial level, this is a statement of philosophy, but the deeper purpose of the remark is to let the addressee off the hook. This remark was classified as [philosophy $=$ off the hook]. Likewise, the statement, “...I wish I'd known..." (in response to boss' request for the speaker to stay at work longer that evening, DCT\#12, AE6) expresses two levels of functional meaning. On one level, the speaker is stating a wish that he could have stayed late and helped the boss, but the underlying message is, "If I'd known sooner, maybe I would have stayed." Thus, this remark was coded as [wish $=$ set condition]. 


\section{System of Classification: Functional Categories (i.e., Refusal Strategies and Adjuncts)}

As stated above, the responses of the three populations to the twelve DCT situations were analyzed in terms of the frequency and content of functional categories used as refusal strategies. As a basis for this examination, a modified version of the functional categories listed by Beebe, Takahashi, and Uliss-Weltz (1990) was used (Modifications to be discussed below.). The classification is based on two primary distinctions: Refusal strategies versus adjuncts, and direct versus indirect refusal strategies. For any given unit, these distinctions were made by asking the following questions:

- Taken on its own, does this remark function as a refusal or not? (i.e., refusal or adjunct). Without the following refusal, an adjunct would not constitute a refusal.

- If the remark does function as a refusal, is it a direct refusal (e.g., 'no', 'I can't', or 'I won't'), or is it indirect, in other words, is a different speech act used to perform the speech act of refusal (e.g., an excuse or an offer of an alternative).

Initially, I had intended to replicate Beebe et al's study, which concentrated on the effects of transfer on frequency, order, and content of functional categories. As I began to examine the data for this study, however, it became apparent that the most interesting and important differences between the three groups of subjects lay in the realm of relative politenss, i.e., the preference for "indiscriminate" face protection versus a willingness to risk confrontation under certain circumstances. This led to a shift in focus (discussed in greater depth in Chapter IV, section on "Focus of Interest and Variables"), which in turn necessitated modification of some of Beebe et al's set of categories. My modifications of Beebe et al's coding system for use in this study was governed by the principle of 
accounting for as much variation within the data as possible while keeping the categories general enough to be readily recognizable as distinct entities. There were two reasons for making changes:

- My data contained instances of strategies not covered in Beebe et al's original set of categories; and

- I considered it necessary to break down three (two) of Beebe et al's categories into smaller units in order to make distinctions relevant to the examination of FTA realization (e.g., to more clearly reflect the different quality of responses given to interlocutors of higher, lower, or equal status).

One of the difficulties I encountered in this research project stemmed from using a method of data analysis described in a relatively brief scholarly paper. Relying on Beebe et al (1990) as my sole source for the classification of refusals, I sought to contact Dr. Beebe for clarification regarding precise definitions of the categories. Unfortunately, these attempts at communication were unsuccessful. Therefore, this analysis is based on my understanding of the categories presented in the article. The paper presents examples of responses to illustrate some of the categories, but does not define them. For some categories, neither a definition nor an example is provided. For this reason, my results may not be fully comparable to Beebe et al because of a different delineation of the functional categories.

For purposes of comparison, the table below displays Beebe et al's original coding system and the modified version used in this study. Only the category headings without explanations or examples are given in an attempt to minimize the unwieldiness of the table. 
(For more information, unabridged versions of both classification systems can be found in Appendices E and F.) A discussion of differences between the two systems follows, providing arguments for construct validity.

Table 3. 2: Comparison of Methods for Classifying Refusals

Classification of Refusals (Beebe, Takahashi, and Uliss-Weltz, 1990, pp. 7273)
Classification of Refusals Used in This Study (derived from Beebe, Takahashi, \& Uliss-Weltz, 1990, pp. 72-73)

\section{Direct}

A. Performative

B. Nonperformative statement

1. "No"

2. Negative willingness/ability
II. Direct

A. Performative

B. Nonperformative statement

1. "No." Also: Opaque "no"

2. Negative willingness: Also Opaque negatve willingness

3. Negative abitity.

4 Vegatve wilingiess 1 ablity

\section{Indirect}

A. Statement of regret

B. Wish

C. Excuse, reason, explanation

D. Statement of alternative

1. I can do X instead of $Y$

2. Why don't you do $X$ instead of $Y$

E. Set condition for future or past acceptance

F. Promise of future acceptance

G. Statement of principle

H. Statement of philosophy

I. Attempt to dissuade interlocutor

1. Threat or statement of negative consequences to the requester

2. Guilt trip

3. Criticize the request/requester, etc. (statement of negative feeling or

\section{Indirect}

A. Statement of regret

B. Wish

Q Oxeuse

D. Reason or explanation

E. Statement of alternative

1. I can do $X$ instead of $Y$

2. Why don't you do $X$ instead of $Y$

3. You can do $\%$ instead of Y

F. Set condition for future or past acceptance

G. Promise of future acceptance. Also: Conditional promise

U statement of principle or philosoply

I. Attempt to dissuade interlocutor

1. Whieat or statenent of regative consequences to the inter loclitor and or to the speaker

2. Guilt trip

3. Chithisn of he inter locutor

4 Insut $1.10 \mathrm{sack}$ 
opinion); insult/attack

4. Request for help, empathy, and assistance by dropping or holding the request.

5. Let interlocutor off the hook

6. Self-defense

J. Acceptance that functions as a refusal

1. Unspecific or indefinite reply

2. Lack of enthusiasm

K. Avoidance

1. Nonverbal
a. Silence
b. Hesitation
c. Do nothing
d. Physical departure

2. Verbal
a. Topic switch
b. Joke
c. Repetition of part of request, etc.
d. Postponement
e. Hedging

f. Critisn of the eliciting speech aet

6. Statement of negative feeling or opinion without criticizing the interbcutor or the eliciting speech act

7 Imperative telling interlocutor to rescind the stggestion, request. offer, etc.

8. Request that interlocutor rescind the suggestion request, offer, etc

9. Let interlocutor off the hook

10. Self-defense

1. Diminish value of the requested object or the object that the interlocutor las damaged and wants to replace

J. Acceptance that functions as a refusal

1. Unspecific or indefinite reply

2. Lack of enthusiasm

K. Avoidance

1. Nonverbal
a. Silence
b. Hesitation
c. Do nothing
d. Physical departure

2. Verbal
a. Topic switch
b. Joke
c. Postponement
d. Hedging

1. Elaboration, ie, information continuing and explaining the preceding utterance

\section{Adjuncts to Refusals}

\section{Adjuncts to Refusals}

1. Statement of positive opinion / feeling or 1 1. Statement of postive opinion / feeling agreement

2. Statement of agreement

3. Compliment

2. Statement of empathy

3. Pause fillers

4. Statement of empathy

5. Pause fillers 


\begin{tabular}{|c|c|}
\hline 4. Gratitude / appreciation & 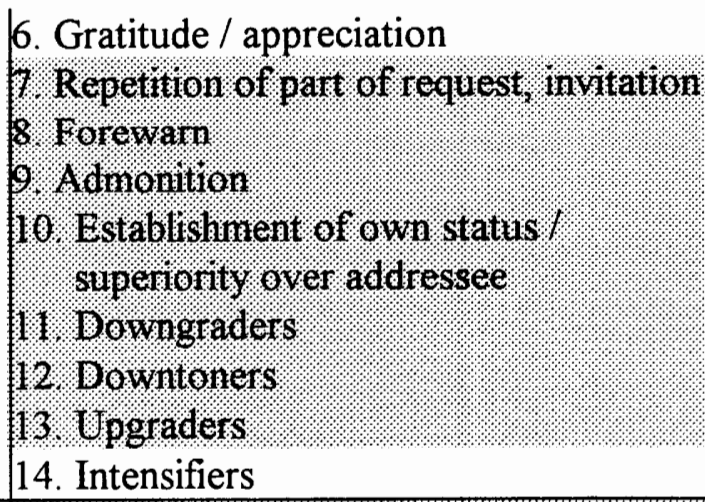 \\
\hline & Mon refusa \\
\hline & 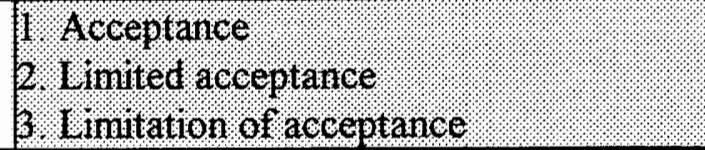 \\
\hline
\end{tabular}

\section{Modifications of Beebe et al's Classification of Functional Categories involved in Refusals:}

\section{Division of Existing Categories:}

Nonperformative Direct Refusals: Beebe et al classified negative willingness and negative ability as one category. There is a great difference in the degree of potential face threat between refusal based on inability and refusal based on unwillingness. Relative status and social distance between speaker and addressee determines whether or not the speaker feels he/she can risk such a face threat to the hearer. I broke this category into three categories because of the different effect and level of politeness between refusal based on unwillingness as opposed to inability: "negative willingness"; "negative ability"; and "negative willingness/ability." The latter, ambiguous category ("negative willingness / ability") was included because some responses did not clearly reflect the motivation to refuse, e.g., "It's out of the question." This is a direct refusal form, but without context or elaboration, there is no way of knowing whether the refusal stems from inability or unwillingness. 
elaboration, there is no way of knowing whether the refusal stems from inability or unwillingness.

In addition, I disagree with Beebe et al's interpretation of the remark, "I don't think so" as a statement of negative ability / willingness. In my view, this utterance should be analyzed as [downgrader + "no"]. As discussed below in the section on downgraders, the form, 'I don't think...', is frequently used to mitigate the impact of an FTA, e.g., "I don't think I can come" or "I don't think that will work." If the remark, "I don't think so" is stripped of the downgrader, what is left is "not so", or "no."

Although negative willingness is a direct refusal strategy, some respondents used forms that expressed negative willingness indirectly. Such remarks were labelled "opaque negative willingness" in this study. An example of this strategy can be found in one subject's angry response to the classmate in DCT\#2 (who repeatedly missed class and wished to borrow the speaker's notes): "Listen: I got up every morning, sat in class and took notes and you stayed in bed. I'm afraid you'll have to ask somebody else!" (GE9). In a different context, this final remark could have been interpreted as a statement of alternative (Why don't you do $\mathrm{X}$ instead of $\mathrm{Y}$ ). Following the speaker's angry outburst, however, the remark obviously is not so much suggesting an alternative course of action as it is asserting the speaker's unwillingness to help the addressee. Thus, the sarcastic use of a downgrader and a statement of alternative resulted in opaque negative willingness.

Excuses, Reasons, and Explanations functioning as Indirect Refusals: In this study, Beebe's et al's category of "excuse, reason, explanation" was broken down into two categories ("excuse" and "reason or explanation") because excuses have a somewhat 
apologetic quality missing from reasons or explanations. They tend to be linked with lower status or refusals of invitations. An excuse implies the need to justify oneself, a plea to be released from an obligation, promise, etc. It implies that the situation is "beyond my control", due to incapacitating circumstances such as work- or school-related duties, previous social obligations, or commitments to spouse and/or family. Sometimes speakers make up excuses; in other words, they tell lies in order to avoid an unwilling acceptance or a face-threatening refusal. A reason, on the other hand, simply explains why the speaker is refusing. Thus, the defining distinction between excuses and reasons in this study is as follows: With a reason, the speaker has a choice; with an excuse, the situation is outside of the speaker's control.

Criticism and Attacks: Beebe et al used one category to cover the following: "criticize the request / requester, etc. (statement of negative feeling or opinion); insult/attack." In terms of the risk of face threat, there is an enormous degree of difference between criticism of the eliciting speech act, criticism of the interlocutor, expression of a negative feeling or opinion, and attacking or insulting one's hearer. The expression of a negative feeling or opinion (as the term is used in this study) is indirect in the sense that it does not actually criticize either the addressee or the eliciting speech act. Thus, this is a relatively "safe" strategy, allowing a good deal of face protection. Criticizing the eliciting speech act obviously is less face-threatening than criticizing the person or behavior of the interlocutor. An attack or insult poses a massive threat to face because it is a clear, undeniable declaration of hostility, openly accepting the possibility of conflict. 
Guilt Trips and Criticism of Interlocutor: Beebe et al had a separate category for "guilt trips" and another category for criticism and negative opinions. It was difficult to distinguish between guilt trips and criticism of the interlocutor, not knowing what criteria Beebe et al used to separate the two categories. The differentiation, however, made sense intuitively. Upon reflection, I arrived at the following distinction: Guilt trips are a subset of criticism of the interlocutor, asserting that the interlocutor's behavior is causing harm to others. According to this reasoning, 'You're lazy' is simply criticism of the interlocutor, whereas 'You let others do your work for you' is a guilt trip. In addition, a guilt trip is an attempt to shame the addressee into changing his/her behavior, while criticism notes the addressee' shortcomings without trying to manipulate a behavioral change.

\section{Added Categories:}

Statements of Alternative used as Indirect Refusals: The category, "You can do X instead of $\mathrm{Y}^{\prime}$, was added because some of my respondents simply stated an alternative possibility, rather than making a suggestion or giving advice. Thus, the category, "Why don't you do X instead of Y?", did not cover these responses. This distinction seemed important because of the different degree of affective involvement between a suggestion and a statement of an alternative, as well as the difference in terms of positive and negative politeness strategies (see Brown \& Levinson).

Threat or Statement of Negative Consequences to the Speaker used as an Indirect

Refusal: The addition of this category reflected responses in my data. It was included in the existing category "threat or statement of negative consequences to the interlocutor." 
Imperative telling Interlocutor to Rescind the Suggestion, Request, Offer, etc., used as an Indirect Refusal: The German data included responses of this type.

Attempt to Dissuade Interlocutor by Diminishing the Value of the Requested Object or Diminishing the Value of the Object that the Interlocutor Wants to Replace: These two categories were added to reflect a number of responses, particularly GE and GG responses.

Elaboration on Preceding Utterance: Some remarks functioned as a extension and "fleshing out" of a previous remark. Both remarks belong to the same category.

Compliments as Adjuncts to Refusals: Some of the respondents made positive statements explicitly related to the interlocutor. Compliments differ from general statements of positive opinion/feeling, because they create greater speaker involvement and commitment to the content of the statement.

Forewarns as Adjuncts to Refusals: Some of the responses in my data contained statements intended to prepare the addressee for the refusal to come. They are the initial suggestion that a refusal will follow.

Admonitions in coniunction with Statements Letting Interlocutor Off the Hook (as

Adjuncts to Refusals): Beebe et al refer to remarks along the lines of "Be more careful from now on." as a "suggested future alternative" (p. 60). I would argue against this interpretation. There is no need to recommend being careful as an alternative to breaking things because the cleaning lady did not choose to break the vase. Rather, the speaker is letting the addressee know that repeated accidents might have a different outcome from 
the present situation. Thus, it appears more appropriate to label such remarks “admonitions."

Establishment of Own Status / Superiority over Addressee as an Adjunct to a

Refusal: Here again, there were several instances of such strategies used in the data.

Downgraders, Downtoners, Intensifiers, and Upgraders as Adiuncts to Refusals:

These four categories were added because these modality markers and gambits have a strong impact on a refusal's effect and degree of politeness. To illustrate this point, one can compare responses containing downgraders and downtoners and the same responses stripped of these softeners: "I don't feel any of you really have it down yet" versus: "None of you have it down yet"; or: "I don't think that'll really work for me" versus: “That won't work for me." The unmitigated forms obviously pose a greater face threat to the hearer than the modified ones.

Downgraders and upgraders are usually embedded in other categories, whereas intensifiers and downtoners are always embedded.

Two of the major downgraders found in the data resemble expressions of gratitude or regret, but differ in a significant way. In the response, "No, thank you", 'thank you' has the function of lessening the impact of the direct refusal ('no') rather than being a full expression of gratitude. Similarly, 'unfortunately' and 'I'm afraid that...' are not a binding apology in the sense that 'I'm sorry' or 'I feel terrible' are. They do not commit the speaker to an expression of regret to the same extent. Instead, their function is simply to mitigate the FTA. 
Some downgraders also function to some extent as forewarns, e.g., 'unfortunately...' or "I can try, but I don't think I can make it. ..." (DCT\#4, AE11). The primary intent of the speaker, however, is to mitigate the FTA. Remarks coded as "forewarns" are more neutral in terms of their mitigating value, e.g., "Well, I'll tell you...", "I've talked it over with my spouse...", focusing more on foreshadowing the refusal rather than softening the impact. Obviously, preparing the hearer for the refusal also softens the impact of the FTA somewhat, so there is some overlap between the two categories.

It is sometimes difficult to distinguish between downgraders, downtoners, forewarns, and intensifiers because they all share the feature of serving primarily to mitigate the impact of an utterance. Downtoners subtly alter a speaker's utterance, weakening the impact of a remark. They are not real carriers of meaning in the sense that downgraders are. What distinguishes downgraders from downtoners is the fact that downgraders are independent of context in terms of their meaning as mitigating forms, while downtoners lose this kind of meaning outside of context. For example, 'unfortunately' or 'thank you' (both downgraders), clearly express politeness or consideration of the hearer's feelings, whereas forms such as, 'you know', 'I mean', or 'kind of' (all downtoners), do not, of themselves, carry such a meaning.

Other modality markers and gambits play a role in the performance of refusals (See Chapter two, Review of the Literature, Kasper's (1981) findings), but for the purposes of this study, the adjuncts listed by Beebe et al and my additions are adequate tools for analysis of the data. It is sufficient to note the effect of various strategies on the FTA of refusal without researching the finer distinctions between modality markers and gambits. 
Thus, in this study, "downgraders" and "downtoners" lessen the face threat of a strategy, "upgraders" increase the face threat, and "intensifiers" add emphasis to a remark without seriously changing the extent of face threat.

In this realm of forms that can subtly alter the impact of utterances, a particular lexical item can serve different functions, depending on the context. A case in point is the word, 'really', which can function:

- as an upgrader, sharpening the force of the FTA (here, the direct refusal strategy, "no" and an attack): "No, really!", "That is really a stupid idea!"

- as an intensifier (here adding emphasis to an expression of regret and to a compliment): "I'm really sorry!", "We really like your work"

- as a downgrader, mitigating the impact of the FTA (here, softening a statement of negative willingness and a statement used for hedging): “I don't really need a diet plan", "I'm not really ready to commit right now" (Compare these utterances to the baldness of: "I don't need a diet plan" and "I'm not ready to commit right now")

Lacking the contextual and other cues (such as intonation and stress) of real face-to-face communication, interpreting such forms can be a matter of the researcher's own judgment, perhaps even to a greater extent than the larger functional categories. These forms serve the sole function of softening, amplifying, or intensifying a strategy used to perform an FTA and are very much a medium for subtleties of intonation and stress. depend to a great extent on . In the utterance, "I really need my notes myself", 'really' does intensify the remark, but it is used primarily to soften the blow of the refusal. In the utterance, “The store really can't afford it right now", for example, 'really' could serve as either an 
intensifier or a downgrader (or both), depending on whether the speaker is emphasizing his/her inability to fulfill the request, or if s/he is softening the impact of the statement of negative ability. "This really isn't a good time for me"(AE9)-intensifying the excuse or softening the utterance (Compare: "This isn't a good time for me."). In terms of the validity of the analysis, discrepancies in rating a particular form as an intensifier or a downgrader would not strongly affect the results because both strategies are "positive adjuncts."

Only intensifiers used in conjunction with statements of regret or gratitude are coded in the data analysis. While intensifiers are often used with other functional categories, such as compliments, choice of a strong lexical item can also produce the same effect. For example, "We really like your work", contains the intensifier 'really', but the statement is no stronger than a compliment without an intensifier, but with words that convey a strong positive image, e.g, "You're a valued asset to the company."

Non-Refusals: Instances of acceptance, limitation of acceptance, and limited acceptance appeared in responses to DCT \#9 (friend's offer of another piece of cake).

\section{Collapsed Category:}

Statements of Philosophy or Principle functioning as Indirect Refusals: Beebe et al had two separate categories for statements of philosophy and statements of principle. I collapsed these into one category because there was so much overlap between the two. In analyzing the data, it was often impossible to distinguish between these categories. 


\section{Shifted Placement of a Category:}

Repetition of Part of Request, Invitation, etc.: Beebe et al categorized this kind of repetition (e.g., "Monday?") as "avoidance", an indirect form of refusal. While repetition obviously could be used as a means of evasion, it also could simply be a request for clarification (e.g., the speaker making sure s/he understood the day correctly). Classifying repetition as "avoidance" attributes an intention to the speaker that a researcher cannot accurately determine without recourse to contextual and nonverbal cues.

In itself, repetition certainly does not constitute a refusal, as the example demonstrates:

A: How about coming over for dinner Sunday night? We're having a small dinner party.

B: Sunday night?

For this reason, repetition is better included in the category of "adjuncts to refusals." Repetition bears a resemblance to pause fillers in that both forms are used by the speaker to "buy time" before giving the actual response.

I include repetition in the category of "mitigating adjuncts" because the wish for clarification signals that inability rather than unwillingness will be the cause of whatever refusal might follow.

\section{Other Modifications:}

Statement of Regret: I differentiated between true statements of regret, i.e., apologies, and downgraders, such as, 'unfortunately' or 'I'm afraid ...', because of their clearly different functions. When apologizing, a speaker takes on some degree of responsibility or 
culpability for a situation whereas a downgrader is used simply to soften the impact of an FTA, without making the speaker responsible.

Although statements of regret, unlike adjuncts, do function as a refusal strategy, they require at least one other unit to complete the refusal, e.g., "I'm sorry, I can't come." The primary function of a statement of regret is mitigating the FTA. This function, combined with dependence on a second unit to make a "real" refusal, are characteristics that statements of regret share with mitigating adjuncts.

Request for Help, Empathy, and Assistance by Dropping or Holding the Request: I reworded this category to better fit the responses within my data using this strategy: Request that interlocutor rescind the suggestion, request, offer, etc.

Attempt to Dissuade Interlocutor: In several of the subdivisions of this category, Beebe et al referred to the "request" or "requester." Because refusals can be responses to four different speech acts, namely invitations, offers, and suggestions, as well as requests, I preferred the more neutral terms, "eliciting speech act" and "interlocutor."

\section{Content Validity and Reliability of the Data Analysis}

Whereas the face validity of the instrument and measures used in this study were established through Beebe et al's study, the content validity is based on careful reflection on speaker intentions, and considerable discussion and debate with other linguists regarding the valid analysis of numerous responses.

In order to establish the reliability of my analysis of the data, a second individual was asked to analyze samples from the data and an interrater reliability test was 
conducted. The individual who analyzed the data for this purpose is a fulltime instructor of English as a Second Language at Portland Community College. She holds an M.A. in Teaching English to Speakers of Other Languages.

The interrater reliability test involved analysis of 10 percent of the data. The questionnaires of four randomly chosen AEs and GEs were examined, the responses coded according to the functional categories discussed above. As a bilingual speaker of English and German, who has lived, studied, and worked in Germany for twelve years, it was determined that my pragmatic competence in German would enable me to classify German and English responses with equal reliability. The accuracy of my translation of the DCT into German, established through the backtranslation, provided concrete evidence of my pragmatic competence in German. For this reason, and because of the difficulty involved in finding an available, qualified German linguist, it was deemed adequate for the interrater reliability test to include only $\mathrm{AE}$ and $\mathrm{GE}$ responses.

The other rater and I discussed and established agreement on the coding system. We then categorized the responses independently. We discussed the discrepancies between our classification of responses until we were able to reach a concensus. Of the 190 functional category units that we both analyzed, we reached consensus on all but 6 items. 


\section{Chapter IV: Results}

As explained in Chapter III, the data elicited for this study was analyzed in terms of the frequency of each functional category (e.g., number of excuses) for each situation and the content of certain functional categories ('I'm busy' vs. 'I have 3 finals tomorrow'). Units of analysis, classification of these units, and analytic techniques are explained in Chapter III, Research Design, section on Procedures of Data Analysis.

\section{Focus of Interest and Variables}

The data analysis reflects the different focus of interest in Beebe et al's study and this study. Beebe et al show a primary interest in pragmatic transfer as it relates to the performance of refusals by Japanese learners of English. My major focus, on the other hand, is on differing pragmatic conventions followed by native speakers of German and American English in the performance of the FTA of refusal and how this relates to the appropriateness of refusal strategies used by German learners of English (This obviously involves transfer issues as well.). I examine functional categories as they relate to the performance of an FTA, in terms of efforts made to mitigate the FTA, show solidarity or sympathy, or, on the other hand, the willingness to be direct and confrontative, even risking conflict resulting from damage to the addressee's face. My analysis builds on Brown and Levinson's $(1978,1987)$ examination of politeness strategies as they relate to FTAs (See Chapter II, Face-Threatening Acts). 
Furthermore, Beebe et al focus their attention on the variables of relative status between the interlocutors (with some consideration of familiarity or social distance as well) and the type of speech act eliciting the refusal. ${ }^{5}$ In this researcher's view, however, other variables strongly affect the respondents' choices of strategies and content of the functional categories. These factors are situation-specific. Obviously, one will respond differently to an ordinary invitation and to one that constitutes a bribe, regardless of the interlocutor's social status. The character of a refusal will be radically different if the speaker perceives the eliciting request as justified or not. Thus, the hard-working, competent employee's request for a raise is likely to be treated differently than a lazy classmate's request to borrow the speaker's notes yet again, quite aside from any considerations of social distance or social status. A particular situation will tend to involve a higher risk of face threat than another (e.g., refusing a friend's invitation have a greater impact on the addressee's positive face than rejecting his/her diet tips), thus calling for a more cautious strategy. The degree of imposition on the speaker if the eliciting speech act were accepted also plays a role (e.g., accepting a job promotion that involves relocation is a greater commitment than accepting an invitation to a party). Strategies used may also reflect the need for a more emphatic refusal

For this reason, other variables related to the context of the individual DCT situations are examined in this study. These issues are very relevant to a study of FTA treatment. Do speakers avoid or risk conflict when the addressee makes an unreasonable

\footnotetext{
${ }^{5}$ Beebe et al themselves acknowledged the existence of other variables besides relative status and different types of eliciting speech acts: “... each questionnaire item was a unique situation, and thus too many variables were involved to run statistical tests." (p. 67)
} 
request, offers an invitation at short notice, makes an unwelcome suggestion, or otherwise imposes on the speaker? To what extent do these factors override consideration of the addressee's higher status? Will a speaker go so far as to be dishonest in order to avoid threatening the addressee's face? Under what conditions does the need to express one's feelings or opinions override the need to save the addressee's face?

In this study's data, one example of evidence for the existence of multiple variables lies in the disparate treatment of interlocutors of the same relative status across DCT items, e.g., the lower-status interlocutors in DCT\#1, \#3, \#7, and \#8: the employee requesting a raise, the salesman inviting the president of a printing company to dinner (a sort of bribe), the cleaning lady offering to pay for a broken vase, and the student suggesting a change in the speaker's language class. While the cleaning lady is treated with great sympathy (as reflected in choice and content of functional categories used), a few of the respondents are less careful with the employee's or the salesman's face needs. Several respondents are exceedingly harsh with the student. The differences in refusal strategies cannot be accounted for with the variables of relative social status and type of speech act eliciting the refusal (e.g., request, offer, invitation, or suggestion).

While the DCT does not isolate the variables of social status and type of eliciting speech act, valid comparisons between the subject groups can be made, as they are all responding to the same situations. When examining a group's preference for a particular strategy, the various factors entering into the speaker's decision must be considered. It is not sufficient to examine differences between refusals uttered to interlocutors of higher, 
lower, and equal status, and refusals of requests, invitations, offers, and suggestions, with all other variables held constant.

Regarding content, Beebe et al primarily examined the content of excuses / reasons and functional categories used by their Japanese subjects (in Japanese and in English), but not used by the AEs in a given DCT item. They view excuses / reasons as "perhaps the most promising area for content analysis" (p. 66). Excuses and reasons are a major focus of my discussion of content as well, but in addition, I also examine the content of other categories.

\section{Procedures for Presenting the Results}

This presentation of the order, frequency, and content of functional categories (i.e., refusal strategies and adjuncts) used in each of the twelve situations is arranged according to the type of refusal stimulus, i.e., eliciting speech act (request, invitation, offer, and suggestion) and interlocutor status (lower, equal, and higher status). Situations involving requests are first, followed by invitations, offers, and finally, suggestions. In each of these four sets, lower status addressees are discussed first, followed by equal status and then higher status.

The sets include refusals of:

Requests:

Lower $^{6}$ \#1 Request raise

\footnotetext{
${ }^{6}$ The terms, "higher", "equal", and "lower" refer to the status of the interlocutor, the one who has made the request, invitation, offer, or suggestion in the DCT item, and to whom the speaker is responding. Unlike Beebe et al, this study refers to the status of the interlocutor rather than the speaker, because in choosing his/her refusal strategy, a speaker processes input on the addressee's characteristics (e.g., the interlocutor's role, such as
} 
Equal \#2 Borrow class notes

Higher \#12 Stay late at the office

\section{Invitations:}

Lower \#3 Fancy restaurant (bribe)

Equal \#10 Dinner at friend's house

Higher \#4 Boss's party

\section{Offers:}

Lower \#7 pay for broken vase

Equal \#9 another piece of cake

Higher \#1 1 Promotion with move to small town

\section{Suggestions:}

Lower \#8 more conversation in foreign language class

Equal \#5 try a new diet

Higher \#6 write little reminders

Within each stimulus group, the discussion will begin with a description of the eliciting speech act in terms of the nature of the refusals it elicits. Next, the three DCT items using that stimulus type will be discussed. Other variables besides social status and type of eliciting speech act that impact respondents' choices of strategies will be examined.

Following this general introduction, the response patterns to the individual DCT items will be examined in terms of frequency of functional categories and content of the functional categories. At the end of the discussion of each set of three DCT items, the findings will be compared and summarized. Following the discussion of the four sets, the impact of the eliciting speech act and relative status, as well as other variables, on the respondents' choices of refusal strategies will be discussed.

"my boss" or "my friend", interpersonal dynamics, such as "s/he is constantly borrowing my notes", extenuating or influencing factors, such as "she has three children to support", etc.). 
In the discussion of individual DCT items, the functional categories are grouped according to their likely impact as strategies used to perform an FTA, that is, whether they increase or decrease the face risk, are direct, evasive or neutral. These groupings underscore functional and structural similarities between different strategies that are relevant to a discussion of FTA performance. Another benefit of grouping the strategies is avoidance of the unwieldiness that would result from discussing each functional category as a discrete entity. Findings regarding the frequency of functional categories will be presented in the following order:

1. Use of Direct Refusal Strategies (performative, "no", negative willingness, negative ability, negative willingness/ability - maybe drop latter category)

2. Excuses and Reasons (including statements of philosophy/principle)

3. Refusal Strategies and Adjuncts that Increase the Face Risk (including threat or statement of negative consequences to the interlocutor and/or to the speaker, guilt trip, criticism of the interlocutor, insult/attack, criticism of the eliciting speech act, statement of negative feeling or opinion, imperative telling interlocutor to rescind the suggestion, request, offer, or invitation, admonition, establishment of own status / superiority over addressee, and upgraders)

4. Evasive Strategies (i.e., acceptance that functions as a refusal, including an unspecific or indefinite reply or lack of enthusiasm; and avoidance ${ }^{7}$ including topic switch, joke, postponement, or hedging)

\footnotetext{
${ }^{7}$ Nonverbal forms of avoidance, such as silence, hesitation, or physical departure, are not included in the tally because the written questionnaire obviously does not allow respondents the option of using these strategies.
} 
5. Strategies that Decrease the Face Risk

A. Positive Forms and Adjuncts (i.e., wish, statement of regret, statement of alternative: I can do $\mathrm{X}$ instead of $\mathrm{Y}$, promise of future acceptance, statement letting the interlocutor off the hook, statement of positive opinion / feeling, statement of agreement, compliment, statement of empathy, statement of gratitude / appreciation, downgraders, and nonrefusal, including acceptance and limited acceptance,)

B. Mitigating Adjuncts (pause fillers, forewarn, downtoners, and repetition of part of the request, invitation, etc.)

C. Number of Positive Forms/Adjuncts per Response

D. Number of Mitigating Adjuncts per Response

6. Other Strategies (i.e., categories that do not fit into the above groupings, e.g., set condition for future or past acceptance, intensifiers, statements of alternative, such as 'Why don't you do $\mathrm{X}$ instead of $\mathrm{Y}$ ' and 'you can do $\mathrm{X}$ instead of $\mathrm{Y}$ ', and various attempts to dissuade the interlocutor, including: request that interlocutor rescind the suggestion, request, offer, etc., self-defense, diminishing the value of the requested object or the object that the interlocutor has damaged and wants to replace. Depending on the individual response, some of these categories can increase or decrease the face risk or serve as an evasive strategy. In such cases, the "other" strategy will be included in the discussion of the grouping it resembles, e.g., a reproachful "set condition" would be included with strategies that increase the face risk.) 
Excuses and reasons are examined separately from other indirect refusal strategies because they represent a major refusal strategy, in terms of both frequency of use and importance of content. Statements of philosophy and principle and included in the tally of excuses and reasons because they are a subset of the reason category.

A joke can function as an evasive strategy but can also increase the face risk. The two instances of jokes used as refusal strategies in my data increased the face threat.

Intensifiers are not tallied separately, but included in the discussion of the strategies they modify because they are details, not a major category.

While limitation of acceptance could be characterized as an evasive strategy in relation to the acceptance, it does not constitute a refusal, so it is, in effect, less evasive than strategies such as postponement or hedging, which succeed in avoiding acceptance. Limitation of acceptance is discussed in conjunction with instances of acceptance

In all of the tables presenting frequencies of the various functional formulas, the three subject groups (AEs, GGs, GEs) are arranged according to the comparative degree of effort to avoid a face-threat to the interlocutor. Thus, the "most polite" (according to Brown and Levinson's definitions) group comes first, followed by the next most polite and the least polite.

Chapter IV is very lengthy. The extensive description of details backs up the researcher's assertions about response patterns and allows the reader to follow the reasoning used in reaching conclusions, rather than just accepting the researcher's claims at face value. An overview of findings is provided in the following section to facilitate perusal of the main body of Chapter IV. 


\section{Overview of Major Findings}

The tables below summarize the major findings, including the subjects' predominant choices of functional categories, choices of FTA strategies, and themes of reasons, excuses, and related functional categories.

Table 4. 1: Refusals of Requests: Predominant Choices of Functional Categories

\begin{tabular}{|c|c|l|}
\hline $\begin{array}{c}\text { DCT } \\
\text { Item }\end{array}$ & $\begin{array}{c}\text { Addressee } \\
\text { Status }\end{array}$ & \multicolumn{1}{c|}{ Features } \\
\hline $\begin{array}{c}\text { DCT } \\
\text { \#1 }\end{array}$ & lower & $\begin{array}{l}\text { The AEs made extensive use of negative ability, excuses, positive } \\
\text { forms/adjuncts and completely avoided forms that would increase } \\
\text { the face risk. They gave warm, even effusive praise. The GGs, on } \\
\text { the other hand, exhibited considerably greater directness in } \\
\text { refusing. They made less use of negative ability and excuses than } \\
\text { the AEs, favoring negative willingness and reasons. They also used } \\
\text { fewer positive forms and a more narrow range of positive form } \\
\text { types. The content of compliments and other positive forms was } \\
\text { restrained. Some face-threatening strategies occurred. The GEs } \\
\text { resembled the GGs, but also used a number of evasive strategies. }\end{array}$ \\
\hline DCT & equal & $\begin{array}{l}\text { There was no predominance of any one strategy, although reasons } \\
\text { and strategies increasing the face threat were fairly important. The } \\
\text { AEs practiced face-saving caution through an emphasis on inability } \\
\text { in direct refusal strategies. They also used the fewest face- } \\
\text { threatening strategies per response and had the highest percentage } \\
\text { of respondents using positive forms and mitigating adjuncts. Both } \\
\text { the GGs and GEs favored direct refusal strategies emphasizing } \\
\text { unwillingness. Amongst the GEs, slightly fewer respondents used } \\
\text { face-threatening strategies than amongst the AEs, and the GEs } \\
\text { used slightly more positive forms per response than the AEs. GEs } \\
\text { who chose to vent negative feelings tended to follow GG patterns } \\
\text { of strategy choices, while GEs with more neutral responses } \\
\text { followed AE patterns. There was little use of positive forms in any } \\
\text { of the three groups, reflecting the fact that the request was not } \\
\text { considered legitimate and that there was no need to flatter the } \\
\text { equal-status interlocutor. }\end{array}$ \\
\hline
\end{tabular}




\begin{tabular}{|l|l|l|}
\hline DCT & higher & $\begin{array}{l}\text { Excuses were the primary feature of responses to DCT\#12, both in } \\
\text { terms of frequency and content. There was a preference of excuses } \\
\text { over reasons and direct refusal strategies in all three groups, } \\
\text { extensive use of positive forms and avoidance of face-threatening } \\
\text { strategies. These features led to strong face protection for the } \\
\text { boss. The Germans, especially the GEs, preferred statements of } \\
\text { regret and downgraders with an apologetic quality, while the AEs } \\
\text { tended to make counter-offers or expressed positive feelings } \\
\text { opinions towards fulfilling the request (NB, Expressions of regret } \\
\text { are more passive than offers of alternative or stating a positive } \\
\text { opinion.). The dearth of mitigating adjuncts reflected the formal } \\
\text { register used with the boss. }\end{array}$ \\
\hline
\end{tabular}

Table 4. 2: Refusals of Invitations: Predominant Choices of Functional Categories

\begin{tabular}{|c|c|c|}
\hline $\begin{array}{l}\text { DCT } \\
\text { Item }\end{array}$ & $\begin{array}{c}\text { Addressee } \\
\text { Status }\end{array}$ & Features \\
\hline $\begin{array}{c}\text { DCT } \\
\# 3\end{array}$ & lower & $\begin{array}{l}\text { Strategy choices depended on whether the response focused on the } \\
\text { dinner invitation in and of itself, the invitation as a questionable } \\
\text { business practice, or on the underlying business deal. Three major } \\
\text { strategies included relatively polite explanations, somewhat polite } \\
\text { evasion, and largely unmitigated confrontational remarks about the } \\
\text { salesman's behavior or product, which led to use of a wide range } \\
\text { of functional categories rather than a predominance of any one } \\
\text { strategy. Excuses, reasons, and statements of principle were all } \\
\text { important, and evasive strategies were used more than in other } \\
\text { DCT items. } \\
\text { Many GGs made high-impact critical remarks, candidly } \\
\text { expressing disapproval of the salesman's dubious invitation, and } \\
\text { not mincing words about the salesman's real intentions underlying } \\
\text { the invitation. The AEs and GEs, on the other hand, protected the } \\
\text { hearer's face and avoided embarrassing mention of dubious } \\
\text { business practices, for the most part responding as though the } \\
\text { invitation involved no ulterior motives. The AEs made minimal use } \\
\text { of evasive strategies and much greater use of the stronger positive } \\
\text { forms than the GGs or GEs. Both the GGs and GEs made } \\
\text { considerable use of evasive strategies. The GGs made very little } \\
\text { use of positive forms, but somewhat more use of mitigating } \\
\text { adjuncts than the other two groups. The GEs made only somewhat } \\
\text { more use of positive forms than the GGs. GG downgraders were } \\
\text { used mostly to cushion the blow of face-threatening strategies } \\
\text { rather than to stress good will, as was the case with the AEs and } \\
\text { Ges. The high GE frequency of excuses indicated hypercorrection. }\end{array}$ \\
\hline
\end{tabular}




\begin{tabular}{|c|c|c|}
\hline $\begin{array}{c}\text { DCT } \\
\# 10\end{array}$ & equal & $\begin{array}{l}\text { There was little use of direct refusal strategies except for use of } \\
\text { negative ability by almost half of the GGs. This served as } \\
\text { protection of the friend's face by avoiding "no" or expressions of } \\
\text { unwillingness. Excuses were predominant, especially in the AE } \\
\text { data, followed by the GEs, and all responses contained either an } \\
\text { excuse or a reason. Use of excuses was associated with white lies. } \\
\text { While the AEs and GEs tended to elaborate on excuses, the GGs } \\
\text { associated excuses with statements of negative ability. All three } \\
\text { groups avoided face-threatening or evasive strategies, reflecting } \\
\text { efforts to protect the face of a hearer perceived to be "deserving" } \\
\text { of tact. The AEs made high use, the GEs moderate use, and the } \\
\text { GGs little use of the stronger positive forms. Statements of } \\
\text { positive opinion and wishes were also associated with white lies. } \\
\text { Downgraders hardly occurred in the AE data, were slightly more } \\
\text { favored by the GGs, and used rather frequently by the GEs. The } \\
\text { GGs used positive forms considerably less often than the other two } \\
\text { groups, but chose mitigating adjuncts more often. }\end{array}$ \\
\hline $\begin{array}{c}\text { DCT } \\
\# 4\end{array}$ & $\overrightarrow{\mathrm{hi}}$ & $\begin{array}{l}\text { All strategy choices in DCT\#4 served to maximize politeness and } \\
\text { minimize any possible face threat. Strategies expressing } \\
\text { unwillingness (i.e., "no", negative willingness, reasons, and face- } \\
\text { threatening forms) were completely avoided. Assertions of inability } \\
\text { were conveyed by all but one respondent through excuses and by } \\
\text { half of the AEs and GGs and a third of the GEs through statements } \\
\text { of negative ability. A number of AEs further increased the } \\
\text { politeness (and formality) of statements of negative ability through } \\
\text { use of the performative-plus-downgrader formula. Positive forms } \\
\text { were prominent in the data of all three groups. The Germans } \\
\text { favored statements of gratitude and regret, which are more } \\
\text { reserved than statements of positive opinion, the form preferred by } \\
\text { the AEs. While the AEs hardly used mitigating adjuncts, the GGs } \\
\text { made some use thereof, and one-third of the GEs used pause } \\
\text { fillers. }\end{array}$ \\
\hline
\end{tabular}


Table 4. 3: Refusals of Offers: Predominant Choices of Functional Categories

\begin{tabular}{|c|c|l|}
\hline $\begin{array}{c}\text { DCT } \\
\text { Item }\end{array}$ & $\begin{array}{c}\text { Addressee } \\
\text { Status }\end{array}$ & \multicolumn{1}{|c|}{ Features } \\
\hline $\begin{array}{c}\text { DCT } \\
\# 7\end{array}$ & lower & $\begin{array}{l}\text { Use of statements letting the interlocutor off the hook } \\
\text { overshadowed all other categories. A number of functional } \\
\text { categories served on a deeper level as "off the hook" remarks: } \\
\text { statements diminishing the value of the damaged object, statements } \\
\text { of philosophy, "no", imperatives to rescind the offer, statements of } \\
\text { empathy, and a statement establishing the speaker's status. The } \\
\text { Germans diminished the value of the broken vase much more } \\
\text { frequently than the AEs, and did not hesitate to make disparaging } \\
\text { remarks about it, which the AEs avoided. The Germans also used } \\
\text { considerably more expressions of empathy than the AEs, and } \\
\text { employed various positive forms that did not appear in the AE } \\
\text { data. In addition, the AEs used strategies that increased the } \\
\text { possibility of a face threat with slightly higher frequency than the } \\
\text { Germans (although all of these were very mild remarks). However, } \\
\text { two GGs deviated from the general tactfulness and kindness of } \\
\text { responses to DCT\#7. While the AEs and GEs made little use of } \\
\text { mitigating adjuncts, a large number of GGs used downtoners. }\end{array}$ \\
\hline
\end{tabular}




\begin{tabular}{|c|c|c|}
\hline $\begin{array}{c}\text { DCT } \\
\# 9\end{array}$ & equal & $\begin{array}{l}\text { The first response section contained frequent use of the formula, } \\
\text { "no"-plus-downgrader, especially by the AEs and GEs, use of bald } \\
\text { "no" by one-fourth of the AEs, and use of negative ability by one- } \\
\text { third of the GGs. There was frequent use of reasons, but little use } \\
\text { of strategies that increased the face threat (only one GG insult, one } \\
\text { GG imperative to drop the offer, a possible AE negative opinion, } \\
\text { and one GE and one GG upgrader). While almost half of the } \\
\text { Germans used compliments, only two AEs did. Downgraders were } \\
\text { used extensively by all three groups. } \\
\text { In the second section, abrupt forms of direct refusal took the } \\
\text { place of 'no, thank you', one-third of the GGs used negative } \\
\text { ability, and one-third of the AEs used reasons. There was } \\
\text { considerable use of innocuous upgraders to reinforce direct } \\
\text { refusals. Amongst the GGs, two upgraders, two guilt trips, and } \\
\text { two imperatives to drop the offer were face threats. One AE made } \\
\text { a rude remark, while the other AEs and the GEs eschewed } \\
\text { antagonistic forms. As for positive forms, the GEs made the most } \\
\text { frequent use of acceptance, while the GGs made the greatest use of } \\
\text { positive forms excluding acceptance. The GGs made considerable } \\
\text { use of downgraders, and a few GGs used compliments and } \\
\text { statements of positive opinion, regret, and gratitude, unlike the } \\
\text { AEs and GEs. }\end{array}$ \\
\hline $\begin{array}{c}\text { DCT } \\
\# 11\end{array}$ & higher & $\begin{array}{l}\text { Half of the GGs and GEs used statements of negative willingness, } \\
\text { as opposed to only one AE. This was slightly balanced out by use } \\
\text { of statements of negative opinion (an unthreatening but } \\
\text { straightforward strategy in DCT\#11) by one-third of the AEs, but } \\
\text { only two GEs and no GGs. One-third of the GEs used negative } \\
\text { ability, which also expressed some unwillingness in the context of } \\
\text { DCT\#11. Reasons, excuses, and statements of philosophy were all } \\
\text { roughly equivalent in terms of face-saving politeness. Reasons } \\
\text { occurred frequently. While AE and GE reasons had a positive } \\
\text { orientation (the benefits of the current situation), about half of the } \\
\text { GG reasons had a negative focus (the undesirability of relocation). } \\
\text { One-third of the GE used excuses, and one-fourth of the AEs } \\
\text { statements of philosophy. The AEs made the most frequent use of } \\
\text { statements of positive opinion, the positive form with the strongest } \\
\text { commitment to positive content. The GGs and GEs tended to } \\
\text { favor the more neutral statement of gratitude and regret. All of the } \\
\text { AEs' and most of the GGs' statements of positive opinion were } \\
\text { enthusiastic, while two-thirds of the GEs' were fairly circumspect. } \\
\text { Downtoners were used by half of the GGs, one-third of the AEs, } \\
\text { and one-fourth of the GEs, and forewarns by one-third of the AEs. }\end{array}$ \\
\hline
\end{tabular}


Table 4. 4: Refusals of Suggestions: Predominant Choices of Functional Categories

\begin{tabular}{|c|c|l|}
\hline $\begin{array}{c}\text { DCT } \\
\text { Item }\end{array}$ & $\begin{array}{c}\text { Addressee } \\
\text { Status }\end{array}$ & \multicolumn{1}{c|}{ Features } \\
\hline $\begin{array}{c}\text { DCT } \\
\text { \#8 }\end{array}$ & lower & $\begin{array}{l}\text { While excuses were rare in DCT\#8, reasons and statements of } \\
\text { philosophy / principle were primary strategies, reflecting the } \\
\text { speaker's free choice to refuse the suggestion. Face-threatening } \\
\text { strategies played a minor role, although all three groups made } \\
\text { remarks aimed at establishing the speaker's status or superiority, } \\
\text { and the GGs criticized the suggestion more frequently than the } \\
\text { other groups. In terms of content, the GEs made the fewest } \\
\text { antagonistic remarks, followed by the AEs, who were slightly } \\
\text { exceeded by the GGs. Positive forms found little use, except for } \\
\text { downgraders (the weakest of the positive forms). The AEs made } \\
\text { more use of positive forms and less use of mitigating adjuncts than } \\
\text { the GGs or GEs, although the GEs had fewer responses lacking a } \\
\text { positive form than the AEs. The AEs also tended to use more } \\
\text { potent positive forms than the other groups. }\end{array}$ \\
\hline $\begin{array}{c}\text { DCT } \\
\text { E5 }\end{array}$ & $\begin{array}{l}\text { There was some use of "no" and statements of negative } \\
\text { willingness, primarily by the Ges and Ggs. AE uses of these direct } \\
\text { forms were all softened by downgraders, in contrast to the } \\
\text { Germans. Reasons were used by one-fourth of the Aes, and } \\
\text { statements of philosophy by over one-third of the Ggs. Statements } \\
\text { of negative opinion and criticism of the suggestion were major } \\
\text { strategies. Upgraders and criticism were used frequently by the } \\
\text { Ggs, posing a clear face threat, and the Ges displayed only slightly } \\
\text { more caution. By contrast, not only did the Aes avoid the harsher } \\
\text { form, criticism of the suggestion, but they also used the milder } \\
\text { form, negative opinion, less frequently than the Germans. The } \\
\text { harshest forms, insult and imperative to rescind the suggestion, } \\
\text { each occurred once amongst the Ggs and Ges, but were eschewed } \\
\text { by the Aes. }\end{array}$ \\
\hline
\end{tabular}




\begin{tabular}{|l|l|l|}
\hline DCT & higher & $\begin{array}{l}\text { The primary strategies in DCT\#6 were self-defense and criticism of } \\
\text { the suggestion, with some prominence of guilt trips in a few GG } \\
\text { responses. There was little or no use of direct refusal strategies, } \\
\text { excuses, reasons, statements of philosophy, or evasion. Positive } \\
\text { forms were generally formulaic politeness routines with little real } \\
\text { content. Positive forms and mitigating adjuncts were scarcely used } \\
\text { in DCT\#6, except for relatively frequent use of downgraders and } \\
\text { downtoners by the AEs. Regarding face-threatening strategies, the } \\
\text { GGs and GEs were more confrontative than the AEs. The GGs } \\
\text { used particularly threatening strategies, eschewed by the other } \\
\text { groups, and both the GGs and GEs were very direct in criticizing } \\
\text { the suggestion. While defensive remarks in the AE data focused on } \\
\text { appeasing the boss and regaining the boss' confidence, the GEs } \\
\text { focused equally on reassuring the boss and evading the suggestion, } \\
\text { and the GGs reassured, evaded, and also defended the speaker by } \\
\text { blaming the boss for the employee's difficulties. In all functional } \\
\text { categories, relative politeness was ranked in the order } \\
\text { AE }>\text { GE }>\text { GG. }\end{array}$ \\
\hline
\end{tabular}

Table 4. 5: Refusals of Requests and Invitations: Choices of FTA Strategies

\begin{tabular}{|c|c|l|}
\hline $\begin{array}{c}\text { DCT } \\
\text { Item }\end{array}$ & $\begin{array}{c}\text { Addressee } \\
\text { Status }\end{array}$ & \multicolumn{1}{c|}{ Features } \\
\hline $\begin{array}{c}\text { DCT } \\
\# 1\end{array}$ & lower & $\begin{array}{l}\text { While AE responses were almost evenly divided between positive } \\
\text { and negative politeness (slightly more positive politeness), fewer } \\
\text { than half of GG and GE responses used positive politeness (and } \\
\text { were cooler in tone than the AE responses in this category, } \\
\text { resembling negative politeness) and about a fourth used negative } \\
\text { politeness. While one-fourth of the GEs refused off record (along } \\
\text { with one GG), a fifth of the GGs refused baldly on record (as well } \\
\text { as one GE). }\end{array}$ \\
\hline $\begin{array}{c}\text { DCT } \\
\# 2\end{array}$ equal & $\begin{array}{l}\text { The most important difference between the three groups involved } \\
\text { the choice to perform the refusal baldly on record: whereas only } \\
\text { one-fourth of the AEs used this approach, half of the GEs and } \\
\text { almost three-fourths of the GGs did. The AEs also used a few off } \\
\text { record refusals, a few respondents chose negative politeness, and } \\
\text { some displayed positive politeness. There was some negative } \\
\text { politeness amongst the GGs, but no positive politeness. A few GEs } \\
\text { refused off record, and there was minimal use of positive politeness } \\
\text { and negative politeness. }\end{array}$ \\
\hline
\end{tabular}




\begin{tabular}{|c|c|l|}
\hline $\begin{array}{c}\text { DCT } \\
\# 12\end{array}$ & higher & $\begin{array}{l}\text { Negative politeness was chosen by the vast majority of } \\
\text { respondents (reflecting the business setting and social distance) } \\
\text { One GG and one AE refused baldly on record. There was no use } \\
\text { of positive politeness or off record refusals. }\end{array}$ \\
\hline $\begin{array}{c}\text { DCT } \\
\text { 33 }\end{array}$ & lower & $\begin{array}{l}\text { Whereas almost all of the AEs used negative politeness, only half } \\
\text { the GEs and less than a third of the GGs did so. Two AEs added a } \\
\text { hint of positive politeness, unlike any of the Germans. About a } \\
\text { third of the Germans refused off record, but only one AE did. No } \\
\text { AE refusals were performed baldly on record, but two GE refusals } \\
\text { and over a third of the GG refusals were (only the GG data } \\
\text { contained face-threatening responses). }\end{array}$ \\
\hline $\begin{array}{c}\text { DCT } \# 10 \\
\text { equal }\end{array}$ & $\begin{array}{l}\text { While AE responses were evenly divided between the positive and } \\
\text { negative politeness categories, two-thirds of the GEs and over } \\
\text { two-thirds of the GGs favored negative politeness. The rest of the } \\
\text { GEs and GGs used positive politeness, although one GG closely } \\
\text { approached a bald on record refusal. }\end{array}$ \\
\hline DCT & higher & $\begin{array}{l}\text { All respondents used negative politeness, except for one GG who } \\
\text { refused off record. Unlike the Germans, almost half of the AEs } \\
\text { added a touch of positive politeness, while a fifth of the GG } \\
\text { responses were direct enough to lean in the direction of refusals } \\
\text { performed baldly on record. }\end{array}$ \\
\hline
\end{tabular}


Table 4. 6: Refusals of Offers and Suggestions: Choices of FTA Strategies

\begin{tabular}{|c|c|l|}
\hline $\begin{array}{c}\text { DCT } \\
\text { Item }\end{array}$ & $\begin{array}{c}\text { Addressee } \\
\text { Status }\end{array}$ & \multicolumn{1}{|c|}{ Features } \\
$\begin{array}{c}\text { DCT } \\
\# 9\end{array}$ & lower & Not applicable, because the refusal in DCT\#7 not an FTA. \\
\hline $\begin{array}{c}\text { DCT } \\
\# 9\end{array}$ & $\begin{array}{l}\text { In the first section, the GEs were evenly divided between negative } \\
\text { and positive politeness. Almost half of the GGs used negative } \\
\text { politeness, and almost half used positive politeness, with a minority } \\
\text { choosing unredressed refusals. Over half of the AEs chose negative } \\
\text { politeness, but only one-sixth used positive politeness, and one- } \\
\text { fourth performed the refusal baldly on record. This was a reversal } \\
\text { of the usual response patterns. } \\
\text { In the second section, a number of respondents performed } \\
\text { the refusal without redress: half of the AEs, 40\% of the GGs, and } \\
\text { one-third of the GEs. Negative politeness occurred only in one- } \\
\text { fifth of the GG responses. One-fourth of the AEs, one-fifth of the } \\
\text { GGs, and only one GE used positive politeness. Over half of the } \\
\text { GEs opted not to perform the FTA (i.e., they accepted the offer), } \\
\text { in contrast to one-fourth and one-fifth of the AEs and GGs, } \\
\text { respectively. This also was a departure from more typical patterns. }\end{array}$ \\
\hline $\begin{array}{c}\text { DCT } \\
\# 11\end{array}$ & higher & $\begin{array}{l}\text { All AEs and GEs implemented negative politeness. While the } \\
\text { majority of the GGs also used negative politeness, two GGs } \\
\text { performed the refusal off record and three GGs performed it baldly } \\
\text { on record (although two of these did use minimal mitigation). }\end{array}$ \\
\hline $\begin{array}{c}\text { DCT } \\
\# 8\end{array}$ & lower & $\begin{array}{l}\text { Most of the AEs and GEs displayed a preference for negative } \\
\text { politeness, as compared with just over half of the GGs. One AE } \\
\text { used positive politeness. While only two AEs and two GEs refused } \\
\text { without redress, almost half of the GGs did. }\end{array}$ \\
\hline equal & $\begin{array}{l}\text { While practically all of the Germans refused without redress, this } \\
\text { was the case with only half of the AEs. In the GG and GE data, } \\
\text { mose were only sparse displays of minimal negative politeness, but } \\
\text { while others chose positive of the AEs used negative politeness, }\end{array}$ \\
\hline
\end{tabular}




\begin{tabular}{|c|l|l|}
\hline $\begin{array}{c}\text { DCT } \\
\text { \#6 }\end{array}$ & higher & $\begin{array}{l}\text { While all the AEs chose negative politeness, only two-thirds of the } \\
\text { GEs and under half of the GGs did so. Additionally, many German } \\
\text { subjects' uses of negative politeness were undermined by } \\
\text { contradiction of the boss. One-third of the GEs and over half of } \\
\text { the GGs performed the refusal baldly on record, risking a face } \\
\text { threat to the boss. }\end{array}$ \\
\hline
\end{tabular}

Table 4. 7:Refusals of Requests: Themes of Reasons, Excuses and Related Functional Categories

\begin{tabular}{|c|c|l|}
\hline $\begin{array}{c}\text { DCT } \\
\text { Item }\end{array}$ & $\begin{array}{c}\text { Addressee } \\
\text { Status }\end{array}$ & \multicolumn{1}{c|}{ Themes } \\
\hline $\begin{array}{c}\text { DCT } \\
\# 1\end{array}$ & lower & $\begin{array}{l}\text { Excuses served as an acknowledgement that the addressee was a } \\
\text { good worker with a valid claim to a raise. The AEs used formulaic, } \\
\text { vague excuses focused on financial inability to comply with the } \\
\text { request. The GEs and GGs, on the other hand, shared more } \\
\text { information about the circumstances of the business, enabling the } \\
\text { interlocutor to understand why the request was denied. Despite the } \\
\text { fact that the addressee was of lower status, excuses were highly } \\
\text { watertight in all three groups because of the importance of the } \\
\text { request to the hearer and the great imposition fulfillment of the } \\
\text { request would mean to speaker. Some reasons also cited financial } \\
\text { considerations, but not necessarily inability to provide the raise, } \\
\text { e.g., that the employee was already well-paid, that it was too soon } \\
\text { to ask for a raise after only one year of employment, or the } \\
\text { concern that other workers would also want a raise. }\end{array}$ \\
\hline $\begin{array}{l}\text { DCT } \\
\# 2\end{array}$ & equal & $\begin{array}{l}\text { Reasons centered on the speaker's own need for the class notes in } \\
\text { order to study for the exam. The relatively few excuses were all } \\
\text { vague and non-watertight, which was understandable, considering } \\
\text { that the hearer had other options for getting what s/he needed, that } \\
\text { the request was perceived as unjustified, and that the interlocutors } \\
\text { were of equal status. Excuses included not having the class notes } \\
\text { along or being in a hurry. }\end{array}$ \\
\hline DCT & higher & $\begin{array}{l}\text { Most excuses claimed that family responsibilities and social } \\
\text { engagements prevented fulfillment of the request, although other } \\
\text { themes appeared as well, a doctor's appointment and feeling weary } \\
\text { or sick. Half of the AEs' and GGs' excuses were specific, but only } \\
\text { three of the AEs' excuses were watertight, whereas almost all GG } \\
\text { excuses were either watertight or "pseudo-watertight" (see } \\
\text { explanation in discussion of DCT\#12). In the GE data, on the } \\
\text { other hand, almost all excuses were specific, and half of those were } \\
\text { watertight (a transferred strategy used to augment politeness). }\end{array}$ \\
\hline
\end{tabular}


Table 4. 8: Refusals of Invitations: Themes of Reasons, Excuses, and Related Functional Categories

\begin{tabular}{|c|c|l|}
\hline $\begin{array}{c}\text { DCT } \\
\text { Item }\end{array}$ & $\begin{array}{c}\text { Addressee } \\
\text { Status }\end{array}$ & \multicolumn{1}{c|}{ Themes } \\
\hline $\begin{array}{c}\text { DCT } \\
\# 3\end{array}$ & lower & $\begin{array}{l}\text { Themes of excuses and reasons involved business considerations or } \\
\text { obligations, not family or social commitments, reflecting the } \\
\text { business setting and social distance. While AE reasons stressed } \\
\text { satisfaction with the company's current equipment, both groups of } \\
\text { Germans avoided divulgence of information. Reasons were direct, } \\
\text { designed to discourage the pressure sales tactics. While both the } \\
\text { AEs and GGs used vague excuses, the GEs used both vague and } \\
\text { specific excuses, indicating a degree of "hyper-correction" (i.e., in } \\
\text { their assumption of the need to increase politeness in English, they } \\
\text { went to more effort with excuses than either group of NSs). }\end{array}$ \\
\hline $\begin{array}{c}\text { DCT } \\
\# 10\end{array}$ & equal & $\begin{array}{l}\text { Excuses focused on obligations and activities within the speaker's } \\
\text { more personal realm, reflecting low social distance and the hearer's } \\
\text { lack of urgency that the invitation be accepted. While the AEs } \\
\text { proffered vague excuses, the GGs gave specific excuses, and the } \\
\text { GEs' excuses were both specific and watertight. It was accurate } \\
\text { for the GEs to increase the politeness of their responses in English, } \\
\text { but in this case they used a means more typical of German NSs } \\
\text { than NSs of American English. }\end{array}$ \\
\hline $\begin{array}{l}\text { DCT } \\
\# 4\end{array}$ & higher & $\begin{array}{l}\text { Family or spousal commitments and trips out of town were the } \\
\text { focus of excuses (the circumstances of the DCT item ruled out } \\
\text { work-related excuses). Half of the AE excuses were vague and the } \\
\text { other half specific. Some effort was made to create convincing } \\
\text { excuses, but these were not particularly watertight. By contrast, } \\
\text { most GG excuses were specific, and the majority of those were } \\
\text { watertight. Very few GGs produced vague excuses, but those that } \\
\text { did, provided enough information to create an impression of } \\
\text { watertightness. All GE excuses were specific and most were } \\
\text { watertight. }\end{array}$ \\
\hline
\end{tabular}


Table 4. 9: Refusals of Offers: Themes of Reasons, Excuses, and Related Functional Categories

\begin{tabular}{|c|c|l|}
\hline $\begin{array}{c}\text { DCT } \\
\text { Item }\end{array}$ & $\begin{array}{c}\text { Addressee } \\
\text { Status }\end{array}$ & \multicolumn{1}{|c|}{ Themes } \\
\hline $\begin{array}{c}\text { DCT } \\
\# 7\end{array}$ & lower & $\begin{array}{l}\text { There were no excuses or reasons in DCT\#7. Almost all } \\
\text { statements of philosophy served to let the interlocutor off the } \\
\text { hook. Most of these were comments along the lines of "Accidents } \\
\text { happen." }\end{array}$ \\
\hline $\begin{array}{c}\text { DCT } \\
\text { DCT }\end{array}$ & equal & $\begin{array}{l}\text { Reasons centered on being full and also, amongst the GGs and } \\
\text { GEs, already having had enough to eat. }\end{array}$ \\
\hline 11 & $\begin{array}{l}\text { heasons with a positive emphasis revolved around contentment } \\
\text { with the current position and benefits of the present location } \\
\text { regarding family stability and proximity of relatives and friends, } \\
\text { while reasons with a negative emphasis emphasized the } \\
\text { unattractiveness of moving. Statements of philosophy asserted the } \\
\text { priority of the speaker's private life and proximity of family and } \\
\text { friends over career advancement and increased salary. Excuses } \\
\text { dealt with familial responsibilities. Only one of three GE excuses } \\
\text { was both specific and watertight, while both GG excuses were } \\
\text { either pseudo-watertight or specific and watertight. }\end{array}$ \\
\hline
\end{tabular}

Table 4. 10: Refusals of Suggestions: Themes of Reasons, Excuses, and Related Functional Categories

\begin{tabular}{|c|c|l|}
\hline $\begin{array}{c}\text { DCT } \\
\text { Item }\end{array}$ & $\begin{array}{c}\text { Addressee } \\
\text { Status }\end{array}$ & \multicolumn{1}{|c|}{ Themes } \\
\hline $\begin{array}{c}\text { DCT } \\
\# 8\end{array}$ & lower & $\begin{array}{l}\text { Reasons, excuses, and statements of principle presented a rationale } \\
\text { for the relative prioritizing of grammar and conversation in the } \\
\text { speaker's language class. }\end{array}$ \\
\hline $\begin{array}{c}\text { DCT } \\
\# 5\end{array}$ & equal & $\begin{array}{l}\text { Most reasons related the unattractiveness of the friend's diet, but a } \\
\text { few stated that the speaker that already found a better means to } \\
\text { lose weight than a diet. Statements of philosophy asserted that } \\
\text { other approaches to losing weight were better than diets. }\end{array}$ \\
\hline $\begin{array}{c}\text { DCT } \\
\# 6\end{array}$ & higher & $\begin{array}{l}\text { There were hardly any excuses, reasons, or statements of } \\
\text { philosophy in response to DCT\#6. Excuses were vague remarks } \\
\text { aimed at appeasing the boss, with no particular thematic pattern. }\end{array}$ \\
\hline
\end{tabular}




\section{Refusals of Requests}

DCT\#1: Lower-Status Interlocutor Requests a Raise

DCT\#2: Equal-Status Interlocutor Wishes to Borrow Class Notes

DCT\#12: Higher-Status Interlocutor Wants Employee to Stay Late at the Office ${ }^{8}$

Although Beebe et al examine their data in terms of only two major variables, namely type of eliciting speech act and relative social status of the interlocutors, it is clear that other variables play a most significant role in determining the respondents' choices of strategies for refusing. When requests are refused, the speaker's ${ }^{9}$ perception of the request's legitimacy (or lack thereof) strongly impacts the response. Other important factors are the extent of the imposition to the speaker if $s /$ he were to fulfill the request and how important fulfillment of the request is to the addressee.

In DCT\#1, the hearer has a high stake in fulfillment of the request, yet providing a pay raise poses a considerable imposition on the speaker. In DCT\#2, the fulfillment of the request is not so important to the hearer because $\mathrm{s} / \mathrm{he}$ can ask another classmate for the notes. Indeed, if $\mathrm{s} / \mathrm{he}$ had been so concerned about the test, $\mathrm{s} / \mathrm{he}$ could have come to class regularly. The imposition on the speaker is moderate. In DCT\#12, the importance of having the speaker work overtime is situation-dependent. The description of the situation in DCT\#12 does not provide enough information to determine how important fulfillment of the request might be to the hearer (i.e., the boss may urgently need the work finished

\footnotetext{
${ }^{8}$ For more information, the text of the DCT can be found in Appendix A, Discourse Completion Test.

"In this study, the "speaker" is the active role taken by the respondent, while "addressee / hearer" refers to the conversational partner whose lines are given in the DCT item.
} 
that same day or $\mathrm{s} /$ he may simply be in the habit of making employees stay in late). Nor does it state how great the imposition to the speaker might be if the request were fulfilled (e.g., how many hours of additional work, how odious the task, how frequently such demands are made, etc.).

DCT\#1, DCT\#2, and DCT\#12 differ in terms of the subjects' perceptions of the requests' legitimacy. In DCT\#1, all of the AEs appeared to view the request as highly justified because the employee was a good worker. The situation evoked solidarity and/or sympathy towards the addressee. Fewer of the German subjects appeared to view the request as legitimate, because they felt the worker had not been employed long enough to merit a raise or because they did not feel it was the employee's place to ask for a raise. These views are reflected in their responses. The request in DCT\#2, on the other hand, was perceived by a majority of the subjects (from all three groups) as not justified because the classmate was constantly missing class. This behavior evoked resentment and the feeling of being taken advantage of. In DCT\#12, the request was fairly neutral because it was within the range of the ordinary demands a boss might make. Also, the request was not huge or unreasonable; thus there was no strong positive or negative "pull" to the DCT item.

The situation in DCT\#1 poses a face risk to both addressee and speaker. Obviously, if the employee feels entitled to a raise and the boss refuses, there is a high face threat to the addressee. It is also possible that the speaker would want to maintain a positive self-image as a boss who treats her/his employees fairly. This was certainly true of the AEs, whose responses strongly reflected an orientation towards protecting the 
addressee's face, by emphasizing the fact that inability, rather than unwillingness, lay behind the refusal, and by making extensive use of polite forms that expressed a sympathetic attitude towards the addressee. Both groups of Germans, by contrast, gave a wider range of responses, from inability to unwillingness, expressing a range of attitudes towards the addressee from empathy to indifference and even irritation and hostility. There was also considerable variability in terms of use or non-use of devices to mitigate the FTA.

The respondents used two major approaches for DCT\#2, based on whether the classmate's request to borrow the speaker's notes was treated as legitimate or not. Thus, some responses were friendly or neutral, giving reasons or excuses for refusing the request and making some use of mitigating forms, while other responses risked full-blown threats to the addressee's face through the use of guilt trips and criticism, venting annoyance or frustration, and remarking on the addressee's personal shortcomings. AEs tended towards conflict avoidance, whereas the GGs in particular, and the GEs to a lesser extent, were often quite direct in expressing disapproval and critical opinions.

Refusal of the boss' request in DCT\#12 poses a face risk to the hearer if the employee fails to give a sufficiently convincing excuse and express politeness because this demonstrates a lack of respect for the boss' position of authority. This, in turn, could pose a threat to the employee's continued employment. Therefore, the employee has a high stake in fulfilling the boss' face needs. With very few exceptions, the respondents in all three groups displayed a great concern for protecting the addressee's face and minimizing the inconvenience that the refusal might impose on the hearer. They were careful to assert 
that inability rather than unwillingness was the basis for the refusal. This is to be expected in a situation of great social distance and a high power differential.

\section{DCT \#1: Refusal of Lower-Status Interlocutor's Request}

\section{Frequency of Functional Categories}

In DCT\#1, direct refusal strategies included statements of negative ability and negative willingness. Obviously, using a statement of negative ability as a refusal strategy constitutes much less of a face risk to the hearer than negative willingness. As noted in Chapter 3, negative ability suggests willingness, were the circumstances different, acknowledges the legitimacy of the request, and implies solidarity with the requester, whereas with negative willingness, the speaker chooses to refuse.

All of the AEs used either negative ability or negative willingness in response to DCT\#1, whereas only $78 \%$ of the GGs and $67 \%$ of the GEs used these categories.

The use of negative ability greatly outweighed negative willingness on the part of the AEs. Eleven out of twelve respondents used negative ability ${ }^{10}$. By contrast, the GEs and GGs used negative ability much less frequently and negative willingness somewhat more frequently than the AEs. Two GGs (14\%) used forms that expressed negative ability, yet had less of a "beyond-my-control" tone than other responses coded as negative ability, sounding more distant and formal than "I can't": .".momentan sehe ich da keine

\footnotetext{
${ }^{10}$ The one respondent who chose negative willingness wrote a somewhat odd response. As the response began with agreement and a compliment, using negative willingness rather than negative ability sounded somewhat strange: "I understand your [sic] prospective. You are a valued asset to this company. Honestly I am unwilling to pay you more
} 
Möglichkeit." (."..At the moment I see no possibility", GG8) and "Da muß ich Sie enttäuschen. ..." ("I must disappoint you", GG14). This further widens the gap between $\mathrm{AE}$ and $\mathrm{GG}$ response patterns and brings $\mathrm{GG}$ use of negative ability more on a par with the GEs.

Other functional categories may express negative willingness indirectly, e.g., reasons, insults / attacks, criticism of the interlocutor or eliciting speech act, guilt trips, and negative consequences for the speaker. Hedging and postponement can also function as "passive-aggressive" strategies for expressing negative willingness. Frequencies of these categories (except reasons, discussed together with excuses) are presented further below.

Table 4. 11 ${ }^{11}$ : Use of Direct Refusal Strategies; Request; Lower-Status Interlocutor ${ }^{12}$ (DCT\#1)

\begin{tabular}{|l|l|l|}
\hline & Negative Ability & Negative Willingness \\
\hline AEs $^{13}$ & $92 \%$ & $8 \%$ \\
\hline GGs & $64 \%$ & $14 \%^{14}$ \\
\hline GEs & $50 \%$ & $17 \%^{15}$ \\
\hline
\end{tabular}

although it has nothing to do with your performance" (AE1). Thus, the one example of negative willingness is a weak case.

${ }^{11}$ N.B.: The fact that there are unequal numbers of subjects in each population group (twelve AEs, fourteen GGs, and twelve GEs) affects the comparability of the percentages.

${ }^{12}$ In the table caption, "request" refers to the speech act that elicited the refusal in this DCT item, and "lower-status interlocutor" refers to the relative status between speaker and hearer (See Appendix D, Classification of DCT Stimulus According to Status of Refuser). This format will be used in all tables presenting information on the frequency of functional categories.

${ }^{13}$ In the frequency tables, the groups of subjects are listed in the order of the "most polite" to "least polite". In other words, the group at the top (here: AEs) has exceeded the other two groups in choosing the functional category that presents the least potential threat to the addressee's face, in avoiding use of the more threatening categories, or in using forms that are particularly positive from the hearer's perspective.

${ }^{14}$ In one case, negative willingness was expressed by way of a reason: “...im Moment wäre eine Gehaltserhöhung noch etwas zu früh." ("...at the moment, a pay raise would be a little premature." - GG1). 
Both excuses and reasons are polite strategies as they acknowledge the addressee's right to an explanation for the refusal and indeed, his or his right to perform the eliciting speech act in the first place. It is a signal that the speaker takes the hearer seriously. The absence of an excuse (or reason) creates a significant difference in the tone of a refusal of a request. To illustrate this point, one can compare the effect of a GG response from my data that lacks an excuse to the same response with an added excuse: "I'm sorry, at the moment I don't see any possibility," versus, "I'm sorry, at the moment I don't see any possibility because business isn't that good."

As stated above, the difference between excuses and reasons (in the context of this study) is that excuses involve a matter beyond the speaker's control, whereas reasons are a matter of choice, i.e., the speaker explains why he/she is choosing to refuse. Because the use of an excuse suggests the situation is beyond the speaker's control, it implies willingness hindered by inability, thus minimizing the face threat.

Excuses are generally more typical when the relative status of the speaker is lower than that of the addressee. In the case of DCT\#1, however, although the subjects are responding in the role of "boss," many of them use excuses rather than reasons. Stating

${ }^{15}$ One GE uses the word, "can't", in his refusal, but obviously means "won't": "Like you said, you're here only for one year. I'm sorry but I can't give you an increase in pay after such a short time." (GE2). For this reason, this response is included as an instance of negative willingness. Another instance of negative willingness is sharpened by the fact that it involves an assertion of the speaker's superiority over the addressee, “... You're really not in the position to demand an increase in pay! If I wanted to raise it up, I'd tell you." (GE1). N.B.: Sometimes the discussion of a particular token (i.e., a functional category used by a particular respondent for a particular DCT item) requires its 
that the situation is beyond the speaker's control is a means of justifying an apparent injustice, namely, the refusal of a legitimate request. Using an excuse suggests a belief that the hearer deserves the requested raise. Of the seven GE excuses, one was only implied and one was used to put limitations on the acceptance of the request. Thus, one could argue that the GE and GG populations were roughly equivalent in their moderate frequency of excuses. The AEs, on the other hand, made extensive use of excuses, considerably more than the GGs and GEs.

Some GGs, and, to a lesser extent, GEs, gave reasons, suggesting that the speaker had a choice in the matter of refusing to give the employee a raise. As noted above in the discussion of negative ability and negative willingness, ability hindered by unwillingness obviously poses a greater face-threat than the excuse strategy.

Table 4. 12: Use of Excuses, Reasons, and Statements of Principle; Request; LowerStatus Interlocutor (DCT\#1)

\begin{tabular}{|l|l|l|l|l|l|}
\hline & Excuses & Reasons & $\begin{array}{l}\text { Both Excuse and } \\
\text { Reason }\end{array}$ & $\begin{array}{l}\text { Neither Excuse nor } \\
\text { Reason }\end{array}$ & Principle \\
\hline AEs & $75 \%$ & - & - & $25 \%$ & - \\
GGs & $43 \%$ & $14 \%$ & $14 \%$ & $29 \%$ & $7 \%$ \\
GEs & $58 \%$ & $17 \%{ }^{16}$ & - & $25 \%$ & $8 \%$ \\
\hline
\end{tabular}

While none of the AEs made use of face-threatening strategies, the GGs used an attack, a guilt trip and criticism of the interlocutor's request. The GEs used a wide range of face-threatening strategies, including an attack, upgraders, criticism of the interlocutor and the request, a guilt trip, and a statement of negative consequences to the speaker.

presentation in context. In such cases, the token being referred to is underlined in order to distinguish it from other tokens that make up its context.

${ }^{16}$ I included in this tally of reasons one instance of negative consequences to the speaker that functioned as a reason: “...if I pay you more money, some of the other workers will ask for more money tomorrow. ..." (GE9). 
Once again, the AEs demonstrated a greater effort to protect the hearer's face than either of the German groups.

Table 4. 13: Percentage ${ }^{17}$ of Strategies that Increase the Face Threat; Request; Lower-Status Interlocutor (DCT\#1)

\begin{tabular}{|l|l|l|l|l|l|l|}
\hline & Attacks & Upgraders & $\begin{array}{l}\text { Criticism of } \\
\text { Interlocutor }\end{array}$ & $\begin{array}{l}\text { Criticism of } \\
\text { Request }\end{array}$ & Guilt Trip & $\begin{array}{l}\text { Negative } \\
\text { Conseq. to } \\
\text { Speaker }\end{array}$ \\
\hline AEs & - & & - & $-21 \%^{18}$ & $-7 \%$ & - \\
GGs & $7 \%$ & - & - & $8 \%$ & $8 \%$ & $8 \%$ \\
GEs & $8 \%$ & $25 \%$ & $8 \%$ & $8 \%$ & $8 \%$ \\
\hline
\end{tabular}

As noted above, evasive strategies can express unwillingness in a "passive-

aggressive" way. The AEs avoided such forms altogether and one GG used postponement, whereas the GEs made fairly significant use of these evasive strategies.

\footnotetext{
${ }^{17}$ Some of the responses contained a particular type of functional category more than once. I considered this information relevant to the tally for DCT\#1, but could not simply list numbers of occurrences because there are different numbers of subjects in the three groups ( $12 \mathrm{AEs}, 12 \mathrm{GEs}$, but $14 \mathrm{GGs}$ ). In order to make these figures comparable, I translated them into percentages. These percentages, however, do not reflect the number of respondents who used a given unit, but rather, the number of times a given unit was used within a population group. For example, if one GE respondent used a given unit once and another GE used the same unit twice, I counted this as three uses. Thus, three uses of a given unit in a population of twelve respondents $=25 \%$.

${ }^{18}$ Two instances of criticism of the eliciting speech act were expressed through reasons, namely, that the employee was already well-paid (suggesting that the request for a pay raise was unjustified), and that it was too soon to ask for a raise after only one year. ${ }^{19}$ In this case, indirect criticism of the request was implied through a forewarn, upgrader, and hedging: "I expected you saying this but you know that I can't decide this here in the store. ..." (GE3)

${ }^{20}$ This guilt trip was embedded in an upgrader and hedging: “.... you know that I can't decide this here in the store. ..." (GE3). This remark implies that the addressee is imposing on the speaker by choosing an inconvenient time and place to request the raise.
} 
Table 4. 14: Percentage ${ }^{21}$ of Evasive Strategies; Request; Lower-Status Interlocutor (DCT\#1)

\begin{tabular}{|l|l|l|}
\hline & Postponement & Hedging \\
\hline AEs & - & - \\
GGs & $7 \%$ & - \\
GEs & $42 \%$ & $17 \%$ \\
\hline
\end{tabular}

Not only did the Americans use negative ability with greater frequency and employ a higher proportion of excuses than the other two groups, they also made greater use of strategies to mitigate the effect of the refusal in DCT\#1 than the GGs or GEs. In addition, the AEs used a much wider range of positive adjuncts than the GGs or GEs, including positive adjuncts such as agreement, compliments, regret, empathy, positive opinion, and downgraders. Of the refusal strategies that display a particularly positive attitude toward the requester, one promise of future acceptance and one wish were used. The GGs' range was only somewhat narrower than the AEs, but the range of functional categories used by the GEs was more restricted than that of the GGs, as the GEs concentrated primarily on compliments and regret. In terms of overall frequency of positive forms, the GGs and GEs were roughly equivalent, except that the GGs made greater use of downgraders.

\footnotetext{
${ }^{21}$ See footnote \#.
} 
Table 4. 15: Percentage of Respondents Using Positive Forms and Adjuncts; Request; Lower-Status Interlocutor (DCT\#1)

\begin{tabular}{|c|c|c|c|}
\hline & AEs & GGs & GEs \\
\hline \multicolumn{4}{|l|}{ Strategies: } \\
\hline Compliments & $50 \%$ & $43 \%{ }^{22}$ & $50 \%$ \\
\hline Regret $^{23}$ & $33 \%$ & $21 \%$ & $42 \%$ \\
\hline Agreement & $25 \%$ & $29 \%$ & $8 \%$ \\
\hline Empathy & $17 \%$ & $7 \%$ & $8 \%$ \\
\hline Positive Opinion & $17 \%$ & $7 \%$ & - \\
\hline Promise & $8 \%$ & -24 & - \\
\hline Wish & $8 \%$ & - & - \\
\hline Acceptance & - & - & $8 \%{ }^{25}$ \\
\hline $\begin{array}{l}\text { Elaboration on } \\
\text { Excuse }\end{array}$ & $8 \%$ & $7 \%$ & - \\
\hline Downgraders & $42 \%$ & $36 \%$ & $17 \%$ \\
\hline Overall & $208 \%$ & $150 \%$ & $133 \%$ \\
\hline
\end{tabular}

As the table below shows, the AEs made greater use of mitigating adjuncts than either of the German groups. Although the GGs made more frequent use of downgraders than the GEs (as the previous table shows), they used fewer mitigating adjuncts.

${ }^{22}$ One GG response contained a remark that could have functioned as an indirect compliment, but, depending on the context, also could have excluded the addressee: “...eine Gehaltserhöhung [ist] selbst fur meine besten Angestellten nicht möglich. ..." (“... a pay increase is not possible, even for my best employees. ..." - GG2). Because it was too indirect to function as much of a compliment, even with the most favorable interpretation, it was not included in the tally of compliments.

${ }^{23}$ Only one $\mathrm{AE}$ and one GE used an intensifier with their statements of regret, i.e., "I'm very sorry" (AE11 and GE8).

${ }^{24}$ One GG response contained a remark that might have been interpreted as an indirect, implied promise of future acceptance. However, it was so noncommital, that I chose not to include it in the tally of promises: "...eine Gehaltserhöhung [ist]...nicht möglich. Zumindest nicht jetzt." ("a pay raise is ... not possible. At least not now." - GG2)

${ }^{25}$ This acceptance was later revoked: “...I'll see what I can do for you. But I have to tell you that the financial situation isn't too good that days..." (GE10). 
Table 4. 16: Percentage of Respondents Using Mitigating Adjuncts; Request; Lower-Status Interlocutor (DCT\#1)

\begin{tabular}{|llll|}
\hline & AEs & GEs & GGs \\
\hline Downtoner & $33 \%$ & $25 \%$ & $7 \%$ \\
\hline Forewarn & $17 \%$ & $8 \%$ & $7 \%$ \\
\hline Pause Filler & $25 \%$ & $17 \%$ & $7 \%$ \\
\hline
\end{tabular}

All of the AEs used at least one positive form per response, in contrast to the GEs and GGs with $25 \%$ and $29 \%$ of the respondents, respectively, using no positive forms. A number of AEs used two or more (up to five) positive forms. None of the GEs and only two of the GGs used more than two positive forms.

All of the AEs used at least one mitigating form, and most of them used two or more. One AE even used four such adjuncts, in addition to an excuse and two statements of negative ability: "Okay, I can understand that. We can talk a little about your needs right now, I'm certainly sympathetic \& we value your position here at the store, but to be honest I can't guarantee anything. Things are tight all over and a pay increase just may not be possible right now" (AE5).

The AEs used a wider range of positive forms than either the GEs or the GGs and they also tended to use more positive forms per response than the GGs or GEs. In other words, the Americans appeared to perceive a strong need to soften their refusals, GEs a more moderate need, and GGs a rather low need.

It should also be noted that most of the instances of GG respondents using two or more positive forms were weakened by other factors. In two cases, the positive adjuncts were followed by an expression of negative willingness or a reason implying negative willingness (GG1 and GG4). In two other cases, responses containing two positive adjuncts also contained implied criticism of the eliciting speech act; one of these also 
contained an indirect guilt trip (GG7 and GG9). In four cases, one of the adjuncts was a downgrader (GG6, GG7, GG9, GG10). Downgraders (i.e., expressions such as "unfortunately") are less of a commitment to positive content than the other adjuncts. Only three GG responses containing two or more positive adjuncts were wholly sympathetic to the addressee-in the other cases, the adjuncts were used to soften "insult added to injury" (i.e., an unpleasant remark in addition to the refusal of the raise).

Table 4. 17: Number of Positive Forms and Adjuncts per Response; Request; Lower-Status Interlocutor (DCT\#1)

\begin{tabular}{|l|l|l|l|l|l|l|}
\hline Number of Positive Forms: & $\mathbf{0}$ & $\mathbf{1}$ & $\mathbf{2}$ & $\mathbf{3}$ & $\mathbf{4}$ & $\mathbf{5}$ \\
\hline AEs & - & $42 \%$ & $33 \%$ & $17 \%$ & - & $8 \%$ \\
GEs & $25 \%$ & $17 \%$ & $58 \%$ & - & - & - \\
GGs & $29 \%$ & $21 \%$ & $36 \%$ & $7 \%$ & $7 \%$ & - \\
\hline
\end{tabular}

Fewer than half of the AEs used no mitigating adjuncts. Most used one or two mitigators per response. Over half of the GEs did not use such mitigation. A sizeable majority of GGs used no mitigating adjuncts and none used more than one.

Table 4. 18: Number of Mitigating Adjuncts per Response; Request; Lower-Status Interlocutor (DCT\#1)

\begin{tabular}{|l|l|l|l|l|}
\hline Number of Mitigating Adjuncts & $\mathbf{0}$ & $\mathbf{1}$ & $\mathbf{2}$ & $\mathbf{3}$ \\
\hline AEs & $42 \%$ & $42 \%$ & $17 \%$ & - \\
GEs & $67 \%$ & $25 \%$ & - & $8 \%$ \\
GGs & $79 \%$ & $21 \%$ & - & - \\
\hline
\end{tabular}

\section{Content of Functional Categories ${ }^{26}$}

Excuses and Reasons: As noted above, none of the AEs gave reasons, perferring excuses instead. In all the AE excuses, financial inability was cited. The GGs, on the other

\footnotetext{
${ }^{26}$ The discussion of content of refusals used for each DCT situation will center on major (i.e., frequently occurring) categories and those categories which give particular insight
} 
hand, gave a wider range of excuses and reasons. Out of six responses containing excuses, two containing reasons, and two responses that included both an excuse and a reason, eight mentioned financial inability, three stated that it was too soon to give a raise after only one year of employment, and one stated that the addressee was already well-paid. The use of a reason following an excuse weakens the mitigating effect of the excuse, as it acknowledges the fact that the refusal is not based solely on considerations beyond the speaker's control. The distribution of GE excuses and reasons lay midway between the GG and AE patterns. Of the seven excuses and two reasons, six clearly cited financial problems, one implied financial reasons, but did not necessarily state that there was financial inability ("I can't pay you more than the ordinary salary, especially in times of recession."), and one stated that it was too soon for a raise. In addition, one GE's expectation of negative consequences to the speaker functioned as a reason, namely, ."..if I pay you more money, some of the other workers will ask for more money tomorrow. ..." (GE9).

Like some of the GGs, but none of the AEs, GE1("not your place to ask") and GE2("one year isn't long enough") suggest that it is inappropriate for the employee to request a raise in the first place. Giving a reason of this nature does not, however, necessarily involve criticism of eliciting speech act, e.g.: ."..Ich halte es nach einem Jahr einfach zu früh um darauf einzugehen." ("I consider it too soon to give you a raise after only one year"-GG13).

into the "flavor" of the refusals performed by each subject group. Minor and less expressive functional categories will not be discussed. 
The excuses given by the AEs tended not to be very specific (e.g., "I cannot fit pay raises in my budget" or "I can't afford any pay raises"). Only three AEs give further explanation: .".business is not that good." (AE4); ."..we don't have enough of a profit coming in." (AE8); ...business has been slow..." (AE12). Although fewer GGs gave excuses than AEs, their excuses tended to be more specific: .".leider sind ... die Umsatzzahlen nicht entsprechend, so daß ich Ihrem Wunsch nicht entsprechen kann." (."..unfortunately, the sales figures are not adequate, so I cannot fulfill your wish."-GG6); ...angesichts unserer geringen Gewinnspanne momentan..." (."..considering our low profit margin at the moment..."-GG7); .".Sie wissen, wie prekär die Situation im Buchhandel ist. ..." (."..you know how precarious the situation is in the bookstore business. ..."-GG9); .".zur Zeit läuft's nicht so gut..." (."..at the moment it's not going so well..."-GG12); ."..Der Buchladen befindet sich noch in der Aufbauphase und finanziell ist da absolut kein Spielraum für eine Gehaltserhöhung." (."..The book store is still in its start-up phase and there is absolutely no latitude for a pay raise."-GG14).

In terms of specificity, the GEs' excuses resembled the GGs', although there was a somewhat lower proportion of specific excuses in the GE data: .".the situation (state) of the store isn't very well at the moment." (GE4); .".the bank wants that I pay the credit back immediately." (GE5); .".the financial situation isn't too good that days..." (GE10); and .".my budget is rather tight." (GE11).

Regardless of the extent of specificity, all of the excuses used by the subjects were fairly watertight and functioned as an elaboration on negative ability. If the boss says that $\mathrm{s} /$ he cannot afford to give any pay raises, the only way the employee could attempt to get 
around the excuse would be to directly contradict the boss, clearly a risky strategy given the power dynamics between the interlocutors.

Compliments: Because certain functional categories exhibit considerable uniformity across responses (i.e., statements of regret, which always took the same form, 'I'm sorry'), the content of only the more expressive positive forms will be discussed, i.e., compliments, statements of empathy, statements of positive opinion, promise of future acceptance and wish.

All of the AEs' compliments strongly emphasized the interlocutor's qualities as an employee: ."..You are a valued asset to this company. ..." (AE1); .... I am pleased with your performance..." (AE3); ."..we value your position here at the store..." (AE5); ."..we really like your work..." (AE6); "you deserve [the raise]" (AE7); and "I really value your good work...” (AE10).

The GGs, on the whole, expressed somewhat less enthusiasm in their compliments than the AEs: ."..wir sind auch sehr zufrieden mit Ihnen..." (."..we're also very satisfied with you...", GG1); .".Ich weiß Ihre Arbeit zu schätzen..." (.”..I value your work...", GG10); .".natürlich bin ich mit Ihrer Arbeit sehr zufrieden..." (."..of course I am very satisfied with your work...", GG11); "Sie sind wirklich gut..." ("You are really good...", GG12).

With the exception of GE12, the GE compliments were somewhat lukewarm, compared to the AEs and GGs: ."..you are a good worker..." (GE6), .".II appreciate your work..." (GE8), .”.. you are a good worker indeed..." (GE10), and, ."..I really enjoy having you working here and so far you did a real good job selling the books..." (GE12). 
In two cases, GG compliments were considerably weakened by their position adjoining an unfavorable (from the hearer's perspective) strategy. Thus, while GG4 stated that, .". Auch mir macht es Spaß mit Ihnen zusammenzuarbeiten. ..." (.".. I also enjoy working with you. ..."), the compliment was followed by negative willingness. In the case of GG9, the compliment, ."..ich [schätze] Ihre Arbeit sehr ..." (.".II value your work very much..."), follows a criticism of the request implying that the request is not really justified because the employee is already in a high pay category. Similarly, a compliment used by one of the GEs, "I know that you are one of my best workers..." (GE9), was followed by a statement of negative consequences to the speaker (namely that other employees would want raises if the addressee received one), which expressed unwillingness to accommodate the request.

Other Positive Forms: Of the statements of empathy, those used by AE5 were stronger than the ones used by GG13 and GE7. While AE5 overflows with solidarity, ...We can talk a little about your needs right now, I'm certainly sympathetic...", the German statements of empathy are more reserved: "Ich kann den Wunsch nach Erhaltserhöhung verstehen..." ("I can understand the wish for a pay raise..."-GG13); and ...I can understand your request..." (GE7).

Similarly, the AE statements of positive opinion are stronger and more of a commitment to the positive content : "I'd love to give you a raise.." (AE9) and .".. [I] would like to increase your pay..." (AE10), as contrasted with ."..es freut mich, daß Sie gerne hier arbeiten..."(.".I'm glad that you enjoy working here..."-GG11). This functional category was not used by the GEs. Two other particularly positive strategies appeared in 
the AE data, but not in either the GG or GE data, a promise: ."..as soon as I can, I will put you at the top of my list." (AE2), and a wish: .".I wish we could give you a raise..." (AE6).

Criticism and Negativity: Four of the GG responses could be perceived as being reproachful or implying criticism (In two of these cases, this negativity was somewhat indirect, and interpretation thereof would depend on other features such as intonation or nonverbal cues, which are, of course, missing in the written responses.). Two of the reasons given by GGs expressed criticism of the employee's request. In one case, the speaker said that it was too soon to ask for a raise after only one year of employment (GG7). In the other instance, the speaker asserted that the employee was already wellpaid, suggesting that the request for the pay raise was unjustified (GG9). The response given by GG3 contained a submerged face threat: "Wenn Sie sich für Ihre Leistungen nicht ausreichend entlohnt fühlen, werde ich mir dies in Ruhe überlegen müssen." ("If you don't feel sufficiently compensated for your achievements, I'll have to think it over undisturbed"). The initial remark carries a possible hint of criticism, as the speaker does not seem to agree with the addressee. The way in which GG3 used postponement holds the interlocutor in limbo and underscores the speaker's power over the hearer. The attack used by GG5 involved criticism of the interlocutor for wanting a raise: "Laut der Wirtschaftlichen Lage müssen Sie froh sein [sic] das Sie einen Job haben." ("In the current economic situation you should be glad to have a job at all"). By emphasizing the weakness of the hearer's position and his/her low status, GG5 made this a response that definitely added insult to injury. There was also a case of implied criticism, in which the speaker 
said, "Mir war klar, daß Sie so eine Forderung stellen [sic] werden. ..." ("It was clear to me that you would make such a demand."-GG7).

Four GE responses involved some sort of negativity. One of the GEs made critical, insulting remarks and asserted his own superiority: "Dear Mr X, who do you think you are?! You're really not in the position to demand an increase in pay! If I wanted to raise it up, I'd tell you." (GE1), and other GE responses could be interpreted as containing a mild implied criticism of the interlocutor's request: "Like you said, you're here only for one year. I'm sorry but I can't give you an increase in pay after such a short time." (GE2) and an indirect guilt trip: ."..but you know that I can't decide this here in the store. ..." (GE3). One GE was rather abrupt in his use of postponement: "I'm very busy at the moment. ..." (GE4).

Attitudes Towards the Interlocutor: There are differences between the Americans and the Germans in the overall tone of their responses in terms of sympathy for the worker's position. Based on features such as use of statements of negative ability, excuses, and positive forms, and the tone and content of these forms, as well as other features described below, one can say that all of the AEs expressed a positive view, whereas only half of the GGs and fewer than half of the GEs were clearly sympathetic. Nearly half of the GGs and half of the GEs displayed a rather neutral attitude towards the employee. At the same time, one GG and one GE exhibited some degree of hostility. Thus, the attitude patterns of the GEs resembled those of the GGs, and both differed from the AEs. 
Table 4. 19: Attitude Expressed Toward Lower-Status Interlocutor Making a Request (DCT\#1)

\begin{tabular}{|l|l|l|l|}
\hline & sympathetic & neutral & hostile \\
\hline AEs & $100 \%$ & $0 \%$ & $0 \%$ \\
GEs & $50 \%$ & $43 \%$ & $7 \%$ \\
GGs & $42 \%$ & $50 \%$ & $8 \%$ \\
\hline
\end{tabular}

The labelling of various responses as "neutral" or "hostile" is based on features that displayed an uncaring attitude or negativity. The neutral responses included:

- a cool forewarn and postponement without any softeners-"Wenn Sie sich für Ihre Leistungen nicht ausreichend entlohnt fühlen, werde ich mir dies in Ruhe überlegen müssen." ("If you don't feel sufficiently compensated for your achievements, I'll have to think it over undisturbed."-GG3);

- implied and overt criticism of the request-"Mir war klar, daß Sie so eine Forderung stellen [sic] werden. Aber ehrlich gesagt, angesichts unserer geringen Gewinnspanne momentan sieht es da leider schlecht aus. Außerdem ist ein Jahr auch nicht gerade ein Zeitraum, nach dessen Ablauf eine Gehaltserhöhung dringend gerechtfertigt wäre." ("I knew that you would make such a demand. But to be honest, considering our low profit margin at the moment, it looks bad, unfortunately. Also, a year isn't exactly a period of time, at the end of which a pay raise would be terribly justified."-GG7);

- a guilt trip and implied criticism of request-"Nun, Sie wissen, wie prekär die Situation im Buchhandel ist. Für mich selbst bleibt weniger als für Sie. Sie werden bereits in e. sehr hohen Tarifgruppe bezahlt, da ich Ihre Arbeit sehr schätze. Aber leider ist momentan nicht mehr drin."("Well, you know how precarious the situation is in the book-selling business. For me there is less left over than for you. You are already very 
high on the wage scale, because I value your work a lot. But unfortunately, nothing more is available at the moment."-GG9); and

- a cool tone and no positive forms or mitigating adjuncts-"Da muß ich Sie enttäuschen. Der Buchladen befindet sich noch in der Aufbauphase und finanziell ist da absolut kein Spielraum für eine Gehaltserhöhung." ("I must disappoint you. The book store is still in its start-up phase and financially, there is absolutely no latitude for a pay raise."GG14).

While GG8 used a statement of regret, the overall tone of the response was cool-"Es tut mir leid, momentan sehe ich da keine Möglichkeit." ("I'm sorry, at the moment I see no possibility").

Amongst the GEs' responses expressing a neutral attitude, there was:

- hedging and postponement without use of any positive forms-“I expected you saying this but you know that I can't decide this here in the store. I have to think about it first and I'll let you know." (GE3);

- similar forms of evasion as in GE3's response but with an added excuse--I'm very busy at the moment. Let's speak about it later on, but I've not so much hope because the situation (state) of the store isn't very well at the moment." (GE4) and "Well, this comes a bit as a surprise. I'm afraid I can't decide this on the spot, but I'll think about. Though I'm afraid my budget is rather tight." (GE11. This response was also a little cool.); and

- content expressing a certain lack of concern for the workers because the speaker gave priority to avoiding requests for raises rather than rewarding merit-"I know that you 
are one of my best workers, but if I pay you more money, some of the other workers will ask for more money tomorrow. I'm sorry." (GE9).

The hostile responses consisted of an attack: "Laut der Wirtschaftlichen Lage müssen Sie froh sein [sic] das Sie einen Job haben." ("In the current economic situation you should be glad to have a job at all"-GG5) and a response containing an insult, criticism of the interlocutor, and assertion of the speaker's superiority over the hearer: "Dear Mr X, who do you think you are?! You're really not in the position to demand an increase in pay! If I wanted to raise it up, I'd tell you." (GE1).

FTA Strategies: Viewing the responses to DCT\#1 from the perspective of Brown and Levinson's (1987) model of the choices involved in performing FTAs (see Chapter 2, Brown and Levinson's Model of Speakers' Considerations when Performing FTAs), differences can be noted between the AEs and the two groups of Germans. All of the AEs went on record ${ }^{27}$ with face-saving politeness. Slightly over half used positive politeness strategies (i.e., they displayed a friendly, appreciative attitude towards the hearer through compliments, statements of positive opinion, etc.) while the rest used negative politeness (i.e., they attempted to compensate for the refusal by showing respect for the hearer's feelings while maintaining social distance). The GGs, on the other hand, made a wider variety of choices. One subject went off record (saying he would take the matter into consideration), three went baldly on record (with unmitigated refusals), four used negative politeness, and six used positive politeness. While a large number of GGs used positive

\footnotetext{
${ }^{27}$ The terminology, "off record", "baldly on record", and "on record with positive / negative politeness", is taken from Brown and Levinson (1987). See discussion in Chapter 2, Brown and Levinson's Model of Speakers' Considerations.
} 
politeness, their compliments tended to be cooler in tone than those used by the AEs (see discussion above). Thus, half of the GG responses using positive politeness exhibited considerably less warmth than the $\mathrm{AE}$ responses in this category and might be considered negative politeness. The distribution of choices in the GE data resembled that of the GGs with slight variation. Three respondents went off record, one was baldly on record, three used negative politeness, and five used positive politeness. Once again, because of the cooler tone of GE compliments, two of the responses involving positive politeness veered towards negative politeness.

\section{Summary of Results: Refusal of Request Made by a Lower-Status Interlocutor (DCT\#1)}

In terms of the frequency and content of functional categories used, the data shows a difference between native speakers of American English and German. The response patterns of the German EFL speakers more closely resembled those of the GGs than the AEs.

Across the board, the AEs consistently made the greatest efforts to meet the addressee's face needs, both in terms of strategy choices and content of the functional categories used. The AEs made a considerable effort to soften the impact of their refusals through extensive use of statements of negative ability, excuses, and positive forms/adjuncts, and complete avoidance of forms that increased the face risk. The GGs and GEs made considerably less use of negative ability and excuses, with a number of respondents expressing unwillingness to fulfill the request and giving reasons why this was the case. While both GGs and GEs used positive forms, they used a lower percentage 
thereof than the AEs and also used a somewhat more narrow range of types of positive forms. The content of their positive forms was also more restrained than that of the AEs. A number of the German responses contained strategies that increased the face risk to the addressee, expressing a critical view of the employee's wish for a pay raise, and in some cases, even a lack of sympathy towards the employee's situation. A number of evasive strategies appeared in GE responses, which implied unwillingness to fulfill the request through passive-aggressive means. The GGs and GEs did not seem to perceive the need to protect the addressee's face to the extent the AEs did.

In DCT\#1, excuses acknowledge that the addressee, a good worker, has a valid claim to a raise. The AEs used excuses with considerably greater frequency than the GGs or GEs.

The content of the excuses given by the AEs was relatively uniform, whereas the GGs and GEs gave a wider range of responses, both excuses and reasons, and with different bases for refusing. The AEs took a more standardized approach to this politeness strategy while the GGs and GEs were more individualistic in their excuses and reasons.

Variability in the degree of specificity in excuses suggests that this strategy serves somewhat different functions for Americans and Germans. The $\mathrm{AE}$ excuses served to underscore inability as the root of the refusal without providing much information on the conditions underlying that inability. Thus, the $\mathrm{AE}$ excuses were more formulaic, part of a politeness routine for refusing a legitimate request. The fact that excuses were used by a high percentage of AEs supports the suggestion that excuses are a typical "ingredient" in such refusals. The Germans, on the other hand, shared more information about the 
circumstances of the business, enabling the interlocutor to follow the speaker's considerations in refusing the request. They wanted the interlocutor to understand the logic behind the refusal, to recognize that the refusal was not arbitrary. Not only was there more originality in the formulation of excuses, but also, excuses were not used so frequently, so automatically, as by the AEs.

The high degree of watertightness of excuses overall in DCT\#1 reflects the importance of the request to the hearer and the considerable imposition that fulfillment of the request would cause the speaker.

Another area of difference between the American and German subjects lay in the content of compliments and other positive forms. The Germans appeared to be more reserved in expressions of praise than the Americans. Other positive forms as well were more restrained in the Germans' responses. While the AEs were warm and friendly in their use of positive forms, and some $\mathrm{AE}$ responses were even relatively effusive, both groups of Germans exhibited a much more reserved approach to positive functional categories. The Americans appeared to emphasize maintaining "good feelings" despite the refusal. This sort of difference between the Americans and Germans in the use of positive forms may underlie some stereotypical views of American speakers held by many Germans: It is possible that Germans would perceive such use of positive forms as excessive and perhaps insincere because it so greatly contrasts with their own usage conventions.

In the overall picture, then, the German subjects were much more direct in refusing the employee's request than the Americans, who made a great effort to soften their refusal and express solidarity with the addressee. 
The AEs all took the role of a boss who saw the employee's point of view, making positive types of utterances, such as compliments or expressions of regret or empathy, and not expressing any negative opinions of either the request or the requester. On the other hand, some of the GG and GE responses stemmed from less sympathetic bosses, even some harsh or callous ones.

\section{DCT \#2: Refusal of Equal-Status Interlocutor's Request}

\section{Frequency of Functional Categories}

As in DCT\#1, the AEs exhibited strong avoidance of statements of negative willingness and the direct refusal form, "no." As the table below demonstrates, the two groups of Germans did not display such a degree of restraint, although the GEs did eschew the form, "no." Use of "no" without a downgrader or downtoner can pose a great face risk to the hearer. The one AE who used "no" softened its impact through efforts to explain his position fairly tactfully, making sure the addressee realized no malice was intended. Although the form "no" stood alone without mitigation, the entire response was softened by the final remark, "I don't want it to come between us" (AE1). Neither of the GG uses of "no" were mitigated in any way, particularly in the case of the GG who simply said, "Nein!!" ("No!!"-GG3).

Negative ability appeared to be the most acceptable direct refusal strategy for the AEs, although it received negligible use amongst the GEs and none by the GGs.

Altogether, in terms of efforts to make polite use of direct refusal strategies: $\mathrm{AE}>\mathrm{GE}>\mathrm{GG}$. 
Table 4. 20: Use of Direct Refusal Strategies; Request; Equal-Status Interlocutor (DCT\#2)

\begin{tabular}{|l|l|l|l|}
\hline & Negative Ability & Negative Willingness & "No" \\
\hline AEs & $25 \%$ & - & $8 \%{ }^{28}$ \\
GEs & $8 \%$ & $25 \%$ & - \\
GGs & - & $21 \%$ & $14 \%{ }^{29}$ \\
\hline
\end{tabular}

The GEs and AEs made equally frequent use of excuses, which were scarcely used in the GG data for DCT\#2. While not as appeasing to the hearer as excuses, reasons nonetheless serve as a face protection device, due to factors discussed above under DCT\#1. Because of this, responses containing either an excuse or a reason were analyzed as being more polite than responses containing neither. As the table shows, the great majority of the GEs, over half of the AEs, but only half of the GGs used either an excuse or a reason.

One GG provided elaboration on an excuse: (GG12), while $1 \mathrm{AE}, 1 \mathrm{GE}$, and 2 GGs gave elaboration on a reason: (AE5; GE3; GG1, GG10). Thus, the GGs exhibited a greater tendency to elaborate on reasons and excuses than the AEs or GEs.

Table 4. 21: Use of Excuses and Reasons; Request; Equal-Status Interlocutor (DCT\#2)

\begin{tabular}{|l|l|l|l|}
\hline & Excuses & Reasons & Neither Excuse Nor Reason \\
\hline GEs & $25 \%$ & $58 \%$ & $17 \%$ \\
AEs & $25 \%$ & $33 \%$ & $42 \%$ \\
GGs & $7 \%$ & $43 \%$ & $50 \%$ \\
\hline
\end{tabular}

\footnotetext{
${ }^{28}$ It should be noted that the only AE who used negative willingness in DCT\#1 was also the only one who used a direct expression of unwillingness in DCT\#2, which suggests that his use of this strategy reflected a personal style atypical for American speakers.

${ }^{29}$ One GG used an opaque form that could have been considered "no" or negative willingness: "...Sorry, aber...." ("...Sorry, but...." - GG6). I chose to include the remark in the tally of statements of negative willingness rather than of the form, "no". The content of this remark is discussed below.
} 
Not only did the GEs show the greatest and GGs the least politeness in their choices to use or not use excuses or reasons, but the same pattern held true for use of strategies that increase the face threat. While the GEs and AEs made greater use of the guilt trip strategy than the GGs, they avoided criticism of the interlocutor entirely, in contrast to the GGs. There was only a minimal difference between the GEs and AEs in their degree of politeness with regard to use of face-threatening strategies. The GEs are listed above the AEs as more polite because the higher $\mathrm{AE}$ use of criticism of the request and negative consequences to the speaker and hearer was interpreted as a greater face threat than the higher GE use of upgraders.

One GG and three GEs used elaboration on guilt trips (GG1 1, twice; GE6, GE9, and GE11).

Table 4. 22: Use of Strategies that Increase the Face Threat; Request; Equal-Status Interlocutor (DCT\#2)

\begin{tabular}{|l|l|l|l|l|l|}
\hline & Guilt Trip & $\begin{array}{l}\text { Criticism of the } \\
\text { Interlocutor }\end{array}$ & $\begin{array}{l}\text { Criticism of the } \\
\text { Request }\end{array}$ & Upgrader & $\begin{array}{l}\text { Negative } \\
\text { Consequences }\end{array}$ \\
\hline GEs & $33 \%$ & - & $8 \%$ & $25 \%$ & \\
AEs & $33 \%$ & - & $17 \%$ & $17 \%$ & $8 \%$ \\
GGs & $21 \%$ & $21 \%$ & $14 \%$ & $21 \%$ \\
\hline
\end{tabular}

Examining the responses that contained these more negative functional categories,

we see an equal percentage of face-threatening strategies amongst the GEs and AEs.

While fewer than half of the AEs and GEs used such forms, over half of the GGs did.

Table 4. 23: Percentage of Respondents Using a Face-Threatening Strategy; Request; Equal-Status Interlocutor (DCT\#2)

\begin{tabular}{|l|l|}
\hline GEs & $42 \%$ \\
\hline AEs & $42 \%$ \\
\hline GGs & $57 \%$ \\
\hline
\end{tabular}


To gain an impression of the effort devoted to expressing negativity towards the addressee, one can examine the number of face-threatening strategies used per response. (Obviously, a short blunt refusal can have just as much or more impact as a drawn-out maligning of the hearer's character, a tirade, or a lecture.)

Table 4. 24: Number of Face-Threatening Strategies Used Per Response; Request; Equal-Status Interlocutor (DCT\#2)

\begin{tabular}{|l|l|l|l|l|l|l|l|}
\hline & 0 & 1 & 2 & 3 & 4 & 5 & 6 \\
\hline AEs & $58 \%$ & $17 \%$ & $8 \%$ & $8 \%$ & - & - & $8 \%$ \\
\hline GEs & $58 \%$ & $8 \%$ & $17 \%$ & - & $17 \%$ & - & - \\
\hline GGs & $36 \%$ & $36 \%$ & $7 \%$ & $7 \%$ & - & $14 \%$ & - \\
\hline
\end{tabular}

None of the respondents made use of an evasive strategy.

There were equal percentages of $\mathrm{AE}$ and $\mathrm{GE}$ use of positive forms and adjuncts, with $\mathrm{AE}$ distribution patterns favoring more strongly positive forms. The GGs showed a good deal less use of such forms than either the AEs or GEs.

The downgraders are listed last because they reflect less of a commitment to the expression of a sympathetic attitude towards the addressee than the other strategies listed.

In DCT\#2, all of these positive adjuncts, with the exception of downgraders, were used in conjunction with an excuse or reason. There was only a single case in which a positive adjunct appeared without an excuse or reason (GG13-regret with no excuse or reason). Downgraders were used both in conjunction with an excuse or reason and also in negative kinds of responses. 
Table 4. 25: Use of Positive Forms / Adjuncts; Request; Equal-Status Interlocutor (DCT\#2)

\begin{tabular}{|lcll|}
\hline & AEs & GEs & GGs \\
\hline Regret $^{\mathbf{3 0}}$ & $33 \%$ & $25 \%$ & $21 \%$ \\
\hline Alternative: I Can ... & $8 \%$ & - & - \\
\hline Positive Feeling & $8 \%$ & - & - \\
\hline Wish & - & $8 \%$ & - \\
\hline Empathy & - & $8 \%$ & - \\
\hline Downgrader & $25 \%$ & $33 \%$ & $21 \%$ \\
\hline Total & $74 \%$ & $74 \%$ & $42 \%$ \\
\hline
\end{tabular}

The AEs and GGs used mitigators with similar frequency, but AE distribution favored the downtoner, which more strongly mitigates than the forewarn or pause filler. Regarding the frequency of use of mitigating adjuncts, $\mathrm{AE}>\mathrm{GG}>\mathrm{GE}$.

Table 4. 26: Use of Mitigating Adjuncts; Request; Equal Status Interlocutor (DCT\#2)

\begin{tabular}{|l|l|l|l|}
\hline & Downtoner & Forewarn & Pause Filler \\
\hline AEs & $33 \%$ & $8 \%$ & $8 \%$ \\
GGs & $21 \%$ & $14 \%$ & $14 \%$ \\
GEs & $17 \%$ & $8 \%$ & - \\
\hline
\end{tabular}

Although the AEs chose more strongly positive forms than the GEs, the GEs slightly exceeded the AEs in the number of positive forms per response. The GGs, once again, were last in line in terms of the number of positive forms per response.

Table 4. 27: Number of Positive Forms / Adjuncts per Response; Request; Equal Status Interlocutor (DCT\#2)

\begin{tabular}{|l|l|l|l|l|}
\hline & $\mathbf{0}$ & $\mathbf{1}$ & $\mathbf{2}$ & $\mathbf{3}$ \\
\hline GEs & $33 \%$ & $58 \%$ & $8 \%$ & - \\
AEs & $42 \%$ & $50 \%$ & - & $8 \%$ \\
GGs & $57 \%$ & $29 \%$ & $14 \%$ & - \\
\hline
\end{tabular}

\footnotetext{
${ }^{30}$ Two subjects used intensification with their statements of regret (GG2 and GE4).

${ }^{31}$ This expression of empathy was somewhat odd because it was followed by a guilt trip at the end of the response. The guilt trip obviously weakened the effect of the empathetic remark.
} 
Although they used fewer positive forms per response than the other two groups, the GGs used more mitigating adjuncts per response than the AEs or GEs, a pattern that appeared in other DCT responses as well. Comparing the previous table with the following table, one sees that the GGs used approximately the same number of positive forms and mitigating adjuncts per response, whereas the other two groups used positive forms more frequently. Although they used more positive forms per response than the other two groups, the GEs used very few mitigators per response.

Table 4. 28: Number of Mitigating Adjuncts per Response; Request; Equal Status (DCT\#2)

\begin{tabular}{|l|l|l|l|l|}
\hline & $\mathbf{0}$ & $\mathbf{1}$ & $\mathbf{2}$ & $\mathbf{3}$ \\
\hline GGs & $57 \%$ & $29 \%$ & $7 \%$ & $7 \%$ \\
AEs & $58 \%$ & $25 \%$ & $17 \%$ & - \\
GEs & $83 \%$ & $8 \%$ & $8 \%$ & - \\
\hline
\end{tabular}

Table 4. 29: Number of Positive and Mitigating Forms / Adjuncts per Response; Request; Equal Status (DCT\#2)

\begin{tabular}{|l|l|l|l|l|l|l|}
\hline & $\mathbf{0}$ & $\mathbf{1}$ & $\mathbf{2}$ & $\mathbf{3}$ & $\mathbf{4}$ & $\mathbf{5}$ \\
\hline AEs & $25 \%$ & $42 \%$ & $25 \%$ & - & - & $8 \%$ \\
GEs & $33 \%$ & $42 \%$ & $17 \%$ & $8 \%$ & - & - \\
GGs & $36 \%$ & $36 \%$ & $7 \%$ & $14 \%$ & $7 \%$ & - \\
\hline
\end{tabular}

Of the three groups, the AEs made the greatest use of mitigators with strategies that involved a face threat (i.e., guilt trip or criticism). The GGs made little use of mitigators in such cases, a tendency that was mirrored to a high degree in the GE data (See discussion above.). This reflects an effort on the part of the AEs to minimize to impact of the face threat, in contrast to the German subjects, who were more blunt in the expression of disapproval or annoyance, not "watering down" their responses with mitigating adjuncts. In responses containing no face threat beyond the refusal itself, mitigating adjuncts, statements of regret and downgraders softened the refusal in half of 
the $\mathrm{AE}$ and $\mathrm{GE}$ responses as compared with $29 \%$ of the $\mathrm{GG}$ responses. In other words, in nonconfrontative responses, GE use of mitigation resembled that of the AEs.

\section{Content of Functional Categories}

Direct Refusal Strategies: As noted above, both groups of Germans were more likely than the AEs to choose the forms of direct refusal that posed a great face threat to the hearer. One GG gave the particularly abrupt response, "Nein!!” ("No!!"-GG3). In two cases, negative willingness (or "no") was expressed in an opaque form, using sarcasm, which added hostility to the responses. One GG used sarcastic regret following a scathing criticism of the addressee: .".Sorry, aber..." (GG6). This translates literally as .".Sorry, but...." The real sentiment of the remark, however, was more along the lines of "Too bad, camper...." It should be noted that the respondent used the English word "sorry", which added an additional sarcastic touch. One GE used opaque negative willingness as well. The surface form appeared to be a statement of alternative (Why don't you do X instead of Y?), but in the context of the hostile response, it was hardly a suggestion of an alternative, but rather an assertion of negative willingness: "I'm afraid you'll have to ask somebody else!" (GE9). The downgrader, "I'm afraid...", added a bit of indignant sarcasm.

Excuses and Reasons: Use of excuses and reasons was tied in with the speaker's attitude towards the addressee. For the most part, respondents who used an excuse or a reason displayed an accepting or at least neutral attitude towards the request. Most of the responses that did not include an excuse or reason expressed a mild reproach or outright hostility. The only exceptions were GG13, GE2, and GE6, who were somewhat 
reproachful and also gave a reason for the refusal, and GE10, who was hostile, but also gave a reason for the refusal. The tally below is based on the respondents' choice of facethreatening and/or face-saving strategies and the content of these functional categories.

Table 4. 30: Attitude of Respondents Towards Request / Requester (DCT\#2)

\begin{tabular}{|l|l|l|l|}
\hline & Accepting & Mildly Reproachful & Hostile \\
\hline AEs & $58 \%$ & $33 \%$ & $8 \%$ \\
GEs & $58 \%$ & $17 \%$ & $25 \%$ \\
GGs & $50 \%$ & $7 \%$ & $43 \%$ \\
\hline
\end{tabular}

Of the AEs who were accepting of the request, four refused because they needed the notes themselves (AE3, AE4, AE5, AE7), and three made excuses (Two said they did not have the notes with them (AE8 and AE9), and one said she was in a hurry (AE11).). The mildly reproachful $\mathrm{AE}$ remarks stated that the addressee was letting others do the work for him/her (AE1, AE2, AE10, AE12), and one $\mathrm{AE}$ expressed concern that this would harm their friendship (AE1). The one hostile AE remark was an abrupt, "You're joking, aren't you? ..." (AE6).

Of the GGs who showed acceptance of the request, five said they needed their notes (GG1, GG2, GG8, GG10, GG14), one made the excuse of not having the notes along (GG12), and two used statements of negative consequences to the addressee as a form of dissuasion, asserting that the addressee would be unable to make sense of their notes (GG7, GG14). The one GG who was mildly reproachful noted that she had already lent the addressee her notes before, and that she needed her notes herself (GG13). The hostile GG remarks included an abrupt "no", harsh guilt trips and criticism of the request and the requester. These face-threatening strategies are discussed below. 
Of the GEs who displayed an accepting attitude towards the request, four said they needed the notes themselves (GE3, GE7, GE8, GE12), and three made excuses, namely that they had left the notes at home, (GE4 and GE5), and that the notes had already been lent to someone else (GE1). Of the mildly reproachful responses, one expressed empathy, but ended with a mild guilt trip, also stating that he needed his notes himself: "I feel sorry for you but I need these notes by myself in the afternoon. Perhaps you'd rather attend class [sic] regulary." (GE2). The other mildly reproachful GE also stated a need to use the notes herself and ended with a mild guilt trip: "I need them myself. You shouldn't miss the class all the time, you would not have this problem then." (GE6). The hostile responses contained upgraders, including a hostile interrogative, criticism of the request and elaborate guilt trips. See discussion of face-threatening strategies below.

There was generally a separation between those respondents who said they needed their notes themselves or gave an excuse (e.g., not having notes along), and those who made some sort of negative remark (i.e., guilt trip, criticism of request or requester, statement of negative consequences to the hearer or to the hearer and speaker). Only three respondents altogether used both a negative remark and stated a need for the notes themselves (one GG and two GEs). In two of these cases, the major focus of the response was the negative remark (GG13, GE10), and in one, the focus was the speaker's own need for the requested object (GE2). One respondent refused the request because she had already lent the addressee her notes before (a remark that took the form of criticism of the eliciting speech act), and mentioned her own need for the notes as a sort of afterthought: ... ich habe Dir meine Aufzeichnungen bereits letztes Mal gegeben und hinsichtlich der 
Prüfung benötige ich sie selbst." (."..I already gave you my notes last time and as far as the test is concerned, I need them myself."-GG13). One respondent criticized the fact that the request had been made the day before the exam, and, like GG13, tacked on the statement of her own need for the notes as an afterthought (the afterthought quality is reinforced by the use of the words, "by the way"): "Don't you think it's a bit too late to ask me for my notes just the day before the exams? I need them for myself, by the way." (GE10). On the other hand, GE2 focused primarily on his own need for the notes, adding the reproach at the end as a sort of addendum: "I feel sorry for you but I need these notes by myself in the afternoon. Perhaps you'd rather attend class [sic] regulary." (GE2).

In summary, the content of most of the excuses revolved around the speaker not having the notes along. Of the two excuses with different themes, one speaker was in hurry doing errands, and the other had already lent the notes to someone else. In all three groups, the excuses used in response to DCT\#2 were neither very specific nor watertight.

Face-Threatening Strategies: There was a good bit of overlap between the categories of "guilt trip", "criticism of interlocutor", and "criticism of eliciting speech act" in this DCT situation. In many cases it was necessary to make a judgment call because some guilt trips involved personal criticism, and some critical remarks tended towards "shaming and blaming." In some instances, criticism was clearly directed toward the unreasonable request (a more neutral, less face-threatening strategy), and in others to the classmate's personal deficiencies (a strategy likely to cause loss of face to the addressee and to provoke resentment). If a respondent mentioned that the classmate was inconveniencing or being unfair to others with his/her behavior, I analyzed this as a "guilt 
trip." If the classmate was called "lazy", "undisciplined", etc., I labeled this "criticism of the interlocutor." More subtle criticism that avoided negative personal statements and focused on the inappropriateness of the request was considered "criticism of the eliciting speech act."

In the next section, the messages expressed in the various face-threatening functional categories are discussed.

As noted above in the discussion of the frequency of functional categories, neither the AEs nor the GEs used criticism of the interlocutor. The messages expressed by GGs by way of this form included: "you're lazy" (GG4). "you've got a lot of gall / nerve" (GG6), and "you lack discipline" (used twice by GG9). All of these statements are "fightin' words", a clear threat to the hearer's face. In Brown and Levinson's terminology, this is an FTA performed baldly on record without redress.

The messages conveyed in guilt trips included the following:

AEs: "you're not doing your work" (three instances-AE1 twice and AE2 once), "you don't come to class enough" (once-AE12), "you always ask me" (once-AE12), and "you're using me" (twice-AE1, AE10).

GGs: "you constantly miss class" (once-GG6), "you depend on me and the others too much" (GG9), "you want a good grade although you've done nothing" (once-GG6), “you let others / me do your work" (three times-GG6, GG9, GG11), whereby one such remark indirectly said, "you're taking advantage of me" (GG11). 
GEs: "you miss class a lot" (twice plus elaboration-GE2, GE6, with elaboration), "you let me do your work and you did nothing" (twice-GE9, GE11), "you ask this favor too often" (once-GE11).

The AEs' and GEs' guilt trip messages were almost the same except for the slightly sharper tone of the GE remark, "you let me do your work and you did nothing", as contrasted with the AE remark, "you're not doing your work." On the other hand, two AEs reproached the hearer for "using me", which none of the GEs did. Thus, the GEs were perhaps a bit more careful in the content of their guilt trips than the AEs. The GGs, by contrast, were somewhat harsher in their choice of words. Unlike the GGs, none of the AEs or GEs made any mention of other people besides the speaker doing work for the hearer.

While the tone of some responses containing criticism of the eliciting speech act may have been face-threatening (see below), the messages (with the exception of AE6) were objective, relatively unthreatening observations. The two messages were: "I have already given you my notes (several times) before" (AE10 and GG13) and "It's too late to ask for my notes now (a day before the test)" (GG5 and GE10). AE6's response did not have a specific message beyond general disapproval of the request: "You're joking, aren't you?."

The relative harshness of the face-threatening responses and use of mitigation are discussed next.

As noted above, the GGs were the only group to use criticism of the interlocutor. Responses containing this functional category were relatively harsh. GG4's response was a 
clear menace to the hearer's face. His initial remark appeared to be a statement of positive opinion, which in context, however, turned out to be a forewarn: "Prinzipiell bin ich immer bereit jdm zu helfen. ..." ("In principle I am always willing to help everyone. ..."). The following remark turned the entire response into a fairly harsh criticism: .... In Deinem Fall möchte ich jedoch nicht Deine Faulheit unterstützen." (.”.. In your case, however, I wouldn't like to support your laziness."-GG4). The impact of the remark was increased by the innocuous beginning. In other words, the speaker would be glad to help anyone, but the addressee is the one exception because of his/her massive character deficiencies. GG6's reponse left the addressee no possibility of saving face: "Ich finde das schon unverfroren von Dir, dauernd blau zu machen $\mathrm{u}$. andere arbeiten zu lassen, und dann 'ne gute Note zu wollen! Sorry, aber..." ("I think you've got a lot a gall, constantly skipping class and letting others work, and then wanting a good grade! Too bad, camper..."). Despite the reproachfulness of her response, GG9 did soften the impact of her criticism and a statement of negative willingness through the use of downgraders: "Ich finde, Du könntest etwas disziplinierter die Seminare besuchen. Bloß, [sic] weiß Dir diese Disziplin so mangelt, soll ich für Dich mitarbeiten? Tut mir leid, aber das sehe ich nun nicht mehr ein, da Du Dich zu sehr auf mich und die anderen zu verlassen scheinst. Außerdem bringt's einen Tag vor der Prüfung auch nicht sehr viel." ("I think you could be more disciplined about going to classes. Just because you lack this discipline, should I do your work for you? Sorry, but that is no longer acceptable to me because you seem to depend too much on me and the others. Besides, it wouldn't be of much use one day before the test anyway.") 
The impact of almost all the guilt trips used by AEs were softened by various means, whereas only one GG (GG11) and no GEs weakened the blow of their guilt trips. A number of guilt trips produced by AEs were expressed in tactful ways. Instead of bluntly asserting that "you're not doing your work" or "you're using me", AE1 states: ... $\operatorname{Im}$ afraid [sic] Im reinforcing you not to do your own work. ... [sic] $\operatorname{Im}[\mathrm{sic}]$ beginng to feel used by you \& I don't want it to come between us." Not only was the first of these remarks preceded by a downgrader, but it was further softened by the syntactic structure of the sentence, which made the speaker the agent. Similarly, in the second sentence quoted, the comment was tempered with a form acknowledging the remark's subjectivity ("I'm beginning to feel..."). In addition, AE1 softened the entire response by emphasizing that his major concern in not letting the classmate take advantage of him was not to let their friendship suffer. The same kind of tactful subjectivity was used by AE10: .". I feel like [sic] your abusing my generosity.."..." One AE guilt trip was preceded by a forewarn and downgrader, and also involved the speaker as a less-than-ideal participant in the affair: "I hate to sound rude, but I think [sic] its time to start doing your own work. ..." (AE2). This remark implies self-criticism for setting up boundaries and pointing out the hearer's transgression of those boundaries. This is not true self-criticism, but rather a polite form used to reduce the face risk to the hearer. Portraying oneself as fallible is a means of keeping speaker and hearer on the same level, of avoiding giving the impression that the speaker considers the hearer morally inferior. Only AE12 used no forms or content to 
soften her guilt trips ${ }^{32}$. The form used by AE12, ."..I'm getting tired of you always asking me.", is somewhat testy, though a milder choice of words than that of GE11, who also involved the speaker as a subjective participant and expressed the same idea thus: "Listen, I'm fed up doing all the work for you. ...."

In contrast to the AEs' handling of guilt trips, two of the GGs expressed criticism of the hearer's person directly, as objective statements: .”.. ich [möchte] nicht Deine Faulheit unterstützen." (.".. I don't want to support your laziness."-GG4); .".. Bloß, [sic] weiß Dir diese Disziplin so mangelt,..." (.”.. Just because you lack this discipline..." GG9). Two GG remarks used the form, "ich finde" ('I think', as an expression of one's opinion), but this form does not acknowledge the subjective quality of the remark to the extent that 'I feel like' does: "Ich finde das schon unverfroren von Dir..." ("I think you've got a lot of gall..."-GG6); "Ich finde, Du könntest etwas disziplinierter die Seminare besuchen. ..." ("I think you could be more disciplined about going to class. ..."-GG9); .... ich finde es irgendwie nicht ganz fair, daß ich mir immer die Mühe mache mitzuschreiben und Du immer nur davon profitierst." (.".. I don't think it's really quite fair that I always make the effort to take notes and you always just benefit from it."-GG11).

With only one exception (GG11), none of the guilt trips used by GGs or GEs involved mitigation. GG9 used an aggressive interrogative: ."..Bloß, [sic] weiß Dir diese Disziplin so mangelt, soll ich für Dich mitarbeiten?..." (.".. Just because you lack this discipline, should I do your work for you?..."-GG9). Both GE2 and GE6 shook their

\footnotetext{
${ }^{32}$ In other DCT items as well, AE12 displayed less face-saving caution than the other AEs. This appeared to be a trademark of personal style. See DCT\#12, Content, section on Face-Threatening Strategies.
} 
fingers at the hearer: .".Perhaps you'd rather attend class [sic] regulary." (GE2) and ...You shouldn't miss the class all the time, you would not have this problem then." (GE6). GE9's remarks were very reproachful: "Listen: I got up every morning, sat in class and took notes and you stayed in bed. ...." The response continued with a downgrader plus a statement of alternative: why don't you do $\mathrm{X}$ instead of $\mathrm{Y}$ : .".. I'm afraid you'll have to ask somebody else!." Viewed in context, the downgrader and statement of alternative were sarcastic and resulted in opaque negative willingness. As noted above, GE11's guilt trip ("I'm fed up...") was fairly hostile. Even GG11, who used a considerable amount of softening, with a downgrader and three downtoners, became quite direct: "Weißt $\mathrm{Du}$, ich finde es irgendwie nicht ganz fair, daß ich mir immer die Mühe mache mitzuschreiben und Du immer nur davon profitierst." ("You know, I don't think it's really quite fair that I always make the effort to take notes and you always just benefit from it"). In the tone of their guilt trips, the GGs were considerably more willing to threaten the interlocutor's face than the AEs or GEs, and the GEs were more willing to do so than the AEs.

The five instances of criticism of the classmate's request were fairly mild, indeed, in two cases, one could argue for an interpretation of the remarks as "reasons" (i.e., refusing because the speaker had already given the hearer his/her notes before; AE10 and GG13). AE10's criticism of the request was a fairly neutral remark (.".I've given you my notes several times..."), whereas GG13 was somewhat disapproving (but polite). A statement of regret preceded the implied criticism in GG13's response, softening the response: "Es tut mir leid; ich habe Dir meine Aufzeichnungen bereits letztes Mal 
gegeben..." ("I'm sorry; I already gave you my notes last time..."). The tone of GG5's refusal was reproachful, expressing a degree of contempt for the hearer and using no mitigation: "Fällt Dir das nicht früher ein." (the rough-edged translation maintains the present tense of the aggressive interrogative and the lack of a question mark, both of which contributed to the contemptuous tone of the remark: "Doesn't that occur to you any sooner.", i.e., "Couldn't you have thought of that sooner?"). Similarly, GE10 allowed some testiness to show through, by using an aggressive interrogative: "Don't you think it's a bit too late to ask me for my notes just the day before the exams?." One AE response used sarcasm as a means of expressing anger and disapproval: "You're joking, aren't you?..." (AE6). The abruptness of AE6's response would leave the hearer little possibility of preserving positive face (i.e., his/her positive self-image, in Brown and Levinson's terminology).

Positive Forms and Mitigating Adjuncts: Most of the positive forms used in response to DCT\#2 were relatively routinized statements of regret and downgraders. Only four positive remarks really stood out as particularly expressive. One AE went "all out" in his use of positive strategies, including a statement of positive feeling: "I'd love to..." and a statement of alternative: I can do X instead of $Y$ : .". If you've got a minute maybe we could copy them [the notes]..." (AE5). One GE expressed sympathy for the addressee with a statement of empathy: "I feel sorry for you..." (GE2) and another GE expressed solidarity: "I would if I could! ..." (GE3). None of these forms were used by other respondents. 
A few of the German respondents used expressions of regret (both apologies and downgraders) in a sarcastic way or as a means of setting boundaries. One GG criticized the interlocutor's lack of discipline, then said, .".Tut mir leid, aber das sehe ich nun nicht mehr ein, da Du Dich zu sehr auf mich und die anderen zu verlassen scheinst. ..." (GG9). ("Sorry, but I don't accept that any more, since you seem to depend on me and the others too much. ..."). The expression of regret served to set limits to the interlocutor's behavior-indeed, it could stand alone (without any further remarks) and function as a refusal. At the same time, it did soften the impact of the following statement, but it certainly did not suggest that the speaker regretted refusing the request. In another case, after a rather harsh reproach, one GG ended his response with the words, ."..Sorry, aber..." ("Sorry, but..."). Occasionally, some words borrowed from English are used to express a flippant attitude or insincerity. Thus, this use of the word added an extra note of sarcasm. One GE criticized the classmate for staying in bed while she went to class and worked, then said, .".I'm afraid you'll have to ask somebody else!" (GE9). Once again, the words did not express real regret, but rather, were used to set boundaries.

Two subjects' uses of mitigating adjuncts warrant special notice because the underlying remarks were so drastically modified. One GG mitigated a guilt trip considerably through extensive use of downtoners and a downgrader: "Weißt Du, ich finde es irgendwie nicht ganz fair,..." (GG11). ("You know, I don't really think it's quite fair, ...." The bald statement without mitigation would be: "Es ist nicht fair..." ("It's not fair..."). One GE used a forewarn, a downgrader, and a downtoner to soften a statement of negative willingness: "To be honest with you, I'd really like not to..." (GE12). Here, the 
bald statement would be: "I don't want to...." Obviously, this indirect form of negative willingness is much more polite than the unmitigated form.

As noted above, one AE's forewarn sought to protect the addressee's face by suggesting the speaker's culpability in pointing out the addressee's shortcomings and in refusing: "I hate to sound rude..." (AE2). On the other hand, the forewarn used by GG4 (discussed above) not only did not mitigate the impact of the criticism of the hearer, but actually sharpened it.

The relative unimportance of positive forms in responses to DCT\#2 reflected a perception that the addressee was not very deserving of fulfillment of the request. Thus, the respondents saw no great need to compensate for the FTA through strong positive forms.

Diminished Value: Of the three groups, the only instances of the strategy of diminishing the value of the requested object were in the GG data (GG7 and GG14). In other DCT items as well, more Germans / GGs? made use of this strategy than the AEs. The basic message of these remarks was: "These notes may serve my purposes, but they won't be of much use to you.." Both of these remarks were slightly self-deprecatory, although this may have been merely rhetorical (to discourage the addressee): ."..meine Notizen bringen Dir gar nichts. Ich hab ziemlich wirr mitgeschrieben. Versteh ich selber schon kaum mehr." (."..my notes won't be of any use to you. I was taking notes in a pretty chaotic way. I hardly understand them myself."-GG7); and ... Du würdest durch meine chaotischen Aufzeichnungen sowieso nicht durchsteigen." (.".. You wouldn't be able to figure out my chaotic notes anyway."-GG14). 
FTA Strategies: Examining the responses according to Brown and Levinson's system highlights some differences between the three subject groups. In DCT\#2, carrying out the FTA on record involved letting the hearer know that the speaker has choosen to refuse. When this was done baldly, there was no mitigation, and in some cases, open censure was used. In DCT\#2, the only negative politeness strategy used for redressive active was the statement of regret (a fairly cool, routinized form). Positive politeness strategies softened the refusal by noting the personal connection between the speaker and the hearer. Off record responses involved excuses, which allowed the speaker to avoid acknowledging whether or not the refusal was intentional.

While a few AEs and GEs went off record, fewer of the GGs did so. A few AEs and GGs went on record with negative politeness, which only one GE did. Although the GGs made no use and the GEs made minimal use of positive politeness, a few AEs chose this strategy.

The greatest difference between the three groups lay in their performance of the FTA baldly on record: while only one-fourth of the AEs did so, half of the GEs and almost three-fourths of the GGs did. This is significant in terms of directness and willingness to risk confrontation.

\section{Summary of Results: Refusal of Request Made by a Equal-Status Interlocutor (DCT\#2)}

Across the board in DCT\#2, the GGs demonstrated the least effort to protect the hearer's face in their choices of functional categories (with the exception of mitigating adjuncts, a relatively minor category). Regarding the content of functional categories, the 
GGs were more outspoken in their critical remarks and demonstrated a considerably greater willingness to risk a serious face threat to the interlocutor than the other two groups. The GGs were the only group to criticize the interlocutor directly. Almost half of the GGs openly expressed hostility, as compared with a fourth of the GEs and only one AE. In addition, the wording of the GGs' face-threatening strategies was also consistently harsher than that of the other two groups.

In terms of strategy choices, there were some areas where the AEs demonstrated more face-saving caution than the GEs and others where the GEs outdid the AEs. The AEs exhibited much greater efforts to minimize the threat to the hearer's face in their choices of direct refusal strategies than either the GEs or the GGs, and the GEs were only slightly more careful than the GGs. In terms of inability versus unwillingness, the Germans apparently perceived less of a need to justify themselves for refusing than the Americans. Also in terms of the number of face-threatening tokens per response and use of positive forms and mitigating adjuncts, the AEs demonstrated the greatest concern for protecting the hearer's face. In other categories, the GEs used more face-protection devices. While the same percentage of AEs and GEs used excuses, more AE responses contained neither excuses nor reasons than GE responses. There was slightly less use of face-threatening strategies in the GE data than in that of the AEs; however, the same percentage of GEs and AEs used a response containing at least one face-threatening strategy. Also, the AEs used slightly fewer face-threatening tokens per response (The apparent inconsistency here lies in the fact that one $\mathrm{AE}$ used six face-threatening tokens, which was atypical for the 
group as a whole. See Table \#26). The GEs also used slightly more positive forms per response than the AEs.

Similar proportions of AEs, GGs, and GEs responded in ways that included a "barb." There was a great deal of difference, however, in the degree of risk to the addressee's face. Most of the AEs who used face-threatening strategies softened them through various means. In contrast, almost all of the GG and GE responses that posed a face threat (beyond that of the refusal itself) were unmitigated, allowing maximum impact and direct confrontation. In addition, the GGs and almost all of the GEs presented criticism and guilt trips as objective statements rather than as more innocuous subjective remarks. Only one GE used a form that acknowledged a degree of subjectivity in her guilt trip and only one GE truly softened his face-threatening response. It seems that when the Germans subjects chose to vent their annoyance, they saw little need to protect the addressee's face or give the addressee a means of saving face.

Also in terms of Brown and Levinson's model, the AEs showed a preference for less threatening strategies, whereas the GGs, and to a lesser extent the GEs, were less reticent to use the more threatening strategies. In other words, the Germans exhibited more openness in expressing censure and displeasure with the hearer than the AEs. As stated above, a large proportion of the GGs (almost half) and a fair proportion of the GEs (one fourth) were quite direct in expressing hostility to the addressee, which was avoided by all of the AEs but one (and that response was not as harsh as many of the GGs' and GEs' remarks). 
The situation in DCT\#2 is certainly one that many Americans would find annoying, a classmate repeatedly missing class and then asking to borrow the notes at the last minute before the test. A considerable number of the AEs, however, avoided broaching the subject of this frustration. Evidently, the convention of avoiding social friction is very powerful in American English. Based on my data, it appears that there are fewer cultural taboos in Germany than in the U.S. against honestly and directly expressing resentment.

The three groups of respondents did not go into great detail with their excuses nor did they make the excuses watertight. The hearer could have easily tried to find a way around such excuses, e.g., suggesting that s/he come by the speaker's home later to pick up the notebook. Apparently none of the three subject groups perceived a need to create watertight excuses in response to an equal-status interlocutor with an unjustified request.

Altogether, positive forms played a minor role in the responses of all three groups to DCT\#2. This was probably due to the fact that most of the respondents did not perceive the request as legitimate nor did they feel a need to flatter an equal-status interlocutor making such a request.

While the GEs resembled the GGs in various characteristics of their refusals, they also tempered their refusals in the direction of American native speaker patterns. The GEs followed the GG pattern of low use of mitigating adjuncts and positive forms when expressing negative feelings towards the addressee. When the tone of the refusal was more neutral, however, they followed AE patterns. 


\section{DCT \#12: Refusal of Higher-Status Interlocutor's Request}

\section{Frequency of Functional Categories}

Except for the responses of one-third of the GEs, who used statements of negative ability, direct refusal strategies played a minor role in DCT\#12. With the higher-status interlocutor, there was a marked preference for the more indirect route of using excuses. While the statements of negative ability softened the refusal, the other two kinds of direct forms detracted from politeness, especially because they were unmitigated: ."..all I want to do is go home \& get away from this place." (AE12); "Das ist ausgeschlossen. ..." ("That's out of the question. ..."-GG14); " Not tonight..." (GE6).

Table 4. 31: Use of Direct Refusal Strategies; Request; Higher-Status Interlocutor (DCT\#12)

\begin{tabular}{|l|l|l|l|}
\hline & Negative Ability & Negative Willingness & "No" \\
\hline GEs & $33 \%$ & - & $8 \%$ \\
AEs & $17 \%$ & $7 \%$ & - \\
GGs & $14 \%$ & - & $7 \%$ \\
\hline
\end{tabular}

Excuses were the primary refusal strategy overall in responses to DCT\#12. Almost all subjects in the three groups gave an excuse, and a large proportion of the subjects either elaborated on their excuses or used more than one excuse. Only one GE and one $\mathrm{AE}$ gave a reason (AE12 and GE12), and only one subject gave neither an excuse nor a reason (GG6).

The use of excuses in responses to DCT\#12 resulted in softened refusals. Not only was there considerable elaboration on excuses, but many excuses were conjoined with intensifiers, and the detail and specificity of the excuses strengthened their face-protecting effect. 
Set conditions are included in the table of excuses and reasons because they are a kind of excuse. Not knowing in advance about the boss' need for the employee to work overtime, the speaker was unable to make the necessary schedule changes. Thus, the fact that the speaker did not fulfill the addressee's request was beyond his/her control. In this sense, the set condition is like an excuse; however, since the speaker notes the interlocutor's responsibility for the last-minute request, the set condition is not as polite as an excuse. In responses to other DCT items, set conditions often lessened face-saving politeness (e.g., in DCT\#4 and DCT\#8), but in the case of DCT\#12, the effect was more neutral.

In the following table, it was a judgment call ranking the AEs rather than the GGs second to the GEs for politeness based on use of excuses and reasons. As the table shows, both groups had similar percentages of excuses and elaboration on excuses. The only difference lay in one AE's use of reasons (AE12) as contrasted with one GG who used neither a reason nor an excuse (GG6). Purely in terms of frequencies, giving a reason is more polite than giving none (for reasons discussed above). Because of this, I ranked the AEs above the GGs. In terms of content and context, however, AE12's use of reasons displayed considerably less face-saving caution than GG6's lack thereof. (See discussion of content.)

Table 4. 32: Use of Excuses, Elaboration on Excuses, Reasons, and Set Conditions; Request; Higher-Status Interlocutor (DCT\#12)

\begin{tabular}{|l|l|l|l|l|}
\hline & Excuse & $\begin{array}{l}\text { Elaboration on Excuse or More Than One } \\
\text { Excuse }\end{array}$ & $\begin{array}{l}\text { Set } \\
\text { Condition }\end{array}$ & Reason \\
\hline GEs & $92 \%$ & $67 \%$ & - & $8 \%$ \\
AEs & $92 \%$ & $42 \%$ & $8 \%$ & $8 \%$ \\
GGs & $93 \%$ & $43 \%$ & $7 \%$ & \\
\hline
\end{tabular}


Only one respondent's speaker risked a true threat to the addressee's face, using criticism of the request and a guilt trip (AE12). One respondent used a statement of negative consequences to the interlocutor, but this posed no face threat (AE1).

Only one response was evasive: GG13's set condition was rather evasive (but only in tone and wording rather than in the choice of functional category) and rather resembled hedging.

Almost the same percentage of AEs, GGs, and GEs made use of positive forms (AEs: $116 \%$, GGs: $114 \%$, GEs: $109 \%{ }^{33}$ ), but the distribution between the particular types of positive forms differed. Not only did the GEs and GGs make more frequent use of apologies than the AEs, but about half of their statements of regret were intensified. By contrast, none of the AEs intensified their apologies. Furthermore, all of the downgraders used for DCT\#12 resembled statements of regret. This widened the gap between the German and American subjects in terms of their basic approaches to softening the refusal. Not only did the GEs transfer the native speaker strategy into English; they increased its usage in their efforts to soften the refusal. Throughout the DCT, the GEs tended to use considerably more redressive action with the FTA of refusal than Germans using their native language. Here, in DCT\#12, they used a transferred strategy for this purpose.

In the context of DCT\#12, there is a similarity between the two strategies, "Alternative: I Can Do X Instead of Y" and "Positive Feeling/Opinion." Both involve an expression of willingness to work overtime. The statement of alternative, however, is an actual commitment to do overtime at a different time, whereas the positive feeling simply

\footnotetext{
${ }^{33}$ The percentages exceed $100 \%$ because some subjects used more than one positive form.
} 
expresses a positive attitude towards working overtime without making a commitment. While similar percentages of AEs and GGs used the more noncommital form, one-third of the AEs made the commitment, as contrasted with a sole GG using this form. The GEs made little use of either form.

Table 4. 33: Use of Regret and Downgraders; Request; Higher-Status Interlocutor (DCT\#12)

\begin{tabular}{|l|l|l|l|}
\hline & Regret & Intensified Regret $^{\mathbf{3 4}}$ & Downgraders $^{-}$ \\
\hline GEs & $67 \%$ & $25 \%$ & $17 \%$ \\
GGs & $50 \%$ & $21 \%$ & $21 \%$ \\
AEs & $42 \%$ & - & - \\
\hline
\end{tabular}

Table 4. 34: Use of Alternative: I Can Do $X$ Instead of $Y$ and Positive Feeling/Opinion; Request; Higher-Status Interlocutor (DCT\#12)

\begin{tabular}{|l|l|l|l|}
\hline & Alternative: I Can Do X Instead of Y & Positive Feeling/Opinion & Wish \\
\hline AEs & $33 \%$ & $33 \%$ & $8 \%{ }^{35}$ \\
GGs & $7 \%$ & $36 \%$ & - \\
GEs & $8 \%$ & $17 \%$ & - \\
\hline
\end{tabular}

There was very little use of mitigating adjuncts in responses to DCT\#12, except that one-fourth of the GEs used pause fillers.

Table 4. 35: Use of Mitigating Adjuncts; Request; Higher-Status Interlocutor (DCT\#12)

\begin{tabular}{|l|l|l|}
\hline & Pause Filler & Forewarn \\
\hline GEs & $25 \%$ & $8 \%$ \\
GGs & $14 \%$ & - \\
AEs & $8 \%$ & - \\
\hline
\end{tabular}

The following table reflects the frequent use of positive forms by all three groups.

\footnotetext{
${ }^{34}$ The subjects counted in this tally of "intensified regret" are also included in the tally of "regret". In other words, $67 \%$ of the GEs used an expression of regret, and nearly half of those, or $25 \%$ of the GEs, used intensified expressions of regret.

${ }^{35}$ This wish also functioned as a set condition. See below (in content section) for discussion.
} 
Table 4. 36: Number of Positive Forms and Adjuncts per Response; Request; Higher-Status Interlocutor (DCT\#12)

\begin{tabular}{|l|l|l|l|l|}
\hline & 0 & 1 & 2 & 3 \\
\hline AEs & $17 \%$ & $50 \%$ & $33 \%$ & - \\
\hline GGs & $21 \%$ & $50 \%$ & $21 \%$ & $7 \%$ \\
\hline GEs & $8 \%$ & $75 \%$ & $17 \%$ & - \\
\hline
\end{tabular}

As noted above, only amongst the GEs was there much use of mitigating adjuncts, the preference being given to more explicitly positive forms such as statements of regret, offers of an alternative, etc.

Table 4. 37: Number of Mitigating Adjuncts per Response; Request; Higher-Status Interlocutor (DCT\#12)

\begin{tabular}{|l|l|l|}
\hline & 0 & 1 \\
\hline GEs & $67 \%$ & $33 \%$ \\
\hline GGs & $86 \%$ & $14 \%$ \\
\hline AEs & $92 \%$ & $8 \%$ \\
\hline
\end{tabular}

The GG population exhibited greater variability in terms of the number of positive forms and mitigating adjuncts used. Compared to the GEs and AEs, there was a higher percentage of GGs of both respondents who did not use any mitigating forms and respondents who used three mitigators. There was more uniformity amongst GEs and AEs in this regard.

Table 4. 38: Number of Positive Forms and Mitigating Adjuncts per Response; Request; Higher-Status Interlocutor (DCT\#12)

\begin{tabular}{|l|l|l|l|l|}
\hline & 0 & 1 & 2 & 3 \\
\hline GEs & $8 \%$ & $58 \%$ & $25 \%$ & $8 \%$ \\
\hline AEs & $17 \%$ & $50 \%$ & $25 \%$ & $8 \%$ \\
\hline GGs & $21 \%$ & $43 \%$ & $21 \%$ & $14 \%$ \\
\hline
\end{tabular}

\section{Content of Functional Categories}

Reasons and Excuses: Both times that reasons were given, they detracted from rather than enhanced politeness. The one $\mathrm{AE}$ reason was of itself fairly neutral in terms of 
politeness. The context, however, expressed hostility. The reason, .".I'm tired..." (AE12), was preceded by criticism of the request and a guilt trip, and followed by a statement of negative willingness (See section below on face-threatening strategies for entire quote and discussion.). The one GE using a reason indirectly let her boss know that she had no interest in staying late: .".I already was deciding to leave in a minute." (GE12).

The bases of the excuses were mostly family responsibilities and social engagements, but one GG and two GEs claimed they had a doctor's appointment, one AE spoke of being weary, and one GE said he was sick. A number of vague excuses only implied duties and appointments (see below).

The GGs and AEs had similar proportions of specific excuses (about half of their excuses), while almost all the GE excuses were specific. One can only speculate that the GEs assumed that there was a greater need for politeness in English and sought to achieve this by giving more specific excuses that would more thoroughtly justify the refusal (In this study, however, the GGs tended to give more specific excuses than the AEs. Thus, this means of increasing politeness involved transfer.). Most of the specific AE excuses were only somewhat watertight (i.e., specific and difficult to cancel): They would not have prevented a persistent boss from trying to negociate, e.g., asking the employee to go to the son's next baseball game instead, to arrange for someone else to pick up "Jill", to postpone the dinner reservations, etc.

Judging the "watertightness" of an excuse is, of course, subjective to some extent. In this researcher's view, the GGs and GEs went further in developing watertight excuses than the AEs. The GGs' watertight excuses were the most elaborate, e.g., needing to tend 
to a sick wife and guests from far away, intending to see friends from the other side of the globe on the last evening before their departure, or fulfilling a promise to accompany her youngest son at his musical debut performance: .".Ich muß heute [sic] abend pünktlich zuhause sein. Meine Frau ist krank und wir haben gerade Besuch aus England." (."..I must get home punctually this evening. My wife is sick and we have visitors from England at the moment."-GG1); "Ich habe mich leider schon mit ein Paar Freunden aus Neuseeland verabredet, die morgen wieder nach Hause fliegen!" ("Unfortunately, I've already made arrangements to see a couple of friends from New Zealand who are flying back home tomorrow!"-GG4); and, ....ich habe meinem jüngsten versprochen ihn bei seinem 1 . Konzert zu begleiten." (."..I promised my youngest to accompany him at his first concert."-GG13). In his excuse, GG5 implied that his daughter's safety depended on his refusal of the request: "Ich muß heute Abend meine Tochter nach der Arbeit abholen, da es um diese Zeit schon dunkel ist möchte ich [sic] Sie nicht warten lassen." ("I must pick up my daughter after work this evening; because it's already dark at this time I wouldn't want to make her wait."). While the GEs created a number of watertight excuses, these were less elaborate: ."..we bought tickets for the opera tonight." (GE2); ...I feel sick today and perhaps I'm getting ill. ..." (GE3); ."..I invited some friends to have dinner at my house and I have to prepare the meal." (GE6); .".I have to see my doctor tonight..." (GE8); .".. I have to see the doctor this evening." (GE10); and .".. It's my mother's birthday ..." (GE11). Only three AE excuses struck this researcher as watertight: ."..I really feel done today \& I know I [sic] wouldnt be much use anyway if I stayed." (AE1), ...I already made plans with my in-laws to have dinner with them at 5:00." (AE8), and 
...I have these symphony tickets for tonight. ..." (AE9). With the exception of AE1's excuse, a boss trying to make the employee cancel his or her plans would be less "cruel" than with the GGs' or the GEs' watertight excuses.

Many respondents added some sort of remark or intensifier to their excuses intended to increase the degree of urgency, e.g., stating explicitly or implying that a promise had been made, or adding a remark about needing to leave right away. Many of the vague excuses were strengthened by adding such a statement of urgency, intended to generate a kind of "pseudo-watertightness", making them harder to overturn, particularly in the case of the GGs.

The GGs exceeded the other two groups in developing excuses that were urgent regardless of whether they were specific or vague. Unlike the other two groups, a typical tactic amongst the GGs was citing an urgent but unspecified engagement or need to get home ( $50 \%$ of the GGs did so), e.g., .". leider habe ich heute abend noch eine Verpflichtung, die ich nicht absagen kann. ..." (...unfortunately I have another responsibility this evening that I cannot cancel. ..."-GG9). These urgent, unspecified excuses were by implication more than merely social or voluntary engagements, but contained no commitment to explicit content. Thus, while AE5 spoke of a "previous engagement", the GGs asserted that their engagements were "nichtzuverschiebend" ("unpostponeable"), “dringend" ("urgent"), “wichtig" ("important"), or "eine Verpflichtung" ("a responsibility"). The following GGs gave urgent excuses without stating the actual circumstances: GG2, GG3, GG7, GG9, GG10, GG14. GG6's response expressed the same urgency, but with negative ability rather than an excuse. 
Another element that characterized the GGs, but did not appear in the AE or GE data were the expressions, "gerade / ausgerechnet heute...", which singled out "today" as being unusual in some way, i.e., that there were unusual circumstances preventing the speaker from fulfilling the request to do overtime on that particular day. This idea could be expressed through circumlocution in English (e.g., "It just so happens that today..." or "Today of all days...", although this would have been more awkward and more ambiguous than in German), but did not figure so prominently in the AE and GE data. Only the use of positive opinion by two GEs and two AEs carried some of this meaning (see quotes of responses by GE1, GE11, AE9, and AE10 below, in discussion of positive forms used in DCT\#12).

In DCT\#12, the respondents used considerable elaboration on excuses, which served to make the excuse stronger or more urgent or to give more specific information, making the excuse more watertight, e.g., .". I've already made plans with my girlfriend and I can't break them." (AE3), ."..my son is playing baseball tonight and I promised him that I would attend" (AE4), .".. I have a previous engagement $\&$ I have to leave straight away" (AE5), .".. I have these symphony tickets for tonight. My boyfriend should be here to pick me up soon." (AE9), .".heute abend habe ich mich nun verabredet und muß deshalb gehen." (."..this evening I have an appointment and must leave for that reason."GG11), ."..I feel sick today and perhaps I'm getting ill. I think I should go to bed as fast as possible." (GE3), .".I invited some friends to have dinner at my house and I have to prepare the meal." (GE6), .".I've promised my husband to pick up the children from school today. So I think I'd better leave now. ..." (GE7), ."..I have to see my doctor 
tonight and as it is always so difficult to get these things fixed, I'm not able to stay longer.” (GE8), “ ... I promised my friend to help her with putting wall-paper in her new appartment. I told her that I would come right after work. ..." (GE9), and .... It's my mother's birthday and I really have to go." (GE11). Some of the watertight excuses discussed above also contained such statements of urgency, e.g., "Ich habe mich leider schon mit ein Paar Freunden aus Neuseeland verabredet, die morgen wieder nach Hause fliegen!" ("Unfortunately, I've already made arrangements to see a couple of friends from New Zealand who are flying back home tomorrow!"-GG4), "Ich muß heute Abend meine Tochter nach der Arbeit abholen, da es um diese Zeit schon dunkel ist möchte ich [sic] Sie nicht warten lassen." ("I must pick up my daughter after work this evening; because it's already dark at this time I wouldn't want to make her wait."-GG5). Along the same lines, some respondents gave two excuses. While the two excuses were stronger than a single excuse, none of these excuses were watertight: .".I need to run some errands and get home at a decent hour" (AE11) and "Gerade heute wollte ich meinem Mann etwas Gutes kochen und die Kinder warten." ("This very evening I wanted to cook something good for my husband, and the children are waiting."-GG12), .".my husband is waiting with the dinner. We have plans for tonight." (GE5).

Face-Threatening Strategies: There was only one venting of negative emotions in the subject populations, only one clearly uncooperative response (AE12). While AE12 did use criticism of the request and a guilt trip, her speaker still remained civil, not naming the addressee explicitly as the responsible party. Only the words "this place" were unmistakably pejorative: “I've already worked 8 hours; I didn't get my breaks; I'm tired; 
and all I want to do is go home \& get away from this place." (AE12). An examination of other responses given by AE12 (particularly responses to bosses) suggests that this subject's undisguised hostility in DCT\#12, which was atypical for the AEs, may have been more indicative of her personal style than of pragmatic rules usually followed by American speakers of English. AE12 was the only AE to risk threatening the boss' face in DCT\#11 (as well as in DCT\#12). In DCT\#4, while the other AEs gave excuses along the lines of prior commitments, only AE12 failed to create an excuse that would carefully protect the boss' face. In DCT\#6, AE12 was one of the AEs who used criticism of the boss' suggestion, and was somewhat more direct than the others. In response to the classmate in DCT\#2, AE12 was the only AE who did not soften her guilt trip either through use of mitigating forms or content.

There was a slight face threat in the message underlying the two instances of set conditions. The message, however, was completely neutralized by the careful wording of the set conditions [Compare to set conditions in DCT\#4: social contact with business colleagues as opposed to working overtime on a regular workday. Apparently conventions hold that an employee should have more choice over free time on weekend than overtime at end of workday]. The AE who used the "set condition" strategy actually used the form of a wish (and was included in the tally of positive forms as well), a very polite way to express the set condition: "I wish I'd known." (AE6). The polite wording expressed a wish to fulfill the request, yet the gist of the remark was, "I can't fulfill your request because you didn't tell me soon enough." or "If you had told me sooner, I could have fulfilled your request." One GG twice implied a set condition for acceptance: "Damit habe 
ich leider nicht gerechnet [sic] das kommt jetzt sehr überraschend..." ("Unfortunately I wasn't expecting that. That comes as quite a surprise"-GG13). As noted above, the wording resembled hedging, but the message was the same as AE6's. This respondent may have made the response sound more like hedging in order to avoid appearing too assertive or provocative towards the higher-status interlocutor.

Statements of negative consequences to the addressee often contain a risk to the hearer's face. In DCT\#12, however, the one instance of this strategy did not pose a face threat but rather, served as a means of making an excuse more watertight: ."..I really feel done today \& I know I [sic] wouldnt be much use anyway if I stayed." (AE1).

Positive Forms and Mitigating Adjuncts: The content of statements of positive opinion in DCT\#12 (used by all three groups but in different frequencies-see above) consisted of remarks expressing a positive attitude towards working overtime without making a future commitment, e.g.,-'I don't mind putting in additional time occasionally for work..." (AE1), "Normally I would..." (AE9), "Ordinarily I would..." (AE10), .".Ansonsten bin ich aber gerne bereit, länger zu bleiben." (."..At any other time, I would gladly be willing to stay longer."-GG2), .".ich bin sonst immer bereit zu Überstunden..." (.".ordinarily, I am always willing to work overtime..."-GG6), "Gerne ein ander Mal..." (“Gladly some other time..." -GG9), ."..prinzipiell natürlich immer..." (."..in principle always, of course..."-GG11), .".normally that wouldn't be a problem, ..." (GE1), and ...usually that's not a problem..." (GE11).

In DCT\#12, offers of alternative: I can do X instead of $\mathrm{Y}$ not only expressed a positive attitude towards working overtime, but actually proposed an alternate time for 
fulfilling the request. Thus, this strategy was more convincing in terms of the speaker's sincerity: ."..Perhaps, I can come in early tomorrow." (AE2), ."..but I'll come in early tomorrow. ..." (AE3), .".. Would tomorrow work?" (AE7), ."..Maybe I could come in a little early tomorrow?" (AE10), ."..Morgen sehe ich jedoch keine Probleme, abends länger zu bleiben." (."..I foresee no problems with staying longer in the evening tomorrow."GG9), .". I could stay longer tomorrow." (GE9). As noted above, this strategy was favored by the AEs, but not the GGs or GEs. In sum, the three subject groups tried different strategies to convince the boss that they could not work overtime that particular evening. While many GGs explicitly stated that on that particular evening it was impossible for them to work overtime, a number of AEs committed themselves to fulfilling the request at a different point in time. The GEs used neither of the strategies, relying on specific and watertight excuses to convey this impression to the hearer.

Certain pause fillers were conjoined with particular functional categories. The pause filler, 'oh' was linked to statements of regret, adding emphasis to the apology: "Oh, I'm so sorry..." (GE12), "Oh, das tut mir aber leid..." (“Oh, I'm very sorry..."-GG3), "Oh, das tut mir leid..." (“Oh, I'm sorry"-GG11), "Oh! I'm sorry..." (AE6 ). The pause filler, 'well', on the other hand, was associated with statements of positive opinion in the GE data (This form did not occur in the AE data): "Well, normally that wouldn't be a problem..." (GE1), "Well, usually that's not a problem..." (GE11).

Efforts to Convey a Cooperative Attitude: In order to investigate the degree of effort made to convince the addressee that the speaker wanted to cooperate, I examined the responses according to use of functional categories that expressed both: a willingness 
but inability to accommodate the request; and sincerity. A response containing three or more of these units counted as a strong effort, two units as a moderate effort and one or none as uncooperative. Use of an excuse counted as one unit. If the excuse was either watertight, elaborated, or both specific and intensified with an expression of urgency, that counted as a second unit. If there were only two vague excuses in a response, I counted them the same as one vague excuse because the second excuse only marginally increased the cooperative effect. Positive forms and statements of negative ability were also considered units in this tally. A response had to contain at least one positive form to qualify for a "strong effort"

Table 4. 39: Degree of Effort to Convince Addressee that Speaker Wanted to Cooperate; Request; Higher-Status Interlocutor (DCT\#12)

\begin{tabular}{|l|l|l|l|l|}
\hline & Strong Effort & Moderate Effort & $\begin{array}{l}\text { Somewhat } \\
\text { Uncooperative }\end{array}$ & Uncooperative \\
\hline AEs & $75 \%$ & $17 \%$ & - & $8 \%$ \\
GEs & $67 \%$ & $25 \%$ & $8 \%$ & - \\
GGs & $57 \%$ & $36 \%$ & $7 \%$ & - \\
\hline
\end{tabular}

The percentage of GGs who used a strong effort is lower than that of the AEs and

GEs. This resulted, to a great extent, because of the nonspecific (if urgent) excuses discussed above and less use of positive forms.

${ }^{36}$ In my view, the following subject(s)

- made a strong effort: $\mathrm{AE} 1,2,3,4,6,7,8,9,10$; GG1, 2, 4, 6, 7, 8, 9, 10, 11, 13; $\mathrm{GE} 1,2,3,4,5,7,8,9,10,11$;

- made a moderate effort: AE5 (no mitigators, excuse intensified but not specific), AE11 (two vague excuses); GG3, 7, and 10 (positive forms, urgent but unspecific excuses), GG5 and GG12 (no positive forms); GE4 (positive form, specific excuse, but no urgency), GE5 (2 vague excuses), and GE6 (specific, elaborated excuse but no mitigation);

- were somewhat uncooperative: GG14 and GE12 (no excuse or negative ability);

- was uncooperative: AE12. 
FTA Strategies: In terms of Brown and Levinson's categories, an off record refusal to DCT\#12 would have consisted of hedging, e.g., 'I need to think about it' or 'I'm not sure'. None of the subjects gave such a response.

Two subjects gave responses that could be viewed as being baldly on record because they involved unmitigated refusals. While GG14 made clear use of a direct refusal strategies without mitigation, there was some degree of negative politeness through the vague but urgent excuse. AE12's refusal was unmitigated and made no pretense of protecting the addressee's face. Indeed, the response appeared to violate Brown and Levinson's set of conditions for performing an FTA baldly on record, namely, 1) when urgency overrides concern for the hearer's face needs, 2) when there is only a small face risk to the hearer, 3 ) when speaker and hearer are socially intimate, or 4) when the speaker has greater social power than the hearer (see Chapter 2, Brown and Levinson's model of considerations for performing FTAs, p. ?). As the boss and employee do not appear to be socially close, the only possible condition is the first one. The urgency which overrides face concerns appears to be the speaker's level of dissatisfaction with her job, which is so great that she is willing to risk a threat to the boss' face, and consequently, a threat to her job security as well. It is unlikely that an employee would use such a strategy unless $\mathrm{s} / \mathrm{he}$ were on the verge of resigning.

Positive politeness, the friendly assertion of common bonds, was not used in DCT\#12. Negative politeness, on the other hand, was chosen by the vast majority of the respondents, even though there were differences in the degree of politeness. This strategy was used by all of the GEs, and all but one of the AEs and GGs (whereby the one GG 
exception, as noted above, was only a partial exception). Use of negative politeness involved compensating for the refusal by being polite, i.e., having a good excuse, expressing regret, or minimizing the imposition to the addressee through an offer of an alternative or a statement of positive opinion ${ }^{37}$. Like excuses, all of the positive forms used in response to DCT\#12 served as expressions of negative politeness. The predominance of negative politeness reflected the business setting in DCT\#12 and the social distance between the interlocutors.

\section{Summary of Results: Refusal of Request Made by a Higher-Status Interlocutor (DCT\#12)}

An overwhelming preference of excuses over reasons and direct refusal strategies characterized $\mathrm{AE}, \mathrm{GG}$, and $\mathrm{GE}$ responses to $\mathrm{DCT} \# 12$. In addition, positive forms were used extensively and face-threatening strategies were avoided. These politeness features combined resulted in refusals that were highly protective of the boss' face.

All three groups made significant use of positive strategies; however, the Germans and the Americans exhibited predilections for different types of positive strategies. While the Germans (especially the GEs) primarily used statements of regret (i.e., apologies) or downgraders involving a sense of regret (e.g., 'unfortunately...'), the Americans preferred making a counter-offer or expressing a positive feeling/opinion towards fulfilling the request. The GEs' frequent use of these forms provides some important clues about their

\footnotetext{
${ }^{37}$ Statements of positive opinion or feeling usually belong to the category of positive politeness. In DCT\#12, however, by their resemblance to offers of alternative: I can do X instead of $Y$, statements of positive opinion minimize the imposition that the refusal causes the hearer.
} 
pragmatic acquisition of English. Throughout the DCT, the GEs displayed a tendency to increase the degree of politeness in English as compared with their L1 (an accurate pragmatic assumption, judging from the GG and AE data). In DCT\#12 the GEs appeared to perceive a need to be more polite in English than they would be in German. As in some other DCT items, they achieved this politeness through means more typical of their L1 than their L2 (an element of pragmatic transfer).

Expressions of regret are more passive than offers of an alternative or expression of a positive attitude, which emphasize the speaker's "free will" in the matter. One can speculate as to possible explanations for the subjects' preference patterns. The AEs' frequent choice of the more active forms may suggest that Americans tend to take a more active role in dealing with their bosses than Germans or that they are more likely to take it for granted that they will be asked to work overtime. One might speculate as to whether the passive expression of regret is more subservient than the offer of an alternative, because an apology implies that the speaker can neither fulfill the request nor evade it. On the other hand, this strategy may allow the speaker to avoid working overtime for a longer period of time rather than just for one evening. By not showing undue eagerness to fulfill the boss' wish for them to work overtime (that is, by not volunteering to come in at a different time), they avoid encouraging the boss to make more such requests.

In DCT\#12, excuses were the most important feature of responses, both in terms of frequency and content. Excuses are very reflective of attitudes. Half of the AEs' excuses were specific, but only three of them were watertight. In the GG data as well, half of the excuses were specific, but almost all of the GG excuses were either watertight or 
"pseudo-watertight", i.e., urgent but unspecified (For description of "pseudo-watertight" excuses, see discussion above.). Half of the excuses fell into the latter category. Almost all of the GEs' excuses were specific, and almost half of those were watertight, once again a case of a transferred strategy used to increase politeness (i.e., the higher frequency of watertight excuses reflects $\mathrm{L} 1$ rather than L2 means of augmenting politeness). By avoiding "pseudo-watertight" excuses, however, the GEs displayed sensitivity to the fact that there is a difference in the quality of excuses given in English and German in such a situation as in DCT\#12. Since the AEs made a greater effort overall to demonstrate a cooperative attitude towards the addressee (see Table 41), but made less effort to develop watertight excuses than the GGs, it would appear that the AEs' frequent use of offers of an alternative created less of a need for watertight excuses. (On the other hand, the AEs may have had a lower expectation that the boss would try to overturn the excuse than the GGs.) The GEs exhibited a combination of GG and AE features in their use of excuses, which suggests partial pragmatic acquisition.

One can speculate as to the reason for the GGs' characteristic use of urgent but nonspecific excuses. It seems unlikely that the GGs would find it harder to come up with a convincing excuse on the spot than the GEs or AEs. The avoidance of telling a lie probably reflects cultural values of being honest (although this did not influence GE responses to the same situation). This tentative assumption is supported by GG responses to DCT\#10, the one DCT situation that allowed an examination of honesty versus "white lies." In DCT\#10, the GGs clearly exhibited a higher degree of honesty than the AEs (See DCT\#10, Content, discussion of honesty). Another plausible explanation for these 
"pseudo-watertight" excuses is a disinclination to reveal private information. Personal privacy appears to be more important as a cultural value to the GGs than to the AEs (The GEs' responses more closely resembled the AEs' in this regard, suggesting good pragmatic acquisition.). While the boss may have a right to expect the employee to have an important reason for denying the request, s/he does not necessarily have the right to know the specifics of the excuse. One might assume that under the same circumstances, an $\mathrm{AE}$ or GE would make something up. Indeed, there is no way of knowing the extent to which excuses are honest or not (except for one respondent who labeled his response a "lie" (AE6). The strategy of withholding information also makes the excuse hard to challenge. The boss would have to be rude and pry into the employee's private affairs in order to do so. Maintaining personal privacy prevents the boss from judging the worthiness of the excuse that the employee deems sufficient.

The low use of mitigating adjuncts, indeed, the absence of downtoners, by all three groups reflects the more formal register used with the boss as well as the need to sound unequivocal about the validity of one's excuse. An excuse loaded with downtoners would sound very uncertain, e.g., "Y'know, I really don't think I can stay late... I really kind of need to...." As the example shows, downtoners also tend to sound casual, an inappropriate register in this setting.

The GEs and AEs displayed a certain degree of uniformity within their populations in terms of the number of mitigating adjuncts and positive forms per response. Most of them used one or two forms per response. In the case of the GGs, on the other hand, there was a wider range, with more responses containing no such forms or three forms, as well 
as the middle range. Thus, the relative uniformity of the $\mathrm{AE}$ and GE patterns contrasted with the variability of the GG responses (a pattern that appeared in other DCT items as well).

\section{Refusals of Invitations}

DCT\#3: Lower-Status Interlocutor (Salesman) Invites Printing Company President to a Fancy Restaurant (Bribe)

DCT\#10: Equal-Status Interlocutor Invites Friend to Dinner at His/Her Home DCT\#4: Higher-Status Interlocutor Invites Employee to a Party ${ }^{38}$

In DCT\#3, the circumstances affecting the choice of refusal strategies go beyond merely refusing a lower-status interlocutor's invitation. This situation also involves a business deal, a salesman's pressure tactics, and bribery (although some respondents might view such an invitation as a normal part of business). The eliciting speech act obviously poses a threat to the speaker's negative face as the salesman's invitation represents an effort to make the company president feel beholden to him and thus more likely to "firm up a contract." At the same time, the speaker's refusal bears a threat to the hearer's negative face, his unimpeded pursuit of making sales. If the speaker questions the scruples of the salesman's business practices, this adds a threat to the hearer's positive face.

Accepting the salesman's invitation probably would not pose a great burden on the speaker, beyond some unease at being subtly indebted to him because of the hospitality,

\footnotetext{
${ }^{38}$ For more information, the text of the DCT can be found in Appendix A, Discourse Completion Test.
} 
and ethical concerns about violating good business practices (of not mixing business and pleasure). For other speakers, accepting the invitation would be perfectly acceptable in terms of business ethics. As one AE commented, "I think that a lot of business is conducted at restaurants. Smoozing is important in business." (AE2). Thus, an interesting variable in DCT\#3 lies in the cultural norms surrounding business ethics.

Refusal of the invitation in DCT\#3 (without criticism on ethical grounds) would not be a great disappointment to the salesman because he could extend another invitation at some other time or find some other way to conduct business with the printing company president.

Two different approaches to responding to DCT\#3 depended on whether the speaker was refusing the dinner invitation itself or the entire business transaction. The former type tended to focus on more polite, formulaic strategies for refusing, whereas the latter type generally involved more honesty and directness, also greater risks to the hearer's face.

The situation in DCT\#10 does not merely consist of the refusal of a friend's invitation to dinner. An additional variable is the speaker's antipathy towards the interlocutor's spouse. This raises issues of honesty and the use of "white lies" to spare the friend's feelings and avoid unpleasantness for oneself as well. There were clear differences between the American and German subjects in the degree of honesty. All three groups demonstrated great hesitancy to tell the friend the actual reason underlying the refusal, but the AEs used considerably more white lies than the two groups of Germans. 
In DCT\#10, the hearer probably does not have a high stake in the speaker's acceptance of the invitation because there are other possibilities for having contact. On the other hand, because the invitation serves as an expression of mutual friendship, its refusal poses a threat to the hearer's positive face, his/her wish for the friend to support his/her positive self-image. From the speaker's point-of-view, accepting the invitation could lead to an imposition ranging from somewhat unpleasant to practically intolerable (but probably on the milder end of the spectrum). Also, the imposition would be of limited duration (only an evening). Since this is not necessarily a situation to be avoided at all costs, the risk of being talked out of the refusal is not serious enough to warrant construction of a particularly strong refusal. The fact that the refusal would not be a dreadful imposition on the hearer also makes a firm refusal unnecessary. The only major consideration in DCT\#10 is the importance of solidarity markers to protect the hearer's positive face.

Not only has the invitation in DCT\#4 been extended by the speaker's boss, but it also involves business. It is not just a social gathering, as evidenced by the interlocutor's remark: ...I am hoping all my top executives will be there with their spouses. ...." Therefore, the speaker is likely to feel a certain sense of obligation to accept the invitation that would be absent (or weaker) if the party were simply a social affair. A further issue in DCT\#4 is the fact that the invitation was made at short notice.

Refusal of the invitation poses a slight face risk to the hearer, primarily to negative face. As the party involves business, having all the top executives present increases the hearer's freedom of action in terms of achieving the goals underlying the gathering. 
For the speaker, accepting the invitation poses a moderate imposition, essentially enduring an additional workday on a Sunday. The party is unlikely to be a relaxing weekend activity. The inability to express one's resentment at such an imposition might increase the feeling of imposition.

As in DCT\#12, which also involved a higher-status interlocutor, the major consideration of almost all the subjects appeared to be meeting the boss' face needs. Great efforts were made to convince the addressee that the speaker wished to attend the party but was unable to do so. Any urges to mention the imposition of being given short notice were repressed in most cases (and the four exceptions to this were very inoffensive).

Responses to these three DCT items give some insight into the subjects' directness and willingness to risk honesty. In DCT\#10, any response that does not allude to incompatibility with the interlocutor's spouse is obviously avoiding mention of the primary motivation for the refusal. Respondents who do not mention the short notice of the boss' invitation may either be acting discreet or may not mind. Responses to the salesman's invitation that make no mention of the business pitch may likewise be acting discreet or may view such "smoozing" as a legitimate business practice, presenting no reason for critical comment.

Only amongst the GGs was there explicit mention of feeling uncomfortable with the friend's spouse, or disapproving of the salesman's business practices. Two AEs and one GE, however, as well as one GG made polite reference to the short notice of the boss' invitation. 


\section{DCT \#3: Refusal of Lower-Status Interlocutor's Invitation}

\section{Frequency of Functional Categories ${ }^{39}$}

In DCT\#3, there was very little use of direct refusal forms by any of the three subject groups, as the table below shows. The GEs made slightly more use of statements of negative ability than the other two groups, but the difference was minimal.

Table 4. 40: Use of Direct Refusal Strategies; Invitation; Lower-Status Interlocutor (DCT\#3)

\begin{tabular}{|l|l|l|l|}
\hline & Negative Ability & Negative Willingness & "No" \\
\hline GEs & $17 \%$ & $8 \%{ }^{40}$ & - \\
GGs & $7 \%$ & - & $7 \%$ \\
AEs & $8 \%$ & $8 \%$ & $8 \%$ \\
\hline
\end{tabular}

In their efforts to follow NS patterns of politeness in English, the GEs actually outdid the AEs in their use of excuses (emphasizing inability to accept the invitation). All three groups displayed a similar (low) use of statements of principle.

Table 4. 41: Use of Excuses, Reasons, and Statements of Principle / Philosophy; Invitation; Lower-Status Interlocutor (DCT\#3)

\begin{tabular}{|l|l|l|l|}
\hline & Excuse & Reason & Statement of Principle \\
\hline GEs & $50 \%$ & $8 \%$ & $17 \%$ \\
AEs & $33 \%$ & $25 \%$ & $17 \%$ \\
GGs & $14 \%$ & $14 \%$ & $7 \%$ \\
\hline
\end{tabular}

As the table below shows, many GGs, in contrast to the AEs and GEs, made use of face-threatening strategies. The GEs followed the same pattern of refraining from criticism as the native speakers of English.

\footnotetext{
${ }^{39}$ Part of one GE's response was not interpretable because the meaning was ambiguous: "In the moment, the company is in a very delicate financial situation, but I know there has to be some improvements." (GE4). It was not possible to determine whether this remark was intended as a vague promise of future acceptance or as acceptance functioning as a refusal through a lack of enthusiasm.
} 
Table 4. 42: Use of Face-Threatening Strategies; Invitation; Lower-Status Interlocutor (DCT\#3)

\begin{tabular}{|l|l|l|l|}
\hline & Criticism of Interlocutor & Criticism of Eliciting Speech Act & Upgraders \\
\hline AEs & - & - & - \\
GEs & - & - & - \\
GGs & $36 \%$ & $14 \%$ & $14 \%$ \\
\hline
\end{tabular}

There was a significant contrast between the AEs and the two groups of Germans

in terms of their use of evasive strategies, with AEs making little use of such strategies and Germans relatively frequent use. In addition, one GG also used elaboration on postponement (GG2). The GEs used evasive strategies to a lesser extent than the GGs, but still greatly exceeded the AEs.

Table 4. 43 Use of Evasive Strategies; Invitation; Lower-Status Interlocutor (DCT\#3)

\begin{tabular}{|l|l|l|}
\hline & Postponement & Hedging \\
\hline AEs & $17 \%$ & $8 \%$ \\
GEs & $33 \%$ & $25 \%$ \\
GGs & $57 \%$ & $14 \%$ \\
\hline
\end{tabular}

The AEs' moderate use of statements of positive opinion contrasted with the GGs and GEs. On the other hand, the GEs resembled the AEs in the frequency with which they used expressions of gratitude. The GGs compensated slightly for the dearth of positive forms in their responses through the use of mitigating adjuncts.

\footnotetext{
${ }^{40}$ This one instance of negative willingness was only implied through the use of hedging: "I'm not yet sure if I want to firm up that contract with you. ..." (GE6).
} 
Table 4. 44: Use of Positive Adjuncts/Forms; Invitation; Lower-Status Interlocutor (DCT\#3)

\begin{tabular}{|l|l|l|l|l|l|l|}
\hline & Gratitude & $\begin{array}{l}\text { Positive } \\
\text { Opinion } \\
\text { /Feeling }\end{array}$ & Compliment & Regret & $\begin{array}{l}\text { Statement } \\
\text { of } \\
\text { Alternative }\end{array}$ & Downgrader \\
\hline AEs & $25 \%$ & $25 \%$ & $8 \%$ & $25 \%$ & $8 \%$ & $17 \%$ \\
GEs & $25 \%$ & - & - & $17 \%$ & - & $33 \%$ \\
GGs & $7 \%$ & $7 \%$ & $7 \%$ & $7 \%$ & - & $21 \%$ \\
\hline
\end{tabular}

As in other DCT situations, the GGs made relatively frequent use of mitigating

adjuncts compared to the other two groups, but comparatively little use of positive forms in DCT\#3. The GEs and AEs made relatively little use of mitigating adjuncts.

Table 4. 45: Use of Mitigating Adjuncts; Invitation; Lower-Status Interlocutor (DCT\#3)

\begin{tabular}{|l|l|l|l|l|}
\hline & Forewarn & Repetition & Downtoner & Pause Filler \\
\hline GGs & $36 \%$ & - & $7 \%$ & $14 \%$ \\
GEs & $8 \%$ & $8 \%$ & $8 \%$ & - \\
AEs & - & - & $17 \%$ & $8 \%$ \\
\hline
\end{tabular}

The table below shows that the AEs made considerably more use of positive forms

overall than the GGs. The GEs found middle ground between the GG and AE positions, though leaning more towards the GGs. In terms of respondents who made no use of positive adjuncts/forms: GG $>$ GE $>$ AE. Compared with the AEs, a slightly higher

\footnotetext{
${ }^{41}$ Two of the downgraders used by GEs in DCT\#3 resembled forms used by GGs, suggesting transfer. One GE's remark, "That's very friendly..." (GE1), appeared to be intended as a statement of gratitude rather than a statement of positive opinion (as it would be in NS English). Such remarks are typical ways of expressing gratitude in German, e.g., 'Das ist (sehr) freundlich / lieb / nett (von Dir / Ihnen)' ('That's (very) friendly / kind / nice (of you)'). The remark resembled GG3's statement of gratitude in DCT\#4: "Das ist sehr aufmerksam von Ihnen..." ("That is very considerate of you..."). Likewise, another GE's remark, "I beg you to be so kind to excuse me..." (GE2), which sounded excessively solicituous in this situation, appeared to depend on a method of stating regret more typical of German than English (e.g., GG5's response in DCT\#4: "Sie müssen mich entschuldigen..." - "You must excuse me...").
} 
percentage of GEs used two positive adjuncts, but overall, AE use of positive forms was more extensive. The GGs used very few positive forms.

Table 4. 46: Number of Positive Adjuncts/Forms per Response; Invitation; LowerStatus Interlocutor (DCT\#3)

\begin{tabular}{|l|l|l|l|}
\hline & $\mathbf{0}$ & $\mathbf{1}$ & $\mathbf{2}$ \\
\hline AEs & $17 \%$ & $58 \%$ & $25 \%$ \\
GEs & $50 \%$ & $17 \%$ & $33 \%$ \\
GGs & $64 \%$ & $21 \%$ & $14 \%$ \\
\hline
\end{tabular}

The GGs used a larger number of mitigating forms per response than the GEs or AEs, demonstrating a preference (by comparison to the other two groups) for weaker mitigating forms such as forewarns and pause fillers rather than stronger positive forms such as statements of gratitude or positive opinion.

Table 4. 47: Number of Mitigating Adjuncts per Response; Invitation; Lower-Status Interlocutor (DCT\#3)

\begin{tabular}{|l|l|l|l|l|}
\hline & $\mathbf{0}$ & $\mathbf{1}$ & $\mathbf{2}$ & $\mathbf{3}$ \\
\hline GGs & $64 \%$ & $21 \%$ & $7 \%$ & $7 \%$ \\
GEs & $75 \%$ & $25 \%$ & - & - \\
AEs & $75 \%$ & $25 \%$ & - & - \\
\hline
\end{tabular}

\section{Content of Functional Categories}

Excuses and Reasons: The themes of the excuses and reasons used for DCT\#3 were all in the realm of business. The three AE reasons used in response to DCT\#3 involved satisfaction with the company's current machinery: ."..at the present time I am very happy with the performance of my current equipment..." (AE3); .".At this time I am happy with the printing machines that we have." (AE4); and .".right now though we're pretty happy with X-co's material..." (AE5). 
Of the two GG reasons, one was slightly ambiguous as to whether it was a reason or an excuse. It was interpreted as being a reason rather than an excuse because of its unapologetic tone and its lack of the conciliatory quality usually found in excuses: "Ich habe keine Zeit für Ihre Einladung..." ("I have no time for your invitation"-GG5). The response continued with a statement that the speaker would consider the salesman's product and contact him after making a decision (thus leaving the door open for a possible contract). In other words, he brushed aside the invitation and focused on the business deal. The other reason also responded to the business deal rather than the dinner invitation: .". bei uns [sind] z. Zt. solch umfangreiche Investitionen nicht vorgesehen. ..." (."..at the moment, we aren't considering such extensive investments" (GG9).

The one GE reason directly but politely focussed on the business transaction underlying the invitation: “As I haven't checked your products properly enough yet, I'd say that it might be too early to speak of a contract." (GE10).

It should be noted that all of the reasons given contained expressions of time that left the door open for possible future negotiation of a contract, i.e., "at the present time", "at this time", "right now", "z. Zt." ("at the moment"), and "yet." In this way, the speakers allowed the salesman to keep some hope of future dealings, a form of protection of the hearer's negative face.

Of the AEs' four excuses, three were thoroughly vague: .".I'm extremely busy..." (AE8); .".I have a lot of other obligations right now" (AE9); and, .... I have other plans for dinner" (AE12). One excuse was somewhat more specific, but still rather vague: .".. we're not in a position to change contracts completely" (AE5). In context (following a 
reason), this excuse sounded almost out of place, although the respondent may have sought to strengthen the refusal by adding an element of inability: .".right now though we're pretty happy with X-co's material \& we're not in a position to change contracts completely.."

The GG data included two excuses, both of which were vague: "Heute kommt mir das leider sehr ungelegen..." ("Unfortunately, that is very inconvenient for me today..." GG8), and "Heute kommt es uns sehr ungelegen..." ("That is very inconvenient for us today..."-GG10).

Of the six excuses used by the GEs, two were vague and four specific. The vague excuses cited "other obligations" (GE1) and "much work" (GE2). The specific excuses were the company's "very delicate financial situation" (GE4), "a meeting of the Vorstand [board of directors]" (GE5), having to "leave for Europe ... because of business affairs" (GE8), and "an important conference ... I can't cancell" (GE11).

In sum, there was a high proportion of vague excuses in the data (except for amongst the GEs), expressing the sentiment that it was none of the addressee's business why the speaker chose to refuse the invitation. Use of specific excuses by GEs was perhaps based on an assumption that English requires greater tact than German (an assumption that the data in this study corroborates) and that this can be achieved through constructing more specific excuses. This was, however, a means of increasing politeness that the NSs of English did not choose, but which reflected German NS strategies for doing so; thus, this was an instance of transfer. 
Statements of Principle versus Face-Threatening Strategies: Whereas reasons used in DCT\#3 focused on the business transaction underlying the dinner invitation, statements of principle emphasized the questionable ethics of conducting business in the setting proposed by the salesman.

In DCT\#3, statements of principle resembled criticism of the invitation in terms of content. In both cases, the speaker questioned of the propriety of combining business and an expensive dinner invitation. Statements of principle, however, avoided any mention of the addressee's guilt (thus protecting his positive face), using more neutral wording or referring to the speaker rather than the hearer.

The statements of principle varied along the lines of explicitness. While some speakers only implied impropriety, others were more direct (and elaborate) in describing their uneasiness at such practices. The following responses fell into the former category: ... I ... would rather conduct meetings in the workplace." (AE2); ."..ich möchte Geschäft und Vergnügen getrennt halten. ..." (."..I'd like to keep business and pleasure separate. ..."-GG6); and, .".II don't connect my privacy with my company" [i.e., "I don't mix business and pleasure."] (GE3). More explicit statements of principle included: ...I consider it unethical to take favors from a vendor because it might color my decision \& therefore the best interests of my firm." (AE1); and, .".I would feel bad to be invited in such an expensive restaurant although I'm not sure if I will buy something." (GE9). While AE1 used the word, "unethical", this did not refer to the salesman's behavior, but rather, stated that it would be unethical for the speaker to accept the invitation. As noted above in discussions of other DCT items regarding politeness strategies, speakers sometimes 
minimize a face threat to the hearer by referring to their own person rather than the addressee's. In addition, AE12 was very careful to protect the addressee's face by embedding the statement of principle in-between a strong downgrader and face-saving elaboration: "I know you mean this dinner offer in good faith but I consider it unethical to take favors from a vendor because it might color my decision \& therefore the best interests of my firm." (AE1).

As for use of face-threatening strategies, the GGs were considerably more confrontative than either of the other two groups. While the GGs risked a great deal of face-threat to the addressee, the AEs and GEs avoided such strategies altogether. The two behaviors that were criticized included the salesman's insistent method of selling and his attempt to bribe the speaker. Altogether three GG respondents clearly criticized the bribery, one subject criticized the pressure tactics, and two criticized both. Those responses criticizing the bribery included: ."..wenn ich mich für ihr Produkt entscheiden sollte, dann aufgrund meiner Überlegungen und nicht wegen eines spesenfreien Zückerchens." (."..if I should choose your product, then I'll do so because of my considerations and not because of you dangling a carrot in front of me."-GG3); ...Verstehen Sie mich nicht falsch, aber es könnte den Eindruck entstehen, daß Sie..." ("Don't get me wrong, but one could get the impression that you..."-GG6); and ."..Und bitte versuchen Sie nicht, mich durch solch e. Ambiente zu bewegen. ..." ("And please don't try to persuade me by using that kind of setting. ..."-GG9). One remark referred to the hard sell: ."..Denken Sie bloß nicht, daß ich jedesmal, wenn ich Interesse zeige, auch etwas kaufen möchte." ("Don't go thinking that every time I show interest I'll also want 
to buy something."-GG4). Two responses targeted both the bribe and the high-pressure salesmanship: "Sie glauben doch nicht etwa, daß ich Druckmaschinen bestelle, die ich nicht brauche, nur weil Sie mich zum Essen einladen?!" ("You don't actually believe that I'll order printing machines that I don't need just because you're inviting me to dinner?!"GG14); and "Das ist mir zu verbindlich. ..." ("That is too binding for me", in other words, "You're trying to put me under too much of an obligation."-GG3).

Two GGs sharpened their criticism of the interlocutor through use of criticism in conjunction with upgraders: .".Denken Sie bloß nicht..." (."..Don't go thinking that ..."GG4); and, "Sie glauben doch nicht etwa...?!" ("You don't actually believe...?!"-GG14).

One instance of criticism of the eliciting speech act was a fairly strong face threat because it involved criticism of the salesman's product (a strategy used by none of the AEs or GEs): "Ich habe Ihr Produkt weitgehends testen lassen u. hege weiterhin meine Bedenken es zu kaufen." ("I've had your product tested extensively und continue to have my doubts about buying it."-GG13).

Depending on interpretation, eight GG responses (the seven uses of criticism quoted above and perhaps GG6's statement of principle) contained a possible face threat. In contrast, none of the $\mathrm{AE}$ respondents made any mention of high-pressure salesmanship, and the $\mathrm{AE}$ data contained only two very careful hints suggesting bribery, which were statements of principle, not criticism (See quotes above). A third subject used a statement of negative opinion in a very diplomatic way as a means of avoiding mention of bribery or pressure tactics: "Thanks for the invitation, but Lutece isn't a restaurant I enjoy. How about (name of [sic] lesser expensive restaurant)?" (AE10). This illustrates the kind 
of tactic a NS of American English might use to express negative content in a situation of great social distance. The remark was so oblique that the hearer probably would have interpreted it as a simple suggestion of an alternate restaurant, not detecting the possible hint of criticism. The parenthetical comment about the less expensive restaurant, however, suggests that this was a means of lessening the scope of the proposed bribe.

All of the GE responses were relatively or very polite. There were no instances of criticism of either pressure tactics or bribery, only the two statements of principle discussed above. Both GE3 and GE9 hinted at bribery, but made no explicit mention of any wrongdoing on the hearer's part. Rather, they focused their remarks on themselves. The fact that GE response patterns more closely resembled target language patterns than L1 patterns signals good pragmatic acquisition. However, the GEs went even further than the AEs in their avoidance of critical remarks, so this was perhaps a case of "hypercorrection."

Evasive Strategies: There was greater use of evasive strategies in DCT\#3 than in many other DCT situations, apparently reflecting an uneasiness at accepting a somewhat unethical invitation or bribe. The two groups of Germans made much greater use of these strategies than the AEs, suggesting that this kind of practice is less acceptable according to German norms.

A few uses of these evasive strategies (all by Germans) subtly asserted the speaker's higher status and power over the hearer, the power to make him wait for a response (GG5, GG7, GE6). Only one use of an evasive strategy, however, actually seemed antagonistic (GG5). Even if this kind of evasion was not always a passive- 
aggressive means of showing one's displeasure at the bribe and the hard sell tactics, it did allow the speaker to retreat from the discomfort of being offered a bribe and being pressured. By comparison, evasive strategies were avoided almost entirely in DCT\#10 and DCT\#4, situations that did not involve a bribe, a salesman's pressure tactics, or a lowstatus interlocutor.

Positive Forms and Mitigating Adjuncts: The Americans made considerably more use than either the GEs or GGs of the positive strategies involving a stronger commitment to the content of the remark, namely statements of gratitude, positive opinion or feeling, compliments, and expressions of regret. While the GEs and GGs made greater use of downgraders than the AEs, it should be noted that downgraders have a milder positive effect than the other positive forms.

Even though positive and mitigating adjuncts are weaker in their positive content than most positive forms, they signal some degree of concern for the hearer's feelings. When they were missing in DCT\#3, responses tended to involve criticism, postponement, or excuses aimed at cutting the discussion short rather than justifying oneself, when the speaker did not care if the addressee believed a half-hearted excuse or not ${ }^{42}$. In all of the

\footnotetext{
${ }^{42}$ The GGs who used neither positive nor mitigating forms included: GG3 (with criticism of the invitation and the interlocutor), GG4 (who used the direct form, "no", in a harsh and unmitigated way, together with criticism of the interlocutor), GG5 (who gave a reason for refusing and also used postponement), GG10 (with a vague excuse and postponement), GG13 (with criticism of the eliciting speech act), and GG14 (who criticized the interlocutor quite sharply).

The GEs who used neither positive nor mitigating forms included: GE6 (with hedging and postponement), GE7 (with postponement and hedging), and GE10 (who gave a reason as well as using postponement). GE5 used repetition (a rather neutral form of mitigation), but no other form of mitigation with an excuse, which also resulted in a less than friendly effect.
} 
GG responses in which the speaker chose not to use positive or mitigating forms, the effect was brusque and served to increase the distance between the interlocutors. By comparison, the GE responses that did not contain these forms were considerably less threatening to the hearer's face, although they were not very friendly and certainly served to increase distance. Rather than criticize directly, as the GGs did, these GEs relied primarily on evasive strategies. The one $\mathrm{AE}$ response without positive or mitigating forms was quite neutral in terms of a risk to the hearer's face or a distancing effect.

The difference between the two groups of Germans in usage patterns of positive forms and mitigating adjuncts suggests that, while German native speakers prefer weaker forms of mitigation in this kind of situation (i.e., forewarns, downtoners, etc. rather than forms that are more explicitly positive), the GEs recognized a need for stronger softening effects in English than in German.

FTA Strategies: In DCT\#3, off record strategies included hedging and postponement. When respondents directly criticized the salesman's pressure tactics or bribery, these remarks were interpreted as being baldly on record. Positive politeness involved the assertion of a wish to be in contact with the addressee or to accept the invitation, and negative politeness maintained the social distance by being polite and civil. This effect was achieved through relatively formal (and formulaic) politeness markers, such as statements of regret, and polite assertions of inability, such as excuses. The strategy of not openly referring to the saleman's commercial intentions obviously was a manifestation of negative politeness because the speaker avoided embarrassing the 
interlocutor. This does not necessarily mean that responses that did mention the underlying purpose of the invitation were lacking in negative politeness, e.g., "I appreciate the offer, but at the present time I am very happy with the performance of my current equipment-thanks anyway." (AE3).

In the $\mathrm{AE}$ population, the major strategy was negative politeness. Only one respondent performed the refusal off record (AE11). Two AEs colored their responses with positive politeness (AE1 and AE5). Although AE1 was relatively direct in letting the addressee know that he did not consider the invitation appropriate, this was not an FTA performed baldly on record because of a downgrader asserting the speaker's approval of the hearer's character: "I know you mean this dinner offer in good faith...." AE5's response differed from all other responses in the degree of social proximity it expressed through its informal register and personally friendly positive forms: "You know, your product sounds really good \& I'd like to discuss it more with you, right now though we're pretty happy with X-co's material ...."

Amongst the GEs, one third of the responses were off record. One of these, however, contained an element of an FTA performed baldly on record. While hedging was used, the remark implied negative willingness: "I'm not yet sure if I want to firm up that contract with you. ..." (GE6). Two GE responses (GE5 and GE9) clearly performed the FTA baldly on record, although they did not convey the same threat to the hearer's face that a number of the GG responses did. None of the GEs used positive politeness. The remaining half of the GEs used negative politeness.

hedging and postponement). 
The GGs performed the refusal off record fairly frequently (over a third of the population). One GG response involved hedging, but also contained an excuse, which did constitute a clear refusal (GG10). Therefore, it was included in the tally of responses using negative politeness. The GGs had the largest proportion of responses performing the FTA baldly on record (more than one third). One of these respondents used postponement, but he also openly refused the invitation by using an unmitigated reason (GG5). Also, he clearly expressed an intention to force the hearer into retreat from his hard sell tactics. The GGs had the lowest percentage of responses using negative politeness (less than onethird).

Focus of Responses: The subjects' fundamental choices in responding to DCT\#3 were:

- whether to focus primarily on refusing the invitation or the business deal, which was the real purpose behind the invitation; and

- whether to treat the invitation as an invitation only or as a dubious business practice.

These choices are important because they reflect preferences for directness versus indirectness, and saving the hearer's face versus voicing unfavorable opinions (i.e., performing the FTA with redressive action or baldly on record).

The AEs were equally divided between responses focusing on the invitation and those that remarked on the contract. Of the six subjects responding primarily to the invitation, two stated that business should be conducted at work rather than at a restaurant. A third response appeared to espouse a similar sentiment because of a parenthetical comment about suggesting a less expensive restaurant (AE10). Without the 
parenthetical remark, however, the response could have been understood as a reply to an ordinary invitation. Three subjects responded as though it had been a simple invitation without acknowledging that the salesman might have had other intentions. Two of these responses were somewhat ambiguous as to whether the invitation rather than the business deal was being refused, but the fact that they spoke of not having time at the moment or in the evenings suggests that they were refusing the more superficial level of invitation: "I'm sorry, but I'm extremely busy during the evenings working on other proposals." (AE8); and, "This really isn't a good time for me-I have a lot of other obligations right now." (AE9).

Considerably fewer of the GGs minced words regarding the salesman's real intentions. Not only did nearly two-thirds of the population focus on the contract, but of those subjects responding to the invitation, only one did not address its underlying contrivance. The refusals focusing on the invitation to dinner all involved criticism of the interlocutor for pressuring and bribery, with the exception of one statement of principle. In other words, the statement was being made that this was not an appropriate way to do business. In comparison to the Americans, the GGs were more overt in acknowledging the actual purpose of the salesman's invitation.

The GE response patterns more closely resembled the AEs than the GGs; indeed, they differed more from the GGs than the AEs. Just over half of the GEs focused on the invitation, and the rest remarked on the contract. Of the seven respondents focusing on the invitation itself, five responded as they might to any, more neutral invitation. Two subjects 
stated that they preferred not to meet on business at a restaurant. In terms of the focus of their responses, the GE group as a whole displayed the greatest face-saving caution.

Table 4. 48: Focus of Responses: Invitation Only, Invitation as Questionable Business Practice, or Business Deal; Invitation; Lower-Status Interlocutor (DCT\#3)

\begin{tabular}{|l|l|l|l|}
\hline & Just Invitation & $\begin{array}{l}\text { Invitation (Mixing } \\
\text { Business and Pleasure) }\end{array}$ & Primarily Business Deal \\
\hline GEs & $42 \%$ & $17 \%$ & $42 \%$ \\
AEs & $25 \%$ & $25 \%$ & $50 \%$ \\
GGs & $7 \%$ & $29 \%$ & $64 \%$ \\
\hline
\end{tabular}

In all of the responses focusing solely on the invitation, excuses were the primary

strategy, with varying degrees of use of positive forms and mitigating adjuncts.

In all but one of the $\mathrm{AE}$ and $\mathrm{GE}$ responses responding to the invitation as a somewhat questionable business practice, the main strategy was using statements of principle. The one exception was an offer of an alternative, which appeared to be an opaque statement of principle because of the subject's parenthetical comment (AE 10). In all but one of the GG responses in this category, however, the major strategy was criticism of the interlocutor. The exception was a response that contained both unambiguous criticism and a statement of principle (GG6).

There was a wider range of strategies used in responses that focused primarily on the business deal. Here again, the respondents faced a choice: clearly refusing or being evasive. Of the clear refusals, the AEs produced one statement of negative willingness and three reasons, and the GEs used one excuse, in contrast to the GGs, who used one critical remark about the salesman's insistent selling methods and one critical remark about the saleman's product. Only two AE responses involved evasion, whereas four GE responses 
used evasive strategies (one of which incorporated a reason in a response emphasizing postponement-GE10). Seven GG responses relied on evasion.

\section{Summary of Results: Refusal of Invitation Made by a Lower-Status Interlocutor (DCT\#3)}

The choice of focus on either the dinner invitation itself, the invitation as a business practice of questionable ethics, or on the underlying business deal, determined the subjects' selection of strategies in DCT\#3. The three major strategies used to refuse the salesman's dinner invitation consisted of relatively polite explanations, somewhat polite (if distant) evasion, and largely unmitigated confrontational remarks about the saleman's behavior or product. Because of these different approaches, there was a relatively wide distribution of different functional categories in responses to DCT\#3, rather than a concentration on one primary strategy (such as the dominance of excuses in DCT\#4, where they were used in all but one response). While direct refusal strategies played a very minor role in DCT\#3, excuses, reasons, and statements of principle were all relatively important, and evasive strategies were much more prominent in DCT\#3 than in most other DCT items.

The themes of excuses and reasons revolved around business considerations or obligations rather than family or social commitments, as was the case in many other DCT items. This reflects the business setting of DCT\#3 as well as the social distance between the interlocutors. 
The directness of reasons was aimed at discouraging the salesman from pressuring the company president to firm up a contract. As noted above, however, all of the reasons included an expression of time that implied the possibility of future negotiations.

The theme of AE reasons was satisfaction with the company's current equipment. None of the Germans used this reason, but opted for reasons that supplied less information, such as not having plans for any big investments or not having thoroughly researched the salesman's product. This may be related to the German subjects' emphasis on preserving the speaker's privacy (i.e., protecting the speaker's negative face) elsewhere in the DCT (e.g., in DCT\#12).

Both the AEs and GGs gave only vague excuses in DCT\#3. There were no specific GG excuses in response to DCT\#3, once again reflecting the importance of personal privacy for German NSs in situations of great social distance. The GEs, on the other hand, used both vague and specific excuses. The fact that the GE data included specific and watertight excuses, unlike the $\mathrm{AE}$ and $\mathrm{GG}$ responses, points to a degree of "hypercorrection" in their use of English. In other words, some GEs assumed that NSs of English go to more effort with excuses than NSs of German (this is true in other DCT items as well). In the case of DCT\#3, acting on this assumption led to excuses that differed from NS choices of strategies.

Two AEs, two GEs, and one GG chose statements of principle as a means of addressing the interlocutor's impropriety (i.e., bribery and insistent selling techniques), whereas half of the GGs chose direct criticism. 
The AEs made considerably greater use of the more potent positive forms than the GEs or GGs. While the GGs made very little of these strategies, the GEs made somewhat more use thereof than the GGs. The GGs used fewer positive forms than the AEs or GEs, but tended to fill this gap with somewhat greater use of mitigating adjuncts than the other two groups.

The fact that the GG downgraders were used primarily to cushion the blow of negative strategies rather than to emphasize good will made them less positive than the $\mathrm{AE}$ or GE downgraders. Combined with other findings, this suggests a difference in approaches to dealing with lower-status interlocutors.

The major points of difference between the GGs and the other two groups included the following:

the willingness of a large proportion of GGs to insult the interlocutor with high-impact critical remarks, while the AEs and GEs opted for protection of the hearer's face; and the GGs' greater candor about the true purpose of the salesman's invitation (namely to propel the business deal), while many AEs and GEs either avoided any mention of dubious business practices or only mildly expressed hesitancy to participate in such an invitation. All but one of the GG responses either focused exclusively on the business deal or pointed out the ulterior motives underlying the invitation, whereas a number of AEs and GEs responded to the invitation as though it were just a simple invitation.

Major differences between the AEs and the German groups included:

the AEs' minimal use of evasive strategies, which played an important role in a large number of the Germans' responses; 
the AEs' much greater use of the stronger positive forms in comparison to the Germans (although they used downgraders quite a bit less than the GEs and slightly less than the GGs); and

differences in terms of FTA strategies. While almost all of the AEs performed the refusal on record with negative politeness, only half of the GEs and less than a third of the GGs did so. None of the German responses had any hint of positive politeness, although two $\mathrm{AE}$ responses in the negative politeness category were tinged with positive politeness. While only one AE performed the refusal off record, one third of the GEs and over a third of the GGs did so. None of the AEs performed the refusal baldly on record, but two of the GEs and over a third of the GGs did (The GE responses in this category, however, posed no face threat, in contrast to their GG counterparts.).

The GEs exceeded the AEs' protection of the hearer's positive face in terms of a higher frequency of excuses, which were used in responses that did not acknowledge the shady aspect of the addressee's invitation. This feature can be considered an instance of over-correction. Overall, based on strategy choices, the GEs were more polite than the GGs, but more reserved than the AEs.

One could speculate that there are two main reasons for the AEs' tactfulness: a pragmatic convention that a speaker should avoid giving offense in a situation of great personal distance, and cultural norms that are fairly accepting of such business practices. The second of these theories is supported by one AE's comment: "I think that a lot of business is conducted at restaurants. Smoozing is important in business." (AE2). It is striking that the two groups of Germans used considerably more evasive forms (which 
indicate a degree of uneasiness) than the AEs in response to the not quite ethical invitation. Combined with the GGs' greater frankness in rejecting the business deal as opposed to the dinner invitation as well as their open expressions of disapproval of the invitation, it seems plausible that Germans in general are less accepting of such business practices than Americans. While the GEs followed AE patterns of not directly confronting the addressee, they nonetheless maintained the German NSs' use of evasive strategies, suggesting partial pragmatic acquisition.

\section{DCT \#10: Refusal of Equal-Status Interlocutor's Invitation}

\section{Frequency of Functional Categories}

There was negligible use of direct refusal strategies in all three groups, except for statements of negative ability used by almost half of the GGs.

Stating that "Sunday evening is bad / won't work", etc., was a typical means of expressing negative ability in the GG population. One AE used the form ."..but Sunday's not good..." (AE10) as an excuse. The remark resembled responses by GG1, GG8, GG10, GG11, GG13, and GG14. The GG forms were coded as negative ability because they were ALL followed by a real excuse; this AE response used the same words, but it functioned as an excuse rather than as a statement of negative ability.

The performative used by a GG co-occurred with a downgrader, resulting in a direct, but polite, refusal that implied a degree of negative ability: .".deswegen sag ich Dir lieber ab..." (."..because of that, I'd better decline..."-GG9). 
One GE softened a statement of negative willingness and a reason considerably through the use of a downgrader and downtoners: .".. But I don't think I'll come, because you know, your wife really doesn't like me." (GE1). The bald statement is much harsher: ... But I won't come because your wife doesn't like me."

Table 4. 49: Use of Direct Refusal Strategies; Invitation; Equal-Status Interlocutor (DCT\#10)

\begin{tabular}{|l|l|l|l|l|}
\hline & Negative Ability & Performative & "No" & Negative Willingness \\
\hline GGs $^{43}$ & $47 \%$ & $7 \%$ & $7 \%$ & - \\
AEs & $17 \%$ & - & $8 \%$ & - \\
GEs & - & - & - & $8 \%$ \\
\hline
\end{tabular}

Every respondent used either an excuse or a reason. The major strategy was the excuse. In addition to giving an excuse, a large number of the GEs and a few of the AEs used elaboration on the excuse. Two of the GEs even elaborated on the excuse twice. Practically none of the GGs, on the other hand, used elaboration. As the preceding table shows, however, the GGs appeared to exhibit a stronger preference for statements of negative ability than the other two groups. Upon closer examination it turned out that every GG who used negative ability also used an excuse (GG1, GG8, GG10, GG11, GG13, GG14). Thus, the GGs on the one hand and the AEs and GEs on the other appeared to use different strategies to fulfill a similar function.

One GE and two GGs made statements that were interpreted as "reasons", rather than "excuses", because they did not cite external factors forcing them to refuse, but rather spoke of not being "in the right mood" (GG3), not feeling "interested in being social

\footnotetext{
${ }^{43}$ One GG gave two alternate responses, one of which was a "white lie" and the other one honest, depending on the relationship between speaker and hearer (GG6). For this reason, the tally computes percentages based on fifteen GG responses rather than fourteen.
} 
at the moment" (GG4), or not being "in the mood to be around people" (GE7). These three responses are discussed further in the content section on "honesty" below.

One respondent did not write an actual excuse, but merely stated the functional category he would use. In a parenthetical comment he said that, depending on his relationship with the addressee, he would either make up an excuse or be honest: "entweder Ausreden (siehe Nr. 4) oder auch (je nach Verhältnis) ehrlich..." ("either excuses (see [DCT]\#4) or (depending on the relationship) honest..."-GG6). He also gave an alternative response that supplied the addressee with an honest explanation for the refusal (see below). One other respondent gave an honest reason for the refusal (GG9) (see below).

Table 4. 50: Use of Excuses and Reasons; Invitation; Equal-Status Interlocutor (DCT\#10)

\begin{tabular}{|l|l|l|l|}
\hline & Excuse & Elaboration on Excuse & Reason \\
\hline AEs & $100 \%$ & $25 \%$ & - \\
GEs & $83 \%$ & $42 \%$ & $17 \%$ \\
GGs & $73 \%$ & $7 \%$ & $27 \%$ \\
\hline
\end{tabular}

In DCT\#10, none of the subjects made use of strategies that increased the face risk.

In terms of evasive strategies, there was one instance of hedging (AE12). One subject made use of repetition of part of the invitation: "Sunday night? ..." (GE10). While Beebe et al consider repetition a form of avoidance, in this researcher's view, the use of repetition is not evasive per se. The speaker in this instance appeared to be making sure she understood correctly what day the interlocutor had meant. Of course, since antipathy towards the friend's spouse played a role in the speaker's decision to refuse the invitation in DCT\#10, GE10's response might have been made up. In that case, the use of repetition 
would have been purely evasive. On the other hand, if the commitment to babysit for her sister was real, the question, "Sunday night?" might have been at least partially honest. In this particular case, this researcher's tendency is to agree with Beebe et al's view of repetition as an avoidant strategy, but only because the real reason for refusing the invitation (i.e., the speaker's dislike of the addressee's spouse is stated in the description of the DCT situation.

Not counting downgraders (the "weakest" of the positive forms and adjuncts), the AEs made fairly heavy use of positive forms, as compared with moderate use by the GEs, and light use by the GGs. While AE use of downgraders was negligible, both groups of Germans made moderate to high use of them. The GEs exceeded the GGs in use of this functional category (apparently sensing a need to increase politeness in English, but choosing a means a doing so that is more characteristic of German than English pragmatic conventions).

One $\mathrm{AE}$ and one GG used downgraders with the direct form, "no", and one GG used a downgrader in conjunction with a statement of negative consequences to the speaker. Of the GEs' downgraders, one preceded an excuse, and three appeared in conjunction with excuses. The fifth downgrader co-occurred with a statement of negative willingness. Thus, the AEs' and GGs' downgraders served to soften less favorable functional categories, which was the case with only one GE downgrader.

Two GEs used a sequence of a downgrader ("such a pity"-GE9, and "that's too bad"-GE12) followed by an excuse in DCT\#10, a pattern which appeared in a couple of GE responses to DCT \#4 as well: "that's a pity" (GE7 and GE12). These forms did not 
occur in the $\mathrm{AE}$ data (although this may be more indicative of differences between American English and British English, which is the target form of English for most of the GEs).

Table 4. 51: Use of Positive Adjuncts / Forms; Invitation; Equal-Status Interlocutor (DCT\#10)

\begin{tabular}{|l|l|l|l|l|l|l|l|}
\hline & Regret & $\begin{array}{l}\text { Positive } \\
\text { Opinion }\end{array}$ & Gratitude & Wish & $\begin{array}{l}\text { Offer of } \\
\text { Alter-native }\end{array}$ & Promise & $\begin{array}{l}\text { Down- } \\
\text { grader }\end{array}$ \\
\hline AEs & $42 \%$ & $33 \%$ & $8 \%$ & $8 \%$ & $8 \%$ & - & $8 \%$ \\
GEs & $42 \%$ & $17 \%$ & $8 \%$ & - & - & - & $42 \%$ \\
GGs & $20 \%$ & $7 \%$ & $7 \%$ & - & $7 \%$ & $7 \%$ & $20 \%$ \\
\hline
\end{tabular}

Two types of mitigating adjuncts appeared in the data: pause fillers and downtoners. Downtoners were used most frequently by the GGs, followed by the AEs, and then, the GEs, whereas the GEs made the greatest use of pause fillers, followed by the AEs, and then the GGs. Thus, preferences for these forms were exactly reversed:

Downtoners: $\mathrm{GG}>\mathrm{AE}>\mathrm{GE}$; pause fillers: $\mathrm{GE}>\mathrm{AE}>\mathrm{GG}$.

Two AEs used interjections to preface their responses. I coded both of these as "downtoners" because, while they expressed somewhat the same sentiment as the downgraders, "Too bad!", "What a pity!" or the German equivalent, "Oh schade!", they did not carry this meaning independently of context: "God, I already made plans..." (AE8) and "Oh, jeez, I wish we could. But..." (AE6).

Amongst the AEs, downtoners were associated with a wish (AE6) and with excuses (AE8 and AE11). The GGs used downtoners with negative ability (GG1, GG8, and $\mathrm{GG1}$ ), regret (GG3), and with reasons (GG4, GG6, and GG9). The GEs used downtoners with reasons (GE1 and GE7). One of these GEs used two downtoners in a 
row with a reason (GE1). Thus, the two groups of Germans used downtoners in similar contexts, and both differed from the AEs.

Although the GGs made considerably less use of positive forms than the other two groups, they chose mitigating adjuncts more frequently. In other words, compared to the others, the GGs were more hesitant to use the more potent positive forms while making greater use of the more restrained means of softening the impact of the refusal.

Table 4. 52: Use of Mitigating Adjuncts; Invitation; Equal-Status Interlocutor (DCT\#10)

\begin{tabular}{|l|l|l|}
\hline & Downtoner & Pause Filler \\
\hline GGs & $47 \%$ & $27 \%$ \\
GEs & $17 \%$ & $50 \%$ \\
AEs & $25 \%$ & $33 \%$ \\
\hline
\end{tabular}

As the table below shows, the AEs had the largest number of positive forms per response, followed by the GEs, and finally the GGs, who made considerably less use of positive forms than the other two groups.

Table 4. 53: Number of Positive Forms / Adjuncts per Response; Invitation; EqualStatus Interlocutor (DCT\#10)

\begin{tabular}{|l|l|l|l|l|}
\hline & 0 & 1 & 2 & 3 \\
\hline AEs & $8 \%$ & $67 \%$ & $25 \%$ & - \\
\hline GEs & $8 \%$ & $75 \%$ & $17 \%$ & - \\
\hline GGs & $60 \%$ & $27 \%$ & $7 \%$ & $7 \%$ \\
\hline
\end{tabular}

The following table illustrates the somewhat greater use of mitigating adjuncts by

GGs as compared with the GEs and AEs.

Table 4. 54: Number of Mitigating Adjuncts per Response; Invitation; Equal-Status Interlocutor (DCT\#10)

\begin{tabular}{|l|l|l|l|l|}
\hline & 0 & 1 & 2 & 3 \\
\hline GGs & $33 \%$ & $60 \%$ & $7 \%$ & - \\
\hline GEs & $42 \%$ & $50 \%$ & - & $8 \%$ \\
\hline AEs & $50 \%$ & $33 \%$ & $17 \%$ & - \\
\hline
\end{tabular}


Regarding the use of other strategies, one subject used a statement of negative consequences to the speaker and a statement of negative consequences to the interlocutor: ... ich denke, ich werde mich dort nicht wohlfühlen. ... deswegen sag ich Dir lieber ab, als an dem Abend Dir wg. meiner schlechten Laune alles zu verderben." (."..I don't think I would feel at ease there. ... for that reason I prefer to decline your invitation rather than ruin everything for you on that evening because of my bad mood."-GG9). Another subject made a statement of negative consequences for both speaker and hearer: ."..bevor der Abend fur alle peinlich wird...." ("rather than let the evening be uncomfortable for everyone...."-GG6). Although these functional categories do sometimes pose a face threat, none of these particular remarks did. The intention behind these remarks was to prevent a situation from occurring that might damage the friendship between speaker and hearer. Also, they were expressed very tactfully. Thus, they are included as "other strategies", rather than face-threatening strategies.

\section{Content of Functional Categories}

Excuses: Choices of excuse themes in response to DCT\#10 were influenced by a number of variables. The day and time of the proposed dinner engagement (Sunday evening) to a large extent preclude the use of work-related excuses because most people would not be working at that time. Because the invitation is only for a casual dinner, acceptance is not of paramount importance to the hearer, so "light-weight" excuses are sufficient. As the interlocutors are friends (little social distance), information about one's personal sphere can be shared. The themes of excuses in the data involved: schoolwork, a previous invitation, babysitting, an early-morning flight the next day, and previously 
planned activities, social engagements, or get-togethers, mostly with friends but also with husbands, mothers, and a nephew. Only two respondents gave specific excuses about work-related obligations: a conference and a report for the boss.

Half of the AEs' excuses were thoroughly vague, involving unspecified "plans" or being "busy" (AE1, AE2, AE3, AE7, AE8, and AE10). Two other AEs' excuses were also rather vague: AE4 mentioned "other friends" and AE9 mentioned "work", but without specifying what kind of work. Thus, altogether, two-thirds of the AE excuses were vague.

The specific AE excuses asserted that: Sunday was the only day for the speaker to get work done for school (AE5), the speaker had been invited to a party by his boss (AE6, who labelled this excuse a lie), the speaker had already planned a quiet evening at home with her husband (AE11), and, the speaker had a big test the next day and needed to study (AE12). Of these, the excuses used by AE5, AE6, and AE12 were fairly watertight.

In contrast to the AEs, very few of the GGs' excuses were vague. In the vague excuses, one speaker had "eine Verabredung" ("an engagement"-GG2), and two others asserted, "ich hab was vor" ("I have plans"-GG10 and GG14).

Of the specific excuses, GG1 had an "Englischprüfung" (an English test), GG5 had "mit dem Musikverein einen Auftritt" (a performance with his musical society), GG7 had "ne Verabredung mit jemandem den ich schon lang nicht mehr gesehen hab." (a date with someone she had not seen for a long time), GG8 had already bought "Konzertkarten" (concert tickets), GG11 said ."..Sonntags paßt es mir immer schlecht, da kommt doch immer mein Neffe zu Besuch." (."..Sunday is always inconvenient for me, my nephew 
always comes to visit me then."), GG12 had made plans to play squash, and GG13 had to go to a "Tagung" (conference) in Zürich. Of these, six were watertight: in the case of GG1, GG5, and GG13, the plans sufficed of themselves for watertightness. In GG7's excuse, the speaker had not seen the person with whom she was meeting for a long time, adding urgency to the excuse. GG8 made her excuse watertight by stating that the concert tickets had already been bought. The way GG11 constructed her response, it implied that the nephew's visits were a regular, long-standing commitment.

Of the GE excuses, only one was vague, citing "other plans" (GE5). All other excuses were specific and were made fairly watertight through elaboration on the speaker's commitment to the content of the excuses. This was achieved by stating how long it had been since the speaker had visited his / her mother (GE6, GE11), saying he / she had already bought tickets for a concert (GE3, GE8), saying she had already committed to another invitation (GE9), explaining an obligation she had to her sister (GE10), going into detail, stating what time he had to get his flight (GE2), mentioning an "urgent" report for the boss (GE4), and stating specific plans, i.e., going to Boston to see the Nutcracker Suite (GE12).

Honesty: Not a single AE mentioned the real reason for refusing the invitation (namely, disliking the interlocutor's spouse). AE6 explicitly labeled his response a "lie." Indeed, not only did the AE respondents refrain from stating the honest reason for refusing, five subjects even added dishonest statements ("white lies") by using statements of positive feelings or a wish: .".I'd love to..." (AE5), "I'd really like to...", (AE10), “I'd 
like to..." (AE11), .".II wish we could. ..." (AE6). One subject even went so far as to say: ...too bad, I would have really liked to be with you two." (AE8).

There was a much higher degree of honesty in the GG responses (although GG6's parenthetical comment about using either an excuse or an honest reply, depending on the interlocutors' relationship, shows that Germans, too, make up false excuses to avoid accepting unwelcome invitations). Two reasons noted above, not being in the mood and not desiring social contact, displayed a certain level of honesty in that the respondents were honest about not wanting to accept the invitation, rather than making false excuses. By saying he was not in the right mood for being sociable, GG3 was perhaps not telling the real reason for refusing, but he was avoiding a lie (The same goes for GG4.). One GE respondent used a similar strategy: .".I'm somehow not in the mood to be around people just right now. I'm not very talkative today." (GE7).

There were no instances of insincere uses of "positive opinion / feelings" in the GG data. Only one respondent made a promise of future acceptance that appeared to be a white lie: ."..Ein anderes Mal aber sehr gerne." (GG2).

Two respondents, both GGs, were directly honest about the reason for the refusal. One of them stated parenthetically that use of such a response would depend on his relationship to the addressee (and he offered both a tactful and an "honest" variant-GG6). Both subjects (GG6 and GG9) used various means to soften the blow of the FTA, namely by preceding the reason with a positive opinion or statement of gratitude, and justifying the refusal by mentioning the threat of negative consequences to the speaker, interlocutor, or both. Both avoided being explicit about their feelings toward the spouse: "Deinetwegen 
würd' ich gern kommen, aber du weißt ja, wie ich deinen Mann finde, und bevor der Abend für alle peinlich wird...." ("I would gladly come to see you, but you know how I feel about your husband, and rather than let the evening be uncomfortable for everyone...."-GG6); "Das finde ich lieb, aber ich denke, ich werde mich dort nicht wohlfühlen. [sic] Liebe treff ich Dich ein ander' Mal, Du weißt ja warum, und deswegen sag ich Dir lieber ab, als an dem Abend Dir wg. meiner schlechten Laune alles zu verderben." ("That's nice of you, but I don't think I would feel at ease there. I'd rather meet you some other time, you know why, and for that reason, I prefer to decline your invitation rather than ruin everything for you on that evening because of my bad mood."GG9).

One of the reasons given by a GE respondent was an interesting turn-around of the real reason for refusing the invitation: ."..your wife really doesn't like me." (GE1). The speaker was somewhat honest in admitting tension between himself and the interlocutor's spouse, without actually mentioning his own antipathy toward the spouse. This allowed the speaker to be fairly honest without making a potentially face-threatening remark.

As noted above, GE7's excuse exhibited a degree of honesty by giving her state of mind as the reason rather than using plans with other people or duties as an excuse: .".. I'm somehow not in the mood to be around people just right now. I'm not very talkative today."

Only two GEs used statements of positive feelings as white lies: .".I'd like to come..." (GE6), and .".I'd love to..." (GE11). 
Use of statements of positive opinion/feeling and wishes were always associated with white lies, except in GG6's honest variant response, "I would gladly come to see you". The somewhat frequent use of these forms by the AEs reflects the AE tendency to protect the addressee from hearing the unpleasant truth. It also suggests that forms such as, 'I'd love to...' have little real meaning and serve primarily as a formula for politely refusing an invitation. The offer of alternative used by GG9, on the other hand, was associated with honesty, i.e., offering to meet the friend without the spouse along. The strategy of stating negative consequences to hearer, speaker, or both, was also associated with honest responses.

FTA Strategies: In DCT\#10, off record refusals would have involved hedging, but there were no clearcut instances of this strategy in the data. One AE used hedging ("I'll have to see. ..."), but continued with a fairly watertight excuse (a "big test" the next day). In context, the hedging was more a gesture of good will towards a friend than a promise to change anything. For this reason, this response was included with the category of positive politeness.

In performing the FTA baldly on record, the speaker would have stated without any mitigation why s/he did not want to accept the invitation. There were no responses of this sort in the data, although one GG response came fairly close: "Nein danke! Ich bin zur Zeit nicht so an Geselligkeit interessiert." ("No thanks! At the moment I am not so interested in being sociable."-GG4). The addressee could have taken offense at such a response. Still, because of the downgrader, "thank you", and the downtoner, "so", this response was interpreted as involving negative politeness. 
By choosing negative politeness, the speaker politely declines, using forms that acknowledge the imposition of the refusal on the addressee (e.g., statements of regret and excuses). In analyzing the responses, the following question aided in distinguishing negative and positive politeness: Could this refusal have been used in a situation of personal distance? A surprisingly large number of responses fell into the category of negative politeness, considering that it was a friend making the invitation. The reason for this may have been to avoid future invitations of this sort (involving the spouse)-or the fact that the DCT situation description provided no information on how close the friendship was. Half of the AEs, two-thirds of the GEs, and over two-thirds of the GGs used negative politeness. Despite the high frequency of negative politeness, the respondents used a casual register with the friend.

A speaker using positive politeness emphasizes the common bonds of friendship between the interlocutors. Half of the $\mathrm{AE}$ responses reflected positive politeness, primarily through the use of statements of positive opinion and a wish. By comparison, one third of the GEs had responses in this category. Two GE responses expressed positive politeness by giving the addressee a somewhat honest reason for the refusal, signalling that "we're close enough that I can tell you this" (GE1 and GE6). The other two GE responses in this category involved statements of positive opinion. Less than one third of the GGs used positive politeness. In the case of GG2, this effect was achieved through a (not completely sincere) promise of future acceptance. Three other responses expressed personal intimacy through the degree of honesty in the reasons they gave (GG3, GG6's honest variant, and GG9). In addition, GG3 preceded his responses with the word, "Du,...", the personal form 
of "you" (as opposed to the formal term, "Sie"), which serves as an intimacy marker. Both GG6 and GG9 used various means to convince the addressee that their friendship should not be harmed by the antipathy between the speaker and the hearer's spouse. Indeed, these two honest responses were the most powerful instances of positive politeness. Based on the data, it seems that white lies may preserve a lesser friendship, but honesty must prevail in a closer relationship. In a close friendship, both parties are sufficiently committed to the relationship to attempt to overcome difficulties that arise.

The fact that statements of positive opinion, though white lies in this case, served to express friendship in DCT\#10, suggests that this form serves as a marker of positive politeness.

\section{Summary of Results: Refusal of Invitation Made by an Equal-Status Interlocutor (DCT\#10)}

In DCT\#10, there was little use of the direct refusal strategies except statements of negative ability, used by almost half of the GGs. Avoidance of the direct refusal form, "no" and statements of negative willingness, by all but three subjects (one in each population group), served to protect the friend's positive face. In other words, the respondents avoided simply saying "no" or expressing unwillingness to accept the invitation.

While all the respondents used either an excuse or a reason, excuses occurred with overwhelming frequency. Obviously, refusing an social invitation requires some sort of explanation in both American and German culture. All of the AEs used excuses, compared with $83 \%$ of the GEs and $73 \%$ of the GGs. Because the initial decision made by 
respondents was the choice between telling the interlocutor the true reason for the refusal or finding a polite way to bow out, the high percentages of respondents using excuses shows an overwhelming preference for the latter strategy. The difference in the proportion of AEs and GGs who used excuses reflects differences in the degree of honesty versus avoidance of unpleasant feelings.

The themes of excuses used for DCT\#10 primarily involved obligations and activities within the speaker's more personal realm: previously planned activities and social engagements with friends (although a few responses mentioned family members or spouse) and schoolwork. Only two excuses in the data cited work-related commitments. These themes reflected the low social distance between the interlocutors, the low degree of urgency from the hearer's perspective that the invitation be accepted, and the fact that the invitation was for a Sunday evening. It should be noted that with the equal-status interlocutor, many of the respondents were "themselves" again, that is, some used excuses that would occur in their real-life situation as students.

There was also a good deal of elaboration on excuses by both the GEs and AEs. The GEs exceeded the AEs' frequency of elaborating on an excuse, a strategy used by very few GGs. In other words, the GEs “outdid" the AEs in using a strategy more typical of English NSs than German NSs, even those they had had somewhat fewer excuses upon which to elaborate. In DCT\#10, the GGs used a different means of underscoring the content of excuses from the AEs and GEs. While the AEs and GEs displayed a preference for elaboration on excuses, the GGs preferred using statements of negative ability in close association with excuses. 
A large majority of AEs used vague excuses, in contrast to the GGs who displayed a preference for specific excuses. All but one of the GE excuses were specific and fairly watertight. This extensive use of specific and watertight excuses indicates that the GEs increased the politeness of their responses (an accurate assumption, based on differences between pragmatic conventions in German and English) by making more frequent use of a strategy more typical of the GGs than the AEs. While the perception that English requires more face-saving politeness was pragmatically accurate, the GEs transferred a technique favored by German NSs for increasing politeness. The fact that this is a means of increasing politeness in German refusals of invitations is evidenced by the higher percentage of specific and watertight excuses in the GG data for DCT\#4 (with the higherstatus interlocutor) as compared with DCT\#10 or DCT\#3 (with equal- and lower-status interlocutors).

The avoidance by all three groups of face-threatening or evasive forms reflected both the fact that the hearer had in no way offended the speaker and the wish to protect the hearer's face.

While the AEs made fairly high use of the positive forms that carry the most positive content, the GEs made moderate use thereof, and the GGs rather little use. This, too, ties in with the issue of honesty. The Americans used the social nicety of white lies much more frequently than the Germans. Apparently they felt more compelled to say something friendly, whether they meant it or not. As for the GGs, they may have avoided a face threat by either making up an excuse or using a real excuse to cover the unpleasant truth about disliking the spouse, they did not perceive a need to add a dishonest, if "nice" 
expression of positive feelings. The GEs, once again, were careful to avoid being offensive, thus they did not state the honest reason for the refusal. Like the GGs, however, they avoided telling white lies unnecessarily. In this regard, then, the GEs' responses more closely resembled the GGs' than the AEs', but they were not as different from the AEs as the GGs were.

As noted above, statements of positive opinion and wishes were white lies in the case of DCT\#10. Thus, they served as a marker of positive politeness, a formula for refusing a friend's invitation, rather than an honest expression of the speaker's true feelings. The AEs' frequent use of this form reflects a tendency on the part of American speakers to say friendly things they do not mean in order to protect the hearer's face and maintain social harmony. Only two GEs chose this strategy. The fact that so few GEs used this form suggests the strength of cultural conventions, the German value of honesty and directness rather than comfortable "nice"-ness.

The GEs used a somewhat more limited range of different types of positive forms than the other two groups.

Practically none of the AEs used downgraders, which were favored somewhat more by the GGs. The GEs, on the other hand, made fairly substantial use of them. This appears to reflect an accurate GE perception that such a refusal needs to be presented with greater tactfulness in English than in German. Using this particular means of increasing politeness, which was more typical of German than American English, however, involved transfer. 
The fact that almost all the GE downgraders were conjoined with functional categories that were already polite, in contrast to the other two groups, suggests hypercorrection. In other words, in trying to achieve NS-like levels of politeness, they went beyond the NSs' degree of politeness in regards to use of downgraders.

While the GGs made considerably less use of positive forms than the other two groups, they chose mitigating adjuncts more frequently. In other words, compared to the GEs and AEs, the GGs were more sparing with the forms that contain the stronger positive content, and more likely to use the weaker forms of mitigation.

Examination of the responses in terms of FTA research revealed the somewhat greater formality and restraint on the part of the German subjects and the stronger tendency amongst the AEs to emphasize social bonds, even at the expense of honesty. While the AEs expressed positive politeness through white lies, the GGs did so through a degree of honesty that signalled personal closeness. The GEs found middle ground between the two positions.

Usage patterns of the various refusal strategies and adjuncts reflected preferences amongst the subject populations for either maintaining social ties with the friend or avoiding dishonest, if "nice", face-saving remarks. The data revealed an emphasis on avoiding social friction on the part of the AEs, and an avoidance of dishonest remarks on the part of the GGs, even at the expense of appearing more reserved. The GEs displayed characteristics of both $\mathrm{GG}$ and $\mathrm{AE}$ responses, with two white lies and two relatively honest reasons, although they were certainly much more restrained in the use of friendly lies than the AEs. 


\section{DCT \#4: Refusal of Higher-Status Interlocutor's Invitation}

\section{Frequency of Functional Categories}

In DCT\#4, there was complete avoidance of the harsher direct refusal strategies, with moderate use of forms that express inability. The GEs used these forms somewhat less than the AEs or GGs. The use of performatives was unusual in the DCT overall, but appeared in one fourth of the $\mathrm{AE}$ responses and in one GG response.

All of the performatives used in DCT\#4 occurred in conjunction with downgraders (i.e., modals such as 'must' or 'have to') and thus functioned as negative ability: ."..I must therefore decline." (AE1); .".I have to decline..." (AE3); ...I'll have to say no. ..." (AE12); .".ich [muß] ... absagen." ("I must ... decline."-GG2). Because performativesplus-downgraders belong to a more formal register, they are analyzed as being more polite forms than statements of negative ability. As the table below shows, the three groups used these strategies with similar frequency. The major difference lay in the AEs' moderate use of performatives conjoined with downgraders, unlike the two groups of Germans.

Table 4. 55: Use of Direct Refusal Strategies; Invitation; Higher-Status Interlocutor (DCT\#4)

\begin{tabular}{|l|l|l|}
\hline & Performative & Negative Ability \\
\hline AEs & $25 \%$ & $17 \%$ \\
GGs & $7 \%$ & $36 \%$ \\
GEs & - & $33 \%$ \\
\hline
\end{tabular}

The most important strategy in responses to DCT\#4 was the excuse. All but one of the subjects used this form (and the one GG who did not use an excuse used hedging plus elaboration on the hedging which resembled an excuse, i.e., which underscored the speaker's inability to accept the invitation). None of the respondents used reasons for this 
DCT item, reflecting their effort to emphasize inability rather than unwillingness. As noted above, excuses are generally a very polite strategy, as they explain circumstances preventing the speaker from accepting the invitation and suggest that it is the speaker's wish to accept, but that $\mathrm{s} / \mathrm{he}$ is hindered by circumstances outside his/her control.

One GG respondent used a statement of principle in DCT\#4. It functioned as elaboration on an excuse: ."..Was ich meiner Frau verspreche, halte ich auch meistens ein." (."..I usually keep my promises to my wife."-GG4).

Table 4. 56: Use of Excuses and Statement of Principle; Invitation; Higher-Status Interlocutor (DCT\#4)

\begin{tabular}{|l|l|l|}
\hline & Excuse & Principle \\
\hline AEs & $100 \%$ & - \\
GEs & $100 \%$ & - \\
GGs & $93 \%$ & $7 \%$ \\
\hline
\end{tabular}

Face-threatening strategies played a very minor role in responses to DCT\#4, both in terms of the number of respondents using such functional categories and in the degree of directness of the forms used. The only face-threatening strategy used in DCT\#4 was the guilt trip, and all guilt trips were implied by way of other strategies. AE1 used an excuse as an indirect guilt trip: .".such short notice puts me into a bind...", while three respondents used the set condition strategy as indirect guilt trips: .".If I'd had more notice, I probably would've been able to make it." (AE10); .".If I'd only known before (earlier)." (GE12); and, .”.. Zu dumm, daß es so kurzfristig ist, sonst könnte ich noch die (...echte / unechte Ausrede / Begründung) .. absagen." (.".. What a drag that it's such short notice, otherwise I could still cancel the (...real / false excuse / reason..)."-GG6). 
Table 4. 57: Use of Strategies that Increase the Face Risk; Invitation; Higher-Status Interlocutor (DCT\#4)

\begin{tabular}{|l|c|}
\hline & Guilt Trip \\
\hline GEs $^{44}$ & $8 \%$ \\
GGs & $7 \%$ \\
AEs & $17 \%$ \\
\hline
\end{tabular}

There was only one instance of an evasive strategy in all the responses to DCT\#4.

The one GG who used the strategy of hedging also elaborated on this hedging, explaining why he was unable to decide at that moment whether to accept or refuse: .".doch muß ich gestehen eine feste Zusage nicht treffen zu können, da ich für meinen Partner nicht kurzfristig eine Entscheidung treffen möchte." (.”..but I must confess that I am unable to make a firm commitment, because I wouldn't like to make a decision for my partner on short notice."-GG3).

Use of positive forms and adjuncts characterized responses to DCT\#4, creating a display of politeness towards the higher-status interlocutor. Of the stronger positive forms, the AEs displayed a preference for statements of positive opinion, the GEs favored expressions of regret, and the GGs used statements of gratitude most frequently. All three groups made frequent use of downgraders; however, the percentage of $\mathrm{AE}$ downgraders was almost twice as high as GG and GE instances of this form.

One $\mathrm{AE}$, one $\mathrm{GE}$, and one $\mathrm{GG}$ used intensifiers with their statements of gratitude: ...really, thank you for the invite..." (AE5); .".vielen Dank für die Einladung. ..." (.".thank you very much for the invitation. ...") (GG9); and, "Thank you very much for the invitation..." (GE10). Two GGs and one GE used intensifiers with statements of

\footnotetext{
${ }^{44}$ The reason why the GEs are placed above the GGs in the table is because the GE guilt trip was milder than the GG one.
} 
regret: "Das bedauere ich nun sehr..." ("I regret this very much...") (GG13); "Das tut mir nun wirklich sehr leid..." ("I'm really very sorry...") (GG14); and, "I'm very sorry..." (GE2).

Table 4. 58: Use of Positive Adjuncts/Forms; Invitation; Higher-Status Interlocutor (DCT\#4)

\begin{tabular}{|l|l|l|l|l|l|l|l|}
\hline & $\begin{array}{l}\text { Positive } \\
\text { Opinion }\end{array}$ & Gratitude & Regret & Promise & Wish & Downgrader & Total \\
\hline AEs & $42 \%$ & $25 \%$ & $25 \%$ & $8 \%$ & $8 \%$ & $75 \%$ & $183 \%$ \\
GEs & $33 \%$ & $17 \%$ & $58 \%$ & - & $8 \%$ & $42 \%$ & $158 \%$ \\
GGs & $14 \%$ & $36 \%$ & $29 \%$ & $7 \%$ & - & $43 \%$ & $129 \%$ \\
\hline
\end{tabular}

Compared to the other two groups, the GEs made fairly frequent use of pause

fillers. This might be related to other research findings that German speakers of English tend to think of the pause filler, "well" as "typically English." In any case, they chose a strategy that was used only slightly by the GGs and not at all by the AEs, and doubled the frequency of use in an effort to mitigate the refusal. They sensed a need to mitigate the refusal but chose a means not used by the NSs of English.

As noted in Chapter 3, repetition of part of the invitation resembles other mitigating adjuncts in function and effect. Like pause fillers, repetition allows the speaker

\footnotetext{
${ }^{45}$ One $\mathrm{AE}$ remark seemed to be a mixture of downgrader and forewarn. It was coded as a downgrader rather than a forewarn because the primary intention of the speaker was to soften the blow of the FTA that followed: "I can try, but I don't think I can make it. ..." (AE11). Some downgraders can serve to forewarn as well as mitigate, e.g., when the downgrader, "unfortunately", is used, something negative is obviously about to follow, but the focus is on mitigation.

${ }^{46}$ One GE used a remark that could have been interpreted as either an expression of gratitude or a statement of positive opinion: “...I'm very honoured about your invitation" (GE1). As discussed above in DCT\#3 (see Content, Positive Forms), such forms are frequently used in German to express gratitude. Thus, this appeared to be an expression of gratitude - and an instance of transfer.
} 
to take a moment to consider the invitation before responding. Like the forewarn, it prepares the hearer for bad news. Like downtoners (and downgraders), repetition softens the impact of the refusal, but it lacks the clearly positive or sympathetic content of downgraders. Repetition can be used in an evasive manner (as was probably the case with GE10 in DCT\#10), not this is not necessarily always true. Both instances of repetition in DCT\#4 used the same words: "Nächsten Sonntag? ..." (GG1) and "Next Sunday? ..." (AE6) and appeared to serve the function of mitigating the refusal without adding an evasive element.

Table 4. 59: Use of Mitigating Adjuncts; Invitation; Higher-Status Interlocutor (DCT\#4)

\begin{tabular}{|l|l|l|}
\hline & Pause Filler & Repetition \\
\hline GEs & $33 \%$ & - \\
GGs & $14 \%$ & $7 \%$ \\
AEs & - & $8 \%$ \\
\hline
\end{tabular}

Only amongst the GG population were there respondents who used no positive forms. As the table shows, a number of respondents used more than one positive form to create more polite refusals.

Table 4. 60: Number of Positive Adjuncts/Forms per Response; Invitation; HigherStatus Interlocutor (DCT\#4)

\begin{tabular}{|l|l|l|l|l|l|l|l|l|}
\hline & $\mathbf{0}$ & $\mathbf{1}$ & $\mathbf{2}$ & $\mathbf{3}$ & $\mathbf{4}$ & $\mathbf{5}$ & $\mathbf{6}$ & $\mathbf{7}$ \\
\hline AEs & - & $33 \%$ & $50 \%$ & - & $17 \%$ & - & - & - \\
GEs & - & $58 \%$ & $25 \%$ & $17 \%$ & - & - & - & - \\
GGs & $21 \%$ & $42 \%$ & $21 \%$ & $7 \%$ & - & - & - & $7 \%$ \\
\hline
\end{tabular}

Once again, the GGs ranked lower in use of positive forms and higher in use of mitigating adjuncts thans the AEs. The AEs' extremely low use of mitigators was in

\footnotetext{
${ }^{47}$ One GE remark was interpreted as a wish. This particular GE used a somewhat ambiguous form: "If there'd be any chance I'd come" (GE3). It was assumed that what he intended to say was: "If it were possible, I'd come", which functions as a wish.
} 
reverse proportion to their extensive use of positive forms and adjuncts. The GEs used mitigating adjuncts with moderate, and positive forms with high frequency.

Table 4. 61: Number of Mitigating Adjuncts per Response; Invitation; HigherStatus Interlocutor (DCT\#4)

\begin{tabular}{|l|l|l|}
\hline & $\mathbf{0}$ & $\mathbf{1}$ \\
\hline GEs & $67 \%$ & $33 \%$ \\
GGs & $79 \%$ & $21 \%$ \\
AEs & $92 \%$ & $8 \%$ \\
\hline
\end{tabular}

\section{Content of Functional Categories}

Excuses: Under the given circumstances of DCT\#4 (the boss inviting the employee to a party on a Sunday), the range of possible "convincing" excuses was somewhat limited. Obviously, work-related obligations could not be used with the boss and would be unlikely on a Sunday (under normal conditions), so the excuses had to be of a more personal nature. Means of increasing the watertightness of excuses included: going out of town, having a special event in the family, such as a birthday, receiving guests from outof-town, and focusing on family commitments.

The themes of the $\mathrm{AE}$ excuses involved commitments to and plans with spouse or family (six subjects), trips out of town (three subjects), and a husband who "isn't much of one for parties."

Half of the $\mathrm{AE}$ excuses were vague, referring to "other plans", "other commitments", and the like. Three vague excuses suggested advance planning through use of the word, "already": .".my wife (spouse) and I have already made plans..." (AE3),.". I already made other plans" (AE8), and .".. My husband and I have had plans for this weekend already" (AE11). In one excuse, the word, "commitments" suggests that the 
excuse entails more than mere "plans": .".I've got some other commitments on Sunday. ..." (AE10). One AE asserted that .".. such short notice puts me into a bind..." (AE1), but did not specify what the conflicting commitment was. Being in "a bind" suggested that the excuse was peremptory. One vague excuse had an added statement of urgency: ."..plans that I'm committed to." (AE2).

The six more specific excuses involved: going to the mountains with his wife (AE4); having in-laws come to visit (AE5); going on a weekend campout for his son's birthday (AE6); having plans to go out of town (AE7); visiting her boyfriend's parents (AE9); and a husband who dislikes parties (AE12). Of the specific excuses, two involved an important commitment or event (in the respondent's estimation): AE5 went into enough detail to sound serious: .".my wife's family is coming into town \& we have plans for that evening.", and AE6 spoke of a commitment to his son: .".but it's my son's birthday and we've made a date to go on a weekend campout.." One AE used the modal, "have to" to make a social engagement sound like an obligation: .".I have to visit my boyfriend's parents that day." (AE9). On the other hand, AE12's excuse, "My husband isn't much of one for parties...", would seem to be a less acceptable excuse from the addressee's perspective. Also, in such a case, the speaker might have been expected to offer to come to the party alone in order to maintain face-saving politeness. This lack of protection of the hearer's face seems to be characteristic of AE12's personal style (See discussion of DCT\#12, content, face-threatening strategies.).

In the GG data, eleven excuses involved commitments to or plans with spouse or family, and six cited out-of-town trips (These grounds for refusing overlapped in some 
responses.). As noted above, the one respondent who did not use an excuse instead used hedging with elaboration (GG3). This strategy resembled an excuse by stressing the speaker's inability to accept the invitation (i.e., he could not make a commitment without first consulting his spouse): ...doch muß ich gestehen eine feste Zusage nicht treffen zu können, da ich für meinen Partner nicht kurzfristig eine Entscheidung treffen möchte." (."... but I must confess that I cannot make a firm commitment because I would not like to make a decision for my partner at short notice.").

Only three GGs used vague excuses, and they gave more information than the AEs' vague excuses. Even the vague GG excuses were worded in ways that made them seem watertight. In GG2's response, ."..leider muß ich aus familiären Gründen absagen." (.".unfortunately I must decline because of family reasons."), "family reasons" implied serious circumstances, not just a trip to the store or an afternoon in front of the television. GG9 used a nonspecific but urgent excuse (the kind that typified GG responses to DCT\#12), stating that she had an important commitment, but not specifying with whom or for what purpose: .".Leider habe ich schon anderweitig eine wichtige Zusage gemacht, und ich befürchte, dort nicht absagen zu können. ..." (."..Unfortunately, I’ve already made another important commitment, and I'm afraid I can't cancel it. ..."). A third respondent did not specifically write an excuse, but noted that he would use one in that situation: ...sonst könnte ich noch die (...echte / unechte Ausrede / Begründung).. absagen." ( ...otherwise I could still cancel the (...real / phony excuse / reason).."-GG6). By implication the response suggested that the excuse involved something too important to be cancelled at short notice. 
GG7's excuse was partially vague, but provided enough information to sound watertight: .". Aber an diesem Wochenende bin ich gar nicht in der Stadt." (.".. But this weekend I won't even be in town.").

Ten excuses were specific, and a large proportion of these (eight or nine) were watertight, involving a serious commitment or important event. In some of these cases, the speakers had made plans long in advance or plans which could not be changed, or were going to be very far away. Other excuses stressed the importance of family commitments. Advance plans with spouse, family, or relatives included: .".aber ich gehe mit meiner Familie zum Circus und habe dafür schon die Karten." (."..but I'm going to the circus with my family and already have the tickets"-GG5); "Am Wochenende wollten mein Mann und ich wegfahren und das Hotelzimmer ist jetzt leider schon gebucht." ("My husband and I wanted to go away for the weekend and unfortunately, the hotel room is now already booked."-GG10); ...Wir haben nun schon geplant am Wochenende zu unseren Verwandten zu fahren..." (."..We've already planned to go to our relatives this weekend..."-GG11). This response implied that the speaker was going out of town and was going there with her family ("we"). Some excuses involved important family commitments: "Sonntag geht bei mir auf gar keinen Fall. Unsere kleine Tochter hat Geburtstag. ... es geht wirklich nicht." ('Sunday is absolutely out of the question for me. It's our little daughter's birthday. ... it's really not possible.")-GG1). The urgent forms surrounding the excuse in GGl's response and the fact that it was the speaker's "little" daughter made the excuse harder to resist. Although GG8's excuse also involved an immediate family member's birthday, the excuse was somewhat less effective than GGl's 
in terms of watertightness: "Am nächsten Sonntag geht es bei mir und meinem Mann nicht, da meine Mutter Geburtstag hat." ("Next Sunday won't work for me and my husband because it's my mother's birthday."). One excuse involved both a spousal commitment and advance planning: "Meine Frau und ich haben schon ein gemütliches Wochenende in der Schweiz geplant. Was ich meiner Frau verspreche, halte ich auch meistens ein." ("My wife and I have already planned a cozy weekend in Switzerland. I usually keep my promises to my wife."-GG4). Another excuse used both advance planning and an important occasion: ."..mein Ehemann u. ich haben schon seit Anfang des

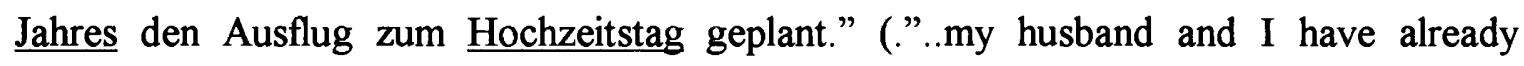
planned our anniversary trip since the beginning of the year."-GG13). Long-distance travel and a major family event appeared in one excuse: "Gerade dieses Wochenende muß ich zu einem Familienfest nach Paris" ("It just so happens that this weekend I must go to Paris for a family reunion."-GG12). GG14 spoke of an important event that was also a spousal commitment: .". Am Sonntag ist die Eröffnung zur kommenden Ausstellung meines Mannes." (.". The opening of my husband's upcoming exhibition is on Sunday.").

The GE data contained no vague excuses. All twelve excuses were specific. Ten excuses involved spouse or family. Four excuses had to do with going out of town, one was about business responsibilities ${ }^{48}$, and one respondent said he was going fishing (GE4). Specifically, the GEs' excuses included going skiing with the children (GE5), already

\footnotetext{
${ }^{48} \mathrm{GE} 3$ 's excuse (quoted in the text) was implausible in the given situation. If the employee were scheduled to sign a contract with a company in Denver and expected to be away for at least three days, the boss would certainly know about this and would not extend the invitation in the first place. The respondent apparently did not fully understand this DCT situation.
} 
having tickets to the National Theatre (GE6), his wedding anniversary (GE1), a relative's birthday (GE2), a visit to her parents-in-law (GE7), visiting her parents (GE8 and GE9), her father's birthday (GE10), her sister's wedding (GE11), going to Denver on an important and lengthy business trip (GE3), a trip to New York for an unspecified reason (GE12), and going fishing (GE4). Only the latter excuse appeared to be too frivolous to protect the addressee's face: .".me \& my friends are going fishing this very day...." Elaboration, however, could have remedied that shortcoming, e.g., the speaker could have said that months ago, he made plans to go on a special fishing trip with friends he rarely sees.

Ten of the respondents made their excuses hard to challenge by choosing an important event, adding remarks emphasizing the difficulty of changing their plans, or letting the hearer know that the plans had been made in advance or that the speaker would be out of town. Events included: ."..my wife and me, we have our wedding-day today." (GE1); .".. It's my father's 60th birthday ..." (GE10); and, ."..it's my sister's wedding. ..." (GE11). Added remarks included: ."..But I'm leaving for Denver on fryday to sign this treaty with Baher Inc. I think this will take a longer time so I'm probably not here on Sunday. ..." ${ }^{49}$ (GE3); ."..My husband bought tickets for the National Theatre, it's the last chance to see the play and I promised to join him." (GE6); .". I promised my parents to visit them next Sunday, and I can't tell them so shortly before that I won't come." (GE8); and .". I told my parents that I would visit them that weekend." (GE9). Comments about advance plans or being out of town included: .".we've already made plans for the

\footnotetext{
${ }^{49}$ See previous footnote.
} 
weekend. We'll go skiing with out children." (GE5. This remark additionally carries the affective impact of not wanting to disappoint the children); ."..we both are invited to my

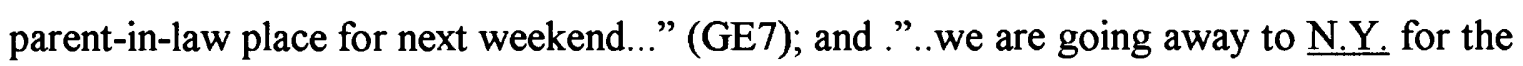
weekend..." (GE12).

Mention of Short Notice: As an indication of honesty and directness, the choice to mention being invited at short notice is important in the discussion of content. This is not to say that respondents who did not bring up the issue were not honest and direct. Perhaps it was not an important consideration for them. Those who did however choose to remark on it demonstrated a willingness to confront the boss, at least to a small degree.

Two AEs remarked on the short notice, implying an indirect guilt trip with, in one case, an excuse, and in the other, a set condition: .".but such short notice puts me into a bind..." (AE1); and, "If I'd had more notice, I probably would've been able to make it." (AE10). It is important to note that in both cases, only the offending act was mentioned, but there was no reference to the addressee as offender. This is important in terms of saving the addressee's face. The remarks could be interpreted as mild, implied reproaches. Only one GG remarked on the last-minute invitation, linking an indirect guilt trip to an excuse. Like the two AEs, he also referred only to the act, but not the perpetrator: " $\mathrm{Zu}$ dumm, daß es so kurzfristig ist, sonst könnte ich noch die (...echte /unechte Ausrede / Begründung).. absagen." ('What a drag that it's such short notice, otherwise I could still have canceled the (...real / phony excuse / reason)')-(GG6). Here the reproach is somewhat more apparent than in the AE examples because of the opening, "zu dumm" ("how dumb", "too bad", "what a drag"). Still, the addressee could easily choose to ignore 
the hint of a reproach. Two GE responses brought up the issue of short notice, but the allusions were so indirect that they could hardly be interpreted as guilt trips: ."..and I can't tell them so shortly before that I won't come." (GE8); "If I'd only known before (earlier)." (GE12). It is unlikely that an addressee would perceive either of these remarks as a face-threat. Since so few responses referred to short notice, it is not really possible to make any cross-cultural generalizations.

FTA Strategies: The one off record response to DCT\#4 involved hedging. A refusal without redress would have involved a face-threat or a clear choice not to come to the boss' party and no mitigation of the refusal; there were, however, no true instances of this strategy in the data. Negative politeness consisted of giving a convincing but not too intimate excuse for impeding the hearer's plans to have all the executives present at the party and/or using restrained positive forms as politeness markers (maintaining social distance). In DCT\#4, positive politeness was expressed through a less formal register and positive forms that emphasized the speaker's interest in being at the party.

All of the AE responses used negative politeness as the major strategy, although five responses contained elements of positive politeness. Only one response contained pronounced positive politeness: AE5's enthusiastic statement of positive feeling and convincing expression of gratitude, along with the personal tone of the response created this effect of genuine personal interest. While the use of statements of positive feeling by AE3, AE7, and AE9 and a wish by AE6 could be considered elements of positive politeness, in context, these forms resembled a polite formula more than an actual commitment to the positive sentiment. 
Only one GG made his refusal off record through the use of hedging (GG3). All of the other GGs used negative politeness, which was also reflected in the formal register of many of their responses. None of the responses contained an element of positive politeness, although three responses (GG4, GG8, and GG12), with their lack of mitigating forms, bore a similarity to refusals made baldly on record (Responses containing excuses, however, would not be considered "baldly on record").

Negative politeness characterized all of the GE responses. One GE response (GE4) appeared to include positive politeness through a statement of positive feeling as well as negative politeness, but it was hard to judge the response along these lines because of the inappropriate excuse ("going fishing"). Two other GEs used statements of positive feelings, but these both sounded more formulaic than genuinely warm.

\section{Summary of Results: Refusal of Invitation Made by a Higher-Status Interlocutor (DCT\#4)}

In DCT\#4, practically all strategy choices were indicative of conscious efforts to maximize politeness, and minimize the face threat to the higher-status interlocutor. Responses were designed to avoid giving any impression of unwillingness to accept the invitation. Respondents of all three groups used only the direct refusal strategies that are associated with inability, eschewing statements of negative willingness and the direct form, "no." Furthermore, other strategies that express unwillingness (i.e., reasons and facethreatening strategies) were completely avoided. All respondents but one gave an excuse (emphasizing inability), and almost half of the AEs and GGs and a third of the GEs used a 
direct refusal form conveying inability. Use of positive forms also played an important role in responses.

The three groups were fairly close in their frequency of use of direct strategies expressing inability, the major difference being the AEs' greater preference for the more formal and more polite performative-plus-downgrader formula. The appearance of performatives conjoined with downgraders in one fourth of the $\mathrm{AE}$ responses and in one GG response served a number of functions: contributing to a formal register, expressing a strong effort to be polite, and strengthening the refusal.

As noted above, the circumstances of the DCT item ruled out work-related excuses, so the themes of the excuses revolved around family or spousal commitments, and trips out of town.

Half of the $\mathrm{AE}$ excuses were vague and the other half were specific. Almost all the vague excuses were mildly strengthened through various means. Of the specific excuses, two involved an important commitment or event and one used the modal, "have to", in a way that suggested that the social engagement cited was an obligation. All in all, some effort was made to produce convincing excuses, but the AEs did not over-exert themselves creating watertight excuses. By contrast, not only did very few GGs (less than one fourth) use vague excuses, but the vague GG excuses provided more information than their vague $\mathrm{AE}$ counterparts, and they were constructed in such a way as to create an illusion of watertightness. Most of the GG excuses were specific and the majority of those were watertight. Many of the GGs further increased the watertightness of their excuses through additional remarks about having made plans long in advance, about the great 
difficulty of cancelling their plans, or about long-distance travel. None of the GEs used vague excuses-all GE excuses were specific and most of them were watertight. Like the GGs, the GEs tended to choose important events and add remarks that made their excuses impervious to challenge.

The degree of commitment to the content of the excuse is important because it determines the stability of the refusal in case it is challenged. In other words, it determines how easy or difficult it might be for the addressee to persuade the speaker to change his/her plans. In addition, when refusing an individual of higher status (in this case, the boss), a lot of cultural perceptions come into play: How acceptable is it to refuse the boss' invitation? Must compelling factors prevent one from coming, or is a more ordinary excuse sufficient? The speaker needs to provide a convincing excuse so that the boss isn't offended, but the boss cannot really force the employee to attend a social event, so "watertight" does not necessarily mean "impossible circumstances" in responses to DCT\#4. Apparently, the majority of the AEs had a greater expectation than the Germans that any fairly reasonable excuse would be accepted by the hearer. They evidently did not feel a need to placate the boss and secure their refusal by having watertight excuses, while both groups of Germans demonstrated a strong concern for providing highly convincing, watertight excuses.

Along the same lines of maximizing face protection and politeness, facethreatening and evasive strategies were eschewed in DCT\#4, except for four indirect (and fairly innocuous) guilt trips addressing the short notice of the invitation, and one very apologetic instance of hedging. At the same time, positive forms figured prominently in all 
three groups' responses to DCT\#4. Regarding each group's preference for a particular positive form, the German subjects made greater use of expressions of gratitude and regret, which are a little more reserved than statements of positive opinion, favored by the AEs (but also used by a number of GEs). With a statement of positive opinion, the speaker says that s/he would have liked to accept the invitation. This represents more of a commitment to the positive content than an apology or expression of gratitude, but can also be a social routine without much depth of sincerity. While the GEs and GGs made frequent use of downgraders, the AEs used them with almost twice the frequency of the two German groups. All in all, it appears that, while the Germans used more solid excuses than the AEs as a means of providing face protection, the AEs focused more on conveying politeness through positive forms and performatives conjoined with downgraders than the Germans.

There was little use of mitigating adjuncts except for the responses of one third of the GEs, who used pause fillers. As in a number of other DCT items, the GGs made the least use of positive forms, but second-highest (or in some cases, such as DCT\#10, highest) use of mitigating adjuncts of the three groups, suggesting a comparative preference for weaker means of mitigating the FTA and dispreference for stronger forms. The AEs made almost no use of mitigators, having made very extensive use of positive forms. In addition to high use of positive forms, the GEs also made fairly frequent use of mitigating adjuncts, incorporating elements of both German and English preferences for softening refusals. 
As one might expect in such a situation, the primary FTA strategy in DCT\#4 was negative politeness, used by all but one of the subjects (One GG refusal was off record.). While all the GEs' responses (except perhaps one) fit quite tidily in the category of negative politeness, almost half of the AEs colored their responses somewhat with positive politeness. On the other hand, because they lacked mitigation, a fifth of the GG responses contained an element of a refusal performed baldly on record.

All in all, the level of politeness was fairly similar in the responses of all three groups. AE use of positive forms was stronger than in the other two groups, and the GGs made the least use thereof, but the difference was not dramatic.

\section{Refusals of Offers}

DCT\#7: Lower-Status Interlocutor Offers to Pay for Broken Vase

DCT\#9: Equal-Status Interlocutor Offers Friend Another Piece of Cake

DCT\#11: Higher-Status Interlocutor Offers Employee a Promotion Involving Relocation to a Small Town ${ }^{50}$

DCT\#7 differs significantly from all other situations in the test because it is the only case in which the refusal is to the addressee's advantage. Acceptance of the offer would pose a hardship for the addressee (paying to replace an object she can't afford). For this reason, certain functional categories shift in terms of quality, e.g., a bald "no" does not pose a face threat, agreement is negative rather than positive (because it is agreement

\footnotetext{
${ }^{50}$ For more information, the text of the DCT can be found in Appendix A, Discourse Completion Test.
} 
that the cleaning lady has caused something bad to happen), and an imperative to rescind the offer is favorable, not uncooperative.

The breaking of the vase by the cleaning lady was unintentional, she is obviously contrite about the mishap, and she is scarcely able to pay for it. For these reasons, and perhaps because students are also often at the bottom of a pecking order, the respondents (who were all students) expressed considerable solidarity with this interlocutor. Another piece in the puzzle of DCT\#7 is the great socioeconomic distance between speaker and hearer, the financially struggling cleaning lady on the one hand, versus the employer, who is sufficiently well-off to afford an expensive vase and regular house-cleaning services. On the other hand, they are close enough socially for the speaker to know about the cleaning lady's personal circumstances.

DCT\#9 differs from the other items on the DCT because it consists of two response sections, the reply to the friend's first offer of another piece of cake, and the rejoinder to the second, "urging" offer. A further difference is that DCT\#9 allows for acceptance of the offer in the second section.

A respondent's reaction to the friend's second offer of more cake in DCT\#9 would probably depend on how $\mathrm{s} / \mathrm{he}$ perceives this offer. Is it simply a social courtesy, the solicitousness of a host/ess making sure the guest's wishes are fulfilled-or is it a lack of sensitivity to the first refusal? In the first case, responses would probably reflect a greater concern for politeness than in the second case, in which some negativity might be expressed. 
For the hearer it is of little consequence whether or not the speaker agrees to take another piece of cake. From the speaker's standpoint, reluctantly consenting to have more cake would not be a tremendous adversity, but it would involve the discomfort of eating more than one wants, and possibly feeling pressured to do so. This would be an imposition, albeit of fairly limited duration. Because of the lack of urgency on either side of the interaction, the speaker can choose rather mild, non-watertight means of refusing.

In DCT\#9, the interlocutors are not necessarily very close friends. The fact that the guest is being served suggests that this is not the most informal situation (and there are no contextual cues to the contrary). This trace of social distance expressed itself in the subjects' responses through standard formulas of politeness, e.g., 'No, thank you...'.

Another consideration in approaching responses to DCT\#9 involves intercultural differences. In Germany, it is much more common to have friends over for cake than in the United States. The institution of having Kaffee und Kuchen ("coffee and cake") on a weekend afternoon (whether at a cafe or at home) is widespread, thus this situation may be more ritualized in German contexts than it would be in the United States.

The offer of a promotion involving relocation in DCT\#11 involves a positive component for the speaker, namely, being considered worthy of such a post. Although the relocation may be undesirable, the offer is otherwise attractive and flattering. It is obviously in the speaker's interest to be agreeable in order to keep the door open for future job advancement. Thus, speakers are likely to refuse in such a way that would not obstruct any future offers that might be more attractive. Positive adjuncts and forms, such as expressions of gratitude, positive opinion, or regret can be expected to occur with high 
frequency. In addition, respondents are unlikely to directly criticize the unattractive aspect of the offer, that is, the relocation to an unappealing locale. Refusal of the job promotion involving relocation is disadvantageous to the boss offering it, but probably not a severe hardship. The refusal must, however, be firm, because of the extensive imposition that unwilling acquiescence would entail.

Social distance is usually inherent in the boss-employee relationship. If, however, the employee is being considered for a promotion that would confer higher status and greater responsibility, the interlocutors have obviously been working together for some period of time and have established a good working relationship. Thus, one could assume that speaker and hearer are not excessively distant.

\section{DCT \#7: Refusal of Lower-Status Interlocutor's Offer}

\section{Frequency of Functional Categories}

Direct refusal strategies were practically absent from DCT\#7. The sole functional category used was "no", and it appeared only in the responses of two GGs and one AE. All of the "no" responses were softened by mitigators: "Oh no..." (AE2); "Nein, nein..."51 ("No, no..." GG9); and, "Ach nein..." (“Oh no...", GG11). All of them functioned as remarks letting the interlocutor off the hook.

\footnotetext{
${ }^{51}$ Nein, nein is considerably gentler than nein ('no').
} 
Table 4. 62: Use of Direct Refusal Strategies ${ }^{52}$; Offer; Lower-Status Interlocutor (DCT\#7)

\begin{tabular}{|l|l|}
\hline & "No" \\
\hline GGs & $14 \%$ \\
AEs & $8 \%$ \\
GEs & - \\
\hline
\end{tabular}

All of the statements of philosophy (with one exception-see discussion of content) functioned as remarks intended to let the interlocutor off the hook. These types of responses are presented separately from other "off the hook" tokens because this pattern was distinctive and ubiquitous enough to warrant differentiation. Also, the content differed between statements of principle and other "off the hook" remarks, in that subjects were giving a philosophical reason for letting cleaning lady off the hook. A further argument for making separate categories for "off the hook" and "philosophy = off the hook" remarks lies in the fact that the respondents did not generally make chains of "off the hook" remarks (several in a row). Chains of remarks alternating between "off the hook" and "philosophy $=$ off the hook", on the other hand, were more acceptable. An example from the data illustrates this point: .".. It is not your fault, that could have happened to anybody. You don't have to pay for that. Forget about it. Don't worry, that's o.k." (GE7). The first three tokens sound fine-and they alternate between "off the hook" and "philosophy = off the hook." But the string of four "off the hook" utterances at the end of the response created a rather awkward effect.

\footnotetext{
${ }^{52}$ As noted above, the "positive / negative" character of various functional categories changed in DCT\#7. These changes are reflected in the distribution of functional categories in the various groupings of "face-threatening" and "positive" strategies. In this particular table, the GGs are listed first, as having made the greater effort to use a polite form, because in DCT\#7, a direct refusal constitutes a favorable response, releasing the interlocutor from the obligation to replace the broken vase.
} 
One GG used elaboration on a statement of philosophy: .".. Das kann ja mal passieren. Das ist ja menschlich." ("That [sort of thing] can happen sometimes. It's only human."-GG12).

Like statements of philosophy, the strategy of diminishing the value of the damaged object also functioned as a means of letting the hearer off the hook.

Table 4. 63: Use of Statements Diminishing the Value of the Damaged Object and Statements of Philosophy/Principle ${ }^{53}$; Offer; Lower-Status Interlocutor (DCT\#7)

\begin{tabular}{|l|l|l|}
\hline & Diminish Value & Philosophy \\
\hline GEs & $67 \%^{54}$ & $42 \%$ \\
AEs & $50 \%$ & $50 \%$ \\
GGs & $43 \%$ & $50 \%$ \\
\hline
\end{tabular}

The strategy of diminishing the value of the damaged object actually played a much stronger role for the two German groups than is reflected in the table above. A number of responses included elaboration or more than one remark diminishing the value of the vase. The following table shows the overall percentage of use of this strategy and elaboration thereupon.

\footnotetext{
${ }^{53}$ There was no use of excuses or reasons in DCT\#7, but these two functional categories (diminishing the value of the damaged object and statements of philosophy) represent strategies related to excuses and reasons.

${ }^{54}$ One GE made a statement letting the interlocutor off the hook that could have been interpreted as involving a hint of the "diminish value" strategy: “...I even don't know how expensive it was, we bought them such a long time ago." (GE8). Because the remark did not unambiguously devalue the vase, it was not included in this tally.
} 
Table 4. 64: Use of Statements Diminishing the Value of the Damaged Object and Elaboration on this Strategy; Offer; Lower-Status Interlocutor (DCT\#7)

\begin{tabular}{|l|l|}
\hline & Diminish Value \\
\hline GGs & $79 \%^{55}$ \\
GEs & $75 \%$ \\
AEs & $50 \%$ \\
\hline
\end{tabular}

While none of the AEs used more than one statement diminishing the value of the vase, one GE and two GGs used two such statements (GE2; GG7, GG10), and one GG used elaboration twice in addition to two "diminish value" tokens (GG14). Also, while the AEs uses no downtoners or downgraders with their remarks that diminished the value of the vase, a number of subjects in the two German groups did so: GG7, GG8, GG14 (downtoners); GE3 (downgrader) and GE11 (downtoner).

Table 4. 65: Number of Statements Diminishing the Value of the Damaged Object per Response; Offer; Lower-Status Interlocutor (DCT\#7)

\begin{tabular}{|l|l|l|l|l|l|}
\hline & $\mathbf{0}$ & $\mathbf{1}$ & $\mathbf{2}$ & $\mathbf{3}$ & $\mathbf{4}$ \\
\hline GGs & $57 \%$ & $21 \%$ & $14 \%$ & - & $7 \%$ \\
GEs & $25 \%$ & $58 \%$ & $8 \%$ & - & - \\
AEs & $50 \%$ & $50 \%$ & - & - & - \\
\hline
\end{tabular}

Face-threatening strategies played a rather minor role in DCT\#7, and were used most frequently by AEs. The GGs made light use thereof, and the GEs avoided these strategies. Although there were more AEs who used admonitions than GGs (two versus one), both AEs used downtoners to mitigate the effect, whereas the GG did not: .".. $\underline{\text { Just }}$ try and be more careful around the house." (AE3); .". Just try to be more careful in the future." (AE10); ....darf aber nicht öfters vorkommen." (."..but [it] mustn't happen too often."-GG5). Thus the AE admonitions sounded much less threatening than the GG one.

\footnotetext{
${ }^{55}$ In other words, there were 11 occurrences of "diminish value" remarks in the population of 14 GGs (79\%), 9 occurrences amongst the 12 GEs (75\%), and 6 occurrences amongst the 12 AEs (50\%).
} 
One GG used the strategy of establishing his own status as a means of letting the interlocutor off the hook. While the end result, excusing the cleaning lady for paying for the broken vase, was advantageous from the addressee's point of view, the means of achieving it was somewhat face-threatening as it emphasized the vast social distance and power differential between speaker and hearer. While the use of elaboration heightened the negative effect, the use of a downtoner and downgrader softened the response somewhat: "Sehen Sie, ich glaube nicht, daß ich auf die Paar DM / \$ angewiesen bin. Noch heute habe ich wieder für mehrere Millionen DM / \$ einen Vertrag abgeschlossen.” ("Look ${ }^{56}$, I believe I can get by without the paltry sum [you're offering me]. I just closed on yet another multi-million-dollar contract today."-GG4).

Table 4. 66: Use of Strategies that Increase the Face Risk; Offer; Lower-Status Interlocutor (DCT\#7)

\begin{tabular}{|l|l|l|l|}
\hline & Agreement & Admonition & Establishment of Own Status \\
\hline GEs & $8 \%$ & - & - \\
GGs & $7 \%$ & $7 \%$ & $7 \%$ \\
AEs & $25 \%$ & $17 \%$ & - \\
\hline
\end{tabular}

Evasive Strategies: No evasive strategies were used in response to DCT\#7. The one use of postponement (by GE1) functioned as an "off the hook" statement and is therefore included in the discussion of positive forms below.

In contrast to other DCT items, the AEs used a very limited range of positive forms-only "off the hook" remarks and two statements of empathy, whereas the GGs used

\footnotetext{
${ }^{56}$ The term, "look", does not quite express the flavor of "sehen Sie". "Look" has a challenging overtone which is missing in the German form, which is more "explanatory" in nature, asking the hearer to consider or understand the truth of what the speaker is about to say.
} 
those strategies, plus imperatives to rescind to offer and downgraders. The GEs used six different types of positive strategies, as the table below shows.

All of the imperatives to rescind the offer functioned as statements letting the interlocutor off the hook: .".. Lassen Sie das mal bleiben mit dem Bezahlen." ("Let's drop the idea of paying."-GG7. The original contained an imperative directed at the hearer, rather than a second person plural imperative.) and .".lassen Sie nur. ..." (."..just forget about it..."-GG9).

Many statements of empathy also had the function of letting the interlocutor off the hook. The criterion for determining which empathetic remarks did so was whether or not the remark could function on its own as a refusal. If it did serve as a refusal, then the remark qualified as an "off the hook" token. Thus, 'Don't worry about it' lets the addressee off the hook ${ }^{57}$, whereas 'Please calm down' does not do so. The following statements of empathy functioned as "off the hook" tokens: ."..[sic] its much more important to me that you use that money to support your kids than to give it to me to replace a vase." (AE1); ...ich [kann] Sie doch in Ihrer Situation unmöglich haftbar machen..." (."..I couldn't possibly hold you liable, in your situation..."-GG6); and, .".. So, please don't [sic] wory about it." (GE3).

The one GE remark classifiable as postponement apparently involved transfer from the L1. Seen from this perspective, the remark actually functioned as a means of releasing

\footnotetext{
${ }^{57}$ Interpretation of some statements of empathy was complicated by the fact that 'Don't worry about it' and 'Don't worry' can be ambiguous, either an idiom used to let the hearer off the hook, or an empathetic remark about avoiding undue anxiety (with somewhat greater emotional content). It was not always absolutely clear which option was intended, especially in the case of GE responses containing this expression.
} 
the hearer from the obligation of paying for the damage she caused. After two tokens letting the interlocutor off the hook (."..I don't think, you're able to do that. It's okay..."), the respondent continued, ."..we'll talk about it some other day." (GE1). The closing remark appears at first glance to reverse the "off the hook" statements with postponement. In this particular context, however, the respondent was obviously not changing his mind about refusing the offer. Upon closer reflection, this revealed itself to be a case of transfer from the German, "Reden wir ein anderes Mal drüber", a dismissive remark which places the discussion into the distant future, rendering it forgotten. By putting off the discussion indefinitely, the speaker let the interlocutor off the hook.

Table 4. 67: Use of Positive Adjuncts/Forms; Offer; Lower-Status Interlocutor (DCT\#7)

\begin{tabular}{|l|l|l|l|}
\hline & GEs & GGs & AEs \\
\hline Off the Hook & $100 \%$ & $100 \%$ & $100 \%$ \\
\hline Empathy & $42 \%$ & $43 \%$ & $17 \%$ \\
\hline Imperative to Rescind Offer & - & $14 \%$ & - \\
\hline Positive Opinion & $8 \%$ & - & - \\
\hline Alternative & $8 \%$ & - & - \\
\hline Postponement & $8 \%$ & - & - \\
\hline Downgrader & $25 \%$ & $21 \%$ & - \\
\hline
\end{tabular}

Downtoners occurred with high frequency in GG responses, moderate frequency in $\mathrm{AE}$ replies and low frequency in GE answers. Pause fillers, on the other hand, were not used by the GGs at all, found light use by AEs, and moderate use by GEs. 
Table 4. 68: Use of Mitigating Adjuncts; Offer; Lower-Status Interlocutor (DCT\#7)

\begin{tabular}{|l|l|l|}
\hline & Downtoner & Pause Filler \\
\hline GGs & $71 \%$ & - \\
AEs & $42 \%$ & $17 \%$ \\
GEs & $17 \%$ & $33 \%$ \\
\hline
\end{tabular}

As the table below shows, most of the responses in all three groups expressed solidarity for the addressee through multiple "off the hook" tokens. The GEs made an even greater effort to demonstrate this kind of support and consideration towards the hearer than the AEs or GGs.

Table 4. 69: Number of "Off the Hook" Tokens $^{58}$ per Response; Offer; LowerStatus Interlocutor (DCT\#7)

\begin{tabular}{|l|l|l|l|l|l|l|}
\hline & $\mathbf{1}$ & $\mathbf{2}$ & $\mathbf{3}$ & $\mathbf{4}$ & $\mathbf{5}$ & $\mathbf{6}$ \\
\hline GEs & - & $8 \%$ & $58 \%$ & $25 \%$ & - & $8 \%$ \\
AEs & $8 \%$ & $33 \%$ & $42 \%$ & $8 \%$ & $8 \%$ & - \\
GGs & $14 \%$ & $29 \%$ & $43 \%$ & - & $14 \%$ & - \\
\hline
\end{tabular}

In terms of the number of positive forms per response (excluding "off the hook" tokens), the GEs once again exhibited the greatest effort to be supportive towards the hearer. While a moderate number of GGs used these forms, they were practically absent from $\mathrm{AE}$ responses.

\footnotetext{
58" Off the hook" tokens included various strategies that functioned in the "off the hook" capacity: "no", imperative to rescind, some statements of empathy, statements of philosophy, statements establishing the speaker's status, statements diminishing the value of the damaged object, postponement, and statements of alternative: I can do X instead of Y.
} 
Table 4. 70: Number of Positive Adjuncts/Forms ${ }^{59}$ per Response; Offer; LowerStatus Interlocutor (DCT\#7)

\begin{tabular}{|l|l|l|l|l|}
\hline & $\mathbf{0}$ & $\mathbf{1}$ & $\mathbf{2}$ & $\mathbf{3}$ \\
\hline GEs & $50 \%$ & $25 \%$ & $17 \%$ & $8 \%$ \\
GGs & $57 \%$ & $29 \%$ & $14 \%$ & - \\
AEs & $92 \%$ & $8 \%$ & - & - \\
\hline
\end{tabular}

Once again as in other DCT items, the GGs showed a higher percentage of usage of mitigating adjuncts than the other two groups. While the GEs had slightly fewer responses without mitigating adjuncts than the AEs, they had no responses with two mitigating adjuncts, which two AEs did.

Table 4. 71: Number of Mitigating Adjuncts per Response; Offer; Lower-Status Interlocutor (DCT\#7)

\begin{tabular}{|l|l|l|l|}
\hline & $\mathbf{0}$ & $\mathbf{1}$ & $\mathbf{2}$ \\
\hline GGs & $29 \%$ & $43 \%$ & $29 \%$ \\
AEs & $58 \%$ & $25 \%$ & $17 \%$ \\
GEs & $50 \%$ & $50 \%$ & - \\
\hline
\end{tabular}

\section{Content of Functional Categories}

Statements of Philosophy used to let the Interlocutor Off the Hook: These forms were quite uniform (especially those used by the AEs, although a little more variety appeared in GG responses), as a list of responses shows: "I understand that accidents happen." (AE2); “Accidents happen." (AE5, AE6, AE12); "These things happen.” (AE7, AE11) ${ }^{60}$; “That happens." (GE5); .".such things happen to everybody." (GE6); ."..that could have happened to anybody." (GE7); "Things like that happen." (GE10, GE11); "So etwas kann eben mal passieren." ("That kind of thing can just happen sometimes."-GG1);

\footnotetext{
${ }^{59}$ These positive forms exclude "off the hook" tokens and consist of downgraders and expressions of empathy that did not serve the purpose of letting the addressee off the hook.
} 
“[sic] daß kann doch jedem mal passieren." and .".das kann [sic] jeden mal passieren." (."..that can happen to anyone."-GG3, GG13); "Es kann passieren,..." ("It can happen,..."-GG5); "So ein kleiner Arbeitsunfall kann mal passieren!!” (“A little workrelated accident like that can happen sometimes."-GG9); "Das kann ja mal passieren. Das ist ja menschlich." (“That [sort of thing] can happen sometimes. It's only human."-GG12). One statement of philosophy did not function as an "off the hook" remark, but rather as elaboration on a statement of empathy: "Gegenstände lassen sich ersetzen." (“Objects can be replaced."-GG11).

Remarks Letting the Interlocutor Off the Hook (including statements of empathy functioning in this capacity): There were differences between the three groups in terms of how formulaic or original (i.e., breaking out of a standardized mold) the "off the hook" remarks were. Most of the $\mathrm{AE}$ remarks in this category were quite unoriginal, routinized utterances along the lines of 'Don't worry about it' or 'That's okay'. Both the GGs and GEs, on the other hand, were more creative, using a fairly wide range of different remarks.

The more common AE remarks included: "You didn't mean to do it" (AE1, AE6); "Don't worry" / "Don't worry about it" / "Don't worry about paying for it" (AE3, AE4, AE5, AE6, AE8, AE11, AE12); "That's okay" / "It's really okay" / "It's okay" (AE7, AE9, AE11, AE12); and, "That's not necessary" (AE5). Only five AE "off the hook" responses were more original: .".I know that you can't afford to buy one." (AE4); ...there's absolutely no way you're going to have to compensate for its loss. ..." (AE10); ... I break things all the time, myself." (AE11); "I'd rather just clean it up and forget

${ }^{60}$ Sometimes these formulas were part of a sentence, rather than separate statements, but 
about it." (AE9); and a statement of empathy letting the addressee off the hook: ."..[sic] its much more imporant to me that you use that money to support your kids than to give it to me to replace a vase." (AE1).

By comparison, the GGs exhibited more uniqueness: .”.. Die Vase werde ich selbstverständlich selbst bezahlen. ..." (."..It goes without saying that I will pay for the vase myself. ..."-GG1); "Machen Sie sich nichts daraus. ..." ("Don't be concerned about it."-GG2); ."..ich glaube nicht, daß ich aus die Paar DM / \$ angewiesen bin. Noch heute habe ich wieder für Millionen DM / \$ einen Vertrag abgeschlossen." ("Look, I believe I can get by without the paltry sum [you're offering me]. I just closed on yet another multimillion-dollar contract today."-GG4); “Aber das ist doch kein Drama ..." ("But it's really not a tragedy ..."-GG6); .".. Lassen Sie das mal bleiben mit dem Bezahlen." (."..Let's drop the idea of paying."-GG7); ."..machen sie sich deswegen keine Sorgen." (.".don't get upset about it."-GG8); "Nein, nein, lassen Sie nur. Das geht schon in Ordnung!! ... Außerdem ist die Vase versichert..." ("No, no, just forget about it. It'll be just fine!! ... And the vase is insured anyway."-GG9); "Das ist nicht nötig. ..." ("That isn't necessary"GG10); "Ach nein, so schlimm ist es ja nicht. ... Sie brauchen auf keinen Fall dafür zu bezahlen." (“Oh no, it's really not that bad. ... You definitely don't need to pay for it."GG11); and, "Ach was ... vergessen wir den Vorfall." (“Oh, come on! ... Let's forget the incident."-GG13). Some of the GG "off the hook" tokens were also statements of empathy: .". Ist doch halb so schlimm. ..." (."..It's not nearly as terrible [as you seem to think it is]. ..."-GG1); .".. u[nd] auch wenn der Schaden groß ist, kann ich Sie doch in 
Ihrer Situation unmöglich haftbar machen ..." (.".. and even if the damage is considerable, I couldn't possibly hold you liable, in your situation ..."-GG6); .". bitte machen Sie sich keine Sorgen!"; and "Da machen Sie sich bitte mal keine Sorgen! ..." ("Please don't worry!"-GG9, GG14). The latter two statements differed from AE remarks and one GG remark telling the cleaning lady not to worry because of their emotional content. "Don't worry about it" is rather neutral emotionally, a fairly standardized way of letting the addressee off the hook. In these two cases, however, the speakers told the addressee not to worry in a way that expressed much more concern for her state of mind.

The GE responses resembled the GG' wide range of "off the hook" tokens: .".I don't think, you're able to do that. It's okay, we'll talk about it some other day." (GE1. See comment about GE1's final sentence in the frequency section.); "Doesn't matter. ..." (GE2); "Don't worry ... The insurance will pay... So, please don't [sic] wory about it." (GE3); .".. So don't be sorry about it. ... If it would be original you couldn't pay anyway. ... The cellar is full of others..." (GE4); .".. You were just doing your job. ..." (GE5); ...that's not necessary. You don't need to pay it..." (GE6); "It is not your fault... You don't have it pay for that. Forget about it. Don't worry, that's o.k." (GE7); “That's really not [sic] neccessary. I even don't know how expensive it was, we bought them such a long time ago." (GE8); ...that's ok!..." (GE9); "If you haven't got an insurance for that kind of accidents you would not have to pay for it, off course. ..." (GE10); .". And I don't want you to pay for it..." (GE11); and, .".. Of course, you needn't pay for it, that would be ridiculous." (GE12). While a few GEs did use the strategy, "statement of 
empathy", only one GE response contained a statement of empathy used to let the addressee off the hook: ."..So please don't [sic] wory about it."(GE3).

Mention of the Interlocutor's Financial Situation: Two subjects in each of the three groups made implicit or explicit mention of cleaning lady's financial situation: ....[sic] its much more important to me that you use that money to support your kids than to give it to me to replace a vase." (AE1);.".. I know that you can't afford to buy one." (AE4); .".I don't think, you're able to do that [pay for the vase]. ..." (GE1); ."..If it would be original you couldn't pay anyway. ..." (i.e., "If it were an original rather than a fake, you couldn't afford to pay for it anyway."-GE4); and, ."..[ich] kann Sie doch in Ihrer Situation unmöglich haftbar machen ..." (."..I couldn't possibly hold you liable, in your situation ..."-GG6). One GG's reference to the cleaning lady's financial circumstances was oblique, made by contrast to his own wealth: .".ich glaube nicht, daß ich auf die Paar DM / \$ angewiesen bin. Noch heute habe ich wieder für mehrere Millionen DM / \$ einen Vertrag abgeschlossen." (."..I believe I can get by without the paltry sum [you're offering me]. I just closed on yet another multi-million-dollar contract today."-GG4). Four of these respondents focused primarily on the issue of financial inability (AE4, GG4, GE1, and GE4) while two articulated the speakers' empathy for the cleaning lady's circumstances (AE1 and GG6).

Statements Diminishing the Value of the Damaged Object: Regarding statements diminishing the worth of the broken vase, the Americans differed from the Germans in two ways: their remarks were much more routinized (i.e., the Germans' remarks were richer in content) and, with only one exception, they made no disparaging remarks about the vase. 
The Germans, on the other hand, stated that the vase was not so valuable or that they did not particularly like it, etc.

Only one AE spoke of not liking the vase, ."..I never did like it. ..." (AE12), while all of the other "diminish value" tokens were broad, general statements: .".. It wasn't that expensive anyway." (AE2); .". It was just a vase..." (AE4); ."..It's just a vase..." (AE11, AE5-but crossed out); ."..It wasn't that important to me." (AE8); and, ."..It wasn't that important to me anyway. ..." (AE9).

The GGs, on the other hand, wrote much more elaborate, specific remarks. On the whole, they also tended to criticize the vase: .".. Ich glaube, daß dies sowieso kein teures oder sehr wertvolles Objekt war." (.".. I don't believe that it was an expensive or very valuable object anyway."-GG2); .".um die ist es nicht schade. So sehr hänge ich auch nicht an ihr. ..." (."..it's no big deal about the vase. I'm not that fond of it anyway. ..."GG7); "So besonders war die Vase auch wiederum nicht..." ("The vase really wasn't all that special..."-GG8); .".. So wertvoll war die Vase gar nicht und gefallen hat sie mir eh noch nie." (.".. The vase wasn't all that valuable and I never liked it anyway."-GG10); "Die Vase hat mir eh nichts bedeutet. ..." ("The vase didn't mean anything to me anyway. ..."-GG12); and, .". Ich hatte sowieso eine ambivalente Einstellung zu der Vase. Eigentlich gefiel sie mir nicht mehr. Ich konnte mich bisher nur noch nicht entschließen, sie wegzustellen. Jetzt ist der Fall auf einfache Art gelöst." (.".. I had an ambivalent attitude towards the vase anyway. I didn't actually like it anymore. Up till now I just couldn't make up my mind to put it away. Now the matter has been settled the easy way."-GG14). 
GE statements diminishing the value of the broken vase resembled GG responses in terms of disparaging remarks, but were on the whole more uniform. Only one GE used a formulaic statement, .".. It was only a vase." (GE10), while the others were more elaborate: .". It wasn't expensive and finally I couldn't see it anymore." (GE2-The second part of the statement is a direct translation of a German idiom that means " $I$ couldn't stand it anymore"); .".I didn't like it anymore. ..." (GE3); ."..It was a fake. ..." (GE4); .".I didn't like the vase anyway." (GE5); .".I didn't like it anyways, ..." (GE9); ...I never really liked the vase anyway." (GE11); and, .".. the China vase is less important [than you are] ..." (GE12). Although GE8's remark did not actually belittle the vase, it did suggest that the vase was no longer important to the subject: ."..we bought them such a long time ago.."

Admonitions and Other Face Threats: Most of the statements of agreement were mild and objective expressions of sadness about the loss of the vase, that did not in any way indict the cleaning lady. Moreover, in the context of convincing statements letting the addressee off the hook and other kindly disposed strategies, none of these strategies were much of a face threat. Similarly, the two admonitions in the AE data hardly posed a threat because of gentle wording and contexts emphasizing pardon.

Of the statements of agreement, the one GE use of this form was perhaps the mildest: .".that's a pitty. ..." (GE1). The one GG use of agreement was a little more threatening because it acknowledged that the broken vase was a great loss (in contrast to the vast number of $\mathrm{GG}$ and $\mathrm{GE}$ responses minimizing the value of the vase!). The context, however, provided considerable face protection: "Aber das ist doch kein Drama u. auch 
wenn der Schaden groß ist, kann ich Sie doch in Ihrer Situation unmöglich haftbar machen ..." ("But it's really not a tragedy, and even if the damage is considerable, I couldn't possibly hold you liable, in your situation.."-GG6). An AE statement of agreement might have tugged at the addressee's conscience because it brought in a personal element of regret, but once again, sympathetic contextual features prevailed over any possible face threat: "I loved that vase but I know you [sic] didnt mean to do it and [sic] its much more important to me that you use that money to support your kids than to give it to me to replace a vase." (AE1). Another $\mathrm{AE}$ put an initial reaction in parentheses (an expletive), which may have meant that this was what the speaker thought rather than said. Also, the expletive seemed quite separate from the rest of the response, which supports the analysis of this remark as an unspoken thought. Even if it had been said, however, the positive context overrode any negativity. The expletive was interpreted as a statement of agreement because it acknowledged that something bad had happened: "(Shit.) Look -- I know you didn't mean to do it. Accidents happen. Don't worry about paying for it." (AE6). The $\mathrm{AE}$ response that came closest to posing a face threat contained both a statement of agreement and an admonition; however, the statement letting the addressee off the hook (embedded between the two less favorable strategies) was very forceful and effective: "Well, I'm pretty dismayed about the vase, but there's absolutely no way you're going to have to compensate for its loss. Just try to be more careful in the future." (AE10). The other AE admonition was fairly mild, as noted above: .".Just try and be more careful around the house." (AE3). Additionally, the two AE admonitions were mitigated by use of the downtoner, 'just'. Only one admonition might have seemed 
intimidating because it implicitly suggested negative consequences for the addressee if such an accident were to occur again. This admonition was made by a GG: "Es kann passieren, darf aber nicht öfters vorkommen." (It can happen, but [it] mustn't happen too often."-GG5).

The GG statement establishing the speaker's status paradoxically served both to exonerate the cleaning lady but also to stress the enormous gap between their socioeconomic positions: Sehen Sie, ich glaube nicht, daß ich auf die Paar DM / \$ angewiesen bin. Noch heute habe ich wieder für mehrere Millionen DM / \$ einen Vertrag abgeschlossen." ("Look, I believe I can get by without the paltry sum [you're offering me]. I just closed on yet another multi-million-dollar contract today."-GG4).

Downgraders and Intensifiers: A few GGs used intensifiers to assert the strength of their conviction that the cleaning lady should not pay for the broken vase, e.g., ."..Die Vase were ich selbstverständlich selbst bezahlen. ..." (."..It goes without saying that I will pay for the vase myself. ..."-GG1); ."..[ich] kann Sie doch in Ihrer Situation unmöglich haftbar machen ..." (.".II couldn't possibly hold you liable, in your situation..."-GG6); and, ...Sie brauchen auf keinen Fall dafür zu bezahlen." (."..You definitely don't need to pay for it."-GG11). Only one AE and one GE used such intensifiers: .".there's absolutely no way you're going to have to compensate for its loss..." (AE10) and .".. Of course, you needn't pay for it, that would be ridiculous." (GE12-The underlined elaboration also served as intensification.).

Upon initial examination, it might seem odd that downgraders and downtoners were used together with statements of empathy or "off the hook" remarks (Downgraders 
occurred in the GE and GG data, but none of the AEs used them.), but they did actually serve a logical purpose. In an "off the hook" remark, a downgrader softened the assertion that the cleaning lady was not stable enough financially to pay for the damage: .".II don't think, you're able to do that [pay for the vase]. ..." (GE1). A related use of a downgrader appeared in conjunction with a statement asserting the speaker's higher status, although the "downgrader" also could have been intended sarcastically: .".ich glaube nicht, daß ich auf die Paar DM / \$ angewiesen bin. ..." (.".. I believe I can get by without the paltry sum..."-GG4). Downtoners minimized the acknowledgement that the cleaning lady did indeed break the vase inherent in "off the hook" remarks: "Look -- I know you didn't mean to do it. ..." (AE6); “Look, it's really okay. ..." (AE9); ."..You were just doing your job. ..." (GE5); and ."..so schlimm ist es ja nicht. ..." (."..it's not that bad. ..."-GG11). In expressions of empathy, downgraders and downtoners prevented utterances such as "calm down" from sounding harsh rather than sympathetic, e.g., ."..bitte machen Sie sich keine Sorgen! ..." (."..please don't worry about it!"-GG9 and similar remarks by GG14 and GE3); "Ja, beruhigen Sie sich doch. .." (“Okay now, calm down. ..."-GG1); or "Please, don't be so upset. ..." (GE11). In remarks diminishing the value of the damaged object, downgraders and downtoners softened the disparaging of the vase: .".strictly speaking, I didn't like it anymore. ..." (GE3); "So besonders war die Vase auch wiederum nicht..." ("The vase really wasn't all that valuable..."-GG8); and, .".Eigentlich gefiel sie mir nicht mehr. ..." (."..I didn't actually like it any more. ..."-GG14). 
As noted in the previous section on admonitions and other face threats, the two admonitions used by AEs were softened by the downtoner, 'just', thus lessening any potential face threat.

FTA Strategies: As the refusal in DCT\#7 ist not an FTA, examination of responses according to these criteria is not applicable. Issues of solidarity, politeness, and face threats are discussed above in the content section.

\section{Summary of Results: Refusal of Offer Made by a Lower-Status Interlocutor (DCT\#7)}

There were no occurrences of excuses or reasons, and practically no uses of direct refusal strategies in DCT\#7. Statements of philosophy occurred in half the AE and GG, and just under half the GE responses. The major strategy consisted of statements letting the interlocutor off the hook and various functional categories serving on a deeper level of meaning as "off the hook" statements ( $100 \%$ of the subjects let the hearer off the hook). The most important of the dual-level strategies were statements diminishing the value of the damaged object and most of the statements of philosophy, but the set also included imperatives to rescind the offer, "no", many of the statements of empathy, and a statement establishing the speaker's status. Indeed, responses to DCT\#7 contained such extensive reinforcement of the "off the hook" strategy, beyond what was needed to convey the message, that one might wonder if the respondents were relieved to display some "magnanimity" after having been forced to produce "negative" refusals for the other DCT items. A few GGs even used intensifiers to emphasize their position that the cleaning lady should not pay for the vase (although only one GE and one AE did so). 
Overall, in terms of strategy choices, the GEs were more similar to the GGs than to the AEs. There was a much greater frequency of statements diminishing the value of the damaged object amongst the German subjects than the AEs (three-fourths of the Germans versus half of the $\mathrm{AE}$ population). This strategy was intended to relieve the hearer by minimizing the seriousness of the mishap. In addition, only one $\mathrm{AE}$ made a remark about not liking the vase, whereas a sizeable number of GGs and GEs made somewhat disparaging remarks about it. The AEs were either more hesitant to express a critical attitude, even towards their own possessions, or they felt less need to add further "off the hook" remarks to their responses.

Almost half of the Germans used expressions of empathy, whereas fewer than onefifth of the AEs did so. Also, a number of other positive forms that were used either by GEs or GGs did not occur in the AE data. Moreover, the AEs used functional categories that increased the possibility of a face threat with slightly higher frequency than the Germans, i.e., statements of agreement (that the hearer had caused damage) and admonitions (It should be noted that the content of all these forms were quite mild. The statements of agreement expressed unhappiness at the loss, but did not even hint at blame. The $\mathrm{AE}$ admonitions were also quite innocuous.). The only instance of a less favorable strategy in the GE data was one harmless statement of agreement, and the GGs made little use of such strategies. However, as the GG admonition was not mitigated and also insinuated negative consequences to the hearer in the event of a reoccurrence, it created a greater potential threat than the two $\mathrm{AE}$ admonitions. Likewise, the one $\mathrm{GG}$ response establishing the speaker's status created a potential face threat because of its somewhat 
condescending dismissal of the cleaning lady's "few dollars" ("paltry sum") and its accentuation of the enormous socioeconomic gap between them. Depending on intonation, even the downgrader in the response could have been intended sarcastically. Thus, unlike all other subjects, these two GGs breached the overall emphasis on tact.

In regards to mitigating adjuncts, a large proportion of GGs used downtoners, while the AEs and GEs made a good deal less use of mitigating adjuncts. An exception to the similarity of strategy choices between the GGs and GEs in DCT\#7 lay in the great disparity in the frequency of downtoners ( $71 \%$ of the GGs versus $17 \%$ of the GEs).

Other forms of tactfulness included: use of downgraders and downtoners with statements of empathy and "off the hook" remarks to soften the assertion that the addressee was not financially able to pay for the vase; use of downgraders and downtoners to soften remarks like "calm down", so that they would sound sympathetic rather than exasperated; and, use of downtoners to mitigate admonitions as well as to minimize the admission that the cleaning lady had caused the damage, which "off the hook" remarks automatically entail.

An important difference between the American and German subjects was the uniformity of $\mathrm{AE}$ responses as contrasted with the GGs' and GEs' greater variety of responses that also were richer in real content. Analysis of the tokens used by the three population groups showed that the AEs chose much more formulaic, standardized utterances to let the interlocutor off the hook than either the GGs or the GEs. The two groups of Germans produced much more individual, inventive responses than the AEs. Only in the case of statements of philosophy used to let the interlocutor off the hook did 
the $\mathrm{GE}$ responses resemble the $\mathrm{AE}$ tokens (which followed two basic formulas), although there still was more variation than in the $\mathrm{AE}$ answers. Here, the GGs used a somewhat wider range of tokens. Statements that let the addressee off the hook by diminishing the value of the damaged vase were more routinized in the $\mathrm{AE}$ data than in the German subjects' responses.

As noted above, the refusal in DCT\#7 did not constitute an FTA; thus, the responses were not examined according to these criteria.

\section{DCT \#9: Refusal of Equal-Status Interlocutor's Offer}

\section{Frequency of Functional Categories}

As described in the introduction to this section (Refusal of Offers, DCT\#7, DCT\#9, and DCT\#11), DCT\#9 contains two parts. Subjects must respond to the friend's first offer of cake with a refusal, but the test item allows the choice of accepting or refusing the second time, when the friend repeats the offer, urging the speaker to have "just a little piece." The twofold structure is presented in the tables below as "I" and "II."

Unlike all the other DCT items, DCT\#9 elicited frequent use of the direct refusal strategy, "no." In the first response section, "no" was almost always conjoined with the downgrader, "thank you": 'no, thank you' or nein, danke. In the second response section, however, only very few respondents added the downgrader, favoring the upgrader, "really": 'no, really'. In both sections, there were a few instances of "bald" negatives (i.e., neither downgraded nor upgraded). 
As the table below shows, the more polite, routinized forms were preferred the first time around, but gave way to more direct forms in answer to the second offer. The forms, bald "no", "no"-plus-upgrader, and statements of negative willingness, were not present in responses to the first offer except for bald "no", used by one fourth of the AEs, one GG and one GE (and the GG had already used "no"-plus-downgrader earlier in the first section). Both the GGs and GEs displayed considerable restraint in their use of direct refusal strategies, making little use of upgraded or bald negatives or statements of negative willingness. The AEs, on the other hand, made moderate use of these forms. Even in the response to the first offer (where the friend could hardly be accused of insistence), one fourth of the AEs used bald "no." The GGs made more frequent use of statement of negative ability than the other two groups.

The AEs were more uniform in their use of direct refusal strategies than the GEs or GGs:-92\% responded with either "no"-plus-downgrader or bald "no" to first section, as compared with $64 \%$ of the GGs and $50 \%$ of the GEs. In the second section, $75 \%$ of the AEs, as compared with $57 \%$ of the GGs and $33 \%$ of the GEs, used some kind of "no" response. 
Table 4. 72: Use of Direct Refusal Strategies; Offer; Equal-Status Interlocutor (DCT\#9)

\begin{tabular}{|c|c|c|c|c|c|c|}
\hline & \multicolumn{2}{|c|}{$\mathrm{GGs}^{61}$} & \multicolumn{2}{|l|}{ GEs } & \multicolumn{2}{|l|}{ AEs } \\
\hline & II & III & II & III & II & III \\
\hline "No" + Downgrader & $64 \%$ & $14 \%$ & $42 \%$ & $8 \%{ }^{62}$ & $67 \%$ & E \\
\hline "No" + Upgrader + Downgrader & F & $14 \%{ }^{63}$ & F & E & F & $17 \%$ \\
\hline "No" + Upgrader & F & $14 \%$ & F & $17 \%$ & F & $25 \%$ \\
\hline Bald "No" & $7 \%{ }^{64}$ & $14 \%$ & $8 \%$ & $8 \%$ & $25 \%$ & $33 \%$ \\
\hline Negative Willingness & F & $7 \%$ & F & F & F & $25 \%$ \\
\hline Negative Ability & $29 \%$ & $29 \%$ & $17 \%$ & $8 \%$ & $8 \%$ & $17 \%$ \\
\hline Performative & - & F & $8 \%{ }^{65}$ & F & $F$ & - \\
\hline
\end{tabular}

While excuses found little use in DCT\#9, reasons were offered very frequently in

the first response section, especially in the AE and GE data. In contrast to the GEs and

GGs, who gave no reasons in the second section, one-third of the AEs did so.

${ }^{61}$ One of the GGs gave two alternative answers for the second section of DCT\#9, one accepting and the other declining the offer (GG6). For this reason, the percentages for the GGs in the second section are based on fifteen responses rather than fourteen.

${ }^{62}$ The GE who produced this form also added an intensifier: “...No, thank you very much. ..$"(\mathrm{GE} 10)$.

${ }^{63}$ One of these GGs had two "no" responses in the second section, one with a downgrader and one with an upgrader: "Nein danke, wirklich nicht..." ("No, thank you, really not..." GG2). To avoid complicating the table, these two "no" responses were "merged" into one and included in this cell (instead of counting one of them as "no" + downgrader and the other as upgrader + "no").

${ }^{64}$ This bald "no" was not very abrupt because it followed an elaborate justification consisting of "no" + downgrader, compliments, and a reason: "Nein, danke; der Kuchen ist sehr gut, aber Du weiß doch, daß ich versuche, meinen Zucker- und Weißmehlinput zu reduzieren - obwohl der Kuchen lecker ist, trotzdem nein!" ("No, thank you; the cake is very good, but you know that I am trying to reduce my consumption of sugar and white flour. Even though the cake is delicious, the answer is still no!" - GG9).

${ }^{65}$ This performative (conjoined with a downgrader) functioned as a statement of negative ability (and was also included in the cell above): "...I have to refuse. ..." (GE1). 
Table 4. 73: Use of Excuses and Reasons; Offer; Equal-Status Interlocutor (DCT\#9)

\begin{tabular}{|l|l|l|l|l|}
\hline & \multicolumn{2}{|l|}{ Excuse } & Reason \\
\hline & I & II & I & II \\
\hline AEs & $17 \%$ & - & $83 \%$ & $33 \%$ \\
\hline GEs & $8 \%$ & - & $83 \%$ & - \\
\hline GGs & - & $7 \%$ & $64 \%$ & - \\
\hline
\end{tabular}

Most of the upgraders in DCT\#9 were were fairly innocuous forms which served to increase the force of the direct refusal strategy, "no" (e.g., "no, really"), without attacking or criticizing the addressee in any way. In other words, they effectively prevented the interlocutor from repeating the offer yet again without creating much of a face threat. Two AEs used upgraders with statements of negative willingness. These uses were only slightly harsher than "no, really": "No, I really [sic] dont want one." (AE1) and "No. I really don't want any more." (AE9). On the other hand, two upgraders used by GGs were exceptions to the relative mildness of upgraders in DCT\#9. One GG upgrader added a reproachful tone to the reason that followed it, implying a lack of consideration on the addressee's part: .".aber du weißt doch, daß ich versuche, meinen Zucker- und Weißmehlinput zu reduzieren..." (."..but you know that I am trying to reduct my consumption of sugar and white flour. ..."-GG9). The other added to the impact of a guilt trip: "Verdammt, aber wenn ich an Verfettung sterben sollte, hoff' ich, daß Du ein schlechtes Gewissen hast." ("Dammit, if I die of obesity, I hope you have a guilty conscience."-GG3).

The GEs completely eschewed the truly face-threatening strategies, while the $\mathrm{AE}$ data contained one fairly crude statement of negative consequences for the interlocutor (AE6) and a reason that possibly involved an indirect statement of negative opinion (AE9, see content section for quotes). Surprisingly, both of these forms were in the first response 
section, not in the second section (where one might expect a little more hostility on the part of the speaker). Amongst the GGs, however, there were a number of clearly facethreatening forms: an insult and an imperative to rescind the offer in the first section, and guilt trips and imperatives to drop the offer in the second section.

Table 4. 74: Use of Strategies that Increase the Face Risk; Offer; Equal-Status Interlocutor (DCT\#9)

\begin{tabular}{|c|c|c|c|c|c|c|}
\hline & \multicolumn{2}{|c|}{ GEs } & \multicolumn{2}{|c|}{ AEs } & \multicolumn{2}{|c|}{ GGs } \\
\hline & I & II & $\bar{I}$ & II & I & II \\
\hline Insult & - & E & - & - & $7 \%$ & 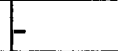 \\
\hline $\begin{array}{l}\text { Negative Conseq. for } \\
\text { Interlocutor }\end{array}$ & $F$ & - & $F$ & $8 \%$ & - & F \\
\hline Guilt Trip & F & - & F & 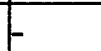 & F & $13 \%{ }^{66}$ \\
\hline Imperative to Drop Offer & F & E & 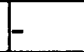 & $T$ & $7 \%$ & $13 \%$ \\
\hline Negative Opinion & $F$ & $F$ & $8 \%{ }^{6}$ & F & - & - \\
\hline Upgrader & $8 \%$ & $17 \%$ & $F$ & $58 \%$ & $7 \%$ & $33 \%$ \\
\hline
\end{tabular}

The only functional categories used in DCT\#9 that could be considered evasive

were: acceptance functioning as a refusal through lack of enthusiasm and a set condition for future acceptance. There was little use of these evasive strategies, and they occurred only in the second response section of the test item. None of the AEs used evasive strategies, and only one GG did so. There was slightly more use of avoidance in the GE data.

\footnotetext{
${ }^{66}$ Lacking intonation and other paralinguistic cues, it was not possible to determine the intention behind a guilt trip used by one of the GGs. Combined with an upgrader, it appeared to function either as true acceptance of the offer or as acceptance that served as a refusal because of a lack of enthusiasm: "Verdammt, aber wenn ich an Verfettung sterben sollte, hoff' ich, daß Du ein schlechtes Gewissen hast." "'Dammit, but if I die of obesity, I hope that you'll have a guilty conscience." GG3). See content section.

${ }^{67}$ The reason + downtoner used by AE9 was possibly intended as a statement of negative opinion: "No thank you. The first one really isn't sitting too well." The discomfort could be a matter of the speaker's digestion, but the remark could also be a subtle criticism of the cake.
} 
Table 4. 75: Use of Evasive Strategies; Offer; Equal-Status Interlocutor (DCT\#9)

\begin{tabular}{|l|l|l|l|l|l|l|l|}
\hline & \multicolumn{2}{|c|}{ AEs } & \multicolumn{2}{c|}{ GGs } & \multicolumn{2}{c|}{ GEs } \\
\hline & I & II & & I & II & \multicolumn{1}{|c|}{ I II } \\
\hline $\begin{array}{l}\text { Acceptance that Functions as a } \\
\text { Refusal: Lack of Enthusiasm }\end{array}$ & & & - & & $7 \%{ }^{68}$ & - & $17 \%{ }^{69}$ \\
\hline $\begin{array}{l}\text { Set Condition for Future } \\
\text { Acceptance }\end{array}$ & & & - & - & - & $8 \%$ \\
\hline
\end{tabular}

With the exception of the various forms of acceptance (which were limited to the

second section by the interlocutor's rejoinder given in the DCT), there was considerably less use of positive forms and adjuncts in the second section than in the first. This was true of all three subject groups.

While only a fifth of the GGs (not including GG3's questionable statement of acceptance) and a fourth of the AEs agreed to have the second piece of cake (including an alternative offer), over half of the GEs did (including a promise of future acceptance). Acceptance of the offer was invariably limited (with the exception of one $\mathrm{AE}$ ) either in the initial statement of consent (e.g., "If you promise just to give me a little piece, okay.") or in a remark following the acceptance (e.g., "Okay, but just a little piece..."). One AE used an offer of an alternative ( $\mathrm{I}$ can do $\mathrm{X}$ instead of $\mathrm{Y}$ ) in a way that served a similar function to limited acceptance: ."..I'd love to take a small piece home, though, if you're trying to get rid of it." (AE10).

${ }^{68}$ This is the ambiguous response noted in footnote \# ?, which could be interpreted either as acceptance functioning as a refusal (through a lack of enthusiasm) or as real acceptance (with mock complaining). Because of the provocative wordings of the response, it seemed more plausible to interpret this as acceptance under protest, so the response is included in this table rather than in the table of positive forms including true acceptance. CHECK - 2 footnotes ago

${ }^{69}$ One of the GEs used this form twice in succession: "Well, if I absolutely have to. Why not." (GE11). 
In the GE data, positive forms such as compliments, statement of gratitude, or apologies appeared fairly frequently in the first response section, but not at all in the second. While the GGs made fairly frequent compliments the first time around, there was only one other positive form, a statement of regret. In the second section, the GG data contained two compliments, one statement of positive opinion, one expression of thanks, and one statement of regret. The AEs used few positive forms, only two compliments in the first section and one in the second.

Downgraders were used rather heavily in the first section by all three groups ( $\mathrm{AE}>\mathrm{GG}>\mathrm{GE}$ ), and still figured fairly prominently in the GG data in the second section. The AEs and GEs, however, made little use of downgraders in the second part. 
Table 4. 76: Use of Positive Forms / Adjuncts; Offer; Equal-Status Interlocutor (DCT\#9)

\begin{tabular}{|l|l|l|l|l|l|l|}
\hline \multicolumn{2}{l}{} & GEs & \multicolumn{2}{l|}{ GGs } & \multicolumn{2}{l|}{ AEs } \\
\hline & I & II & I & II & I & II \\
\hline Acceptance & - & $25 \%$ & - & $20 \%$ & - & $8 \%$ \\
\hline Limitation of Acceptance ${ }^{70}$ & & $25 \%$ & - & $20 \%$ & - & - \\
\hline Limited Acceptance & & $25 \%$ & - & - & - & $8 \%$ \\
\hline Promise & - & $8 \%$ & - & - & - & - \\
\hline $\begin{array}{l}\text { Alternative: I Can Do X Instead } \\
\text { of Y }\end{array}$ & - & - & - & - & $8 \%$ \\
\hline Compliment & $42 \%$ & & $43 \%$ & $13 \%$ & $17 \%$ & $8 \%$ \\
\hline Positive Opinion & - & & - & $7 \%$ & - & - \\
\hline Regret & $17 \%$ & - & $7 \%$ & $7 \%$ & - & - \\
\hline Gratitude & $25 \%{ }^{71}$ & - & - & $7 \%$ & - & - \\
\hline Downgrader & $58 \%$ & $8 \%$ & $64 \%$ & $40 \%$ & $67 \%$ & $17 \%$ \\
\hline
\end{tabular}

Of the mitigating adjuncts, downtoners played a very minor role in the first part

and did not occur in the second. Pause fillers were scarcely used by the AEs and GGs, but appeared somewhat more frequently in the GE data.

\footnotetext{
${ }^{70}$ In other words, all of the GEs and all but one of the GGs who accepted the offer also limited their acceptance. The one AE who accepted the offer did not limit it.

${ }^{71}$ Two GEs prefaced their responses with "Thank you..." (GE1 and GE9). These seemed to contain an element of transfer from German (i.e., the downgrader part of "no"-plusdowngrader) rather than being pure statements of gratitude. In English, it seems somewhat anomalous to preface the refusal with 'thank you', which normally would imply acceptance, e.g.:

Friend: How about another piece of cake?

You: Thank you, but I have to refuse.

In German, on the other hand, the term, danke ('thank you'), is used on its own to refuse offers (in the sense of 'no, thank you'). It is noteworthy in this connection that no AEs used statements of gratitude in similar contexts. These two utterances were coded as statements of gratitude rather than downgraders, because the word, "but" in both responses signalled a contradiction. In other words, if "thank you" had been meant only as a downgrader, the word, "but" would not have been necessary.
} 
Table 4. 77: Use of Mitigating Adjuncts; Offer; Equal-Status Interlocutor (DCT\#9)

\begin{tabular}{|l|l|l|l|l|}
\hline & \multicolumn{3}{|l|}{ Downtoner } & \multicolumn{2}{l|}{ Pause Filler } \\
\hline & $\Gamma$ & II & I & II \\
\hline AEs & $17 \%$ & - & - & $8 \%$ \\
\hline GGs & $14 \%$ & - & $7 \%$ & - \\
\hline GEs & $8 \%$ & - & $25 \%$ & $17 \%$ \\
\hline
\end{tabular}

While the GEs used more positive forms and/or adjuncts in the first section than the GGs, in the second section, the GGs exceeded the GEs in the production of positive forms. By contrast to the German subjects, who made moderate use of positive forms, almost all of the AEs either used no positive forms or just one, in both the first and second sections.

Table 4. 78: Number of Positive Forms / Adjuncts per Response; Offer; EqualStatus Interlocutor (DCT\#9)

\begin{tabular}{|l|l|c|c|c|c|c|c|c|}
\hline & \multicolumn{2}{|c|}{ 0 } & \multicolumn{2}{c|}{1} & \multicolumn{2}{|c|}{2} & \multicolumn{2}{|c|}{3} \\
\hline & I & II & I & II & I & II & I & II \\
\hline GEs & $8 \%$ & $42 \%$ & $50 \%$ & $50 \%$ & $33 \%$ & $8 \%$ & $8 \%$ & - \\
\hline GGs & $21 \%$ & $33 \%$ & $43 \%$ & $40 \%$ & $29 \%$ & $20 \%$ & $7 \%$ & $7 \%$ \\
\hline AEs & $25 \%$ & $50 \%$ & $67 \%$ & $50 \%$ & $8 \%$ & - & - & - \\
\hline
\end{tabular}

In terms of the number of mitigating adjuncts per response, the GEs exceeded the AEs, who in turn exceeded the GGs.

Table 4. 79: Number of Mitigating Adjuncts per Response; Offer; Equal-Status Interlocutor (DCT\#9)

\begin{tabular}{|l|c|c|c|c|l|l|}
\hline & \multicolumn{2}{|c|}{ 0 } & \multicolumn{2}{c|}{$\mathbf{1}$} & \multicolumn{2}{c|}{$\mathbf{2}$} \\
\hline & I & II & I & II & I & II \\
\hline GEs & $67 \%$ & $83 \%$ & $33 \%$ & $17 \%$ & - & - \\
\hline AEs & $83 \%$ & $92 \%$ & $17 \%$ & $8 \%$ & - & - \\
\hline GGs & $87 \%$ & $100 \%$ & $7 \%$ & - & $7 \%$ & - \\
\hline
\end{tabular}

\footnotetext{
${ }^{72}$ Downtoners play a stronger role in mitigating an FTA than do pause fillers. For this reason, they are listed first (as the more potent mitigator), and the ordering of the subject groups in terms of politeness reflects use of downtoners more than pause fillers.
} 


\section{Content of Functional Categories}

Reasons: The three groups differed in terms of originality and uniformity of reasons. $\mathrm{AE}$ reasons were extremely uniform, with the same words used over and over in most responses: "I'm full" or "I'm stuffed", whereas the GGs showed a degree of individuality, and the GEs found a position inbetween the other two groups. The AEs were the only group to give reasons in both the first and second response sections. All of the AEs who gave a reason the second time around had already given a reason in the first part. The second reason in each case was an intensification of the preceding one: (AE2)-1. ...I'm full.", 2. .".I'm full!"; (AE4)-1. ."..I'm full. ...", 2. .".I'm really full. ..."; and (AE7)-1. ."..one was plenty.", 2. ."..I'm really pretty full.." Only one of these showed any measure of originality: (AE11)-1. .".I'm really full.", 2. ."..I think my stomach has shrunk since I've been trying to eat less. I get full a lot faster.." All the remaining reasons but one consisted of two formulas: "I'm full..." (AE3 and AE12) and .".I'm stuffed." (AE5, AE6, and AE10). The one exception to the sameness of the AEs' reasons is discussed below with "Face Threats in the First Section": ."..The first one really isn't sitting too well." (AE9).

The GGs used reasons only in the first part. One GG used a reason concerning attempts to avoid unhealthy food, while the rest of the reasons had to do with already having had enough to eat. While a few reasons were somewhat direct, they were all relatively polite: ."..ich habe schon 2 Stückchen gehabt. ..." (.”..I already had two little pieces. ..."-GG1); ."..ich habe schon etwas zu mir genommen." (."..I've already eaten something."-GG5); .".Das war jetzt genau die richtige Menge." (."..That was exactly the 
right amount."-GG7); .".ich habe absolut keinen Appetit." (."..I have absolutely no appetite."-GG8); .".ich versuche, meine Zucker- und Weißmehlinput zu reduzieren..." (.".I'm trying to reduce my consumption of sugar and white flour..."-GG9); ."..ich hatte schon zwei Stück..." (.".II already had two pieces..." GG11); ."..jetzt bin ich satt." (."..I'm full now."-GG12); ."..ich hatte bereits zwei." (.".I already had two."-GG13); ."..Eines reicht mir." (.".. One is enough for me."-GG14).

The GE reasons contained a mixture of $\mathrm{AE}$ and $\mathrm{GG}$ characteristics, combining some of the AEs' unvaried reasons with the GGs' remarks about having already had enough to eat: .".I'm totally full." (GE1); ...I'm stuffed." (GE2); .".I've had enough." (GE5); .".I already ate [sic] to much..." (GE6); .".I'm full" (GE7); ."..it really is enough for me now." (GE8); ."..I ate too much already." (GE9); .".I'm [sic] quiet happy now..." (GE10); .".I'm absolutely full. I had too much to eat already." (GE11); and .".I already had three!..." (GE12).

Face Threats in the First Section: One AE gave a reason that might have been intended as an indirect statement of negative opinion: ."..The first one [piece of cake] really isn't sitting too well." (AE9). The addressee might have found this remark somewhat insulting, implying that the cake gave the speaker an upset stomach because it was of poor quality. On the other hand, the hearer had the out of assuming that the cake was "not sitting too well" because the speaker had already eaten too much before or had a delicate digestive system. In comparison, one GG made an ungracious remark that was clearly insulting, leaving the addressee no out: "Das Stück ist mir zu süß." ("The cake is too sweet for me."-GG4). Another GG made very direct use of an imperative telling the 
addressee to rescind the offer: .".Laß mal..." (."..Back off..." in the sense of ."..Stop pressuring me..."-GG3).

Level of Hostility towards the Second Offer: Despite the various elements of politeness in GG responses, the data for this group also contained the greatest number of the harsher strategies. None of the GEs' responses expressed hostility, but two subjects let the hearer know that they felt uncomfortable and pressured: "If I can do you a favor, o.k.." (GE3); and "Well, if I absolutely have to. Why not." (GE11). Only the forced, unenthusiastic acceptances displayed any degree of irritation toward the addressee; otherwise the refusals of the second offer treated the eliciting speech act as a normal behavior on the part of the friend offering the cake. Only one AE gave a hostile response, a threat of negative consequences for the interlocutor that posed a face risk because of its rudeness. In that sense it was almost an insult, although it in no way attacked or criticized the addressee: "If you don't mind me vomiting on your rug." (AE6). By contrast, three GG responses expressed some real hostility. One face-threatening response consisted of an imperative to rescind the offer and a brusque statement of negative willingness: "Jetzt hör doch auf! Ich nehme mir schon eins, wenn ich will." ("Now stop it! I'll take a piece if I want to."-GG4). (This response is indeed a far cry from a GE set condition that also stated that the speaker wished to serve herself: .".. But don't worry, I will feel myself at home and just take another piece later on if I'd like to."-GE10.) Another GG's guilt trip commingled reproachfulness and empathy, implying that the addressee was attempting to manipulate the speaker through her hurt feelings: "Bitte respektier's doch und versuche nicht, mir etwas aufzuzwingen! Meine Entscheidungen möchte ich gerne selber treffen 
können, ohne Dich zu verletzen." ("Please respect [what I said] and don't try to force something on me! I'd like to be able to make my own decisions without hurting your feelings."-GG9). A third GG's response in the second section did serve as an acceptance of the offer, but beyond that, the speaker's intentions in the written response were ambiguous. Without contextual and paralinguistic cues it could not be determined if the speaker was giving in somewhat willingly and playfully blaming his friend for the temptation, or if he was accepting unwillingly because he has been hassled into it. If the remark was intended seriously, then this would have been a strong expression of resentment: "Verdammt, aber wenn ich an Verfettung sterben sollte, hoff" ich, daß Du ein schlechtes Gewissen hast." ("Dammit, if I die of obesity, I hope you'll have a guilty conscience."-GG3).

Tone of Acceptance: There was considerable divergence between the various remarks used to accept the offer in terms of the willingness or reluctance couched in the acceptance. Those responses expressing amenability (even if the acceptance was subsequently limited by requesting a small slice) included the following (one $\mathrm{AE}$, three GGs, and six GEs): "Well... maybe just a little!" (AE5); an offer of alternative functioning similarly to acceptance: ."..I'd love to take a small piece home, though, if you're trying to get rid of it." (AE10); "Also gut. Das ganz kleine da, aber dann ist Schluß.” (“Oh, alright. The real small one there, but that's it."-GG1); "Also gut, aber wirklich nur ein winziges.." ("Oh, alright, but really just a tiny one.."-GG6a); "Also gut, aber nur weil er so lecker war und bitte nur noch ein ganz kleines." ("Oh, alright, but only because it was so delicious, and please just a very small one."-GG11); "O.K. But just a very little one." (GE1); "Okay, 
but a very small one, please." (GE6); "But really a very little piece." (GE8); "If you promise just to give me a little piece, ok." (GE9); "Well-O.k., you're right, why not?! Just a little one." (GE12). One GE used a promise and a set condition that expressed a certain willingness to accept the offer: .". But don't worry, I will feel myself at home and just take another piece later on if I'd like to." (GE10).

A number of respondents (one $\mathrm{AE}$, one $\mathrm{GG}$, and two $\mathrm{GEs}$ ) allowed their disinclination to shine through, ranging from balking somewhat to accepting with such apparent unwillingness, that the remark actually served as a refusal: "Oh, all right." (AE8); "Verdammt, aber wenn ich an Verfettung sterben sollte, hoff' ich, daß Du ein schlechtes Gewissen hast." ("Dammit, if I die of obesity, I hope you have a guilty conscience."GG3); "If I can do you a favor, o.k.." (GE3); and, "Well, if I absolutely have to. Why not." (GE11). One GE accepted only conditionally: "If it's made of carrots \& without sugar, then, okay." (GE4).

FTA Strategies: In the first response section, the most frequently chosen FTA strategy was negative politeness, followed by positive politeness, with minor use of "bald on record" refusals. This shifted to acceptance (i.e., opting not to perform the FTA), and increased use of positive politeness and "bald on record" responses in the second part. There were no off record refusals (which would have involved postponement, e.g., "Maybe later...").

In DCT\#9, negative politeness consisted of responses involving statements of regret or gratitude, "no"-plus-downgraders, and/or polite reasons. To be included in this category, responses had to contain some sort of positive form. Negative politeness was 
chosen by over half of the AEs, half of the GEs, and just under half of the GGs in the first section. The placement of one particular AE response in this category was uncertain because of the possible face risk involved in the speaker's reason (discussed above): "No thank you. The first one really isn't sitting too well." (AE9). Taken as a simple remark about the speaker's digestion, however, the response as a whole could be viewed as an instance of negative politeness. In the second section, out of all the subjects, only three GGs used this strategy. One reply in particular created a good deal of distance, both because of its formal tone and because it appeared to be a transparent untruth, unrelated to the reason given in the first response section and intended to cut the discussion shortThe overall effect was polite, if stiffly formal: 1. "Nein danke, ich habe schon etwas zu mir genommen." 2. "Du mußt mich dafür entschuldigen aber ich bin zur Zeit auf Diät." (1. "No, thank you, I've already eaten something." 2. "You must excuse me, but I am on a diet at the moment."-GG5).

Responses reflecting positive politeness contained compliments, statements of positive opinion, and excuses that provided a somewhat more personal disclosure of information in, signaling closeness. In the first section, the GEs displayed the greatest proclivity for this category, followed closely by the GGs (half of the GEs, and just under half of the GGs). Contrary to the usual pattern in the DCT, the AEs made considerably less use of positive politeness in the first section than the Germans (only two AEs). One of the GG responses and one of the GE responses included in this tally were a little more formal than the others, but the use of compliments signaled a wish to make the hearer "feel good": "Nein [sic] Danke. Der Kuchen ist sehr gut, aber ich kann wirklich nicht mehr." 
("No, thank you. The cake is very good, but I really can't eat any more."-GG10) and "Oh, no, thank you. It's delicious but I'm full." (GE7). While a fourth of the AEs used positive politeness in the second section, only a fifth of the GGs and one GE did. A number of respondents who had used negative politeness in the first part switched to positive politeness in the second, adding a compliment or some other sign of friendliness to convince the host/ess that they were not refusing out of modesty.

A number of respondents chose the option of not performing the FTA in the second section (i.e., accepting the offer rather than refusing. This was not possible in the first section because of the interlocutor's rejoinder.). There were, however, great differences to the degree of willingness or lack of enthusiasm expressed in these responses. Those on the more unwilling end of the continuum closely approached refusals performed baldly on record (See discussion of the "Tone of Acceptance"). While over half of the GEs accepted willingly and somewhat willingly (technically, two-thirds of the GEs accepted), only one-fourth of the AEs and one-fifth of the GGs did.

On the less tactful side, a number of respondents chose to perform the refusal without redressive action. In the first part, only one-fourth of the AEs, two GGs, and no GEs used this strategy. In the second section, however, in order to increase the impact of the refusal, half of the AEs, $40 \%$ of the GGs, and one-third of the GEs used this strategy. One of these GE responses was an acceptance in form, but so baldly expressed the speaker's unwillingness to have more cake that it seemed more appropriate to include it in this classification: "Well, if I absolutely have to. Why not." (GE11). 
Summary of Results: Refusal of Offer Made by an Equal-Status Interlocutor (DCT\#9)

Regarding direct refusal strategies, all three groups made frequent use of the polite routinized form, "no, thank you" in the first response section, particularly the AEs and GGs. The brusque negative forms (i.e., "no"-plus-upgrader, bald "no", and statements of negative willingness) were avoided, with the exception of bald "no", used by only one GG and one GE, but one-fourth of the AEs. While almost one-third of the GGs used statements of negative ability, the strategy found little use in the other two groups. Use of the more abrupt forms of direct refusal increased considerably in the second section, while the "no"-plus-downgrader strategy practically vanished, particularly amongst the AEs. As in the first section, almost one-third of the GGs used statements of negative ability.

While the two groups of Germans displayed more face-saving politeness in regards to their use of direct refusal strategies than the AEs, the reverse was the case in terms of frequencies of reasons, and to a very small degree, excuses. While little use was made of excuses in either section, reasons were highly prominent in the first section. In the second section, none of the German subjects used reasons, but one-third of the AEs did. AE reasons exhibited considerable uniformity, while the GGs produced somewhat more original reasons, and the GEs found middle ground between the two positions. Reasons focused on being full or already having had enough to eat.

No evasive strategies occurred in the first section, but in the second, one GG and two GEs used acceptance that functioned as a refusal, and one GE used a set condition for future acceptance. 
Regarding strategies that increased the face risk, there was practically no use of these forms in the first section, although one GG insult, one GG imperative to rescind the offer, and a possible $\mathrm{AE}$ statement of negative opinion occurred, and there was one GE and one GG upgrader. In the second section, use of these strategies increased, especially upgraders (used by over half of the AEs and one-third of the GGs, but only two GEs). The vast majority of upgraders were an unthreatening means of reinforcing direct refusals. There were only two exceptions to the otherwise mild tone of upgraders in DCT\#9: two GGs, one of whom added an element of reproach to her response through an upgrader, while the other increased the force of a guilt trip by using an expletive. While the GEs showed complete restraint with unfavorable forms, two GEs did let the addressee know that they did not appreciate being pressured to accept another piece of cake. One $\mathrm{AE}$ made a crude remark coded as a statement of negative consequences to the interlocutor, and the GG data included two guilt trips and two imperatives to drop the offer. All in all, the GGs produced more instances of antagonistic strategies than the other two groups.

In the second response section, the AEs and GEs reacted to the friend's insistence mostly by dropping the downgraders present in the first section and adding upgraders / intensifiers and more elaborate reasons. While the frequency of GG downgraders dropped off somewhat in the second section, there was by no means the contrast that occurred in the GE and AE data. In the second section, the GGs had by far the largest number of positive forms (not counting the various acceptance strategies), and a considerably higher proportion of GEs accepted the offer than the other groups. While over half of the GEs 
accepted the second offer, only a fourth of the AEs and a fifth of the GGs did so. A few acceptances expressed a degree of reluctance.

In all three groups, positive forms and adjuncts found more extensive use in the first than in the second section, except for acceptance (which was restricted to the second section by the text of the DCT item). In the first section, almost half of the German subjects used compliments, in contrast to the AEs' slight use thereof. A few GEs also used statements of regret and gratitude, while only one GG used a statement of regret, and none of the AEs did. In the second section, neither the GEs nor the AEs used the stronger positive forms except for one AE compliment, but a few GGs used compliments and statements of positive opinion, regret, and gratitude. Downgraders found extensive use in the first section in all three groups, but was only used frequently in the second section by GGs. The GEs had the greatest number of positive forms and mitigating adjuncts per response. Overall, mitigating adjuncts played only a very minor role in DCT\#9. The abundance of compliments in the GG and GE data for DCT\#9 and the dearth thereof amongst the AEs reversed the usual pattern of responses to the DCT. This phenomenon is discussed further in Chapter 5 .

Regarding distribution patterns of FTA strategies, over half of the AEs, half of the GEs, and just under half of the GGs used negative politeness in the first section, while half of the GEs, just under half of the GGs, but only one-sixth of the AEs used positive politeness (a reversal of the usual relative frequency of positive politeness between the American and German subjects). While none of the GEs performed the refusal baldly on record in the first section, one-fourth of the AEs and two GGs did so. 
In the second section, negative politeness was used only in one-fifth of the GG, and none of the $\mathrm{AE}$ or $\mathrm{GE}$ responses. Positive politeness occurred in one-fourth of the $\mathrm{AE}$ and one-fifth of the GG responses, but in only one GE response. Over half of the GEs opted not to perform the FTA (i.e., they accepted the offer), whereas only one-fourth of the AEs and one-fifth of the GGs did so. A fairly significant number of respondents performed the refusal baldly on record in the second section: half of the AEs, $40 \%$ of the GGs, and one-third of the GEs.

The Germans' greater politeness and formality in this situation as compared with the AEs can perhaps be explained by intercultural differences. The German custom of having coffee and cake on weekend afternoons may be enough of a tradition to be steeped in conventions governing linguistic behavior, while the AEs tended to view the situation more casually (see discussion in Chapter 5). Despite the overall tendency of GG and GE responses to be more polite than those of the AEs, however, it was only amongst the GGs (and one $\mathrm{AE}$ ) that a real face threat was risked.

\section{DCT \#11: Refusal of Higher-Status Interlocutor's Request}

\section{Frequency of Functional Categories}

While the AEs made practically no use of direct refusal strategies (a sole statement of negative willingness), half of the GEs and GGs used statements of negative willingness and a third of the GEs produced statements of negative ability.

A number of these direct refusal strategies were softened through the use of downtoners or downgraders. One GG softened the form, "no", with a downgrader (GG6). 
Two GGs (GG6, GG10) and two GEs (GE6, GE9) conjoined their statements of negative willingness with downtoners. One GE (GE4) mitigated a statement of negative ability with a downtoner, another GE (GE12) used a downgrader for the same purpose, and a third one (GE1) used two downgraders. On the other hand, one GG sharpened her statement of negative willingness with an upgrader (GG7).

The one AE using negative willingness (AE12) elaborated on that strategy by way of a statement of philosophy.

There were a number of amalgamated forms combining statements of negative willingness with reasons (GE5, GE6) or statements of philosophy (GG7); and a statement of negative willingness/ability with a reason/excuse (GG11).

Table 4. 80: Use of Direct Refusal Strategies; Offer; Higher-Status Interlocutor (DCT\#11)

\begin{tabular}{|l|l|l|l|l|l|}
\hline & "No" & $\begin{array}{l}\text { Negative } \\
\text { Willingness }\end{array}$ & $\begin{array}{l}\text { Negative Willingness } \\
\text { Ability }\end{array}$ & Negative Ability & Performative \\
\hline AEs & & $8 \%$ & - & & - \\
\hline GEs & & $50 \%$ & - & $33 \%{ }^{74}$ & $8 \%{ }^{75}$ \\
\hline GGs & $14 \%$ & $50 \%$ & $7 \%$ & - & - \\
\hline
\end{tabular}

The excuses and reasons given in this particular DCT item were nearly equally

polite. By presenting the speaker's reservations about accepting the position through the use of excuses, there was an appearance of the situation being "out of my control", while the reasons honestly acknowledged an unwillingness to relocate. Upon closer examination

\footnotetext{
${ }^{73}$ Two of the GEs and three of the GGs used opaque negative willingness (one of which was expressed by way of an offer of alternative: Why don't you do X instead of Y? GG4). See content section.

${ }^{74}$ One of these Ges expressed negative ability by way of a performative conjoined with two downgraders: “...I think I have to refuse." (GE1)

${ }^{75}$ This is the same GE subject who was mentioned in the previous footnote.
} 
of the content, however, the excuses revealed themselves to be only somewhat disguised expressions of unwillingness. For this reason, these strategies were considered equally tactful for the ranking of the three subject groups in terms of relative politeness.

Normally, the functional category, "statement of negative opinion", clearly belongs to the set of strategies that increase the face threat to the addressee. In the case of DCT\#11, however, all instances of negative opinion were in effect a subset of the "reason" category. They differed from other reasons in that they specifically mentioned the "down sides" of relocation and thus did not enhance politeness. None of them, however, posed a particular face threat either (e.g., ."..I don't like moving." (AE4), or ."..I don't think I would enjoy living that far away." (AE9).

Over half of the respondents in all three groups gave reasons for declining the offer. Use of other related forms was less frequent: one-third of the GEs gave excuses, one-fourth of the AEs produced statements of philosophy, and one-third of the AEs made statements of negative opinion. Otherwise, use of these forms was limited.

A number of subjects mitigated their reasons with downtoners (AE4, AE5, GG1, GG2, GG8) or downgraders (GE8). The GG who used a reason / excuse softened it with a downgrader (GG11). One AE elaborated on his reason (AE3) and another AE gave two reasons (AE2). Two GGs also gave two reasons (GG2 and GG8). One GE elaborated on his reason (GE3) and another gave two reasons (GE8). Excuses were mitigated through downtoners by GG9 and GG12. One GG gave two excuses (GG12).

${ }^{75}$ This is the same GE subject who was mentioned in the previous footnote. 
negative willingness, as was a reason / excuse and a statements of negative willingness / ability.

One AE stated two negative opinions, softening one with a downgrader and the other with a downtoner (AE9). AE11 used a downtoner with her negative opinion. Another amalgamated her negative opinion with a statement of philosophy (AE10). Both of the GEs who stated a negative opinion conjoined them with a downgrader (GE1 and GE4).

Table 4. 81: Use of Excuses, Reasons, Statements of Philosophy, Negative Opinion, and Set Condition; Offer; Higher-Status Interlocutor (DCT\#11)

\begin{tabular}{|l|l|l|l|l|l|l|}
\hline & $\begin{array}{l}\text { Set } \\
\text { Condition }\end{array}$ & Excuse & Reason & $\begin{array}{l}\text { Ambiguous } \\
\text { Reason/Excuse }\end{array}$ & Philosophy & $\begin{array}{l}\text { Negative } \\
\text { Opinion }\end{array}$ \\
\hline GEs & - & $33 \%$ & $58 \%$ & - & $17 \%$ & $17 \%$ \\
AEs & $8 \%$ & - & $67 \%$ & - & $25 \%$ & $33 \%$ \\
GGs & $-14 \%$ & $50 \%$ & $7 \%$ & $21 \%$ & - \\
\hline
\end{tabular}

Face-Threatening Strategies: There was only one portion of a remark that

functioned as a mild upgrader, with a slight possibility of increasing the face risk: "Danke, aber [sic] will auf keinen Fall einen Ortswechsel für höheres Gehalt in Kauf nehmen.” ("Thank you, but there's no way I want to put up with relocation for the sake of a higher salary."-GG7). This upgrader might have posed a face risk because of the uncompromising stance it expressed. While other respondents made it clear that they wished or needed to refuse the offer, this subject closed the door on further negotiation.

None of the GEs and only one AE used an evasive strategy, but the GGs made light use of these functional categories.

\footnotetext{
${ }^{76}$ This strategy is listed first because in its one occurrence, it was particularly polite towards the addressee: "...If I didn't have to leave here, I'd jump on it like a shot." (AE6).
} 
None of the GEs and only one AE used an evasive strategy, but the GGs made light use of these functional categories.

Table 4. 82: Use of Evasive Strategies; Offer; Higher-Status Interlocutor (DCT\#11)

\begin{tabular}{|l|l|l|}
\hline & Hedging & Postponement \\
\hline GEs & - & - \\
AEs & $8 \%$ & - \\
GGs & $14 \%$ & $14 \%$ \\
\hline
\end{tabular}

While over half of the AEs and just under half of the GEs and GGs made statements of positive opinion, the only other prominent uses of positive forms were statements of gratitude in one-third of the GE responses, and downgraders in around onethird of the GE and GG replies.

Preferences for certain positive forms differed between the American and German subjects. While the AEs favored statements of positive opinion, which were the stronger forms in terms of positive content, they made little use of the weaker forms. The Germans, on the other hand, made somewhat less use of statements of positive opinion than the AEs, but used the weaker forms more frequently.

Table 4. 83: Use of Positive Forms / Adjuncts; Offer; Higher-Status Interlocutor (DCT\#11)

\begin{tabular}{|l|l|l|l|l|}
\hline & Positive Opinion $^{\mathbf{7 8}}$ & Gratitude & Regret & Downgrader \\
\hline AEs & $58 \%$ & $8 \%$ & $8 \%$ & $8 \%$ \\
GEs & $42 \%$ & $33 \%$ & $17 \%$ & $33 \%$ \\
GGs & $43 \%$ & $21 \%$ & $14 \%$ & $29 \%$ \\
\hline
\end{tabular}

Mitigating adjuncts figured in a number of responses to DCT\#11, especially forewarns in the $\mathrm{AE}$ data, and downtoners in all three groups.

\footnotetext{
${ }^{77}$ One of these statements of philosophy was only implied: “...and, sure, 'raise of pay' always sounds good..." (GE7). See content section for discussion.
} 
Table 4. 84: Use of Mitigating Adjuncts; Offer; Higher-Status Interlocutor (DCT\#11)

\begin{tabular}{|l|l|l|l|}
\hline & Forewarn & Downtoner & Pause Filler \\
\hline AEs & $33 \%$ & $33 \%$ & $8 \%$ \\
GGs & $7 \%$ & $50 \%$ & $14 \%$ \\
GEs & $17 \%$ & $25 \%$ & $17 \%$ \\
\hline
\end{tabular}

The AEs and GGs were similarly polite in terms of the number of positive forms per response, except that the distribution patterns differed (the GGs had both more respondents with no positive forms and respondents with two positive forms).

Table 4. 85: Number of Positive Forms / Adjuncts per Response; Offer; HigherStatus Interlocutor (DCT\#11)

\begin{tabular}{|l|l|l|l|l|l|l|}
\hline & $\mathbf{0}$ & $\mathbf{1}$ & $\mathbf{2}$ & $\mathbf{3}$ & $\mathbf{4}$ & $\mathbf{5}$ \\
\hline GES & $8 \%$ & $67 \%$ & $17 \%$ & - & - & $8 \%$ \\
GGs & $29 \%$ & $43 \%$ & $29 \%$ & - & - & - \\
AEs & $25 \%$ & $58 \%$ & $17 \%$ & - & - & - \\
\hline
\end{tabular}

Here again the AEs and GGs were nearly equivalent in terms of using mitigating adjuncts as a means to increase harmony between speaker and hearer. The difference is once again a matter of distribution.

Table 4. 86: Number of Mitigating Adjuncts per Response; Offer; Higher-Status Interlocutor (DCT\#11)

\begin{tabular}{|l|l|l|l|l|}
\hline & $\mathbf{0}$ & $\mathbf{1}$ & $\mathbf{2}$ & $\mathbf{3}$ \\
\hline AEs & $42 \%$ & $50 \%$ & - & $8 \%$ \\
GGs & $43 \%$ & $43 \%$ & $14 \%$ & - \\
GEs & $50 \%$ & $42 \%$ & $8 \%$ & - \\
\hline
\end{tabular}

\section{Content of Functional Categories}

Statements of Negative Willingness and Negative Ability: Statements of negative willingness and negative ability were an important feature in the GE and GG data, but not

\footnotetext{
${ }^{78}$ Statements of positive opinion weighed in more heavily than the other positive forms in determining which subject group chose the most polite strategies because they carried the strongest commitment to positive content.
} 
amongst the AEs. As stated above, even statements of negative ability let a good deal of unwillingness show through, although cloaked in assertions of circumstances beyond the speaker's control. Like opaque statements of negative willingness, they were a means of increasing the tactfulness of firm refusals.

Explicit statements of negative willingness in the GG data included: ."..ich [bin] nicht bereit einen Ortswechsel zu vollführen. ..." (."..I'm not willing to carry out a relocation. ..."-GG3), ."..ich will eigentlich nicht weg. ..." (."..I don't really want to leave. ..."-GG6), ."..[ich] will auf keinen Fall einen Ortswechsel für höheres Gehalt in Kauf nehmen." (."..there's no way I want to put up with relocation for the sake of a higher salary."-GG7), and, .".Das kommt furr mich nicht in Frage. ..."("That's out of the question for me. ..."-GG14).

Three GEs directly expressed unwillingness: .".I don't want to leave this area." (GE5); .".II really don't want to move. ..." (GE6); and, .".I really don't want to move. ..." (GE9). Only one AE used a statement of negative willingness, which then lapsed into expression of a negative attitude (This was the $\mathrm{AE}$ discussed earlier, who tended to use much harsher responses than the other AEs, and who was the only AE to risk open confrontation with the boss in DCT\#12. See description in content section of DCT\#12.): .".I don't want to move. I don't care how much money I'll make." (AE12).

One GG statement could have functioned as either negative willingness or ability (and the ambiguity was not clarified through the explanatory statement about the speaker's family): .".ein Umzug kommt leider wegen meiner Familie nicht in Frage." (.".I'm afraid a move is out of the question because of my family."-GG11). 
Several instances of opaque negative willingness occurred amongst the GEs and GGs in response to the boss' offer. This strategy was interesting in its complexity. Although statements of negative willingness are by definition direct, these forms expressed unwillingness in terms of content, but in a very indirect way, avoiding explicit mention of the offer that was being rejected. Many, but not all, opaque statements of negative willingness were fairly tactful and somewhat evasive. For example, by stating that the speaker would rather keep the old position, a much more face-threatening remark along the lines of, "I don't want to go there" was avoided. The two GE remarks in this category were: .".I'd rather stay here..." (GE11), and "I couldn't even if I'd want,..." (i.e., "I couldn't, even if I wanted to, ..."-GE2). The latter remark presupposed that "I don't want to."

Three GGs expressed unwillingness by way of opaque negative willingness: ."..[ich möchte] doch lieber meine alte Stelle behalten." (."..I'd rather keep my old position."GG10). One GG made a remark that was so polite (almost altruistic) and indirect that, on the surface, it almost appeared to be a statement of alternative: .".ich lasse lieber jemandem anderen den Vortritt" ("I'd rather let someone else be given precedence"GG1). On a deeper linguistic level, however, the actual function was opaque negative willingness. This was a more polite version of another GG's suggestion of an alternative (you can do $\mathrm{X}$ instead of $\mathrm{Y}$ ), which also functioned as opaque negative willingness: "Suchen Sie sich jemand anderen." ("Find yourself someone else."-GG4). The brusqueness of the latter remark stemmed from the unmitigated imperative and mention of the addressee as agent. This remark might have led to a face threat. 
Statements of negative ability were used only by the GEs: ."..I couldn't even if I'd want..." (GE2-this remark was directly followed by an opaque statement of negative willingness), and ."..I won't be able to move. ... I won't be able to do it." (GE12). One GE used a performative with two downgraders as a means of expressing negative ability: ...I think it's too far away from my home and my family. ... I think I have to refuse." (GE1). One could argue that in context, both GE1's and GE2's remarks expressed inability only in their outward form; on a deeper level, they actually indicated unwillingness.

Statements of Positive Opinion and Gratitude: There was a considerable difference in the frequency of enthusiastic statements of positive opinion or gratitude in the $\mathrm{AE}$ and GG data on the one hand, and in the GE data on the other. A large proportion of AEs and GGs used highly convincing words to convey their appreciation of the offer, while the GEs on the whole were more circumspect.

Such AE responses included: "[sic] Im very flattered that you offer this to me. ..." (AE1); "I'm honored that you believe in my skills..." (AE2); "Thanks, I really do appreciate the offer..." (AE3); "I would love it..." (AE4); "I'm honored / flattered that you've considered me for this position..." (AE5); .... it sounds like a great opportunity. ..." (AE6); "It sounds great..." (AE9); and, "Your offer is certainly tempting..." (AE10).

Emphatic GG statements included: .".Danke für das tolle Angebot..." (."..Thank you for the great offer..."-GG1); "Das ehrt mich, daß [sic] sie ein solches Vertrauen in mich setzen..." ("It's an honor that you place such confidence in me..."-GG3); "Klingt fast zu verlockend..." (“Sounds almost too tempting..."-GG6); ....es [wäre] sehr verlockend." 
(."..it would be very tempting."-GG8); "Das finde ich sehr freundlich, daß Sie MIR die Stelle anbieten. ..." ("I'm very grateful to you for offering ME the position. ..."-GG9); "Ihr Angebot klingt sehr verlockend..." ("Your offer sounds very tempting..."-GG10); and, "Natürlich klingt das Angebot sehr verlockend..." ("The offer sounds very tempting, of course..."-GG11). A number of GGs used the same wording, suggesting a certain degree of routinization.

The following GE remarks made a strong positive statement: ...I'm [sic] quiet honored by your offer..." (GE1); "I really appreciate that..." (GE5); and, ."..I feel very honoured by your offer. ..." (GE11).

A number of other GG and GE statements expressed a more ordinary level of intensity: "Ich [sic] Danke Ihnen für dieses Angebot..." ("I thank you for this offer..."GG5); "Danke..." ("Thank you..."-GG7); "Thank you..." (GE2); "Thank you for this offer..." (GE3 and GE9); "I'm interested in the job..." (GE6); "This would be a good chance for me, of course. ..." (GE10); and, "Sounds good, of course..." (GE12).

Reasons: Reasons varied along the dimension of positive or negative emphasis. Themes of positive reasons revolved around family stability, satisfaction with the current position, and proximity of family and friends in the current locale, whereas negative reasons cited the unappealing aspects of moving.

All but one of the $\mathrm{AE}$ reasons were either positive or followed immediately by positive reasons. These included: ."..all of my friends and family are here, and I just couldn't bear to leave them or this town." (AE3); ."..I really would like to stay here..." (AE4); .".I'm really happy where I am." (AE5); ."..we just moved here a couple months 
ago." (AE8); and, ."..my family and friends live here..." (AE12). In two cases, respondents gave a negative and a positive reason, whereby the negative one was balanced out by the positive one: .".I would find it too difficult to move that far away. My family lives here." (AE2) and .".I'm not really excited about having to relocate. My whole family is here in town." (AE11). Only one respondent gave a reason with a less positive approach, focusing solely on the negative aspect: ."..it would be very difficult for us to relocate right now." (AE7), but this was still phrased carefully and tactfully.

Like the AEs, all but one GE focused on the positive aspects of the current locale or position in their reasons: .".I bought a house here recently and I [sic] planed to settle down." (GE3); ....I don't want to leave this area." (GE5); .".. I don't want to live [sic] to far away from my family." (GE6); .".I'm feeling completely comfortable with my position here." (GE8); .". I like this town and my friends live here." (GE9); and, .".. I feel very much at home here." (GE11). The one exception to the overall positive focus was an ambiguous remark that cited unspecified "reasons." Implicitly, the focus of the reason leaned towards the more negative view: ."..there are too many reasons that stand against this new job." (GE7).

GG reasons ranged from positive to negative, with fairly equal distribution between the two poles. Reasons that focused on the benefits of staying put included: ...ich [bin] hier mit meiner Anstellung sehr, sehr zufrieden. ..." (."..I'm very, very satisfied with my position here. ..."-GG1); ."..ich bin hier eigentlich mit allem sehr glücklich. ..." (.".. I'm actually very happy with everything here. ..."-GG2); ."..ich wohne hier sehr gern..." (."..I like living here very much..."-GG3); .".. Mir gefällt's sehr gut hier, der Job 
füllt mich aus..." (.".I like it here a lot; the job fulfills me..."-GG6); and, "Eigentlich fühle ich mich in meiner jetzigen Position recht wohl..." ("Actually, I feel very comfortable in my current position..."-GG8).

A number of $\mathrm{GG}$ reasons reflected a negative attitude toward moving. One GG expressed his negative view indirectly through use of the word, zumuten ("to expect too much of someone, to impose on someone"): ."..ich [möchte] dies meiner Familie nicht zumuten." (.".I wouldn't want to impose this on my family."-GG2). In context, GG14's reason suggested a negative attitude towards moving, although this was not unambiguous: ...Das kommt für mich nicht in Frage. Im Moment kann ich mir nicht vorstellen umzuziehen." (.".. That's out of the question for me. At the moment I can't imagine moving."-GG14). Another reason implied a negative view: .”..[sic] an Betrachts des nötigen Umzuges..." (...in view of the required move..."-GG10).

One GG made a statement that was ambiguous in terms of whether it was a reason or an excuse. This remark possibly involved an implied negative view, depending on interpretation, i.e., if the speaker was suggesting that a move would be something disruptive and unpleasant for the family: .".ein Umzug kommt leider wegen meiner Familie nicht in Frage." (."..unfortunately, a move is out of the question because of my family."-GG11). This clever remark could be taken to mean that circumstances beyond the family's control made it absolutely impossible to move, but it could also mean that the family was dead set against moving.

Statements of Negative Opinion: While this strategy occurred fairly frequently amongst the AEs, only two GEs and none of the GGs used statements of negative opinion. 
As noted in the frequency section, statements of negative opinion were not particularly face-threatening in the case of DCT\#11-they were merely a subset of the "reason" category that made mention of the negative aspects of relocation. Negative opinions of the AE data included: .".I don't like moving." (AE4), ."..I don't think I would enjoy living that far away." (AE9); .".the idea of relocation is not one which appeals to me at all..." (AE10); .".I'm not really excited about having to relocate. ..." (AE11); .".. I'm not really interested in moving. ..." (AE9); and, ."..the idea of relocation is not one which appeals to me at all for any amount of money." (AE10). AE8's use of hedging to air her "second thoughts" was related to this strategy: "I don't know... I'm having second thoughts because we just moved here a couple months ago.." Two GEs voiced negative opinions: ...but I think it's too far away from my home and my family" (GE1); and, .".. And seven hours is just to much I think" (GE4).

Statements of Philosophy: Statements of philosophy in DCT\#11 articulated the greater priority of one's private life or environment over a more prestigious position or a higher salary. The AEs' and GGs' statements of philosophy gave rise to a potential face threat because they depreciated the value of the position. Indeed, most of these statements insinuated that money would be the only incentive to accept the position. The GEs' statements of philosophy, on the other hand, were considerably more subtle and tactful than the other two groups'.

Two AEs and the three GGs explicitly mentioned that the money would not be worth the move, and another $\mathrm{AE}$ said that the position was not worth it. The three $\mathrm{AE}$ remarks included: .".living here is more important than the executive position." (AE1); 
...the idea of relocation is not one which appeals to me at all for any amount of money." (AE10, an amalgamation of statements of negative opinion and philosophy); and, .".I don't want to move. I don't care how much money I'll make." (AE12, a statement of philosophy used as elaboration on a statement of negative willingness). One GG statement of philosophy displayed a fairly negative attitude (from the hearer's perspective) despite its focus on the positive aspects of remaining at the current position. This was due to the speaker's explicitness in stating that his principle reason for taking the new position would be to make more money, and that it would not be a worthwhile trade-off: "Mir ist mein jetziges Umfeld wichtiger, als mehr Geld." ("My present environment is more important to me than more money."-GG4). While GG6 also made a statement about money as a primary consideration, it followed a statement about finding his current job meaningful (quoted in the previous paragraph), while GG4's remark implied that the most important thing about a job was the money. In addition, GG6's comment about money was phrased in a more philosophical, tactful manner: .".. Mir gefällt's sehr gut hier, der Job füllt mich aus und nur des Geldes wegen..., ..." (."..I like it here very much, the job fulfills me, and just for the money......."-GG6). In another GG response, an amalgamation of a statement of negative willingness and a statement of philosophy implied a negative attitude: ."..[ich] will auf keinen Fall einen Ortswechsel für höheres Gehalt in Kauf nehmen." (.”.there's no way I want to put up with relocation for the sake of a higher salary."-GG7).

While the GEs stressed the importance of considerations besides job and salary, this was done in an indirect fashion: ."..one has to think of his private life, too. ..." (GE10) and, ."..and, sure, 'raise of pay' always sounds good..." (GE7). The latter remark was only 
an implied statement of philosophy. Expressed in more direct terms, the respondent was saying that accepting relocation in order to get a pay raise is a poor trade-off.

Excuses: The AEs used no excuses. Themes of all the GG and GE excuses involved family responsibilities. One of the GE excuses was rather weak, from a boss' perspective: ."..my son has only 4 years and he wouldn't like to leave all the friends he got." (GE2). Another GE excuse made a statement about being married and having children. This was presented as a situation forcing the speaker to decline the offer, although no specific explanation was given: "Sorry, but I'm married \& have 3 children..." (GE4). Another GE asserted that, .... I can't leave my parents alone." (GE10). While GE10's excuse was both specific and watertight, GE2's was specific, but fairly flimsy, and GE4's was vague and only pretending to be watertight.

All of the GG excuses used strong language emphasizing the impossibility of consenting to the move, but only one was specific (GG12): .".meine familiären Verpflichtungen [halten] mich davon ab, das Angebot anzunehmen..." (.".my familial responsibilities prevent me from accepting the offer..."-GG9) and ."..ich muß meine kranke Oma versorgen und wir haben grade das neue Haus gebaut." (."..I have to take care of my sick grandma and we just built the new house."-GG12).

FTA Strategies: The primary FTA strategy in DCT\#11 was negative politeness, expressed through statements of gratitude and regret, excuses, reasons, statements of philosophy, and statements of positive opinion. While the latter functional category, statement of positive opinion, is often associated with positive politeness, in the setting of DCT\#11, appreciative remarks were in the professional realm, directed towards the value 
of the offer, rather than the interlocutors' interpersonal association. As might be expected, positive politeness did not occur in this business-oriented exchange. All of the AEs and GEs exhibited negative politeness, although four AEs and GEs were not as thoroughly ingratiating as the rest. Most of the GGs also preferred negative politeness, but two GGs refused off record through postponement and hedging, one GG clearly performed the refusal baldly on record, and two other GGs' refusals were bald except for a perfunctory "thanks" or "I'm sorry" in an otherwise uncompromising and unabashed rejection of the offer.

\section{Summary of Results: Refusal of Offer Made by a Higher-Status Interlocutor (DCT\#11)}

While half of the German subjects used statements of negative willingness (a number of which were opaque), only one $\mathrm{AE}$ did. This discrepancy indicated greater frankness on the part of the German subjects, revealing an outlook that the boss might not have liked. On the other hand, the fact that one-third of the AEs used statements of negative opinion (which only two GEs and no GGs did), adding an element of directness, compensated slightly for the disparity in frequencies of statements of negative willingness. In the context of DCT\#11, however, statements of negative opinion were not facethreatening, but only mentioned the undesirability of relocation. The only other direct refusal strategy receiving noteworthy use was the statement of negative ability, which occurred in one-third of the GE responses, but in neither of the other two groups'. In terms of content, statements of negative ability expressed a degree of unwillingness in DCT\#11. 
As noted above, excuses and reasons were nearly equivalent in terms of facesaving politeness. While reasons found frequent use in all three groups, similar forms were used less frequently; aside from production of excuses in one-third of the GEs' responses, and inclusion of statements of philosophy in one-fourth of the AEs' replies, these functional categories hardly occurred. Less favorably oriented reasons remarked on the disadvantages of moving. Reasons with a more positive orientation involved satisfaction with the speaker's current job, the family's stable circumstances, and the nearby presence of relatives and friends in the present location. While the AEs and GEs focused almost exclusively on positive reasons, GGs reasons were fairly equally distributed between positive and negative content. Excuses revolved around family responsibilities. Only one of the three GE excuses was both specific and watertight. One GG excuse was specific and watertight, while the other was vague, but pseudo-watertight.

Reasons were given much more frequently than excuses in DCT\#11, despite the fact that the addressee was of higher status than the speaker. Because relocation would have a great impact on the speaker's life and be a considerable imposition, a reason, which implied unwillingness rather than inability, provided a more solid basis for refusing the offer than an excuse would have. Refusing the offer does not pose a great risk to the addressee's face because the position itself is not being rejected, but rather the distance of the location. (It might be noted that no respondents made any negative remarks about "Hicktown.")

With statements of philosophy, speakers expressed views placing the importance of their home life and social network above promotions and higher salaries. While GE 
statements of philosophy were tactful, the AEs and GGs risked a degree of face threat by letting the addressee know that the major incentive for considering the new position was the additional money.

Face-threatening and evasive strategies found extremely little use in DCT\#11.

The AEs made more frequent use of statements of positive opinion, the functional category with the most persuasive assertion of positive content, than the two groups of Germans. The GGs and GEs, on the other hand, made somewhat more use of statements of gratitude and regret than the AEs. All the AEs used emphatic statements of positive opinion or gratitude, as did most of the GGs, but only one-third of the GEs' positive statements displayed a degree of enthusiasm. While downtoners occurred relatively frequently in responses of all three groups (half of the GGs, one-third of the AEs, and onefourth of the GEs), the only other noteworthy use of mitigating adjuncts was the inclusion of forewarns by one-third of the AEs.

Regarding FTA strategies, all of the AEs and GEs chose negative politeness, although a few respondents were somewhat less deferential than the others. Negative politeness also occurred in the majority of GG responses, but two GGs refused off record, and bald refusals were used by three GGs (although two of these did include a perfunctory mitigating agent).

In sum, the $\mathrm{AE}$ responses showed careful control for tactfulness, avoiding any hint of a negative attitude (with the exception of one $\mathrm{AE}$ who had been untypically confrontative by $\mathrm{AE}$ standards in other $\mathrm{DCT}$ items as well). Many $\mathrm{AE}$ responses commenced with an emphatic statement of positive opinion or gratitude. When giving 
reasons for refusing the offer, $\mathrm{AE}$ respondents avoided critical or negative remarks about relocating, choosing rather to emphasize the positive aspects of staying put. Similarly, when a negative opinion was stated, this was expressed very indirectly. Indeed, in some cases, it required repeated examination and reflection to recognize these remarks as instances of negative opinion. While the German subjects also tended to use polite strategies with the higher-status interlocutor, they were more explicit in expressing unwillingness to accept the offer. Although several GGs used strong statements of positive opinion (but fewer than the AEs), three GGs performed bald refusals, and a number of GG reasons had a more negative focus. The GEs all displayed negative politeness, but were less enthusiastic in their use of positive forms.

\section{Refusals of Suggestions}

DCT\#8: Lower-Status Interlocutor Suggests Having More Conversation in Foreign Language Class

DCT\#5: Equal-Status Interlocutor (Friend) Recommends a New Diet

DCT\#6: Higher-Status Interlocutor Suggests that Employee Write Him/Herself Little Reminders $^{79}$

It is the nature of suggestions that the interlocutor believes $s /$ he has perceived a problem and found a way to solve it. Refusing the suggestion is a threat to the hearer's positive face, because of the possible implication (or explicit statement) that the hearer's idea is not valued. Major methods for refusing suggestions include denying the problem, 
stating an unwillingness to try the advice, criticizing the suggestion, paying lip service to its virtue while finding some excuse why it cannot be followed, or evading it. A characteristic of the two suggestions in DCT\#5 and DCT\#6 is that they are refused because the speaker does not want to accept them-the speaker in DCT\#5 does not want to try the diet and the speaker in DCT\#6 does not want to add little notes to the already existing clutter. The difference between the two DCT items is that with the equal-status, socially close interlocutor, the speaker needs not beat around the bush about his/her unwillingness, whereas with the higher-status, more distant addressee, all this must be expressed with tact. In DCT\#8, on the other hand, the refusal could be based on inability (e.g., constraints of the university's language program, or the fact that it is too late in the term to implement the idea).

The eliciting speech act in DCT\#8 is a suggestion only in terms of its form; its actual content is that of a request. This is evidenced by the fact that a number of strategy choices respond not to the suggestion, but to the request (e.g., the use of statements of alternative, either proposing another option for fulfilling the content of the request or stating the availability of other options). On the other hand, a number of subjects also responded to the form of the suggestion, which, in this context, was perhaps more of a face threat than the form of a request. In other words, a student suggesting that the professor make changes in the class could be perceived as more offensive than a student requesting such changes. The hearer's suggestion poses a face threat to both the speaker's positive and negative face, as compliance would interfere with the teacher's planning, and

\footnotetext{
${ }^{79}$ For more information, the text of the DCT can be found in Appendix A, Discourse
} 
the suggestion might be interpreted as subtle criticism of the speaker's teaching. This is reflected in a number of fairly hostile responses given by subjects.

From the hearer's perspective, the refusal (without additional face-threatening remarks) might be dismaying, but s/he could expect to find other options for getting conversational practice. Thus, the hearer probably does not have a high stake in acceptance of the suggestion. For the speaker, on the other hand, accepting the request underlying the suggestion would require a fairly significant imposition, reorganizing the entire curriculum for a course that is already in progress. These factors are reflected in the responses: the respondents saw little need to greatly soften their refusals, they chose straightforward explanations for the speaker's refusal (e.g., via statements of principle and reasons), and vented undisguised irritation in a number of replies.

In DCT\#5, not only are the interlocutors of equal status, but the social distance is also very low. They are close enough for the speaker to say that s/he has been "eating like a pig" and for the friend to recommend a diet, a fairly intimate suggestion. Regarding the hearer's stake in having the suggestion accepted, this is a matter that really only concerns the speaker, so the friend should not be particularly perturbed by the outcome. These features of the DCT item permit responses with a simple structure-most respondents saw little or no need to soften their refusals, merely explaining why they were unwilling to try the diet.

At the same time, however, it appears that the friend has some emotional investment in the outcome, implied in the text of the DCT item through a remark about 
previous urging,: .".this new diet I've been telling you about...." Acceptance of the suggestion would obviously be an imposition on the speaker if $s / h e$ is not interested in dieting in general or in that diet specifically. In addition, there is the imposition of being harried into doing something one does not want to do, into accepting an unwelcome suggestion. The DCT item also implies interpersonal dynamics resembling a tug-of-war, the friend repeatedly urging the speaker to try the diet and the speaker repeatedly refusing (Indeed, DCT\#5 provides more hints of interpersonal dynamics that most of the DCT items.). These factors led, in some cases (mostly in the GG and GE data), to remarks signaling irritation at the hearer's persistence.

Forms emphasizing inability scarcely appeared in the data for DCT\#5, i.e., statements of negative ability or excuses (Obviously, it would be hard to make up an excuse for not going on a diet after complaining about "eating like a pig" and not having one's clothes fit.).

The suggestion that elicits a refusal in DCT\#6 is clearly useless, indeed counterproductive, but it is the boss' suggestion. Responding appropriately requires a careful weighing of priorities: the natural inclination to shun ineffectual advice versus the expediency of placating the boss. As might be expected, most respondents avoided contradicting the boss.

The trigger event for the boss' suggestion is the employee's inability to find a report on his/her cluttered desk. Such circumstances obviously set the stage for a degree of uneasiness on the part of the employee. Defensive response patterns in the data seemed to indicate that a number of subjects perceived the boss' suggestion as face-threatening 
criticism. Statements of self-defense played an important role in attempts to restore a positive image of the employee in the boss' eyes. Some respondents made up contrived excuses because of "power-over" dynamics. More aggressive responses reflected a perception that the employee was criticized unjustly or that the boss made unreasonable demands.

In DCT\#6, the addressee does not have a high stake in the employee's agreement to try the suggestion or not. The boss might be expected to anticipate a courteous response, maintaining the social status quo. Also, regardless of whether the advice is accepted or rejected, the boss would expect the employee to develop some means of reducing inefficiency in the future. For the speaker, unwillingly accepting the absurd advice would increase the disorder and chaos that is already causing trouble. Thus, the tendency for a speaker would be to make a firm refusal while maintaining adequate politeness (although not all respondents chose to do so).

\section{DCT \#8: Refusal of Lower-Status Interlocutor's Suggestion}

\section{Frequency of Functional Categories}

While the AEs and GEs both made negligible use of direct refusal strategies, these functional categories played at least a small role in the GG data.

All of the instances of statements of negative ability in the responses to DCT\#8 were actually less explicit expressions of negative willingness. For this reason, they are interpreted here (unlike in the analysis of other DCT situations) as being only slightly less hard-nosed towards the interlocutor than negative willingness. All statements of negative 
willingness and negative ability either preceded, followed, or were amalgamated with reasons that revolved, for the most part, around having already set up the curriculum and being unwilling to make changes. See below (Content) for specifics.

A few responses contained amalgamations of negative willingness and reasons: ...I wouldn't change the curriculum this far into the term." (AE7); .".. [ich] habe eigentlich nicht vor, sie [meine Lehrmethode] zu ändern, weil ich sie so für sehr gut halte." ("I really don't plan to change it [my teaching method], because I consider it very good as it is."-GG2); and, "I have a very organized plan \& I don't want to change it..." (GE4). Similarly, a few responses conjoined statements of negative ability (as an expression of negative willingness) with reasons: ."..can't do it, [sic] its too late in term." (AE8); "Jetzt kann ich meinen Unterrichtsplan aber nicht mehr neu strukturieren. ..." ("But now I can't restructure my syllabus any more. ..."-GG7); "Ich habe jetzt den Semesterplan schon zusammengestellt und daher kann ich jetzt nicht mehr alles umändern." ("I've already put together the syllabus now, so I can't change everything any more."-GG10).

One of the two AEs using a direct refusal strategy modified the form with a downgrader: .".I wouldn't change the curriculum..." (AE7), and one of the GGs used a downtoner: .". [ich] habe eigentlich nicht vor, sie [meine Lehrmethode] zu ändern..." (.".. I really don't plan to change it [my teaching method]..."-GG2). The other AE, the other three GGs, and the one GE who chose a direct refusal strategy, all used no mitigation, e.g., .".I don't want to change it [my plan]..." (GE4). 
Table 4. 87: Use of Direct Refusal Strategies; Suggestion; Lower-Status Interlocutor (DCT\#8)

\begin{tabular}{|l|l|l|l|}
\hline & "No" & Negative Willingness & Negative Ability = Negative Willingness \\
\hline GEs & - & $8 \%$ & - \\
AEs & - & $8 \%$ & $8 \%$ \\
GGs & $7 \%$ & $7 \%$ & $14 \%$ \\
\hline \multicolumn{2}{|c|}{ As the table below shows, statements of philosophy/principle and reasons }
\end{tabular}

accounted for a large proportion of the subjects' strategy choices. While excuses and statements of philosophy tended to protect the hearer's face by stressing inability or higher guiding principles overriding the students' wishes, reasons in DCT\#8 generally posed a face threat because the teacher's convenience took precedence over the students' concerns. While the inclusion of a reason produces a less face-threatening response than a simple "no" or statement of negative willingness, in the case of DCT\#8, the content of most of the reasons prevented them from being analyzed as increasing politeness. For this reason, the GEs are listed below the AEs in the table below (i.e., in the ranking of politeness) despite the fact that they used reasons with greater frequency.

The set condition for acceptance likewise posed a face threat because it made the addressee responsible for the refusal: "I wish you would have expressed these concerns earlier-can't do it, [sic] its too late in term." (AE8). The set condition is included in the discussion of excuses and reasons because it functioned as an explanation of why the speaker was refusing the suggestion.

The tactfulness of all the excuses in DCT\#8 was increased through various means. The excuses used by the AEs and the GGs both involved downgraders and elaboration: ...the department curriculum demands that I test you on grammar, \& unfortunately there is not time for both in the class hour." (AE5); "Dieser Kurs ist leider auf eine bestimmte 
Prüfung ausgerichtet, deren Bestehen für Sie äußerst relevant ist. Und deswegen ist der Unterricht nur auf diese Prüfung und deren Inhalte hin geplant. ..." ("Unfortunately, this class is designed as preparation for a certain test that is extremely important for you to pass. For this reason, the instruction is planned with only the test and its subject matter in mind. ..."-GG9). The GE excuse was preceded by a statement of positive opinion: .".I'd like to give you more practice, but my boss told me to teach you grammar." (GE9).

Only one of the five $\mathrm{AE}$ reasons was softened; however, all but one of the $\mathrm{AE}$ reasons were presented in a context of negative politeness. The Germans softened a number of their reasons through elaboration, downgraders, downtoners, or giving a second reason, but a number of reasons involved an assertion of the speaker's higher status or criticism of the interlocutor.

The softened AE reason was conjoined with a downgrader: ."..I don't feel any of you have it [grammar] down yet." (AE12).

Three GGs gave two reasons (GG1, GG2, and GG7), and two GGs elaborated on their reasons (GG8-via a statement of principle; GG14). Two GGs used downgraders: .".doch meine ich, daß die Gewichtung innerhalb meiner Vorlesung durchaus dem Kursniveau und den Kurszielen entspricht!" (.".but $\underline{I}$ think that the weighting [of conversation versus grammar] within my class corresponds to the levels and goals of the course!"-GG3);and, .".das ist leider bei diesm Kurs nicht der Fall [d.h., die Studenten beherrschen die grammatikalischen Grundregeln nicht]." (."..unfortunately, that is not the case with this class [i.e., the students do not master the basic rules of grammar]."-GG6). One GG softened his reason with a downgrader, but implied his own superiority over the 
interlocutor: ."..[ich] glaube, wie die Erfahrung es zeigte, daß es richtig ist, wie ich den Unterricht gestalte." (.".I believe, as experience has shown, that the way I design the course is the right way."-GG5).

Only one GE used elaboration on her reason (GE11). Two GEs used downgraders: ."..So I think we still have to concentrate on that [grammar]."(GE7). One of them also expressed the reason by way of a statement establishing his status. The actual meaning of the remark was obscured through syntactic features: .". I guess my practice in teaching is as well as I know how to do for having the best results as possible." (GE2). Two possible interpretations of the remark were: "I can't do any better than my experience allows," and "I know of no better way than my own for achieving the best results." In the context of refusing a suggestion for improvement, it seems probable that the latter interpretation was the one intended by the subject. One GE used a downtoner: ...the thing is that you need to know about the grammar first. ..." (GE12). One GE used a downgrader and a downtoner with her reason, which involved some criticism of the interlocutor, and added elaboration conjoined with a downtoner: .".. But I'm afraid you're simply not good enough yet to have intelligent and intelligable convers. in ... You simply have to improve on you grammar first, before you can start on conversations." (GE11).

Statements of principle were mostly unmitigated and without elaboration except for one AE downtoner and two GE uses of elaboration (.".. you know, grammar is the basis of any conversation. ..."-AE11; GE6 and GE12). A third GE used two statements of principle (GE8). None of the GGs used either elaboration or mitigation with statements of principle. 
One GG's statement of principle functioned as elaboration on a reason: ...Die Praxis erhalten sie dann im Land von selbst."(."..You'll automatically get [conversational] practice in the country."-GG8). One GE's statement of principle functioned as a promise: ...conversation comes later." (GE4).

Table 4. 88: Use of Excuses, Reasons, Statements of Philosophy/Principle, and Set Conditions; Suggestion; Lower-Status Interlocutor (DCT\#8)

\begin{tabular}{|l|l|l|l|l|}
\hline & Excuse & Philosophy/Principle & Reason & Set Condition \\
\hline AEs & $8 \%$ & $50 \%$ & $42 \%$ & $8 \%$ \\
GEs & $8 \%$ & $50 \%$ & $58 \%$ & - \\
GGs & $7 \%$ & $36 \%$ & $64 \%$ & - \\
\hline
\end{tabular}

One GG used three instances of insults / attacks (GG4). Of the uses of criticism of the interlocutor, one was made by way of an insult (GG4), one was implied by way of a statement establishing the speaker's status / superiority over the hearer (AE10), and another was mildly implied by way of a reason (GE11). In three responses, criticism of the suggestion was expressed by way of an insult (GG4), by establishing the speaker's status / superiority over the hearer (AE10), and implied in the form of a forewarn (GE7). Some remarks aimed at establishing the speaker's status or superiority took the form of an attack or insult (AE3, GG4), one was implied in a reason (GG5), another served as the reason for the refusal (GE2), and one remark that functioned as an attack involved sarcasm based on the addressee's inferiority to the speaker (GE1). These remarks are discussed in the content section. 
Table 4. 89: Use of Strategies that Increase the Face Threat; Suggestion; LowerStatus Interlocutor (DCT\#8)

\begin{tabular}{|llll|}
\hline & AEs & GGs & GEs \\
\hline Insult / Attack & $\mathbf{8 \%}$ & $\mathbf{7 \%}$ & $\mathbf{8 \%}$ \\
\hline Criticism of Interlocutor & $\mathbf{8 \%}$ & $\mathbf{7 \%}$ & $17 \%$ \\
\hline Criticism of Suggestion & $\mathbf{8 \%}$ & $21 \%$ & $\mathbf{8 \%}$ \\
\hline Establish Own Status / Superiority & $17 \%$ & $14 \%$ & $17 \%$ \\
\hline Upgrader $^{\text {Negative Opinion }}{ }^{\mathbf{8 0}}$ & - & - & $\mathbf{8 \%}$ \\
\hline Request to Rescind $^{\mathbf{8 1}}$ & $\mathbf{8 \%}$ & - & - \\
\hline
\end{tabular}

Evasive Strategies: These strategies were inconsequential in responses to DCT\#8; only one $\mathrm{AE}$ used postponement (AE7).

Positive forms played a relatively unimportant role in the data of all three groups in DCT\#8, with somewhat higher frequencies amongst the AEs, followed by the GEs, and finally, the GGs.

One $\mathrm{AE}$ used agreement twice and elaborated on the agreement (AE6). One GG used elaboration on a statement of agreement (GG1).

The downgraders were used primarily in conjunction with excuses and reasons. One $\mathrm{AE}$ used a downgrader together will a statement of negative willingness (AE7), one GG used a downgrader with elaboration on a statement of alternative: Why don't you do $X$ instead of $Y$ (GG9). One GE used a downgrader in conjunction with criticism of the interlocutor (GE11), and another GE used a downgrader with a remark establishing the speaker's status (GE2).

\footnotetext{
${ }^{80}$ This use of negative opinion was quite "harmless", carrying only a remote possibility of face risk: "[sic] Grammer is a fundamental part of any language. What's the use of saying something if you say it improperly?" (AE2).

${ }^{81}$ The face risk of the remark itself (the request to rescind the suggestion) was minimal, but in context, the remark was face-threatening: "Well, since I'm the one who is educated in
} 
Table 4. 90: Use of Positive Forms / Adjuncts; Suggestion; Lower-Status Interlocutor (DCT\#8)

\begin{tabular}{|c|c|c|c|}
\hline & AEs & GEs & GGs \\
\hline Agreement $^{82}$ & $17 \%$ & $8 \%$ & $7 \%$ \\
\hline Positive Opinion & - & $8 \%$ & $7 \%$ \\
\hline Empathy & $17 \%$ & $8 \%$ & - \\
\hline Regret & $8 \%$ & - & $7 \%$ \\
\hline Promise $^{83}$ & - & $17 \%$ & $7 \%$ \\
\hline Gratitude $^{84}$ & - & $8 \%$ & - \\
\hline Downgrader & $25 \%$ & $25 \%$ & $29 \%$ \\
\hline
\end{tabular}

Once again, as in other DCT items, the GGs used a lower frequency of positive forms than the AEs, but exceeded them in the production of mitigating adjuncts. The GEs surpassed the GGs in use of mitigating adjuncts, thus accurately (in terms of pragmatics) increasing the politeness of their responses in English, but using a transferred means of doing so.

Most of the downtoners were used in conjunction with reasons or elaboration on a reason. One downtoner co-occurred with a statement of principle (AE11), another was

this field and I know better than you what you'll need to know, how about if we stick with my syllabus as I've planned it?" (AE10).

${ }^{82}$ The functional categories are arranged in order of the degree of commitment to a positive content from the hearer's perspective. The more positive strategies are at the top and the less positive (more neutral) ones are at the bottom. Because the AEs showed a slightly higher preference for the more positive strategies than the GEs, they are listed first in the table, as the "most polite", even though the GEs exhibited a slightly higher total percentage overall of positive functional categories.

${ }^{83}$ Although the promise strategy could be particularly positive from the hearer's perspective, the instances of promises used here are fairly indirect and neutral (See discussion of content).

${ }^{84}$ Gratitude, likewise, can be a highly positive strategy. The one use of gratitude here, however, is fairly lukewarm, more of a social nicety than a "real" expression of gratitude (See discussion of content). This remark was coded as a statement of gratitude rather than a statement of positive opinion because it appeared to transfer the German expression, Das ist sehr lieb von Ihnen, a means of expressing gratitude in German: "You're very nice..." (GE2). 
used with a statement of negative willingness (GG2), and another appeared with criticism of the interlocutor (GE11).

Table 4. 91: Use of Mitigating Adjuncts; Suggestion; Lower-Status Interlocutor (DCT\#8)

\begin{tabular}{|l|l|l|l|}
\hline & Downtoner & Forewarn & Pause Filler \\
\hline GEs & $17 \%$ & $8 \%$ & $17 \%$ \\
GGs & $14 \%$ & $7 \%$ & - \\
AEs & $8 \%$ & - & $25 \%$ \\
\hline
\end{tabular}

In terms of having the least number of responses containing no positive forms and the highest percentage of responses containing at least one positive form, GE $>\mathrm{AE}>\mathrm{GG}$.

Table 4. 92: Number of Positive Forms / Adjuncts per Response; Suggestion; LowerStatus Interlocutor (DCT\#8)

\begin{tabular}{|l|l|l|l|l|l|}
\hline & 0 & 1 & 2 & 3 & 4 \\
\hline GEs & $42 \%$ & $42 \%$ & $8 \%$ & $8 \%$ & - \\
\hline AEs & $50 \%$ & $33 \%$ & $8 \%$ & - & $8 \%$ \\
\hline GGs & $57 \%$ & $29 \%$ & $7 \%$ & $7 \%$ & - \\
\hline
\end{tabular}

The GEs also used the higher number of mitigating adjuncts per response.

Table 4. 93: Number of Mitigating Adjuncts per Response; Suggestion; LowerStatus Interlocutor (DCT\#8)

\begin{tabular}{|l|l|l|l|}
\hline & 0 & 1 & 2 \\
\hline GEs & $75 \%$ & - & $25 \%$ \\
\hline AEs & $75 \%$ & $17 \%$ & $8 \%$ \\
\hline GGs & $79 \%$ & $21 \%$ & - \\
\hline
\end{tabular}

Other Strategies: Two kinds of statements of alternative, Why don't you do $\mathrm{X}$ instead of $\mathrm{Y}$ ? and You can do $\mathrm{X}$ instead of $\mathrm{Y}$, figured in a few responses. The AEs slighted exceeded the other two groups in frequency of these forms.

One subject used elaboration with her statement of alternative (GG9). See discussion of content. 
Table 4. 94: Use of Other Strategies (Statement of Alternative: Why Don't You Do $X$ Instead of $Y$ ? and You Can Do $X$ Instead of $Y$ ); Suggestion; Lower-Status Interlocutor (DCT\#8)

\begin{tabular}{|l|l|l|}
\hline & Why Don't You Do X Instead of $\mathbf{Y}^{85}$ & You Can Do X Instead of Y \\
\hline AEs & $17 \%$ & - \\
GGs & $7 \%$ & - \\
GEs & - & $7 \%$ \\
\hline
\end{tabular}

\section{Content of Functional Categories}

Considerations for Distinguishing between Statements of Principle and Reasons: A number of responses contained remarks about the importance of grammar as a basis for conversation or as a necessary component of language instruction. These items were analyzed as "statements of principle", although one might argue that these were "reasons" why the interlocutor's suggestion was being refused. There is a good deal of proximity, even overlap, between the categories, "statement of principle / philosophy" and "reason." Indeed, in this context, a statement of principle is always a kind of reason or explanation. However, it seemed important to distinguish "principles" from "reasons", because of the difference in tone and because statements of principle implied consideration of the students' needs that was absent from reasons such as, .". I see nothing wrong with the curriculum at the present time." (AE3); .".the department curriculum demands that I test you on grammar..." (AE5); or, ."..I wouldn't change the curriculum this far into the term." (AE7).

The distinguishing criterion was this: if a response declared the necessity or the importance of grammar as a basis for conversation, it was interpreted as a "statement of 
principle", e.g., "You need grammar in order to put words together for conversation." (AE4). If there was no such explicit statement, then the remark was interpreted as a "reason", even though the same principle probably underlay the remark, e.g., "But I think I should try to improve the class's grammatical competence, first. ..." (GE3). Also, if it was only vaguely implied that principles were guiding the speaker's decisions, this was interpreted as a "reason" rather than a "principle", e.g., .". This program is structured this way because the department feels that it is the best way to learn a language." (AE9).

Excuses, Statements of Principle, and Reasons: Both excuses and statements of principle displayed some consideration of the addressee's feelings or needs, either by suggesting that the matter was beyond the speaker's control, or by taking the trouble to explain how the speaker's guiding principles prevented compliance with the students' wants. Reasons, on the other hand, served a different function in DCT\#8. While the mere act of giving a reason validates the legitimacy of the interlocutor's suggestion (i.e., not simply brushing it off as ridiculous or unjustified without any explanation), most of the reasons here posed a mild threat to the hearer's face. For example, a reason stating that it was too late in the term to change the curriculum could have left the addressee feeling that minimizing effort was a higher priority to the speaker than taking the students' wishes into consideration. Being in a position of lower status, the hearer may have felt the frustration of not being able to openly express dissatisfaction with such an attitude.

\footnotetext{
${ }^{85}$ In DCT\#8, the instances of "Why don't you do X instead of Y?" (AE1, AE11, GG9) clearly displayed more supportiveness than the one instance of "You can do X instead of Y' (GE9). See discussion of content.
} 
Excuses in DCT\#8 explained why the emphasis on grammar was required, either by departmental mandate or because the course's purpose was to prepare the students for a particular exam: .".the department curriculum demands that I test you on grammar, \& unfortunately there is not time for both in the class hour." (AE5); "Dieser Kurs ist leider auf eine bestimmte Prüfung ausgerichtet, deren Bestehen für Sie äußerst relevant ist. Und deswegen ist der Unterricht nur auf diese Prüfung und deren Inhalte hin geplant. ..." ("Unfortunately, this class is designed as preparation for a certain test that is extremely important for you to pass. For this reason, the instruction is planned with only the test and its subject matter in mind. ..."-GG9); and, .".my boss told me to teach you grammar." (GE9).

The one theme of statements of principle was the need for grammar as a basis for developing conversational proficiency: .".strengthen[ing] grammar will in turn improve conver[sation] skills." (AE1); "[sic] Grammer is a fundamental part of any language. ..." (AE2); "You need grammar in order to put words together for conversation." (AE4); ...by mastering the grammar now, you'll be able to converse more fluently later." (AE6); ...grammar is the basis of any conversation. ..." (AE11); "In order to practice conversations, you need to know the grammar..." (AE12); "Es ist nun mal erwiesen, daß für Konversation die grammatik. Grundregeln nicht nur bekannt sondern gekonnt sein müssen..." ("It has been proven that conversation requires not only recognition, but also mastery of the basic rules of grammar..."-GG6); .".man [braucht] die Grammatik zuerst als Grundlage für alles [sic] ander und das [ist] am allerwichtigsten." (.".grammar is needed first as a basis for everything else and that is the most important thing."-GG11); 
"Aber um reden zu können, muß man erst mal die Grammatik können. ..." ("But to be able to speak, one must first master the grammar. ..."-GG12); "Ich denke um dem Thema vollends folgen zu können ist die Grammatik ein notwendiges aber nicht umgängliches Übel." ("I think that in order to fully comprehend this subject, grammar is a necessary, but unavoidable evil."-GG13. This statement of principle also implied agreement with the students' dispreference for grammar by referring to it as an "evil."); "You should know the grammar first before you do conversation." (GE5); ....grammar is necessary for good conversation, you really have to learn it." (GE6); "One should always practice the things one has not yet acquired and once you managed grammar conversation will be no problem." (GE8); "I made the experience that you can't really do any conversation without the basics of grammar." (GE10); and, ."..it [grammar] is just the essential basis and we need to do it." (GE12). One GG's statement of principle served as elaboration on a reason: "Mit meinem Unterricht möchte ich [sic] sie erstmal in die Lage versetzen eine gute Konversation zu führen. Die Praxis erhalten [sic] sie dann im Land von selbst." ("With my instruction I'd first of all like to give you the basis for leading a good conversation. You'll automatically get [conversational] practice when you go to the country."-GG8).

In terms of the potential face threat, the reasons used in DCT\#8 can be divided into two types. "Neutral" reasons focused on relatively objective considerations. Less favorable ones were based either on the speaker's unwillingness to make an extra effort to accommodate the students' wishes or the speaker's belief that his/her way of teaching the class was superior to any suggestions. The "neutral" category included considerations 
such as course / test / department requirements, the students' lack of command of the grammar, and the belief that conversation could be practiced outside the university context, but that learning grammar required classroom study. The "negative" category, on the other hand, included disagreement with the students regarding the need for changes in the curriculum, the instructor's conviction that his/her approach to the course was the only truly valid one, and an unwillingness to change the syllabus during the term (i.e., a dismissing of the students' concerns to avoid inconvenience for the instructor). While a number of $\mathrm{AE}$ and $\mathrm{GG}$ reasons contained a clear or potential face threat, the GEs displayed great caution in this regard.

A few reasons clearly reflected efforts to be polite: .".dieser Kurs ist einfach eher theorieorientiert. ... wir haben einfach nicht mehr Zeit für Konversationsübungen." (.”..this course is simply more oriented towards theory... we simply don't have enough time for conversation practice."-GG1); "But I think I should try to improve the class's grammatical competence, first. ..." (GE3); ."..you need to know about the grammar first. ..." (GE12); and, ."..You simply have to improve on your grammar first, before you can start on conversations." (GE11). These three GE reasons (or in one case, elaboration on a reason) closely approached the realm of statements of principle, but were not explicit enough about being guided by a principle to qualify for that categorization.

In several more neutral responses, the speaker disagreed with the addressee, which might not have been tremendously favorable from the hearer's point of view, but the speaker did at least express some tact: ."..The program is structured this way because the department feels that it is the best way to learn a language." (AE9); .".I don't feel any of 
you have it [grammar] down yet." (AE12); ."..ich [meine], daß die Gewichtung innerhalb meiner Vorlesung durchaus dem Kursniveau und den Kurszielen entspricht!" (."..ich think that the weighting [of grammar versus conversation] in my course corresponds to the level and goals of the course!"-GG3); and, ."..Konversationspraxis können Sie in jedem Gespräch außerhalb der Uni erwerben. Die grammatischen Grundlagen dagegen werden Sie sich wohl kaum im Selbststudium aneignen." (."..You can get your conversational practice in any conversation outside of the university. But you will hardly gain mastery of the underlying principles of grammar in independent study."-GG14). One GE response would have avoided a face threat were it not for its rather tactless assessment of the students' grammatical competence: ."..So [because your grammar is really bad] I think we still have to concentrate on that [grammar]." (GE7). One GG put forth a principle regarding the importance of grammar as a foundation for conversation (quoted above) and continued with a reason (i.e., that the conditions of the statement of principle had not been met) involving a negative assessment of the students' proficiency with grammar: "Es ist nun mal erwiesen, daß für Konversation die grammatik. Grunkregeln nicht nur bekannt sondern gekonnt sein müssen; das ist leider bei diesem Kurs nicht der Fall." ("It has been proven that conversation requires not only recognition, but also mastery of the basic rules of grammar; unfortunately that isn't the case in this class."-GG6).

Other reasons posed a face threat: ."..I see nothing wrong with the curriculum at the present time." (AE3); .".I wouldn't change the curriculum this far into the term." (AE7); ."..[sic] its too late in term." (AE8); "Jetzt kann ich meinen Unterrichtsplan aber nicht mehr neu strukturieren. Außerdem müssen wir den vorgegebenen Stoff 
durchbekommen." ("But at this point I can't restructure my syllabus any more. Besides, we have to get through the required material."-GG7); and, "Ich hab jetzt den Semesterplan schon zusammengestellt..." ("At this point, I've already put the syllabus together...."-GG10).

A few responses created a face threat by simply dismissing the addressee's ideas without considering them: "Ich bin mit meiner Lehrmethode bis jetzt immer sehr gut "gefahren.".. ich [halte] sie für sehr gut." ("I've always managed very well with my teaching method until now ... I consider it very good."-GG2); "Ich...glaube, wie die Erfahrung es zeigte, daß es richtig ist, wie ich den Unterricht gestalte." ("I... think, as experience has shown, that the way I design the course is the right way."-GG5); and, "I have a very organized plan..." (GE4. This remark is discussed further in the section on face-threatening strategies.). A remark that might have appeared to be an excuse (."..I have some regulations in teaching my class."-GE1) revealed itself to be a reason (i.e., a matter of choice) with a dismissive quality in context. As discussed in the section on the content of face-threatening strategies, the initial remark in the response involved sarcasm, intended as a means of belittling the addressee: "Dear Mark, I'm very pleased, that you try to help my organizing my lessons, but I have some regulations in teaching my class." (GE1).

Face-Threatening Strategies: The remarks that posed a face threat either took a stance of superiority over the interlocutor, gave no consideration to the interlocutor's suggestion, or belittled the hearer. As noted above, some of the reasons given in response to DCT\#8 also presented a certain threat to the hearer's face, i.e., in cases where the 
instructor's convenience took precedence over the students' wishes (e.g., GG7 and GG10's expression of unwillingness to modify the curriculum to meet student needs) or where the suggestion was summarily dismissed (e.g., GG5's reason. See discussion of reasons above.). Unmitigated expressions of unwillingness to comply with the request underlying the suggestion also posed a threat to the hearer's face. On the other hand, the one statement of negative opinion in the data hardly posed a face threat: "[sic] Grammer is a fundamental part of any language. What's the use of saying something if you say it improperly?" (AE2).

A number of the face-threatening remarks combined elements of different strategies, e.g.:

- criticism of the interlocutor expressed by way of: an insult (GG4), a statement establishing the speaker's status (AE10), and a reason (GE11);

- criticism of the suggestion via: an insult (GG4), a statement establishing the speaker's status (AE10), and a forewarn (GE7);

- establishment of the speaker's superiority over the hearer by way of: an attack (AE3 and GG4), and a reason (GG5 and GE2); and

- an attack via sarcasm and an insinuation about the hearer's inferiority (GE1), and a statement establishing the speaker's superior status (AE3).

The major strategy used to increase the face threat of responses to DCT\#8 was establishment of the speaker's status or superiority over the interlocutor. A few responses contained remarks of varying degrees of pomposity and impoliteness aimed at taking a stance of superiority over the addressee, being patronizing, or asserting the speaker's 
status. Indeed, only one respondent showed humility: .".I've realized that you aren't particularly thrilled by my teaching method. ..." (GE11).

One GG response in particular abused the power differential between the interlocutors and denigrated the addressee, invalidating the student's right to even make the suggestion / request: "Na hören Sie mir mal gut zu. Als ich noch so jung und unerfahren wie Sie war, hatte ich auch solche irren Ideen. Im Verlauf meines Lebens bin ich aus diesen Schuhen hinausgewachsen." ("Now you listen to me. Back when I was as young and inexperienced as you are, I also had crazy ideas like that. In the course of my life I've grown out of those shoes."-GG4). Another GG remark made use of unequal power dynamics, putting the addressee in his/her place through rather a blatant assertion of the speaker's higher status: "Ich bin hier als Sprachlehrerin schon längere Jahre tätig und glaube, wie die Erfahrung es zeigte, daß es richtig ist, wie ich den Unterricht gestalte." ("I've been working here as a language instructor for many long years and believe, as experience has shown, that the way I design the course is the right way."GG5).

One GG respondent used a reason that carried a subtle overtone of the "status / superiority" strategy as well: "Ich bin mit meiner Lehrmethode bis jetzt immer sehr gut 'gefahren'..." ("So far, I've always been very successful with my teaching method..."GG2), followed as it was by a fairly direct statement of negative willingness: .".. und habe eigentlich nicht vor, sie zu ändern..." (“and I don't really intend to change it..."). In other words, the speaker's reason was: "my way is good, so I won't change." He neither considered the student's idea nor provided evidence for the validity of his own position, 
counting on his superiority status to block any argument from the interlocutor. This response (GG2) actually rather closely resembled GG5's response in terms of the insinuation that "I know better than you do", that the speaker's judgment is superior to the requester's.

The AE data as well contained some surly, arrogant retorts. One AE remark was an attack along the lines of "Who do you think you are?": "Well when you teach your own class, you can pay more attention to conversation. I see nothing wrong with the curriculum at the present time." (AE3). Another AE speaker held up her credentials in the addressee's face, an obvious act of aggression, and continued with request to rescind the suggestion. A request rather than an imperative to drop the suggestion is a somewhat polite functional category, but in context, the content of the remark was not very polite because the response gave no reason for refusing the addressee's suggestion other than the speaker's superior grasp of the situation: "Well, since I'm the one who is educated in this field and I know better than you what you'll need to know, how about if we stick with my syllabus as I've planned it?" (AE10). This is a case where the written response did not provide enough information for an unambiguous interpretation. Depending on intonation and other features of delivery, the first part of AE10's response could be interpreted as a fairly hostile remark criticizing both the interlocutor and the suggestion, or even an attack along the lines of, "Who do you think you are?!" Assuming more neutral delivery in a more amicable teacher-student exchange, the remark would simply establish the speaker's status and/or superiority over the addressee, used as a means of persuasion. While social power would still clearly play a role in this strategy, constituting a certain degree of face- 
risk to the addressee, it would not carry the volatile force of an attack (although it would still imply criticism of the interlocutor's suggestion and possibly of the interlocutor as well). The request to rescind the suggestion could be interpreted in different ways as well. With hostile delivery, it could be a sarcastic remark, intended and understood as a putdown, but with neutral delivery, it could be a fairly temperate request to drop the issue. All in all, whatever interpretation one might choose, the student's ideas were summarily dismissed without explanation or mitigation (except for the pause filler, "well", at the beginning of the response). The possibility of an intended attack notwithstanding, AE10's response was still considerably milder than GG4's, which was clearly an attack, even without reference to intonation (See quote above.).

Three GE remarks appeared to contain elements of the "superiority" strategy. One GE's condescending upgrader and attack used sarcasm based on the addressee's inferiority to speaker: "Dear Mark, I'm very pleased, that you try to help my organizing my lessons..." (GE1). This response seemed to follow the same pattern as GE1's response to DCT\#1: "Dear Mr X, who do you think you are?!." It is possible that "dear $\mathrm{X}+$ comment" is a "formula" that this respondent uses for putting people in their place.

GE4's remark, "I have a very organized plan...", could have been interpreted as self-defense were it not for the statement of negative willingness following it, ."..\& I don't want to change it..." In context, the remark brusquely rejected the addressee's suggestion/request, directly contradicting the addressee's idea and implicitly asserting the speaker's superior judgment. The statement of negative willingness made it clear that the addressee had no power to impact the speaker's decisions. 
As discussed above in the frequency section, syntactic features clouded the conversational intention of one GE remark, rendering it ambiguous as to whether it was a statement of self-defense or an assertion of the speaker's superiority experience: .".my practice in teaching is as well as I know how to do for having the best results as possible." As stated above, the decision was made to interpret the remark as meaning, "My way is the best way I know of' (GE2. See discussion above.). The remark was preface by a polite adjunct, "You're very nice but I guess ...", but this did not clarify the ambiguity of the preceding remark because it could serve with equal plausibility in either alternative (i.e., self-defense or statement of superior status).

Most of the face-threatening strategies were related to the status differential between speaker and hearer, and were discussed in the previous section, so only a few additional comments are necessary.

Remarks made by AE10 and GG4 criticized both the suggestion and the interlocutor: .".I know better than you what you'll need to know..." (AE10) and ."..Als ich noch so jung und unerfahren wie Sie war, hatte ich auch solche irren Ideen. ..." (."..Back when I was as young and inexperienced as you are, I also had crazy ideas like that. ..."-GG4).

Three other remarks involved criticism of the suggestion. One such remark was fairly innocuous: .".I remember the beginning of the term when almost everybody said that they needed more exercise on grammar and I noticed that too, that your grammar is really bad. ..." (GE7). Use of criticism of the suggestion by GG11 and GG14, on the other hand, was quite direct and rather impolite. Both respondents made little effort to 
"package" these plain-spoken remarks in a non-face-threatening manner, although they at least explained their reasoning in the following parts of their responses. "Nein, [sic] das wäre wirklich nicht gut..." ("No, that really wouldn't be good..."-GG11) and "Davon halte ich gar nichts. ..." ("I think absolutely nothing of that [idea]"-GG14).

Word choice, as well as the message itself, affected the degree of the face threat in criticism of the interlocutor, as a comparison of two responses illustrates: Both GE7 and GE11 stated that the class had to continue focusing on grammar because the students' lack of proficiency in grammar prevented them from engaging successfully in conversation. While GE11's response was relatively tactful, thanks to downgraders and choice of words ("But I'm afraid you're simply not good enough yet to have intelligent and [sic] intelligable convers. in [name of language]. ..."), GE7's statement could have been taken as an insult: .".your grammar is really bad." Examining the remark in its context, it appears that GE7 made an unfortunate choice of words, rather than intending a face-threat: "Well, you know, I remember the beginning of the term when almost everybody said that they needed more exercise on grammar and I noticed that too, that your grammar is really bad. So I think we still have to concentrate on that."

Responses containing attacks / insults belittled the hearer in ways related to his/her inferior status (AE3, GG4, and GE1). These responses were discussed above.

Positive Forms: Most of the positive forms used in DCT\#8 were polite but fairly lukewarm. The indirectness and neutrality of the promises of future acceptance in DCT\#8 made them considerably less positive from the hearer's perspective than this strategy normally would be: ...Danach haben wir immer noch genug Zeit zum reden." 
(."..Afterwards, we'll still have enough time to talk."-GG12); ."..Next term there'll be more conversation practices." (GE3); and, ."..conversation comes later." (GE4).

Only two respondents' remarks stand out as displaying a strong concern for the student's feelings: “Ja, ich sehe das Problem auch, daß es einfach zu wenig Konversationsübungen für unsere Studenten gibt. ..." ("Yes, I also view it as a problem that there are simply too few conversation classes for our students. ..."-GG1) and "Yeah, I don't blame you. I don't like grammar either; it's kind of boring. ..." (AE6). A third subject's statement of positive opinion was somewhat persuasive: .".I'd like to give you mor practice..." (GE9).

FTA Strategies: Most responses reflected varying degrees of negative politeness, ranging from replies consisting of nothing more than a statement of principle standing alone to more elaborate answers containing a number of strategies designed to communicate interest in protecting the hearer's face. The major difference between the groups lies in the fact that, while the $\mathrm{AE}$ and GE data each contained only two responses in the "baldly on record" category, almost half of the GGs' replies fit that description (Two of the GG refusals that were baldly on record were very direct in criticizing the suggestion, but one of these was followed by a statement of principle (GG11) and the other by a reason (GG14), adding some small measure of negative politeness.). A number of these respondents "pulled rank" in a way that threatened the hearer's face, were very direct in criticizing the suggestion or stating their unwillingness to accept it, used sarcasm, or expressed a general unwillingness to consider the hearer's position. 
Only one response was tinged with positive politeness: AE6's statement of empathy and repeated use of agreement expressed a degree of identification with the students' feelings. There were no off record refusals.

\section{Summary of Results: Refusal of Suggestion Made by a Lower-Status Interlocutor (DCT\#8)}

A large proportion of subjects either gave reasons or stated a philosophy/principle as a primary means of performing the refusal in DCT\#8. There was relatively little use of the more confrontative functional categories, and minor use of positive forms, except for the more subtly positive downgrader. In most categories, the AEs chose the most polite forms, reflecting their greater face-protective efforts. The GEs were more careful than the GGs except for their slightly more frequent use of face-threatening strategies. As in other DCT items, AE use of the positive forms was higher and use of mitigating adjuncts lower than in the case of the German subjects.

There were scarcely any appearances of direct refusal strategies in responses to DCT\#8, except for minor use by the GGs. All statements of negative ability actually served as an expression of negative willingness, but in a less direct manner.

The sparse appearance of excuses in the data underscores the fact that the decision to refuse the suggestion was not outside the speaker's control. The high frequency of statements of principle (particularly by the AEs and GEs) demonstrates the speakers' concern for the students' learning needs. The fact that reasons were used most frequently by the GGs, followed fairly closely by the GEs, and less by the AEs, reflects the Americans' greater effort not to appear callous, whereas the Germans were more 
straightforward about their unwillingness to comply with the students' wishes. The GEs found middle ground between the AEs and GGs, but leaned towards the German NS patterns.

The GGs' choice to use fewer statements of principle and more reasons than the AEs or GEs meant that, to some extent, the strength of their refusals relied more on the power of the speaker's superior status and less on convincing the addressee of the validity of the speaker's view than the AEs' or GEs' refusals. The GEs' greater use of reasons compared to the AEs puts them in a position between the GGs and AEs, but closer to the AEs, in this regard.

In terms of content, $\mathrm{GE}$ reasons were the most polite, whereas $\mathrm{AE}$ and $\mathrm{GG}$ reasons were in the neutral-to-face-threatening range.

Themes of reasons, excuses, and statements of principle all involved considerations for determining the relative position of grammar and conversation in the language course.

None of the individual face-threatening strategies occurred with great frequency, but viewed as a whole, these strategies played a strong enough role to color the overall character of responses to DCT\#8. Frequencies that bear mention include the somewhat more frequent use of criticism of the suggestion by the GGs (in comparison to the other groups) and the appearance of remarks establishing the speaker's status or superiority in the data of all three groups. Direct and indirect assertions of the speaker's superior status permeated numerous responses-indeed, this was the primary means of increasing the face threat in responses to DCT\#8 (An explanation for this feature is offered in Chapter 5.). A 
few respondents in each group used remarks emphasizing the power differential, although two of the three GE remarks cited could not be placed unambiguously in this category.

Regarding the content of face-threatening strategies, the GEs had the lowest proportion of harsh remarks, and the GGs somewhat exceeded the AEs in the production of overbearing comments.

The GEs and AEs were roughly equally polite in terms of their use of positive forms, the difference being one of distribution. While the GEs had fewer responses lacking a positive form than the AEs, the AEs tended to choose the more strongly positive forms. Positive forms played somewhat less of a role in the GG data, compared to the AEs and GEs. The relative lack of emphasis on positive forms in DCT\#8 reflected the lack of urgency on the hearer's part that the suggestion / request be accepted, as well as the absence of compelling disadvantages to the speaker if the face of a lower-status interlocutor is not protected.

Regarding FTA strategies, the GGs were more confrontative in putting the hearer in his/her place for making an unwelcome suggestion than the other two groups. The GEs' responses resembled the AEs' in their strong preference for negative politeness. Seen from the perspective of responses to the entire $\mathrm{DCT}$, the use of positive politeness by one $\mathrm{AE}$ reflects the Americans' more frequent tendency to emphasize some sort of personal connection between the interlocutors, here, shared attitudes towards grammar, and empathy for the hearer's feelings.

A number of remarks contained more than one functional layer, e.g., GE4 statement of principle functioned as a promise, GG8's statement of principle functioned as 
elaboration on a reason, GE2's assertion of the speaker's higher status served as a reason, GG4 used an insult as a means of expressing criticism of the interlocutor, and AE10's assertion of superiority expressed criticism of the interlocutor.

Except for the "arrogant instructors", most of the AE and GE subjects' answers seemed to reflect a cultural value that a teacher refusing a student's suggestion for improving a class should be able to give ideological reasons (i.e., statements of principle) for refusing. The two groups of Germans seemed more at ease with directly expressing unwillingness to comply with the students' wishes, but the content of such forms in the GE data was considerably more tactful.

\section{DCT \#5: Refusal of Equal-Status Interlocutor's Suggestion Frequency of Functional Categories}

All three groups used direct refusal strategies with similar low frequencies. The frequency of statements of negative willingness was slightly higher in the GE and GG data than in the AE data.

Both AEs who said "no" softened this form by adding one or two downgraders: "No thanks..." (AE1); and .".. Thanks but no thanks." (AE5). Only one of the GEs used a downgrader with "no": "No thanks. ..." (GE7). None of the GGs did so, using just a bald "no." In terms of efforts to make the form, "no", more palatable to the interlocutor, $\mathrm{AE}>\mathrm{GE}>\mathrm{GG}$.

The one $\mathrm{AE}$ who used a statement of negative willingness used both a downtoner and elaboration: "I don't really need a diet plan, just more [sic] excercise." (AE7). Thus, 
the face threat was minimized, in contrast to the GG and GE responses that used this strategy. One of the GGs who expressed negative willingness used an opaque form: ."..ich [habe] für so etwas nichts übrig..." (.”.. I have a very low opinion of such ideas."-GG3).

All in all, then, not only did the AEs make less use of statements of negative willingness and the form, "no" than the German subjects, but also, all instances of these forms in the AE data were softened through downgraders, downtoners, and/or elaboration, in contrast to the GEs and GGs, with only one instance of a softened direct refusal form.

Table 4. 95: Use of Direct Refusal Strategies; Suggestion; Equal-Status Interlocutor (DCT\#5)

\begin{tabular}{|l|l|l|l|}
\hline & "No" & Negative Willingness & Negative Ability \\
\hline AEs & $17 \%$ & $8 \%$ & $8 \%$ \\
GEs & $20 \%$ & $20 \%$ & -87 \\
GGs & $14 \%$ & $21 \%$ & - \\
\hline
\end{tabular}

No excuses were used in responses to DCT\#5, underscoring the fact that the speaker neither wanted to accept the suggestion nor felt any pressure to conceal that fact from the equal-status, close-proximity interlocutor.

Reasons played a moderate role only in $\mathrm{AE}$ responses and statements of philosophy figured importantly only in the GG data (over one third of the responses).

\footnotetext{
${ }^{86}$ The responses of two Ges (GE3 and GE9) were not interpretable. The respondents did not seem to understand the DCT item. Because of this, the percentages given in the frequency section are based on ten, rather than twelve, GE respondents.

${ }^{87}$ One GE used a remark in the form of a statement of negative ability that obviously functioned as a statement of negative willingness: "Oh no, I can't do that. I really dislike all these grains and vegetables!" Thus it is included in the tally in negative willingness rather than negative ability.
} 
One statement of philosophy was adequate for most of the subjects. One GG, however, used two statements of philosophy and elaboration on a statement of philosophy (GG9, quoted below in content section).

Table 4. 96: Use of Reasons and Statements of Philosophy; Suggestion; Equal-Status Interlocutor (DCT\#5)

\begin{tabular}{|l|l|l|}
\hline & Reason & Philosophy \\
\hline GGs & $7 \%$ & $36 \%$ \\
AEs & $25 \%$ & $17 \%$ \\
GEs & - & $10 \%$ \\
\hline
\end{tabular}

In terms of face-threatening strategies, there was no sharp dividing line between statements of negative opinion and criticism of the suggestion. The criterion used to distinguish between the two strategies was whether the speaker specifically criticized the addressee's diet or expressed negative views of diets in general. There is a greater face threat in criticizing the suggested diet in particular because the speaker is saying that $s /$ he thinks little of an idea that the hearer considers good. Also, criticizing the fact that the addressee made the suggestion is a face threat because it criticizes the hearer's behavior. Denouncing diets in general, on the other hand, is less of a face threat because the hearer has the "out" of believing that the two interlocutors simply have different feelings about diets.

All but one of the AEs eschewed criticism of the suggestion, insults, and imperatives to rescind the suggestion, displaying a preference for the gentler strategy of stating a negative opinion. Even so, they used fewer statements of negative opinion than the German subjects. The one exception to the $\mathrm{AE}$ avoidance of strong negative forms was only implied (AE12). Underlying the statement that "Fad diets don't work..." was the unspoken view that the hearer's diet is a fad diet (and "fad diet" is invariably pejorative). It 
should be noted that in other DCT items as well, AE12 gave answers that were uncharacteristically harsh for the AE population as a whole (See discussion of AE12's response pattern in the content section of DCT\#12). In sum, the one appearance of criticism in the $\mathrm{AE}$ data was only indirect and in addition, was produced by a subject whose responses were sharper than the bulk of $\mathrm{AE}$ responses.

The GEs used more statements of negative opinion and less criticism of the suggestion than the GGs, but the data of each of the two groups contained one insult and an imperative to drop the suggestion, the testier of the strategies. The GGs expressed the least restraint with regards to risking confrontation in expressing their views on diets in general or the hearer's diet in particular, using the highest frequencies of upgraders and criticism of the suggestion.

Three of the GGs used the form, ach, which serves both as an upgrader and as a means of implying a statement of negative opinion or criticism of the eliciting speech act (see discussion of ach below in the content section). One GE (GE6) used the word, "ah", in much the same way as the GGs used ach; apparently this was an instance of transfer from the native language.

Statements of negative opinion appeared in the data in both intensified and mitigated forms. This functional category frequently appeared in amalgamation with an upgrader. As a means of mitigating a statement of negative opinion, one $\mathrm{AE}$ and one GE each used two downtoners: "I'm not really into dieting, you know..." (AE11); and .".. I've been trying all kinds of diets and nothing really worked out. I'm pretty much fed up with 
all that diet business." (GE12). The addition of downtoners obviously mitigates the utterance of a negative opinion and thus expresses negative politeness.

Table 4. 97: Use of Strategies that Increase the Face Threat; Suggestion; EqualStatus Interlocutor (DCT\#5)

\begin{tabular}{|l|c|c|c|}
\hline & AEs & GEs & GGs \\
\hline Negative Opinion & $50 \%$ & $80 \%$ & $64 \%$ \\
\hline Neg. Opinion Twice, or Elaboration on Neg. Opinion & $42 \%$ & $40 \%$ & $36 \%$ \\
\hline Upgrader & $25 \%$ & $20 \%$ & $43 \%$ \\
\hline Criticism of Suggestion & $7 \%$ & $20 \%$ & $36 \%$ \\
\hline Insult & - & $10 \%$ & $7 \%$ \\
\hline Imperative to Drop Suggestion & - & $10 \%$ & $7 \%$ \\
\hline
\end{tabular}

Using more than one statement of negative opinion, or intensifying a statement of negative opinion by adding an upgrader or elaboration heightens the negative effect, bringing it closer in tone to actual criticism of the suggestion. Elaboration can, on the other hand, add a rationalization for rejecting the suggestion, making it sound more like the idea has been considered, but rejected on the basis of that reflection, rather than summarily dismissed. The table below shows individual respondents' strategy choices in terms of sharpening or softening the effect of statement of negative opinion through the use of upgraders, more than one statement of negative opinion, and elaboration. Strategies that had a softening effect are marked + . 
Table 4. 98: Use of Statements of Negative Opinion with Upgraders, More Than One Statement of Negative Opinion, and Elaboration; Suggestion; Equal-Status Interlocutor (DCT\#5)

\begin{tabular}{|l|l|l|l|l|l|l|}
\hline & $\begin{array}{l}\text { Use with an } \\
\text { Upgrader }\end{array}$ & Used Twice & $\begin{array}{l}\text { Used Three } \\
\text { Times }\end{array}$ & Elaboration & $\begin{array}{l}\text { Elaboration } \\
\text { Twice }\end{array}$ & $\begin{array}{l}\text { Elaboration } \\
\text { Three Times }\end{array}$ \\
\hline AE2 & & & & $x$ & & \\
\hline AE4 & & & & $x$ & & \\
\hline AE5 & $x$ & $x$ & & & & \\
\hline AE6 & $x$ & & & & $x$ & \\
\hline AE10 & & & & & $x+$ & \\
\hline GG2 & & & & & & $x+$ \\
\hline GG6 & $x$ & $x$ & & & & \\
\hline GG8 & & $x$ & & & & \\
\hline GG9 & $x$ & & & & & \\
\hline GG11 & $x$ & & & $x$ & & \\
\hline GG13 & $x$ & & & $x$ & & \\
\hline GE4 & & & $x$ & & & \\
\hline GE6 & & & & $x$ & & \\
\hline GE8 & & & & $x$ & & \\
\hline GE11 & $x$ & & & $x$ & & \\
\hline GE12 & & & & & $x$ & \\
\hline
\end{tabular}

Evasive strategies: These functional categories played a very limited role in

responses to DCT\#5. There were only two occurrences of hedging in the data (one $\mathrm{AE}$ and one GG; no GEs).

Positive forms were of minor importance in DCT\#5. Only two AEs, just one GE, and no GGs used such forms, and most of the forms used were downgraders, the weakest of the positive forms in terms of strength of positive content. This mirrors the fact that the interlocutors are sufficiently close to allow direct statements without redressive action. As Brown and Levinson state, one of the sets of circumstances under which FTAs are performed baldly on record is when closeness permits the speaker to dispense with politeness strategies (See Chapter 2, discussion of FTA strategies). 
Table 4. 99: Use of Positive Adjuncts/Forms; Suggestion; Equal-Status Interlocutor (DCT\#5)

\begin{tabular}{|l|l|l|}
\hline & Promise & Downgrader \\
\hline AEs & $8 \%^{88}$ & $17 \% \%^{89}$ \\
GEs & - & $10 \%$ \\
GGs & - & - \\
\hline
\end{tabular}

Mitigating adjuncts likewise were relatively unimportant in DCT\#5, although they were used with moderate frequency by the GEs.

Table 4. 100: Use of Mitigating Adjuncts; Suggestion; Equal-Status Interlocutor (DCT\#5)

\begin{tabular}{|l|l|l|l|}
\hline & Downtoner & Forewarn & Pause Filler \\
\hline GEs & $20 \%$ & - & $20 \%$ \\
AEs & $17 \%$ & - & - \\
GGs & $7 \%$ & $7 \%$ & - \\
\hline
\end{tabular}

The following two tables show the high percentage of respondents who used no positive forms or mitigating adjuncts, and the rarity of more than one such form per response.

Table 4. 101: Number of Positive Forms / Adjuncts per Response; Suggestion; Equal-Status Interlocutor (DCT\#5)

\begin{tabular}{|l|l|l|l|}
\hline & $\mathbf{0}$ & $\mathbf{1}$ & $\mathbf{2}$ \\
\hline AEs & $75 \%$ & $17 \%$ & $8 \%$ \\
GEs & $90 \%$ & $10 \%$ & - \\
GGs & $100 \%$ & - & - \\
\hline
\end{tabular}

Table 4. 102: Number of Mitigating Adjuncts per Response; Suggestion; EqualStatus Interlocutor (DCT\#5)

\begin{tabular}{|l|l|l|l|l|}
\hline & $\mathbf{0}$ & $\mathbf{1}$ & $\mathbf{2}$ & $\mathbf{3}$ \\
\hline GEs & $70 \%$ & $20 \%$ & - & $10 \%$ \\
AEs & $83 \%$ & $\mathbf{8} \%$ & $\mathbf{8} \%$ & - \\
GGs & $93 \%$ & $7 \%$ & - & - \\
\hline
\end{tabular}

\footnotetext{
${ }^{88}$ This was a conditional promise: "I already have another diet I just started, but if it doesn't work out I'll talk to you about it (the diet) later." (AE3)

${ }^{89}$ One AE used two downgraders: “... Thanks but no thanks." (AE5).
} 
Use of Other Strategies: The only other functional category that appeared in the data was one instance of self-defense by a GE who used this strategy twice: .".. I'm not as big. Just today I've been eating too much." (GE2). This response was not at all plausible, considering the speaker's previous lines given in the dialogue of the test item.

\section{Content of Functional Categories}

Statements of Philosophy: In DCT\#5, the content expressed in statements of philosophy was that the speaker considered other means of losing weight a better option than going on a diet. Such responses included: ."..[sic] its not a matter of dieting as much as simply not being excessive." (AE1); .”..Entweder das klappt von alleine oder eben nicht." (.".It's [i.e., losing weight] either gonna happen or it isn't." in the sense of ...Either it [losing weight] works itself out automatically or it just doesn't happen."GG7); "Ich finde es reicht, wenn man einfach etwas bewußt ist..." ("I think just being a little more aware is sufficient..."-GG10); ."..man muß seine Eßgewohnheiten konsequent ändern." (."..you have to be consistent in changing your eating habits."-GG12); and, "I think I'll lose enough weight, if I just eat less for a while." (GE5).

Two statements of philosophy were implausible in the context of the DCT item (after confessing to a recent bout of overeating) ${ }^{90}$ : .... I just try to eat healthy food, and only eat when I'm hungry." (AE11); and, .”.. Ich versuche gerade, meine Ernährung

\footnotetext{
${ }^{90} \mathrm{~A}$ number of responses to DCT\#5 were illogical in the context of the given text, e.g., stating that the speaker was already on a diet (having just said that $\mathrm{s} / \mathrm{he}$ had been overeating). Apparently, the subjects were either loath to take on the role of someone who eats like a pig or did not read DCT text carefully enough. The two GE responses that were not interpretable (GE3 and GE9) were probably related to the incongruent responses of AE3, AE11, GG9, GE2, and possibly GG5.
} 
langfristig umzustellen, und auch diese ewig-verführerischen Naschereien wegzulassen. Es ist sehr schwer, wie Du Dir denken kannst, wird aber langfristig das einzig Richtige sein." (.".. I'm trying to make long-term changes in my eating habits and also to do without these ever-tempting snack foods. It is very difficult, as you can imagine, but in the long run, that's the only right way to go."-GG9).

In one GG's response, a statement of philosophy followed an insult in what was apparently intended as humor. The statement of philosophy probably was not meant seriously: "Das ist doch Weibersache! Männer arbeiten sich das Fett ab!" ("That's for broads $^{91} !$ Men work off their fat!"-GG4). (The insult is discussed below.)

Reasons: Reasons given for rejecting the suggestion either involved the previous choice of another alternative for losing weight or explained why the speaker did not want to try the friend's diet: "I already have another diet I just started..." (AE3); ."..ich habe mich entschlossen, FDH zu machen." (.".I've decided to simply eat only half as much as I want to."-GG5); ...I just like food. ..." (AE5); and "I can't use that diet-I'm a vegetarian." (AE9).

Imperatives to Drop the Suggestion: The data contained two fairly strong imperatives to rescind the suggestion: "Ach, geh mir weg mit diesen Diäten. ..." ("Ugh, stop pestering me with these diets. ..."-GG14); and, ."..stop pestering me with your diettips!" (GE11).

\footnotetext{
91"Broads" is not an ideal translation for Weiber. Both are disparaging terms for women but have a different "feel". Another possible translation would be: "That's for females!", but some of the deprecatory character of the statement would be lost. In this context, use of the term Weiber accentuates the suggestion that women are interested in foolish ideas that men would never stoop to consider.
} 
Criticism of the Suggestion: As discussed above, the distinction made between statements of negative opinion and criticism of the suggestion depended on whether the speaker's faultfinding targeted diets in general or the particular diet recommended by the friend. Only one of the AEs remarked-indirectly-on the friend's diet. There were two other indirect uses of criticism (GE7 and GG9), while three GGs and one GE specifically criticized it. The content of criticism was an overall damning of the diet related to its fruitlessness, rather than specific complaints.

As observed above, AE12 did not directly criticize the friend's diet, however, her response, "Fad diets don't work, I keep telling you that!", implied that the diet was a "fad diet." In much the same way, one GG indirectly criticized the hearer's diet by referring to "solche Kurzzeiternährungsumstellungen" ("such short-term changes in one's eating habits"): "Du weißt genau, daß ich von solchen Kurzzeiternährungsumstellungen nicht viel halte. ..." ("You know very well that I have a very low opinion of such short-term changes in one's eating habits."-GG9). Similarly, one GE remark implied criticism of the friend's diet: .".I've heard about [it]. ..." (GE7). In this context, what the speaker has heard was obviously judged in a negative way.

The other GGs and the one other GE using this functional category were more direct. .".die [ist] auch nicht viel anders als die alten. ..." (.".. that one isn't any different from the old ones either. ..."-GG1), "Du weißt genau, daß ich für so etwas nichts übrig habe..." ("You know very well that $\underline{I}$ have a very low opinion of such ideas."-GG3 ${ }^{92}$ ); .".II

\footnotetext{
${ }^{92} \mathrm{GG3}$ 's response continued with an opaque statement of negative willingness that bears
} special mention: “...Aber 'Du darfst' ja." (“...If you think it's such a good idea, you do it!" 
can't imagine that this one works better." (GE6). One GG remark that might have been interpreted as a statement of negative opinion on its own, served as criticism of the suggestion in context. Following an imperative to drop the suggestion, the remark asserted that the friend's diet, like all diets, was worthless: “Ach, geh mir weg mit diesen Diäten. Die sind doch alle gleich und nützen gar nichts." ("Ugh, stop pestering me with these diets. They're all the same: completely worthless."-GG14).

Statements of Negative Opinion: The themes of statements of negative opinion and elaboration thereon revolved primarily around the futility of diets. In addition, two AEs and two GEs remarked on disliking diet food (AE2, AE5, GE1, and GE7), and two GGs expressed a view of diets as being stressful (GG7 and GG10).

The statements of negative opinion asserting that diets don't work included: "I don't believe in diets. They never work."(AE4); ....I've tried every diet there is, and all they are is a bunch of crap. They don't work." (AE6); "Diets never work for me. I always feel unhealthy while I'm on them and then I gain the weight back afterwards." (AE10); "I'm not really into dieting..." (AE11); "Ich habe schon so viele Diäten ausprobiert, leider erfolglos, und mittlerweile habe ich mich damit abgefunden. Zudem habe ich kein Vertrauen zu Diäten mehr." ("I've already tried so many diets, without success, I'm afraid, and in the meantime I've accepted that. Besides, I no longer have any confidence in diets."-GG2); .".ich hab' das schon x-mal probiert. Bei mir hat noch nie was geholfen, außer FdH-Methode." (."..I've already tried that countless times. Nothing has ever helped me except for eating half as much as I want."-GG6); "Ich glaube nicht an die Wirkung

- GG3). The remark was also probably a pun, making reference to a diet margarine 
von Diäten, da nimmt man nachher noch mehr zu." ("I don't believe in the effectiveness of diets-afterwards a person gains back even more weight."-GG8); .".ich [halte] von solchen Kurzzeiternährungsumstellungen nicht viel. ..." (.”.I don't think much of that kind of short-term change in eating habits. ..."-GG9); ."..ich habe schon so viele von diesen Diäten versucht-leider alle ohne Erfolg...!" (.".I've already tried so many of these dietsall without success, unfortunately...!"-GG11); "Ich glaube daß Diäten nichts nützen ..." ("I believe that diets don't do any good..."-GG12); and ."..ich habe schon sovieles ausprobiert u. nichts hat bisher geholfen." (."..I've already tried out so many [ways to lose weight] and nothing has helped yet."-GG13); ."..I am tired to try this new diets, they have no use at all, nothing changes. ..." (GE4), ."..I tried so many diets and none of them had any effect. ..." (GE6); "I tried a lot of new diets and they never worked." (GE8); "I'm fed up with any diet!!!" (GE10); .".I've tried about every bloody diet there is, but nothing works. ..." (GE11); and, .".I've been trying all kinds of diets and nothing really worked out. I'm pretty much fed up with all that diet business." (GE12). One GG remark only implied the futility of diets: "Diät, wenn ich das schon höre. ..." ("Diet, just the mere mention. ..."-GG1).

Negative opinions related to diet food included: "I don't like diet food. It tastes disgusting." (AE2); .".I hate trying to eat according to someone else's menu. ..." (AE5); ...I really dislike all these grains and vegetables!" (GE1); and, ."..Eating only fruits every day just isn't my thing." (GE7).

product called "Du darfst" ("you may"). 
Negative views of diets related to stressfulness included: .". Das ist mir zu stressig. ..." (.".. That's too stressful for me. ..."-GG7); and, .".diesen Diätstreß..." (."..that diet-stress..."-GG10).

\section{Acknowledgment of Subjective Attitude towards Diets versus Wholesale Rejection} of Diets: Some respondents acknowledged the subjective nature of their views of diets, e.g., "Diets never work for me. ..." (AE10), while others made a blanket condemnation of diets, e.g., "Ich glaube daß Diäten nichts nützen..." ("I believe that diets don't do any good..."-GG12) and .".Die sind doch alle gleich und nützen gar nichts." (."..They're all the same and they are totally worthless."-GG14). The GGs tended to make more blanket statements rejecting diets universally than the AEs and GEs, half of whom modified critical remarks by saying that diets did not work for them, leaving the possibility open that diets may be fine for other people. Of those making negative comments about diets, just over one half of the AEs made sweeping statements (AE2, AE4, AE6, AE12), while just under half of the AEs acknowledged the subjectivity of their experience (AE5, AE10, and AE11). Two-thirds of the GGs' negative remarks displayed sweeping contempt for diets (GG1, GG3, GG4, GG7, GG8, GG9, GG10, GG12, GG14), while over one third of the GGs' statements of negative opinion were tempered with an acknowledgment that this was only the speaker's own experience (GG2, GG6, GG11, GG13). The GEs were evenly divided between the two kinds of remarks. Blanket statements included responses by GE4, GE10, and GE11. The more temperate remarks included the responses of GE6, GE8, and GE12. In this area, then, the GE response patterns followed those of the AEs rather than the GGs, signaling good acquisition. 
Mention of Addressee in a Negative Context: There were differences between the American and German subjects regarding hints of negativity towards the addressee. Only one $\mathrm{AE}$ made a comment that implicitly expressed a mildly negative feeling towards the interlocutor (exasperation): "Fad diets don't work, I keep telling you that!" (AE12), whereas both German groups made several such remarks, some of which were more explicit. The GG data contained three upgraders and an imperative to drop the suggestion that signaled annoyance and implied criticism of the addressee's repeated attempts to recommend diets that the speaker considered worthless: "Du weißt genau..." ("You know very well..."-GG3 and GG9); .".geh mir weg mit diesen Diäten. ..." (.".don't pester me with these diets. ..."-GG14); and "Du, ..." (literally, "you", but in this context, "Listen, ...", in the sense of "Hör mir mal zu"-GG6). The latter upgrader, 'du', added directness, immediacy, and intensity. One male GG's term, "Weibersache" (GG4), was aimed at the female addressee in the German version of the DCT. As noted above, Weiber is a pejorative term for 'women', suggesting limited intelligence and sundry other deficiencies. While the intent of the remark may have been playful, it still would have been insulting to a female interlocutor, implying that only a woman would make such a stupid suggestion. One GG's statement of negative opinion possibly belongs in this category. Although the hearer was not explicitly mentioned, this remark obliquely expressed annoyance at the hearer's insistence: "Diät, wenn ich das schon höre. ..." ("Diet, just the mere mention. ..."GG1). Even just having the friend mention a diet irritated the speaker.

A few of the GEs' remarks in this category resembled GG comments: GE11 and GE12's pause filler, "Listen...", was reminiscent of "Du..." or "Du weißt genau." 
Similarly, GE11's remark, "Stop pestering me..." was reminiscent of .".geh mir weg...." In addition to these remarks, one GE used an expletive as a means of insulting the addressee: "Oh, fuck you." (GE2).

Upgraders: In connection with GG responses to DCT\#5, a tiny, but eloquent, word should be discussed. Ach is an interjection which can be used to signal disagreement, scoffing, disgust, frustration, and irritation. It can express the sentiment, "That's ridiculous!", in a single syllable. To properly render "ach" in English, one would need either context or intonation. Many English equivalents of this interjection do not have real written forms. In oral communication there might be a groan of annoyance, dismissal, disagreement, or disgust, with eyes rolled heavenward, or a click of the tongue and a slight shaking of the head. A highly expressive word, ach can also express distress, disbelief, curiosity, interest, and perhaps a host of other human conditions. In DCT\#5, ach was an upgrader that also implied a negative opinion or criticism of the eliciting speech act.

Three GGs used the term, ach to signal irritation and disagreement (GG11, GG13, and GG14). One GE apparently transferred use of the word, ach, using the word, "ah" in the same context as her GG counterparts (GE6), namely, followed by a statement of negative opinion and/or criticism of the eliciting speech act (GE6 continued with both a statement of negative opinion and criticism of the suggestion).

Similarly, other terms were used by a number of GGs as an exclamation of negativity at the beginning of their responses, signaling annoyance and a critical attitude: "Diät..." ("Diet..."-GG1); "Du weißt genau..." ("You know very well..."-GG3 and GG9); 
“Das ist doch Weibersache!..." (“That's for broads!..."-GG4); “Du..." ("Listen..."-GG6); and "Nee..." ("No..."-GG7).

FTA Strategies: The only instance of a refusal performed off record in the data for DCT\#5 was the use of hedging by AE8. Most of the responses fell into the category of refusing baldly on record. Such straightforward refusals were unmitigated and direct. While only half of the AE responses clearly belonged in this category, all but two of the GG responses and all but one of the GE responses did. The exceptions in the GG and GE data were a combination of bald refusals and negative politeness, making some use of explanations (e.g., excuses or statements of philosophy) or at least acknowledging the suggestion (e.g., through statement of gratitude). Of the five remaining AE responses, one clearly expressed negative politeness (AE1), and three others were a mixture of "baldly on record" and "negative politeness", softened as described above (AE5, AE10, and AE11). One $\mathrm{AE}$ added an element of positive politeness to his bald refusal by showing some interest in the hearer's diet (AE3).

\section{Summary of Results: Refusal of Suggestion Made by an Equal-Status Interlocutor (DCT\#5)}

The social proximity between the interlocutors in DCT\#5 allowed more directness and less face protection than in other DCT items, which is reflected in strategy choices and the uncomplicated structure of the responses. All three groups displayed considerable candor. The speakers were straightforward, directly stating why they chose to refuse and expressing their honest opinions without the intricacies of redressive action. While direct refusal strategies, "no" and statements of negative willingness were not used with 
enormous frequency, they still appeared more often than in many other DCT items. This reflects irritation at the unwelcome suggestion as well as the low social distance and equal status. At the same time, however, the speakers did show enough face-saving tact to offer explanations for the refusal, even if they were often in the form of statements of negative opinion. Even if this was not complete conflict-avoidance, it was still considerably less of a face threat than an unexplained direct "no" or statement of negative willingness would have been.

The AEs made less use of "no" and statements of negative willingness than the GEs and GGs. All AEs who used these direct forms softened them with downgraders, downtoners, and elaboration. Of all the GE and GG instances of these functional categories, only one GE used a downgrader with it. Thus, the AEs made greater efforts to lessen the face threat associated with direct refusal forms than either the GGs or GEs.

No excuses were used in DCT\#5 as there was no need to feign inability to accept the suggestion. It is interesting that none of the participants in the study used the strategy of saying they were unable to stay on a diet. There was some use of reasons (by one fourth of the AEs and one GG) and statements of philosophy (by over one third of the GGs, one GE and two AEs).

In terms of content, reasons were used to explain that the speaker did not find the friend's diet attractive or had already found a different way to lose weight, and statements of philosophy contended that there were better ways to lose weight than going on a diet.

A large proportion of the responses depended on statements of negative opinion or criticism of the suggestion. While criticism of the suggestion involved comments devaluing 
the friend's diet, statements of negative opinion expressed skeptical views of diets in general. The most frequent complaint was the futility of dieting, but stressfulness and unappealing food options were other deterrents. The wording of both criticism and negative opinions was uninhibited and candid. With only one exception, the AEs avoided the harsher forms of face-threatening strategies, opting for the milder statement of negative opinion, but using even this milder form much less frequently than the two groups of Germans. The one instance of criticism in the AE data was only implied. The GGs, on the other hand, displayed a much greater willingness to risk a face threat to the addressee, using upgraders and criticism of the suggestion with a relatively high frequency. The GEs displayed somewhat more caution than the GGs, but less than the AEs. In the GG and GE data, there was one instance each of the particularly harsh forms, insult and imperative to rescind the suggestion, forms which did not appear in AE responses. A large proportion of statements of negative opinion used by all three groups were intensified through the use of upgraders, a second or third statement of negative opinion, and/or elaboration.

The GGs also displayed a much stronger tendency to condemn diets universally than the AEs or GEs. While two-thirds of the GGs expressed sweeping disdain for diets, half of the AEs and GEs who criticized diets also acknowledged the subjectivity of this aversion.

The AEs avoided mention of the hearer in a negative context except for one very indirect remark, whereas the Germans displayed a greater willingness to risk this kind of face threat, even extending to personal insults in the case of one GE and one GG. 
Both the GEs and GGs displayed more negativity in terms of the frequency of face-threatening strategies than the AEs. By totaling the percentages of statements of negative opinion and criticism of the suggestion in the GE and GG data, one finds that these strategies received the same percentage of use in both groups (100\%-see table 99$)$. Usage frequencies of insults and imperatives to rescind the suggestion were comparable. The GGs were somewhat more unrestrained, using a higher frequency of the harsher form, criticism of the suggestion, but negative forms in general were used with equal frequency, thus, the stronger face threat amongst the GGs was more a matter of degree. The GGs used more upgraders, but the GEs used somewhat more elaboration on negative opinions or doubling of statements of negative opinion.

The degree of confrontativeness follows the pattern: $\mathrm{GG}>\mathrm{GE}>\mathrm{AE}$. As in some other DCT situations, the GEs followed German native speaker patterns in openly venting negative feelings and perceptions, unlike the AEs. One might ask if this implies that Germans resent advice of this sort more than Americans do (although the data is obviously insufficient to support an assertion to that effect).

There was practically no use of evasive strategies. Obviously, they were not necessary with the friend. The low use of positive forms and mitigating adjuncts similarly reflected the low need to protect the hearer's face in a situation of very low social distance.

In terms of FTA strategies, almost all of the German subjects performed the refusal baldly on record, with only very few uses of minimal negative politeness. This was true of only half of the AEs. The other half sought ways of avoiding that kind of directness, 
mostly by adding negative politeness, but also by displaying some positive politeness or refusing off record. Even though this DCT item involved low social distance between the interlocutors, the situation was not one that called for positive politeness, or the expression of mutual bonds because there is not much possibility of face loss in having one's diet suggestion rejected (indeed, the lack of redress was the major feature reflecting intimacy in DCT\#5).

\section{DCT \#6: Refusal of Higher-Status Interlocutor's Suggestion}

\section{Frequency of Functional Categories}

Direct Refusal Strategies: Direct refusal strategies were practically absent in responses to DCT\#6. There was only one instance of such a strategy, the direct form, "no", used by a GG. Not only were direct forms avoided, but the one appearance of "no" was in a softened form: .". Nein, nein..." (."..No, no..."-GG1. Nein, nein is considerably gentler than nein).

There was only very light use of the functional categories of excuses, reasons, and statements of philosophy. While excuses were given by two AEs and two GEs, and statements of philosophy by one AE and one GE, these forms did not appear in the GG data. On the other hand, one GG gave a reason, in contrast to the AEs and GEs, who did not use this strategy. 
Table 4. 103: Use of Excuses, Reasons, and Statements of Philosophy/Principle; Suggestion; Higher-Status Interlocutor (DCT\#6)

\begin{tabular}{|l|l|l|l|}
\hline & Excuse & Reason & Philosophy \\
\hline AEs $^{\mathbf{9 3}}$ & $18 \%$ & - & $9 \%$ \\
GEs & $17 \%$ & - & $8 \%$ \\
GGs & - & $7 \%$ & - \\
\hline
\end{tabular}

The most face-threatening categories in DCT\#6 were guilt trips, upgraders, and criticism of the suggestion. While a joke might ordinarily be considered an evasive strategy, both of the jokes used for DCT\#6 posed a face threat to the addressee. Without mitigation or reversal (i.e., "getting serious" and responding favorably to the suggestion), these jokes could have been taken as an affront, mocking the suggestion (and the boss!). These jokes are discussed in the content section. Statements of negative opinion, while somewhat disagreeable for the addressee, posed a relatively small face threat in DCT\#6.

In this study, a remark is coded as criticism of the eliciting speech act when the respondent actually says that the idea is flawed in some way. Negative opinion, on the other hand, is a much more indirect critical strategy. In DCT\#6, unfavorable remarks that did not specifically mention the boss' suggestion, only related ideas for maintaining order, were classified as statements of negative opinion. Statements of negative opinion posed less of a face threat than criticism because the addressee had the "out" of assuming that his or her suggestion did not belong to the set of ideas being viewed skeptically.

Three fairly face-threatening strategies were used only by GG subjects: guilt trips, upgraders, and jokes. While just over a third of the AEs produced criticism of the

\footnotetext{
${ }^{93}$ The response of one of the AEs to DCT\#6 (AE6) was not intended seriously. For this reason, this response is not included in the frequency counts. Thus, percentages are based on eleven, rather than twelve, AE respondents. AE6's response is discussed in the content section.
} 
suggestion, over half of the GEs and somewhat less than half of the GGs did so. Statements of negative opinion played a small role in the three groups' responses.

None of the GGs mitigated their guilt trips, although one guilt trip was only implied (GG9. For quotes of responses mentioned here, see content section.). Every instance of criticism of the suggestion used by AEs was mitigated internally, either through downgraders, downtoners, or both. All but two instances of criticism were preceded by positive strategies. One $\mathrm{AE}$ used elaboration on the criticism, and another $\mathrm{AE}$ used criticism twice. Only one GG and two GEs, on the other hand, mitigated their criticism internally. Three GE responses containing criticism began with a pause filler or forewarn, and a fourth began with a statement of regret and ended with a statement of gratitude. None of the GGs used positive or mitigating forms preceding or following the criticism (See content section). Two GGs used elaboration on the criticism (GG3 and GG14), and two GGs made rather curt remarks (consisting of upgraders and postponement) that implied criticism of the suggestion (GG10 and GG11. See content section.). One GE made two critical remarks (GE4), another GE made two critical remarks and elaborated on one of them (GE6).

Two GGs used the upgrader, ach, which implied a negative opinion or criticism of the suggestion (GG1 and GG14. See discussion of ach in the content section of DCT\#5.). Other upgraders that created a similar effect included: ("Ich weiß, ich weiß..." ("I know, I 
know..." GG3), "Ja, ja..." (“OK, OK...."94_GG10 and GG11). One upgrader took the form of an aggressive interrogative (GG4. See content section.).

One AE produced two statements of negative opinion and another used three (AE1 and AE9). Indirectness and an element of self-defense maximized politeness in the $\mathrm{AE}$ statements of negative opinion. While the GG statement of negative opinion also contained some measure of self-defense, its faultfinding content was intensified through use with an upgrader (GG14). GE statements of negative opinion were neither softened nor intensified (GE1 and GE10).

Table 4. 104: Use of Strategies that Increase the Face Threat; Suggestion; HigherStatus Interlocutor (DCT\#6)

\begin{tabular}{|l|l|l|l|l|l|}
\hline & Guilt Trip & Upgrader & $\begin{array}{l}\text { Criticism of } \\
\text { Suggestion }\end{array}$ & Joke $^{95}$ & Negative Opinion \\
\hline AEs & - & - & $36 \%$ & - & $18 \%$ \\
GEs & - & $67 \%$ & - & $8 \%$ \\
GGs & $21 \%$ & $43 \%$ & $43 \%$ & $14 \%$ & $7 \%$ \\
\hline
\end{tabular}

Evasive Strategies: There was little use of evasive functional categories in DCT\#6, only two instances of postponement in the GG data

As for positive forms and adjuncts, these strategies played a small role in the $\mathrm{AE}$ and GE data, although downgraders appeared frequently in $\mathrm{AE}$ responses. The GGs made very little use of positive forms.

\footnotetext{
94"'Okay, okay..." does not give the exact "feel" of $j a, j a$. The German upgrader has a belittling quality, whereas the English form sounds more harried. $J a$, ja implies that the suggestion is very stupid, but that the speaker is humoring the addressee.

${ }^{95}$ Both of the jokes here are indeed forms of "verbal avoidance" (Beebe et al's classification), but more importantly for the discussion at hand, they also increased the face threat to the interlocutor. For this reason, they are included in this table.
} 
None of the respondents used intensifiers with expressions of regret, but one GG and one GE used intensifiers with their statements of gratitude (GG8 and GE1). The AEs used no intensification.

Many of the positive forms were used to soften criticism of the eliciting speech act (AE5, AE11, AE12, GG3, GE6, and GE9). Of these, GE6 had two uses of criticism with a downgrader. Two AEs and one GG each used a downgrader in conjunction with selfdefense (AE1, AE10, GG6), and one GG used a downgrader following a joke to lessen its impact (GG6).

Table 4. 105: Use of Positive Adjuncts/Forms; Suggestion; Higher-Status Interlocutor (DCT\#6)

\begin{tabular}{|l|l|l|l|l|l|}
\hline & Agreement & Gratitude & Positive Opinion & Regret & Downgrader \\
\hline AEs & $18 \%$ & $18 \%$ & $9 \%$ & - & $55 \%$ \\
GEs & $8 \%$ & $8 \%$ & $17 \%$ & $17 \%$ & $17 \%$ \\
GGs & - & $7 \%$ & - & - & $14 \%$ \\
\hline
\end{tabular}

Regarding use of mitigating adjuncts, downtoners occurred frequently in $\mathrm{AE}$ responses, though forewarns and pause fillers were not used. The GEs made light use of all three forms, whereas the GG data contained only one downtoner, two forewarns, and no pause fillers.

Table 4. 106: Use of Mitigating Adjuncts; Suggestion; Higher-Status Interlocutor (DCT\#6)

\begin{tabular}{|l|l|l|l|}
\hline & Downtoner & Forewarn & Pause Filler \\
\hline AEs & $55 \%$ & - & - \\
GEs & $17 \%$ & $8 \%$ & $17 \%$ \\
GGs & $7 \%$ & $14 \%$ & - \\
\hline
\end{tabular}

The table below shows the high percentage of GGs using no positive forms in their responses, as compared with the AEs and GEs. The AEs well exceeded the GEs in the number of positive forms used per response. 
Table 4. 107: Number of Positive Adjuncts/Forms per Response; Suggestion; Higher-Status Interlocutor (DCT\#6)

\begin{tabular}{|l|l|l|l|}
\hline & $\mathbf{0}$ & $\mathbf{1}$ & $\mathbf{2}$ \\
\hline AEs & $18 \%$ & $64 \%$ & $18 \%$ \\
GEs & $42 \%$ & $42 \%$ & $17 \%$ \\
GGs & $79 \%$ & $14 \%$ & $7 \%$ \\
\hline
\end{tabular}

The response patterns displayed in the table above held true for mitigating adjuncts as well.

Table 4. 108: Number of Mitigating Adjuncts per Response; Suggestion; HigherStatus Interlocutor (DCT\#6)

\begin{tabular}{|l|l|l|}
\hline & 0 & 1 \\
\hline AEs & $45 \%$ & $55 \%$ \\
GEs & $58 \%$ & $42 \%$ \\
GGs & $79 \%$ & $21 \%$ \\
\hline
\end{tabular}

A major strategy in DCT\#6 that rarely occurred elsewhere in the DCT was selfdefense. In some cases, self-defense provided a means of restoring the boss' confidence in the employee's competence (which might have been questioned because of his/her inability to find the report on his/her messy desk); some of these defensive remarks resembled excuses. In other cases, self-defense was a way to sidestep the boss' suggestion without risking offense. In some GG responses, self-defense linked with guilt trips indicted the boss for the employee's inadequate performance. In terms of politeness towards the addressee, self-defense ran the gamut from highly polite to face-threatening, from an effort to cooperate with the boss to the contrary. The ranking of the three groups in the following table is based on the politeness of individual defensive remarks rather than on frequency percentages, because defensive remarks in the $\mathrm{AE}$ data tended to increase politeness, while GE remarks were more neutral, and a number of the GG remarks increased the face threat (See content section.). 
Table 4. 109: Use of Other Strategies (Self-Defense); Suggestion; Higher-Status Interlocutor (DCT\#6)

\begin{tabular}{|l|l|l|l|l|}
\hline & Self-Defense & Self-Defense, 2x & Self-Defense, 3x & Implied Self-Defense \\
\hline AEs & $36 \%$ & $9 \%$ & - & $18 \%$ \\
GEs & $33 \%$ & $8 \%$ & - & - \\
GGs & $36 \%$ & $7 \%$ & $14 \%$ & $7 \%$ \\
\hline
\end{tabular}

\section{Content of Functional Categories}

Self-Defense: As noted above, the boss' advice in DCT\#6 provoked a number of defensive responses. Self-defense was directed toward either the unwanted suggestion or the speaker's perception of criticism underlying the suggestion (The boss' initial remark stated that the employee should be better organized, and the suggestion was made because the employee was unable to find a report in the clutter on his/her desk). The degree of defensiveness apparently reflected the extent to which the boss' remark was perceived as a face threat.

Using the strategy of self-defense served two major cooperative purposes: the attempt to reestablish the boss' positive image of the employee despite his/her apparent disorderliness; and avoidance of contradicting the boss while dodging pressure to follow unhelpful advice. By relating deficiencies of the proposed solution to one's own preferences and tendencies rather than to the weaknesses of the idea, a face threat was averted. In the cases in which self-defense was a response to perceived criticism, most of the respondents sought to regain the boss' confidence, but some GGs used defensive responses for a third purpose, namely to defend the speaker by blaming the boss, e.g., for keeping the employee so overworked that it was impossible to maintain order. 
For the AEs, the primary purpose of remarks involving self-defense was to restore the boss' confidence in the employee, as well as to appease the boss and express a cooperative attitude. A few defensive remarks contained an evasive element. Through subtle means, the AEs minimized any impression that they might be contradicting the boss, even though contradiction was often inherently present in self-defense directed against perceived criticism. A higher proportion of AEs made efforts to soften defensive remarks than the German subjects did, mirroring the more positive content of $\mathrm{AE}$ statements of self-defense. Of the six instances of explicit $\mathrm{AE}$ self-defense, downgraders or downtoners were used four times: ."..I find that my disorganization rarely affects my work seriously..." (AE1. Here, self-defense was conjoined with a downgrader, "I find that."); "I know that it may seem unorganized to someone else but I know where everything is. Usually." (AE2. This defense was preceded and followed by disclaimers. "Usually" at the end of the response served as a downtoner.); "Believe it or not, I'm far more organized than I seem. It's actually quite rare that I misplace something." (AE10. Self-defense was preceded by the downgrader, "believe it or not." The phrase, "more organized than I seem", acknowledged that the speaker was indeed responsible for having a messy desk and that the boss was not unjustified in viewing the speaker as disorganized. In the second sentence, "actually" is a downtoner.); "Usually I have no problem finding anything. I've just been very busy lately." (AE4. The word, "usually", softened the assertion, which also was followed by an excuse so vague that the addressee would have been unlikely to interpret it as blame.); and, "[sic] Your probably right, but I normally have a good system 
worked out. ..." (AE8. Preceded by a statement of agreement, this remark also contained the word, "normally", which functioned as "usually" did in AE4's statement.).

While a few GEs sought to recover the boss' confidence, evasion played an equally important role. Almost all the defensive GE comments asserted that the speaker's difficulties in finding the report was an anomaly: ."..normally I don't have problems in managing my things." (GE2); .".normaly it's no problem to find anything here because usually everything is organized here." (GE3); and, .".. Usually I'm very well organized. ..." (GE11). One GE self-defense openly contradicted the boss: ."..I'm always successive in finding things without organization." (GE8). One GE focused primarily on appeasing the boss and displaying a willingness to cooperate, but said little to assure the boss of the speaker's competence. This respondent's second use of self-defense was ambiguous as to whether the speaker blamed herself or the method for the unsatisfactory outcome, and was the only one of the six GE instances of self-defense that was mitigated (by the downtoner, “actually"): "Actually I do write little notes myself, but I can't help it, they always get lost." (GE10).

In the GG data, the nature of defensive remarks was more diverse. While a few instances of self-defense focused on reassuring the boss of the employee's capabilities, some of these were cooperative, but others were evasive. Some defensive comments were linked to guilt trips and defended the employee by blaming the boss. Of the eight explicit GG self-defense remarks, only two involved use of a downgrader or downtoner: “Ach, ich komme eigentlich hier gut zurecht. ..." (“Aw, I'm actually getting along fine here."-GG1. The downtoner is underlined. This was the only instance of self-defense in the data 
combined with an upgrader, i.e., ach.); and, .".ich weiß, es klingt komisch, aber ich brauche dieses kreative Chaos." (."..I know that it sounds funny, but I need this creative chaos."-GG6. The downgrader is underlined). GG1's defensive remark was actually a veiled contradiction of the boss' remark, rejecting the boss' suggestion. The same was true of GG6's response, but this was expressed in a somewhat coy fashion. Two similar utterances were direct and unapologetic: "Normalerweise komme ich mit meinem System aber gut zurecht." ("Normally my system works out just fine."-GG7) and "Ich habe schon ein System in meinen Unterlagen..." ("I do have a system in my filing..."-GG8). The latter response included an expression of gratitude, which mitigated the effect. One GG acknowledged the employee's difficulties but only after a strong assertion of the employee's usual competence: "Das ist nur eine Ausnahme. Ich hatte in letzter Zeit viel um die Ohren und kam einfach nicht dazu, regelmäßig meinen Schreibtisch aufzuräumen." ("This is just an exception. I've been up to my ears lately and I simply didn't get around to cleaning up my desk regularly."-GG2). Neither the AEs nor the GEs used self-defense in conjunction with guilt trips, but three GGs did so, blaming the interlocutor for the speaker's messy desk and trouble finding things (statements of self-defense are underlined): "Sie geben mir einfach zuviel Arbeit. Außerdem bringen Sie mich immer unter Zeitdruck. Da soll einer noch Ordnung halten können?" ("You're simply giving me too much work. In addition to that, you always put me under time pressure. How's anyone supposed to be able to stay organized under these conditions?!"-GG4); "Ich habe zur Zeit keine Zeit, weil alles sehr nervös hier im Betrieb abläuft." ("Here of late I don't have any time, because everything that goes on here at work is very nervous."-GG5); and, "Ich 
versuche eben, immer alles gleich zu erledigen. Da aber im Moment soviel bzw. zuviel auf meinem Schreibtisch landet, habe ich den Überblick verloren. Aber den hab ich bald wieder, keine Sorge." ("I just always try to take care of everything right away. But because so much-or to put it more precisely, too much-stuff is landing on my desk at the moment, I've lost track of the big picture. But I'll be right back on track, don't worry."GG9). While the latter speaker hinted at the mess being the boss' fault, she also strove to convince the boss of her competence.

The two cases of implied self-defense in the AE data were both embedded in an indirect statement of negative opinion (See discussion of statements of negative opinion below.): "[sic] Ive tried different approaches like that to improve my organization..." (AE1); and, "I've tried that! ..." (AE9). The GG who used a similar form also embedded it in negative opinion, but included an upgrader as well: "Ach, das habe ich auch schon probiert. ..." (“Argh, I've tried that already, too."-GG14).

A number of GGs asserted a preference for their own disorderly system to justify their rejection of the boss' suggestion: .".ich habe da mein eigenes System." (“I have my own system"-GG1); ...ich brauche dieses kreative Chaos." (."..I need this creative chaos."-GG6); "Normalerwise komme ich mit meinem System aber gut zurecht." ("But normally I manage just fine with my system."-GG7); "Ich habe schon ein System in meinen Unterlagen..." ("I do have a system in my filing..."-GG8). None of these remarks indicated that the boss' idea might also be valid, but two of them were preceded or followed by "softening agents": ....ich weiß, es klingt komisch, aber..." (."..I know it sounds funny, but..."-GG6), and ."..aber vielen Dank für den Ratschlag." (.”..but thank 
you very much for the advice."-GG8). There were fewer such remarks in the AE and GE data. Only one GE made such a statement: .'.I'm always successive in finding things without organization." (GE8). The AE remarks in this category seemed somewhat less uncompromising than those of the GGs and the one GE: .".this unorganized mess is the best way for me to stay organized." (AE3); .".I normally have a good system worked out. ..." (AE8); and, ."..This system just seems to work better for me..." (AE9).

Face-Threatening Strategies: Of the functional categories that increased the face threat of the refusal, guilt trips, upgraders, and jokes were used only by the GGs. All three groups used criticism of the suggestion and statements of negative opinion. In terms of the degree of risk to the addressee's face in the content of these forms, there were important differences between the three groups.

While the AE group did use criticism of the boss' suggestion and statements of negative opinion, the effect was softened considerably through various means. The criticism hardly came across as such, and was veiled, inoffensive, and mild. This effect was created:

- through the use of downgraders: ."..but I don't think that'll work for me. ..." (AE12), and

- a downgrader together with a downtoner: "I'd probably just lose the notes too..." (AE11); "This system just seems to work better for me..." (AE9); and .". but somehow I think notes stuck everywhere would just add to the clutter!" (AE5). Very careful not to be offensive despite his misgivings about the suggestion, the latter subject also preceded his criticism by saying, "That's a great idea, ..."! 
- by appearing to criticize oneself rather than the suggestion: "I'd probably lose the notes in this mess!" (AE7); ."..when I'm super-organized it just gets worse." (AE9); "I'd probably just lose the notes too..." (AE11); and, ... I tried it once, I forgot where I put the notes." (AE12).

- by saying he / she has tried such a method, but only implying that it did not work out, not saying so explicitly: "I've tried that! This system just seems to work better for me..." (AE9). This respondent also avoided directly criticizing the boss' suggestion by referring to the employee's system, rather than explicitly mentioning the boss' idea.

- by relating the deficiencies of the suggested remedy to one's own personal preferences or characteristics: .". \& various [sic] skemes I try to [sic] orgaize [sic] dont work for me anyway." (AE1); ."..This system just seems to work better for me..." (AE9. The remark additionally focused on the positive features of the speaker's method as opposed to the negative features of the hearer's.); and, .".but I don't think that'll work for me. ..." (AE12). This strategy prevented face-risk to the addressee by allowing the hearer the out of believing that the advice might be fine for other people.

While only one GG and one GE made use of negative opinions, the rest of the German subjects opted for the directness of criticism of the eliciting speech act. This criticism was, for the most part, unapologetic and direct, unmitigated by any softeners, in contrast to the AEs, whose uses of criticism were all softened internally. There were great differences between the American and the German subjects in terms of making or avoiding explicit mention of the shortcomings of the boss' idea. While the AEs avoided the risk of criticizing the idea by focusing on the speaker's personal inclinations or weaknesses, the 
Germans tended to cite the invalidity of the idea to explain the refusal of the boss' advice. One GG respondent, for example, wrote: ."..Kleine Notizen würde ich nur nicht wiederfinden. ..." ("The only effect would be that I wouldn't be able to find the little notes again.", in the sense of .".the little notes would only add to the clutter..."-GG1). This response continued with a reason for refusing the suggestion :."..Nein, nein, ich habe da mein eigenes System." (."..No, no, I have my own system."). The effect was unapologetic and direct, simply dismissing the boss' method. One can contrast this last remark with a typical AE response using a comparable strategy: "This system just seems to work better for me..." (AE9). As noted above, the AE response avoided directly criticizing the boss' suggestion by making no explicit mention of the boss' idea, and included a downgrader and a downtoner. The GG response, on the other hand, was much more abrupt, and also followed criticism of the boss' idea. While the GG speaker acknowledged that he himself erected the obstacles to implementing the boss' suggestion, there was no hint of selfcriticism as in some of the $\mathrm{AE}$ responses, nor a diplomatic "out" associating the idea's failings with the speaker's idiosyncractic preferences. In other words, the addressee could not save face by believing that the speaker thought the advice might work well for other individuals. In other GG responses, directly mention of the speaker did not guarantee the hearer an "out" because they contained a graphic image of the problems the speaker would encounter by following the advice: .".glauben [sic] sie mir, so etwas würde bei mir nicht funktionieren, da lägen denn ja noch mehr Notizen rum und zuerst den Notizzettel suchen?" (."..believe me, something like that wouldn't work for me-then even more notes would be lying around and I'd first have to look for the pieces of paper with the notes on 
them."-GG3. The remark was, however, preceded by the downgrader, "believe me"); and, "Dann hab ich noch mehr Zettel auf meinem Tisch und finde noch weniger." ("Then I'd have even more scraps of paper on my desk and would find even less."-GG12); and, .". Aber dann verlege ich die Notizen, oder verlege die Gegenstände auf die sich die Notizen beziehen, ohne die Notizen zu ändern, und das Chaos wird noch größer." (.”..But then I would misplace the notes, or misplace the objects that the notes are referring to, without changing the notes, and the chaos would be even worse."-GG14).

Two GG respondents made use of upgraders and postponement as a refusal strategy that also indirectly criticized the eliciting speech act. These responses signalled impatience with the boss because the suggestion did not help towards fulfilling the immediate need and only interferred with the speaker's efforts to find the lost report: "Ja, ja, aber jetzt muß ich erst mal den Bericht finden." (“Okay, okay, but right now I first have to find the report."-GG10); and, "Ja, ja ... aber im Moment muß ich erstmal den Bericht finden." ("Okay, okay... but at the moment I first of all need to find the report."-GG11). GE5's remark, "That wouldn't help me to find the report now.", resembled these two responses, but was more direct in criticizing the suggestion. However, it lacked an English equivalent of the irritable interjection, "ja, ja."

The GEs were hardly more tactful than the GGs. Although context provided some mitigation of criticism, a number of GE responses pointed out the shortcomings of the boss' idea: .". it [this method] didn't help me to organize myself. ..." (GE1. A statement of regret preceded and a statement of gratitude-plus-intensifier followed the criticism. The speaker faulted the idea rather than himself.); .".if I organized my desk, I'll find nothing 
any longer because I don't know where to look for. Also little notes are useless for me, I'd lose them." (GE4. A forewarn preceded the criticism. This GE did imply that the boss' method would not be effective for him, although it was somewhat ambiguous if that was the fault of the method or the speaker's personal style. The term, "useless", was potentially face-threatening, and the speaker described problems that would be caused by following the advice.); "That wouldn't help me to find the report now." (GE5); "Oh, I think then I would have a mess of little notes and I would spend my time searching for the right one. I don't think that's a solution." (GE6. A pause filler preceded the two uses of criticism, which were both conjoined with downgraders, "I think..." and "I don't think...." Despite the downtoner, "I don't think", it still was a rather direct rejection of the boss' idea and graphically described the problems the boss' idea would create.); "Little notes wouldn't be sufficient in that mess..." (GE8. The criticism was followed by self-defense. The phrase, "that mess", vaguely acknowledged the speaker's own responsibility, but still blamed the idea rather than herself.); "I'm afraid I'd just loose the notes. ..." (GE9. The criticism was conjoined with a downgrader, "I'm afraid...." The speaker also referred to herself.); “Actually I do write little notes myself, but I can't help it, they always get lost." (GE10. The criticism was preceded by self-defense. In context, the speaker acknowledged some responsibility, but "I can't help it" could also imply that the idea, rather than the speaker, was to blame.); and, "Well, but then, I'll lose those little notes..." (GE12. A pause filler preceded the criticism. While the speaker mentioned herself, she still blamed the idea.). 
As noted above, the AEs' statements of negative opinion displayed the same kind of cautious delivery used with criticism of the suggestion. One $\mathrm{AE}$ gave two negative opinions and another gave three. In both cases, one of the statements of negative opinion was indirect, with a touch of self-defense: "[sic] Ive tried different approaches like that to improve my organization ..." (AE1), and "I've tried that! ..." (AE9). While AE1 did produce one fairly direct statement of negative opinion, he carefully kept the comment about "schemes to get organized" general and vague: .".various [sic] skemes I try to [sic] orgaize [sic] dont work for me anyway.." AE9's second one was veiled and the third one focused on the speaker's idiosyncrasies: .". This system just seems to work better for me... When I'm super-organized it just gets worse.." On the other hand, the GG who used a statement of negative opinion remarked on having already tried the boss' method, with a slight undercurrent of self-defense, like the AEs, but sharpened the response by conjoining it with an upgrader: "Ach, das habe ich auch schon probiert. ..." ("Argh, I've already tried that as well. ..."-GG14). The upgrader, ach, depending on intonation, could have been either an expression of frustration over fruitless efforts or a dismissal of the suggestion, of a method that has not worked out in the past. Another difference from the AEs was the fact that GG14 went on to illustrate the shortcomings of this method: .".. Aber dann verlege ich die Notizen, oder verlege die Gegenstände, auf die sich die Notizen beziehen, ohne die Notizen zu ändern, und das Chaos wird noch größer." (.".. But then I misplace the notes, or misplace the objects that the notes are referring to, without changing the notes, and then the chaos becomes even worse."-GG14). It should be noted, however that the first part of the response ("I've already tried that as well") did allow the possibility that 
the speaker might be responsible for the mess, as opposed to other GG respondents who either said that they usually had no problem finding things (GG1, GG7, GG8), that the problem was an exception (GG2), that they were too busy to be as organized as they undoubtedly would be otherwise (GG2, GG5, GG9), or that blamed the boss in the form of explicit guilt trips (GG4, GG5). The GE negative opinion was neither softened nor sharpened and was also followed by criticism of the suggestion: .".I've tried this method sometime and it didn't help me to organize myself. ..." (GE1). By speaking of "this method" and "it didn't help", GE1 was more blatant than AE1, who spoke of "approaches like that" and "various skemes." GE1 clearly blamed the system, not himself.

Another difference between $\mathrm{AE}$ and GG / GE responses of the "I've tried that" variety was the degree of defensiveness involved. Two of the AEs tried to demonstrate their efforts to improve their organization through elaboration ("I've tried different approaches like that to improve my organization..."-AE1) or emphasis using an exclamation point ("I've tried that!"-AE9). A third AE was less defensive (and the remark was coded as criticism of the suggestion), but still put the blame on herself: .".. I tried it once, I forgot where I put the notes." (AE12). GG14's use of this strategy contained only a slight undertone of self-defense: “Ach, das habe ich auch schon probiert..." (“Argh, I've already tried that as well..."-GG14). Of the two GEs using this strategy, one was not defensive: .".I've tried this method sometime and it didn't help me to organize myself..." (GE1). The criticism of the method following the "I've tried it" part clearly blamed the method. In the other GE response of this type, self-defense outweighed any hint of negative opinion, though the response ended with criticism of the suggestion: "Actually I 
do write little notes myself, but I can't help it, they always get lost." (GE10). This response differed from the others by its location in the present. Unlike the other speakers who had tried and discarded the suggested method, this speaker was currently using the method, albeit unsuccessfully. Also, this speaker took some of the blame upon herself for this lack of success.

The three GG guilt trips varied in terms of the directness of the reproach aimed at the interlocutor. One GG used explicit censure by combining guilt trips with self-defense and an upgrader (i.e., an aggressive interrogative): "Sie geben mir einfach zuviel Arbeit. Außerdem bringen Sie mich immer unter Zeitdruck. Da soll einer noch Ordnung halten können?" ("You're simply giving me too much work. In addition to that, you always put me under time pressure. How's anyone supposed to be able to stay organized under these conditions?!"-GG4). (The only AE response containing anything of this nature was the humorously intended response of an employee gone berserk: "You know, I'm sick of your nagging. I've had it -- with you, with this job, with life. I'd shoot myself if I could find my gun." (AE6). The humorous effect was achieved through deliberate violation of conventions surrounding social status and distance as well as the Gricean maxim of manner, i.e., an exaggerated response to a small irritation.). Another GG used more indirect criticism: "Ich habe zur Zeit keine Zeit, weil alles sehr nervös hier im Betrieb abläuft." ("Here of late I don't have any time because everything that goes on here at work is very nervous."-GG5), while another GG indirectly chided the boss: .".Da aber im Moment soviel bzw. zuviel auf meinem Schreibtisch landet, habe ich den Überblick 
verloren. ..." (."..But because so much-or to put it more precisely, too much- stuff is landing on my desk at the moment, I've lost track of the big picture. ..."-GG9).

Two of the GGs used jokes as a refusal strategy. While one of the GGs got serious after joking, the other one did not, creating an effect that could have been potentially insulting to the boss: "Sie kennen ja den Spruch: wer Ordnung hält, ist nur zu faul zum Suchen-Im Ernst, ich weiß, es klingt komisch, aber ich brauche dieses kreative Chaos." ("You know the old saying: the person who keeps everything in order is just too lazy to look for things. But seriously, I know it sounds funny, but I need this creative chaos."GG6); and "[sic] 'Sie kennen den Satz: Der kleine Geist hält Ordnung-das Genie [sic] beherscht den Chaos."' ("[sic] 'You know the saying: the small / weak mind keeps things orderly-genius masters [the art of] chaos."-GG13). The latter joke could almost be taken as ridicule. Both jokes were preceded by a forewarn. GG6 prevented a face threat to the boss by using a downgrader, "but seriously..." followed by another downgrader: "I know it sounds funny...", followed by self-defense (actually a serious version of the joke).

A number of upgraders in the GG data implied negative opinions or criticism of the eliciting speech act and signalled irritation and disagreement. As noted above in the discussion of DCT\#5, the word, ach as a dismissive form is very expressive of dissent, derision, and annoyance. In this DCT situation, it was used to express rejection of the boss' suggestion in varying degrees of intensity. It was rather mild in one response: "Ach, ich komme eigentlich hier gut zurecht. ..." (“Aw, I'm actually managing quite well here. ..."-GG1), but in context, it implied that the boss' belief that the speaker needed advice was unfounded. In the response, "Ach, das habe ich auch schon probiert. ..." (“Argh, I've 
already tried that as well. ..."-GG14), ach served to dismiss the suggestion, followed by the explanation that the speaker had already tried that approach, and that it had only caused the mess to get worse. Other similar interjections were actually rather rude by American English standards: "Ich weiß, ich weiß..." ("I know, I know..."-GG3) and "Ja, ja..." ("Okay, okay..."-GG10 and GG11. The discrepancy between the original form and the translation was noted in the frequency section.). One GE used the word, "oh", which might have been transfer of ach, depending on intonation, but not necessarily (It was coded as a pause filler.): “hㅡ, I think then I would have a mess of little notes..." (GE6).

Positive Forms: Of the stronger positive forms, statements of agreement and positive opinion were used only by the AEs and GEs. Statements of regret occurred only in the GE data. The only positive form besides downgraders used by the GGs as well as the other two groups was the statement of gratitude. Both statements of gratitude and regret in DCT\#6 were more of a formality rather than truly expressive positive forms. Statements of positive opinion were only somewhat more expressive of positive content: "That's a great idea..." (AE5) and "That's a good idea..." (GE2 and GE3). Statements of agreement appeared to be aimed at appeasing the boss: "I know that it may seem unorganized to someone else..." (AE2); "[sic] Your probably right..." (AE8); and, "I don't know how many people have told me that already. ..." (GE7). Thus, in terms of facesaving efforts, only a few of the $\mathrm{AE}$ and GE positive forms went beyond minimal face protection.

Excuses: Excuses in DCT\#6 followed no particular pattern except for all being vague means of appeasing the boss: .".I think I'm just used to it [the mess]." (GE7); 
.".I've just been very busy lately." (AE4); .".. It's just one of those days..." (GE11); and, ... I hate Mondays." (AE8). There was a bit of thematic similarity between the two latter excuses.

FTA Strategies: In DCT\#6, there were no instances of positive politeness and none of the respondents refused off record. Although two GGs did use postponement, these remarks clearly were not aimed at tactfully evading the suggestion, but rather expressed criticism.

Refusals performed baldly on record involved deliberate face threats, such as criticism of the suggestion and guilt trips. While none of the AEs chose to make such unmitigated threats, a third of the GEs' and over half of the GGs' responses fell into this category.

Negative politeness was expressed by avoiding critical mention of the boss suggestion, by making defensive remarks directed at appeasing the boss or restoring the boss' confidence in the employee's conscienciousness, by using vague excuses that avoided any hint of blame, by adding polite forms such as statements of regret, gratitude, agreement, and positive opinion. While statements of positive opinion do often express positive politeness, the impersonal nature of such statements in DCT\#6 reflected negative politeness. Downgraders and downtoners enhanced negative politeness. All of the AEs used negative politeness in one form or another. Although AE7 and AE11's responses described the problems that would result from following the suggestion, these problems were related to the speakers' personal deficiencies rather than the fallibility of the suggestion. By contrast, less than half of the GGs' responses involved negative politeness, 
and half of those were not thoroughly polite (because of evasiveness, abruptness, inclusion of a face-threatening joke, or insinuation of a guilt trip). While two-thirds of the GEs used negative politeness, the politeness of two of these was compromised by the directness of criticism or contradiction of the boss' view.

\section{Summary of Results: Refusal of Suggestion Made by a Higher-Status Interlocutor (DCT\#6)}

The major strategies in DCT\#6 were self-defense and criticism of the suggestion, and guilt trips played an important role in a few GG responses. No direct forms were used in DCT\#6 except a single softened version of the direct form, "no" by a GG. There was minimal use of excuses and statements of philosophy by AEs and GEs, and none by GGs. A single reason was used, given by a GG. Evasive strategies were practically absent from the data, the exception being two GG uses of postponement (although these functional categories served more as a form of criticism rather than evasion). Positive forms often occurred as a means of softening criticism of the eliciting speech act. Most positive forms in DCT\#6 were fairly routinized politeness formulas without greatly expressive positive content. Aside from relatively frequent use of downgraders and downtoners by the AEs, positive forms and mitigating adjuncts found little use in DCT\#6.

In all functional categories, ranking of politeness was in the order $\mathrm{AE}>\mathrm{GE}>\mathrm{GG}$. In terms of the frequency of face-threatening functional categories, the two groups of Germans exceeded the AEs in confrontativeness, the GGs through their use of guilt trips, upgraders, and jokes, which did not appear in AE or GE responses, and both the GGs and the GEs through their more frequent use of criticism of the suggestion. 
The GGs made use of face-threatening functional categories not used by the other two groups (guilt trips, upgraders, and jokes), but eschewed the strongest of the positive forms used by the AEs and GEs (statements of agreement, positive opinion, and regret). Not only did the GGs use harsh strategies avoided by the other subjects, but they also delivered these more negative strategies with greater directness and less mitigation. While the AEs made a great effort to soften criticism of the suggestion and statements of negative opinion through cautious delivery expressed by way of a number of means, the GGs and GEs expressed these strategies very directly and unapologetically.

A number of GGs (and to a somewhat lesser extent, the GEs) did not mince words in criticizing the suggestion, and most of them blamed the method directly rather than appearing to fault themselves or their preferences for its shortcomings, in contrast to the AEs, who emphasized tact, even to the point of self-criticism. Many GGs and GEs did not spare the hearer graphic descriptions of the negative results that would ensue from following the suggestion. Two GGs also tactlessly dismissed the suggestion by way of postponement, displaying impatience at the intrusion of an unwelcome suggestion that interfered with the employee's search for the report. Furthermore, two GG jokes bordered on ridicule of the boss, and only one of these continued with a remark that averted a fullscale face threat.

Self-defense played different roles in responses of the three groups. The AEs strove to restore the boss' positive image of the employee and appease the boss, with only a few responses emphasizing evasion. Their defensive remarks were all softened, they avoided contradicting the boss, and they related shortcomings of the boss' proposed 
solution to the speaker's idiosyncrasies and preferences rather than to the inadequacy of the advice. The GEs, on the other hand, focused equally on regaining the boss' confidence and evading the suggestion. Most GE self-defense emphasized the anomalous nature of the speaker's inability to find the report. There was more variety in GG self-defense: while reassurance and evasion both played a role, in addition, some GGs defended the speaker by faulting the boss (These remarks were associated with guilt trips.).

In terms of FTA strategies, all the AEs chose the negative politeness strategy, while only two-thirds of the GEs and fewer than half of the GGs did so. Even so, a number of the Germans' responses involving negative politeness were compromised by contradiction of the boss. One-third of the GEs and over half of the GGs chose to risk a clear face threat to the boss by performing the refusal baldly on record (through criticism and guilt trips).

\section{Major Differences between the three Groups}

A fundamental difference between the American and the German respondents in this study pertains to the degree to which subjects allowed certain variables to affect the nature of their responses. The AEs displayed a general tendency to be polite and friendly to interlocutors throughout the DCT. They seemed to almost "automatically" dispense tactfulness, regardless of the circumstances of individual DCT items, although there was some variability based on social distance and status. The German subjects, on the other hand, employed a more diverse range of approaches based on the particulars of each given situation. The influence of status and social distance on the degree of politeness in German 
subjects' responses was more apparent in DCT situations in which the speech act eliciting the refusal was perceived as legitimate (e.g., an invitation without ulterior motives, a justified request, a welcome offer, or a useful suggestion). Status and social distance were less of a determining factor in GG choices to risk confrontation with the interlocutor than the respondents' perception that the addressee "deserved" censure or some expression of negativity. The GGs did not mince words, regardless of whether the addressee was a boss, an employee, or a friend, if the addressee had somehow crossed a line of acceptable behavior. In GE responses, outright face threats were much less common; however, the GEs followed German NS patterns in making the choice to be direct (e.g., in voicing unwillingness).

These inclinations become apparent when comparing response patterns to the different DCT items. To facilitate an examination of these differences, characteristic response trends are presented below, grouped according to addressee status.

\section{Dealings with Higher-Status Interlocutors (Bosses)}

In DCT\#12, almost all respondents used negative politeness, reflecting the business setting and social distance of the situation. The AE preference for more "active" types of positive forms, as compared to more "passive" ones in the GG and GE data, seemed to reflect both greater efforts to maintain rapport between the interlocutors and a more active, somewhat less subservient approach to dealing with the boss (see summary section of DCT\#12 for more detailed arguments). On the other hand, the Germans' avoidance of a show of eagerness to fulfill the boss' request may have served as a means 
of discouraging future requests of this nature. Very few $\mathrm{AE}$ excuses were watertight, in stark contrast to the GGs and GEs.

While nearly all respondents used negative politeness in DCT\#4, half of the AEs leaned towards positive politeness and one-fifth of the GGs used very little redressive action. What this indicates is that even in this situation with a higher-status interlocutor who had committed no transgressions (other than making the invitation at short notice), a minority of the GGs chose to be very direct. The Americans tended to be oriented towards the interpersonal aspect, while the Germans were more impersonal, directed towards the issue at hand. This orientation is underscored by the fact that the Germans secured the refusal through solid excuses, whereas the AEs seemed to feel that any reasonable excuse would be accepted and focused more on using polite forms to convey a positive attitude. There was less difference in the degree of politeness used by the three groups in DCT\#4 and DCT\#12, situations involving an "innocent" higher-status interlocutor, than in situations where the addressee was of equal or lower status or where the addressee had given the speaker some cause to feel irritated.

In DCT\#6, the GGs were considerably more confrontational than either of the other two groups, although the GEs closely approached them in terms of directness. Their responses left much less of a face-saving "out" for the interlocutor. While all the AEs used negative politeness, a sizeable proportion of the German subjects refused without redress. This seems to indicate that the Germans considered it appropriate to be direct with a boss when their irritation at useless advice outweighed the need to be respectful towards someone in a position of power. The Americans, on the other hand, maintained their usual 
efforts to promote accord with the boss. Across all functional categories, the AEs exceeded the GEs in terms of politeness, who in turn were more polite than the GGs.

In DCT\#11, while the AEs avoided direct expressions of unwillingness and negative remarks, making enthusiastic use of positive forms and focusing on the benefits of staying in the current position, the GGs and GEs were considerably more direct in stating their unwillingness to accept the offer. While a number of GGs also used emphatic statements of positive opinion, the GG data also contained bald refusals, and several GG reasons were negative in their orientation. The GEs all exhibited negative politeness, but their use of positive forms was largely unenthusiastic.

In situations where the boss' behavior was neutral (as in the justified request in DCT\#12 and the courteous business-related invitation in DCT\#4), all three groups were relatively close in terms of politeness. However, when circumstances (averting a major negative change in one's life) warranted a firm refusal (as in DCT\#11) or when the boss' behavior was irritating (making an obnoxious suggestion in DCT\#6), the German subjects became considerably more direct (even aggressive, in the case of the GGs) in their responses than the AEs. For the German subjects, taking a stand on the invalidity of the suggestion in DCT\#6 took precedence over showing deference towards a higher status interlocutor. The Germans' considerably more frequent use of statements of negative willingness was indicative of greater straightforwardness and honesty in communicating attitudes that the boss might have found disagreeable, warranted by the necessity of a firm refusal in DCT\#11 (to escape the flattering but unattractive offer). 
In dealing with the bosses, the Germans offered solid excuses in DCT\#4 and DCT\#12 and were direct in relating their position in DCT\#6 and DCT\#11. The AEs, on the other hand, relied heavily on the use of positive forms, emphasizing the upholding of good feelings and accord. The AEs went to considerably less trouble than the Germans to create watertight excuses in DCT\#4 and DCT\#12 .

\section{Interactions with Equal-Status Addressees (Friends, Acquaintances, and Classmate)}

While the data for all three groups in DCT\#2 contained face-threatening strategies, the AEs softened them through various means, but the GGs and GEs left them unmitigated and used harsh wording, maximizing the impact and possibility of confrontation. Only one AE conveyed testiness towards the classmate in DCT\#2, while almost half of the GGs and one-fourth of the GEs openly expressed hostility. Most GG and GE criticism and guilt trips were presented as objective statements. The GGs were outspoken in their critical remarks, displaying a considerably greater willingness to risk a serious face threat than the AEs or GEs. Indeed, the GGs made the least effort to protect the hearer's face in their choices of functional categories and content. While the Germans emphasized unwillingness in their direct refusal strategies, the AEs stressed inability. Only one-fourth of the AEs refused without redress, as compared with half of the GEs and almost three-fourths of the GGs. The other AEs refused off record or used negative or positive politeness. The remaining German subjects mostly used negative politeness.

While all three groups tended to protect the addressee's face in DCT\#10, the stronger positive forms were used very frequently by the AEs, moderately by the GEs, and 
rarely by the GGs (who made more frequent use of mitigating adjuncts, a weaker means of softening refusals, than the other groups). Use of excuses, statements of positive opinion and wishes were associated with the telling of white lies, and found most use in the $\mathrm{AE}$ data (The issue of honesty is discussed below.). While the AEs made equal use of positive and negative politeness, the majority of the German subjects chose negative politeness, with most of the remainder using positive politeness. The AEs made vague excuses, while GG excuses were specific, and GE excuses were both specific and watertight.

A departure from the usual patterns of FTA strategies and relative politeness occurred in DCT\#9 (discussed below). The AEs displayed somewhat more directness than the Germans, making more frequent use of bald "no" in the first section, and more frequent use of reasons in the second than the German subjects. On the other hand, only one $\mathrm{AE}$ remark was antagonistic, whereas the $\mathrm{GG}$ data contained a few forms that posed a clear face threat. The GE eschewed such strategies. In the second section, the GEs made the greatest use of acceptance, while the GGs made the most frequent use of the other positive forms. It was also striking that the Germans made much more frequent use of compliments than the AEs.

Half of the respondents in the three groups used negative politeness in the first response section. Although the other half of the Germans mostly used positive politeness, only one-sixth of the AEs did so, with one-fourth of the AEs refusing without redress. In the second section, a higher proportion of AEs refused baldly than GGs or GEs (the GEs had the lowest percentage of responses in this category). On the other hand, a somewhat higher proportion of AEs used positive politeness (and again, the GEs were at the bottom, 
frequency-wise). Over half of the GEs opted not to perform the FTA, i.e., they accepted the offer, as compared with one-fourth of the AEs and one-fifth of the GGs.

Of all the DCT items, there was probably the greatest social proximity between the interlocutors in DCT\#5 (See discussion of DCT\#5 in introduction to "Refusals of Suggestions"), which was reflected in the candid tone and uncomplicated structure of the responses. The GGs and GEs allowed a much higher potential of face risk to the addressee than the AEs, both through criticism of the suggestion and mention of the hearer with negative overtones (the GEs to a slightly lesser extent). Unlike the GGs and GEs, the AEs not only avoided use of the harshest face-threatening strategies and the more offensive direct refusal strategies, but also softened all the direct forms they employed. Nearly all the Germans performed the refusal baldly on record, as opposed to only half of the AEs, the other half of whom used negative or positive politeness, or refused off record.

In response to the unjustified request in $\mathrm{DCT} \# 2$, the $\mathrm{AE}$ data did include some bald refusals, but all face threats were mitigated and most AEs provided face protection and declared their inability to help the addressee. A large proportion of German subjects refused without redress, emphasizing unwillingness and using unmitigated face threats, even open hostility, although the GGs were more outspoken and harsh than the GEs. In DCT\#10, the friend's cordial invitation met with politeness in all three groups, although the German subjects focused on negative politeness, while the AEs used both positive and negative politeness. The AEs were somewhat more direct than the Germans in expressing their unwillingness to accept the friendly, but insistent, offer in DCT\#9, but real face threats occurred only in the GG data. The German subjects used both positive and 
negative politeness, with a majority of the GEs accepting the offer in the second response section and the GGs making the most frequent use of positive forms besides acceptance. The unwelcome suggestion in DCT\#5 provoked face threats and uncompromising direct refusal forms from the German respondents, while the AEs avoided these strategies and softened the direct forms they did use. While bald refusals predominated in GG and GE responses, only half of the AEs refused without redress.

The degree of social intimacy between the interlocutors impacted the character of responses. Differences in the nature of responses to the equal-status interlocutors in DCT\#5 and DCT\#10 seemed to be based on various factors. In the scenarios of the DCT items, the interlocutors in DCT\#5 appear to be socially closer (e.g., the speaker makes personal remarks, saying s/he has been eating like a pig, and the friend is close enough to recommend a diet), whereas in DCT\#10, nothing in the description of the situation suggests that the relationship is close except the word "friend", which could also mean "acquaintance". Also, the suggestion in DCT\#5 is somewhat irritating - apparently this is not the first time that the topic has come up, whereas the invitation is an imposition only because of the spouse - and obviously, it is not the friend's fault that the speaker dislikes the spouse. Perhaps the subjects' greater politeness in DCT\#10 is also in compensation for rejecting the friend's spouse (even if this is not stated explicitly). German subjects responded to the situation in DCT\#9 as though it involved acquaintances rather than friends, while the AEs apparently perceived the situation as a more casual event. In $\mathrm{DCT} \# 2$, it is quite probable that there was little personal involvement between the interlocutors. They were not necessarily individuals who had contact with each other 
outside of class, so in choosing to make the refusal an affront to the addressee there was less at stake emotionally and socially.

\section{Interchanges with Lower-Status Addressees (Employee, Salesman, Cleaning Lady, Student)}

The AEs displayed solidarity and sympathy towards the employee who wanted a raise in DCT\#1, while the GGs and GEs were less sympathetic. Avoidance of potential face threats and extensive use of statements of negative ability, excuses, positive forms, and hearty praise characterized $\mathrm{AE}$ responses. Both groups of Germans refused more directly, favoring statements of negative willingness and reasons, using fewer positive forms, giving more lukewarm compliments, and including some possible threats to the addressee's face. The GEs also made some use of evasive strategies. While AE responses expressed either positive or negative politeness (with a slight predominance of the former), the Germans made much less use of negative politeness and somewhat less use of positive politeness than the AEs (and a number of these responses were cooler in tone than the AEs'). One-fourth of the GEs refused off record while one-fifth of the GGs refused without redress. At the same time, the AEs used fairly formulaic excuses that underscored inability in a vague manner, while the two groups of Germans presented more information about the condition of the business, allowing the hearer to follow the logic underlying denial of the request. Taking into account these various features, the Germans seemed to focus more on the issue, whereas the Americans displayed more concern for maintaining a harmonious relationship with the addressee. 
In DCT\#3, many GGs were candid about their disapproval of the salesman's dubious invitation and high-pressure salesmanship, neither mincing words nor avoiding high-impact criticism. By contrast, the AEs and GEs protected the addressee's face, sparing him the embarrassment of being confronted with his questionable business practices, but the GEs were much more reserved than the AEs. Indeed, most AEs and GEs responded as though there were no ulterior motives underlying the invitation. Unlike the AEs, the two groups of Germans made extensive use of evasive strategies. The AEs made much greater use of the stronger positive forms than the GGs or GEs. The GGs made greater use of mitigating adjuncts, the weaker form of softening, than the others. The AEs made considerably more use of negative politeness than the Germans, with a touch of positive politeness in two responses. Unlike the AEs, a number of GGs and GEs refused off record, and a third of the GGs and two GEs refused without redress.

While statements letting the cleaning lady off the hook were predominant in all three groups in DCT\#7, the Germans made a somewhat greater effort to put the addressee at ease (This reversal of the usual pattern is discussed below.). The GGs and GEs diminished the value of the vase more frequently and employed considerably more expressions of empathy than the AEs, as well as using a number of positive forms that did not occur in $\mathrm{AE}$ responses. The AEs also used a slightly higher frequency of remarks that increased the risk to the addressee's face, but it was amongst the GGs that the only two remarks were made that truly departed from the otherwise tactful and sympathetic stance of responses to DCT\#7. 
DCT\#8 was the only DCT situation in which the strategy of establishing the speaker's status or superiority appeared so frequently (indeed, a number of speakers crossed the line into arrogance). A possible explanation lies in the fact that the suggestion in DCT\#8 is the only eliciting speech act from a lower-status interlocutor that potentially undermines the speaker's authority. Thus, some speakers perceived a need to assert and solidify their control of the situation. The GGs "pulled rank" most often, while the majority of the AEs and GEs provided a conceptual justification for refusing the student's suggestion. Both groups of Germans were less hesitant to directly express unwillingness to comply with the students' wishes than the AEs, who made some efforts to display sympathy. While the GE position was somewhat more accommodating than the GGs', GE response patterns more closely resembled those of the German NSs than of the American English speakers. Not only did the AEs made more use of positive forms than the GGs or GEs, but they also tended to use stronger positive forms. While most of the AEs and GEs displayed negative politeness, only slightly over half of the GGs did. The other half of the GGs performed the refusal baldly on record, as compared with only two AEs and two GEs. One AE used positive politeness.

In sum, the AEs made consistent efforts to display politeness to all four lowerstatus interlocutors, favoring the FTA strategies of positive and negative politeness. GG and GE response patterns depended on the circumstances of the DCT items. In DCT\#1, some of the German subjects appeared to consider the request inappropriate, which was reflected in a less sympathetic stance, and much less use of negative politeness and a little less use of positive politeness than amongst the AEs, replaced with evasion in the GE data 
and unredressed refusals amongst the GGs. In DCT\#3, assessment of the invitation ranged from acceptable to unethical, leading to instances of evasiveness in GG and GE responses, and candor and disapprobation in the GG data. The cleaning lady in DCT\#7 was deserving of sympathy and the German respondents treated her with greater efforts to be kind than the AEs. Some respondents seemed to feel that the suggestion in DCT\#8 undermined the speaker's authority. Consequently, it met with occasional remarks aimed at establishing the speaker's status and superiority, especially amongst the GGs. Both groups of Germans were more direct than the AEs in expressing their unwillingness to accept the suggestion, but the GEs were more tactful. While negative politeness predominated amongst the AEs and GEs, the GGs used negative politeness and bald refusals.

As noted above, the AEs' slightly greater use of the less favorable strategies and somewhat more limited use of positive forms in DCT\#7 presented a reversal of the usual pattern. The AEs' narrow and the Germans' wide range of different positive forms in DCT\#7 was likewise a turnaround of the usual trend in DCT responses. In their refusals to the offer in DCT\#9, the AEs again displayed less tact relative to the German subjects than might have been expected, based on response patterns to most DCT items. In both DCT\#7 and DCT\#9, the eliciting act is an offer and the interlocutor is a familiar (a friend in DCT\#9 and a cleaning lady in DCT\#7 whom the speaker knows well enough to be familiar with her personal circumstances). It is possible that the AEs felt less need for social niceties in refusing offers in settings of low social distance, but the study does not provide sufficient data to go beyond conjecture on this issue. The German subjects' greater display of sympathy in DCT\#7 may have been linked to a perception of the cleaning lady as 
"deserving" of clemency. This tentative explanation is supported by the fact that the German subjects tended to increase the harshness of their responses towards an interlocutor who appeared to be "undeserving".

In DCT\#9, the frequency of compliments in the responses of the German and American subjects was in inverse relation to the usual response patterns in the data, and contradicted both Wolfson's $(1983,1989)$ and Manes' (1983) assertions and my own experience in the United States and Germany. While compliments found frequent use amongst the German subjects in the first section, they were hardly used by the AEs, yet Americans have been observed using compliments more frequently and in a wider range of functions (including softening the blow of FTAs) than many other nationalities. During my stay in Germany, I found that NSs often considered my use of compliments excessive. In DCT\#7, however, it was the German subjects who used compliments more frequently. In addition, choices of FTA strategies also reversed the usual trends. Indeed, the AE responses were a source of bewilderment, violating my NS intuitions for appropriately refusing an offer of cake - not only in regards to the dearth of compliments, but also for the complete lack of statements of gratitude, positive opinion, or regret.

In DCT\#9 the issue arises as to whether or not the situation has the same cultural significance for Germans and Americans. As Kasper (1990) and Blum-Kulka and House (1989) point out, in studies involving cross-cultural and cross-linguistic comparison, researchers face the problem of ascertaining whether the subjects groups perceive contextual factors similarly or differently. The fact that the Germans were more polite and formal, and used more routinized forms in this situation than the Americans, may have 
been based on a cross-cultural difference. Because having Kaffee und Kuchen ("coffee and cake") on weekend afternoons is an institution in Germany, behavioral norms for offering and refusing may be more ritualized (i.e., surrounded by more conventions). The AEs obviously envisioned DCT\#9 as a very casual setting.

\section{Other Features}

Rapport versus Honesty: DCT\#10 was the only DCT item that permitted unambiguous comparisons of honesty versus use of "white lies" in the data of the three groups. In other cases, there was no way to tell if an excuse or statement of positive opinion was sincere or not, but in DCT\#10, the situation was presented in such a way as to imply that the refusal was due to the speaker's antipathy for the addressee's spouse.

The German subjects clearly exhibited greater honesty than the AEs. While a number of AEs actively incorporated white lies into their responses, both the GEs and GGs avoided doing so. The GGs' use of urgent but nonspecific excuses in DCT\#12 also seemed to reflect an avoidance of telling lies - or an unwillingness to reveal particulars of one's private life (although the GEs did not follow this particular pattern). It appears that the American subjects felt compelled to make friendly remarks in DCT\#10, even at the expense of sincerity, in order to protect the hearer's face (in the case of DCT\#10, the friend's positive face). In tandem with other features in the overall data, it seems that Americans give precedence to the maintenance of social ties and avoidance of social friction, while Germans value honesty and directness more highly, avoiding insincere "nice" remarks. For the AEs maintaining good feelings seemed to be more important than 
honesty. The GEs tended to be more direct and honest than the AEs, but also more conciliatory than the GGs.

Protection of the Speaker's Privacy: It appears that an emphasis on personal privacy in GG excuses and reasons may be a signal of high social distance between the interlocutors. There is insufficient data in this study to make any conclusive statements on this issue, but responses to a few DCT items suggest a possible trend. In DCT\#3, both groups of Germans displayed considerably more reticence about sharing information about their business with the addressee than the AEs. GE and GG reasons preserved the speaker's privacy, revealing as little information as possible, while a number of AEs openly mentioned their satisfaction with their company's equipment. In both DCT\#3 and DCT\#12, a high proportion of the GGs used vague excuses, which differed, however, in terms of urgency. With the lower-status interlocutor in DCT\#3, none of the GGs saw any reason to be either specific or urgent, while GG excuses in DCT\#12 (with the boss) emphasized watertightness and urgency (See discussion of content, DCT\#12). In DCT\#4, unlike DCT\#12, GG excuses were specific and watertight. Here, the boss and employee were close enough for the boss to invite the speaker to her/his home. Also, the setting of a party at the boss' home is considerably more personal than that of an employee working overtime at the office (even if the party involves business associates).

Uniformity versus Individuality: The most significant and comprehensive tendency towards uniformity in the AE data lay in the overall "automatic" nature of choices to be tactful, regardless of the hearer's status or behavior, whereas the German subjects tended to base face protection and tact on the legitimacy of the speech act that 
elicited the refusal and the extent to which the addressee's behavior merited such forbearance.

This difference extended to other levels as well. The GGs were not as predictable as the AEs in terms of their choices of functional categories. This corresponds with other research findings about native speakers of German versus native speakers of English (Edmondson, House, Kasper, and Stemmer, 1982; House 1978, 1989a. See Chapter II, section comparing routinized utterances in German and English.).

Throughout the DCT, the AEs gave more uniform, routinized kinds of responses than the GGs, who used a wider range of categories. The content of some of the categories also exhibited more variety amongst the GGs. The GEs often leaned towards the German NSs' preferences or took a position between the two poles. Some examples from the data include the following:

- In DCT\#1, the content of AE excuses was relatively uniform (primarily a politeness routine for refusing a legitimate request), while the GGs' and GEs' were more unique and original;

- In DCT\#12, there was a degree of uniformity in $\mathrm{GE}$ and $\mathrm{AE}$ responses in terms of the number of mitigating adjuncts and positive forms per response, whereas the GGs used a wider range;

- In DCT\#7, remarks letting the addressee off the hook and diminishing the value of the vase, were very uniform amongst the AEs, while the GGs and GEs used a greater variety of responses that also contained more real content. The AEs tended to use 
formulaic remarks to release the interlocutor from any liability (almost always the same words), while German remarks in this category were more individual and inventive;

- In DCT\#9, the content of AE reasons was more formulaic and routinized than the GGs', while the GEs took a position between the two poles.

Formulaic Politeness versus "Real Content": In some cases in the AE data, statements of positive opinion and other positive forms may have been a social routine rather than a sincere expression of feelings. AE use of politeness "routines" with quite uniform wording and less actual content than GG or GE responses seemed to occur almost automatically in a number of DCT items, e.g., DCT\#1. As noted above, in DCT\#10, a number of AEs even actively incorporated white lies (i.e., statements of positive opinion) into their responses. The GGs and GEs were more restrained than the AEs in the use of compliments and other positive forms, both in terms of frequency and content. On the other hand, the Germans tended to give much more specific and/or watertight excuses and more informative reasons than the AEs. In DCT\#4 for instance, the Germans provided face protection through the use of solid excuses while the AEs relied on positive forms and performatives-plus-downgraders.

All of these features taken together seem to indicate an American emphasis on maintaining "good feelings", while the Germans put greater priority in directness, honesty, and efforts to let the hearer understand their reasoning.

Willingness to Risk Confrontation: Particularly in situations of high social distance, $\mathrm{AE}$ responses seemed to reflect a pragmatic convention that a speaker should avoid offending the hearer (regardless of the circumstances). The GGs obviously did not 
operate according to the same taboo. Not only did they vent their resentment, but they also appeared to see little need to protect the addressee's face or provide the addressee with a tactful means of saving face. The GGs frequently performed refusals baldly on record, in situations where the AEs were carefully focused on tact. The GEs, while less provocative than the GGs, still followed the German NS pattern of directness.

Examples of this difference abound in the data, a few of which are discussed here. In DCT\#2, the German subjects' use of open censure contrasted with innocuous AE responses. Even though many Americans would be irritated by classmate in DCT\#2, avoidance of social friction took precedence over venting negative feelings in the $\mathrm{AE}$ data. In DCT\#6, a large number of GGs (and a somewhat smaller number of GEs) did not mince words in pointing out the inadequacy of the boss' suggestion, in some cases, almost to an insulting degree, while the AEs tended to relate difficulties in implementing the suggestion to the speaker's personal preferences and idiosyncrasies, even to the point of seeming self-effacement. The Germans were also much less hesitant to contradict the boss. In DCT\#5, not only did the GGs and GEs favor harsher forms of criticism in contrast to the AEs' milder choices, they also used face-threatening forms avoided by the AEs. On the other hand, the GEs tempered their criticism, as did the AEs, by acknowledging their subjectivity: While most of the GGs tended towards wholesale condemnation of diets, half of the GEs and AEs who criticized diets also conceded that their views were based on personal experience. The Germans made considerable use of statements of negative willingness in DCT\#11, while the AEs almost completely avoided this strategy, indicative of the Germans' greater degree of directness. The AEs' more frequent use of statements 
of negative opinion, however, slightly narrowed the gap (in DCT\#11, this functional category was a non-confrontative means of being direct). Even in DCT\#9, where the usual relative distributions of FTA strategies and relative frequencies of positive forms, were reversed, with less tact amongst the AEs and greater politeness amongst the German subjects, it was still within the GG data that a few speakers confronted the hearer with potential face threats (The GEs, on the other hand, avoided all contrariety.).

GG Preference for Mitigating Adjuncts over Positive Forms: In nine of the twelve DCT items, the GGs used positive forms considerably less frequently than the other two groups. In two cases where they used positive forms least frequently, they used mitigating adjuncts most frequently (DCT\#3 and DCT\#10). In other cases they came in second to the GEs (DCT\#4 and DCT\#8) or to the AEs (DCT\#11) in the frequency of mitigating adjusts. In other words, to some extent they gave preference to the weaker forms of FTA mitigation, being more economical with the forms that contain the more potent positive content.

FTA Strategies: Examination of preferred FTA strategies amongst the three groups (based on Brown and Levinson's 1987 model of speaker's considerations when performing FTAs) provided a good indication of propensities for directness and confrontativeness, formality and polite restraint, or maintenance of social bonds and "good feelings".

Choices of FTA strategies reflected a somewhat higher degree of formality and restraint amongst the German subjects and a greater tendency on the part of the AEs to emphasize social bonds (sometimes even at the expense of honesty, as in DCT\#10). The 
fact that the largest proportion of bald refusals occurred in the GG data reflected their greater inclination towards risking confrontation.

\section{Associations between Refusal Stimuli and Functional Categories: Different} types of refusal stimuli (e.g., requests, invitations, suggestions, and offers) take a different range of refusal strategies, e.g., in response to an invitation, a speaker would be more likely to use statements of gratitude, regret, or positive opinion, and avoid direct refusal strategies expressing unwillingness, than in reply to a suggestion. The kinds of strategies which were completely polite and appropriate for declining the offer in DCT\#11 would be very face-threatening in response to an invitation, as the following examples (responses to DCT\#11, modified for the context of an invitation) demonstrate: "I really would rather stay home"; "I'm not really excited about having to drive out to your house"; or, "I appreciate the invitation, but I'm really happy staying home." The difference lies in the fact that accepting an invitation involves a relatively small imposition, so the strategy of expressing unwillingness in any way is ruled out unless a face threat is intended. Also, invitations fulfill a social bonding function, in which both inviter and invitee participate. If an invitation is declined without some expression of appreciation, regret, inability, or esteem, this violation of the social bonding principle is apt to be taken as a personal affront. Even in DCT\#3, many of the respondents gave excuses despite the shady nature of the salesman's invitation, reflecting this unspoken rule about invitations. The responses that did not do so were all solidly focused on the business/bribe aspect of the invitation. 
Interesting as such differences may be, examining them is, however, nonessential to this study's focus on differences between the three subject groups, rather than between the range of functional categories associated with a particular refusal stimulus.

\section{GE Response Patterns}

The GEs often resembled the GGs more than the AEs in their strategic choices, but across all DCT items, the GEs were considerably more polite and less facethreatening. In other words, they were direct in a less aggressive manner. In this regard, the GEs exhibited a high level of pragmatic acquisition. GE response patterns resembled those of the GGs in situations in which the GGs' level of politeness exceeded that of the AEs (DCT\#7 and DCT\#9), where all three groups used a similar level of politeness (DCT\#4, DCT\#10, and DCT\#12), and in the cases of unwelcome suggestions (DCT\#5 and DCT\#6), a flattering but unattractive offer (DCT\#11), and unjustified requests (DCT\#1 and DCT\#2). In DCT\#2, GEs who chose to vent negative feelings followed German NS response patterns, while those who made more neutral replies more closely resembled the AEs. The GEs and AEs were similarly polite in their refusals of invitations (DCT\#3, DCT\#4, and DCT\#10), although the GEs were more reticent and evasive in response to the invitation that was ethically ambiguous.

In DCT\#3 and DCT\#8, GE response patterns resembled those of the GGs in some dimensions and those of the AEs in other dimensions. In DCT\#3, a situation in which there seemed to be ambiguity amongst the respondents as to whether the invitation was ethical or not, traits shared with the AEs were an avoidance of confrontation and use of positive forms. The GEs were, however, considerably more reticent and guarded than the 
AEs. Traits shared with the GGs included evasiveness and less use of negative politeness than amongst the AEs. In DCT\#8, which involves a suggestion that potentially diminishes the speaker's authority, traits shared with the GGs included direct expression of unwillingness (although the GEs were more tactful) and a dearth of positive forms. Traits that the GEs and the AEs held in common were a predominance of negative politeness and justification of refusals through philosophical arguments (rather than merely "pulling rank").

By scanning the ranking of relative politeness in the tables in the frequency sections, one can see that the most typical patterns were $\mathrm{AE}>\mathrm{GE}>\mathrm{GG}$ or $\mathrm{GE}>\mathrm{AE}>\mathrm{GG}$. It was rare that the GGs made the most polite choices of functional categories. In the former pattern, the GEs found middle ground between the directness, confrontativeness, or lack of mitigation of GG responses on the one hand, and the tactfulness of $\mathrm{AE}$ responses on the other. The latter pattern suggests hyper-correction, with the GEs exceeding the AEs in the degree of politeness, apparently due to (correct) perceptions that greater tact is called for in American English pragmatic conventions than in German. There were rare exceptions to the two patterns. For example, in DCT\#11, despite the AEs' and GGs' emphatic statements of positive opinion and gratitude, the GEs tended to be more reserved with these positive forms.

In a number of DCT items, the GEs accurately increased the level of politeness in their responses relative to the German NS group, but achieved this effect through means more typical of their L1 than the L2 (in other words, through pragmatic transfer). In DCT\#10 and DCT\#12, for instance, the GE increased politeness through the use of 
specific (and in many cases, watertight) excuses, while a large proportion of $\mathrm{AE}$ excuses were vague. (In DCT\#10, GG excuses were specific but not watertight, and in DCT\#12, they were either watertight or pseudo-watertight). Also, strong GE use of downgraders in DCT\#10 reflected an effort to increase politeness, but with a means more typical of the German NSs. In DCT\#3, the GEs followed the AE tendency to avoid direct confrontation, but nonetheless retained the German NS use of evasive strategies (which the AEs eschewed). In DCT\#4, the GEs' high use of positive forms and fairly frequent use of mitigating adjuncts incorporated elements of both German and English NS preferences for softening refusals.

Another feature in GE responses was "hyper-correction", that is, the GEs outdid the AEs in using a strategy more typical of English NSs than German Nss, going beyond the degree of politeness the AEs chose. In DCT\#10, for instance, the GEs exceeded the AE frequency of elaboration on excuses, a strategy that hardly occurred in the GG data. The GE tendency to conjoin downgraders with functional categories that were already polite went beyond the two NS groups' levels of politeness. In DCT\#8, although the AEs used fewer face-threatening remarks than the GGs, the GEs outdid the AEs in avoiding these strategies. 


\section{Chapter V: Summary and Discussion}

This chapter contains a brief review of the study's purpose and methodology and a summary of the findings. Answers to the research questions are discussed and conclusions are drawn about the meaning of the results. Limitations of the study, its implications for second language instruction, and suggestions for further research are considered.

\section{Summary of Research Purpose and Methodology}

As described above, this study investigated the linguistic performance of German speakers of English as compared with native speakers of English and German in the production of refusals in order to study the effects of pragmatic transfer in the performance of a face-threatening speech act.

Data was elicited by means of a Discourse Completion Test (DCT) composed of a set of twelve refusal situations, including four refusal stimulus types (requests, invitations, offers, and suggestions) and responses to interlocutors of higher, lower, and equal status (see Appendices A and E). Thirty-eight university students participated as subjects in the study, including: twelve native speakers of English, using English (AEs), fourteen native speakers of German using German (GGs), and twelve native speakers of German using English as a Foreign Language (GEs). The data was analyzed by identifying and classifying strategies used in the refusal responses of the three groups (see Appendices F, $\mathrm{K}, \mathrm{L}$, and $\mathrm{M}$ ). The frequency and content of functional categories were examined, and differences between the three groups were assessed. 


\section{Major Findings}

\section{Differences between the Subject Groups}

The most striking difference in the baseline data for the German NSs and the NSs of American English consisted of the finding that the GGs were considerably more direct, more confrontational, and more willing to risk a threat to the addressee's face in the performance of refusals than the AEs. Throughout the DCT, whenever there was some reason to disapprove of the hearer, regardless of the interlocutors' relative status, the GGs tended to be much more outspoken with critical remarks and willing to risk confrontation than the AEs. The AEs, on the other hand, emphasized diplomacy and face-protection. Throughout the DCT, the American subjects opted for milder, less offensive, more routinized responses. They displayed a tendency to make fairly "automatic" choices of non-face-threatening strategies. One $\mathrm{AE}$ made a comment that provides some insight into the pragmatic awareness of a NS of American English: "If on my responses I did not address the issue presented in the dialog, that, for myself, is a natural means of politely dealing with a situation." (AE5).

As noted in Chapter IV, the AEs tended to be almost "indiscriminately" friendly and polite in the DCT situations. The most important variable impacting their degree of politeness was social distance. All of the DCT situations in which the AEs were somewhat less polite than usual involved low social distance (The equal-status interlocutors were closer to the speaker than the higher- or lower-status addressees.). This finding parallels Beebe et al's observation about the effect of social distance on $\mathrm{AE}$ responses. Beebe et al noted that familiarity or social distance plays a greater role than social status in $\mathrm{AE}$ 
patterns of refusing invitations, supporting Wolfson's (1981) assertion that Americans distinguish between a familiar addressee (e.g., a friend or acquaintance) and a stranger or an intimate. Also, the AEs tended to be somewhat more polite towards higher- than lower-status interlocutors. The balance between positive and negative politeness shifted towards the latter with higher-status interlocutors. Thus, the greatest politeness was directed towards higher-status interlocutors in settings of high social distance, followed by lower-status interlocutors in high-distance settings, and less politeness was exhibited towards equal-status in situations of low social distance.

The Germans using their native language tended to be more outspoken than the Americans, more likely to say what they really thought, even in situations where this posed a face threat to the addressee. This supports House and Kasper's (1981) observation about differing social norms in English and German, which was also quoted in Chapter II: ...attacking one's interlocutor's identity seems to be a taboo in the British cultural context, while it seems perfectly appropriate behavior for Germans under specific interactional conditions" (p. 183). They maintain that even if this difference resulted from the artificial communicative situation of data collection, the assertion is still valid:

...if speakers behave more consciously norm-oriented under experimental than under natural conditions, the different use of directness levels in English and German rather confirms the assumption that different social norms obtain in the two speech communities." (p. 183).

In contrast to the AEs, the GGs risked directness and / or face threats if it appeared to be warranted by the addressee's behavior (e.g., an unjustified request or unethical invitation). Otherwise, status and social distance influenced the level of politeness. The GGs were most polite with bosses who had created no infringements, and the largest proportion of 
bald refusals appeared when a socially close, equal-status interlocutor had overstepped some boundary (DCT\#2 and DCT\#5) followed by the situation in which a lower-status interlocutor made a suggestion that potentially undermined the speaker's authority (DCT\#8).

The GEs seemed to assess situational factors in much the same way as the German NSs, choosing to be direct in the same situations as the GGs, but they tempered the realization of their refusals. When the hearer was perceived as having overstepped some boundary, GE responses generally more closely resembled those of Germans using their native language (i.e., more direct and often more willing to risk confrontation and express censure) than AE patterns. Like the GGs, the GEs used a larger proportion of bald refusals with socially close interlocutors who had aggravated them. When there was no cause to feel irritation towards the addressee, however, the GEs seemed to follow the assumption that they should use a greater degree of politeness in English than in German. In other words, in situations not involving "misbehavior" on the part of the speaker, the GEs' degree of politeness tended to follow the AE pattern of being more polite than the GGs. What this suggests about the GEs' pragmatic acquisition is that they recognized the need to increase tactfulness in English when they perceived a situation as requiring facesaving politeness. When they perceived a need to let the addressee know that $\mathrm{s} / \mathrm{he}$ was being out of line, however, they lapsed into pragmatic patterns of their native language. It seems that in more polite situations they probably responded according to what they had been explicitly taught about English, but in the situations involving some degree of anger, they responded more on a "gut level." 
Some GEs brought an element of evasiveness into responses to ambiguous situations that might have created a degree of uneasiness in the speaker. Other features that these DCT items shared were high social distance and lower-status addressees: in DCT\#8, it was legitimate for the student to want the class to fulfill his/her needs, but the suggestion carried the threat of undermining the speaker's authority; in DCT\#3, the salesman's invitation involved bribery to some extent, but it also represented a not unusual business practice; in DCT\#1, while it was understandable that the employee might ask for a raise, s/he had only been working at the business for a year and also, some respondents may have felt that it was not the employee's place to demand the raise.

The AEs were very polite towards the bosses in DCT\#4, DCT\#11, and DCT\#12, and polite towards the boss in DCT\#6 (the one with the stupid suggestion). Circumstances had only a slight effect on the level of politeness towards a higher-status, high distance. The Germans, by contrast, were very polite in DCT\#4 and DCT\#12, but in DCT\#6 and DCT\#11, other factors clearly outweighed status in determining the level of face protection.

In DCT\#2, DCT\#5, and DCT\#9, all situations of low social distance with equalstatus interlocutors, the AEs were not as polite as elsewhere in the DCT (although they still maintained a fair degree of face protection). The Germans treated DCT\#9 (offer of cake) and DCT\#10 (dinner invitation) more formally than the AEs, although the interlocutors were friends / acquaintances, and were polite. In DCT\#2 and DCT\#5, however, the unjustified request and unwelcome suggestion met with face threats and bald refusals. So while social distance seemed to be the more important variable in determining 
AE levels of politeness, the German subjects' choices were determined to a much greater degree by specific features of the situation.

In DCT\#1, the AEs were very polite, displaying solidarity with the employee, and were polite in DCT\#3, DCT\#7, and DCT\#8. Once again, the German subjects' orientation was more situation-specific. The Germans were direct in DCT\#1, with a degree of politeness. Some GGs refused baldly, while some GEs chose evasive approaches. In DCT\#3, the GGs were candid in voicing their disapproval, while once again some GEs became evasive. Here the GEs departed from the GG patterns, affording the addressee considerably more face protection. In DCT\#7, the Germans were highly sympathetic towards an addressee who merited empathy. In DCT\#8, the Germans were direct in expressing their unwillingness to accept the suggestion, but while half of the GGs refused baldly, most of the GEs used negative politeness, as did the AEs.

All in all, the GGs were candid, even hostile if the addressee overstepped some boundary, and were particularly friendly towards the well-meaning cleaning lady. A number of GEs veered towards evasiveness in DCT\#1, DCT\#3, and DCT\#8, and were much more polite than the GGs in DCT\#8, and offered much more face protection in DCT\#3 than the GGs.

With regards to the speech act of apologizing, Olshtain (1983) states that the major strategies are universally available across languages, but that preferences for a particular strategy or combination of strategies tend to be language-specific. This is certainly true of the data in this study regarding the more frequent use of statements of negative willingness and reasons by the German subjects and the AEs' preference for 
statements of negative ability and excuses. In terms of AE use of direct refusal strategies, there seemed to be almost a taboo against using negative willingness or the direct refusal form, "no" in many situations, whereas the Germans showed fewer inhibitions about using these somewhat face-threatening strategies.

The German subjects frequently provided informative reasons or excuses for their refusals while maintaining a more aloof stance, while the AEs offered vague, more routinized excuses, relying on extensive use of positive forms aimed at preserving rapport and social ties. The AEs focused on preserving rapport via use of positive forms, while the German subjects emphasized their seriousness and reliability by way of solid excuses. Indeed, for the AEs, rapport seemed to take precedence even over honesty. Positive politeness was a feature that appeared much more frequently in the AE data than in that of the other two groups, the reflection of a more informal, friendliness-oriented culture. Even in DCT\#1 and DCT\#4, despite the socially distant roles played by the interlocutors, the AEs displayed leanings towards positive politeness, in the one case to soften the disappointment of a deserving employee, and in the other case, as a response to the boss' invitation to his/her home. Thus, the Germans seemed to be more task-focused, while the Americans were oriented towards a core value of "being nice", perhaps even at the expense of accomplishing the task (e.g., producing a firm refusal that could not be overturned by the hearer). These differences may reflect the polarity between a society that stresses order and structure versus one that emphasizes informality.

The Germans and Americans operated according to a different set of priorities as they decided whether to point out the shortcomings of the addressee's behavior or to save 
the hearer's face at all costs, as they weighed the need for honesty versus the smooth, friction-free conducting of social interactions. Another major difference between the AEs and the two groups of Germans was the fact that the content of the Germans' responses was not as formulaic as the $\mathrm{AE}$ responses. These differing response patterns coincide with folk knowledge about NSs of German and American English. Many Germans have a stereotypical image of Americans saying "nice" things they do not mean, displaying friendliness and politeness that are superficial and insincere. Conversely, many Americans view Germans as being brusque and blunt. The data in this study indeed suggests that German NSs are more likely to say what they really think.

These findings concurred with the results of other studies citing the greater indirectness and conformity of formulas in English than in German, including House (1978, 1989a), House-Edmondson (1986), House and Kasper (1981), Kasper (1981), Fill (1989), and Edmondson, House, Kasper, and Stemmer (1982) (see Chapter II, Studies Comparing Speakers of English and German). The results of this study also confirmed many of my own observations about German and English in cross-cultural encounters. Examining the data made it very clear why I had run into misunderstandings based on violations of pragmatic conventions. My diplomatic remarks as a NNS of German were often viewed as insincerely polite and friendly, while German NSs' remarks often seemed unduly direct and harsh to me. 


\section{A Consideration of the Research Questions}

The following questions guided the research:

- Do German learners of English perform the speech act of refusal in ways that differ from the performance of NSs of American English speaking English and NSs of German speaking German?

- Does native language transfer affect German speakers of English in the performance of the refusal speech act, and if so, how?

This particular group of Germans speaking EFL was obviously sophisticated enough in their acquisition of English to appreciate the existence of differences between the conventions of their $\mathrm{L} 1$ and $\mathrm{L} 2$ and modify their responses accordingly to accommodate a perceived need for greater politeness. To some degree, these results may have been an artifact of the conditions of data elicitation (i.e., differences in how the DCT was administered to the GEs as compared with the AEs and GGs (See Chapter 5, section on limitations). The higher proportion of female GEs may also partially account for the high level of politeness exhibited in GE responses. Sometimes the GEs' efforts to produce responses that exceeded German NS levels of politeness led to "hyper-correction", going beyond the degree of politeness used by NSs of American English. The GEs also sometimes used means of increasing politeness that were more typical of their L1 than their L2; in other words, in terms of pragmatic acquisition, the GEs accurately increased politeness in English, but transferred German NS strategies for doing so. 
On the other hand, in situations where the addressee had somehow incurred the speaker's disapproval, whether for an unjustified request, an unethical invitation, or a useless suggestion, the GEs followed German NS response patterns, confronting the addressee with a high degree of directness and even risking face threats (The GEs on the whole did not allow nearly the frequency of face threats that the GGs did.). Despite their sophistication, the GEs still tended to follow their German NS instincts to address a hearer's "violation", rather than maintain bland, polite neutrality like the NSs of American English.

What these features mean in terms of intercultural communication between German speakers of English and NSs of American English is that at times, a German might be perceived as being almost excessively polite, only to shock the NS by his/her unexpected candor and confrontativeness in situations of potential conflict. Because of the proximity of the two cultures and the GEs' near approach of NS norms on various levels, the dissonance could be particularly startling.

Olshtain and Cohen (1983) suggest that NNSs might deviate from NS norms in their choices of communication strategies because of a lack of linguistic rather than sociocultural proficiency. This seemed unlikely in the case of the GEs, considering their high level of linguistic proficiency.

\section{Limitations}

Limitations affecting this study stemmed from less than ideal conditions in the data gathering process and constraints imposed by the instrument of data elicitation (i.e., using 
a written test as opposed to observing communication in natural settings or using role plays. A further limitation concerns distinctions made between functional categories.

\section{Limitations Associated with the DCT}

The so-called Discourse Completion Test (DCT) was first developed by BlumKulka (1982), and has been used by a number of researchers, including Olshtain and Cohen, Beebe, and Eisenstein and Bodman. As Wolfson (1989) notes, a DCT can be used for the purpose of collecting data for cross-linguistic comparison and investigating the sociolinguistic problems faced by second language learners, for examining the degree to which the pragmatic or sociolinguistic rules of the first language are transferred to the second language, and for providing baseline data on native speaker norms for comparison with nonnative speaker performance.

As a number of researchers point out (e.g., Hatch, 1983; Wolfson, 1989; Beebe et al, 1990; and Johnson, 1992), eliciting data through the use of a DCT has various advantages and disadvantages compared with gathering data by observing naturally occurring oral language. Negative features of DCTs in general and of the DCT used in this study in particular include the following:

- The scope of a questionnaire is too limited to provide all pertinent information about the complexities and subtleties of how a speech act is performed in spontaneous interactions. Johnson (1992) asserts that DCTs are "limited in addressing situational context and discourse factors that might affect speech-act realization" (pp. 193-94). 
Beebe, Takahashi, and Uliss-Weltz themselves say that this kind of data collection method "is limiting and may bias the results" (p. 67).

- The nature of the elicitation process can produce responses that differ from spontaneous occurrences of a given speech act. According to Hatch (1983), completion questionnaires do not necessarily reflect what the subject would say in a real-life situation, but rather what he or she thinks he or she would (or should) say.

- Conversation is a joint effort with an element of negotiation. Both participants in a conversational exchange contribute to its development, as Interlocutor B's response to Interlocutor A prompts A's next choice of functional categories. This cannot be addressed realistically in a dialogue questionnaire which leaves only one blank per item for the subject's response. While written DCTs can be used to elicit displays of knowledge, they lack the interactional dimension of role plays or natural speech. Eisenstein and Bodman's (1993) use of questionnaires, role-plays, and naturalistic data allowed comparisons of these instruments, pointing out the lack of interaction in the written instrument.

- The conventions for spoken and written communication differ considerably (as one respondent noted, "I think that there will usually be a different response in a written, hypothetical situation than in an actual, spoken situation." (AE4). Beebe et al observe that there can be significant differences between written and spoken refusals to the same request, citing Beebe and Cummings' (1985) findings that spoken telephone 
refusals tend to be much longer and more elaborate than written role-played ones, employing a wider variety of semantic formulas and involving more negotiation. ${ }^{96}$

- Written data lacks important elements of oral communication, such as intonation, stress, or haptics (nonverbal cues), which often carry a significant amount of information pertinent to pragmatics. The pragmatic meaning of a number of responses was ambiguous because these features were missing. Such cases necessitated judgment calls, interpreting responses in the way that seemed most plausible. An example from the data illustrates the problem of interpreting responses without recourse to context, intonation, and other features of real communication. One GG wrote the following answers to the friend's two offers of cake in DCT\#9: 1. "Ich kann echt nicht mehr. Laß mal Sonst muß ich morgen wieder joggen."; 2. "Verdammt, aber wenn ich an Verfettung sterben sollte, hoff' ich, daß Du ein schlechtes Gewissen hast." (1. "I really can't eat any more. Back off. Otherwise I'll have to go jogging again tomorrow."; 2. "Dammit, if I die of obesity, I hope you have a guilty conscience."-GG3). Lacking paralinguistic cues, it is not possible to say definitively whether the speaker was genuinely annoyed because he felt that the hearer was undermining his efforts not to gain weight, or if the intent was humorous, with jovial remarks about the dire consequences of eating another piece of cake, i.e., having to go jogging the next day, or dying of obesity. Choosing one interpretation over the other impacted classification of functional categories. For instance, the acceptance of the offer could have been

96For more information, see Beebe, L., and Cummings, M. (1985). Speech act performance: A function of the data collection procedures? Paper presented at TESOL Convention, New York. 
intermingled with a guilt trip, functioned as a refusal because of a lack of enthusiasm, or been genuine, with mock exasperation.

- Writing an answer gives the respondent more time to plan and evaluate the response than participating in an ongoing conversation, thus, questionnaire responses might not be very natural. In role plays, subjects must engage both their comprehension and production faculties, and assess contextual factors and formulate responses in ongoing time.

- In terms of Brown and Levinson's (1987) model of strategy options in the performance of face-threatening acts (see Chapter II, Review of the Literature, section on "Face-Threatening Acts"), the DCT used in this study does not allow subjects the choice of avoiding performance of the FTA altogether because of the interlocutor's rejoinder. It was also hard for respondents to use evasive strategies (i.e., to perform the refusal off record). For example, a number of AEs commented that they would have accepted the boss' suggestion in DCT\#6, had the DCT not prevented them from doing so. This may have given a false impression about the extent to which various strategies of avoidance would actually have been used in live communication. As a few respondents remarked:

"Most of the questions, except \#7, seemed negative. Sometimes I could not give the response I wanted, because the following comment was negative." (AE12).

"Die Möglichkeiten eine gute Antwort zu geben sind zu sehr eingeschränkt, dadurch wird die zu benutzende Sprache zu sehr vorgegeben (indirekt). ..." ("The possibilities for giving a good answer are too limited; because of that, there is too much pre-determination of the language that the respondent uses (through indirect means)..."-GG8) 
"Schwierig zu beantworten, da meist / immer eine Ablehnung / Zurückweisung erfolgen mußte (liegt mir nicht sehr)..." ("Difficult to respond, because most of the time / always a refusal / rejection had to be used (not my style)..."-GG9).

- Comments made by the respondents pointed out limitations based on DCT situations that were foreign to the respondents' real lives. The respondents were forced to take on roles associated with features of social status, social class, or occupation that they as students had never experienced:

"It seems as if a lot of these situations dealt with responding as a person in power or in a class (social) I've never experienced. It was difficult for me to answer as I would $\underline{\&}$ also as I presumed someone in power (which I've never been) or in an upper class (which I've never been) would answer." (AE10)

“... Sehr außerreale Situationen für StudentInnen...” (“...Very unrealistic situations for students..."-GG9)

Despite the disadvantages involved in the use of written dialogue questionnaires, this method of data elicitation is a valuable tool for the researcher. Written dialogue questionnaires allow researchers greater control over the variables involved, giving coherence to the findings. Setting up fixed discourse situations provides consistency for comparing selection and content of functional categories amongst subject groups. DCTs also make it possible to collect a considerable amount of data on a given speech behavior within a much shorter time frame than through observation of spontaneously occurring communication. Not only is the collection of spontaneous speech samples in natural settings time-consuming, but refusals do not occur frequently and are situation-dependent. In addition, it is considerably easier to guarantee protection of the privacy of the human subjects involved in a study when using a DCT than when observing naturally occurring language. As Olshtain (1983) asserts: 
"Although it may appear more desirable to obtain spontaneous data in a natural setting, it seemed to us that in order to arrive at a comparison of native and nonnative usage, we needed to construct well-defined situations which would allow us to focus on controlled responses" (p. 237).

Despite the inherent limitations of data elicitation via a written dialogue questionnaire and limitations due to the scope of the study, it is my belief that this study provides insight into issues of native language transfer and sociopragmatic competence.

\section{Limitations Related to the Gathering of the Data}

The relative politeness of the GE responses could have be influenced by factors relating to the data elicitation process. The selection of the AEs and GGs was based on the availability of volunteers, who completed the DCT in locations and at times based on individual convenience. Members of the $\mathrm{AE}$ group were tested piecemeal by the researcher, a stranger with no authority dynamics, and the GGs were given the DCT by friends or acquaintances. On the other hand, the setting and circumstances under which the DCT was administered to the GEs was considerably more formal than for the other two groups. Participation in the study was voluntary (that is, the GEs had the same opportunity to refrain from participation as the other two groups), but completing the DCT was a regular classroom activity, under the supervision of their professor, an authority figure. It is possible that in the classroom setting, the GEs might have been more careful to express themselves politely than they would have been otherwise. In addition, the fact that the GE subjects were all students in either a Discourse Analysis or a Second Language Acquisition class may have contributed to the face-saving caution they displayed. First of all, this made them a less randomly selected group than the others (The 
AEs were recruited from beginning Linguistics classes, and the GGs were friends and acquaintances of the GEs, university students not necessarily involved in Linguistics at all.). Secondly, as participants in more advanced Linguistics classes, it is likely that the GEs were more conscious of pragmatic differences between their native language and their target language than a more randomly selected group of German EFL learners might be.

A limitation associated with analysis of the data involves distinguishing between functional categories. As noted above, interpreting responses in terms of pragmatic categories is an art as well as a science, requiring struggles with ambiguity. In this study, the distinction between "excuses" and "reasons" made sense intuitively and had descriptive value, but the criteria for assigning these classifications were not absolutely objective. Disagreement may be possible between researchers regarding coding of responses in these two categories. It is hoped that future research might devise more objective categories.

\section{Suggestions for Further Study}

An initial suggestion for further study would be to conduct basically the same study, but with a more random sample of German university students in the GE group. Instead of having the subjects complete the DCT during a regular class session, the GEs could be volunteers recruited from different classes and tested outside the classroom by someone other than their professor. It might also make sense to use a group of German EFL speakers who are not English majors (or at least not participating in advanced courses like Second Language Acquisition or Discourse Analysis). If it were feasible, such 
a study could include observation of the performance of refusals in naturalistic settings or examine data elicited through role plays.

Further research building on the proposed study could examine methods of instruction designed to achieve the goal of developing pragmatic competence in language learners.

Another interesting issue associated with cross-cultural differences in speech act performance concerns gender-based differences: Are there differences between male and female L2 learners in acquiring pragmatic competence? What is the degree of sensitivity to gender-specific linguistic behavior in L2 learners?

Beebe et al's suggestions for continued study include: differences between natural speech and questionnaire responses; the extent to which negotiation is used in refusals; the degree of directness in the refusal speech act (which was addressed in this study); the speaker's "sense of obligation" to the requester; and feelings of frustration that arise in making a refusal.

\section{Implications for TESOL}

The results of this study underscore the importance of developing sensitivity to cross-cultural differences in pragmatic conventions. While the GEs recognized the need to reduce the risk of confrontation in English, they were still considerably more direct than the AEs in voicing their unwillingness to accept or fulfill the interlocutors' suggestions, requests, etc. The pragmatic differences between NSs of German and American English could lead to miscommunication, particularly for less proficient German EFL speakers. 
Because of the German tendency to be more straightforward with critical or negative remarks and direct expressions of unwillingness, there could be negative consequences for Germans speaking English in terms of how they are perceived by NSs.

Language teaching professionals should familiarize language learners with pragmatic aspects of the target language and provide instruction in native speaker norms regarding correct usage in order to help them avoid misunderstandings and interact more successfully with native speakers. In the case of German learners of English this would involve increasing their sensitivity to the need for conflict avoidance and making them aware of the different degree of directness in the two languages.

Kasper (1981), House and Kasper (1981), and Fill (1989) all recommend teaching pragmatic aspects of language use in order to help German learners of English avoid the kinds of misunderstandings that could result from pragmatic differences between German and English speakers. Fill states that advanced EFL classes should make learners aware of pragmatic differences and provide them with the linguistic means to be polite and tactful in settings with NSs of English. House and Kasper recommend teaching the "interpretation and use of politeness in utterances" (p. 184):

"It seems also to be advisable for the teacher to explicitly point out to the learner that politeness markers are an integral part of the foreign cultural system, and should neither be used nor interpreted by reference to the learner's native system. More effective teaching of the behavioral component may minimize native cultural interference and prevent impolite, ineffective, or otherwise inappropriate behavior on the part of the learner" (p. 184).

Paulston (1990) maintains that it is necessary to explicitly teach sociocultural rules of speaking, but to avoid any value judgment, i.e., any implication that one rule might be inherently superior to another. Here, language learning consists of adding rules, rather 
than substituting rules. Wolfson (1989) urges instructors not to try to change the value systems of people from other cultures, and stresses the benefit of providing information that will help language learners to interpret and respond to native speaker sociolinguistic behavior appropriately. Students should be equipped to express themselves in exactly the way they intend, be it rudely, tactfully, or politely. The fundamental goal is to prevent the student from being unintentionally boorish or obsequious. Students need to know the likely consequences of various types of linguistic behavior.

Schmidt (1993) asserts that learners cannot acquire pragmatic knowledge merely through exposure to sociolinguistically appropriate input because learners are unlikely to recognize the linguistic realizations of pragmatic functions and relevant contextual factors on their own. For the learning of L2 pragmatics, attention should be drawn explicitly to linguistic forms, functional meanings, and the relevant contextual features. Obviously, teachers should be careful to provide accurate information about the pragmatics of the second language that is not based on fallible native speaker intuitions.

A large body of literature provides recommendations for the development of pragmatic competence in the classroom. A few highlights are briefly noted here.

Olshtain and Cohen recommend five techniques for teaching speech acts, illustrating these techniques with the example of apologies. As a preparation for these activities, students should first be exposed to the realization patterns associated with the speech act (see Chapter II, section on speech acts) and sensitized to the sociocultural factors involved in the choice of strategies (e.g., in the case of apologies, they need to gain 
insight into the kinds of offenses which would be considered serious in the target culture). The five teaching techniques include:

- diagnostic assessment of the students' level of awareness regarding speech acts in general and the particular speech act to be taught and the extent to which students transfer realization patterns or sociocultural judgements from their first language, in order to plan teaching goals and procedures.

- model dialogues.

- evaluation of a situation.

- role-play activities.

- feedback and discussion.

Venditti and Bahruth (1986) recommend "interactive errands", such as "human bingo" and "idiom search", as opportunities for students to practice pragmatic functions such as greetings, turn-taking, requests, and leave-taking with NSs.

Richards (1983) emphasizes the importance of providing students with opportunities to practice particular speech acts with interlocutors of different ages and social status, modifying the form of the speech acts based on these social variables.

This research contributes to the body of empirical knowledge concerning crosscultural pragmatics. It is hoped that language teaching professionals will be able to work with this material to support the development of pragmatic competence in their students. 


\section{References}

Alatis, J. (Ed.) (1968). Contrastive linguistics and its pedagogical implications. Washington, D.C.: Georgetown University Press.

Andersen, R. (1983). Transfer to somewhere. In S. Gass and L. Selinker (Eds.), Language transfer in language learning (177-201). Rowley, MA: Newbury House Publishers, Inc.

Ard, J., and Homburg, T. (1983). Verification of language transfer. In S. Gass and L. Selinker (Eds.), Language transfer in language learning (157-176). Rowley, MA: Newbury House Publishers, Inc.

Austin, J. (1962). How to do things with words. Cambridge, MA and Oxford: Harvard and Oxford University Presses.

Beebe, L., and Cummings, M. (1985). Speech act performance: A function of the data collection procedures? Paper presented at the International TESOL Convention, New York.

Beebe, L., and Takahashi, T. (1989). Sociolinguistic variation in face-threatening speech acts. In M. Eisenstein (Ed.), The dynamic interlanguage (199-218). New York: Plenum.

Beebe, L., Takahashi, T., and Uliss-Weltz, R. (1990). Pragmatic transfer in ESL refusals. In R. Scarcella, E. Andersen, and S. Krashen (Eds.), Developing communicative competence in a second language (55-73). Cambridge, MA: Newbury House.

Bergman, M., and Kasper, G. (1993). Perception and performance in native and nonnative apology. In G. Kasper and S. Blum-Kulka (Eds.), Interlanguage pragmatics (82107). New York; Oxford: Oxford University Press.

Bialystok, E. (1993). Symbolic representation and attentional control in pragmatic competence. In G. Kasper and S. Blum-Kulka (Eds.), Interlanguage pragmatics (43-57). New York; Oxford: Oxford University Press.

Blum-Kulka, S. (1982). Learning to say what you mean in a second language: A study of the speech act performance of learners of Hebrew as a second language. Applied Linguistics 3(1), 29-59.

Blum-Kulka, S. (1983). Interpreting and performing speech acts in a second language-a cross-cultural study of Hebrew and English. In N. Wolfson and E. Judd (Eds.). 
Sociolinguistics and language acquisition (36-55). Rowley, MA: Newbury House Publishers, Inc.

Blum-Kulka, S., and House, J. (1989). Cross-cultural and situational variation in requestive behaviour in five languages. In S. Blum-Kulka, J. House, and G. Kasper (Eds.), Cross-cultural pragmatics: Requests and apologies (123-54). Norwood, NJ: Ablex.

Blum-Kulka, S., House, J., and Kasper, G. (Eds.) (1989). Cross-cultural pragmatics: Requests and apologies. Norwood, NJ: Ablex.

Blum-Kulka, S., and Levenston, E. (1987). Lexical-grammatical pragmatic indicators. Studies in Second Language Acquisition, 9, 155-70.

Blum-Kulka, S., and Olshtain, E. (1984). Requests and apologies: a cross-cultural study of speech act realization patterns (CCSARP). Applied Linguistics 5(3), 196-212.

Blum-Kulka, S., and Sheffer, H. (1993). The metapragmatic discourse of American-Israeli families at dinner. In G. Kasper and S. Blum-Kulka (Eds.), Interlanguage pragmatics (196-223). New York; Oxford: Oxford University Press.

Boggs, S. (1972). The meaning and questions and narratives to Hawaiian children. In C. Cazden, V. John, and D. Hymes (Eds.), Function of language in the classroom. New York: Teachers College Press.

Brown, H. (1987). Principles of language learning and teaching, 2nd ed. Englewood Cliffs, NJ: Prentice Hall Regents.

Brown, P., and Levinson, S. (1978). Universals in language usage: Politeness phenomena. In E. Goody (Ed.), Questions and politeness: Strategies in social interaction (56311). Cambridge, England: Cambridge University Press.

Brown, P., and Levinson, S. (1987). Politeness. Cambridge: Cambridge University Press.

Campbell, R, and Wales, R. (1970). The study of language acquisition. In J. Lyons (Ed.), New horizons in linguistics. Baltimore: Penguin Books.

Canale, M., and Swain, M. (1980). Theoretical bases of communicative approaches to second language teaching and testing. Applied Linguistics, 1(1), 1-47.

Chomsky, N. (1965). Aspects of the theory of syntcax. Cambridge, MA: M.I.T. Press.

Chomsky, N. (1977). Essays on form and interpretation. New York: Elsevier NorthHolland, Inc. 
Clancy, P. (1986). The acquisition of communicative style in Japanese. In B. Schieffelin and E. Ochs (Eds.), Language socialization across cultures (213-49). Cambridge: Cambridge University Press.

Clark, H., and Clark, E. (1977). Psychology and language: An introduction to psycholinguistics. New York: Harcourt Brace Jovanovich.

Clyne, M. (1979). Communicative competences in contact. ITL, 43, 17-37.

Cohen, A., and Olshtain, E. (1981). Developing a measure of sociocultural competence: The case of apology. Language Learning, 31(1), 113-134.

Davison, A. (1975). Indirect speech acts and what to do with them. In P. Cole and J. Morgan (Eds.), Speech acts. Vol. 3 of Syntax and semantics (143-184). New York: Academic Press.

Demuth, K. (1986). Prompting routines in the language socialization of Basotho children. In B. Schieffelin and E. Ochs (Eds.), Language socialization across cultures (5179). Cambridge: Cambridge University Press.

Dulay, H., and Burt, M. (1974). Errors and strategies in child second language acquisition. TESOL Quarterly, 8(2), 129-136.

Dulay, H., Burt, M., and Krashen, S. (1982). Language two. New York: Oxford University Press.

Dumont, R. (1972). Learning English and how to be silent: Studies in Sioux and Cherokee classrooms. In C. Cazden, V. John, and D. Hymes (Eds.), Function of language in the classroom. New York: Teachers College Press.

Edmondson, W. (1977). Gambits in foreign language teaching. In: H. Christ and H. Piepho (Eds.), Kongreßdokumentation der 7. Arbeitstagung der Fremdsprachendidaktiker, Gießen 1976 (45-48). Limburg: Frankonius.

Edmondson, W., House, J., Kasper, G., and Stemmer, B. (1982). Kommunikation: Lernen und Lehren. Berichte und Perspektiven aus einem Forschungsprojekt. Heidelberg: Groos.

Eisenstein, M., and Bodman, J. (1986). "I very appreciate": Expressions of gratitude by native and non-native speakers of American English. Applied Linguistics, 7(2), 167-185. 
Eisenstein, M., and Bodman, J. (1993). Expressing gratitude in American English. In G. Kasper and S. Blum-Kulka (Eds.), Interlanguage pragmatics (64-81). New York; Oxford: Oxford University Press.

Faerch, C., and Kasper, G. (1989). Internal and external modification in interlanguage request realization. In S. Blum-Kulka, J. House, and G. Kasper (Eds.), Crosscultural pragmatics (221-47). Norwood, NJ: Ablex.

Fill, A. (1989). Der Beziehungsaspekt als Teil der pragmatischen Dimension des Fremdsprachenunterrichts. In B. Kettemann, P. Bierbaumer, A. Fill, and A. Karpf (Eds.), Englisch als Zweitsprache. Tübingen: Gunter Narr Verlag.

Fraser, B. (1980). On apologizing. In F. Coulmas (Ed.), Conversational routines. The Hague: Mouton.

Fraser, B. (1985). Direct illocutionary force potential. Unpublished MS, Boston University. (Cited by Rintell, 1990).

Fraser, B., Rintell, E., and Walters, J. (1980). An approach to conducting research on the acquisition of pragmatic competence in a second language. In D. Larsen-Freeman (Ed.), Discourse analysis in second language research (75-91). Rowley, MA: Newbury House.

Gass, S. (1983). Language transfer and universal grammatical relations. In S. Gass and L. Selinker (Eds.), Language transfer in language learning. (69-82). Rowley, MA: Newbury House Publishers, Inc.

Giles, H. (1979). Ethnicity markers in speech. In K. Scherer and H. Giles (Eds.), Social markers in speech. Cambridge: Cambridge University Press.

Giles, H., and Saint Jacques, B. (Eds.) (1979). Language and ethnic relations. Oxford: Pergamon Press.

Gleason, J., and Perlmann, R. (1985). Acquiring social variation in speech. In H. Giles and R. St. Clair (Eds.), Recent advances in language, communication, and social psychology. London: Lawrence Erlbaum.

Goffman, E. (1972). On face-work: An analysis of ritual elements in social interaction. In J. Laver and S. Hutcheson (Eds.), Communication in face-to-face interaction (319-346). Harmondsworth: Penguin.

Graham, J. (1981). Cross-cultural negotiations. Unpublished MS, University of Southern California (Cited by Scarcella, 1990). 
Green, G. (1989). Pragmatics and natural language understanding. Hillsdale, NJ: Lawrence Erlbaum Associates, Publishers.

Grice, H. (1975). Logic and conversation. In P. Cole and J. Morgan (Eds.), Syntax and semantics, vol. 3: Speech acts (41-58). New York: Academic Press.

Gumperz, J. (1972). Sociolinguistics and communication in small groups. In J. Pride and J. Holmes (Eds.), Sociolinguistics: Selected readings (203-224). Harmondsworth, England: Penguin Books.

Gumperz, J. (1978). The conversational analysis of interethnic communication. In E. Lamar Ross (Ed.), Interethnic communication. Athens, GA: University of Georgia Press.

Gumperz, J. (1987). Foreword to P. Brown, and S. Levinson, Politeness. Cambridge: Cambridge University Press.

Gumperz, J., and Tannen, D. (1979). Individual and social differences in language use. In $\mathrm{W}$. Wang and C. Fillmore (Eds.), Individual differences in language ability and language behavior. New York: Academic Press.

Halliday, M. (1975). Learning how to mean: Explorations in the development of language. New York: Elsevier North-Holland, Inc.

Hammerly, H. (1982). Contrastive phonology and error analysis. International Review of Applied Linguistics 20, 17-32.

Hatch, E. (1983). Foreword. In N. Wolfson and E. Judd (Eds.), Sociolinguistics and language acquisition (ix-xviii). Rowley, MA: Newbury House Publishers, Inc.

Heath, S. (1982). Questioning at home and at school: A comparative study. In G. Spindler (Ed.), Doing the ethnography of schooling: Educational anthropology in action. New York: Holt, Rinehart and Winston.

House, J. (1978). Versuch eines Vergleiches von Interaktionsnormen in deutschen und englischen Alltagsdialogen. In M. Hartig and H. Wode (Eds.), Kongreßberichte der 8. Jahrestagung der Gesellschaft für Angewandte Linguistik GAL e.V. (2128). Stuttgart: HochschulVerlag.

House (House-Edmondson), J. (1986). Cross-cultural pragmatics and foreign language teaching. In K.-R. Bausch, F. Königs, and R. Kogelheide (Eds.), Probleme und Perspektiven der Sprachlehrforschung (281-295). Frankfurt am Main: Scriptor Verlag. 
House, J. (1989a). "Oh excuse me please...": Apologizing in a foreign language. In B. Kettemann, P. Bierbaumer, A. Fill, and A. Karpf (Eds.), Englisch als Zweitsprache (303-327). Tubingen: Gunter Narr Verlag.

House, J. (1989b). Politeness in English and German: The functions of "please" and "bitte." In S. Blum-Kulka, J. House, and G. Kasper (Eds.), Cross-cultural pragmatics: Requests and apologies (96-119). Norwood, NJ: Ablex.

House, J., and Kasper, G. (1981). Politeness markers in English and German. In F. Coulmas (Ed.), Conversational routine (157-185). The Hague: Mouton.

House, J., and Kasper, G. (1987). Interlanguage pragmatics. Requesting in a foreign language. In W. Lörscher and R. Schulze (Eds.), Perspectives on language in performance: Studies in linguistics, literary criticism, and language teaching and learning. Festschrift for Werner Hüllen on the occasion of his 60th birthday (1250-88). Tübingen: Gunter Narr Verlag.

Hyltenstam, K. (1977). Implicational patterns in interlanguage syntax variation. Language Learning 27(2), 3 83-411.

Hymes, D. (1962). The ethnography of speaking. In T. Gladwin and W. Sturdevant (Eds.), Anthropology and human behavior. (15-53). Washington, D.C.: Anthropological Society of Washington. Reprinted in J. Fishman (Ed.) (1968). Readings in the Sociology of Language. (99-138). The Hague: Mouton.

Hymes, D. (1964). Directions in (ethno)linguistic theory. American Anthropologist 6,3 (part 2), 6-56.

Hymes, D. (1972a). Editorial introduction to Language in Society 1(1), 1-14.

Hymes, D. (1972b). On communicative competence. In J. Pride and J. Holmes (Eds.), Sociolinguistics. Harmondsworth, Middlesex. Penguin Books.

Hymes (1972c). Models of the interaction of language and social life. In J. Gumperz and D. Hymes (Eds.), Directions in sociolinguistics: The ethnography of communication. New York: Holt, Rinehart and Winston.

Hymes, D. (1974). Foundations in sociolinguistics: An ethnographic approach. Philadelphia: University of Pennsylvania Press.

Jaramillo, M. (1973). Cultural differences in the ESOL classroom. TESOL Quarterly, $7(51), 60$. 
Johnson, D. (1992). Approaches to research in second language learning. New York and London: Longman.

Jordens, P. (1977). Rules, grammatical intuitions and strategies in foreign language learning. Interlanguage Studies Bulletin. 2(2), 5-76.

Kasper, G. (1981). Pragmatische Aspekte in der Interimsprache. Eine Untersuchung des Englischen fortgeschrittener deutscher Lerner. Tübingen, Germany: Narr.

Kasper, G. (1990). Linguistic politeness: Current research issues. Journal of Pragmatics, $14,193-218$.

Kasper, G., and Blum-Kulka, S. (1993). Interlanguage pragmatics: An introduction; and editors' introduction to chapter on speech act realization. In G. Kasper and S. Blum-Kulka (Eds.), Interlanguage pragmatics (3-17; 59-63). New York; Oxford: Oxford University Press.

Kellerman, E. (1977). Towards a characterisation of the strategies of transfer in second language learning. Interlanguage Studies Bulletin. 2(1), 58-145.

Kellerman, E. (1978). Giving learners a break: Native language intuitions as a source of predictions about transferability. Working Papers on Bilingualism, 15, 59-92

Kellerman, E. (1983). Now you see it, now you don't. In: S. Gass and L. Selinker (Eds.), Language transfer in language learning (112-134). Rowley, MA: Newbury House Publishers, Inc.

Kellerman, E. and Sharwood-Smith, M. (Eds.) (1986). Cross-linguistic influence in second language acquisition. New York; Oxford: Pergamon Press.

King, K., and Silver, R. (1993). "Sticking points": Effects of instruction on NNS refusal strategies. Working Papers in Educational Linguistics 9(1), 47-82.

Koutsoudas, A., and Koutsoudas, O. (1962). A contrastive analysis of the segmental phonemes of Greek and English. Language Learning 12, 211-230.

Krashen, S. (1981). Second language acquisition and second language learning. New York; Oxford, England: Pergamon Press.

Lado, R. (1957). Linguistics across cultures. Ann Arbor: University of Michigan Press.

Lakoff, R. (1973). The logic of politeness: Or minding your p's and q's. In C. Corum, T. Smith-Stark, and A. Weiser (Eds.), Papers from the Ninth Regional Meeting of the Chicago Linguistic Society (292-305). Chicago: Chicago Linguistic Society. 
Lakoff, R. (1975). Language and woman's place. New York: Harper \& Row, Publishers.

Larsen-Freeman, D., and Long, M. (1991). An introduction to second language acquisition research. New York: Longman Inc.

Leech, G. (1977). Language and tact. L.A.U.T. paper 46, Trier.

Leech, G. (1983). Principles of pragmatics. London: Longman.

Long, M. (1990). Group work and communicative competence in the ESOL classroom. In R. Scarcella, E. Andersen, and S. Krashen (Eds.), Developing communicative competence in a second language (303-315). Cambridge, MA: Newbury House.

Long, M. (in press). Task-based language teaching. Oxford: Basil Blackwell (Cited by Schmidt 1993).

Long, M., and Sato, C. (1984). Methodological issues in interlanguage studies: An interactionist perspective. In A. Davies, C. Criper, and A. Howatt (Eds.), Interlanguage (253-279). Edinburgh University Press.

Lovik, T. (1987). Pragmatic pitfalls of learning/teaching German. Die Unterrichtspraxis, 20(1), 36-44.

Lyons, J. (Ed.) (1970). New horizons in linguistics. Harmondsworth, England: Penguin Books.

Manes, J. (1983). Compliments: A mirror of cultural values. In N. Wolfson and E. Judd (Eds.), Sociolinguistics and language acquisition (96-102). Rowley, MA: Newbury House Publishers, Inc.

Manes, J., and Wolfson, N. (1981). The compliment formula. In F. Coulmas (Ed.), Conversational routine (115-132). The Hague: Mouton.

Mohatt, G., and Erickson, F. (1981). Cultural differences in teaching styles in an Odawa school: A sociolinguistic approach. In H. Trueba, G. Pung Gunthrie, and K. HuPei Au (Eds.), Culture and the bilingual classroom. New York: Newbury House Publishers.

Ochs, E. (1979). Planned and unplanned discourse. In T. Givon (Ed.), Syntax and semantics, (Vol. 12): Discourse and syntax (51-80). New York: Academic Press. 
Ochs, E. (1986). From feelings to grammar: A Samoan case study. In B. Schieffelin and E. Ochs (Eds.), Language socialization across cultures (251-272). Cambridge: Cambridge University Press,

Olshtain, E. (1983). Sociocultural competence and language transfer: The case of apology. In S. Gass and L. Selinker (Eds.), Language transfer in language learning (23249). Rowley, MA.: Newbury House.

Olshtain, E. and Blum-Kulka, S. (1985). Degree of approximation: Nonnative reactions to native speech act behavior. In S. Gass and C. Madden (Eds.), Input in second language acquisition (303-32). Rowley, MA: Newbury House Publishers, Inc.

Olshtain, E., and Blum-Kulka, S. (1989). Happy Hebrish: Mixing and switching in American-Israeli family interactions. In S. Gass, C. Madden, D. Preston, and L. Selinker (Eds.), Variation in second language acquisition: Discourse and pragmatics (59-83). Clevedon; Philadelphia: Multilingual Matters.

Olshtain, E., and Cohen, A. (1981). The speech act set. Presentation at the Discourse Analysis and Language Learning Symposium, The Sixth International Congress of Applied Linguistics, Lund, Sweden.

Olshtain, E., and Cohen, A. (1983). Apology: A speech-act set. In N. Wolfson and E. Judd (Eds.), Sociolinguistics and language acquisition (18-35). Rowley, MA: Newbury House Publishers, Inc.

Olshtain, E., and Cohen, A. (1989). Speech act behavior across languages. In H. Dechert and M. Raupach (Eds.), Transfer in language production (53-67). Norwood, NJ: Ablex.

Olshtain, E., and Cohen, A. (1991). Teaching speech act behavior to nonnative speakers. In M. Celce-Murcia (Ed.), Teaching English as a second or foreign language, 2nd ed. (154-65). Boston: Heinle \& Heinle Publishers.

Olshtain, E., and Weinbach, L. (1993). Interlanguage features of the speech act of complaining. In G. Kasper and S. Blum-Kulka (Eds.), Interlanguage pragmatics. New York; Oxford: Oxford University Press

Paulston, C. (1990). Linguistic and communicative competence. In R. Scarcella, E. Andersen, and S. Krashen (Eds.), Developing communicative competence in a second language (287-301). Cambridge, MA: Newbury House.

Philips, S. (1970). The acquisition of rules of appropriate usage. In J. Alatis (Ed.), Monograph series on language and linguistics. Washington, D. C.: Georgetown University Press. 
Philips, S. (1972). Participant structures and communicative competence: Warm Springs children in community and classroom. In C. Cazden, V. John, and D. Hymes (Eds.), Functions of language in the classroom (370-394). New York: Teachers College Press.

Philips, S. (1983). The invisible culture: Communication in the classroom and community in the Warm Spring Indian reservation. New York: Teachers College Press.

Pike, K. (1967). Language in relation to a unified theory of the structure of human behavior, 2nd ed. The Hague: Mouton.

Richards, J. (1983). Communicative needs in foreign language learning. In N. Wolfson and E. Judd (Eds.), Sociolinguistics and language acquisition (242-52). Rowley, MA: Newbury House Publishers, Inc.

Rintell, E. (1984). But how did you feel about that? The learner's perception of emotion in speech. Applied Linguistics, 5(3).

Rintell, E. (1990). That's incredible: Stories of emotion told by second language learners and native speakers. In R. Scarcella, E. Andersen, and S. Krashen (Eds.), Developing communicative competence in a second language (75-94). Cambridge, MA: Newbury House.

Rubin, J. (1983). How to tell when someone is saying "no" revisited. In N. Wolfson and E. Judd (Eds.), Sociolinguistics and language acquisition (10-17). Rowley, MA: Newbury House Publishers, Inc.

Scarcella, R. (1979a). "Watch up!": Prefabricated routines in adult second language performance. Working Papers on Bilingualism. 19, 79-88. Toronto, OISE.

Scarcella, R. (1979b). On speaking politely in a second language. In C. Yorio, K. Perkins, and J. Schachter (Eds.), On TESOL '79: The learner in focus (275-287). Washington, D.C.: TESOL.

Scarcella, R. (1990). Communication difficulties in second language production, development, and instruction. In R. Scarcella, E. Andersen, and S. Krashen (Eds.), Developing communicative competence in a second language (337-352). Cambridge, MA: Newbury House.

Schachter, J. (1983). A new account of language transfer. In: S. Gass and L. Selinker (Eds.), Language transfer in language learning (98-111). Rowley, MA: Newbury House Publishers, Inc. 
Scherer, K., and Giles, H. (1979). Social markers in speech. Cambridge: Cambridge University Press.

Schmidt, R. (1983). Interaction, acculturation and the acquisition of communicative competence. In N. Wolfson and E. Judd (Eds.), Sociolinguistics and language acquisition (137-74). Rowley, MA: Newbury House.

Schmidt, R. (1993). Consciousness, learning and interlanguage pragmatics. In G. Kasper and S. Blum-Kulka (Eds.), Interlanguage pragmatics (21-42). New York; Oxford: Oxford University Press.

Schmidt, R., and Richards, J. (1980). Speech acts and second language learning. Applied Linguistics 1(2), 129-158.

Searle, J. (1969). Speech acts: An essay in the philosophy of language. Cambridge: Cambridge University Press.

Searle, J. (1975). Indirect speech acts. In P. Cole and J. Morgan (Eds.), Speech acts. Vol. 3 of Syntax and semantics (59-82). New York: Academic Press.

Searle, J. (1976). A classification of illocutionary acts. Language in Society, 5(1), 1-23.

Searle, J. (1979). Expression and Meaning. Cambridge. Cambridge University Press.

Selinker, L. (1983). Language transfer. In: S. Gass and L. Selinker (Eds.), Language transfer in language learning (33-53). Rowley, MA: Newbury House Publishers, Inc.

Sharwood-Smith, M. (1983). Cross-linguistic aspects of second language acquisition. Applied Linguistics 4, 192-199.

Sinclair, J., and Coulthard, M. (1975). Towards an analysis of discourse: the English used by teachers and pupils. London: Oxford University Press.

Sjöholm, K. 1976. A comparison of the test results in grammar and vocabulary between Finnish- and Swedish-speaking applicants for English, 1974. In H. Ringbom and R. Palmberg (Eds.), Errors made by Finns and Swedish-speaking Finns in the learning of English. AFTIL vol. 5 (54-137). Publications of the Department of English, Åbo Akademi.

Slobin, D. (1973). Cognitive prerequisites for the development of grammar. In C. Ferguson and D. Slobin (Eds.), Studies of child language development (175-208). New York: Holt, Rinehart and Winston. 
Slobin, D. (1977). Language change in childhood and history. In J. Macnamara (Ed.), Language learning and thought (175-208). New York. Academic Press.

Spindler, G., and Spindler, L. (Eds.) (1987). Interpretive ethnography of education at home and abroad (363-384). Hillsdale, NJ: Erlbaum.

Takahashi, T., and Beebe, L. (1987). The development of pragmatic competence by Japanese learners of English. JALT Journal, 8(2), 131-155.

Takahashi, T., and Beebe, L. (1993). Cross-linguistic influence in the speech act of correction. In G. Kasper and Blum-Kulka, S. (Eds.), Interlanguage pragmatics (138-157). New York; Oxford: Oxford University Press.

Tannen, D. (1985). Cross-cultural communication. In T. Van Dijk (Ed.), Handbook of discourse analysis (Vol. 4, 203-215). London: Academic Press.

Thomas, J. (1983). Cross-cultural pragmatic failure. Applied Linguistics 4(2), 91-112.

Trosborg, A. (1987). Apology strategies in natives/nonnatives. Journal of Pragmatics, 11, $147-67$.

Venditti, P., and Bahruth, R. (1986). Enhancing communicative competence and cultural adaptation of ESL students using dialogue journals and interactive errands. ERIC: ED 275132.

Vollmer, H., and Olshtain, E. (1989). The language of apologies in German. In S. BlumKulka, J. House, and G. Kasper (Eds.), Cross-cultural pragmatics: Requests and apologies (197-218). Norwood, NJ: Ablex

Wardhaugh, R. (1986). An introduction to sociolinguistics. Oxford: Bail Blackwell.

Watson-Gegeo, K., and Gegeo, D. (1986). Calling-out and repeating routines among Kwara'ae children. In B. Schieffelin and E. Ochs (Eds.), Language socialization across cultures (17-50). Cambridge: Cambridge University Press.

Weeks, T. (1983). Discourse, culture, and interaction. In B. Robinette and J. Schachter (Eds.), Second language learning. Ann Arbor: University of Michigan Press.

Weinreich, U. (1953). Language in contact. Linguistic Circle of New York.

Weltens, B., de Bot, K., and van Els, T. (1986). Language attrition in progress. Dordrecht: Foris. 
Whitman, R., and Jackson, K. (1972). The unpredictability of contrastive analysis. Language Learning 22, 29-41.

Wode, H. (1978). The L1 vs. L2 acquisition of English negation. Working Papers on Bilingualism 15, 37-57.

Wolfson, N. (1979). "Let's have lunch together sometime": Perceptions of insincerity. Paper presented at TESOL, Boston.

Wolfson, N. (1981). Compliments in cross-cultural perspective. TESOL Quarterly, 15(2), $117-124$.

Wolfson, N. (1983a). An empirically based analysis of complimenting in American English. In N. Wolfson and E. Judd (Eds.), Sociolinguistics and language acquisition (82-95). Rowley, MA: Newbury House Publishers, Inc.

Wolfson, N. (1983b). Introduction to Chapter 1, "Patterns of Rules of Speaking." In N. Wolfson and E. Judd (Eds.), Sociolinguistics and language acquisition. Rowley, MA: Newbury House Publishers, Inc.

Wolfson, N. (1986). Compliments in cross-cultural perspective. In Valdes, J. (Ed.) (1990), Culture bound: Bridging the cultural gap in language teaching, 4th ed. (112120). Cambridge: Cambridge University Press.

Wolfson, N. (1989). Perspectives: Sociolinguistics and TESOL. Cambridge, New York, Philadelphia, etc.: Newbury House Publishers.

Wolfson, N., and Judd, E. (Eds.) (1983). Sociolinguistics and language acquisition. Rowley, MA: Newbury House Publishers, Inc.

Zobl, H. 1980a. The formal and developmental selectivity of L1 influence on L2 acquisition. Language Learning. 30(1), 43-57.

Zobl, H. 1980b. Contact-induced language change, learner-language, and the potentials of a modified CA. Paper presented at the Third Los Angeles Second Language Research Forum, UCLA, February 19-March 2.

Zobl, H. 1980c. Developmental and transfer errors: their common bases and (possibly) differential effects on subsequent learning. TESOL Quarterly. 14(4), 469-479. 


\section{Appendix A \\ Dialogue Completion Test}

(used in this study and derived from Beebe, Takahashi, \& Uliss-Weltz, 1990, pp. 69-72)

Instructions: Please read the following twelve situations. After each situation you will be asked to write a response in the blank after "you." Your response should fit in with what your conversational partner says before and after your lines. Respond as you would in actual conversation.

1. You are the owner of a bookstore. One of your best workers asks to speak to you in private.

Worker: As you know, I've been here just a little over a year now, and I know you've been pleased with my work. I really enjoy working here, but to be quite honest, I really need an increase in pay.

You:

Worker: Then I guess I'll have to look for another job.

2. You are a junior in college. You attend classes regularly and take good notes.

Your classmate often misses a class and asks you for the lecture notes.

Classmate: Oh, no! We have an exam tomorrow, but I don't have notes from last week.

I am sorry to ask you this, but could you please lend me your notes once again?

You:

Classmate: O.K., then I guess I'll have to ask somebody else.

3. You are the president of a printing company. A salesman from a printing machine company invites you to one of the most expensive restaurants in New York. 
Salesman: We have met several times to discuss your purchase of my company's products. I was wondering if you would like to be my guest at Lutece in order to firm up a contract?

You:

Salesman: Perhaps we can talk some other time.

4. You are a top executive at a very large accounting firm. One day the boss calls you into her office.

Boss: Next Sunday my husband and I are having a little party. I know it's short notice but I am hoping all my top executives will be there with their spouses. What do you say?

You:

Boss: That's too bad. I was hoping everyone would be there.

5. You're at a friend's house watching T.V. He/She offers you a snack. You: Thanks, but no thanks. I've been eating like a pig and I feel just terrible. My clothes don't even fit me.

Friend: Hey, why don't you try this new diet I've been telling you about?

You:

Friend: You should try it anyway.

6. You're at your desk trying to find a report that your boss just asked for. While you're searching through the mess on your desk, your boss walks over.

Boss: You know, maybe you should try and organize yourself better. I always write myself little notes to remind me of things. Perhaps you should give it a try! 
You:

Boss: Well, it's an idea anyway.

7. You arrive home and notice that your cleaning lady is extremely upset. She comes rushing up to you.

Cleaning lady: Oh my, I'm so sorry! I had an awful accident. While I was cleaning I bumped into the table and your china vase fell and broke. I feel just terrible about it. I'll pay for it.

You: (Knowing that the cleaning lady is supporting three children.) You:

Cleaning lady: No, I'd feel better if I paid for it.

8. You're a language teacher at a university. It is just about the middle of the term now and one of your students asks to speak to you.

Student: Ah, excuse me, some of the students were talking after class recently and we kind of feel that the class would be better if you could give us more practice in conversation and less on grammar.

You:

Student: O.K., it was only a suggestion.

9. You are at a friend's house for lunch.

Friend: How about another piece of cake?

You:

Friend: Come on, just a little piece? 
You

10. A friend invites you to dinner, but you really can't stand this friend's husband/wife.

Friend: How about coming over for dinner Sunday night? We're having a small dinner party.

You:

Friend: Well, maybe we can see each some other time.

11. You've been working in an advertising agency now for some time. The boss offers you a raise and promotion, but it involves moving. You don't want to go. Today, the boss calls you into his office.

Boss: I'd like a offer you an executive position in our new offices in Hicktown. It's a great town -- only 7 hours from here by car. And, a nice raise comes with the position.

You:

Boss: Well, maybe you should give it some more thought before turning it down.

12. You are at the office in a meeting with your boss. It is getting close to the end of the day and you want to leave work.

Boss: If you don't mind, I'd like you to spend an extra hour or two tonight so that we can finish up with this work.

You:

Boss: That's too bad. I was hoping you could stay. 
Background Information

Gender: male female

Age:

Native Language(s):

Country of Origin: 


\section{Appendix B Discourse Completion Test}

(from Beebe, Takahashi, \& Uliss-Weltz, 1990, pp. 69-72)

Instructions: Please read the following twelve situations. After each situation you will be asked to write a response in the blank after "you." Respond as you would in actual conversation.

1. You are the owner of a bookstore. One of your best workers asks to speak to you in private.

Worker: As you know, I've been here just a little over a year now, and I know you've been pleased with my work. I really enjoy working here, but to be quite honest, I really need an increase in pay.

You:

Worker: Then I guess I'll have to look for another job.

2. You are a junior in college. You attend classes regularly and take good notes. Your classmate often misses a class and asks you for the lecture notes.

Classmate: Oh God! We have an exam tomorrow, but I don't have notes from last week. I am sorry to ask you this, but could you please lend me your notes once again?

You:

Classmate: O.K., then I guess I'll have to ask somebody else.

3. You are the president of a printing company. A salesman from a printing machine company invites you to one of the most expensive restaurants in New York.

Salesman: We have met several times to discuss your purchase of my company's products. I was wondering if you would like to be my guest at Lutece in order to firm up a contract?

You:

Salesman: Perhaps another time.

4. You are a top executive at a very large accounting firm. One day [your] boss calls you into his office.

Boss: Next Sunday my spouse and I are having a little party. I know it's short notice but I am hoping all my top executives will be there with their spouses. What do you say?

You:

Boss: That's too bad. I was hoping everyone would be there. 
5. You're at a friend's house watching T.V. He/She offers you a snack.

You: Thanks, but no thanks. I've been eating like a pig and I feel just terrible. My clothes don't even fit me.

Friend: Hey, why don't you try this new diet I've been telling you about?

You:

Friend: You should try it anyway.

6. You're at your desk trying to find a report that your boss just asked for. While you're searching through the mess on your desk, your boss walks over.

Boss: You know, maybe you should try and organize yourself better. I always write myself little notes to remind me of things. Perhaps you should give it a try!

You:

Boss: Well, it's an idea anyway.

7. You arrive home and notice that your cleaning lady is extremely upset. She comes rushing up to you.

Cleaning lady: Oh God, I'm so sorry! I had an awful accident. While I was cleaning I bumped into the table and your china vase fell and broke. I feel just terrible about it. I'll pay for it.

You: (Knowing that the cleaning lady is supporting three children.)

You:

Cleaning lady: No, l'd feel better if I paid for it.

8. You're a language teacher at a university. It is just about the middle of the term now and one of your students asks to speak to you.

Student: Ah, excuse me, some of the students were talking after class recently and we kind of feel that the class would be better if you could give us more practice in conversation and less on grammar.

You:

Student: O.K., it was only a suggestion.

9. You are at a friend's house for lunch.

Friend: How about another piece of cake?

You:

Friend: Come on, just a little piece?

You: 
10. A friend invites you to dinner, but you really can't stand this friend's husband/wife. Friend: How about coming over for dinner Sunday night? We're having a small dinner party.

You:

Friend: O.K., maybe another time.

11. You've been working in an advertising agency now for some time. The boss offers you a raise and promotion, but it involves moving. You don't want to go. Today, the boss calls you into his/her office.

Boss: I'd like a offer you an executive position in our new offices in Hicktown. It's a great town -- only 7 hours from here by car. And, a nice raise comes with the position. You:

Boss: Well, maybe you should give it some more thought before turning it down.

12. You are at the office in a meeting with your boss. It is getting close to the end of the day and you want to leave work.

Boss: If you don't mind, I'd like you to spend an extra hour or two tonight so that we can finish up with this work.

You:

Boss: That's too bad. I was hoping you could stay. 


\section{Appendix C Modifications of the Discourse Completion Test}

As noted in Chapter 3, Research Design, the original Discourse Completion Test (DCT) designed by Beebe et al underwent some minor alterations for the purposes of this study. Among the cultural clashes that might have been faced when using an unaltered version of Beebe et al's DCT with a German population were the following items:

- item \#2: At German universities, there is generally only a big final exam at the end of the entire course of study rather than several exams for each course -although once in a great while, tests are given in individual classes. This difference to the American grading system, however, did not appear to be serious enough to warrant changing the instrument.

- item \#5: A direct translation of "I've been eating like a pig" would result in a very harsh statement ("Ich fresse zur Zeit wie ein Schwein"), which would have been inappropriate in this context. For this reason, the German DCT was changed to express the same idea of overeating, but with more appropriate wording.

- item \#8 -German students might be more likely to opt for "voting with their feet" rather than confronting the professor with their suggestions for improvement because, under the German academic system, there is formal registration only for certain classes and students frequently do not take classes for credit. They might simply seek a different class with a different professor that would better suit their needs. It did seem plausible, however, that a student might request that a professor include more conversation practice in a language class, so this item was left unaltered.

- item \#9 - Since cake would probably not be offered at lunchtime in Germany, the setting of the German version was changed to "afternoon coffee" (similar to British "tea time").

- item \#11 - In Germany, one could hardly be three hours away by plane from another German city, so both the English and German versions were changed to "seven hours by car."

Beebe et al's questionnaire was somewhat gender-biased: the boss and top executives in \#4 and the boss in \#11 are male and the cleaning lady in \#7 is female. This suggests a tendency for the higher status positions to be filled with men and the lower status positions to be filled with women. I attempted to make the English version of the questionnaire gender-neutral, and divided the higher, same, and lower status situations evenly between male and female interlocuters in the German version.

Four situations in Beebe et al's English original assigned gender (through pronouns and expressions like "my wife" or "cleaning lady"). They happened to be two lower status and two higher status categories. As one of the lower status situations had a masculine interlocuter (\#3) and the other a feminine one (\#7), I made no changes there. Both of the higher status interlocuters, however, were masculine, so I made one masculine and one feminine: \#4-feminine; \#11-masculine. (In \#5 and \#10, both same social status situations, Beebe et al opted for gender neutrality by writing "he/she" and "husband/wife." 
I made no changes here, either.) In \#4, I changed Beebe et al's word, "wives", to "spouses" in order to avoid the stereotype that none of the top executives have husbands.

Attempting to maintain gender neutrality in the German translation would have resulted in an extremely awkward text, because the German language assigns gender to all nouns. It seemed to me to be too clumsy to write in both masculine and feminine forms for each conversational partner (especially since I had already written in both possibilities for the subjects' roles in each dialogue). I was forced to choose the gender of the interlocuter in German and ultimately decided to distribute gender assignment evenly between the social status categories. In order to alternate between masculine and feminine interlocuters (i.e., to avoid having three situations in a row with feminine interlocuters) within the English and German versions of the questionnaire, one gender assignment discrepancy resulted: in item \#11, the interlocuter is masculine in the English version and feminine in the German version. There might be differences in the responses that subjects would give a male or female interlocuter of higher, lower, or equal status, but as my study does not address the issue of gender differences, I do not believe that the discrepancy has affected the validity of the data.

At the suggestion of the Human Subjects Research Review Committee, I changed the wording in \#2 and \#7 from "Oh God" to "Oh, no" (\#2) and "Oh my" (\#7) in order to avoid an expression that might be offensive to some participants.

In items \#3 and \#10 of Beebe et al's original test, the interlocuters' rejoinders do not allow the respondent to give an honest reason for his/her refusal. In \#3, for example (where the salesmen is inviting the printing company president to an expensive restaurant), the respondent could not say, "I don't accept luxurious dinner invitations from sales representatives." In \#10 (where the respondent is being invited to dinner by a friend, but can't stand the friend's spouse), Beebe et al's rejoinder assumes that the respondent will fib and doesn't allow for an honest statement of why the respondent is refusing. The respondent could not say, "You know, I'd really love to see you, Ann, but I just don't feel all that comfortable around Bill. I hope I'm not offending you." The changes I made to items \#3 and \#10 were very minor: In \#3, "Perhaps another time," became "Perhaps we can talk some other time," and in \#10, I changed, "O.K., maybe another time," to "Well, maybe we can see each some other time." 


\section{Appendix D \\ German Translation of Discourse Completion Test}

\section{Dialogergänzungstest}

Anleitung : Lesen Sie bitte die folgenden zwölf Situationen durch. Nach jeder

Situationsbeschreibung werden Sie gebeten, eine Antwort in den Freiraum hinter "Sie" zu schreiben. Ihre Antwort sollte zu dem passen, was Ihr Gesprächspartner vor und nach Ihren Zeilen sagt. Antworten Sie so wie Sie es in einem tatsächlichen Gespräch täten.

1. Sie sind EigentümerIn eines Buchladens. Eine Ihrer besten Angestellten bittet darum, mit Ihnen privat zu sprechen.

Angestellte: Wie Sie wissen, bin ich inzwischen seit etwas über einem Jahr hier, und ich weiß, daß Sie mit meiner Arbeit zufrieden sind. Es macht mir viel Spaß, hier zu arbeiten, doch ehrlich gesagt, brauche ich nun wirklich eine Gehaltserhöhung.

Sie:

Angestellte: Also, dann werde ich wohl eine andere Stellung suchen müssen.

2. Sie sind im 5. Semester an der Universität. Sie besuchen regelmäßig den Unterricht und schreiben immer gut mit. Ein Kommilitone von Ihnen fehlt häufig und bittet Sie um Ihre Aufzeichnungen.

Kommilitone: O je! Wir haben morgen eine Prüfung, aber mir fehlen die Notizen von letzter Woche. Meinst du, du könntest mir deine Notizen noch einmal leihen? Sie:

Kommilitone: Nun gut, dann werde ich wohl jemanden anderen bitten müssen.

3. Sie sind LeiterIn einer Druckerei. Ein Vertreter einer Druckmaschinenfirma lädt Sie in eines der teuersten Restaurants in Frankfurt ein. 
Vertreter: Wir haben uns nun mehrere Male getroffen, um zu besprechen, ob Sie daran interessiert sind, Produkte von meiner Firma zu kaufen. Könnte ich Sie zum “Frankfurter Hof"einladen, um einen Bestellungsvertrag festzulegen?

Sie:

Vertreter: Vielleicht können wir uns ein anderes Mal unterhalten.

4. Sie sind leitende/r Angestellte/r an einer großen Buchhaltungsfirma. Eines Tages bittet Sie ihre Chefin in ihr Büro.

Chefin: Am nächsten Sonntag planen mein Mann und ich eine kleine Feier. Ich weiß, daß dies eine kurzfristige Ankündigung ist, aber ich hoffe, daß alle meine leitenden Angestellten mit ihren Ehepartnern da sein können. Was sagen Sie dazu?

Sie:

Chefin: Das ist aber schade. Ich hatte gehofft, daß alle da sein könnten.

5. Sie schauen fern bei einer Freundin. Sie bietet Ihnen etwas zum Naschen an.

Sie: Danke, aber in letzter Zeit futtere ich viel zuviel und ich bin gar nicht glücklich damit. Meine Kleidung paßt mir nicht mal.

Freundin: Hör mal, warum probierst du nicht die neue Diät, von der ich dir öfters erzählt habe?

Sie:

Freundin: Du solltest sie trotzdem mal versuchen.

6. Sie sind am Schreibtisch und versuchen, einen Bericht zu finden, um welchen Sie Ihr Chef eben gebeten hat. Während Sie das Durcheinander auf Ihrem Schreibtisch durchsuchen, kommt Ihr Chef zu Ihnen herüber. 
Chef: Wissen Sie, vielleicht sollten Sie versuchen, besser Ordnung zu halten. Ich selbst schreibe mir immer kleine Notizen, um mich an Dinge zu erinnern. Vielleicht sollten Sie das mal probieren!

Sie:

Chef: Naja, es war nun einmal eine Idee.

7. Sie kommen nach Hause und bemerken, daß Ihre Putzfrau völlig außer Fassung ist. Sie kommt auf Sie zugeeilt.

Putzfrau: $O$ je, es tut mir furchtbar leid! Ich hatte einen schrecklichen Unfall. Während ich am Putzen war, bin ich gegen den Tisch gestoßen, und Ihre Porzelanvase ist 'runtergefallen und kaputtgegangen. Ich bereue es sehr. Ich werde dafür bezahlen.

Sie (in Erwägung ziehend, daß die Putzfrau drei Kinder zu ernähren hat):

Putzfrau: Nein, mir wäre es angenehmer, wenn ich dafür bezahlen würde.

8. Sie sind SprachlehrerIn an einer Universität. Es ist nun fast Mitte des Semesters und einer Ihrer Studenten bittet Sie um ein Gespräch.

Student: Ach, Entschuldigung. Einige Studenten haben sich neulich nach dem Unterricht unterhalten, und wir meinen, daß der Kurs vielleicht besser wäre, wenn Sie uns mehr Konversationspraxis und weniger Grammatik geben würden.

Sie:

Student: Also gut, es war nur ein Vorschlag.

9. Sie sind bei einem Bekannten zum Kaffee eingeladen.

Bekannter: Wie wär's mit noch einem Stück Kuchen? 
Sie

Bekannter: Ach, komm, nur ein kleines Stückchen?

Sie:

10. Eine Bekannte lädt Sie zum Abendessen ein, aber Sie können den Ehemann dieser Bekannten wirklich nicht ausstehen.

Bekannte: Wie wär's, Sonntagabend zum Essen hierher zu kommen? Wir werden ein paar Leute zum Abendessen einladen.

Sie:

Bekannte: Naja, vielleicht können wir uns ein anderes Mal wiedersehen.

11. Sie arbeiten jetzt seit einiger Zeit in einer Werbeagentur. Die Chefin bietet Ihnen eine Gehaltserhöhung und eine Beförderung an, doch dies bringt einen Ortswechsel mit sich. Sie wollen nicht umziehen. Heute ruft Sie die Chefin in ihr Büro.

Chefin: Ich möchte Ihen eine leitende Stelle in unseren neuen Büros in Hinterbimpflingen anbieten. Es ist ein wunderbares Städtchen -- nur 7 Stunden Autofahrt von hier entfernt. Und eine gute Gehaltserhöhung kommt mit der Stelle.

Sie:

Chefin: Nun, vielleicht sollten Sie es sich länger überlegen, bevor Sie ablehnen.

12. Sie sind im Büro bei einer Konferenz mit Ihrem Chef. Es wird bald Arbeitsschluß sein, und Sie wollen den Arbeitsplatz verlassen.

Chef: Wenn es Ihnen nichts ausmacht, hätte ich gerne, daß Sie heute Abend noch ein oder zwei Stunden länger bleiben, damit wir diese Arbeit erledigen können. 
Sie:

Chef: Das ist aber schade. Ich hatte gehofft, Sie könnten bleiben.

Information zum Proband

Geschlecht: männlich weiblich

Alter:

Muttersprache(n):

Nationalität: 


\section{Appendix E \\ Classification of Discourse Completion Test (DCT) Stimulus According to Status of Addressee}

(derived from Beebe, Takahashi, \& Uliss-Weltz, 1990, p. 72)

\begin{tabular}{|c|c|c|c|}
\hline Stimulus & $\begin{array}{l}\text { Addressee Status } \\
\text { (relative to speaker) }\end{array}$ & DCT item & Situation \\
\hline Request & $\begin{array}{l}\text { Lower } \\
\text { Equal } \\
\text { Higher }\end{array}$ & $\begin{array}{l}\# 1 \\
\# 2 \\
\# 12\end{array}$ & $\begin{array}{l}\text { Request raise } \\
\text { Borrow class notes } \\
\text { Stay late at night }\end{array}$ \\
\hline Invitation & $\begin{array}{l}\text { Lower } \\
\text { Equal } \\
\text { Higher }\end{array}$ & $\begin{array}{l}\# 3 \\
\# 10 \\
\# 4\end{array}$ & $\begin{array}{l}\text { Fancy restaurant (bribe) } \\
\text { Dinner at friend's house } \\
\text { Boss's party }\end{array}$ \\
\hline Offer & $\begin{array}{l}\text { Lower } \\
\text { Equal } \\
\text { Higher }\end{array}$ & $\begin{array}{l}\# 7 \\
\# 9 \\
\# 11\end{array}$ & $\begin{array}{l}\text { Pay for broken vase } \\
\text { Piece of cake } \\
\text { Promotion with move to } \\
\quad \text { small town }\end{array}$ \\
\hline Suggestion & $\begin{array}{l}\text { Equal } \\
\text { Higher }\end{array}$ & $\begin{array}{l}\# 5 \\
\# 6\end{array}$ & $\begin{array}{l}\text { More conversation in } \\
\text { foreign language } \\
\text { class }\end{array}$ \\
\hline
\end{tabular}




\title{
Appendix $F$ \\ Classification of Refusals used in this Study
}

\author{
(derived from Beebe, Takahashi, \& Uliss-Weltz, 1990, pp. 72-73)
}

\section{Direct}

A. Performative (e.g., "I refuse", "I decline")

B. Nonperformative statement

1. "No." Also: Opaque "no" (See discussion, p....)

2. Negative willingness ("I won't."). Also: Opaque negative willingness (See discussion, p....)

3. Negative ability ("I can't.")

4. Negative willingness/ability (ambiguous forms, e.g., "Moving is out of the question for me."; "That won't work.")

II. Indirect (i.e., use of a different speech act to perform a refusal)

A. Statement of regret (a real apology, e.g., "I'm sorry..."; "I feel terrible...")

B. Wish (e.g., "I wish I could help you..."; "I would if I could")

C. Excuse (e.g., "My children will be home that night."; "I have a headache.")

D. Reason or explanation (e.g., "I have already had enough to eat"; "I need them [my notes] myself to study for the test")

E. Statement of alternative

1. I can do $X$ instead of $Y$ (e.g., "I'd rather..."; "I'd prefer...")

2. Why don't you do $\mathbf{X}$ instead of $\mathbf{Y}$ (e.g., "Why don't you ask someone else?")

3. You can do $\mathbf{X}$ instead of $\mathbf{Y}$ (e.g., to a student who would like some conversation practice in a class that focuses on grammar: "We also have conversation classes at the university")

F. Set condition for future or past acceptance (e.g., "If you had asked me earlier, I would have...")

G. Promise of future acceptance (e.g., "I'll do it next time"; "I promise I'll..."; "Next time I'll..." - using "will" of promise or "promise"). Also: Conditional promise (e.g., "If my current diet doesn't work out, I'll try yours.").

H. Statement of principle or philosophy (e.g., "I don't mix business and pleasure"; "I consider it unethical to take favors from a vendor"; "I just try to eat healthy food, and only eat when I'm hungry."; "Accidents happen.")

I. Attempt to dissuade interlocutor

1. Threat or statement of negative consequences to the interlocutor and/or to the speaker (e.g., "I won't be any fun tonight" to refuse an invitation; "I'm going to be sick if I eat more.")

2. Guilt trip (e.g., "You're abusing my generosity"; or: Waitress to customers who want to sit a while: "I can't make a living off people who just order coffee.") 
3. Criticism of the interlocutor (e.g., "You're lazy."; "You've got a lot of nerve!"; "Your grammar is really bad"; "You don't understand what you're talking about")

4. Insult / attack (e.g., "Who do you think you are?")

5. Criticism of the eliciting speech act, i.e., the request, suggestion, etc., criticizing either the fact that it was performed or its content (e.g., "That's a terrible idea!"; "It's too late to ask for my notes a day before the exam"; "It's too soon to ask for a raise after only one year")

6. Statement of negative feeling or opinion without criticizing the interlocutor or the eliciting speech act (e.g., company president to a salesman trying to use a dinner invitation as a bribe: "Lutece isn't a restaurant I enjoy")

7. Imperative telling interlocutor to rescind the suggestion, request, offer, etc. (e.g., "Stop asking me!"; "Don't try to force me!")

8. Request that interlocutor rescind the suggestion, request, offer, etc. (e.g., "How about if we stick with my syllabus as I've planned it?")

9. Let interlocutor off the hook (e.g., "Don't worry about it."; "That's okay."; "You don't have to."; "I know you didn't mean to do it."; "I know that you can't afford to buy one.")

10. Self-defense (e.g., "I'm trying my best."; "I'm doing all I can do."; "I find that my disorganization rarely affects my work seriously."; "I know where everything is."; "I normally have a good system worked out.")

11. Diminish value of the requested object or the object that the interlocutor has damaged and wants to replace (e.g., "My notes are so messy you'd have a hard time understanding them." "It's just a vase." "I never really liked it anyway.")

J. Acceptance that functions as a refusal

1. Unspecific or indefinite reply

2. Lack of enthusiasm (e.g., in response to an offer of another piece of cake:

"Well, if I absolutely have to." "If I can do you a favor by having another piece...")

K. Avoidance

1. Nonverbal
a. Silence
b. Hesitation
c. Do nothing
d. Physical departure

2. Verbal
a. Topic switch
b. Joke
c. Repetition of part of request, invitation, etc. (e.b., "Monday?")
d. Postponement (e.g., "I'll think about it.")
e. Hedging (e.g., "Gee, I don’t know."; "I'm not sure.") 
L. Elaboration, i.e., information continuing and explaining the preceding utterance (e.g., "I consider it unethical to take favors from a vendor because it might color my decision and therefore the best interests of my firm" = [philosophy] [elaboration of philosophy] ) 


\section{Adjuncts to Refusals}

1. Statement of positive opinion / feeling (e.g., "That's a good idea..."; "I'd love to...")

2. Statement of agreement (e.g., "I agree..."; "Yeah, I can understand that")

3. Compliment, i.e., a remark about a positive attribute or action on the part of the addressee (e.g., "Your cake is delicious"; "You're a good worker")

4. Statement of empathy (e.g., "I realize you are in a difficult situation.")

5. Pause fillers (e.g., "uhh"; "well"; "oh"; "uhm")

6. Gratitude / appreciation (e.g., "Thank you.")

7. Forewarn, i.e., a statement that prepares the interlocutor for the unpleasant speech act (i.e., the refusal) that will follow (e.g., "Well, I'll tell you..."; "I hate to sound rude..."; "I've talked it over with my spouse...")

8. Admonition (e.g., "Try and be more careful around the house.")

9. Establishment of own status / superiority over addressee (e.g., "When you teach your own class, you can pay more attention to conversation."; "I'm the one who is educated in this field and I know better than you what you'll need to know.")

10. Downgraders (including various devices that lessen the impact of an FTA, such as politeness markers and "play-downs", syntactic devices such as use of negation, interrogative, and modal, e.g., "Please..."; "No, thank you"; "I'm afraid I can't give you a raise..."; "Unfortunately, the business can't afford it..."; "I don't think I can make it"; Mightn't it be a good idea...?"; "I may not be able...")

11. Downtoners, like downgraders, are devices that soften utterances and make them more acceptable to the hearer, but unlike downgraders, they are "filler words" with no real meaning in the sense of mitigating an FTA outside of context, e.g., "you know"; "I mean"; "you see"; and some impossible-to-translate German forms: "ja"; "also"; "doch"; "schon"; "mal"; "eigentlich"; and "eben").

12. Upgraders, i.e., devices that increase the impact of the FTA, e.g., adverbial modifiers such as "absolutely"; "terribly"; "I'm absolutely disgusted that..."; aggressive interrogatives such as "Why haven't you told me before?"; and intensifiers such as "No, really!."

13. Intensifiers, i.e., devices that add emphasis and/or urgency to an utterance without affecting the degree of face threat (e.g., "I'm very sorry").

Downgraders and upgraders are usually embedded in another category, and downtoners and intensifiers are always embedded. If a downgrader or upgrader appears as a full statement, then it is analyzed as a separate category (e.g., "...but it has nothing to do with your performance").

\section{Non-refusal}

1. Acceptance (e.g., "Okay")

2. Limited acceptance (e.g., "If you promise to give me a little piece, okay.")

3. Limitation of acceptance (e.g., “... but just a tiny piece”) 


\section{Appendix G Classification of Refusals}

(from Beebe, Takahashi, and Uliss-Weltz, 1990, pp. 72-73)

I. Direct

A. Performative (e.g., "I refuse")

B. Nonperformative statement

1. "No"

2. Negative willingness / ability ("I can't." "I won't." "I don't think so.")

\section{Indirect}

A. Statement of regret (e.g., "I'm sorry..."; "I feel terrible...")

B. Wish (e.g., "I wish I could help you...")

C. Excuse, reason, explanation (e.g., "My children will be home that night."; "I have a headache.")

D. Statement of alternative

1. I can do $\mathbf{X}$ instead of $\mathbf{Y}$ (e.g., "I'd rather..." "I'd prefer...")

2. Why don't you do $\mathbf{X}$ instead of $\mathbf{Y}$ (e.g., "Why don't you ask someone else?")

E. Set condition for future or past acceptance (e.g., "If you had asked me earlier, I would have...")

F. Promise of future acceptance (e.g., "I'll do it next time"; "I promise I'll..." or "Next time I'll..." - using "will" of promise or "promise")

G. Statement of principle (e.g., "I never do business with friends.")

H. Statement of philosophy (e.g., "One can't be too careful.")

\section{Attempt to dissuade interlocutor}

1. Threat or statement of negative consequences to the requester (e.g., "I won't be any fun tonight" to refuse an invitation)

2. Guilt trip (e.g., waitress to customers who want to sit a while: "I can't make a living off people who just order coffee.")

3. Criticize the request / requester, etc. (statement of negative feeling or opinion); insult / attack (e.g., "Who do you think you are?"; "That's a terrible idea!")

4. Request for help, empathy, and assistance by dropping or holding the request.

5. Let interlocutor off the hook (e.g., "Don't worry about it." "That's okay." "You don't have to.")

6. Self-defense (e.g., "I'm trying my best." "I'm doing all I can do." "I no do nutting wrong.")

J. Acceptance that functions as a refusal

1. Unspecific or indefinite reply

2. Lack of enthusiasm

K. Avoidance 
1. Nonverbal
a. Silence
b. Hesitation
c. Do nothing
d. Physical departure

2. Verbal
a. Topic switch
b. Joke
c. Repetition of part of request, etc. (e.g., "Monday?")
d. Postponement (e.g., "I'll think about it.")
e. Hedging (e.g., "Gee, I don't know." "I'm not sure.")

\section{Adjuncts to Refusals}

1. Statement of positive opinion / feeling or agreement ("That's a good idea..."; "I'd love to...")

2. Statement of empathy (e.g., "I realize you are in a difficult situation.")

3. Pause fillers (e.g., "uhh"; "well"; "oh"; "uhm")

4. Gratitude / appreciation 


\section{Appendix $\mathrm{H}$ Script of AE Responses}

\section{Profile of AE Males:}

AE1-age 25; English; USA

AE2-age 22; “" “

AE3-age 24; “ “

AE4-age 27; “ “ “

AE5-age 28; English, USA / Syria

AE6-age 34; English; USA

\section{Profile of AE Females:}

AE7-age 28; English USA

AE8-age 24;

AE9-age 20, “ “

AE10-age 28; “ “

AE11-age 23;

AE12-age 23; “" “

\section{DCT \#1}

AE1: I understand your [sic] prospective. You are a valued asset to this company. Honestly I am unwilling to pay you more although it has nothing to do with your performance.

AE2: I'm sorry. As it stands right now, I cannot fit pay raises in my budget. But, as soon as I can, I will put you at the top of my list.

$\underline{\text { AE3: }}$ Well, I am pleased with your performance, but at this time I can't afford any pay raises.

AE4: Unfortunately I cannot afford to give you a raise because business is not that good.

AE5: Okay, I can understand that. We can talk a little about your needs right now, I'm certainly sympathetic \& we value your position here at the store, but to be honest I can't 
guarantee anything. Things are tight all over and a pay increase just may not be possible right now.

AE6: Well, I'll tell you... we really like your work. I wish we could give you a raise, but it's not possible right now.

AE7: I'm afraid I just can't do that right now, although I agree that you deserve it. [natural answer not possible]

AE8: I'm sorry, I can't give it to you because we don't have enough of a profit coming in.

AE9: I'd love to give you a raise, but the store really can't afford it right now.

$\underline{\mathrm{AE} 10}$ : I really value your good work and would like to increase your pay, but financially, that just isn't feasible right now.

AE11: Well-the financial situation we're in right now makes that impossible, but I'm very sorry and I hope you understand.

AE12: I'm sorry, but business has been slow and I can't afford to give you a raise right now. [odd situation; natural answer not possible]

\section{DCT \#2}

AE1: No, [sic] Im afraid [sic] Im reinforcing you not to do your own work. I know you are capable of doing it yourself and frankly [sic] Im [sic] beginng to feel used by you \& I don't want it to come between us.

AE2: I hate to sound rude, but I think [sic] its time to start doing your own work. Part of this class is attendance and notes.

AE3: I really need my notes to study. I'm afraid I can't lend any of them out.

AE4: I'm sorry but I can't. I need my notes to study for the test.

AE5: I'd love to, but I actually need them myself tonight. If you've got a minute maybe we could copy them, but I've got to study tonight for the exam too \& really need my notes. (Sorry!).

AE6: You're joking, aren't you? ...

AE7: I can't, sorry -- I'm going to need them tonight myself. 
AE8: I didn't bring all of them with me. Besides, I missed class today.

AE9: I'm sorry, I didn't bring that notebook with me today.

AE10: You know, I've given you my notes several times and now I feel like [sic] your abusing my generosity.

AE11: Well, I'm kind of in a hurry. I have to pick my boyfriend up downtown and then take my dog to the vet. -(lie) -

AE 12: If you came to class more often you wouldn't need to borrow my notes. And, [sic] fankly, I'm getting tired of you always asking me.

\section{DCT \#3}

AE1: I know you mean this dinner offer in good faith but I consider it unethical to take favors from a vendor because it might color my decision \& therefore the best interests of my firm.

AE2: No thank you. I am interested in your product but would rather conduct meetings in the workplace. [AE2 said that a natural answer is not possible for \#3. Note: "I think that a lot of business is conducted at restaurants. Smoozing is important in business."]

AE3: I appreciate the offer, but at the present time I am very happy with the performance of my current equipment-thanks anyway.

AE4: Sorry. At this time I am happy with the printing machines that we have.

AE5: You know, your product sounds really good \& I'd like to discuss it more with you, right now though we're pretty happy with X-co's material \& we're not in a position to change contracts completely.

AE6: (Name), I appreciate your invitation, but we won't be doing any buying right now. [AE6 considered this an odd situation]

AE7: I'd like to discuss the possibility sometime, but I'm really not ready to commit right now. [natural answer not possible]

AE8: I'm sorry, but I'm extremely busy during the evenings working on other proposals. [natural answer not possible]

AE9: This really isn't a good time for me-I have a lot of other obligations right now. 
AE10: Thanks for the invitation, but Lutece isn't a restaurant I enjoy. How about (name of lesser expensive restaurant)

AE11: I'm not positive yet about what I want to go with. I need a little more time to consider.

AE12: I'm sorry, but I have other plans for dinner. [odd situation; natural answer not possible]

\section{$\underline{\text { DCT \#4 }}$}

AE1: [sic] Its important for me to socialize outside of work with my [sic] collegues but such short notice puts me into a bind and I must therefore decline.

AE2: Thank you for the invitation but I'm afraid that I've already made plans that I'm committed to.

AE3: I would love to come, but I am afraid I have to decline because my wife (spouse) and I have already made plans-I'm sorry. [natural answer not possible]

AE4: Very sorry but my wife and I had plans to go to the mountains

AE5: Oh, I'd love to! But that's the weekend my wife's family is coming into town \& we have plans for that evening. I don't think we can make it, but really, thank you for the invite, maybe some other time.

AE6: Next Sunday? Oh, I wish I could, but it's my son's birthday and we've made a date to go on a weekend campout.

AE7: That sounds great, but I'm afraid we have plans to go out of town next weekend.

AE8: I'm sorry, I already made other plans.

AE9: I'd really like to see your place, but unfortunately, I have to visit my boyfriend's parents that day.

AE10: I'm afraid I've got some other commitments on Sunday. If I'd had more notice, I probably would've been able to make it.

AE11: I can try, but I don't think I can make it. My husband and I [sic] have had plans for this weekend already. 
AE12: My husband isn't much of one for parties, I'll have to say no. But thanks for asking. [odd situation; natural answer not possible]

\section{DCT \#5}

AE1: No thanks but [sic] its not a matter of dieting as much as simply not being excessive.

AE2: I don't like diet food. It tastes disgusting.

AE3: I already have another diet I just started, but if it doesn't work out I'll talk to you about it (the diet) later.

AE4: I don't believe in diets. They never work.

AE5: Argh! Diets! they never work for me; I hate trying to eat according to someone else's menu. I just like food. Thanks but no thanks.

AE6: Oh God, I've tried every diet there is, and all they are is a bunch of crap. They don't work. [natural answer not possible]

AE7: I don't really need a diet plan, just more [sic]excercise.

AE8: I don't know.

AE9: I can't use that diet-I'm a vegetarian.

AE10: Diets never work for me. I always feel unhealthy while I'm on them and then I gain the weight back afterwards.

AE11: I'm not really into dieting, you know, I just try to eat healthy food, and only eat when I'm hungry. [odd situation]

AE12: Fad diets don't work, I keep telling you that!

\section{DCT \#6}

$\underline{\mathrm{AE} 1}$ : [sic] Ive tried different approaches like that to improve my organization but I find that my disorganization rarely affects my work seriously \& various [sic] skemes I try to [sic] orgaize [sic] dont work for me anyway. [AE1 said natural answer not possible on \#6] 
AE2: I know that it may seem unorganized to someone else but I know where everything is. Usually.

AE3: Thanks, but this unorganized mess is the best way for me to stay organized. [natural answer not possible]

AE4: Usually I have no problem finding anything. I've just been very busy lately. [natural answer not possible]

$\underline{\text { AE5: }}$ That's a great idea, but somehow I think notes stuck everywhere would just add to the clutter!

AE6: You know, I'm sick of your nagging. I've had it -- with you, with this job, with life. I'd shoot myself if I could find my gun.

AE7: I'd probably lose the notes in this mess! [natural answer not possible]

AE8: [sic] Your probably right, but I normally have a good system worked out. I hate Mondays. [natural answer not possible]

AE9: I've tried that! This system just seems to work better for me... When I'm superorganized it just gets worse. [natural answer not possible]

AE10: Believe it or not, I'm far more organized than I seem. It's actually quite rare that I misplace something.

AE11: I'd probably just lose the notes too, and then they'd just add to the mess and make it messier.

AE12: Thanks for the suggestion, but I don't think that'll work for me. I tried it once, I forgot where I put the notes. [ natural answer not possible; odd situation]

\section{DCT \#7}

AE1: I loved that vase but I know you [sic] didnt mean to do it and [sic] its much more important to me that you use that money to support your kids than to give it to me to replace a vase.

AE2: Oh no. I understand that accidents happen. It wasn't that expensive anyway.

AE3: Well don't worry about it. I understand.-Just try and be more careful around the house. 
AE4: Don't worry about it. It was just a vase and I know that you can't afford to buy one.

AE5: Oh, that's not necessary, accidents happen. Don't worry about it. [crossed out: ] It's just an

AE6: (Shit.) Look -- I know you didn't mean to do it. Accidents happen. Don't worry about paying for it.

AE7: That's OK, These things happen.

AE8: Don't worry about it-It wasn't that important to me.

AE9: Look, it's really okay. It wasn't that important to me anyway. I'd rather just clean it up and forget about it.

AE10: Well, I'm pretty dismayed about the vase, but there's absolutely no way you're going to have to compensate for its loss. Just try to be more careful in the future.

AE11: That's okay. Don't worry about it. It's just a vase, and these things happen. I break things all the time, myself.

AE12: Accidents happen, don't feel bad; it's okay. It was a gift anyway from my motherin-law's I never did like it. Don't worry.

\section{DCT \#8}

AE1: I understand why you might say that. However I suggest that you get together outside of class to practice so we can use classtime to strengthen grammar which will in turn improve convo. skills.

AE2: [sic] Grammer is a fundamental part of any language. What's the use of saying something if you say it improperly?

AE3: Well when you teach your own class, you can pay more attention to conversation. I see nothing wrong with the curriculum at the present time. [natural answer not possible]

AE4: You need grammar in order to put words together for conversation. [natural answer not possible]

AE5: I agree, but the department curriculum demands that I test you on grammar, \& unfortunately there is not time for both in the class hour. 
AE6: Yeah, I don't blame you. I don't like grammar either; it's kind of boring. But by mastering the grammar now, you'll be able to converse more fluently later. [AE6 considered this an odd situation]

AE7: I'll take it under consideration, but I wouldn't change the curriculum this far into the term.

AE8: I wish you would have expressed these concerns earlier-can't do it, [sic] its too late in term. [natural answer not possible]

AE9: I'm sorry you feel that way. This program is structured this way because the department feels that it is the best way to learn a language.

AE10: Well, since I'm the one who is educated in this field and I know better than you what you'll need to know, how about if we stick with my syllabus as I've planned it?

AE11: Well-you know, grammar is the basis of any conversation. Maybe you can practice yourselves in a conversation group. [natural answer not possible]

AE12: In order to practice conversations, you need to know the grammar \& I don't feel any of you have it down yet. [natural answer not possible]

\section{$\underline{\text { DCT \#9 }}$}

AE1: No thanks.

No, I really [sic] dont want one.

AE2: No thanks. I'm full.

No, really. I'm full!

AE3: No, I'm full-I can't eat another bite.

No I'm going to explode!-I don't want anymore.

AE4: No. I'm full. I ate a big lunch.

No. I'm really full. I can't eat anything else.

AE5: Gosh, no thanks, I'm stuffed.

Well... maybe just a little!

AE6: No thanks; it's good, but I'm stuffed.

If you don't mind me vomiting on your rug.

AE7: No, thank you-one was plenty. 
No, really. It's very good, but I'm really pretty full.

AE8: naw.

Oh, all right.

AE9: No thank you. The first one really isn't sitting too well.

No. I really don't want any more.

AE10: It looks delicious, but I'm stuffed.

No, really, I couldn't eat another bite. I'd love to take a small piece home, though, if you're trying to get rid of it.

AE11: No thanks, I'm really full.

Really, no thanks. I think my stomach has shrunk since I've been trying to eat less.

I get full a lot faster. [natural answer not possible]

AE12: No, thanks. I just had lunch! I'm full.

No, really; thanks.

\section{$\underline{\text { DCT \#10 }}$}

$\underline{\mathrm{AE} 1}$ : No thank you, [sic] Im [sic] bussy.

AE2: Oh, I already have plans. Thank you, anyway.

AE3: I'm sorry I can't I have made other plans.

AE4: Sorry. But I made plans to go out with some other friends.

AE5: Really... well I'd love to, but I have to get some work done before school Monday $\&$ Sunday's my only free time...

AE6: Oh, jeez, I wish we could. But my boss and her husband already invited us to a party Sunday. [AE6 labeled this response a "lie."]

AE7: I'm sorryand I already have plans.

AE8: God, I already made plans-too bad, I would have really liked to be with you two.

AE9: I'm sorry. I won't be able to make it. I have a lot of work to do that night.

AE10: I'd really like to, but Sunday's not good-let's try to get together for lunch soon. 
AE11: I'm sorry, I'd like to but I sort of have plans already. My husband and I had planned a quiet evening at home.

AE12: Well, I'll have to see. I have a really big test Monday, I need to study. [natural answer not possible]

\section{DCT \#11}

AE1: [sic] Im very flattered that you offer this to me. However I know myself well enough to say that I know living here is more important than the executive position.

AE2: I'm honored that you believe in my skills but I would find it too difficult to move that far away. My family lives here.

AE3: Thanks, I really do appreciate the offer, but all of my friends and family are here, and I just couldn't bear to leave them or this town.

AE4: I would love it but I really would like to stay here. I don't like moving.

AE5: I'm honored /flattered that you've considered me for this position, but I'm really happy where I am.

AE6: Like I've said, it sounds like a great opportunity. If I didn't have to leave here, I'd jump on it like a shot.

AE7: I've talked it over with (my spouse) and it would be very difficult for us to relocate right now.

AE8: I don't know... I'm having second thoughts because we just moved here a couple months ago.

AE9: It sounds great, but I'm not really interested in moving. I don't think I would enjoy living that far away.

AE10: Your offer is certainly tempting, but the idea of relocation is not one which appeals to me at all for any amount of money.

AE11: Well-I've thought about it, but I'm not really excited about having to relocate. My whole family is here in town.

AE12: Sorry, but my family and friends live here and I don't want to move. I don't care how much money I'll make. 


\section{$\underline{\text { DCT \#12 }}$}

AE1: I [sic] dont mind putting in additional time occasionally for work but I really feel done today \& I know I [sic] wouldnt be much use anyway if I stayed.

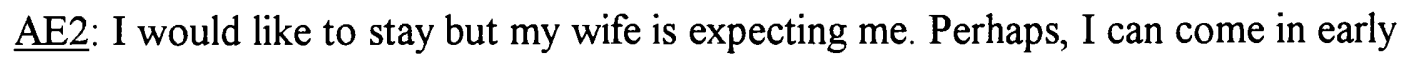
tomorrow.

AE3: I can't tonight, but I'll come in early tomorrow. I've already made plans with my girlfriend and I can't break them.

AE4: Sorry sir, but my son is playing baseball tonight and I promised him that I would attend. [natural answer not possible]

AE5: I can't, I have a previous engagement \& I have to leave straight away.

AE6: Oh! I'm sorry -- I wish I'd known. I have to pick Jill up at 5:45. [AE6 labeled this a "lie."]

AE7: I'm sorry-I have dinner reservations at 6:00. Would tomorrow work?

Further comments relating to the DCT in general:

AE8: [sic] Im sorry, I already made plans with my in-laws to have dinner with them at 5:00.

AE9: Normally I would, but I have these symphony tickets for tonight. My boyfriend should be here to pick me up soon.

AE10: Ordinarily I would, but I really need to get home tonight. Maybe I could come in a little early tomorrow?

AE11: I'm sorry, I need to run some errands and get home at a decent hour.

AE12: I've already worked 8 hours; I didn't get my breaks; I'm tired; and all I want to do is go home \& get away from this place. 


\section{Appendix I \\ Script of GG Responses}

\section{Profile of GG Males:}

GG1-age 25; German, German

GG2-age23; German/French; German/French

GG3-age 22; German; German

GG4-age 26; German; German

GG5-age 23; “ “ “

GG6-age 43; “ “ “

\section{Profile of GG Females:}

GG7-age 23; German, German

GG8-age 20; “ “ “

GG9-age 25; “ “ "

GG10-age 20; “ “ “

GG1 1-age 23; “ “ “

GG12-age 22; “ “ “

GG13-age 30; “ “ “

GG14-age 38; “ “

\section{$\underline{\text { DCT \#1 }}$}

GG1: Ja, wir sind auch sehr zufrieden mit Ihnen, aber im Moment wäre eine Gehaltserhöhung noch etwas zu früh.

GG2: Auf Grund der finanziellen Situation meines Geschäftes ist eine Gehaltserhöhung selbst für meine besten Angestellten nicht möglich. Zumindest nicht jetzt. [ nat. Ant. nicht $\mathrm{m}$.]

GG3: Wenn Sie sich für Ihre Leistungen nicht ausreichend entlohnt fühlen, werde ich mir dies in Ruhe überlegen müssen.

GG4: Ich stimme völlig mit Ihnen überein. Auch mir macht es Spaß mit Ihnen zusammenzuarbeiten. Eine Gehaltserhöhung ist dieses Jahr jedoch tabu. [ nat. Ant. nicht m.] 
GG5: Laut der Wirtschftlichen Lage müssen Sie froh sein [sic] das Sie einen Job haben. / Laut Wirts. Lage muß ich auch einsparen. / Halte mich an die Tarif-Regelung.

GG6: Was Sie sagen, ist richtig, doch leider sind-wie Sie auch wissen-die Umsatzzahlen nicht entsprechend, so daß ich Ihrem Wunsch nicht entsprechen kann.

GG7: Mir war klar, daß Sie so eine Forderung stellen [sic] werden. Aber ehrlich gesagt, angesichts unserer geringen Gewinnspanne momentan sieht es da leider schlecht aus.

Außerdem ist ein Jahr auch nicht gerade ein Zeitraum, nach dessen Ablauf eine Gehaltserhöhung dringend gerechtfertigt wäre. [seltsame Sit.]

GG8: Es tut mir leid, momentan sehe ich da keine Möglichkeit.

GG9: Nun, Sie wissen, wie prekär die Situation im Buchhandel ist. Für mich selbst bleibt weniger als für Sie. Sie werden bereits in e. sehr hohen Tarifgruppe bezahlt, da ich Ihre Arbeit sehr schätze. Aber leider ist momentan nicht mehr drin. [nat. A. nicht $\mathrm{m}$.]

GG10: Es tut mir leid. Ich weiß ihre Arbeit zu schätzen, aber wir können eine Gehaltserhöhung zur Zeit leider finanziell nicht verkraften.

GG11: Ja, natürlich bin ich mit Ihrer Arbeit sehr zufrieden und es freut mich, daß Sie gerne hier arbeiten, aber ihr Gehalt kann ich aus finanziellen Gründen nicht erhöhen, tut mir leid.

GG12: Sie sind wirklich gut, aber Sie wissen ja, zur Zeit läuft's nicht so gut und darum kann ich Ihnen jetzt keine Gehaltserhöhung geben.

GG13: Ich kann den Wunsch nach Erhaltserhöhung verstehen-aber ich halte es nach einem Jahr einfach zu früh um darauf einzugehen.

GG14: Da muß ich Sie enttäuschen. Der Buchladen befindet sich noch in der Aufbauphase und finanziell ist da absolut kein Spielraum für eine Gehaltserhöhung. [nat. A. nicht m.]

\section{DCT \#2}

GG1: Hey, das ist echt etwas ungeschickt für mich. Ich habe auch noch nichts gelernt und mache mich heute daran. Tut mir leid.

GG2: Es tut mir sehr leid, aber gerade wegen der morgigen Prüfung benötige ich meine Aufzeichnungen zur Vorbereitung selbst. [nat. Ant. nicht m.] 
GG4: Prinzipiell bin ich immer bereit [sic] jdn zu helfen. In Deinem Fall möchte ich jedoch nicht Deine Faulheit unterstützen.

GG5: Fällt Dir das nicht früher ein.

GG6: Ich finde das schon unverfroren von Dir, dauernd blau zu machen $u$. andere arbeiten zu lassen, und dann 'ne gute Note zu wollen! Sorry, aber....

GG7: Also ehrlich gesagt glaube ich, meine Notizen bringen Dir gar nichts. Ich hab ziemlich wirr mitgeschrieben. Versteh ich selber schon kaum mehr.

GG8: Eigentlich wollte ich heute nochmal alles durchlesen.

GG9: Ich finde, Du könntest etwas disziplinierter die Seminare besuchen. Bloß, [sic] weiß Dir diese Disziplin so mangelt, soll ich für Dich mitarbeiten? Tut mir leid, aber das sehe ich nun nicht mehr ein, da Du Dich zu sehr auf mich und die anderen zu verlassen scheinst. Außerdem bringt's einen Tag vor der Prüfung auch nicht sehr viel. [seltsame S.]

GG10: Ehrlich gesagt, hab ich selber noch nicht viel für die Prüfung getan und wollte mir die Notizen heute selber nochmal anschauen. [selt. S.] [nat. A. nicht m.]

GG11: Weißt Du, ich finde es irgendwie nicht ganz fair, daß ich mir immer die Mühe mache mitzuschreiben und Du immer nur davon profitierst.

GG12: Ich hab die jetzt gar nicht dabei. Mein Ordner ist daheim.

GG13: Es tut mir leid; ich habe Dir meine Aufzeichnungen bereits letztes Mal gegeben und hinsichtlich der Prüfung benötige ich sie selbst.

GG14: Nein, das geht nicht. Ich möchte heute abend das Seminar nacharbeiten und brauche meine Notizen selbst. Du würdest durch meine chaotischen Aufzeichnungen sowieso nicht durchsteigen. [selt. S.]

\section{DCT \#3}

GG1: Also, ehrlich gesagt, bin ich mir noch etwas unsicher darüber. Den

Bestellungsvertrag festzulegen scheint mir noch etwas früh. Lassen Sie mir noch etwas Bedenkzeit. [seltsame Situation]

GG2: Leider brauche ich noch ein bißchen Zeit, um genau sagen zu können, welche Gelder mir zur Verfügung stehen und was ich genau für meine Firma benötige. 
GG3: Das ist mir zu verbindlich, wenn ich mich für ihr Produkt entscheiden sollte, dann aufgrund meiner Überlegungen und nicht wegen eines [sic] Spesenfreien Zückerchens.

GG4: Nein, heute nicht! Denken Sie bloß nicht, daß ich jedesmal, wenn ich Interesse zeige, auch etwas kaufen möchte. [ selt. Sit.] [nat. Ant. nicht m.]

GG5: Ich habe keine Zeit für Ihre Einladung werde mir über Ihr Produkt Gedanken machen, und Sie dann anrufen wenn ich mich entschlossen habe. [seltsame Sit.]

GG6: Besten Dank für die Einladung, aber ich möchte Geschäft und Vergnügen getrennt halten. Verstehen Sie mich nicht falsch, aber es könnte den Eindruck entstehen, daß Sie... [seltsame S]

GG7: Da muß ich ehrlich sein und ihnen sagen, daß ich das heute abend nicht entscheiden kann. [ nat. Ant. nicht m.]

GG8: Heute kommt mir das leider sehr ungelegen, tut mir leid.

GG9: Wie ich Ihnen bereits vorher mitgeteilt hatte, sind bei uns z. Zt. solch umfangreiche Investitionen nicht vorgesehen. Wir können uns gern nach einem längeren Zeitraum wieder diesbezüglich sprechen. Und bitte versuchen Sie nicht, mich durch solch e. Ambiente zu bewegen. Ich schätze Sie sehr, doch sind mir z. Zt. einfach die H:ande gebunden.

GG10: Heute kommt es uns sehr ungelegen und außerdem möchte ich mir die Sache nochmal durch den Kopf gehen lassen.

GG11: Also, wissen Sie, wenn ich ehrlich bin, ich bin immer noch nicht zu einer Entscheidung in dieser Sache gelangt. [nat. A. nicht m.]

GG12: Ich muß mir das nochmal überlegen, aber ich bin schon interessiert.

GG13: Ich habe Ihr Produkt weitgehends testen lassen u. hege weiterhin meine Bedenken es zu kaufen.

GG14: Sie glauben doch nicht etwa, daß ich Druckmaschinen bestelle, die ich nicht brauche, nur weil Sie mich zum Essen einladen?!

\section{DCT \#4}

GG1: Nächsten Sonntag? Oh schade! Sonntag geht bei mir auf gar keinen Fall. Unsere kleine Tochter hat Geburtstag. Danke für die Einladung, aber es geht wirklich nicht. [seltsame Situation] 
GG2: Ich danke Ihnen für die Einladung, aber leider muß ich aus familiären Gründen absagen.

GG3: Das ist sehr aufmerksam von Ihnen, doch muß ich gestehen eine feste Zusage nicht treffen zu können, da ich für meinen Partner nicht kurzfristig eine Entscheidung treffen möchte.

GG4: Meine Frau und ich haben schon ein gemütliches Wochenende in der Schweiz geplant. Was ich meiner Frau verspreche, halte ich auch meistens ein.

GG5: Sie müssen mich entschuldigen, daß ich verhindert bin, aber ich gehe mit meiner Familie zum Circus und habe dafur schon die Karten.

GG6: Danke für die Einladung. $\mathrm{Zu}$ dumm, daß es so kurzfristig ist, sonst könnte ich noch die (...echte / unechte Ausrede / Begrundung) .. absagen.

GG7: Tja, ich freue mich natürlich über ihre Einladung. Aber an diesem Wochenende bin ich gar nicht in der Stadt.

GG8: Am nächsten Sonntag geht es bei mir und meinem Mann nicht, da meine Mutter Geburtstag hat.

GG9: Das freut mich sehr, vielen Dank für die Einladung. Leider habe ich schon anderweitig eine wichtige Zusage gemacht, und ich befurchte, dort nicht absagen zu können. Ich hoffe, Sie haben dafür Verständnis, und freue mich auf eine andere Möglichkeit, in e. lockeren Rahmen mich mit Ihnen treffen zu können. [ seltsame S.] \{nat. Ant. nicht m.]

GG10: Am Wochenende wollten mein Mann und ich wegfahren und das Hotelzimmer ist jetzt leider schon gebucht.

GG11: Oh, das tut mir leid. Wir haben nun schon geplant am Wochenende zu unseren Verwandten zu fahren...

GG12: Gerade dieses Wochenende muß ich zu einem Familienfest nach Paris.

GG13: Das bedauere ich nun sehr aber mein Ehemann u. ich haben schon seit Anfang des Jahres den Ausflug zum Hochzeitstag geplant.

GG14: Das tut mir nun wirklich sehr leid, aber mein Mann und ich können da leider nicht kommen. Am Sonntag ist die Eröffnung zur kommenden Ausstellung meines Mannes. 


\section{$\underline{\text { DCT \#5 }}$}

GG1: Diät, wenn ich das schon höre. Außerdem ist die auch nicht viel anders als die alten.

Nein, Diät, das fang ich erst gar nicht an.

GG2: Ich habe schon so viele Diäten ausprobiert, leider erfolglos, und mittlerweile habe ich mich damit abgefunden. Zudem habe ich kein Vertrauen zu Diäten mehr.

GG3: Du weißt genau, daß ich für so etwas nichts übrig habe. Aber "Du darfst” ja.

GG4: Das ist doch Weibersache! Männer arbeiten sich das Fett ab! [nat. Ant. nicht m.]

GG5: Ich habe schon darüber nachgedacht, aber ich habe mich entschlossen, FDH zu machen.

GG6: Du, ich hab' das schon $\mathrm{x}$-mal probiert. Bei mir hat noch nie was geholfen, außer FdH-Methode.

GG7: Nee, ich hab kein Bock auf ne Diät. Das ist mir zu stressig. Entweder das klappt von alleine oder eben nicht. [seltsame Sit.]

GG8: Ich glaube nicht an die Wirkung von Diäten, da nimmt man nachher noch mehr zu.

GG9: Du weißt genau, daß ich von solchen Kurzzeiternährungsumstellungen nicht viel halte. Ich versuche gerade, meine Ernährung langfristig umzustellen, und auch diese ewigverführerischen Naschereien wegzulassen. Es ist sehr schwer, wie Du Dir denken kannst, wird aber langfristig das einzig Richtige sein. [nat. A. nicht $\mathrm{m}$.]

GG10: Ich finde es reicht, wenn man einfach etwas bewußt ist, ohne sich diesen Diätenstreß anzutun.

GG11: Ach, ich weiß nicht, ich habe schon so viele von diesen Diäten versucht-leider alle ohne Erfolg...!

GG12: Ich glaube daß Diäten nichts nützen, man muß seine Eßgewohnheiten konsequent ändern.

GG13: Ach-ich habe schon sovieles ausprobiert u. nichts hat bisher geholfen.

GG14: Ach, geh mir weg mit diesen Diäten. Die sind doch alle gleich und nützen gar nichts. 


\section{DCT \#6}

GG1: Ach, ich komme eigentlich hier gut zurecht. Der Bericht ist gleich da. Kleine Notizen würde ich nur nicht wiederfinden. Nein, nein, ich habe da mein eigenes System.

GG2: Das ist nur eine Ausnahme. Ich hatte in letzter Zeit viel um die Ohren und kam einfach nicht dazu, regelmäßig meinen Schreibtisch aufzuräumen.

GG3: Ich weiß, ich weiß, aber glauben sie mir, so etwas würde bei mir nicht funktionieren, da lägen denn ja noch mehr Notizen rum und zuerst den Notizzettel suchen?

GG4: Sie geben mir einfach zuviel Arbeit. Außerdem bringen Sie mich immer unter Zeitdruck. Da soll einer noch Ordnung halten können?

GG5: Ich habe zur Zeit keine Zeit, weil alles sehr nervös hier im Betrieb abläuft. [seltsame Sit.]

GG6: Sie kennen ja den Spruch: wer Ordnung hält, ist nur zu faul zum Suchen-Im Ernst, ich weiß, es klingt komisch, aber ich brauche dieses kreative Chaos.

GG7: Normalerweise komme ich mit meinem System aber gut zurecht.

GG8: Ich habe schon ein System in meinen Unterlagen, aber vielen Dank für den Ratschlag.

GG9: Ich versuche eben, immer alles gleich zu erledigen. Da aber im Moment soviel bzw. zuviel auf meinem Schreibtisch landet, habe ich den Überblick verloren. Aber den hab ich bald wieder, keine Sorge. [seltsame S.] [nat. Ant. nicht m.]

GG10: Ja, ja, aber jetzt muß ich erst mal den Bericht finden. [seltsame S.]

GG11: Ja, ja ... aber im Moment muß ich erstmal den Bericht finden. [selt. S.] [nat. A. nicht $\mathrm{m}$.]

GG12: Dann hab ich noch mehr Zettel auf meinem Tisch und finde noch weniger.

GG13: "Sie kennen den Satz: Der kleine Geist hält Ordnung-das Genie [sic] beherscht den Chaos."

GG14: Ach, das habe ich auch schon probiert. Aber dann verlege ich die Notizen, oder verlege die

Gegenstände, auf die sich die Notizen beziehen, ohne die Notizen zu ändern, und das Chaos wird noch größer. 


\section{DCT \#7}

GG1: Ja, beruhigen Sie sich doch. Ist doch halb so schlimm. Die Vase werde ich selbstverständlich selbst bezahlen. So etwas kann eben mal passieren.

GG2: Machen Sie sich nichts daraus. Ich glaube, daß dies sowieso kein teures oder sehr wertvolles Objekt war. [nat. A. nicht m.]

GG3: Aber, jetzt beruhigen sie sich doch, [sic] daß kann doch jedem mal passieren.

GG4: Sehen Sie, ich glaube nicht, daß ich auf die Paar DM / \$ angewiesen bin. Noch heute habe ich wieder für mehrere Millionen DM / \$ einen Vertrag abgeschlossen.

GG5: Es kann passieren, darf aber nicht öfters vorkommen.

GG6: Aber das ist doch kein Drama u. auch wenn der Schaden groß ist, kann ich Sie doch in Ihrer Situation unmöglich haftbar machen ...

GG7: Ach wissen Sie, um die ist es nicht schade. So sehr hänge ich auch nicht an ihr. Lassen Sie das mal bleiben mit dem Bezahlen.

GG8: So besonders war die Vase auch wiederum nicht, machen sie sich deswegen keine Sorgen.

GG9: Nein, nein, lassen Sie nur. Das geht schon in Ordnung!! So ein kleiner Arbeitsunfall kann mal passieren!! Außerdem ist die Vase versichert; bitte machen Sie sich keine Sorgen! [seltsame S.]

GG10: Das ist nicht nötig. So wertvoll war die Vase gar nicht und gefallen hat sie mir eh noch nie.

GG11: Ach nein, so schlimm ist es ja nicht. Viel schlimmer wäre es, wenn Ihnen etwas passiert wäre. Gegenstände lassen sich ersetzen. Sie brauchen auf keinen Fall dafür zu bezahlen.

GG12: Die Vase hat mir eh nichts bedeutet. Das kann ja mal passieren. Das ist ja menschlich.

GG13: Ach was-das kann jeden mal passieren vergessen wir den Vorfall. 
GG14: Da machen Sie sich bitte mal keine Sorgen! Ich hatte sowieso eine ambivalente Einstellung zu der Vase. Eigentlich gefiel sie mir nicht mehr. Ich konnte mich bisher nur noch nicht entschließen, sie wegzustellen. Jetzt ist der Fall auf einfache Art gelöst.

\section{DCT \#8}

GG1: Ja, ich sehe das Problem auch, daß es einfach zu wenig Konversationsübungen für unsere Studenten gibt. Aber dieser Kurs ist einfach eher theorieorientiert. Tut mir leid, wir haben einfach nicht mehr Zeit für Konversationsübungen.

GG2: Ich bin mit meiner Lehrmethode bis jetzt immer sehr gut "gefahren" und habe eigentlich nicht vor, sie zu ändern, weil ich sie so für sehr gut halte. [ nat. Ant. nicht m.]

GG3: Das ist sehr aufmerksam von Ihnen, doch meine ich, daß die Gewichtung innerhalb meiner Vorlesung durchaus dem Kursniveau und den Kurszielen entspricht!

GG4: Na hören Sie mir mal gut zu. Als ich noch so jung und unerfahren wie Sie war, hatte ich auch solche irren Ideen. Im Verlauf meines Lebens bin ich aus diesen Schuhen hinausgewachsen. [nat. Ant. nicht m.]

GG5: Ich bin hier als Sprachlehrerin schon längere Jahre tätig und glaube, wie die Erfahrung es zeigte, daß es richtig ist, wie ich den Unterricht gestalte.

GG6: Es ist nun mal erwiesen, daß für Konversation die grammatik. Grundregeln nicht nur bekannt sondern gekonnt sein müssen; das ist leider bei diesem Kurs nicht der Fall.

GG7: Jetzt kann ich meinen Unterrichtsplan aber nicht mehr neu strukturieren. Außerdem müssen wir den vorgegebenen Stoff durchbekommen.

GG8: Mit meinem Unterricht möchte ich sie erstmal in die Lage versetzen eine gute Konversation zu führen. Die Praxis erhalten sie dann im Land von selbst.

GG9: Dieser Kurs ist leider auf eine bestimmte Prüfung ausgerichtet, deren Bestehen für Sie äußerst relevant ist. Und deswegen ist der Unterricht nur auf diese Prüfung und deren Inhalte hin geplant. Spezielle Konversationskurse finden auch statt; leider muß ich Sie dorthin verweisen!! [nat. Ant. nicht m.]

GG10: Ich hab jetzt den Semesterplan schon zusammengestellt und daher kann ich jetzt nicht mehr alles umändern. [ selt. S.] [ nat. A. nicht $\mathrm{m}$.]

GG11: Nein, [sic] daß wäre wirklich nicht gut, da man die Grammatik zuerst als Grundlage für alles [sic] ander braucht und das am allerwichtigsten ist. 
GG12: Aber um reden zu können, muß man erst mal die Grammatik können. Danach haben wir immer noch genug Zeit zum reden.

GG13: Ich denke um dem Thema vollends folgen zu können ist die Grammatik ein notwendiges aber nicht umgängliches Übel.

GG14: Davon halte ich gar nichts. Konversationspraxis können Sie in jedem Gespräch außerhalb der Uni erwerben. Die grammatischen Grundlagen dagegen werden Sie sich wohl kaum im Selbststudium aneignen.

\section{$\underline{\text { DCT \#9 }}$}

GG1: Nein danke, ich habe schon 2 Stückchen gehabt. Schmeckt übrigens wirklich prima. // Also gut. Das ganz kleine da, aber dann ist Schluß.

GG2: Nein, vielen Dank. // Nein danke, wirklich nicht, aber er war sehr gut.

GG3: Ich kann echt nicht mehr. Laß mal Sonst muß ich morgen wieder joggen. // Verdammt, aber wenn ich an Verfettung sterben sollte, hoff' ich, daß Du ein schlechtes Gewissen hast.

GG4: Das Stück ist mir zu süß. // Jetzt hör doch auf! Ich nehme mir schon eins, wenn ich will.

GG5: Nein danke, ich habe schon etwas zu mir genommen. // Du mußt mich dafur entschuldigen aber ich bin zur Zeit auf Diät.

GG6: Du ich platz' jetzt schon; der Kuchen ist wirklich ausgezeichnet, aber.. // a) Also gut, aber wirklich nur ein winziges.. b) danke, aber ich kann wirklich nicht mehr

GG7: Hm, eigentlich kann ich nicht mehr. Das war jetzt genau die richtige Menge. // Nee, echt nicht mehr, sonst bin ich so voll. Wird mir noch schlecht davon.

GG8: Nein [sic] Danke, ich habe absolut keinen Appetit. // Wirklich nicht, danke.

GG9: Nein, danke; der Kuchen ist sehr gut, aber Du weißt doch, daß ich versuche, meinen Zucker- und Weißmehlinput zu reduzieren-obwohl der Kuchen lecker ist, trotzdem nein! // Bitte respektier's doch und versuche nicht, mir etwas aufzuzwingen! Meine Entscheidungen möchte ich gerne selber treffen können, ohne Dich zu verletzen.

GG10: Nein [sic] Danke. Der Kuchen ist sehr gut, aber ich kann wirklich nicht mehr. // Nein wirklich. Sonst platz ich! 
GG11: Nein danke, ich hatte schon zwei Stück. Aber er war sehr lecker. // Also gut, aber nur weil er so lecker war und bitte nur noch ein ganz kleines.

GG12: Nee danke. Er ist echt gut, aber jetzt bin ich satt. // Nein, danke, das ist nett, aber ich kann wirklich nicht mehr.

GG13: "Tut mir leid ich hatte bereits zwei." // Nein-ich kann nicht mehr auch wenn es ein verlockendes Angebot ist.

GG14: Nein, danke. Eines reicht mir. // Nein, ich kann wirklich nicht mehr.

\section{$\underline{\text { DCT \#10 }}$}

GG1: Sonntag ist bei mir etwas schlecht. Ich habe am Montag eine wichtige Englischprüfung. Tut mir leid, [sic] Sonntag abend geht wirklich nicht.

GG2: Tut mir leid, aber ich habe schon eine Verabredung. Ein anderes Mal aber sehr gerne.

GG3: Du, das tut mir leid, aber dafür bin ich nicht in der richtigen Stimmung. [selt. Sit.]

GG4: Nein danke! Ich bin zur Zeit nicht so an Geselligkeit interessiert.

GG5: Ich habe am Sonntagabend mit dem Musikverein einen Auftritt.

GG6: entweder Ausreden (siehe Nr 4) oder auch (je nach Verhältnis) ehrlich:

Deinetwegen würd' ich gern kommen, aber du weißt ja, wie ich deinen Mann finde, und bevor der Abend für alle peinlich wird....

GG7: Ach, [sic] Sonntag abend hab ich schon ne Verabredung mit jemandem den ich schon lang nicht mehr gesehen hab.

GG8: Weißt Du, Sonntag ist wirklich schlecht, da haben wir schon Konzertkarten

GG9: Das finde ich lieb, aber ich denke, ich werde mich dort nicht wohlfühlen. [sic] Liebe treff ich Dich ein ander' Mal, Du weißt ja warum, und deswegen sag ich Dir lieber ab, als an dem Abend Dir wg. meiner schlechten Laune alles zu verderben.

GG10: Oh. am Sonntagabend ist es ganz schlecht, da hab ich jetzt schon was vor. [selt. S.]

GG11: Ach, weißt Du, [sic] Sonntags paßt es mir immer schlecht, da kommt doch immer mein Neffe zu Besuch. [selt. S.] [nat. A. nicht m.] 
GG12: Sonntagabend bin ich beim Squash-Spielen verabredet.

GG13: Oh Sonntagabend ist denkbar ungünstig am Sonntag wollte ich bereits zur Tagung nach Zürich fahren.

GG14: Sonntagabend geht es schlecht bei mir, da habe ich schon was vor.

\section{DCT \#11}

GG1: Also, eigentlich bin ich hier mit meiner Anstellung sehr, sehr zufrieden. Danke für das tolle Angebot, aber ich lasse lieber jemandem anderen den Vortritt.

GG2: Nun, ich bin hier eigentlich mit allem sehr glücklich. Außerdem möchte ich dies meiner Familie nicht zumuten. [nat. Ant. nicht m.]

GG3: Das ehrt mich, daß sie ein solches Vertrauen in mich setzen, doch bin ich nicht bereit einen Ortswechsel zu vollführen. ich wohne hier sehr gern und hoffe, daß sie mich verstehen können.

GG4: Suchen Sie sich jemand anderen. Mir ist mein jetziges Umfeld wichtiger, als mehr Geld. [selt. Sit.] [nat. Ant. nicht m.]

GG5: Ich [sic] Danke Ihnen für dieses Angebot, aber ich möchte mich jetzt noch nicht festlegen, ich wollte wenn es ginge einige Zeit zum überlegen.

GG6: Klingt fast zu verlockend, nur.... ich will eigentlich nicht weg. Mir gefällt's sehr gut hier, der Job füllt mich aus und nur des Geldes wegen..., also ich glaube nicht...

GG7: Danke, aber [sic] will auf keinen Fall einen Ortswechsel für höheres Gehalt in Kauf nehmen.

GG8: Eigentlich fühle ich mich in meiner jetzigen Position recht wohl, obwohl es schon sehr verlockend wäre.

GG9: Das finde ich sehr freundlich, daß Sie MIR die Stelle anbieten. Sie wissen jedoch auch, daß meine familiären Verpflichtungen mich davon abhalten, das Angebot anzunehmen-wie ich sehr bedauere. [nat. A. nicht $\mathrm{m}$.]

GG10: Ihr Angebot klingt sehr verlockend, aber [sic] an Betrachts des nötigen Umzuges, möchte ich doch lieber meine alte Stelle behalten. 
GG11: Natürlich klingt das Angebot sehr verlockend, aber ein Umzug kommt leider wegen meiner Familie nicht in Frage.

GG12: Sie wissen, ich muß meine kranke Oma versorgen und wir haben grade das neue Haus gebaut.

GG13: Oje das kommt jetzt aber aus heiterem Himmel-das muß ich mir erst überlegen.

GG14: Nein, das tut mir leid. Das kommt für mich nicht in Frage. Im Moment kann ich mir nicht vorstellen umzuziehen.

\section{$\underline{\text { DCT \#12 }}$}

GG1: Tut mir leid, aber ich muß heute abend pünktlich zuhause sein. Meine Frau ist krank und wir haben gerade Besuch aus England.

GG2: Bitte seien sie mir nicht böse, aber gerade heute Abend habe ich noch einen wichtigen Termin. Ansonsten bin ich aber gerne bereit, länger zu bleiben. [nat. Antwort nicht $\mathrm{m}$.]

GG3: Oh, das tut mir aber leid, da ich gerade heute einen nichtzuverschiebenden Termin habe.

GG4: Ich habe mich leider schon mit ein Paar Freunden aus Neuseeland verabredet, die morgen wieder nach Hause fliegen!

GG5: Ich muß heute Abend meine Tochter nach der Arbeit abholen, da es um diese Zeit schon dunkel ist möchte ich [sic] Sie nicht warten lassen.

GG6: Tut mir sehr leid, Herr N.N. Sie wissen, ich bin sonst immer bereit zu Überstunden, aber heute kann ich wirklich nicht....

GG7: Es tut mir schrecklich leid, aber ich muß gerade heute dringend pünktlich weg.

GG8: Tut mir leid, heute geht es absolut nicht, da ich noch einen Arzttermin habe. [nat. Ant. nicht $\mathrm{m}$.]

GG9: Gerne ein ander Mal, aber leider habe ich heute abend noch eine Verpflichtung, die ich nicht absagen kann. Morgen sehe ich jedoch keine Probleme, abends länger zu bleiben.

GG10: Das wäre im Prinzip gar kein Problem, nur ausgerechnet heute muß ich ganz dringend weg. 
GG11: Oh, das tut mir leid, prinzipiell natürlich immer, aber gerade heute abend habe ich mich nun verabredet und muß deshalb gehen.

GG12: Gerade heute wollte ich meinem Mann etwas Gutes kochen und die Kinder warten.

GG13: Damit habe ich leider nicht gerechnet das kommt jetzt sehr [sic] überaschenddenn ich habe meinem jüngsten versprochen ihn bei seinem 1. Konzert zu begleiten.

GG14: Das ist ausgeschlossen. Ich habe nach Feierabend einen wichtigen Termin. 


\section{Appendix J Script of GE Responses}

\section{Profile of GE Males:}

GE1- age 20; German, German, 9 years, 10 day sojourn, BE

GE2-age 20; German, German, 6 years, 5 week, Virginia slang

GE3-age 23; German, German, 12 years, 7 weeks, BE

GE4-age 22; German, German, 7 years, no sojourn, BE

\section{Profile of GE Females:}

GE5-age 24; German, Germany, 10 years, 3 weeks, Jamaican Patois

GE6-age 21; German, Germany, 7 years, no sojourn, BE

GE7-age 20; German, Germany, 9 years, more than 10 weeks, AE \& BE

GE8-age 22; German, Germany, 11 years, no sojourn, AE

GE9-age 24; German, Germany, 14 years, 1 year, AE

GE10-age 21; German, Germany, 11 years, 2 weeks, no specific variety, but tendency towards $\mathrm{BE}$

GE11-age 27; German, Germany, 17 years, 1 year, BE

GE12-age 23; German, Germany, 10 years, 6 months, AE

Note: This transcription quotes all of the responses exactly. All errors are quoted from the original and are not marked "[sic]" due to the frequency with which the marking would be necessary.

\section{DCT\#1}

GE1: Dear Mr X, who do you think you are?! You're really not in the position to demand an increase in pay! If I wanted to raise it up, I'd tell you.

GE2: Like you said, you're here only for one year. I'm sorry but I can't give you an increase in pay after such a short time.

GE3: I expected you saying this but you know that I can't decide this here in the store. I have to think about it first and I'll let you know.

GE4: I'm very busy at the moment. Let's speak about it later on, but I've not so much hope because the situation (state) of the store isn't very well at the moment. 
GE5: I'm sorry, but I can't do it right now, the bank wants that I pay the credit back immediately.

GE6: It's true, you are a good worker. But I have to follow the market principles. I can't pay you more than the ordinary salary, especially in times of recession.

GE7: I'm sorry, I can understand your request but I just can't afford it to give you more money.

GE8: I' $m$ very sorry and I appreciate your work but I'm not able to give you an increase in pay.

GE9: I know that you are one of my best workers, but if I pay you more money, some of the other workers will ask for more money tomorrow. I'm sorry.

GE10: As you are a good worker indeed, I'll see what I can do for you. But I have to tell you that the financial situation isn't too good that days...

GE11: Well, this comes a bit as a surprise. I'm afraid I can't decide this on the spot, but I'll think about. Though I'm afraid my budget is rather tight.

GE12: Well, I really enjoy having you working here and so far you did a real good job selling the books, but actually I just can't afford to increase your pay.

\section{$\underline{\text { DCT \#2 }}$}

GE1: Sorry, but I just lent it to Charles.

GE2: I feel sorry for you but I need these notes by myself in the afternoon. Perhaps you'd rather attend class regulary.

GE3: I would if I could! But I haven't done anything for this exam so far and I think I should prepare myself.

GE4: I am so sorry, but today I've left my notes at home.

GE5: (I'm sorry, but I need them for myself, I haven't started learning yet.) I don't have them with me.

GE6: I need them myself. You shouldn't miss the class all the time, you would not have this problem then. 
GE7: I am sorry, too. You know, I need my notes, as well, in order to learn for the exam.

GE8: I think that's not possible because I need them myself in order to prepare for the exam.

GE9: Listen: I got up every morning, sat in class and took notes and you stayed in bed. I'm afraid you'll have to ask somebody else!

GE10: Don't you think it's a bit too late to ask me for my notes just the day before the exams? I need them for myself, by the way.

GE11: Listen, I'm fed up doing all the work for you. It's okay asking me once or twice, but this has become a habit. I guess, I can't help you any more.

GE12: To be honest with you, I'd really like not to, because I need them today for preparing the exam.

\section{DCT \#3}

GEl: That's very friendly, but unfortunately I've got some other obligations tonight.

GE2: I beg you to be so kind to excuse me but this evening I'm absolutely not able to dinner with you because I have much work to do.

GE3: Thank you for your invitation but I don't connect my privacy with my company. (translation $=$ I don't mix business $\&$ pleasure)

GE4: In the moment, the company is in a very delicate financial situation, but I know there has to be some improvements.

GE5: Today? We have a meeting of the ? Vorstand today.

GE6: I'm not yet sure if I want to firm up that contract with you. I still need some time to compare your offer to those of other companies.

GE7: I think it would be the best if I talked to my colleagues first. I'm not sure yet about firming up a contract already.

GE8: I regret but unfortunately I have to leave for Europe this evening because of business affairs.

GE9: To be honest: I would feel bad to be invited in such an expensive restaurant although I'm not sure if I will buy something. 
GE10: As I haven't checked your products properly enough yet, I'd say that it might be too early to speak of a contract.

GE11: Thank you very much for the invitation. But I'm afraid I can't accept it. I'll have an important conference at the time, I can't cancell.

GE12: Actually, I haven't decided yet about the contract. I'm still thinking about it.

\section{DCT \#4}

GE1: Oh, I'm very honoured about your invitation, but unfortunately I can't come, because my wife and me, we have our wedding-day today.

GE2: I'm very sorry but one of my husband's relatives is celebrating his birthday.

GE3: If there'd be any chance I'd come. But I'm leaving for Denver on fryday to sign this treaty with Baher Inc. I think this will take a longer time so I'm probably not here on Sunday. Sorry.

GE4: I'd really like to be there, but me \& my friends are going fishing this very day, so...

GE5: I'm sorry, but we've already made plans for the weekend. We'll go skiing with our children.

GE6: I'm sorry, I can't come to your party. My husband bought tickets for the National Theatre, it's the last chance to see the play and I promised to join him.

GE7: Oh, that's a pitty. We would have loved to come but we both are invited to my parents-in-law place for next weekend. I'm sorry for that.

GE8: Unfortunately I promised my parents to visit them next Sunday, and I can't tell them so shortly before that I won't come.

GE9: Thank you for the invitation, but I'm sorry, I can't come. I told my parents that I would visit them that weekend.

GE10: Thank you very much for the invitation but I can't be there. It's my father's 60th birthday next Sunday.

GE11: Well, I'd love to come, but I'm afraid it's my sister's wedding. Sorry. 
GE12: Oh, that's a pity, but we are going away to N.Y. for the weekend... If I'd only known before (earlier).

\section{DCT \#5}

GE1: Oh no, I can't do that. I really dislike all these grains and vegetables!

GE2: Oh, fuck you. I'm not as big. Just today I've been eating to much.

GE3: But I already told you that I can't eat anything now. In a few hours it'll be better, definitively!

GE4: You know, I am tired to try this new diets, they have no use at all, nothing changes. I think diets aren't the things I need.

GE5: I think I'll lose enough weight, if I just eat less for a while.

GE6: Ah, I tried so many diets and none of them had any effect. I can't imagine that this one works better.

GE7: No thanks. I've heard about. Eating only fruits every day just isn't my thin g.

GE8: I tried a lot of new diets and they never worked.

GE9: I'm sure that my stomach will be ok tomorrow, I'll just eat less today, tomorrow I'll be fine again.

GE10: I'm fed up with any diet!!!

GE11: Listen, I've tried about every bloody diet there is, but nothing works. So stop pestering me with your diet-tips!

GE12: Well, listen, I've been trying all kinds of diets and nothing really worked out. I'm pretty much fed up with all that diet business.

\section{DCT \#6}

GE1: Sorry, Mr. X. But I've tried this method sometime and it didn't help me to organize myself. But, thank you very much for that tip. 
GE2: That's a good idea, actually. But normally I don't have problems in managing my things.

GE3: That's a good idea but normaly it's no problem to find anything here because usually everything is organized here.

GE4: Once [translation: first of all], if I organized my desk, I'll find nothing any longer because I don't know where to look for. Also little notes are useless for me, I'd lose them.

GE5: That wouldn't help me to find the report now.

GE6: Oh, I think then I would have a mess of little notes and I would spend my time searching for the right one. I don't think that's a solution.

GE7: I don't know how many people have told me that already. I think I'm just used to it.

GE8: Little notes wouldn't be sufficient in that mess besides I'm always successive in finding things without organization.

GE9: I'm afraid I'd just loose the notes. I think I'll have to change my whole concept of keeping my desk tidy.

GE10: Actually I do write little notes myself, but I can't help it, they always get lost.

GE11: I'm sorry. Usually I'm very well organized. It's just one of those days, you know.

GE12: Well, but then, I'll lose those little notes...

\section{DCT \#7}

GE1: Oh, that's a pitty. It's very honorable from you, that you wanna pay for it, but I don't think, you're able to do that. It's okay, we'll talk about it some other day.

GE2: Doesn't matter. It wasn't expensive and finally I couldn't see it anymore.

GE3: Don't worry, you shouldn't care about this that much. The insurance will pay, and strictly speaking, I didn't like it anymore. So, please don't wory about it.

GE4: First: It was a fake. So don't be sorry about it. Second: If it would (?) be original you couldn't pay anyway. Third: The cellar is full of others, so calm down!

GE5: That happens. You were just doing your job. I didn't like the vase anyway. 
GE6: Oh, that's not necessary. You don't need to pay it, such things happen to everybody.

GE7: Oh, don't feel sorry. It is not your fault, that could have happened to anybody. You don't have to pay for that. Forget about it. Don't worry, that's o.k.

GE8: That's really not neccessary. I even don't know how expensive it was, we bought them such a long time ago.

GE9: Oh, that's ok! I didn't like it anyways, it was a present. I'll try to glue it and then I'll put it some more at the back of the shelf. Nobody will see that it was broken.

GE10: If you haven't got an insurance for that kind of accidents you would not have to pay for it, of course. Things like that happen. It was only a vase.

GE11: Please, don't be so upset. Things like that happen. And I don't want you to pay for it, I never really liked the vase anyway.

GE12: First of all, I'm glad, you are alright... the China vase is less important. Of course, you needn't pay for it, that would be ridiculous.

\section{DCT \#8}

GEl: Dear Mark, I'm very pleased, that you try to help my organizing my lessons, but I have some regulations in teaching my class.

GE2: You're very nice but I guess my practice in teaching is as well as I know how to do for having the best results as possible.

GE3: But I think I should try to improve the class's grammatical competence, first. Next term there'll be more conversation practices.

GE4: I have a very organized plan \& I don't want to change it; conversation comes later.

GE5: You should know the grammar first before you do conversation.

GE6: I know that most of you like the practice in conversation better than the one in grammar. But grammar is necessary for good conversation, you really have to learn it.

GE7: Well, you know, I remember the beginning of the term when almost everybody said that they needed more exercise on grammar and I noticed that too, that your grammar is really bad. So I think we still have to concentrate on that. 
GE8: One should always practice the things one has not yet aquired and once you managed grammar conversation will be no problem.

GE9: We have extra conversation classes at this university, too. I'd like to give you more practice, but my boss told me to teach you grammar.

GE10: I made the experience that you can't really do any conversation without the basics of grammar.

GE11: I thought about this, too, because I've realized that you aren't particularly thrilled by my teaching method. But I'm afraid you're simply not good enough yet to have intelligent and intelligable convers. in ... You simply have to improve on your grammar first, before you can start on conversations.

GE12: Well, the thing is that you need to know about the grammar first. it is just the essential basis and we need to do it.

\section{$\underline{\text { DCT \#9 }}$}

GE1: Thank you, but I have to refuse. I'm totally full. // O.K. But just a very little one.

GE2: I'm sorry but I'm stuffed. // No, I'd really die by eating it.

GE3: No, sorry, but I can't eat more. // If I can do you a favor, o.k.

GE4: You know, I am just trying a new diet. // If it's made of carrots \& without sugar, then, okay.

GE5: No, thank you I've had enough. // No, really, I'm getting fat anyway.

GE6: No, thank you. I already ate to much, really. // Okay, but a very small one, please.

GE7: Oh, no thank you. It's delicious but I'm full. // No, really not. I can't eat anything else.

GE8: Oh, thank you. It is delicious but after your excellent meal it really enough for me now. // But really a very little piece.

GE9: Thank you, it was very good, but I ate too much already. // If you promise just to give me a little piece, ok. 
GE10: It's an excellent cake, but I'm quiet happy now, thank you. // No, thank you very much. But don't worry, I will feel myself at home and just take another piece later on if I'd like to.

GE11: No, thanks. It's really lovely, but I'm absolutely full. I had too much to eat already. // Well, if I absolutely have to. Why not.

GE12: Oh, no, thanks, I already had three! I think I'm going to explode! // Well-O.k., you're right, why not?! Just a little one.

\section{DCT \#10}

GE1: Oh, thank you very much. But I don't think I'll come, because you know, your wife really doesn't like me.

GE2: I feel very sorry but Monday I've to get up really soon in order to get the flight at six-thirty.

GE3: Sorry, but I'm going out with Laura that evening and we have cards for a concert, so I'm supposed to go out with her.

GE4: Sorry, but at the moment I have to write an urgent report for my boss, sooo...

GE5: We've made other plans for Sunday.

GE6: Oh, I'd like to come but I promised my mother to visit her on Sunday night. I haven't visited her for half a year now.

GE7: Sorry name, but I'm somehow not in the mood to be around people just right now. I'm not very talkative today.

GE8: I'm very sorry but my husband's already bought tickets for a concert (?) on Saturday night.

GE9: Oh, such a pity. Yesterday my friend Sue invited me to a party at her house and I already told her I would come.

GE10: Sunday night? Oh, unfortunately I promised to my sister to look after their children. They want to go out, you know.

GE11: Oh, I'd love to, but I'm afraid I really have to go and see my mother. I haven't been over for 2 weeks. You know how mothers are. 
GE12: Oh, that's too bad, but I already made plans to go to Boston to see the Nutcracker Sunday night...

\section{DCT \#11}

GE1: Well, I'm quiet honored by your offer, but I think it's too far away from my home and my family. Sorry, but I think I have to refuse.

GE2: Thank you, but I couldn't even if I'd want because my son has only 4 years and he wouldn't like to leave all the friends he got.

GE3: Thank you for this offer but I bought a house here recently and I planed to settle down.

GE4: Sorry, but I'm married \& have 3 children, at the moment I really see no possibility to move. And seven hours is just to much I think.

GE5: I really appreciate that, but I don't want to leave this area.

GE6: I'm interested in the job but I really don't want to move. I don't want to live to far away from my family.

GE7: I thought about and, sure, "raise of pay" always sounds good, but on the other hand there are too many reasons that stand against this new job.

GE8: I think here I like it very much and I'm feeling completely comfortable with my position here.

GE9: Thank you for this offer, but I really don't want to move. I like this town and my friends live here.

GE10: This would be a good chance for me, of course. But one has to think of his private life, too. I can't leave my parents alone.

GE11: Well, I feel very honoured by your offer. But to be quite honest, I'd rather stay here, because I feel very much at home here.

GE12: Sounds good, of course, but I won't be able to move. It would cause so many problems to my family. So I'm afraid I won't be able to do it. 


\section{DCT \#12}

GE1: Well, normally that wouldn't be a problem, but tonight I have to go home, because my wife is going out today and I have to tend our kids.

GE2: I'm sorry but me husband and me, we bought tickets for the opera tonight.

GE3: I'm sorry sir but I feel sick today and perhaps I'm getting ill. I think I should go to bed as fast as possible.

GE4: I am so sorry, but I was going to meet friends tonight in a restaurant.

GE5: I'm sorry, but my husband is waiting with the dinner. We have plans for tonight.

GE6: Not tonight, I invited some friends to have dinner at my house and I have to prepare the meal.

GE7: To be honest, I've promised my husband to pick up the children from school today. So I think I'd better leave now. Sorry for that.

GE8: Unfortunately I have to see my doctor tonight and as it is always so difficult to get these things fixed, I'm not able to stay longer.

GE9: I'm really sorry, but I can't stay. I promised my friend to help her with putting wallpaper in her new appartment. I told her that I would come right after work. I could stay longer tomorrow.

GE10: I'm sorry but it isn't possible today. I have to see the doctor this evening.

GE11: Well, usually that's not a problem, as you know. But I'm afraid I can't make it tonight. It's my mother's birthday and I really have to go.

GE12: Oh, I'm so sorry about that, but I already was deciding to leave in a minute. 


\section{Appendix K \\ Classification of AE Responses in terms of Functional Categories}

\section{$\underline{\text { DCT \#1 }}$}

AE1: 1. [agreement] 2. [compliment] 3. [negative willingness] 4. [downgrader]

AE2: 1. [regret] 2. [negative ability] 3. [excuse] 4. [promise] Amalgamation of negative ability and excuse.

AE3: 1. [pause filler] 2. [compliment] 3. [negative ability] 4. [excuse] Amalgamation of negative ability and excuse.

AE4: 1. [downgrader + negative ability] 2. [excuse] 3. [elaboration on excuse] Amalgamation of negative ability and excuse.

AE5: 1. [agreement] 2. [empathy] 3. [empathy] 4. [compliment] 5. [forewarn] 6. [negative ability] 7. [excuse] 8. [downtoner + downgrader + negative ability] AE6: 1. [pause filler] 2. [forewarn] 3. [compliment] 4. [wish] 5. [negative ability] AE7: 1. [downgrader + downtoner + negative ability] 2. [agreement] 3. [compliment] Amalgamation of agreement and compliment.

AE8: 1. [regret] 2. [negative ability] 3. [excuse]

AE9: 1. [positive opinion] 2. [downtoner + negative ability] 3. [excuse] Amalgamation of negative ability and excuse.

AE10: 1. [compliment] 2. [positive opinion] 3. [excuse] 4. [downtoner + negative ability] Amalgamation of excuse and negative ability.

AE11: 1. [pause filler] 2. [excuse] 3. [negative ability] 4. [intensifier + regret] 5. [downgrader] Amalgamation of excuse and negative ability.

AE12: 1. [regret] 2. [excuse] 3. [negative ability] 4. [excuse] Amalgamation of negative ability and excuse (3. \& 4.).

\section{DCT \#2}

AE1: 1. ["No"] 2. [downgrader + guilt trip] 3. [guilt trip] 4. [upgrader + guilt trip] 5. [negative consequences to interlocutor and speaker]

AE2: 1. [forewarn] 2. [downgrader + guilt trip] 3. [principle]

AE3: 1. [downtoner + reason] 2. [downgrader + negative ability]

AE4: 1. [regret] 2. [negative ability] 3. [reason]

AE5: 1. [positive feeling] 2. [downtoner + reason] 3. [alternative: I can do $X$ instead of Y] 4. [reason] 5. [downtoner + elaboration on reason] 6. [regret]

AE6: 1. [criticism of eliciting speech act-sarcasm]

AE7: 1. [negative ability] 2. [regret] 3. [reason] 
AE8: 1. [excuse] 2. [excuse]

AE9: 1. [regret] 2. [excuse]

AE10: 1. [downtoner + implied criticism of eliciting speech act] 2. [guilt trip]

AE11: 1. [pause filler] 2. [excuse + downtoner] 3. [excuse] 4. [excuse] ("lie")

AE12: 1. [guilt trip] 2. [upgrader + guilt trip]

\section{$\underline{\text { DCT \#3 }}$}

AE1: 1. [downgrader] 2. [philosophy] 3. [elaboration of philosophy]

AE2: 1. ["No" + downgrader] 2. [positive opinion] 3. [philosophy]

AE3: 1. [gratitude] 2. [reason] 3. [gratitude]

AE4: 1. [regret] 2. [reason]

AE5: 1. [pause filler] 2. [compliment] 3. [positive feeling] 4. [reason] 5. [negative ability] 6. [excuse] Amalgamation of negative ability and excuse.

AE6: 1. [gratitude] 2. [negative willingness]

AE7: 1. [positive feeling] 2. [downtoner + postponement]

AE8: 1. [regret] 2. [excuse]

AE9: 1. [downtoner + excuse] 2. [elaboration on excuse]

AE10: 1. [gratitude] 2. [negative opinion] 3. [alternative-I can do X instead Y]

AE11: 1. [hedging] 2. [postponement]

AE12: 1. [regret] 2. [excuse]

\section{DCT \#4}

AE1: 1. [positive opinion] 2. [excuse $=$ indirect guilt trip] 3. [downgrader + performative $=$ negative ability]

AE2: 1. [gratitude] 2. [downgrader + excuse] 3. [elaboration on excuse]

AE3: 1. [positive feeling] 2. [downgrader + downgrader + performative $=$ negative ability] 3. [excuse] 4. [regret]

AE4: 1. [regret] 2. [excuse]

AE5: 1. [positive feeling] 2. [excuse] 3. [elaboration on excuse] 4. [downgrader + negative ability] 5. [intensifier + gratitude] 6. [promise]

AE6: 1. [repetition] 2. [wish] 3. [excuse] 4. [elaboration on excuse]

AE7: 1. [positive opinion] 2. [downgrader + excuse]

AE8: 1. [regret] 2. [excuse]

AE9: 1. [positive feeling] 2. [downgrader + excuse]

AE10: 1. [downgrader + excuse] 2. [set condition for past acceptance, involving an indirect guilt trip]

AE 11: 1. [downgrader + downgrader + negative ability] 2. [excuse]

AE12: 1. [excuse] 2. [downgrader + performative $=$ negative ability] 3. [gratitude] 


\section{$\underline{\text { DCT \#5 }}$}

AE1: 1. ["no" + downgrader] 2. [philosophy]

AE2: 1. [negative opinion] 2. [elaboration on negative opinion]

AE3: 1. [reason] 2. [conditional promise]

AE4: 1. [negative opinion] 2. [elaboration on negative opinion]

AE5: 1. [upgrader + negative opinion] 2. [negative opinion] 3. [reason] 4. [downgrader + "no" + downgrader]

AE6: 1. [upgrader + negative opinion] 2. [elaboration on negative opinion] 3. [elaboration on negative opinion]

AE7: 1. [negative willingness + downtoner] 2. [elaboration on negative willingness]

AE8: 1. [hedging]

AE9: 1. [negative ability] 2. [reason]

AE10: 1. [negative opinion] 2. [elaboration on negative opinion] 3. [elaboration on negative opinion]

AE11: 1. [downtoner + negative opinion + downtoner] 2. [philosophy]

AE12: 1. [implied criticism of eliciting speech act + upgrader]

\section{$\underline{\mathrm{DCT} \# 6}$}

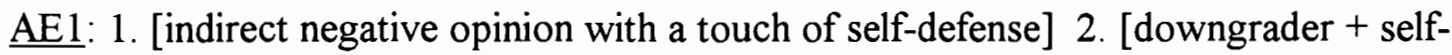
defense] 3. [negative opinion]

AE2: 1. [agreement] 2. [self-defense + downtoner]

AE3: 1. [gratitude] 2. [philosophy]

AE4: 1. [self-defense] 2. [excuse]

$\underline{\mathrm{AE}}$ : : 1. [positive opinion] 2. [downtoner + downgrader + criticism of eliciting speech act]

AE6: 1. [downtoner + guilt trip] 2. [negative opinion] (Note: This response was not intended seriously.)

AE7: 1. [downtoner + criticism of eliciting act]

AE8: 1. [agreement] 2. [self-defense] 3. [implied excuse]

AE9: 1. [indirect negative opinion with a touch of self-defense] 2. [downtoner + downgrader + indirect negative opinion] 3. [veiled negative opinion]

AE10: 1. [downgrader + self-defense] 2. [downtoner + self-defense]

AE11: 1. [downgrader + downtoner + criticism of eliciting speech act] 2. [elaboration on criticism of speech act]

AE12: 1. [gratitude] 2. [downgrader + criticism of the eliciting speech act] 3. [criticism of the eliciting speech act]

\section{DCT \#7}


AEl: 1. [agreement] 2. [off the hook] 3. [empathy = off the hook]

AE2: 1. [downtoner + "no" = off the hook] 2. [philosophy = off the hook] 3. [diminish value $=$ off the hook $]$

AE3: 1. [pause filler] 2. [off the hook] 3. [off the hook] 4. [downtoner + admonition]

AE4: 1. [off the hook] 2. [diminish value = off the hook] 3. [off the hook]

AE5: 1. [off the hook] 2. [philosophy = off the hook] 3. [off the hook]

AE6: 1. [agreement] 2. [downtoner + off the hook] 3. [philosophy $=$ off the hook] 4. [off the hook]

AE7: 1. [off the hook] 2. [philosophy = off the hook]

AE8: 1. [off the hook] 2. [diminish value $=$ off the hook]

AE9: 1. [downtoner + off the hook] 2. [diminish value = off the hook] 3. [off the hook]

AE10: 1. [pause filler] 2. [agreement] 3. [off the hook] 4. [downtoner + admonition]

AE11: 1. [off the hook] 2. [off the hook] 3. [diminish value $=$ off the hook] 4 .

[philosophy $=$ off the hook] 5. [off the hook]

AE12: 1. [philosophy $=$ off the hook] 2. [empathy] 3. [off the hook] 4. [diminish value $=$ off the hook] 5. [off the hook]

\section{$\underline{\text { DCT \#8 }}$}

AE1: 1. [empathy] 2. [alternative-why don't you do X instead of $\mathrm{Y}$ ] 3. [principle]

AE2: 1. [principle] 2. [negative opinion]

$\underline{\mathrm{AE} 3}$ : 1. [pause filler] 2. [establish own status $=$ attack] 3. [reason]

AE4: 1. [principle]

AE5: 1. [agreement] 2. [excuse] 3. [downgrader + elaboration on excuse]

AE6: 1. [agreement] 2. [empathy] 3. [agreement] 4. [elaboration on agreement] 5. [principle]

AE7: 1. [postponement] 2. [downgrader + negative willingness] 3. [reason]

Amalgamation of negative willingness and reason.

AE8: 1. [set condition for past acceptance] 2. [negative ability = negative willingness] 3 . [reason]

AE9: 1. [regret] 2. [reason]

AE10: 1. [pause filler] 2. [establish own status / superiority] 3. [establish own status /superiority = criticism of eliciting speech act and implied criticism of interlocutor] 4 . [request to rescind]

AE 11: 1. [pause filler] 2. [downtoner + principle] 3. [alternative: why don't you do X instead of $\mathrm{Y}]$

AE12: 1. [principle] 2. [downgrader + reason]

\section{$\underline{\text { DCT \#9 }}$}

AE1: 1. ["no" + downgrader] // 1. ["no"] 2. [upgrader + negative willingness] 
AE2: 1. ["no" + downgrader] 2. [reason] // 1. ["no" + upgrader] 2. [reason + emphasis] AE3: 1. ["no"] 2. [reason] 3. [negative ability] // 1. ["no"] 2. [negative consequences to speaker] 3. [negative willingness]

AE4: 1. ["no] 2. [reason] 3. [excuse] // 1. ["no"] 2. [reason] 3. [negative ability] AE5: 1. [downtoner + "no" + downgrader] 2. [reason] // 1. [pause filler] 2. [limited acceptance]

AE6: 1. ["no" + downgrader] 2. [compliment] 3. [reason] // 1. [negative consequences to interlocutor]

AE7: 1. ["no" + downgrader] 2. [reason] // 1. ["no" + upgrader] 2. [compliment] 3. [reason]

AE8: 1. ["no"] // 1. [acceptance]

AE9: 1. ["no" + downgrader] 2. [downtoner + reason, involving possible negative opinion] // 1. ["no"] 2. [upgrader + negative willingness]

AE10: 1. [compliment] 2. [reason] // 1. ["no" + upgrader] 2. [negative ability] 3. [alternative: I can do $\mathrm{X}$ instead of $\mathrm{Y}$ ]

AE11: 1. ["no" + downgrader] 2. [reason] // 1. [upgrader + "no" + downgrader] 2. [reason] 3. [elaboration of reason]

AE12: 1. ["no" + downgrader] 2. [excuse] 3. [reason] // 1. ["no" + upgrader + downgrader]

\section{DCT \#10}

AE1: 1. ["no" + downgrader] 2. [excuse]

AE2: 1. [pause filler] 2. [excuse] 3. [gratitude]

AE3: 1. [regret] 2. [negative ability] 3. [excuse]

AE4: 1. [regret] 2. [excuse]

AE5: 1. [pause filler] 2. [pause filler] 3. [positive opinion] 4. [excuse] 5. [elaboration on excuse]

AE6: 1. [pause filler] 2. [downtoner + wish] 3. [excuse]

AE7: 1. [regret] 2. [excuse]

AE8: 1. [downtoner + excuse] 2. [positive feeling] 3. [elaboration of positive feeling]

AE9: 1. [regret] 2. [negative ability] 3. [excuse]

AE10: 1. [positive feeling] 2. [excuse] 3. [alternative: I can do X instead of $Y$ ]

AE11: 1. [regret] 2. [positive feeling] 3. [downtoner + excuse] 4. [elaboration on excuse]

AE12: 1. [pause filler] 2. [hedging] 3. [excuse] 4. [elaboration on excuse]

\section{DCT \#11}

AE1: 1. [positive opinion] 2. [forewarn] 3. [philosophy]

AE2: 1. [positive opinion] 2. [reason] 3. [reason] 
AE3: 1. [gratitude] 2. [intensifier + gratitude] 3. [reason] 4. [elaboration on reason]

AE4: 1. [positive opinion] 2. [downtoner + reason] 3. [negative opinion]

AE5: 1. [positive opinion] 2. [downtoner + reason]

AE6: 1. [forewarn] 2. [positive opinion] 3. [set condition]

AE7: 1. [forewarn] 2. [reason]

AE8: 1. [hedging] 2. [hedging] 3. [reason]

AE9: 1. [positive opinion] 2. [downtoner + negative opinion] 3. [downgrader + negative opinion]

AE10: 1. [positive opinion] 2. [negative opinion] 3. [philosophy] Amalgamation of negative opinion and philosophy.

AE11: 1. [pause filler] 2. [forewarn] 3. [downtoner + negative opinion] 4. [reason] AE12: 1. [regret] 2. [reason] 3. [negative willingness] 4. [philosophy = elaboration on negative willingness]

\section{$\underline{\text { DCT \#12 }}$}

AE1: 1. [positive opinion] 2. [excuse] 3. [negative consequences to the interlocutor]

AE2: 1. [positive feeling] 2. [excuse] 3. [alternative: I can do X instead of $Y$ ]

AE3: 1. [negative ability] 2. [alternative: I can do X instead of Y] 3. [excuse] 4. [negative ability $=$ elaboration on excuse]

AE4: 1. [regret + politeness marker] 2. [excuse] 3. [elaboration on excuse]

AE5: 1. [negative ability] 2. [excuse] 3. [elaboration on excuse]

AE6: 1. [pause filler] 2. [regret] 3. [wish $=$ set condition] 4. [excuse]

AE7: 1. [regret] 2. [excuse] 3. [alternative: I can do $X$ instead of $Y$ ]

AE8: 1. [regret] 2. [excuse]

AE9: 1. [positive opinion] 2. [excuse] 3. [elaboration on excuse]

AE 10: 1. [positive opinion] 2. [excuse] 3. [alternative: I can do X instead of Y]

AE 11: 1. [regret] 2. [excuse] 3. [excuse]

AE12: 1. [criticism of eliciting speech act] 2. [guilt trip] 3. [reason] 4. [negative willingness] 


\section{Appendix L \\ Classification of GG Responses in terms of Functional Categories}

\section{DCT \#1}

GG1: 1. [agreement] 2. [compliment] 3. [reason implying negative willingness]

GG2: 1. [excuse] 2. [possible indirect compliment] 3. [negative ability] 4. [implied conditional promise] Amalgamation of excuse, compliment, and negative ability.

GG3: 1. [forewarn] 2. [postponement]

GG4: 1. [agreement] 2. [compliment] 3. [negative willingness]

GG5: 1. [attack] (separate entries, therefore not included in tally: / 1. [reason] / 1. [principle] )

GG6: 1. [agreement] 2. [downgrader + excuse] 3. [negative ability]

GG7: 1. [implied criticism of eliciting speech act] 2. [downgrader + excuse] 3.

[downgrader + negative ability] 4. [reason = implied criticism of eliciting speech act]

GG8: 1. [regret] 2. [negative ability]

GG9: 1. [pause filler] 2. [excuse with a touch of request to rescind] 3. [guilt trip] 4. [reason with implied criticism of eliciting speech act] 5. [compliment] 6. [downgrader + negative ability]

GG10: 1. [regret] 2. [compliment] 3. [negative ability + downgrader] 4. [excuse] Amalgamation of negative ability and excuse.

GG11: 1. [agreement] 2. [compliment] 3. [positive opinion] 4. [negative ability] 5. [excuse] 6. [regret] Amalgamation of negative ability and excuse.

GG12: 1. [compliment] 2. [excuse] 3. [negative ability]

GG13: 1. [empathy] 2. [downtoner + reason]

GG14: 1. [negative ability] 2. [excuse] 3. [elaboration on excuse]

\section{$\underline{\text { DCT \#2 }}$}

GG1: 1. [pause filler] 2. [downtoner + reason] 3. [elaboration on reason] 4. [regret]

GG2: 1. [regret + intensifier] 2. [reason]

GG3: 1. ["no" + emphasis]

GG4: 1. [forewarn] 2. [criticism of interlocutor]

GG5: 1. [criticism of eliciting speech act]

GG6: 1. [criticism of interlocutor] 2. [guilt trip] 3. [guilt trip] 4. [guilt trip] 5. [opaque "no" or negative willingness] 
GG7: 1. [pause filler] 2. [downgrader + downgrader + negative consequences to interlocutor] 3. [diminish value of requested object] 4. [elaboration: diminish value of requested object]

GG8: 1. [downtoner + reason]

GG9: 1. [downgrader + criticism of interlocutor] 2. [criticism of interlocutor] 3. [guilt trip] 4. [downgrader + negative willingness] 5. [guilt trip] 6. [negative consequences to interlocutor]

GG10: 1. [forewarn] 2. [reason] 3. [elaboration on reason]

GG11: 1. [downtoner + downgrader + downtoner + downtoner + guilt trip] 2.

[elaboration on guilt trip] 3. [elaboration on guilt trip]

GG12: 1. [excuse] 2. [elaboration on excuse]

GG13: 1. [regret] 2. [implied criticism of eliciting speech act] 3. [reason]

GG14: 1. ["no"] 2. [negative willingness] 3. [reason] 4. [negative consequences to interlocutor + diminish value of requested item]

\section{$\underline{\text { DCT \#3 }}$}

GG1: 1. [pause filler] 2. [forewarn] 3. [hedging] 4. [postponement] 5 [postponement] GG2: 1. [downgrader + postponement] 2. [elaboration on postponement]

GG3: 1. [criticism of eliciting speech act] 2. [criticism of interlocutor]

GG4: 1. ["no" + upgrader] 2. [upgrader + criticism of interlocutor]

GG5: 1. [reason] 2. [postponement]

GG6: 1. [gratitude] 2. [principle] 3. [forewarn + criticism of interlocutor]

GG7: 1. [forewarn] 2. [postponement]

GG8: 1. [excuse + downgrader] 2. [regret]

GG9: 1. [forewarn] 2. [reason] 3. [postponement] 4. [downgrader + criticism of interlocutor] 5. [compliment] 6. [negative ability]

GG10: 1. [excuse] 2. [postponement]

GG11: 1. [pause filler] 2. [downtoner + forewarn] 3. [hedging]

GG12: 1. [postponement] 2. [positive opinion]

GG13: 1. [criticism of eliciting speech act (i.e., salesman's product)]

GG14: 1. [upgrader + criticism of interlocutor]

\section{DCT \#4}

GG1: 1. [repetition] 2. [downgrader] 3. [negative ability] 4. [excuse] 5. [gratitude] 6. [negative ability]

GG2: 1. [gratitude] 2. [downgrader + excuse] 3. [downgrader + performative $=$ negative ability] Amalgamation of excuse and performative.

GG3: 1. [gratitude] 2. [downgrader + hedging] 3. [elaboration on hedging-explanation why he can't decide now] 
GG4: 1. [excuse] 2. [principle = elaboration on excuse]

GG5: 1. [regret] 2. [negative ability] 3. [excuse] 4. [elaboration on excuse]

GG6: 1. [gratitude] 2. [set condition = indirect guilt trip] 3. [excuse] Amalgamation of set condition and excuse.

GG7: 1. [pause filler] 2. [positive opinion] 3. [excuse]

GG8: 1. [negative ability] 2. [excuse]

GG9: 1. [positive opinion] 2. [intensifier + gratitude] 3. [downgrader + excuse] 4. [downgrader + negative ability $=$ elaboration on excuse] 5. [downgrader] 6. [positive opinion] 7. [promise] Amalgamation of positive opinion and promise.

GG10: 1. [excuse] 2. [elaboration on excuse + downgrader]

GG11: 1. [pause filler] 2. [regret] 3. [excuse]

GG12: 1. [excuse]

GG13: 1. [regret + intensifier] 2. [excuse]

GG14: 1. [intensifier + regret] 2. [downgrader + negative ability] 3. [excuse]

\section{DCT \#5}

GG1: 1. [negative opinion] 2. [criticism of eliciting speech act] 3. ["no"] 4. [negative willingness]

GG2: 1. [negative opinion] 2. [elaboration on negative opinion] 3. [elaboration on negative opinion] 4. [elaboration on negative opinion]

GG3: 1. [upgrader + criticism of eliciting speech act] 2. [opaque negative willingness]

GG4: 1. [insult] 2. [philosophy]

GG5: 1. [forewarn + downtoner] 2. [reason]

GG6: 1. [upgrader + negative opinion] 2. [negative opinion]

GG7: 1. ["no"] 2. [negative willingness] 3. [negative opinion] 4. [philosophy]

GG8: 1. [negative opinion] 2. [negative opinion]

GG9: 1. [upgrader + criticism of eliciting speech act] 2. [philosophy] 3. [philosophy] 4. [elaboration on philosophy]

GG10: 1. [philosophy] 2. [negative opinion]

GG11: 1. [upgrader ( with implied negative opinion or criticism of eliciting speech act) + hedging] 2. [negative opinion] 3. [elaboration on negative opinion]

GG12: 1. [negative opinion] 2. [philosophy]

GG13: 1. [upgrader (with implied negative opinion or criticism of eliciting speech act) + negative opinion] 2. [elaboration on negative opinion]

GG14: 1. [upgrader (with implied negative opinion or criticism of eliciting speech act) + imperative to rescind] 2. [criticism of eliciting speech act]

\section{$\underline{\text { DCT \#6 }}$}


GG1: 1. [upgrader (with implied criticism of eliciting speech act) + downtoner + selfdefense] 2. [self-defense] 3. [criticism of eliciting speech act] 4. ["no"] 5. [reason] GG2: 1. [self-defense] 2. [self-defense] 3. [elaboration on self-defense]

GG3: 1. [upgrader (with implied criticism of eliciting speech act)] 2. [downgrader + criticism of eliciting speech act] 3. [elaboration on criticism of eliciting speech act] GG4: 1. [guilt trip] 2. [guilt trip] 3. [guilt trip combined with self-defense + upgrader (through aggressive interrogative)]

GG5: 1. [self-defense] 2. [guilt trip]

GG6: 1. [forewarn] 2. [joke] 3. [downgrader] 4. [downgrader + self-defense]

GG7: 1. [self-defense]

GG8: 1. [self-defense] 2. [intensifier + gratitude]

GG9: 1. [self-defense] 2. [self-defense + implied guilt trip] 3. [self-defense]

GG10: 1. [upgrader (with implied criticism of eliciting speech act)] 2. [postponement (with implied criticism of eliciting speech act)]

GG11: 1. [upgrader (with implied criticism of eliciting speech act)] 2. [postponement (with implied criticism of eliciting speech act)]

GG12: 1. [criticism of eliciting speech act]

GG13: 1. [forewarn] 2. [joke]

GG14: 1. [upgrader + negative opinion with a touch of self-defense] 2. [criticism of

eliciting speech act] 3. [elaboration on criticism of eliciting speech act]

\section{$\underline{\text { DCT \#7 }}$}

GG1: 1. [downtoner + empathy + downtoner] 2. [off the hook] 3. [off the hook] 4. [philosophy $=$ off the hook + downtoner]

GG2: 1. [off the hook] 2. [diminish value = off the hook]

GG3: 1. [downtoner + empathy + downtoner] 2. [downtoner + philosophy $=$ off the hook]

GG4: 1. [downtoner + downgrader + establish own status $=$ off the hook] 2. [elaboration of establish own status $=$ off the hook]

GG5: 1. [philosophy = off the hook] 2. [admonition]

GG6: 1. [off the hook + downtoner] 2. [agreement] 3. [empathy $=$ off the hook]

GG7: 1. [downtoner + diminish value $=$ off the hook] 2. [diminish value $=$ off the hook]

3. [imperative to drop $=$ off the hook + downtoner]

GG8: 1. [diminish value $=$ off the hook + downtoner] 2. [off the hook]

GG9: 1. ["no" + downtoner = off the hook] 2. [imperative to drop =off the hook] 3. [off the hook] 4. [philosophy $=$ off the hook + downtoner] 5. [off the hook] 6. [downgrader + empathy]

GG10: 1. [off the hook] 2. [diminish value $=$ off the hook] 3. [diminish value $=$ off the hook]

GG11: 1. [downtoner + "no" = off the hook] 2. [off the hook] 3. [empathy] 4. [philosophy = elaboration on empathy] 5. [off the hook] 
GG12: 1. [diminish value $=$ off the hook] 2. [philosophy $=$ off the hook + downtoner] 3 . [elaboration on philosophy $=$ off the hook + downtoner]

GG13: 1. ["ach was" = off the hook] 2. [philosophy = off the hook] 3. [off the hook] GG14: 1. [downgrader + empathy $=$ off the hook] 2. [diminish value $=$ off the hook] 3 . [downtoner + diminish value $=$ off the hook] 4 . [elaboration-diminish value $=$ off the hook] 5. [elaboration-diminish value $=$ off the hook]

\section{DCT \#8}

GG1: 1. [agreement] 2. [elaboration on agreement] 3. [reason] 4. [regret] 5. [downtoner + reason]

GG2: 1. [reason] 2. [negative willingness + downtoner] 3. [reason]

GG3: 1. [positive opinion] 2. [downgrader + reason]

GG4: 1. [attack] 2. [insult involving criticism of interlocutor / criticism of eliciting speech act and establish own status / superiority] 3. [insult involving establish own status / superiority over interlocutor]

GG5: 1. [establish own status / superiority over interlocutor] 2. [downgrader + reasonimplies own superiority over interlocutor]

GG6: 1. [forewarn] 2. [principle] 3. [downgrader + reason (i.e., conditions of 1. not met)]

GG7: 1. [negative ability = negative willingness] 2. [reason] 3. [reason] Amalgamation of negative ability and first reason.

GG8: 1. [reason] 2. [principle = elaboration of reason]

GG9: 1. [excuse + downgrader] 2. [elaboration on excuse] 3. [elaboration on excuse] 4. [alternative-why don't you do X instead of Y] 5. [downgrader + elaboration on alternative-why don't you do $\mathrm{X}$ instead of $\mathrm{Y}]$

GG10: 1. [reason] 2. [negative ability = negative willingness]

GG11: 1. ["no"] 2. [criticism of eliciting speech act] 3. [principle]

GG12: 1. [principle] 2. [promise]

GG13: 1. [principle]

GG14: 1. [criticism of eliciting speech act] 2. [reason] 3. [elaboration on reason]

\section{$\underline{\text { DCT \#9 }}$}

GG1: 1. ["no" + downgrader] 2. [reason] 3. [compliment] // 1. [acceptance] 2. [limitation of acceptance] 3. [limitation of acceptance]

GG2: 1. ["no" + downgrader] // 1. ["no" + downgrader] 2. [upgrader + "no"] 3. [compliment]

GG3: 1. [negative ability] 2. [imperative to drop] 3. [negative consequences to speaker (possibly with humorous intent)] // 1 . [depending on context, intonation, etc.: upgrader + 
guilt trip $=$ acceptance; or, upgrader + guilt trip $=$ acceptance that functions as a refusallack of enthusiasm]

GG4: 1. [insult] // 1. [imperative to drop] 2. [negative willingness]

GG5: 1. ["no" + downgrader] 2. [reason] // 1. [regret] 2. [excuse]

GG6: 1. [downtoner + negative ability] 2. [compliment] // a) 1. [acceptance] 2.

[limitation of acceptance] b) 1. [downgrader of "no"-"danke"] 2. [negative ability]

GG7: 1. [pause filler] 2. [downtoner + negative ability] 3. [reason] // 1. ["no" + upgrader] 2. [negative consequences to speaker] 3. [elaboration on negative consequences to speaker]

GG8: 1. ["no" + downgrader] 2. [reason] // 1. [upgrader + "no" + downgrader]

GG9: 1. ["no" + downgrader] 2. [compliment] 3. [upgrader + reason] 4. [compliment] 5. ["no"] // 1. [downgrader + imperative to drop] 2. [guilt trip]

GG10: 1. ["no" + downgrader] 2. [compliment] 3. [negative ability] // 1. ["no" + upgrader] 2. [negative consequences to speaker]

GG11: 1. ["no" + downgrader] 2. [reason] 3. [compliment] // 1. [acceptance] 2. [compliment] 3. [downgrader + limitation of acceptance]

GG12: 1. ["no" + downgrader] 2. [compliment] 3. [reason] // 1. ["no" + downgrader] 2. [gratitude] 3. [negative ability]

GG13: 1. [regret] 2. [reason] // 1. ["no"] 2. [negative ability] 3. [positive opinion]

GG14: 1. ["no" + downgrader] 2. [reason] // 1. ["no"] 2. [negative ability]

\section{DCT \#10}

GG1: 1. [negative ability + downtoner] 2. [excuse] 3. [regret] 4. [negative ability]

GG2: 1. [regret] 2. [excuse] 3. [promise]

GG3: 1. [downtoner + regret] 2. [reason]

GG4: 1. ["no" + downgrader] 2. [reason + downtoner]

GG5: 1. [excuse]

GG6: 1. [excuse] OR 1. [positive opinion] 2. [downtoner + reason] 3. [negative consequences to interlocutor \& speaker] -- one alternative honest, depending on relationship

GG7: 1. [pause filler] 2. [excuse] 3. [elaboration on excuse]

GG8: 1. [downtoner + negative ability] 2. [excuse]

GG9: 1. [gratitude] 2. [downgrader + negative consequences to speaker] 3. [alternativeI can do X instead of $\mathrm{Y}$ ] 4. [downtoner + reason] 5. [downgrader + performative] 6. [negative consequences to interlocutor]

GG10: 1. [pause filler] 2. [negative ability] 3. [excuse]

GG11: 1. [pause filler] 2. [downtoner + negative ability] 3. [excuse]

GG12: 1. [excuse]

GG13: 1. [pause filler] 2. [negative ability] 3. [excuse]

GG14: 1. [negative ability] 2. [excuse] 


\section{$\underline{\text { DCT \#11 }}$}

GG1: 1. [pause filler] 2. [downtoner + reason] 3. [gratitude] 4. [opaque negative willingness]

GG2: 1. [pause filler] 2. [downtoner + reason] 3. [reason]

GG3: 1. [positive opinion] 2. [negative willingness] 3. [reason] 4. [downgrader]

GG4: 1. [alternative--why don't you do $x$ instead of $Y=$ opaque negative willingness] 2 .

[philosophy]

GG5: 1. [gratitude] 2. [hedging] 3. [downgrader + postponement]

GG6: 1. [positive opinion] 2. [negative willingness + downtoner] 3. [reason] 4. [reason] 5. [philosophy] 6. [downgrader + "no"]

GG7: 1. [gratitude] 2. [negative willingness + upgrader] 3. [philosophy] Amalgamation of negative willingness and philosophy.

GG8: 1. [downtoner + reason] 2. [positive opinion]

GG9: 1. [positive opinion] 2. [downtoner + excuse] 3. [regret + intensifier]

GG10: 1. [positive opinion] 2. [reason] 3. [downtoner + opaque negative willingness]

GG11: 1. [positive opinion] 2. [downgrader + reason / excuse] 3. [negative ability /

willingness] Amalgamation of reason / excuse and negative ability / willingness.

GG12: 1. [downtoner + excuse] 2. [excuse]

GG13: 1. [forewarn-Oje-"uh-oh"] 2. [hedging] 3. [postponement]

GG14: 1. ["no"] 2. [regret] 3. [negative willingness] 4. [reason]

\section{$\underline{\text { DCT \#12 }}$}

GG1: 1. [regret] 2. [excuse] 3. [elaboration on excuse] 4. [elaboration on excuse]

GG2: 1. [regret] 2. [excuse] 3. [positive opinion]

GG3: 1. [pause filler] 2. [regret + intensifier] 3. [excuse]

GG4: 1. [excuse + downgrader] 2. [elaboration of excuse]

GG5: 1. [excuse] 2. [elaboration of excuse]

GG6: 1. [regret + intensifier] 2. [positive opinion] 3. [negative ability]

GG7: 1. [regret + intensifier] 2. [excuse]

GG8: 1. [regret] 2. [negative ability] 3. [excuse]

GG9: 1. [positive opinion] 2. [downgrader + excuse] 3. [elaboration on excuse] 4. [alternative-I can do $\mathrm{X}$ instead of $\mathrm{Y}$ ]

GG10: 1. [positive opinion] 2. [excuse]

GG11: 1. [pause filler] 2. [regret] 3. [positive opinion] 4. [excuse] 5. [elaboration on excuse]

GG12: 1. [excuse] 2. [excuse]

GG13: 1. [implied set condition for acceptance + downgrader] 2. [implied set condition for acceptance] 3. [excuse]

GG14: 1. ["no"- "Das ist ausgeschlossen" ("That's out of the question.")] 2. [excuse] 


\section{Appendix M \\ Classification of GE Responses in terms of Functional Categories}

\section{$\underline{\text { DCT \#1 }}$}

GE1: 1. [upgrader + insult/attack] 2. [criticism of interlocutor] 3. [negative willingness via asserting own superiority]

GE2: 1. [upgrader + reason] 2. [regret] 3. [negative ability = negative willingness] 4. [reason]

GE3: 1. [forewarn] 2. [upgrader + hedging-includes an indirect guilt trip] 3.

[postponement] possible implied mild criticism of eliciting speech act in forewarn, upgrader, and hedging

GE4: 1. [postponement] 2. [postponement] 3. [negative ability] 4. [excuse]

GE5: 1. [regret] 2. [negative ability] 3. [excuse]

GE6: 1. [agreement] 2. [compliment] 3. [principle] 4. [negative ability] 5. [implied excuse]

GE7: 1. [regret] 2. [empathy] 3. [downtoner + negative ability] 4. [excuse] Amalgamation of negative ability and excuse.

GE8: 1. [regret + intensifier] 2. [compliment] 3. [negative ability]

GE9: 1. [compliment] 2. [negative consequences for speaker] 3. [regret]

GE10: 1. [compliment] 2. [acceptance] 3. [excuse = limitation of acceptance]

GE11: 1. [pause filler] 2. [hedging] 3. [downgrader + postponement] 4. [postponement] 5. [downgrader + excuse]

GE12: 1. [pause filler] 2. [compliment] 3. [compliment] 4. [downtoner + downtoner + negative ability] 5. [excuse] Amalgamation of negative ability \& excuse.

\section{$\underline{\text { DCT \#2 }}$}

GE1: 1. [regret] 2. [excuse]

GE2: 1. [empathy] 2. [reason] 3. [guilt trip]

GE3: 1. [wish] 2. [reason] 3. [downgrader + elaboration on reason]

GE4: 1. [intensifier + regret] 2. [excuse]

GE5: 1. [excuse]

GE6: 1. [reason] 2. [guilt trip] 3. [elaboration of guilt trip]

GE7: 1. [regret] 2. [downtoner + reason]

GE8: 1. [downgrader + negative ability] 2. [reason] 
GE9: 1. [upgrader + guilt trip] 2. [elaboration on guilt trip] 3. [opaque negative willingness (through sarcastic use of downgrader + alternative: why don't you do X instead of $\mathrm{Y})]$

GE10: 1. [upgrader (aggressive interrogative) + criticism of eliciting speech act] 2. [reason]

GE11: 1. [upgrader + guilt trip] 2. [guilt trip] 3. [elaboration on guilt trip] 4. [downgrader + negative ability $=$ negative willingness]

GE12: 1. [forewarn] 2. [downgrader + downtoner + negative willingness] 3. [reason]

\section{$\underline{\text { DCT \#3 }}$}

GE1: 1. [gratitude] 2. [downgrader + excuse]

GE2: 1. [regret + intensifiers] 2. [negative ability] 3. [excuse]

GE3: 1. [gratitude] 2. [principle]

GE4: 1. [excuse] 2. [Two possible interpretations: Acceptance that functions as a refusal:

Lack of enthusiasm; or vague promise of future acceptance. Meaning obscured by grammar-not interpretable.]

GE5: 1. [repetition] 2. [excuse]

GE6: 1. [hedging, implying possible negative willingness] 2. [postponement]

GE7: 1. [postponement] 2. [hedging]

GE8: 1. [regret] 2. [downgrader + excuse]

GE9: 1. [forewarn] 2. [philosophy]

GE10: 1. [reason] 2. [downgrader + downgrader + postponement]

GE11: 1. [gratitude + intensifier] 2. [downgrader + negative ability] 3. [excuse] 4.

[elaboration on excuse]

GE12: 1. [downtoner + hedging] 2. [postponement]

\section{$\underline{\text { DCT \#4 }}$}

GE1: 1. [pause filler] 2. [positive opinion] 3. [downgrader + negative ability] 4. [excuse]

GE2: 1. [regret + intensifier] 2. [excuse]

GE3: 1. [wish-"If there'd be any chance I'd come" (= "If it were possible, I'd come"] 2.

[excuse] 3. [elaboration on excuse] 4. [regret]

GE4: 1. [positive opinion] 2. [excuse]

GE5: 1. [regret] 2. [excuse] 3. [elaboration on excuse]

GE6: 1. [regret] 2. [negative ability] 3. [excuse] 4. [elaboration on excuse] 5.

[elaboration on excuse]

GE7: 1. [pause filler] 2. [downgrader] 3. [positive opinion] 4. [excuse] 5. [regret]

GE8: 1. [downgrader + excuse] 2. [elaboration of excuse]

GE9: 1. [gratitude] 2. [regret] 3. [negative ability] 4. [excuse]

GE 10: 1. [gratitude + intensifier] 2. [negative ability] 3. [excuse]

GE11: 1. [pause filler] 2. [positive opinion] 3. [downgrader + excuse] 4. [regret] 
GE12: 1. [pause filler] 2. [downgrader + excuse] 3. [set condition for past acceptanceslight hint of guilt trip]

\section{$\underline{\text { DCT \#5 }}$}

GE1: 1. ["no"] 2. [negative ability = negative willingness] 3. [negative opinion]

GE2: 1. [pause filler] 2. [insult] 3. [self-defense] 4. [self-defense]

GE3: Not interpretable: Respondent did not seem to understand the DCT item.

GE4: 1. [downtoner + negative opinion] 2. [negative opinion] 3. [negative opinion] 4. [negative willingness]

GE5: 1. [philosophy]

GE6: 1. [implied negative opinion or criticism of eliciting speech act-transfer of "ach"] 2 . [negative opinion] 3. [elaboration on negative opinion] 4. [criticism of eliciting speech act]

GE7: 1. ["no" + downgrader] 2. [implied criticism of eliciting speech act] 3. [negative opinion]

GE8: 1. [negative opinion] 2. [elaboration on negative opinion]

GE9: Not interpretable: Respondent did not seem to understand DCT item.

GE10: 1. [negative opinion]

GE11: 1. [upgrader + negative opinion] 2. [elaboration on negative opinion] 3 .

[imperative telling addressee to drop suggestion]

GE12: 1. [pause filler] 2. [upgrader + negative opinion] 3. [elaboration on negative opinion + downtoner] 4. [downtoner + elaboration on negative opinion]

\section{DCT \#6}

GE1: 1. [regret] 2. [negative opinion] 3. [criticism of eliciting speech act] 4. [gratitude + intensifier]

GE2: 1. [positive opinion] 2. [self-defense]

GE3: 1. [positive opinion] 2. [self-defense]

GE4: 1. [forewarn] 2. [criticism of eliciting speech act] 3. [criticism of eliciting speech act]

GE5: 1. [criticism of eliciting speech act]

GE6: 1. [pause filler] 2. [downgrader + criticism of eliciting speech act] 3. [elaboration on criticism of eliciting speech act] 4. [downgrader + criticism of eliciting speech act]

GE7: 1. [agreement] 2. [excuse]

GE8: 1. [criticism of eliciting speech act] 2. [self-defense]

GE9: 1. [downgrader + criticism of eliciting speech act] 2. [philosophy]

GE10: 1. [downtoner + self-defense] 2. [self-defense] 3. [criticism of eliciting speech act]

GE11: 1. [regret] 2. [self-defense] 3. [excuse + downtoner] 
GE12: 1. [pause filler] 2. [criticism of eliciting speech act]

\section{DCT \#7}

GE1: 1. [pause filler] 2. [agreement] 3. [positive opinion] 4. [downgrader + off the hook] 5. [off the hook] 6. [postponement $=$ off the hook (involving transfer)] GE2: 1. [off the hook] 2. [diminish value $=$ off the hook] 3. [diminish value $=$ off the hook]

GE3: 1. [off the hook] 2. [empathy] 3. [off the hook] 4. [downgrader + diminish value $=$ off the hook] 5. [downgrader + empathy $=$ off the hook]

GE4: 1. [diminish value $=$ off the hook] 2. [off the hook] 3. [off the hook] 4. [off the hook] 5. [empathy]

GE5: 1 . [philosophy $=$ off the hook] 2. [downtoner + off the hook] 3. [diminish value $=$ off the hook]

GE6: 1. [pause filler] 2. [off the hook] 3. [off the hook] 4. [philosophy =off the hook] GE7: 1. [pause filler] 2. [empathy] 3. [off the hook] 4. [philosophy $=$ off the hook] 5. [off the hook] 6. [off the hook] 7. [off the hook] 8. [off the hook]

GE8: 1. [off the hook] 2. [off the hook with a touch of diminish value]

GE9: 1. [pause filler] 2. [off the hook] 3. [diminish value $=$ off the hook] 4. [alternativeI can do $\mathrm{X}$ instead of $\mathrm{Y}=$ off the hook] 5. [elaboration on alternative $=$ off the hook]

GE10: 1. [off the hook] 2. [philosophy $=$ off the hook] 3. [diminish value $=$ off the hook] GE11: 1. [downgrader + empathy] 2. [philosophy $=$ off the hook] 3. [off the hook] 4. [diminish value $=$ off the hook + downtoner]

GE12: 1. [empathy] 2. [diminish value $=$ off the hook] 3. [off the hook] 4. [elaboration on off the hook]

\section{$\underline{\text { DCT \#8 }}$}

GEl: 1. [upgrader + attack-sarcasm based on addressee's inferiority to speaker] 2. [reason] [Note: In DCT\#1: "Dear Mr X, who do you think you are?!"-so perhaps this is a "formula" that this respondent uses for putting people in their place.]

GE2: 1. [gratitude-transfer: "You're very nice..."] 2. [downgrader + establish own status $=$ reason]

GE3: 1. [reason] 2. [promise]

GE4: 1. [reason] 2. [negative willingness] 3. [principle $=$ promise]

GE5: 1. [principle]

GE6: 1. [empathy] 2. [principle] 3. [elaboration on principle]

GE7: 1. [pause filler] 2. [forewarn with implied criticism of eliciting speech act] 3.

[criticism of interlocutor] 4. [downgrader + reason]

GE8: 1. [principle] 2. [principle]

GE9: 1. [alternative-You can do X instead of $\mathrm{Y}$ ] 2. [positive opinion] 3. [excuse] 
GE10: 1. [principle]

GE11: 1. [agreement] 2. [downgrader + downtoner + reason, with some criticism of interlocutor] 3. [downtoner + elaboration on reason]

GE12: 1. [pause filler] 2. [downtoner + reason] 3. [principle] 4. [elaboration on principle]

\section{$\underline{\text { DCT \#9 }}$}

GE1: 1. [gratitude] 2. [downgrader + performative = negative ability] 3. [reason] // 1. [acceptance] 2. [limitation of acceptance]

GE2: 1. [regret] 2. [reason] // 1. ["no"] 2. [negative consequence to speaker]

GE3: 1. ["no"] 2. [regret] 3. [negative ability] // 1. [lack of enthusiasm]

GE4: 1. [downtoner + excuse] // 1. [limited acceptance (conditional acceptance)]

GE5: 1. ["no" + downgrader] 2. [reason] // 1. ["no" + upgrader] 2. [negative consequences to speaker]

GE6: 1. ["no" + downgrader] 2. [reason + upgrader] // 1. [acceptance] 2. [limitation of acceptance]

GE7: 1. [pause filler] 2. ["no" + downgrader] 3. [compliment] 4. [reason] // 1. ["no" + upgrader] 2. [negative ability]

GE8: 1. [pause filler] 2. [gratitude] 3. [compliment] 4. [compliment] 5. [reason] // 1. [limited acceptance]

GE9: 1. [gratitude] 2. [compliment] 3. [reason] // 1. [limited acceptance]

GE10: 1. [compliment] 2. [reason + downgrader] // 1. ["no" + downgrader + intensifier] 2. [promise] 3. [set condition for future acceptance]

GE11: 1. ["no" + downgrader] 2. [compliment] 3. [reason] 4. [elaboration on reason] // 1. [pause filler] 2. [lack of enthusiasm] 3. [lack of enthusiasm]

GE12: 1. [pause filler] 2. ["no" + downgrader] 3. [reason] 4. [negative consequences to speaker] // 1. [pause filler] 2. [acceptance] 3. [limitation of acceptance]

\section{$\underline{\text { DCT \#10 }}$}

GE1: 1. [pause filler] 2. [gratitude + intensifier] 3. [downgrader + negative willingness]

4. [downtoner + downtoner + reason]

GE2: 1. [regret + intensifier] 2. [excuse]

GE3: 1. [regret] 2. [excuse] 3. [elaboration on excuse] 4. [elaboration on excuse]

GE4: 1. [regret] 2. [excuse]

GE5: 1. [excuse]

GE6: 1. [pause filler] 2. [positive opinion] 3. [excuse] 4. [elaboration on excuse]

GE7: 1. [regret] 2. [downtoner + reason] 3. [elaboration on reason]

GE8: 1. [regret + intensifier] 2. [excuse]

GE9: 1. [pause filler] 2. [downgrader] 3. [excuse] 4. [elaboration on excuse] 
GE10: 1. [repetition] 2. [pause filler] 3. [downgrader + excuse] 4. [elaboration on excuse]

GE11: 1. [pause filler] 2. [positive opinion] 3. [downgrader + excuse] 4. [elaboration on excuse] 5. [elaboration on excuse]

GE12: 1. [pause filler] 2. [downgrader + excuse]

\section{DCT \#11}

GE1: 1. [pause filler] 2. [positive opinion] 3. [downgrader + negative opinion] 4.

[regret] 5. [downgrader + downgrader + performative $=$ negative ability]

GE2: 1. [gratitude] 2. [negative ability] 3. [opaque negative willingness] 4. [excuse]

GE3: 1. [gratitude] 2. [reason] 3. [elaboration on reason]

GE4: 1. [regret] 2. [excuse] 3. [downtoner + negative ability] 4. [negative opinion + downgrader]

GE5: 1. [intensifier + gratitude] 2. [negative willingness] 3. [reason] Amalgamation of negative willingness and reason.

GE6: 1. [positive opinion] 2. [downtoner + negative willingness] 3. [negative willingness] 4. [reason] Amalgamation of negative willingness and reason (3. \& 4.).

GE7: 1. [forewarn] 2. [implied philosophy] 3. [reason]

GE8: 1. [downgrader + reason] 2. [reason]

GE9: 1. [gratitude] 2. [downtoner + negative willingness] 3. [reason]

GE10: 1. [positive opinion] 2. [philosophy] 3. [excuse]

GE11: 1. [pause filler] 2. [positive opinion] 3. [forewarn] 4. [opaque negative willingness] 5. [reason]

GE12: 1. [positive opinion] 2. [negative ability] 3. [excuse] 4. [downgrader + negative ability]

\section{$\underline{\text { DCT \#12 }}$}

GE1: 1. [pause filler] 2. [positive opinion] 3. [excuse] 4. [elaboration on excuse]

GE2: 1. [regret] 2. [excuse]

GE3: 1. [regret] 2. [excuse] 3. [elaboration of excuse]

GE4: 1. [regret + intensifier] 2. [excuse]

GE5: 1. [regret] 2. [excuse] 3. [excuse]

GE6: 1. ["no"-"Not tonight..."] 2. [excuse] 3. [elaboration on excuse]

GE7: 1. [forewarn] 2. [excuse] 3. [elaboration on excuse] 4. [regret]

GE8: 1. [downgrader + excuse] 2. [elaboration on excuse] 3. [negative ability]

GE9: 1. [regret + intensifier] 2. [negative ability] 3. [excuse] 4. [elaboration on excuse]

5. [alternative-I can do $\mathrm{X}$ instead of $\mathrm{Y}]$

GE10: 1. [regret] 2. [negative ability] 3. [excuse] 
GE11: 1. [pause filler] 2. [positive opinion] 3. [downgrader + negative ability] 4 . [excuse] 5. [elaboration on excuse]

GE12: 1. [pause filler] 2. [regret + intensifier] 3. [reason] 